\title{
IntechOpen
}

\section{Basic and Clinical \\ Endocrinology Up-to-Date}

Edited by Fulya Akin

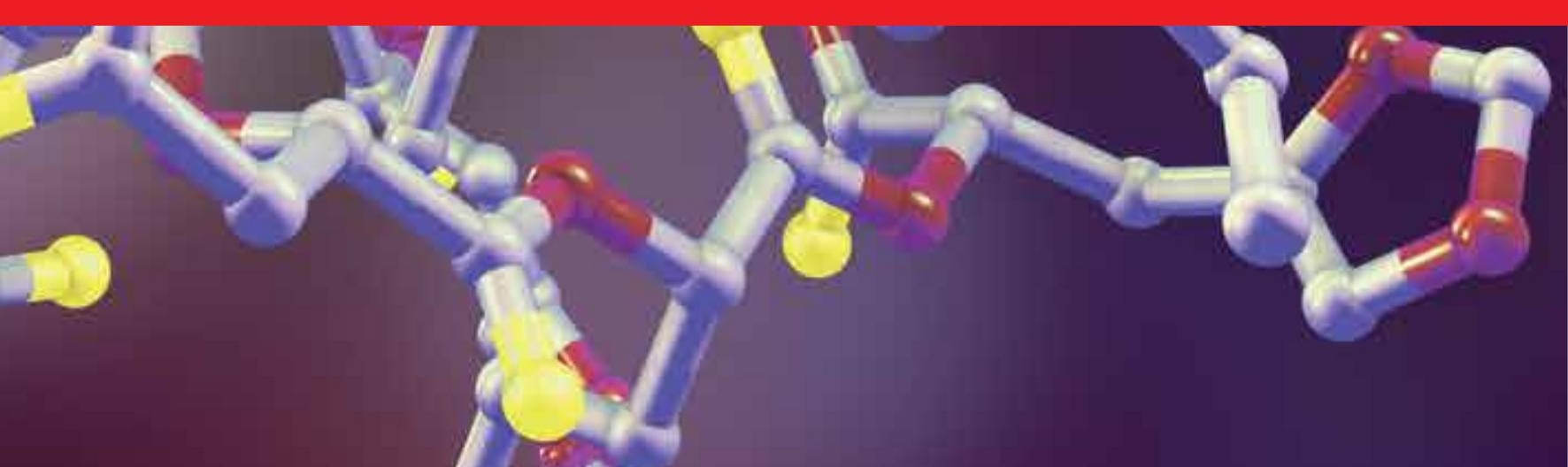





\section{BASIC AND CLINICAL ENDOCRINOLOGY UP-TO-DATE}

Edited by Fulya Akin 


\section{Basic and Clinical Endocrinology Up-to-Date}

http://dx.doi.org/10.5772/1016

Edited by Fulya Akin

\section{Contributors}

XingJia Wang Wang, Olivier Levillain, Cyril Degletagne, Dominique Letexier, Henri Déchaud, Guzin Fidan Yaylali, Yalin Tolga Yaylali, Drahomira Springer, Zdenka Limanova, Tomas Zima, Ma Guadalupe Guijarro de Armas, Carlos Hermenegildo, Susana Novella, Philippe CARON, Delphine Vezzosi, Antoine Bennet, Jean-Christophe Maiza, Alexandre Buffet, Solange Grunenwald, Josette Fauvel, Frédéric Courbon, Philippe Otal, Nicolas Carrere, Manuel Estrada, Carlos Wilson, Rodrigo Maass, Akihiko Saito, Michihiro Hosojima, Hiroyoshi Sato, Mercedes Ferrer, Evanthia Diamanti-Kandarakis, Francesco Squadrito, Alessandra Bitto, Bruce Burnett, Francesca Polito, Robert Levy, Herbert Ryan Marini, Domenica Altavilla, Laura Sterian Ward, Natássia Bufalo, Aline Carolina Silva, Raquel Barbieri, Marjory Marcello, Lucas Cunha, Elaine Morari, Lluis Tort, Mariana Teles, Olli Peltoniemi, Claudio Oliviero, Markus Schubert, Lorna Moll, Johanna Zemva

\section{(c) The Editor(s) and the Author(s) 2011}

The moral rights of the and the author(s) have been asserted.

All rights to the book as a whole are reserved by INTECH. The book as a whole (compilation) cannot be reproduced, distributed or used for commercial or non-commercial purposes without INTECH's written permission.

Enquiries concerning the use of the book should be directed to INTECH rights and permissions department (permissions@intechopen.com).

Violations are liable to prosecution under the governing Copyright Law.

\section{(cc) BY}

Individual chapters of this publication are distributed under the terms of the Creative Commons Attribution 3.0 Unported License which permits commercial use, distribution and reproduction of the individual chapters, provided the original author(s) and source publication are appropriately acknowledged. If so indicated, certain images may not be included under the Creative Commons license. In such cases users will need to obtain permission from the license holder to reproduce the material. More details and guidelines concerning content reuse and adaptation can be foundat http://www.intechopen.com/copyright-policy.html.

\section{Notice}

Statements and opinions expressed in the chapters are these of the individual contributors and not necessarily those of the editors or publisher. No responsibility is accepted for the accuracy of information contained in the published chapters. The publisher assumes no responsibility for any damage or injury to persons or property arising out of the use of any materials, instructions, methods or ideas contained in the book.

First published in Croatia, 2011 by INTECH d.o.o.

eBook (PDF) Published by IN TECH d.o.o.

Place and year of publication of eBook (PDF): Rijeka, 2019.

IntechOpen is the global imprint of IN TECH d.o.o.

Printed in Croatia

Legal deposit, Croatia: National and University Library in Zagreb

Additional hard and PDF copies can be obtained from orders@intechopen.com

Basic and Clinical Endocrinology Up-to-Date

Edited by Fulya Akin

p. cm.

ISBN 978-953-307-340-8

eBook (PDF) ISBN 978-953-51-6524-8 


\section{We are IntechOpen, \\ the world's leading publisher of Open Access books}

Built by scientists, for scientists

\section{$4,100+$}

Open access books available

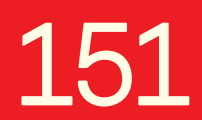

Countries delivered to
$116,000+$

International authors and editors
$120 \mathrm{M}+$

Downloads

Our authors are among the

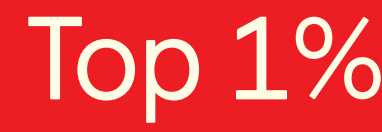

most cited scientists

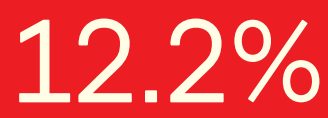

Contributors from top 500 universities

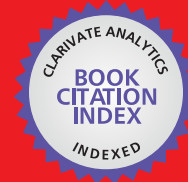

WEB OF SCIENCE ${ }^{\mathrm{TM}}$

Selection of our books indexed in the Book Citation Index in Web of Science ${ }^{\mathrm{TM}}$ Core Collection (BKCI)

Interested in publishing with us?

Contact book.department@intechopen.com

Numbers displayed above are based on latest data collected.

For more information visit www.intechopen.com

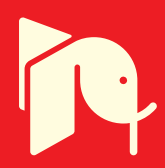





\section{Meet the editor}

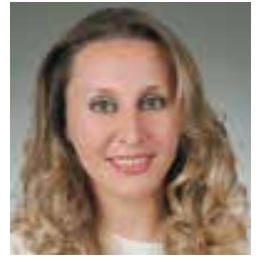

Fulya Akin is associate professor of Internal Medicine and Head of Endocrinology Department at Pamukkale University. She received her medical degree from Cerrahpasa Medical Faculty of Istanbul University where she also completed fellowship training in endocrinology. She has completed internal medicine training in the Istanbul Haydarpaşa Numune State Hospital. Since 2005, Dr. Akin has been working as a lecturer in department of endocrinology and Metabolism at Pamukkale University. Her research topics are sex hormone binding globulin, insulin resistance, genetic polymorphism, acromegaly, subclinical thyroid disease. Dr. Akin is a member of the Society of Endocrinology and Metabolism of Turkey (SEMT). She has authored more than 30 publications in peer-reviewed journals in PubMed and has had some presentations in several prestigious meetings. 



\section{Contents}

\section{Preface XI}

\section{Part 1 Thyroid Disease 1}

Chapter 1 Thyroid Disruptors: How They Act and How We React 3 Natassia Elena Bufalo, Aline Carolina de Nadai da Silva, Raquel Bueno Barbieri, Marjory Alana Marcello, Lucas Leite Cunha, Elaine Cristina Morari and Laura Sterian Ward

\section{Part 2 Pregnancy and Endocrine Disease 35}

Chapter 2 Thyroid in Pregnancy 37

Drahomira Springer, Zdenka Limanova and Tomas Zima

Chapter 3 Adrenal Disease and Pregnancy $\mathbf{5 1}$ Guadalupe Guijarro de Armas

\section{Part 3 Effects of Androgens 61}

Chapter 4 Cardiovascular Effects of Androgens 63

Carlos Wilson, Rodrigo Maass and Manuel Estrada

Chapter 5 Testosterone Therapy and the Heart 79

Güzin Fidan Yaylalı and Yalın Tolga Yaylalı

Chapter 6 Androgens and Vascular Function 91 Mercedes Ferrer

Chapter 7 Orchidectomy Upregulates While Testosterone Treatment Downregulates the Expression of Ornithine Aminotransferase Gene in the Mouse Kidney 115 Olivier Levillain, Cyril Dégletagne, Dominique Letexier and Henri Déchaud 
Part 4 Insulinomas 133

Chapter 8 Diagnosis and Treatment of Insulinomas in the Adults D. Vezzosi, A. Bennet, J.C. Maiza, A. Buffet, S. Grunenwald, J. Fauvel, F. Courbon, P. Otal, N. Carrere and Ph. Caron

Part 5 Aging and Endocrinology 177

Chapter 9 Natural Flavonoids in StAR Gene Expression and Testosterone Biosynthesis in Leydig Cell Aging 179

Xing Jia Wang

Chapter 10 Role of Central Insulin-Like Growth Factor-1 Receptor Signalling in Ageing and Endocrine Regulation 209 Lorna Moll, Johanna Zemva and Markus Schubert

Part 6 Endocrinology of Stress 261

Chapter 11 The Endocrine Response to Stress -

A Comparative View 263

Lluis Tort and Mariana Teles

Part 7 Steroid Induced Osteoporosis

Chapter 12 Genistein Aglycone Demonstrates a Protective and Reversible Effect on the Development of Steroid-Induced Secondary Osteoporosis and Increases Bone Breaking Strength in Rats 289

Alessandra Bitto, Francesca Polito, Bruce P. Burnett, Herbert Marini, Robert Levy, Domenica Altavilla and Francesco Squadrito

Part 8 Chronic Renal Disease and Endocrinology 303

Chapter 13 Hormonal Actions and Interactions in Proximal Tubule Cells Associated with the Development of Chronic Kidney Disease 305

Akihiko Saito, Michihiro Hosojima and Hiroyoshi Sato

Part 9 Estrogens and Endothelium 321

Chapter 14 Estradiol Regulation of Prostanoids Production in Endothelium 323

Susana Novella and Carlos Hermenegildo

Part 10 Factors Affecting Farrowing 339

Chapter 15 Factors Affecting Physiology and Endocrinology of Farrowing 341

Olli Peltoniemi and Claudio Oliviero 


\section{Preface}

This book provides the most up-to-date information on the basic and clinical aspects of endocrinology. It offers both researchers and clinicians experts, gold-standard analysis of endocrine research and translation into the treatment of diseases such as insulinoma, endocrine disease in pregnancy and steroid induced osteoporosis.

Investigates both the endocrine functions of the kidneys and how the kidney acts as a target for hormones from other organ systems.

Presents a uniquely comprehensive look at all aspects of endocrine changes in pregnancy and cardiovascular effects of androgens. Clear translational presentations by the top endocrinologists in each specific hormone or functional/systems field.

This book contains many important innovations.

I would like to thank our authors who have helped in the preparation of this book. We hope it would be useful as an up-to-date resource for endocrinology.

We are particularly grateful for support of our publishers. Their efforts have been essential in ensuring the successful publication of this high quality book.

As always, we would like to acknowledge the debt we owe to our families for their support during the inevitable periods when'book work' intruded on family life.

Fulya Akin, M.D.

Pamukkale University Medical School

Denizli/Turkey 



\section{Part 1}

Thyroid Disease 



\title{
Thyroid Disruptors: How They Act and How We React
}

\author{
Natassia Elena Bufalo, Aline Carolina de Nadai da Silva, \\ Raquel Bueno Barbieri, Marjory Alana Marcello, Lucas Leite Cunha, \\ Elaine Cristina Morari and Laura Sterian Ward \\ State University of Campinas - UNICAMP \\ Brazil
}

\section{Introduction}

\subsection{Actual thyroid disease demographics}

Thyroid diseases increase in a ubiquitous global phenomenon suspected to further rise in the upcoming decades (Dua et al. 2008). Thyroid cancer is the most common endocrine malignancy, representing $2 \%$ of all malignancies. A rapid global rise in its incidence has been seen in recent decades, especially concerning the papillary type, which has been increasing in several countries (Liu et al. 2001; Reynolds et al. 2005; Davies and Welch 2006; Enewold et al. 2009; Kilfoy, Devesa et al. 2009; Kilfoy, Zheng et al. 2009). An estimated 44,670 new cases of thyroid cancer are expected to be diagnosed in the United States of America in 2010, with three out of four cases occurring in women. The incidence rate of thyroid cancer has been increasing sharply since the mid-1990s, and it is the fastest growing cancer in both men and women, as well as the ninth most common human malignancy in the USA (American Cancer Society: Cancer Facts and Figures 2010).

The reasons for the increase in occurrences of this type of cancer are still unclear and controversial. Earlier studies suspected that the upward trend was caused by the widespread use of radiation therapy for benign conditions of the head and neck among children and adolescents from the early 1920s to the late 1950s (Weiss 1979; Pottern et al. 1980). Other studies suggested that this trend could be associated with atmospheric nuclear fallouts (Catelinois et al. 2004; Gilbert et al. 1998; Kazakov, Demidchik, and Astakhova 1992; Kerber et al. 1993; Takahashi et al. 2003) or constant diagnostic X-ray exposures (Prokop 2001; Ron et al. 1995) suffered especially by children (Brenner et al. 2001; Golding and Shrimpton 2002; Maitino et al. 2003). More recent studies suggested that the prevalence of thyroid nodules depends on the screening method and population evaluated according to geographic regions and racial groups, indicating that the widespread use of ultrasonography and socioeconomic indicators of health care access could be the major players in this new demography of the thyroid cancer (Morris and Myssiorek 2010; Sprague, Warren Andersen, and Trentham-Dietz 2008).

The steep increase in thyroid cancer is certainly related to better cancer detection by ultrasonography and other imaging techniques in a population growing older, as well as a larger and easier access to health care and robust laboratory diagnostic tools such as TSH and thyroid antibody dosages (Davies and Welch 2006; Ward and Graf 2008). However, 
there are strong indicators that other causes may be involved. Better techniques and larger access to health care cannot be held responsible for the increasing incidence rates of larger tumors, which have been similar to papillary microcarcinoma (Hughes et al. 2011).

In addition, an epidemiological study of thyroid cancer cases in a highly radiated territory in Poland - i.e. in the province of Opole after 1986 - indicate a significant increase in thyroid cancer incidence in males and females during the period 1995-2002, when comparing with the years 1987-1994. The data comprises all the thyroid cancer cases registered in Opole province in the years 1987-2002, originated from the Provincial Cancer Registry in Opole (Tukiendorf, Miszczyk, and McEwan 2010). Finally, the proportion of local staged thyroid cancer increased by $24 \%$ in the Black group, $14.4 \%$ in the Hispanic white group, $14.3 \%$ in the non-Hispanic white group, and only $4.0 \%$ in the Asian group between the periods 1992-1996 and 2000-2004. Five-year survival rates of patients with papillary tumor were approximately $95 \%$; however, that of anaplastic tumor ranged from $5.6 \%$ to $11.4 \%$ among REGs (Race/Ethnicity Groups) (Yu et al. 2010).

Autoimmune thyroid disorders, comprising Graves' disease and Hashimoto's thyroiditis, are considered polygenic, multifactorial diseases characterized by an abnormal activation of the immune system as a result of interactions between genetic predisposition and environmental factors, the former accountant for approximately $70-80 \%$ of liability to develop autoimmune thyroid disorders (Wiersinga 1999). Accumulating data confirm that the burden of autoimmune diseases is rising as well, affecting 5 to $10 \%$ of the world population. They are a significant cause of morbidity and mortality accounting for soaring health care costs, comparable to those of cancer and heart disease (Cooper, Bynum, and Somers 2009; Eaton et al. 2007; Shoenfeld et al. 2008).

Hashimoto's disease and Graves' disease are the two most common forms of autoimmune thyroiditis, the archetypal organ-specific autoimmune disease in humans. Both are characterized by lymphocytic infiltrate and autoreactivity against thyroid autoantigens (Michels and Eisenbarth 2010; Rapoport and McLachlan 2001; Zenewicz et al. 2010). There are strong evidences for a major role of heredity in Graves' disease, as demonstrated with a population-based study of two Danish twin cohorts (Brix et al. 2001). This study indicated that $21 \%$ of the causes involved in Graves' disease development can be attributed to environmental factors (Brix et al. 2001; Prummel, Strieder, and Wiersinga 2004). However, recent analysis of thyroid disease demographics indicate that environmental factors probably have been playing an important role in the observed rise in thyroid disease incidence all over the world (Morris and Myssiorek 2010). Among these environmental causes, viral infections have been repeatedly demonstrated related to type 1 diabetes mellitus and multiple sclerosis (Cabrera-Rode et al. 2003; Dahlquist et al. 1995; Hiltunen et al. 1997; Hyoty and Taylor 2002; Lonnrot, Korpela et al. 2000; Lonnrot, Salminen et al. 2000). In addition, other factors including ionizing radiation, dietary iodine intake, reproductive factors like estrogens, and cigarette smoking might be considered as thyroid disruptors, working as triggers for thyroid disease.

\section{Main disruptors}

\section{1 lonizing radiation}

Ionizing radiation has been being described as the known major risk factor for thyroid cancer, especially papillary carcinoma, the most common thyroid cancer type (Nikiforov 2010). Convincing evidence exists of an association between exposure to external radiation 
and an increased risk of thyroid cancer (Mushkacheva et al. 2006; Pottern et al. 1990; Ron et al. 1995; Ron et al. 1989; Schneider et al. 1993; Shore et al. 1993; Shore et al. 2003; Yoshimoto et al. 1995); however, risks from internally deposited radioactive iodine were not well studied until recently (Zablotska et al. 2011; Kazakov, Demidchik, and Astakhova 1992; Shibata et al. 2001; Takahashi et al. 2003; Dobyns et al. 1974).

Well-documented examples include medical therapeutic external beam radiation and accidental exposure to c-radiation and radioiodine as a result of nuclear weapon explosions or nuclear reactor accidents (Ron et al. 1995).

Both radiations (Ostroumova et al. 2009) and thyroid benign nodules (Lyon et al. 2006; Brent 2010) are related to autoimmune processes.

\subsection{Radiation and thyroid nodules}

The growing incidence of thyroid cancer over the last decades is entirely due to papillary carcinomas, whereas the incidence of other thyroid cancer types, including the follicular type, remains unchanged or is decreasing (Nikiforov 2010). A better understanding of the biology and etiologic factors responsible for the development of papillary carcinomas is particularly important for unraveling the reasons behind the general increase in thyroid cancer incidence.

Mahoney et al (Mahoney et al. 2004) have described that marked increases in the incidence of thyroid cancer after the Chernobyl incident have occurred in all areas of the Republic of Belarus and among all age groups. However, the greatest increases have occurred in children, suggesting that a high prevalence of pre-existing iodine deficiency in combination with unique susceptibility among younger people might have contributed to potential carcinogenic exposures to the thyroid.

Ron et al. (Ron et al. 1995) presented a pooled analysis of five cohort and two case-control studies concerning external radiation and thyroid cancer. The study reported a statistically significant excess relative risk per Gy for individuals exposed before 15 years of age. There was no evidence of increased thyroid cancer risk for individuals exposed at older ages. More recent analyses of atomic bomb survivors confirmed a strong inverse association between ERR/Gy and age at exposure, but suggested that adult exposure is associated with a small increase in thyroid cancer risk (Preston et al. 2007). In 2011, Schonfeld et al. (Schonfeld, Lee, and Berrington de Gonzalez 2011) presented an overview of the use of radiation for medical purposes and its significance for thyroid cancer, especially among children, who seem to be more susceptible to the effects of ionizing radiation. In their study, Schonfeld et al analyzed data concerning $x$-ray use for dental purposes and did not find significant differences among patients that were more exposed to that type of radiation. In what concerns nuclear medicine, there are no data relating that segment to thyroid cancer, and the authors link that to the fact that kids are hardly ever exposed to those types of exams. To analyze data on diagnostic computed tomography, Schonfeld et al used Analytica software for the calculations to estimate means and $95 \%$ uncertainty limits. Using this methodology, they calculated that about 1000 future thyroid cancers could be related to computed tomography scans conducted in the United States of America during the year 2007.

There are also some reports on the effects of radiotherapy for cancers and development of thyroid cancer. Thyroid cancer is one of the most common second cancers after radiotherapy during childhood for Hodgkin lymphoma, and significant increased risks of thyroid cancer have been observed from 5 to more than 40 years after childhood radiotherapy $(\mathrm{Ng}$ et al. 2010). In addition to cancer treatment, radiotherapy for the treatment of benign conditions, 
including (but not restricted to) tinea capitis, hemangioma, and enlarged thymus, has been clearly associated with increased thyroid cancer risk (Ron 2003).

Hayashi et al (Hayashi et al. 2010) found a statistically significant radiation dose-response for the prevalence of these tumors, with an excess odds ratio (OR) per gray of radiation (Gy) of 0.57 . The excess risk was limited to women, and among them, the excess OR was $2.4 \mathrm{~Gy}$. These data raise the possibility that the incidence of thyroid microcarcinomas may in fact be related to radiation exposure and point to another interesting issue on the fact that this effect is more important in females.

In fact, many studies have been associating thyroid cancer with exposure to ${ }^{131} \mathrm{I}$, which can cause several molecular alterations in genes such as RET, NTRK1, RAS, and BRAF (Nikiforov et al. 1997). Remarkably, the mechanisms of activation of these genes are quite different in tumors associated with radiation exposure when compared with those from the general population. The dominant mutation mechanism in radiation-induced tumors consists of chromosomal rearrangements, such as those leading to the formation of oncogenic RET/PTC, TRK, and BRAF/AKAP9 fusions. A very different mutation mechanism, i.e. a point mutation, is the most prevalent in sporadic tumors, which typically carry point mutations of BRAF and RAS genes (Nikiforov 2010). Correlation between radiation exposure and high frequency of RET/PTC in papillary carcinomas has been seen after accidental radiation exposure from Chernobyl, in patients treated by external beam radiation and, more recently, in atomic bomb survivors in Japan (Hamatani et al. 2008). In the study reported by Hamatani et al, the presence of RET/PTC rearrangement had direct correlation with increasing radiation dose, whereas BRAF point mutation had strong inverse correlation with the dose.

\subsection{Radiation and thyroid autoimmune diseases}

The most common thyroid manifestation of radiation is hypofunction, in addition to thyroid nodules and thyroid cancer. Autoimmune thyroid disease has been linked to therapeutic medical radiation, as well as environmental radiation exposure (Brent 2010; Sklar et al. 2000; Dunkelmann et al. 2004; Simon et al. 2009). Both the atomic bomb detonations in Japan and nuclear contamination from the Chernobyl nuclear power plant accident were associated with an increased risk of autoimmune thyroid disease (Hamatani et al. 2008; Sklar et al. 2000; Brent 2010). This association, however, has not been a consistent finding, with several studies showing no effect (Imaizumi et al. 2006; Agate et al. 2008). Radiation effects are generally associated with greater radiation exposure and can be tracked with position of the exposed individual at time of the accident or, in the case of the Chernobyl exposure, the pattern of the wind currents dispersing radiation. The initial study of atomic bomb survivors in Japan showed an increase in the incidence of thyroid autoimmunity (Nagataki et al. 1994), but another study, with longer follow-up, did not confirm initial data (Sklar et al. 2000). The effect of radiation may, in fact, be related to the iodine intake by exposed individuals. The risk of both thyroid cancer and autoimmunity seems to be enhanced if diets deficient in stable iodine result in chronic thyroid stimulation. Exposure to ${ }^{131} \mathrm{I}$ alone appears to be associated with a lower risk when compared with acute exposures to the atomic bomb or medical radiotherapy, perhaps due to the associated low dose rate and nonuniform distribution of dose in the gland. A study of children exposed to radiation from Chernobyl showed an increase in thyroid size, higher serum TSH levels, and a greater incidence of thyroid autoantibody positivity in areas where the iodine intake was low (Vermiglio et al. 1999). A more recent study of those exposed to radiation from the Chernobyl accident showed an increase in thyroid autoantibodies, but 
not in the incidence of hypothyroidism (Agate et al. 2008). These discrepant data may also be related to the study population. A study regarding exposures to radiation of Hiroshima and Chernobyl (Boice 2006) found disagreeing data on the effects of those exposures and their correlation with thyroid diseases and also suggested that the radiosensitivity of the young thyroid gland is high and most likely relates to subsequent proliferative activity of the gland during puberty and growth, but the reasons for the absence of risk following adult exposures are not entirely clear (Lyon et al. 2006).

A recent publication also confirmed antithyroid antibody production and autoimmune thyroid disease in patients submitted to external radiation for Hodgkin's disease (Brent 2010). In addition, patients receiving 131I for toxic goiter, later develop Graves' disease and, in some cases, Graves' ophthalmopathy (Dunkelmann et al. 2004). In patients treated with radioiodine for thyroid autonomy, a sensitive TSH receptor antibody measurement showed that low level thyroid autoantibody positivity was associated with the development of Graves' disease after using radioiodine (Dunkelmann et al. 2004).

Although there are several studies reporting the relationship between radiation and thyroid disorders, the mechanisms and the pathways involved in that relationship remain not well understood and should be investigated (Ostroumova et al. 2009) The unfortunate recent events in Japan, i.e. the successive earthquake, tsunami, nuclear plants problems, as well as its weather conditions, led a large population to be exposed to radiation effects, demonstrating the urgent need to adopt international contingency measures related to radiation accidental exposure.

\section{4 lodide}

The following text is a report of travelers who visited Brazil between the years 1873 and 1875 (Wells 1886). They traveled throughout different regions in the country and were able to report some interesting aspects of life of Brazilians in the Nineteenth century. Their observations demonstrate the ravaging effect of iodide deficiency, especially on certain segments of the population.

"Goiter is very prevalent amongst the very poor peasants, but is rarely seen in the more well-to-do farmers. The sex seems to make no difference, neither does the colour, for the lightcoloured, brown, and black appear to be equally disfigured. In some instances the excrescence attains an enormous size, like a huge feather pillow hung round the front of the neck and extending to the shoulders on each side, hanging over the chest and forcing the head backwards; they apply various herbs and burnt sponge, but admit that it is almost useless to treat it; a change of locality will often stop its continual development, and very rarely cause it to become reabsorbed. The presence of lime in the waters of the streams and a humid atmosphere are considered the primary causes of the evil; but a poor diet, indolent habits, and an absence of all hygiene and cleanliness, either in person or houses, are undoubtedly great promoting causes." In.: "Exploring and travelling three thousand miles through Brazil from Rio de Janeiro to Maranhão".

It was already clear in these early years that the mineral composition of water, diet profile, and habits were related to the presence of goiter. In addition, the travelers reported that these risk factors, but not gender and color, seemed to be associated with goiter. However, more than one 100 years after this publication, we still do not fully understand the mechanisms involved in goitrogenesis or thyroid disorders overall. Epidemiological evidences suggest that iodide play a key role not only as a major determinant of thyroid disorders but also influencing other factors affecting the thyroid, as previously explained concerning the effect of ionizing radiation. 


\subsection{Thyroid physiology is closely related to iodide homeostasis}

Thyroid hormones are the only iodine-containing compounds with established physiologic significance in vertebrates. The thyroid gland produces two hormones, L-thyroxine (tetraiodothyronine, T4) and L-triiodothyronine (T3). Iodine is an indispensable component of these hormones. Ingested iodine is absorbed through the small intestine and transported in the plasma to the thyroid, where it is concentrated. Thyroid hormone synthesis requires the uptake of iodide by active transport, thyroglobulin (Tg) biosynthesis, oxidation and binding of iodide to thyroglobulin, and within this protein matrix, oxidative coupling of two iodotyrosines into iodothyronines. Initial $\mathrm{Tg}$ iodination produces monoiodotyrosine (MIT) and diiodotyrosine (DIT). Further iodination couples two DIT residues, both still in peptide linkage, to produce T4. When thyroid hormone is needed, Tg is internalized at the apical pole of thyrocytes, conveyed to endosomes and lysosomes and digested by proteases. After $\mathrm{Tg}$ digestion, T4 and T3 are released into the circulation. In addition, iodide is able to regulate thyroid activity by a mechanism called "autoregulation". Autoregulation in the thyroid refers to the regulation of iodine metabolism within the thyroid gland, independent of TSH. Wolff and Chaikoff reported that organic binding of iodide within the rat thyroid was blocked when the plasma iodide level achieved a critical threshold (Wolff and Chaikoff 1948). This inhibition defines the Wolff-Chaikoff effect. Afterwards, the researchers demonstrated that this inhibitory effect of excess iodide was transient, lasting from 26-50 hours, and that the thyroid escaped from or adapted to prolonged iodide excess, resuming near-normal hormone synthesis (Wolff, Chaikoff, and et al. 1949). The mechanism responsible for the acute Wolff-Chaikoff effect is not completely understood. Raben et al. demonstrated that the critical parameter of the Wolff-Chaikoff effect was the amount of intrathyroidal iodide but not plasma concentration (Raben 1949). In addition, WolffChainkoff effect has been postulated to be caused by organic iodocompounds formed within the thyroid (Dugrillon 1996).

Studies on iodine metabolism were carried out in rats and demonstrated that adaptation to long-term iodide exposure was caused by a decrease in iodine transport, thereby reducing the intrathyroid iodine concentration below the critical inhibitory levels, therefore, allowing iodination to resume (Braverman and Ingbar 1963). Eng et al. suggested that iodide administration decreases both NIS mRNA and protein expression by a mechanism that is likely to be, at least in part, transcriptional. Their findings support the hypothesis that the escape from the acute Wolff-Chaikoff effect is caused by a decrease in NIS, with a resultant decreased iodide transport into the thyroid (Eng et al. 2001). Even though the control of NIS mRNA abundance by iodide excess is mainly associated with a transcriptional effect, there is evidence suggesting that it might occur at a posttranscriptional level. In fact, SerranoNascimento et al. showed for the first time that NIS mRNA abundance and poly(A) tail length were significantly reduced in all periods of iodide treatment, suggesting that iodide is able to regulate in a complex manner thyroid cell metabolism (Serrano-Nascimento, CalilSilveira, and Nunes 2010).

\subsection{Disturbs in iodine-intake are closely related to thyroid disorders}

If the autoregulatory mechanism is not sufficient to keep thyroid hormone production normal, a further enhancement of thyroid activity will occur by an hypothalamic-pituitary feedback and other mechanisms that tend to stabilize the production of active thyroid hormone (Obregon, Escobar del Rey, and Morreale de Escobar 2005). These mechanisms are 
able to guarantee that even small supplies of iodine will be sufficient to keep the thyroid function at a level 5 .

Most recently, the situation has inverted: many patients are exposed to large quantities of iodide present in proprietary medications, food, and x-ray contrast media. Furthermore, there are data indicating an excess of iodine intake, probably related to salty snacks and industrialized food largely ingested in many occidental countries, especially by young people and children (Medeiros-Neto 2009).

Despite the widespread use of excess iodide in many places, a few apparently normal subjects with normal thyroid function prior to iodide exposure develop thyroid dysfunction, as previously reviewed (Markou et al. 2001). Many studies indicate that even a small change in the level of iodine intake by a population will lead to a reduced frequency of some thyroid disorders, including goiter, follicular cancer and thyroid nodules; however, other types of disease, such as autoimmune thyroiditis and papillary carcinomas, will become more common (Knobel and Medeiros-Neto 2007; Ward et al. 2007). Despite the evidence provided by previous studies, it is still controversial whether completely normal subjects may develop thyroid function disturbances when exposed to large doses of iodide, since there are some evidences that increased iodine intake is not associated with thyroid dysfunction (Markou et al. 2001; Nauman and Wolff 1993)

The only population in the world in which excessive intake of iodine had been described as a main cause of disease lived in some coastal areas of the Japanese island Hokkaido (Suzuki et al. 1965). The excessive iodine intake in this population was attributed to the daily use of iodine-rich seaweed for consumption. Iodide-induced goiter occurred in approximately $10 \%$ in the coastal regions of Hokkaido, a northern island of Japan (Higuchi 1964; Suzuki et al. 1965). Goiter has now disappeared after the restriction of intake of kelp products in the affected areas (Tajiri et al. 1986; Yoshinari et al. 1983). However, Kono et al. reported that the prevalence of nonautoimmune hypothyroidism was still $9.7 \%$ in coastal areas of the Hokkaido Islands, and it was proportional to iodide intake, whereas the incidence of nonautoimmune thyrotoxicosis was not related to iodide consumption (Konno et al. 1994). In addition, they also reported that when the iodine intake was restricted, the increased serum TSH concentrations were normalized in patients with negative antithyroid antibodies, but remained elevated in those with positive antibodies (Konno et al. 1993). This result suggests that both iodine intake and immunological features interact in the physiopathogeny of hypothyroidism.

In fact, histological examination of the thyroid of patients with iodine-induced hypothyroidism revealed extensive lymphocytic infiltration in half of the examined thyroids (Mizukami et al. 1993). Various findings were observed in other specimens, including hyperplasia in the follicles with papillary foldings, columnar or cuboidal changes in cells with clear and vesicular cytoplasm and markedly reduced colloid. Most of these findings may be reversed after iodine withdrawal (Mizukami et al. 1993). In vivo studies showed that while excess iodine is not necessary for the induction of thyroiditis, the ingestion of excess iodine works to exacerbate autoimmune thyroiditis in this genetically predisposed population (Burek and Talor 2009). Clearly, excess iodine intake has many roles in thyroid dysfunction, and one of these roles is to increase thyroglobulin immunogenicity (Papanastasiou et al. 2007), while another is to increase adhesion molecules on the thyrocyte itself (Sharma et al. 2005; Sharma et al. 2008).

Dietary iodine intake is among the possible environmental influences on the incidence and prevalence of thyroid disease in general and thyroid cancer in particular (Wartofsky 
2010). Worldwide, incidence rates of thyroid cancer may vary widely, with the causes potentially related to inherent racial or ethnic, and geographical or environmental differences, including iodine excess or deficiency, and possible radiation exposure (Ain 1995). Increasing papillary thyroid cancer has also been related to increased dietary iodine intake (Dijkstra et al. 2007).

Cardis et al. indicated that iodine deficiency increases the risk of ${ }^{131}$ I-related thyroid cancer (Cardis et al. 2005). In addition, they indicated that the use of a dietary iodine supplement containing potassium iodide can reduce the risk of ${ }^{131}$ I-related thyroid cancer (Cardis et al. 2005). These authors reported that there would be two mechanisms by which dietary iodine supplementation could be related to the incidence of thyroid cancer after exposure to radioiodines. First, stable iodine given shortly before, during, or immediately after exposure reduces the radioactive iodine uptake by the thyroid and, therefore, reduces the radiation dose to the thyroid (Nauman and Wolff 1993; Zanzonico and Becker 2000). Second, longterm dietary iodine supplementation reduces the size of the thyroid in iodine-deficient areas, and a reduction in thyroid growth, particularly in children, would be expected to be associated with reduced incidence of cancer (Cardis et al. 2005).

In conclusion, iodine is very important for thyroid function and also plays a critical role on the pathogenesis of most thyroid disorders. Even though a body of evidence points iodide as one of the most important thyroid disruptors, it cannot explain, by itself, the increase in thyroid diseases that we have been experiencing in recent years. As stated long before on the above historic report of travellers in Brazil, multiple factors might be related to thyroid diseases, and we remain far from completely understanding how they work.

\subsection{Reproductive factors - estrogen}

In addition to their key role on the physiologic control of female development and reproduction, and the coordination of many other tissues and organ systems to support reproduction, estrogens are also associated with the development of cancers in estrogenresponsive tissues such as breast, uterus, and pituitary, and to thyroid diseases (Jeng and Watson 2011).

Thyroid diseases occur with a marked higher frequency in women than in men. Papillary thyroid carcinoma usually appears during the reproductive age (30-49 years old), in a ratio of three to five females to one male and has the highest incidence in premenopausal women (Ito and Miyauchi 2009; Pinchera 2007; Yeung and Serpell 2008). Thyroid autoimmune diseases are also five to 10 times more common in women than in men (Vanderpump et al. 1995).

Innumerous studies have demonstrated that the human thyroid gland expresses a low level of estrogen receptors (Ceresini et al. 2006; Kawabata et al. 2003; Money et al. 1989). Estrogen receptors expression seems to increase with proliferation of thyroid glandular tissue, both in cases of benign hyperplasia and, in certain instances, of thyroid malignancies as well (Ceresini et al. 2006; Kawabata et al. 2003; Money et al. 1989). Estrogen receptors are presented, in general, as two different isoforms: Estrogen receptors -alpha and Estrogen receptors -beta. It has been hypothesized that an imbalance in the expression of these two isoforms might play a role in the proliferation of thyroid lesions in the setting of estrogen exposure. This molecular interplay has been put forth as a key factor in the prevalence of thyroid carcinoma in young female patients (Ceresini et al. 2006; Zeng et al. 2007; Lee et al. 2005; Inoue et al. 1993).

Treatment with oral estrogen results in a marked increase in thyroxine-binding globulin (Tahboub and Arafah 2009), leading to an increase in the total serum capacity for thyroid 
hormone. In normal subjects, this results in an increase in total T4 but only in a transient drop in free T4. However, in hypothyroid patients receiving thyroxine, a persistent elevation of TSH is observed and dose adjustments are necessary. This effect is not observed with transdermal estrogen therapy, as the absence of liver passage of the drug results in a much weaker effect on thyroxine binding globulin synthesis (Tahboub and Arafah 2009).

Soy protein and soybean isoflavones have been associated with reduced T4 absorption (important for hypothyroid infants on soy formula), interference with thyroid hormone action (Messina and Redmond 2006), and increased thyroid autoimmune disease. The usual intake of dietary soy in those with normal thyroid function has no consistent adverse effects (Doerge and Sheehan 2002). Doerge and Sheehan studied isoflavone interference with thyroid hormone action in vitro (Doerge and Sheehan 2002).

Chemicals with estrogen-mimicking activities were first documented as causing endocrine disruption in the 1950s. Starting the 1990s, additional mechanisms were demonstrated to be involved, encompassing androgen antagonism and disruption of thyroid hormone transport and action, as well as activities mediated by retinoid and peroxisome proliferator-activated receptors, steroidogenic enzymes and neurotransmitter receptors (Diamanti-Kandarakis et al. 2009). Environmental estrogens are manufactured products that contaminate food, water or air, which humans and animals are exposed to (Foster 2008; Sonnenschein and Soto 1998; Tapiero, Ba, and Tew 2002) Many environmental estrogens readily accumulate in the environment and in animal tissues and have been shown to affect both reproductive and nonreproductive organs/systems in animals and humans (Han et al. 2004; Hossaini et al. 2001; Moon et al. 2007; Tsai 2006). Although the genomic effects of these environmental estrogens have been studied extensively and found to be weak (causing government regulatory agencies to consider them "safe"), until recently little, it was known about their nongenomic effects of estrogens (Jeng and Watson 2011). A prominent characteristic that has greatly contributed to the confusion over their toxicity is the nonmonotonic concentration dependence of their nongenomic responses (Palanza, Parmigiani, and vom Saal 2001; Vandenberg et al. 2006; Watson, Jeng, and Kochukov 2010). Environmental estrogens are suspected of affecting a wide variety of functions by interfering with the actions of physiologic estrogens, but sufficiently sensitive techniques for quantitative documentation of these disruptions have generally been lacking (Jeng and Watson 2011).

In summary, estrogens are thought to be related to thyroid hormone deregulation, although the specific mechanisms involved in their action remain unclear.

\subsection{Cigarette smoking}

Tobacco consumption has multiple effects both on thyroid function and thyroid morphology. These include minor and probably physiologically unimportant alterations in thyroid hormones (Christensen et al. 1984; Hegedus et al. 1985; Karakaya et al. 1987; Lio et al. 1989; Petersen et al. 1991; Hegedus et al. 1992; Melander et al. 1981; Eden et al. 1984; Sepkovic, Haley, and Wynder 1984; Nystrom et al. 1993) and thyrotropin concentrations (Christensen et al. 1984; Hegedus et al. 1985; Karakaya et al. 1987; Lio et al. 1989; Petersen et al. 1991; Hegedus et al. 1992; Melander et al. 1981; Eden et al. 1984; Sepkovic, Haley, and Wynder 1984), central (thyroid) and peripheral antithyroid actions (Muller et al. 1995; Utiger 1995), thyroid gland stimulation or goitrogenic effects (Christensen et al. 1984; Hegedus et al. 1985; Lio et al. 1989; Ericsson and Lindgarde 1991), carcinogenic properties (McTiernan, Weiss, and Daling 1984; Ron et al. 1987; Kolonel et al. 1990; Preston-Martin et al. 1993; Shore et al. 1993; Hallquist et al. 1994; Galanti et al. 1996; Rossing et al. 2000; Hallquist et al. 1993; 
Kreiger and Parkes 2000) and also an increase in the susceptibility to Graves' disease (Bartalena et al. 1995; Bufalo et al. 2008; Prummel and Wiersinga 1993) and, in particular, in the incidence and clinical severity of thyroid-associated ophthalmopathy (Bartalena, Pinchera, and Marcocci 2000).

\subsection{Graves' disease and ophthalmopathy}

There are innumerous environmental factors that can contribute to the development of Graves' disease (at least $20-30 \%$ ), which certainly include smoking, probable stress, iodine and selenium intake, several drugs, irradiation, pollutants, viral and bacterial infections, allergy, pregnancy, and postpartum (Tanda et al. 2009). Cigarette smoking is one of the most studied environmental factor and has been demonstrated to increase the risk of Graves' disease (Bartalena et al. 1995; Bufalo et al. 2008; Prummel and Wiersinga 1993; Vestergaard et al. 2002) and decrease the chance of remission of hyperthyroidism, following antithyroid drug treatment (Glinoer, de Nayer, and Bex 2001; Kimball et al. 2002).

Graves' ophthalmopathy (Heufelder 1998; Krassas and Heufelder 2001) is more frequent and severe, and less responsive to medical treatment in smokers than in non-smokers (Prummel and Wiersinga 1993; Bartalena et al. 1989; Bartalena et al. 1998). The first possible connection between cigarette smoking and Graves' ophthalmopathy was made by Hagg and Asplund who showed that 10 out of 12 patients were current smokers, a figure much higher than that observed in Graves' patients without ophthalmopathy $(46 \%)$ or in control subjects (31\%). In addition, the prevalence of heavy smokers was higher in patients with more severe ophthalmopathy (Hagg and Asplund 1987). In a cross-sectional study reviewing the smoking habits of patients with different thyroid diseases, Bartalena et al (Bartalena et al. 1989 ) found a $64 \%$ prevalence of smokers among patients with Graves' ophthalmopathy, a percentage much higher than that of Graves' disease without eye involvement $(48 \%)$, and $30 \%$ in patients with nontoxic goiter, toxic nodular goiter and Hashimoto's thyroiditis. Finally, Tellez et al showed that the prevalence of eye disease correlated not only with smoking but also with ethnicity. The percentage of smokers was higher in Caucasian than in Asian patients (42\% and $7.7 \%$, respectively). This suggests that the genetic background and/or geographic location may influence the prevalence of Graves' ophthalmopathy. Furthermore, this study demonstrated that the effect of smoking was dose-related with a higher proportion of patients developing eye involvement with increasing cigarette consumption (Tellez, Cooper, and Edmonds 1992).

Smoking probably affects cytokine production and effect on the orbit. In this regard, smoke extracts have been shown to synergistically interact with interleukin- 1 to increase adipocyte differentiation of orbital preadipocytes in culture (Cawood et al. 2006) and to stimulate glycosaminoglycan production (Cawood et al. 2007). It is well accepted that cytokines play an important role in the pathogenesis of Graves' ophthalmopathy (Krassas and Heufelder 2001; Heufelder 1995; Krassas et al. 2001). Cigarette smoking may affect this process because smoking-induced hypoxia in the retrobulbar tissue has been shown to increase the release of cytokines from orbital fibroblasts and endothelial cells (Metcalfe and Weetman 1994) and thereby may enhance the expression of adhesion molecules (Heufelder and Bahn 1992). Based on this evidence, refrain from smoking should be strongly recommended to patients with Graves' disease and Graves' ophthalmopathy (Bartalena et al. 2008). In an observational study, smoking cessation was associated with Graves' patients with a decreased risk to develop exophthalmos and diplopia (Pfeilschifter and Ziegler 1996). Smoking seems to influence not only the occurrence and the course of Graves' 
ophthalmopathy, but also the response to various therapeutic interventions, such as orbital radiotherapy and glycocorticoid administration (Bartalena et al. 1998), reported that in patients submitted to orbital radiotherapy and high-dose systemic glucocorticoid treatment for severe Graves' ophthalmopathy; a favorable response to treatment was observed in 61 of 65 non-smokers (94\%) but only in 58 of 85 smokers (68\%).

\subsection{Smoking and autoimmune thyroid diseases (AITD)}

Hegedus et al (Hegedus et al. 1992) found no differences in thyroid-stimulating immunoglobulins (TSIS) among smoking and non-smoking healthy individuals.

Smoking is an independent risk factor for the development of both Graves' disease and Hashimoto's thyroiditis (Prummel and Wiersinga 1993; Vestergaard et al. 2002).

However, the effect of smoking on Hashimoto's disease seems to be the opposite of its effect on Graves' ophthalmopathy. A relationship between smoking and an increased risk of subsequent hypothyroidism has been demonstrated, possibly associated with an antithyroid effect of thiocyanate generated on tobacco smokers (Fukata, Kuma, and Sugawara 1996). Smoking also increased the risk of later development of hypothyroidism in a follow-up study of the general population (Nystrom et al. 1993). Furthermore, smoking seems to impair the effects of thyroid hormones, aggravating the effects of hypothyroidism in a dosedependent manner (Muller et al. 1995). A study that evaluated the prevalence of eye signs in patients with Hashimoto's thyroiditis showed that there was no significant relationship between cigarette smoking and either eye abnormalities or calsequestrin or collagen XIII antibodies in these patients. The eye signs correlated only modestly with calsequestrin and collagen XIII antibodies. In contrast to patients with Graves' disease, where cigarette smoking is shown to be a major risk factor for ophthalmopathy (Bartalena and Tanda 2009; Lim et al. 2008; Nassar et al. 2009), there was no relationship between smoking status and eye abnormalities in patients with Hashimoto's thyroiditis (Tjiang et al. 2010).

Muller et al. found that among women with subclinical hypothyroidism, smokers had higher serum TSH levels, higher serum ratio of T3 to free T4, and also higher cholesterol and low-density lipoprotein cholesterol concentrations than non-smokers (Muller et al. 1995). In contrast, patients with overt hypothyroidism, either smokers or non-smokers, had similar serum TSH and thyroid hormone levels (Muller et al. 1995). These results do not indicate that smoking causes hypothyroidism, but that it may increase the severity of the effects of hypothyroidism (Utiger 1995).

Conversely, a decreased prevalence of TPO-Ab in smokers compared with non-smokers was reported among women of the Amsterdam autoimmune thyroid disorders cohort (Strieder, Prummel et al. 2003). The OR of current smoking for the presence of TPO-Ab was 0.69 (95\% CI, 0.48-0.99). Data from the third National Health and Nutrition Examination Survey (NHANES III) (Belin et al. 2004) indicated that fewer smokers (11\%; 95\% CI, 10-13) had $\mathrm{TPO}-\mathrm{Ab}$ and/or Tg-Ab compared with non-smokers (18\%; 95\% CI, 17-19). The relationship persisted when analyzing the presence of one antibody independently of the status of the other antibody. A Danish population study (Pedersen et al. 2008) found that smoking was negatively associated with the presence of thyroid antibodies, with the strongest association between smoking and $\mathrm{Tg}-\mathrm{Ab}(\mathrm{OR}, 0.5-0.6)$. More recently, Grigoris et al performed a prospective study that demonstrated that the discontinuation of smoking increased the risk of de novo occurrence of serum TPO-Ab and/or $\mathrm{Tg}-\mathrm{Ab}$ in subjects susceptible for developing autoimmune thyroid disorders. The OR of smoking for developing TPO-Ab and/or Tg-Ab were 0.62 [95\% confidence interval $(\mathrm{CI}), 0.37-1.04]$ one year before seroconversion, and 0.59 
(95\% CI, 0.35-0.99) at seroconversion. When only conversion to TPO-Ab is considered, the OR of smoking were $0.58(95 \% \mathrm{CI}, 0.31-1.09)$ one year before seroconversion and 0.54 (95\% CI, 0.29-1.02) at the time of seroconversion (Effraimidis, Tijssen, and Wiersinga 2009). These studies showed good evidence that smoking decreases the prevalence (Strieder, Prummel et al. 2003; Belin et al. 2004; Pedersen et al. 2008) and incidence (Effraimidis, Tijssen, and Wiersinga 2009) of antibodies TPO and Tg, raising an important issue on the physiopathology of such opposite effects of smoking on autoimmunity.

\subsection{Smoking and goiter}

Differing results have been published concerning the association between tobacco smoking and goiter. Some authors found no association between smoking habits and goiter prevalence (Prummel and Wiersinga 1993; Bartalena et al. 1989; Petersen et al. 1991) or thyroid volume (Gomez et al. 2000; Olbricht and Hoff 1988; Berghout et al. 1987). Others have found a positive association between smoking habits and goiter prevalence (Hegedus et al. 1985; Ericsson and Lindgarde 1991; Christensen et al. 1984; Brix et al. 2000) or thyroid volume (Nygaard et al. 1993; Barrere et al. 2000; Hegedus et al. 1985; Georgiadis et al. 1997). It has been suggested that these discrepancies could be caused by differences in iodine status, as the association seems to be stronger in iodine-deficient areas (Bartalena et al. 1995; Bertelsen and Hegedus 1994). In addition, the association between smoking and thyroid volumes is stronger in areas with iodine deficiency. Serum thyroglobulin is also positively associated with smoking habits, and multiple nodules are found more often in smokers than in non-smokers (Knudsen et al. 2002). All these effects are most likely mediated by thiocyanate acting as a competitive inhibitor of iodine uptake and organification (Knudsen et al. 2002).

\subsection{Thiocyanate}

Thiocyanate, a perchlorate-like goitrogen, acts by preventing iodine trapping (Karakaya et al. 1987). It is generated from cigarette smoke as a detoxifying product of cyanide (Karakaya et al. 1987). The levels of the thiocyanate in the blood are related to the amount of cigarette smoke inhalation (Karakaya et al. 1987).

The competitive inhibition of iodide transport by thiocyanate may be important for understanding the action of thiocyanate in vivo. In fact, thiocyanate concentrations obtained by smoking competitively inhibit iodide transportation into the thyroid gland in vitro study on porcine thyroid follicles (Fukayama et al. 1992). Thiocyanate also acts independently of the TSH concentration, inhibiting iodide organification and increasing iodide efflux from the cells (Fukayama et al. 1992). Iodine deficiency may enhance the antithyroid action of thiocyanate and iodide excess may diminish this effect. Thereby, thiocyanate may be responsible for the goitrogenic effect of cigarette smoking seen at least in iodine deficient areas (Hegedus et al. 1985). This mechanism may, in part, explain the diverging results and the regional differences in the goitrogenic effect of cigarette smoking.

Although nicotine content in cigarette smoking does not influence iodide turnover (Fukayama et al. 1992), it might cause sympathetic activation, which could increase thyroid secretion (Melander et al. 1981; Bertelsen and Hegedus 1994). Alternatively, nicotine or other component(s) of tobacco smoking, such as benzopyrene, may have direct thyroidstimulatory actions or stimulating effects on hepatic oxidative metabolism, which in turn may stimulate hepatic conversion of T4 to T3 (Jusko 1979).

It is well known that many factors are involved in the regulation of thyroid volume. TSH levels, iodine concentration, the presence of thyroid autoimmunity and several goitrogens 
are generally accepted factors but others, such as sex, age, body weight or personal habits (e.g. cigarette smoking, alcohol abuse) are controversial in regard to their effect on thyroid volume (Pontikides and Krassas 2002).

\subsection{Thyroid cancer}

During the last two decades, several studies have reported a reduced risk of thyroid cancer, mainly in women, although not always statistically significant, in association with cigarette smoking (McTiernan, Weiss, and Daling 1984; Ron et al. 1987; Kolonel et al. 1990; PrestonMartin et al. 1993; Shore et al. 1993; Hallquist et al. 1994; Galanti et al. 1996; Rossing et al. 2000), in the two major histological groups (papillary and follicular cancers) from all geographic regions (Mack et al. 2003).

Kreiger and Parkers recently explored the association of cigarette smoking with thyroid cancer in both sexes in a case-control study (Kreiger and Parkes 2000). Reduced risk was observed for ever/never cigarette smokers of both sexes with an odds ratio of 0.71 for females (95\% confidence interval $(\mathrm{CI})=0.60-0.83)$ and $0.77(95 \% \mathrm{CI}=0.58-1.02)$ for males.

Since thyroid cancer occurs more frequently in women than in men, hormonal factors may also be involved in its pathogenesis. The mechanism (s) by which cigarette smoking may be protective for thyroid cancer probably involves the lowering of endogenous levels of TSH $[1,8,13,42]$. It has been suggested that increased levels of TSH or elevated levels of other thyroid stimulators, as occurs during pregnancy, are associated with an increased risk of thyroid cancer (Ron et al. 1987). Female preponderance of thyroid cancer has led to the hypothesis that estrogen metabolism may play a role in its pathogenesis. In fact, it has been suggested by some studies that smoking may have an anti-estrogen effect (Baron, La Vecchia, and Levi 1990). However, there is no evidence that smoking has similar effect(s) on androgen metabolism (Dai et al. 1988).

A highly significant correlation has been demonstrated between thiocyanate levels in the mother and cord blood, a finding indicating that thiocyanate freely crosses the placenta (Othman et al. 1990). An inverse correlation was found between thiocyanate levels in cord blood, birth weight, significantly decreased serum TSH levels and increased T4 levels in newborn babies of smoking mothers when compared with non-smoking ones (Othman et al. 1990). Thiocyanate has a biological half-life of 1-2 weeks (Gasparoni et al. 1998). Therefore, measurements in plasma may be used to detect the degree of exposure to smoking from days to weeks after the last consumption. Gasparoni et al (Gasparoni et al. 1998) found that infants whose mothers and fathers smoked had higher cord serum thyroglobulin and thiocyanate concentrations in comparison with infants whose parents did not smoke. However, the infants had no other evidence of thyroid abnormalities, such as increased T4, T3 or decreased TSH concentrations (Meberg and Marstein 1986).

Our group demonstrated an inverse association of germline cytochrome P4501A1 (CYP1A1) inheritance and smoking with the risk of thyroid nodules and papillary carcinomas, helping to explain the reduced risk of differentiated thyroid cancer in tobacco consumers observed in epidemiologic studies (Bufalo et al. 2006).

\subsection{Infections}

Infections have been implicated in the pathogenesis of several autoimmune, endocrine and nonendocrine diseases (Tomer and Davies 1993). Furthermore, they have long been invoked as an underlying etiology or trigger factor for the induction of autoimmune thyroid 
diseases, such as subacute thyroiditis and autoimmune thyroiditis. They are also suspected to be involved in carcinogenesis and in the onset of thyroid lymphomas (Desailloud et al. 2009). Both viral and bacterial infections might represent a risk factor for autoimmune thyroiditis development in genetically predisposed individuals (Desailloud and Hober 2009; Lehmann et al. 2008; Thomas et al. 2008; Tozzoli et al. 2008; Tomer and Davies 1993).

It is possible that multiple exposures to infections are necessary to train our immune system to perform well, but some infections are able to break the tolerance of susceptible individuals and allow autoimmune diseases to develop (Davies 2008). Specific infections could be a triggering factor to disease initiation by liberating antigens (via cell destruction or apoptosis), by forming altered antigens or causing molecular mimicry, by cytokine and chemokine secretion, or by inducing aberrant human leukocyte antigen (HLA)-DR expression and toll-like receptor activation (Harii et al. 2005). Clearance of cell debris can lead to abnormal antigen presentation, especially that of previously sequestered antigens (Mackay, Leskovsek, and Rose 2008). Infection of a rat cell line with reovirus types 1 and 3 induces thyroid cell major histocompatibility complex class II, which may allow presentation of thyroid antigen to the immune system and participate in the initiation of autoimmune thyroid disease (Neufeld, Platzer, and Davies 1989).

Paradoxically, infections may both enhance autoimmune thyroiditis and also act as a protection against autoimmune thyroiditis. There is growing acceptance of a hygiene hypothesis which implies that the immune system is educated by multiple exposures to different infections, allowing better controlled autoimmune responses (Bach 2005; Bloomfield et al. 2006). Thus, improved living standards and decreased exposure to infections are associated with an increased risk of autoimmune disease and lower socioeconomic groups have a reduced prevalence of thyroid autoantibodies (Bach 2005; Kondrashova et al. 2008). A recent study carried out in two adjacent regions of Finland (good socioeconomic and hygiene conditions) and Russia (lower socioeconomic and hygiene conditions), with likely similar genetic background, showed that the presence of chronic autoimmune thyroiditis (and subclinical hypothyroidism) among schoolchildren was much higher in the Finnish population than in the Russian population (Kondrashova et al. 2008).

The best-studied infection in autoimmune thyroiditis is that with Yersinia enterocolitica. Humoral and cellular immunity against Yersinia enterocolitica in patients with autoimmune thyroid diseases has been demonstrated (Bech et al. 1974; Lidman et al. 1974), and Wenzel et al (Wenzel et al. 1988; Wenzel et al. 2003) have found antibodies against virulent plasmidencoded proteins of Yersinia enterocolitica in a large proportion of patients with autoimmune diseases. A potential mechanism could be molecular mimicry (Albert and Inman 1999). In a recent Dutch study, an increased prevalence of antibodies to enteropathogenic Yersinia enterocolitica virulence proteins was found in relatives of autoimmune diseases patients, but this was unrelated to the higher prevalence of TPO antibodies in these subjects (Strieder, Wenzel et al. 2003). According to this hypothesis, the generated Yersinia-specific immune response cross-reacts with thyroid-specific components to cause tissue damage and disease (Albert and Inman 1999).

Epstein-Barr virus seems to play a role in the natural killer/T-cell lymphoma subtype of the orbit, as has long been described for Burkitt lymphoma. Bacteria seem to induce reactive lymphoid proliferation, while viruses directly infect the lymphoid cells, affecting the cell cycle and suppressing apoptosis, with subsequent malignant transformation. In general, proteins leading to cell cycle progression, like retinoblastoma protein, are elevated, and proteins inhibiting cell cycle progression, like p16 and p21, are absent or unable to function 
normally. Inactivation of p53 by mutation of its DNA, which leads to elevation of defective p53 protein and inhibition of apoptosis, allows oncogenic by-chance mutations to become effective (Auw-Hadrich, Gobel, and Illerhaus 2010). Although apoptosis could help to control the reproduction of abnormal cells and, therefore, play a role in the protection of host cells against viral infection and antiviral immune response, there is also some evidence that it can also trigger autoimmunity. Virally induced apoptosis is considered to be at least partially responsible for the various associated pathologies (Young, Dawson, and Eliopoulos 1997). There is increasing evidence that apoptosis could play a role in the development of autoimmune thyroid diseases. Apoptosis induction may result in thyrocyte destruction and lymphocytic infiltration of the thyroid (Wang and Baker 2007)

Human herpesviruses are ubiquitous with widespread tissue tropism and have been found in the thyroid, which can be a reservoir of latent (Nahmias, Lee, and Beckman-Nahmias 1990; Staras et al. 2008). Herpesvirus infection might be involved in the pathophysiology of several chronic autoimmune inflammatory processes (Posnett 2008; Scotet et al. 1999). In fact, herpesviruses were demonstrated in thyroid tissues with both nodular and autoimmune diseases. Thomas et al isolated herpesviruses from $72.22 \%$ of thyroid tissue blocks of patients with Graves' disease and Hashimoto's thyroiditis (Thomas et al. 2008). Krueger et al showed that herpesviruses types 6 and 7 are highly prevalent in the healthy population with a cumulative probability for seropositivity of almost $100 \%$ in young age (Krueger et al. 1998). In addition, herpesviruses may use the thyroid gland and the gastrointestinal system as reservoirs (Kim et al. 2010). Like other infectious agents, herpes infection potentially increases the efficiency of $\mathrm{T}$ cell activation by enhanced expression of costimulatory molecules, upregulation of HLA expression on specialized antigen-presenting cells, and attraction of dendritic cells from peripheral to secondary lymphoid tissues (Leite et al. 2010). Herpesviruses human antiviral response includes two reciprocal cellular programs: cell survival with the production of protective cytokines and other cytokines that could lead to apoptosis for the elimination of infected cells; by that mechanism, virus would be involved in the initiation and progression of autoimmune thyroid disease. Continued activation of innate immunity against herpesviruses infection can also potentiate immune disorders. Using a subset of 280 Graves' disease patients carefully paired with a control group of 284 individuals, we demonstrated that patients with 72TP53 Pro/Pro variants (inherited diminished TP53 apoptotic function) had five times more chance to develop Graves' disease and almost three times more chance to be infected by human herpesviruses type 7. This infection was associated with an increase of three times the susceptibility to Graves' disease (Leite et al. 2010). We suggested that human herpesviruses type 7 may take advantage of the poorer apoptotic ability of $72 \mathrm{TP} 53$ variants to trigger the autoimmune process that leads to Graves' disease. Thus, the inheritance of less efficient TP53 genes would increase the risk of Graves' disease development and also favor human herpesviruses type 7 infection and perpetuation, which in turn may initiate and perpetuate the autoimmune process in Graves' disease (Leite et al. 2010).

Viruses are one of the high-risk factors closely related to human cancers. Many widespread chronic diseases, previously thought to be due to metabolic imbalances or genetic modifications, are increasingly linked to infectious events.

It is estimated that viruses are a contributory cause of $20 \%$ of all human cancers (Dimmock and Primrose 1994). Viruses, such as specific types of human papillomaviruses, EpsteinBarr virus, and human herpesviruses type 8 , have been emerging as major causal factors of some human cancers (Tsai et al. 2005). Viral infection significantly affects the tumor 
microenvironment, induces angiogenesis, and favors the development of metastases (Tsuji et al. 2008). There are several indicators of a possible role for viruses in thyroid cancer. Activation of virus-inducible signaling pathways, such as Toll-like receptor (TLR) signaling, has been shown in papillary thyroid carcinomas (McCall et al. 2007). Parvovirus B19 has been detected in thyroid cancer samples (Wang et al. 2008) and Epstein-Barr virus protein expression was demonstrated in poorly differentiated thyroid cancer (Shimakage et al. 2003). In vitro studies showed expression of herpesviruses entry mediator and nectin-1 in thyroid cancer cell lines (Huang et al. 2007).

Recent evidences also demonstrated that viruses could be directly involved in regulation of the epithelial-to-mesenchymal transition and contribute to the development of metastases. It has been shown that Epstein-Barr virus proteins can control the expression of Twist (Horikawa et al. 2007) and the development of metastases by regulating the metastasis suppressor Nm23 (Kaul et al. 2009).

In humans, herpes simplex virus DNA was detected in thyroid samples from patients with autoimmune disorders (Thomas et al. 2008). Herpes simplex virus replication in epithelial cells is associated with activation of the RAS/MEK/MAPK pathway, which might be important to thyroid carcinogenesis (Smith et al. 2000), since these genes are commonly activated in thyroid cancer. Jensen et al showed that herpes simplex virus can be frequently detected in thyroid cancers, suggesting that during tumor progression, thyroid tumor cells acquire increased susceptibility to herpes simplex virus due to increased expression of nectin-1 and activation of mitogenic signaling (Jensen et al. 2010).

A viral disease is the result of an interaction between virus and host, in which the genetic background plays a role (Desailloud and Hober 2009). Further studies are needed to clarify the pathogenic mechanisms implicated in viruses-induced thyroid disease, aiming to propose new therapeutic strategies.

\subsection{Thyroid disruptor action and human reaction}

Endocrine disruptors act by physiological mechanisms replacing the hormones in our organism, blocking their natural action, or altering (increasing or decreasing) the original amount of hormones, thereby causing important endocrine function disturbances (Santamarta 2001). Most endocrine disruptor agents reduce circulating thyroid hormone levels or impair thyroid hormone action, and some may influence the pituitary and thyrotropin secretion, or even be partial thyroid hormone receptor agonists (Brent 2010). However, the thyroid is able to compensate their effect by increasing serum TSH and continue to produce a normal amount of thyroid hormone despite disruption (Brent, Braverman, and Zoeller 2007). Conversely, most carcinogens do not produce their biological effects per se, but require metabolic activation before they can interact with cellular macromolecules (Cascorbi 2006). Many compounds are converted to reactive electrophilic metabolites by oxidative (phase I) enzymes such as cytochrome P-450, which presumably most important effect is to activate the majority of carcinogens. Nevertheless, phase II enzymes usually act as inactivating enzymes catalyzing the conjugations of carcinogenic substance (Hein 2002). Phase II group of enzymes includes glutathione S-transferase, UDPglucuronosyltransferase and N-acetyltransferase systems (Hein 2002).

We demonstrated that the inheritance of a series of these enzyme systems is involved in the risk for thyroid cancer development and in thyroid autoimmune disease susceptibility (Bufalo et al. 2006; Bufalo et al. 2008; Granja et al. 2005). Identifying a risk profile for thyroid diseases may help delineate polygenic models of susceptibility and prognosis. Such models 
are particularly interesting, considering the elevated prevalence of thyroid diseases in the population, and may help select individuals for specific preventive interventions and determine which patients are most likely to benefit from specific measures.

\section{References}

Agate, L., S. Mariotti, R. Elisei, P. Mossa, F. Pacini, E. Molinaro, L. Grasso, L. Masserini, T. Mokhort, T. Vorontsova, A. Arynchyn, M. D. Tronko, A. Tsyb, U. Feldt-Rasmussen, A. Juul, and A. Pinchera. 2008. Thyroid autoantibodies and thyroid function in subjects exposed to Chernobyl fallout during childhood: evidence for a transient radiation-induced elevation of serum thyroid antibodies without an increase in thyroid autoimmune disease. J Clin Endocrinol Metab 93 (7):2729-36.

Ain, K. B. 1995. Papillary thyroid carcinoma. Etiology, assessment, and therapy. Endocrinol Metab Clin North Am 24 (4):711-60.

Albert, L. J., and R. D. Inman. 1999. Molecular mimicry and autoimmunity. N Engl J Med 341 (27):2068-74.

American Cancer Society: Cancer Facts and Figures 2010. (Last accessed July 15, 2010), http://www.cancer.org/acs/groups/content/@nho/documents/document/acspc -024113.pdf.

Auw-Hadrich, C., N. Gobel, and G. Illerhaus. 2010. [Infectious agents in ocular adnexal tumours]. Klin Monbl Augenheilkd 227 (7):530-7.

Bach, J. F. 2005. [Infections and autoimmunity]. Rev Med Interne 26 Spec No 1:32-4.

Baron, J. A., C. La Vecchia, and F. Levi. 1990. The antiestrogenic effect of cigarette smoking in women. Am J Obstet Gynecol 162 (2):502-14.

Barrere, X., P. Valeix, P. Preziosi, M. Bensimon, B. Pelletier, P. Galan, and S. Hercberg. 2000. Determinants of thyroid volume in healthy French adults participating in the SU.VI.MAX cohort. Clin Endocrinol (Oxf) 52 (3):273-8.

Bartalena, L., L. Baldeschi, A. J. Dickinson, A. Eckstein, P. Kendall-Taylor, C. Marcocci, M. P. Mourits, P. Perros, K. Boboridis, A. Boschi, N. Curro, C. Daumerie, G. J. Kahaly, G. Krassas, C. M. Lane, J. H. Lazarus, M. Marino, M. Nardi, C. Neoh, J. Orgiazzi, S. Pearce, A. Pinchera, S. Pitz, M. Salvi, P. Sivelli, M. Stahl, G. von Arx, and W. M. Wiersinga. 2008. Consensus statement of the European group on Graves' orbitopathy (EUGOGO) on management of Graves' orbitopathy. Thyroid 18 (3):33346.

Bartalena, L., F. Bogazzi, M. L. Tanda, L. Manetti, E. Dell'Unto, and E. Martino. 1995. Cigarette smoking and the thyroid. Eur J Endocrinol 133 (5):507-12.

Bartalena, L., C. Marcocci, M. L. Tanda, L. Manetti, E. Dell'Unto, M. P. Bartolomei, M. Nardi, E. Martino, and A. Pinchera. 1998. Cigarette smoking and treatment outcomes in Graves ophthalmopathy. Ann Intern Med 129 (8):632-5.

Bartalena, L., E. Martino, C. Marcocci, F. Bogazzi, M. Panicucci, F. Velluzzi, A. Loviselli, and A. Pinchera. 1989. More on smoking habits and Graves' ophthalmopathy. J Endocrinol Invest 12 (10):733-7.

Bartalena, L., A. Pinchera, and C. Marcocci. 2000. Management of Graves' ophthalmopathy: reality and perspectives. Endocr Rev 21 (2):168-99.

Bartalena, L., and M. L. Tanda. 2009. Clinical practice. Graves' ophthalmopathy. N Engl J Med 360 (10):994-1001. 
Bech, K., J. H. Larsen, J. M. Hansen, and J. Nerup. 1974. Letter: Yersinia enterocolitica infection and thyroid disorders. Lancet 2 (7886):951-2.

Belin, R. M., B. C. Astor, N. R. Powe, and P. W. Ladenson. 2004. Smoke exposure is associated with a lower prevalence of serum thyroid autoantibodies and thyrotropin concentration elevation and a higher prevalence of mild thyrotropin concentration suppression in the third National Health and Nutrition Examination Survey (NHANES III). J Clin Endocrinol Metab 89 (12):6077-86.

Berghout, A., W. M. Wiersinga, N. J. Smits, and J. L. Touber. 1987. Determinants of thyroid volume as measured by ultrasonography in healthy adults in a non-iodine deficient area. Clin Endocrinol (Oxf) 26 (3):273-80.

Bertelsen, J. B., and L. Hegedus. 1994. Cigarette smoking and the thyroid. Thyroid 4 (3):32731.

Bloomfield, S. F., R. Stanwell-Smith, R. W. Crevel, and J. Pickup. 2006. Too clean, or not too clean: the hygiene hypothesis and home hygiene. Clin Exp Allergy 36 (4):402-25.

Boice, J. D., Jr. 2006. Thyroid disease 60 years after Hiroshima and 20 years after Chernobyl. JAMA 295 (9):1060-2.

Braverman, L. E., and S. H. Ingbar. 1963. Changes in Thyroidal Function during Adaptation to Large Doses of Iodide. J Clin Invest 42:1216-31.

Brenner, D., C. Elliston, E. Hall, and W. Berdon. 2001. Estimated risks of radiation-induced fatal cancer from pediatric CT. AJR Am J Roentgenol 176 (2):289-96.

Brent, G. A. 2010. Environmental exposures and autoimmune thyroid disease. Thyroid 20 (7):755-61.

Brent, G. A., L. E. Braverman, and R. T. Zoeller. 2007. Thyroid health and the environment. Thyroid 17 (9):807-9.

Brix, T. H., P. S. Hansen, K. O. Kyvik, and L. Hegedus. 2000. Cigarette smoking and risk of clinically overt thyroid disease: a population-based twin case-control study. Arch Intern Med 160 (5):661-6.

Brix, T. H., K. O. Kyvik, K. Christensen, and L. Hegedus. 2001. Evidence for a major role of heredity in Graves' disease: a population-based study of two Danish twin cohorts. J Clin Endocrinol Metab 86 (2):930-4.

Bufalo, N. E., J. L. Leite, A. C. Guilhen, E. C. Morari, F. Granja, L. V. Assumpcao, and L. S. Ward. 2006. Smoking and susceptibility to thyroid cancer: an inverse association with CYP1A1 allelic variants. Endocr Relat Cancer 13 (4):1185-93.

Bufalo, N. E., R. B. Santos, A. N. Cury, R. A. Andrade, J. Morari, E. C. Morari, J. L. Leite, O. Monte, J. H. Romaldini, and L. S. Ward. 2008. Genetic polymorphisms associated with cigarette smoking and the risk of Graves' disease. Clin Endocrinol (Oxf) 68 (6):982-7.

Burek, C. L., and M. V. Talor. 2009. Environmental triggers of autoimmune thyroiditis. J Autoimmun 33 (3-4):183-9.

Cabrera-Rode, E., L. Sarmiento, C. Tiberti, G. Molina, J. Barrios, D. Hernandez, O. DiazHorta, and U. Di Mario. 2003. Type 1 diabetes islet associated antibodies in subjects infected by echovirus 16. Diabetologia 46 (10):1348-53.

Cardis, E., A. Kesminiene, V. Ivanov, I. Malakhova, Y. Shibata, V. Khrouch, V. Drozdovitch, E. Maceika, I. Zvonova, O. Vlassov, A. Bouville, G. Goulko, M. Hoshi, A. Abrosimov, J. Anoshko, L. Astakhova, S. Chekin, E. Demidchik, R. Galanti, M. Ito, E. Korobova, E. Lushnikov, M. Maksioutov, V. Masyakin, A. Nerovnia, V. Parshin, 
E. Parshkov, N. Piliptsevich, A. Pinchera, S. Polyakov, N. Shabeka, E. Suonio, V. Tenet, A. Tsyb, S. Yamashita, and D. Williams. 2005. Risk of thyroid cancer after exposure to $131 \mathrm{I}$ in childhood. J Natl Cancer Inst 97 (10):724-32.

Cascorbi, I. 2006. Genetic basis of toxic reactions to drugs and chemicals. Toxicol Lett 162 (1):16-28.

Catelinois, O., P. Verger, M. Colonna, A. Rogel, D. Hemon, and M. Tirmarche. 2004. Projecting the time trend of thyroid cancers: its impact on assessment of radiationinduced cancer risks. Health Phys 87 (6):606-14.

Cawood, T. J., P. Moriarty, C. O'Farrelly, and D. O'Shea. 2006. The effects of tumour necrosis factor-alpha and interleukin1 on an in vitro model of thyroid-associated ophthalmopathy; contrasting effects on adipogenesis. Eur J Endocrinol 155 (3):395403.

2007. Smoking and thyroid-associated ophthalmopathy: A novel explanation of the biological link. J Clin Endocrinol Metab 92 (1):59-64.

Ceresini, G., S. Morganti, V. Graiani, M. Saccani, B. Milli, E. Usberti, G. Valenti, G. P. Ceda, and L. Corcione. 2006. Estrogen receptor (ER)-beta, but not ER-alpha, is present in thyroid vessels: immunohistochemical evaluations in multinodular goiter and papillary thyroid carcinoma. Thyroid 16 (12):1215-20.

Christensen, S. B., U. B. Ericsson, L. Janzon, S. Tibblin, and A. Melander. 1984. Influence of cigarette smoking on goiter formation, thyroglobulin, and thyroid hormone levels in women. J Clin Endocrinol Metab 58 (4):615-8.

Cooper, G. S., M. L. Bynum, and E. C. Somers. 2009. Recent insights in the epidemiology of autoimmune diseases: improved prevalence estimates and understanding of clustering of diseases. J Autoimmun 33 (3-4):197-207.

Dahlquist, G. G., S. Ivarsson, B. Lindberg, and M. Forsgren. 1995. Maternal enteroviral infection during pregnancy as a risk factor for childhood IDDM. A populationbased case-control study. Diabetes 44 (4):408-13.

Dai, W. S., J. P. Gutai, L. H. Kuller, and J. A. Cauley. 1988. Cigarette smoking and serum sex hormones in men. Am J Epidemiol 128 (4):796-805.

Davies, L., and H. G. Welch. 2006. Increasing incidence of thyroid cancer in the United States, 1973-2002. JAMA 295 (18):2164-7.

Davies, T. F. 2008. Infection and autoimmune thyroid disease. J Clin Endocrinol Metab 93 (3):674-6.

Desailloud, R., and D. Hober. 2009. Viruses and thyroiditis: an update. Virol J 6:5.

Desailloud, R., F. Sane, D. Caloone, and D. Hober. 2009. Persistent infection of a carcinoma thyroid cell line with coxsackievirus B. Thyroid 19 (4):369-74.

Diamanti-Kandarakis, E., J. P. Bourguignon, L. C. Giudice, R. Hauser, G. S. Prins, A. M. Soto, R. T. Zoeller, and A. C. Gore. 2009. Endocrine-disrupting chemicals: an Endocrine Society scientific statement. Endocr Rev 30 (4):293-342.

Dijkstra, B., R. S. Prichard, A. Lee, L. M. Kelly, P. P. Smyth, T. Crotty, E. W. McDermott, A. D. Hill, and N. O'Higgins. 2007. Changing patterns of thyroid carcinoma. Ir J Med Sci 176 (2):87-90.

Dimmock, N. J., and S. B. Primrose. 1994. Introduction to modern virology. 4th ed ed, Basic microbiology. Oxford: Blackwell Scientific.

Dobyns, B. M., G. E. Sheline, J. B. Workman, E. A. Tompkins, W. M. McConahey, and D. V. Becker. 1974. Malignant and benign neoplasms of the thyroid in patients treated for 
hyperthyroidism: a report of the cooperative thyrotoxicosis therapy follow-up study. J Clin Endocrinol Metab 38 (6):976-98.

Doerge, D. R., and D. M. Sheehan. 2002. Goitrogenic and estrogenic activity of soy isoflavones. Environ Health Perspect 110 Suppl 3:349-53.

Dua, Tarun, Paul Rompani, World Health Organization., and Multiple Sclerosis International Federation. 2008. Atlas : multiple sclerosis resources in the world, 2008. Geneva, Switzerland: World Health Organization.

Dugrillon, A. 1996. Iodolactones and iodoaldehydes--mediators of iodine in thyroid autoregulation. Exp Clin Endocrinol Diabetes 104 Suppl 4:41-5.

Dunkelmann, S., R. Wolf, A. Koch, C. Kittner, P. Groth, and C. Schuemichen. 2004. Incidence of radiation-induced Graves' disease in patients treated with radioiodine for thyroid autonomy before and after introduction of a high-sensitivity TSH receptor antibody assay. Eur J Nucl Med Mol Imaging 31 (10):1428-34.

Eaton, W. W., N. R. Rose, A. Kalaydjian, M. G. Pedersen, and P. B. Mortensen. 2007. Epidemiology of autoimmune diseases in Denmark. J Autoimmun 29 (1):1-9.

Eden, S., R. Jagenburg, G. Lindstedt, P. A. Lundberg, and D. Mellstrom. 1984. Thyroregulatory changes associated with smoking in 70-year-old men. Clin Endocrinol (Oxf) 21 (6):605-10.

Effraimidis, G., J. G. Tijssen, and W. M. Wiersinga. 2009. Discontinuation of smoking increases the risk for developing thyroid peroxidase antibodies and/or thyroglobulin antibodies: a prospective study. J Clin Endocrinol Metab 94 (4):1324-8.

Enewold, L., K. Zhu, E. Ron, A. J. Marrogi, A. Stojadinovic, G. E. Peoples, and S. S. Devesa. 2009. Rising thyroid cancer incidence in the United States by demographic and tumor characteristics, 1980-2005. Cancer Epidemiol Biomarkers Prev 18 (3):784-91.

Eng, P. H., G. R. Cardona, M. C. Previti, W. W. Chin, and L. E. Braverman. 2001. Regulation of the sodium iodide symporter by iodide in FRTL-5 cells. Eur J Endocrinol 144 (2):139-44.

Ericsson, U. B., and F. Lindgarde. 1991. Effects of cigarette smoking on thyroid function and the prevalence of goitre, thyrotoxicosis and autoimmune thyroiditis. J Intern Med 229 (1):67-71.

Foster, W. G. 2008. Environmental estrogens and endocrine disruption: importance of comparative endocrinology. Endocrinology 149 (9):4267-8.

Fukata, S., K. Kuma, and M. Sugawara. 1996. Relationship between cigarette smoking and hypothyroidism in patients with Hashimoto's thyroiditis. J Endocrinol Invest 19 (9):607-12.

Fukayama, H., M. Nasu, S. Murakami, and M. Sugawara. 1992. Examination of antithyroid effects of smoking products in cultured thyroid follicles: only thiocyanate is a potent antithyroid agent. Acta Endocrinol (Copenh) 127 (6):520-5.

Galanti, M. R., L. Hansson, E. Lund, R. Bergstrom, L. Grimelius, H. Stalsberg, E. Carlsen, J. A. Baron, I. Persson, and A. Ekbom. 1996. Reproductive history and cigarette smoking as risk factors for thyroid cancer in women: a population-based casecontrol study. Cancer Epidemiol Biomarkers Prev 5 (6):425-31.

Gasparoni, A., M. Autelli, M. F. Ravagni-Probizer, A. Bartoli, M. Regazzi-Bonora, G. Chirico, and G. Rondini. 1998. Effect of passive smoking on thyroid function in infants. Eur J Endocrinol 138 (4):379-82. 
Georgiadis, E., C. Papapostolou, T. Korakis, K. Evagelopoulou, C. Mantzoros, and M. Batrinos. 1997. The influence of smoking habits on thyroid gland volume: an ultrasonic approach. J R Soc Health 117 (6):355-8.

Gilbert, E. S., R. Tarone, A. Bouville, and E. Ron. 1998. Thyroid cancer rates and 131I doses from Nevada atmospheric nuclear bomb tests. J Natl Cancer Inst 90 (21):1654-60.

Glinoer, D., P. de Nayer, and M. Bex. 2001. Effects of 1-thyroxine administration, TSHreceptor antibodies and smoking on the risk of recurrence in Graves' hyperthyroidism treated with antithyroid drugs: a double-blind prospective randomized study. Eur J Endocrinol 144 (5):475-83.

Golding, S. J., and P. C. Shrimpton. 2002. Commentary. Radiation dose in CT: are we meeting the challenge? Br J Radiol 75 (889):1-4.

Gomez, J. M., F. J. Maravall, N. Gomez, A. Guma, and J. Soler. 2000. Determinants of thyroid volume as measured by ultrasonography in healthy adults randomly selected. Clin Endocrinol (Oxf) 53 (5):629-34.

Granja, F., E. C. Morari, L. V. Assumpcao, and L. S. Ward. 2005. GSTO polymorphism analysis in thyroid nodules suggest that GSTO1 variants do not influence the risk for malignancy. Eur J Cancer Prev 14 (3):277-80.

Hagg, E., and K. Asplund. 1987. Is endocrine ophthalmopathy related to smoking? Br Med J (Clin Res Ed) 295 (6599):634-5.

Hallquist, A., L. Hardell, A. Degerman, and L. Boquist. 1993. Occupational exposures and thyroid cancer: results of a case-control study. Eur J Cancer Prev 2 (4):345-9.

1994. Thyroid cancer: reproductive factors, previous diseases, drug intake, family history and diet. A case-control study. Eur J Cancer Prev 3 (6):481-8.

Hamatani, K., H. Eguchi, R. Ito, M. Mukai, K. Takahashi, M. Taga, K. Imai, J. Cologne, M. Soda, K. Arihiro, M. Fujihara, K. Abe, T. Hayashi, M. Nakashima, I. Sekine, W. Yasui, Y. Hayashi, and K. Nakachi. 2008. RET/PTC rearrangements preferentially occurred in papillary thyroid cancer among atomic bomb survivors exposed to high radiation dose. Cancer Res 68 (17):7176-82.

Han, X. D., Z. G. Tu, Y. Gong, S. N. Shen, X. Y. Wang, L. N. Kang, Y. Y. Hou, and J. X. Chen. 2004. The toxic effects of nonylphenol on the reproductive system of male rats. Reprod Toxicol 19 (2):215-21.

Harii, N., C. J. Lewis, V. Vasko, K. McCall, U. Benavides-Peralta, X. Sun, M. D. Ringel, M. Saji, C. Giuliani, G. Napolitano, D. J. Goetz, and L. D. Kohn. 2005. Thyrocytes express a functional toll-like receptor 3: overexpression can be induced by viral infection and reversed by phenylmethimazole and is associated with Hashimoto's autoimmune thyroiditis. Mol Endocrinol 19 (5):1231-50.

Hayashi, Y., F. Lagarde, N. Tsuda, S. Funamoto, D. L. Preston, K. Koyama, K. Mabuchi, E. Ron, K. Kodama, and S. Tokuoka. 2010. Papillary microcarcinoma of the thyroid among atomic bomb survivors: tumor characteristics and radiation risk. Cancer 116 (7):1646-55.

Hegedus, L., H. Bliddal, S. Karstrup, and K. Bech. 1992. Thyroid stimulating immunoglobulins are not influenced by smoking in healthy subjects. Thyroidology 4 (2):91-2.

Hegedus, L., S. Karstrup, D. Veiergang, B. Jacobsen, L. Skovsted, and U. Feldt-Rasmussen. 1985. High frequency of goitre in cigarette smokers. Clin Endocrinol (Oxf) 22 (3):28792. 
Hein, D. W. 2002. Molecular genetics and function of NAT1 and NAT2: role in aromatic amine metabolism and carcinogenesis. Mutat Res 506-507:65-77.

Heufelder, A. E. 1995. Pathogenesis of Graves' ophthalmopathy: recent controversies and progress. Eur J Endocrinol 132 (5):532-41.

1998. T-cell restriction in thyroid eye disease. Thyroid 8 (5):419-22.

Heufelder, A. E., and R. S. Bahn. 1992. Graves' immunoglobulins and cytokines stimulate the expression of intercellular adhesion molecule-1 (ICAM-1) in cultured Graves' orbital fibroblasts. Eur J Clin Invest 22 (8):529-37.

Higuchi, T. 1964. [the Study of Endemic Seashore Goiter in Hokkaido (1)]. Nippon Naibunpi Gakkai Zasshi 40:982-95.

Hiltunen, M., H. Hyoty, M. Knip, J. Ilonen, H. Reijonen, P. Vahasalo, M. Roivainen, M. Lonnrot, P. Leinikki, T. Hovi, and H. K. Akerblom. 1997. Islet cell antibody seroconversion in children is temporally associated with enterovirus infections. Childhood Diabetes in Finland (DiMe) Study Group. J Infect Dis 175 (3):554-60.

Horikawa, T., J. Yang, S. Kondo, T. Yoshizaki, I. Joab, M. Furukawa, and J. S. Pagano. 2007. Twist and epithelial-mesenchymal transition are induced by the EBV oncoprotein latent membrane protein 1 and are associated with metastatic nasopharyngeal carcinoma. Cancer Res 67 (5):1970-8.

Hossaini, A., M. Dalgaard, A. M. Vinggaard, H. Frandsen, and J. J. Larsen. 2001. In utero reproductive study in rats exposed to nonylphenol. Reprod Toxicol 15 (5):537-43.

Huang, Y. Y., Z. Yu, S. F. Lin, S. Li, Y. Fong, and R. J. Wong. 2007. Nectin-1 is a marker of thyroid cancer sensitivity to herpes oncolytic therapy. J Clin Endocrinol Metab 92 (5):1965-70.

Hughes, D. T., M. R. Haymart, B. S. Miller, P. G. Gauger, and G. M. Doherty. 2011. The most commonly occurring papillary thyroid cancer in the United States is now a microcarcinoma in a patient older than 45 years. Thyroid 21 (3):231-6.

Hyoty, H., and K. W. Taylor. 2002. The role of viruses in human diabetes. Diabetologia 45 (10):1353-61.

Imaizumi, M., T. Usa, T. Tominaga, K. Neriishi, M. Akahoshi, E. Nakashima, K. Ashizawa, A. Hida, M. Soda, S. Fujiwara, M. Yamada, E. Ejima, N. Yokoyama, M. Okubo, K. Sugino, G. Suzuki, R. Maeda, S. Nagataki, and K. Eguchi. 2006. Radiation doseresponse relationships for thyroid nodules and autoimmune thyroid diseases in Hiroshima and Nagasaki atomic bomb survivors 55-58 years after radiation exposure. JAMA 295 (9):1011-22.

Inoue, H., K. Oshimo, H. Miki, M. Kawano, and Y. Monden. 1993. Immunohistochemical study of estrogen receptors and the responsiveness to estrogen in papillary thyroid carcinoma. Cancer $72(4): 1364-8$.

Ito, Y., and A. Miyauchi. 2009. Prognostic factors and therapeutic strategies for differentiated carcinomas of the thyroid. Endocr J 56 (2):177-92.

Jeng, Y. J., and C. S. Watson. 2011. Combinations of physiologic estrogens with xenoestrogens alter ERK phosphorylation profiles in rat pituitary cells. Environ Health Perspect 119 (1):104-12.

Jensen, K., A. Patel, A. Larin, V. Hoperia, M. Saji, A. Bauer, K. Yim, V. Hemming, and V. Vasko. 2010. Human herpes simplex viruses in benign and malignant thyroid tumours. J Pathol 221 (2):193-200. 
Jusko, W. J. 1979. Influence of cigarette smoking on drug metabolism in man. Drug Metab $\operatorname{Rev} 9$ (2):221-36.

Karakaya, A., N. Tuncel, G. Alptuna, Z. Kocer, and G. Erbay. 1987. Influence of cigarette smoking on thyroid hormone levels. Hum Toxicol 6 (6):507-9.

Kaul, R., M. Murakami, K. Lan, T. Choudhuri, and E. S. Robertson. 2009. EBNA3C can modulate the activities of the transcription factor Necdin in association with metastasis suppressor protein Nm23-H1. J Virol 83 (10):4871-83.

Kawabata, W., T. Suzuki, T. Moriya, K. Fujimori, H. Naganuma, S. Inoue, Y. Kinouchi, K. Kameyama, H. Takami, T. Shimosegawa, and H. Sasano. 2003. Estrogen receptors (alpha and beta) and 17beta-hydroxysteroid dehydrogenase type 1 and 2 in thyroid disorders: possible in situ estrogen synthesis and actions. Mod Pathol 16 (5):437-44.

Kazakov, V. S., E. P. Demidchik, and L. N. Astakhova. 1992. Thyroid cancer after Chernobyl. Nature 359 (6390):21.

Kerber, R. A., J. E. Till, S. L. Simon, J. L. Lyon, D. C. Thomas, S. Preston-Martin, M. L. Rallison, R. D. Lloyd, and W. Stevens. 1993. A cohort study of thyroid disease in relation to fallout from nuclear weapons testing. JAMA 270 (17):2076-82.

Kilfoy, B. A., S. S. Devesa, M. H. Ward, Y. Zhang, P. S. Rosenberg, T. R. Holford, and W. F. Anderson. 2009. Gender is an age-specific effect modifier for papillary cancers of the thyroid gland. Cancer Epidemiol Biomarkers Prev 18 (4):1092-100.

Kilfoy, B. A., T. Zheng, T. R. Holford, X. Han, M. H. Ward, A. Sjodin, Y. Zhang, Y. Bai, C. Zhu, G. L. Guo, and N. Rothman. 2009. International patterns and trends in thyroid cancer incidence, 1973-2002. Cancer Causes Control 20 (5):525-31.

Kim, J. H., E. S. Jung, Y. Kwon, E. Y. Choi, H. Jeong, S. Kim, C. G. Park, S. J. Kim, and E. S. Hwang. 2010. Infection of porcine cells with human herpesviruses. Transplant Proc 42 (6):2134-7.

Kimball, L. E., E. Kulinskaya, B. Brown, C. Johnston, and N. R. Farid. 2002. Does smoking increase relapse rates in Graves' disease? J Endocrinol Invest 25 (2):152-7.

Knobel, M., and G. Medeiros-Neto. 2007. Relevance of iodine intake as a reputed predisposing factor for thyroid cancer. Arq Bras Endocrinol Metabol 51 (5):701-12.

Knudsen, N., P. Laurberg, H. Perrild, I. Bulow, L. Ovesen, and T. Jorgensen. 2002. Risk factors for goiter and thyroid nodules. Thyroid 12 (10):879-88.

Kolonel, L. N., J. H. Hankin, L. R. Wilkens, F. H. Fukunaga, and M. W. Hinds. 1990. An epidemiologic study of thyroid cancer in Hawaii. Cancer Causes Control 1 (3):223-34.

Kondrashova, A., H. Viskari, A. M. Haapala, T. Seiskari, P. Kulmala, J. Ilonen, M. Knip, and H. Hyoty. 2008. Serological evidence of thyroid autoimmunity among schoolchildren in two different socioeconomic environments. J Clin Endocrinol Metab 93 (3):729-34.

Konno, N., H. Makita, K. Yuri, N. Iizuka, and K. Kawasaki. 1994. Association between dietary iodine intake and prevalence of subclinical hypothyroidism in the coastal regions of Japan. J Clin Endocrinol Metab 78 (2):393-7.

Konno, N., K. Yuri, H. Taguchi, K. Miura, S. Taguchi, K. Hagiwara, and S. Murakami. 1993. Screening for thyroid diseases in an iodine sufficient area with sensitive thyrotrophin assays, and serum thyroid autoantibody and urinary iodide determinations. Clin Endocrinol (Oxf) 38 (3):273-81.

Krassas, G. E., and A. E. Heufelder. 2001. Immunosuppressive therapy in patients with thyroid eye disease: an overview of current concepts. Eur J Endocrinol 144 (4):311-8. 
Krassas, G. E., N. Pontikides, D. Doukidis, G. Heufelder, and A. E. Heufelder. 2001. Serum levels of tumor necrosis factor-alpha, soluble intercellular adhesion molecule-1, soluble vascular cell adhesion molecule-1, and soluble interleukin-1 receptor antagonist in patients with thyroid eye disease undergoing treatment with somatostatin analogues. Thyroid 11 (12):1115-22.

Kreiger, N., and R. Parkes. 2000. Cigarette smoking and the risk of thyroid cancer. Eur J Cancer 36 (15):1969-73.

Krueger, G. R., B. Koch, N. Leyssens, Z. Berneman, J. Rojo, C. Horwitz, T. Sloots, M. Margalith, J. D. Conradie, S. Imai, I. Urasinski, M. de Bruyere, V. Ferrer Argote, and J. Krueger. 1998. Comparison of seroprevalences of human herpesvirus- 6 and -7 in healthy blood donors from nine countries. Vox Sang 75 (3):193-7.

Lee, M. L., G. G. Chen, A. C. Vlantis, G. M. Tse, B. C. Leung, and C. A. van Hasselt. 2005. Induction of thyroid papillary carcinoma cell proliferation by estrogen is associated with an altered expression of Bcl-xL. Cancer J 11 (2):113-21.

Lehmann, H. W., N. Lutterbuse, A. Plentz, I. Akkurt, N. Albers, B. P. Hauffa, O. Hiort, E. Schoenau, and S. Modrow. 2008. Association of parvovirus B19 infection and Hashimoto's thyroiditis in children. Viral Immunol 21 (3):379-83.

Leite, J. L., N. E. Bufalo, R. B. Santos, J. H. Romaldini, and L. S. Ward. 2010. Herpesvirus type 7 infection may play an important role in individuals with a genetic profile of susceptibility to Graves' disease. Eur J Endocrinol 162 (2):315-21.

Lidman, K., U. Eriksson, A. Fagraeus, and R. Norberg. 1974. Letter: Antibodies against thyroid cells in Yersinia enterocolitica infection. Lancet 2 (7894):1449.

Lim, S. L., A. K. Lim, M. Mumtaz, E. Hussein, W. M. Wan Bebakar, and A. S. Khir. 2008. Prevalence, risk factors, and clinical features of thyroid-associated ophthalmopathy in multiethnic Malaysian patients with Graves' disease. Thyroid 18 (12):1297-301.

Lio, S., G. Napolitano, G. Marinuzzi, and F. Monaco. 1989. Role of smoking in goiter morphology and thyrotropin response to TRH in untreated goitrous women. $J$ Endocrinol Invest 12 (2):93-7.

Liu, S., R. Semenciw, A. M. Ugnat, and Y. Mao. 2001. Increasing thyroid cancer incidence in Canada, 1970-1996: time trends and age-period-cohort effects. $\mathrm{Br} J$ Cancer 85 (9):1335-9.

Lonnrot, M., K. Korpela, M. Knip, J. Ilonen, O. Simell, S. Korhonen, K. Savola, P. Muona, T. Simell, P. Koskela, and H. Hyoty. 2000. Enterovirus infection as a risk factor for beta-cell autoimmunity in a prospectively observed birth cohort: the Finnish Diabetes Prediction and Prevention Study. Diabetes 49 (8):1314-8.

Lonnrot, M., K. Salminen, M. Knip, K. Savola, P. Kulmala, P. Leinikki, T. Hyypia, H. K. Akerblom, and H. Hyoty. 2000. Enterovirus RNA in serum is a risk factor for betacell autoimmunity and clinical type 1 diabetes: a prospective study. Childhood Diabetes in Finland (DiMe) Study Group. J Med Virol 61 (2):214-20.

Lyon, J. L., S. C. Alder, M. B. Stone, A. Scholl, J. C. Reading, R. Holubkov, X. Sheng, G. L. White, Jr., K. T. Hegmann, L. Anspaugh, F. O. Hoffman, S. L. Simon, B. Thomas, R. Carroll, and A. W. Meikle. 2006. Thyroid disease associated with exposure to the Nevada nuclear weapons test site radiation: a reevaluation based on corrected dosimetry and examination data. Epidemiology 17 (6):604-14.

Mack, W. J., S. Preston-Martin, L. Dal Maso, R. Galanti, M. Xiang, S. Franceschi, A. Hallquist, F. Jin, L. Kolonel, C. La Vecchia, F. Levi, A. Linos, E. Lund, A. 
McTiernan, K. Mabuchi, E. Negri, G. Wingren, and E. Ron. 2003. A pooled analysis of case-control studies of thyroid cancer: cigarette smoking and consumption of alcohol, coffee, and tea. Cancer Causes Control 14 (8):773-85.

Mackay, I. R., N. V. Leskovsek, and N. R. Rose. 2008. Cell damage and autoimmunity: a critical appraisal. J Autoimmun 30 (1-2):5-11.

Mahoney, M. C., S. Lawvere, K. L. Falkner, Y. I. Averkin, V. A. Ostapenko, A. M. Michalek, K. B. Moysich, and P. L. McCarthy. 2004. Thyroid cancer incidence trends in Belarus: examining the impact of Chernobyl. Int J Epidemiol 33 (5):1025-33.

Maitino, A. J., D. C. Levin, L. Parker, V. M. Rao, and J. H. Sunshine. 2003. Nationwide trends in rates of utilization of noninvasive diagnostic imaging among the Medicare population between 1993 and 1999. Radiology 227 (1):113-7.

Markou, K., N. Georgopoulos, V. Kyriazopoulou, and A. G. Vagenakis. 2001. IodineInduced hypothyroidism. Thyroid 11 (5):501-10.

McCall, K. D., N. Harii, C. J. Lewis, R. Malgor, W. B. Kim, M. Saji, A. D. Kohn, R. T. Moon, and L. D. Kohn. 2007. High basal levels of functional toll-like receptor 3 (TLR3) and noncanonical Wnt5a are expressed in papillary thyroid cancer and are coordinately decreased by phenylmethimazole together with cell proliferation and migration. Endocrinology 148 (9):4226-37.

McTiernan, A. M., N. S. Weiss, and J. R. Daling. 1984. Incidence of thyroid cancer in women in relation to reproductive and hormonal factors. Am J Epidemiol 120 (3):423-35.

Meberg, A., and S. Marstein. 1986. Smoking during pregnancy--effects on the fetal thyroid function. Acta Paediatr Scand 75 (5):762-6.

Medeiros-Neto, G. 2009. Iodine nutrition in Brazil: where do we stand? Arq Bras Endocrinol Metabol 53 (4):470-4.

Melander, A., E. Nordenskjold, B. Lundh, and J. Thorell. 1981. Influence of smoking on thyroid activity. Acta Med Scand 209 (1-2):41-3.

Messina, M., and G. Redmond. 2006. Effects of soy protein and soybean isoflavones on thyroid function in healthy adults and hypothyroid patients: a review of the relevant literature. Thyroid 16 (3):249-58.

Metcalfe, R. A., and A. P. Weetman. 1994. Stimulation of extraocular muscle fibroblasts by cytokines and hypoxia: possible role in thyroid-associated ophthalmopathy. Clin Endocrinol (Oxf) 40 (1):67-72.

Michels, A. W., and G. S. Eisenbarth. 2010. Immunologic endocrine disorders. J Allergy Clin Immunol 125 (2 Suppl 2):S226-37.

Mizukami, Y., T. Michigishi, A. Nonomura, T. Hashimoto, N. Tonami, F. Matsubara, and E. Takazakura. 1993. Iodine-induced hypothyroidism: a clinical and histological study of 28 patients. J Clin Endocrinol Metab 76 (2):466-71.

Money, S. R., W. Muss, W. L. Thelmo, O. Boeckl, W. Pimpl, H. Kaindl, P. Sungler, J. Kirwin, H. Waclawicek, B. M. Jaffe, and et al. 1989. Immunocytochemical localization of estrogen and progesterone receptors in human thyroid. Surgery 106 (6):975-8; discussion 979.

Moon, H. J., S. Y. Han, J. H. Shin, I. H. Kang, T. S. Kim, J. H. Hong, S. H. Kim, and S. E. Fenton. 2007. Gestational exposure to nonylphenol causes precocious mammary gland development in female rat offspring. J Reprod Dev 53 (2):333-44. 
Morris, L. G., and D. Myssiorek. 2010. Improved detection does not fully explain the rising incidence of well-differentiated thyroid cancer: a population-based analysis. Am J Surg 200 (4):454-61.

Muller, B., H. Zulewski, P. Huber, J. G. Ratcliffe, and J. J. Staub. 1995. Impaired action of thyroid hormone associated with smoking in women with hypothyroidism. $N$ Engl J Med 333 (15):964-9.

Mushkacheva, G., E. Rabinovich, V. Privalov, S. Povolotskaya, V. Shorokhova, S. Sokolova, V. Turdakova, E. Ryzhova, P. Hall, A. B. Schneider, D. L. Preston, and E. Ron. 2006. Thyroid abnormalities associated with protracted childhood exposure to 131I from atmospheric emissions from the Mayak weapons facility in Russia. Radiat Res 166 (5):715-22.

Nagataki, S., Y. Shibata, S. Inoue, N. Yokoyama, M. Izumi, and K. Shimaoka. 1994. Thyroid diseases among atomic bomb survivors in Nagasaki. JAMA 272 (5):364-70.

Nahmias, A. J., F. K. Lee, and S. Beckman-Nahmias. 1990. Sero-epidemiological and sociological patterns of herpes simplex virus infection in the world. Scand I Infect Dis Suppl 69:19-36.

Nassar, M. M., A. J. Dickinson, C. Neoh, C. Powell, D. Buck, E. Galal, and M. P. Clarke. 2009. Parameters predicting outcomes of strabismus surgery in the management of Graves' ophthalmopathy. J AAPOS 13 (3):236-40.

Nauman, J., and J. Wolff. 1993. Iodide prophylaxis in Poland after the Chernobyl reactor accident: benefits and risks. Am J Med 94 (5):524-32.

Neufeld, D. S., M. Platzer, and T. F. Davies. 1989. Reovirus induction of MHC class II antigen in rat thyroid cells. Endocrinology 124 (1):543-5.

$\mathrm{Ng}$, A. K., L. B. Kenney, E. S. Gilbert, and L. B. Travis. 2010. Secondary malignancies across the age spectrum. Semin Radiat Oncol 20 (1):67-78.

Nikiforov, Y. E. 2010. Is ionizing radiation responsible for the increasing incidence of thyroid cancer? Cancer 116 (7):1626-8.

Nikiforov, Y. E., J. M. Rowland, K. E. Bove, H. Monforte-Munoz, and J. A. Fagin. 1997. Distinct pattern of ret oncogene rearrangements in morphological variants of radiation-induced and sporadic thyroid papillary carcinomas in children. Cancer Res 57 (9):1690-4.

Nygaard, B., P. Gideon, H. Dige-Petersen, N. Jespersen, K. Solling, and A. Veje. 1993. Thyroid volume and morphology and urinary iodine excretion in a Danish municipality. Acta Endocrinol (Copenh) 129 (6):505-10.

Nystrom, E., C. Bengtsson, L. Lapidus, K. Petersen, and G. Lindstedt. 1993. Smoking--a risk factor for hypothyroidism. J Endocrinol Invest 16 (2):129-31.

Obregon, M. J., F. Escobar del Rey, and G. Morreale de Escobar. 2005. The effects of iodine deficiency on thyroid hormone deiodination. Thyroid 15 (8):917-29.

Olbricht, T., and H. G. Hoff. 1988. [Factors affecting thyroid gland volume. A contribution to the epidemiology of struma]. Med Klin (Munich) 83 (8-9):279-84.

Ostroumova, E., A. Brenner, V. Oliynyk, R. McConnell, J. Robbins, G. Terekhova, L. Zablotska, I. Likhtarev, A. Bouville, V. Shpak, V. Markov, I. Masnyk, E. Ron, M. Tronko, and M. Hatch. 2009. Subclinical hypothyroidism after radioiodine exposure: Ukrainian-American cohort study of thyroid cancer and other thyroid diseases after the Chornobyl accident (1998-2000). Environ Health Perspect 117 (5):745-50. 
Othman, S., D. I. Phillips, A. B. Parkes, C. J. Richards, B. Harris, H. Fung, C. Darke, R. John, R. Hall, and J. H. Lazarus. 1990. A long-term follow-up of postpartum thyroiditis. Clin Endocrinol (Oxf) 32 (5):559-64.

Palanza, P., S. Parmigiani, and F. S. vom Saal. 2001. Effects of prenatal exposure to low doses of diethylstilbestrol, o,p'DDT, and methoxychlor on postnatal growth and neurobehavioral development in male and female mice. Horm Behav 40 (2):252-65.

Papanastasiou, L., I. A. Vatalas, D. A. Koutras, and G. Mastorakos. 2007. Thyroid autoimmunity in the current iodine environment. Thyroid 17 (8):729-39.

Pedersen, I. B., P. Laurberg, N. Knudsen, T. Jorgensen, H. Perrild, L. Ovesen, and L. B. Rasmussen. 2008. Smoking is negatively associated with the presence of thyroglobulin autoantibody and to a lesser degree with thyroid peroxidase autoantibody in serum: a population study. Eur J Endocrinol 158 (3):367-73.

Petersen, K., G. Lindstedt, P. A. Lundberg, C. Bengtsson, L. Lapidus, and E. Nystrom. 1991. Thyroid disease in middle-aged and elderly Swedish women: thyroid-related hormones, thyroid dysfunction and goitre in relation to age and smoking. J Intern Med 229 (5):407-13.

Pfeilschifter, J., and R. Ziegler. 1996. Smoking and endocrine ophthalmopathy: impact of smoking severity and current vs lifetime cigarette consumption. Clin Endocrinol (Oxf) 45 (4):477-81.

Pinchera, A. 2007. Thyroid incidentalomas. Horm Res 68 Suppl 5:199-201.

Pontikides, N., and G. E. Krassas. 2002. Influence of cigarette smoking on thyroid function, goiter formation and autoimmune thyroid disorders. Hormones (Athens) 1 (2):91-8.

Posnett, D. N. 2008. Herpesviruses and autoimmunity. Curr Opin Investig Drugs 9 (5):505-14.

Pottern, L. M., M. M. Kaplan, P. R. Larsen, J. E. Silva, R. J. Koenig, J. H. Lubin, M. Stovall, and J. D. Boice, Jr. 1990. Thyroid nodularity after childhood irradiation for lymphoid hyperplasia: a comparison of questionnaire and clinical findings. J Clin Epidemiol 43 (5):449-60.

Pottern, L. M., B. J. Stone, N. E. Day, L. W. Pickle, and J. F. Fraumeni, Jr. 1980. Thyroid cancer in Connecticut, 1935-1975: an analysis by cell type. Am J Epidemiol 112 (6):764-74.

Preston-Martin, S., F. Jin, M. J. Duda, and W. J. Mack. 1993. A case-control study of thyroid cancer in women under age 55 in Shanghai (People's Republic of China). Cancer Causes Control 4 (5):431-40.

Preston, D. L., E. Ron, S. Tokuoka, S. Funamoto, N. Nishi, M. Soda, K. Mabuchi, and K. Kodama. 2007. Solid cancer incidence in atomic bomb survivors: 1958-1998. Radiat Res 168 (1):1-64.

Prokop, M. 2001. [Optimizing dosage in thoracic computerized tomography]. Radiologe 41 (3):269-78.

Prummel, M. F., T. Strieder, and W. M. Wiersinga. 2004. The environment and autoimmune thyroid diseases. Eur J Endocrinol 150 (5):605-18.

Prummel, M. F., and W. M. Wiersinga. 1993. Smoking and risk of Graves' disease. JAMA 269 (4):479-82.

Raben, M. S. 1949. The paradoxical effects of thiocyanate and of thyrotropin on the organic binding of iodine by the thyroid in the presence of large amounts of iodide. Endocrinology 45 (3):296-304.

Rapoport, B., and S. M. McLachlan. 2001. Thyroid autoimmunity. J Clin Invest 108 (9):1253-9. 
Reynolds, R. M., J. Weir, D. L. Stockton, D. H. Brewster, T. C. Sandeep, and M. W. Strachan. 2005. Changing trends in incidence and mortality of thyroid cancer in Scotland. Clin Endocrinol (Oxf) 62 (2):156-62.

Ron, E. 2003. Cancer risks from medical radiation. Health Phys 85 (1):47-59.

Ron, E., R. A. Kleinerman, J. D. Boice, Jr., V. A. LiVolsi, J. T. Flannery, and J. F. Fraumeni, Jr. 1987. A population-based case-control study of thyroid cancer. J Natl Cancer Inst 79 (1):1-12.

Ron, E., J. H. Lubin, R. E. Shore, K. Mabuchi, B. Modan, L. M. Pottern, A. B. Schneider, M. A. Tucker, and J. D. Boice, Jr. 1995. Thyroid cancer after exposure to external radiation: a pooled analysis of seven studies. Radiat Res 141 (3):259-77.

Ron, E., B. Modan, D. Preston, E. Alfandary, M. Stovall, and J. D. Boice, Jr. 1989. Thyroid neoplasia following low-dose radiation in childhood. Radiat Res 120 (3):516-31.

Rossing, M. A., K. L. Cushing, L. F. Voigt, K. G. Wicklund, and J. R. Daling. 2000. Risk of papillary thyroid cancer in women in relation to smoking and alcohol consumption. Epidemiology 11 (1):49-54.

Santamarta, José. 2001. A ameaça dos disruptores endócrinos. Revista Agroecologia e Desenvolvimento Rural Sustentável 2 (3).

Schneider, A. B., E. Ron, J. Lubin, M. Stovall, and T. C. Gierlowski. 1993. Dose-response relationships for radiation-induced thyroid cancer and thyroid nodules: evidence for the prolonged effects of radiation on the thyroid. J Clin Endocrinol Metab 77 (2):362-9.

Schonfeld, S. J., C. Lee, and A. Berrington de Gonzalez. 2011. Medical Exposure to Radiation and Thyroid Cancer. Clin Oncol (R Coll Radiol).

Scotet, E., M. A. Peyrat, X. Saulquin, C. Retiere, C. Couedel, F. Davodeau, N. Dulphy, A. Toubert, J. D. Bignon, A. Lim, H. Vie, M. M. Hallet, R. Liblau, M. Weber, J. M. Berthelot, E. Houssaint, and M. Bonneville. 1999. Frequent enrichment for CD8 T cells reactive against common herpes viruses in chronic inflammatory lesions: towards a reassessment of the physiopathological significance of $\mathrm{T}$ cell clonal expansions found in autoimmune inflammatory processes. Eur J Immunol 29 (3):973-85.

Sepkovic, D. W., N. J. Haley, and E. L. Wynder. 1984. Thyroid activity in cigarette smokers. Arch Intern Med 144 (3):501-3.

Serrano-Nascimento, C., J. Calil-Silveira, and M. T. Nunes. 2010. Posttranscriptional regulation of sodium-iodide symporter mRNA expression in the rat thyroid gland by acute iodide administration. Am J Physiol Cell Physiol 298 (4):C893-9.

Sharma, R. B., J. D. Alegria, M. V. Talor, N. R. Rose, P. Caturegli, and C. L. Burek. 2005. Iodine and IFN-gamma synergistically enhance intercellular adhesion molecule 1 expression on NOD.H2h4 mouse thyrocytes. J Immunol 174 (12):7740-5.

Sharma, R., K. Traore, M. A. Trush, N. R. Rose, and C. L. Burek. 2008. Intracellular adhesion molecule-1 up-regulation on thyrocytes by iodine of non-obese diabetic.H2(h4) mice is reactive oxygen species-dependent. Clin Exp Immunol 152 (1):13-20.

Shibata, Y., S. Yamashita, V. B. Masyakin, G. D. Panasyuk, and S. Nagataki. 2001. 15 years after Chernobyl: new evidence of thyroid cancer. Lancet 358 (9297):1965-6.

Shimakage, M., K. Kawahara, T. Sasagawa, H. Inoue, M. Yutsudo, A. Yoshida, and S. Yanoma. 2003. Expression of Epstein-Barr virus in thyroid carcinoma correlates with tumor progression. Hum Pathol 34 (11):1170-7. 
Shoenfeld, Y., C. Selmi, E. Zimlichman, and M. E. Gershwin. 2008. The autoimmunologist: geoepidemiology, a new center of gravity, and prime time for autoimmunity. $J$ Autoimmun 31 (4):325-30.

Shore, R. E., N. Hildreth, P. Dvoretsky, E. Andresen, M. Moseson, and B. Pasternack. 1993. Thyroid cancer among persons given X-ray treatment in infancy for an enlarged thymus gland. Am J Epidemiol 137 (10):1068-80.

Shore, R. E., M. Moseson, N. Harley, and B. S. Pasternack. 2003. Tumors and other diseases following childhood $x$-ray treatment for ringworm of the scalp (Tinea capitis). Health Phys 85 (4):404-8.

Simon, Z., Z. Ress, J. Toldi, A. Trauninger, Z. Miltenyi, and A. Illes. 2009. Rare association of Hodgkin lymphoma, Graves' disease and myasthenia gravis complicated by postradiation neurofibrosarcoma: coincidence or genetic susceptibility? Int J Hematol 89 (4):523-8.

Sklar, C., J. Whitton, A. Mertens, M. Stovall, D. Green, N. Marina, B. Greffe, S. Wolden, and L. Robison. 2000. Abnormalities of the thyroid in survivors of Hodgkin's disease: data from the Childhood Cancer Survivor Study. J Clin Endocrinol Metab 85 (9):322732.

Smith, C. C., J. Nelson, L. Aurelian, M. Gober, and B. B. Goswami. 2000. Ras-GAP binding and phosphorylation by herpes simplex virus type 2 RR1 PK (ICP10) and activation of the Ras/MEK/MAPK mitogenic pathway are required for timely onset of virus growth. J Virol 74 (22):10417-29.

Sonnenschein, C., and A. M. Soto. 1998. An updated review of environmental estrogen and androgen mimics and antagonists. J Steroid Biochem Mol Biol 65 (1-6):143-50.

Sprague, B. L., S. Warren Andersen, and A. Trentham-Dietz. 2008. Thyroid cancer incidence and socioeconomic indicators of health care access. Cancer Causes Control 19 (6):58593.

Staras, S. A., W. D. Flanders, S. C. Dollard, R. F. Pass, J. E. McGowan, Jr., and M. J. Cannon. 2008. Cytomegalovirus seroprevalence and childhood sources of infection: A population-based study among pre-adolescents in the United States. J Clin Virol 43 (3):266-71.

Strieder, T. G., M. F. Prummel, J. G. Tijssen, E. Endert, and W. M. Wiersinga. 2003. Risk factors for and prevalence of thyroid disorders in a cross-sectional study among healthy female relatives of patients with autoimmune thyroid disease. Clin Endocrinol (Oxf) 59 (3):396-401.

Strieder, T. G., B. E. Wenzel, M. F. Prummel, J. G. Tijssen, and W. M. Wiersinga. 2003. Increased prevalence of antibodies to enteropathogenic Yersinia enterocolitica virulence proteins in relatives of patients with autoimmune thyroid disease. Clin Exp Immunol 132 (2):278-82.

Suzuki, H., T. Higuchi, K. Sawa, S. Ohtaki, and Y. Horiuchi. 1965. "Endemic coast goitre" in Hokkaido, Japan. Acta Endocrinol (Copenh) 50 (2):161-76.

Tahboub, R., and B. M. Arafah. 2009. Sex steroids and the thyroid. Best Pract Res Clin Endocrinol Metab 23 (6):769-80.

Tajiri, J., K. Higashi, M. Morita, T. Umeda, and T. Sato. 1986. Studies of hypothyroidism in patients with high iodine intake. J Clin Endocrinol Metab 63 (2):412-7.

Takahashi, T., M. J. Schoemaker, K. R. Trott, S. L. Simon, K. Fujimori, N. Nakashima, A. Fukao, and H. Saito. 2003. The relationship of thyroid cancer with radiation 
exposure from nuclear weapon testing in the Marshall Islands. J Epidemiol 13 (2):99107.

Tanda, M. L., E. Piantanida, A. Lai, V. Lombardi, I. Dalle Mule, L. Liparulo, N. Pariani, and L. Bartalena. 2009. Thyroid autoimmunity and environment. Horm Metab Res 41 (6):436-42.

Tapiero, H., G. N. Ba, and K. D. Tew. 2002. Estrogens and environmental estrogens. Biomed Pharmacother 56 (1):36-44.

Tellez, M., J. Cooper, and C. Edmonds. 1992. Graves' ophthalmopathy in relation to cigarette smoking and ethnic origin. Clin Endocrinol (Oxf) 36 (3):291-4.

Thomas, D., V. Liakos, V. Michou, N. Kapranos, G. Kaltsas, V. Tsilivakos, and A. Tsatsoulis. 2008. Detection of herpes virus DNA in post-operative thyroid tissue specimens of patients with autoimmune thyroid disease. Exp Clin Endocrinol Diabetes 116 (1):35-9.

Tjiang, H., H. Lahooti, T. McCorquodale, K. R. Parmar, and J. R. Wall. 2010. Eye and eyelid abnormalities are common in patients with Hashimoto's thyroiditis. Thyroid 20 (3):287-90.

Tomer, Y., and T. F. Davies. 1993. Infection, thyroid disease, and autoimmunity. Endocr Rev 14 (1):107-20.

Tozzoli, R., O. Barzilai, M. Ram, D. Villalta, N. Bizzaro, Y. Sherer, and Y. Shoenfeld. 2008. Infections and autoimmune thyroid diseases: parallel detection of antibodies against pathogens with proteomic technology. Autoimmun Rev 8 (2):112-5.

Tsai, J. H., C. H. Tsai, M. H. Cheng, S. J. Lin, F. L. Xu, and C. C. Yang. 2005. Association of viral factors with non-familial breast cancer in Taiwan by comparison with noncancerous, fibroadenoma, and thyroid tumor tissues. J Med Virol 75 (2):276-81.

Tsai, W. T. 2006. Human health risk on environmental exposure to Bisphenol-A: a review. J Environ Sci Health C Environ Carcinog Ecotoxicol Rev 24 (2):225-55.

Tsuji, A., N. Wakisaka, S. Kondo, S. Murono, M. Furukawa, and T. Yoshizaki. 2008. Induction of receptor for advanced glycation end products by EBV latent membrane protein 1 and its correlation with angiogenesis and cervical lymph node metastasis in nasopharyngeal carcinoma. Clin Cancer Res 14 (17):5368-75.

Tukiendorf, A., L. Miszczyk, and P. McEwan. 2010. Recent epidemiological results of thyroid cancer in the most radiated territory in Poland. Cent Eur J Public Health 18 (3):157-60.

Utiger, R. D. 1995. Cigarette smoking and the thyroid. N Engl J Med 333 (15):1001-2.

Vandenberg, L. N., P. R. Wadia, C. M. Schaeberle, B. S. Rubin, C. Sonnenschein, and A. M. Soto. 2006. The mammary gland response to estradiol: monotonic at the cellular level, non-monotonic at the tissue-level of organization? J Steroid Biochem Mol Biol 101 (4-5):263-74.

Vanderpump, M. P., W. M. Tunbridge, J. M. French, D. Appleton, D. Bates, F. Clark, J. Grimley Evans, D. M. Hasan, H. Rodgers, F. Tunbridge, and et al. 1995. The incidence of thyroid disorders in the community: a twenty-year follow-up of the Whickham Survey. Clin Endocrinol (Oxf) 43 (1):55-68.

Vermiglio, F., M. G. Castagna, E. Volnova, V. P. Lo Presti, M. Moleti, M. A. Violi, A. Artemisia, and F. Trimarchi. 1999. Post-Chernobyl increased prevalence of humoral thyroid autoimmunity in children and adolescents from a moderately iodinedeficient area in Russia. Thyroid 9 (8):781-6. 
Vestergaard, P., L. Rejnmark, J. Weeke, H. C. Hoeck, H. K. Nielsen, J. Rungby, P. Laurberg, and L. Mosekilde. 2002. Smoking as a risk factor for Graves' disease, toxic nodular goiter, and autoimmune hypothyroidism. Thyroid 12 (1):69-75.

Wang, J. H., W. P. Zhang, H. X. Liu, D. Wang, Y. F. Li, W. Q. Wang, L. Wang, F. R. He, Z. Wang, Q. G. Yan, L. W. Chen, and G. S. Huang. 2008. Detection of human parvovirus B19 in papillary thyroid carcinoma. Br J Cancer 98 (3):611-8.

Wang, S. H., and J. R. Baker. 2007. The role of apoptosis in thyroid autoimmunity. Thyroid 17 (10):975-9.

Ward, L. S., and H. Graf. 2008. [Thyroid cancer: increased occurrence of the disease or simply in its detection?]. Arq Bras Endocrinol Metabol 52 (9):1515-6.

Ward, L. S., E. C. Morari, J. L. Leite, N. E. Bufalo, A. C. Guilhen, P. P. Araujo, A. J. Tincani, L. V. Assumpcao, and P. S. Matos. 2007. Identifying a risk profile for thyroid cancer. Arq Bras Endocrinol Metabol 51 (5):713-22.

Wartofsky, L. 2010. Increasing world incidence of thyroid cancer: increased detection or higher radiation exposure? Hormones (Athens) 9 (2):103-8.

Watson, C. S., Y. J. Jeng, and M. Y. Kochukov. 2010. Nongenomic signaling pathways of estrogen toxicity. Toxicol Sci 115 (1):1-11.

Weiss, W. 1979. Changing incidence of thyroid cancer. J Natl Cancer Inst 62 (5):1137-42.

Wells, James W. 1886. Exploring and travelling three thousand miles through Brazil from Rio de Janeiro to Maranhao. With an appendix containing statistics and observations on climate, railways central sugar factories, mining, commerce, and finance: the past, present and future, and physical geography of Brazil. Philadelphia,: J.B. Lippincott company.

Wenzel, B. E., J. Heesemann, K. W. Wenzel, and P. C. Scriba. 1988. Antibodies to plasmidencoded proteins of enteropathogenic Yersinia in patients with autoimmune thyroid disease. Lancet 1 (8575-6):56.

Wenzel, B. E., T. M. Strieder, E. Gaspar, and W. M. Wiersinga. 2003. Chronic infection with Yersinia enterocolitica in patients with clinical or latent hyperthyroidism. Adv Exp Med Biol 529:463-6.

Wiersinga, W. M. 1999. Environmental factors in autoimmune thyroid disease. Exp Clin Endocrinol Diabetes 107 Suppl 3:S67-70.

Wolff, J., and I. L. Chaikoff. 1948. Plasma inorganic iodide as a homeostatic regulator of thyroid function. J Biol Chem 174 (2):555-64.

Wolff, J., I. L. Chaikoff, and et al. 1949. The temporary nature of the inhibitory action of excess iodine on organic iodine synthesis in the normal thyroid. Endocrinology 45 (5):504-13, illust.

Yeung, M. J., and J. W. Serpell. 2008. Management of the solitary thyroid nodule. Oncologist 13 (2):105-12.

Yoshimoto, Y., H. Ezaki, R. Etoh, T. Hiraoka, and S. Akiba. 1995. Prevalence rate of thyroid diseases among autopsy cases of the atomic bomb survivors in Hiroshima, 19511985. Radiat Res 141 (3):278-86.

Yoshinari, M., K. Okamura, T. Tokuyama, A. Shiroozu, T. Nakashima, K. Inoue, and T. Omae. 1983. Clinical importance of reversibility in primary goitrous hypothyroidism. Br Med J (Clin Res Ed) 287 (6394):720-2.

Young, L. S., C. W. Dawson, and A. G. Eliopoulos. 1997. Viruses and apoptosis. Br Med Bull 53 (3):509-21. 
Yu, G. P., J. C. Li, D. Branovan, S. McCormick, and S. P. Schantz. 2010. Thyroid cancer incidence and survival in the national cancer institute surveillance, epidemiology, and end results race/ethnicity groups. Thyroid 20 (5):465-73.

Zablotska, L. B., E. Ron, A. V. Rozhko, M. Hatch, O. N. Polyanskaya, A. V. Brenner, J. Lubin, G. N. Romanov, R. J. McConnell, P. O'Kane, V. V. Evseenko, V. V. Drozdovitch, N. Luckyanov, V. F. Minenko, A. Bouville, and V. B. Masyakin. 2011. Thyroid cancer risk in Belarus among children and adolescents exposed to radioiodine after the Chornobyl accident. Br J Cancer 104 (1):181-7.

Zanzonico, P. B., and D. V. Becker. 2000. Effects of time of administration and dietary iodine levels on potassium iodide (KI) blockade of thyroid irradiation by 131I from radioactive fallout. Health Phys 78 (6):660-7.

Zenewicz, L. A., C. Abraham, R. A. Flavell, and J. H. Cho. 2010. Unraveling the genetics of autoimmunity. Cell 140 (6):791-7.

Zeng, Q., G. G. Chen, A. C. Vlantis, and C. A. van Hasselt. 2007. Oestrogen mediates the growth of human thyroid carcinoma cells via an oestrogen receptor-ERK pathway. Cell Prolif 40 (6):921-35. 


\section{Part 2}

Pregnancy and Endocrine Disease 



\title{
Thyroid in Pregnancy
}

\author{
Drahomira Springer, Zdenka Limanova and Tomas Zima \\ First Faculty of Medicine of the Charles University Prague \\ Czech Republic
}

\section{Introduction}

Many changes in the functioning of the thyroid gland occur during pregnancy and some diseases of the thyroid gland can affect both the pregnant woman and the fetus. (Casey et all., 2006; Lazarus \& Premawardhana, 2005; Poppe et all., 2007). Hypothyroidism is the most serious disorder of those occurring during pregnancy, and it might go unnoticed as some 'nonspecific' problem. Pregnant women with subclinical hypothyroidism seem to escape early clinical detection (Lazarus, 2002). While the hyperfunction during pregnancy usually manifests itself by clinical symptoms or a relapse of a previously cured disease (mostly Graves - Basedow) (Abalovich et all., 2007), lowered functioning is much more dangerous because of its non-specific symptoms. During the $1^{\text {st }}$ trimester, the fetus is completely dependent upon thyroxin produced by the mother (Smallridge \& Landerson, 2001). Even a small unnoticed malfunction of the thyroid gland, which doesn't have to endanger the course of the pregnancy, can affect the psychomotor developement of the child (Morreale de Escobar et all., 2004; Mitchell \& Klein, 2004)). Some women with subclinical hypothyroidism are absolutely asymptomatic and there is no reliance on the clinical image, while diagnostic of thyroid dysfunction (Klein et all., 2001).

Malfunction of the thyroid gland during pregnancy is long-term, and still not a sufficiently solved problem (Lazarus, 2002). On many pages of scientific literature and specialist literature there are still new arguments to systematically screen pregnant women for thyroid dysfunction and asymptomatic chronic thyroiditis in order to give such women the appropriate treatment (Surks et all., 2004). Results of surface population screenings are slightly varied, depending upon on level of medical care and approach to prevention, geographical conditions, supplementing with iodine, and other circumstances (including used diagnostic criteria) (Vaidya et all., 2007). Evaluating thyroidal function during pregnancy is difficult, considering the other differing influences of pregnancy.

Guidelines for management of thyroid dysfunction during pregnancy and postpartum (Abalowich et al. 2007) recommend not universal but only case finding screening. The first aim of the study was to assess the value of this recommendation. The other aim was to introduce an estimation of thyroid dysfunction during pregnancy, selection of suitable biochemical markers and determination of reference intervals for these markers in pregnancy.

\section{Investigation of thyroidal dysfunction in pregnancy}

In cooperation with General insurance company in Czech Republic was in 2009 started a pilot project for universal screening of thyroid dysfunction among women in the first 
trimester of pregnancy. A pilot project was performed during 2009-2010 in 13 regions, (only 4 regions in 2010) of the Czech Republic. The data from 3577 pregnant women with sufficient iodine intake were available. The blood for TSH (thyroid stimulating hormone), TPO Ab (antibodies to thyroid peroxidase) and FT4 (free thyroxine) estimation was collected in 9-11 week of pregnancy. All participating pregnant women gave informed written consent with this subsequent investigation.

\subsection{Conditions for screening}

First question is what we want to find? Which disorders are mostly indicated in pregnancy and what is really danger for pregnant women. Former studies resolve problems, which laboratory parameters are the best for investigation, the sampling of blood from pregnant women timing and also applicability of commonly used reference intervals for each parameter (Lazarus \& Premawardhana, 2005; Poppe et all., 2007). Iodine supplementation is also usually asked (Glinoer et all., 1995).

\subsubsection{Thyroid disorders in pregnant women}

Evaluating thyroidal function during pregnancy is difficult, considering the other differing influences of pregnancy (Dayan et all., 2002; Lazarus, 2002). New thyroid nodules should be aggressively investigated during pregnancy because of a high incidence of malignancy. Radioactive Iodine is contraindicated in pregnancy. Nursing mothers who have radioactive iodine uptake scans should pump and discard their milk for 48-72 hours after the test.

\subsubsection{Hypothyroidism}

Hypothyroidism is the most serious disorder of those occurring during pregnancy, and it might go unnoticed as some 'nonspecific' problem. Pregnant women with subclinical hypothyroidism seem to escape early clinical detection. The implications are staggering when one considers that there is a significant increase in intrauterine deaths, spontaneous abortions, premature births, and pre-eclampsia; also the development of the fetus, such as major malformations and loss of IQ (Haddow et all., Pop et all., 2003). It has been clearly proven that even slight (subclinical) hypothyroidism affects not only the course of pregnancy, but (especially later-on) the neuropsychological development of the child. Symptoms of hypothyroidism (fatigue, lowered performance, sleepiness, psychological lability) can also accompany the physiological pregnancy; some women with subclinical hypothyroidism are absolutely asymptomatic and there is no reliance on the clinical image, while diagnostic of functional failure. Untreated patients with hypothyroidism rarely conceive and carry a pregnancy. Treated hypothyroidism usually has no associated pregnancy complications. Patients will require increased levothyroxine doses during their pregnancies. Monitoring of thyroid function tests each trimester and at other clinically indicated times is recommended (Dashe 2005).

Prenatal vitamins can decrease the absorption of levothyroxine.

\subsubsection{Hyperthyroidism}

The hyperfunction during pregnancy usually manifests itself by clinical symptoms or a relapse of a previously cured disease. $95 \%$ of hyperthyroidism in pregnancy is secondary to Graves - Basedow disease. A good pregnancy outcome can be expected in patients with good control. Untreated hyperthyroidism is associated with decreased fertility, an increased rate of miscarriage, intrauterine growth retardation (IUGR), premature labor, and perinatal 
mortality (Poppe et all., 2007). Poorly controlled thyrotoxicosis is associated with thyroid storm especially at labor and delivery. Beta blockers and propylthiouracil (PTU) can be safely used in pregnancy and in nursing mothers. PTU crosses the placenta but does not usually cause fetal hypothyroidism and goiter unless used in high doses. Treatment goals favor mild hyperthyroidism over hypothyroidism. Like other immune mediated diseases in pregnancy, Grave's disease tends to improve in the third trimester. Exacerbations may occur in the first trimester and postpartum. Neonatal and fetal thyrotoxicosis may occur because of transplacental passage of thyroid stimulating antibodies.

\subsubsection{Postpartum thyroiditis}

Postpartum thyroiditis is a destructive autoimmune thyroiditis that begins with a period of hyperthyroidism followed by a period of hypothyroidism (Negro et all., 2007). The gland is often enlarged. There is usually complete recovery but a chance of recurrence in subsequent pregnancies exists. $80-85 \%$ of patients will have positive antithyroid antibodies. A radioactive iodine uptake scan can differentiate postpartum thyroiditis from an exacerbation of Graves- Basedow disease.

TPO $\mathrm{Ab}$ antibodies are markers of autoimmune process in the thyroid gland, their determination is diagnostically and prognostically important. Presence of TPO Ab during pregnancy also alerts to the danger of development of postpartum tyreoiditidis (Nicholson at all., 2006; Dosiou et all., 2008); about 50\% of TPO Ab positive women have some thyroid dysfunction after delivery (Premawardhana et all., 2004; Nicholson at all., 2006), so it is necessary to follow-up these women. Postpartum thyroiditis is in an important consideration in women with postpartum depression.

\subsubsection{Hyperemesis gravidarum}

Hyperemesis is associated with abnormal thyroid function tests in a significant number of cases. Hyperthyroidism may be the cause of hyperemesis or hyperemesis may be the cause of the hyperthyroidism (Goodwin et all., 1992).

\subsection{2 lodine supplementation in pregnancy}

The iodine requirement during pregnancy is sharply elevated because of an increase in maternal thyroxine production to maintain maternal euthyroidism and to transfer thyroid hormone to the fetus, iodine needs to be transferred to the fetus for fetal thyroid hormone production in later gestation and a probable increase in renal iodine clearance. The recommended dietary allowance for nonpregnant, nonlactating women aged $\geq 14$ year is 150 $\mu \mathrm{g} / \mathrm{d}$, for pregnant women is it $220 \mu \mathrm{g} / \mathrm{d}$ (Zimmermann \& Delange, 2004),. In Czech Republic has been iodized salt in regular use since the 1950s, a good level of iodine supplementation can be expected also on Zamrazil study (Zamrazil, 2004). Women in this study were in addition supplemented by 100-150 ug of iodide daily.

\subsubsection{Timing of the blood taking}

The study group consists of 3577 asymptomatic pregnant women (in their $9^{\text {th }}-11^{\text {th }}$ week of pregnancy, 99\% Caucasian) who were undergoing their first trimester prenatal screening. In the pilot project were used laboratories, which were able to investigate serum for the first trimester screening (investigation of PAPP-A and free $\beta$ hCG) and simultaneously in the same sample determine TSH (thyroid stimulating hormone), TPO Ab (antibodies to thyroid peroxidase) and FT4 (free thyroxine). 


\subsubsection{Selection of laboratory parameters}

The thyroid gland increases slightly in size during pregnancy.

Determining TSH in the serum is a basic searching procedure in the diagnosis of function of the thyroid gland in the general population. Its regulation is based on feedback, however during pregnancy there are also other mechanisms taking place. Suppressed serum TSH concentration during gestation follow hyperthyroidism as well as hyperemesis gravidarum or high hCG levels. Lower serum TSH in pregnancy is influenced by the thyrotropic activity of elevated circulating human chorionic gonadotropin concentrations, mainly in the first trimester (Abalovich 2007; Dashe 2005).

The comparision two groups of women, on pregnant and the other nonpregnant shows shift levels of TSH in pregnancy. On Fig.1 is possible to see only low levels of TSH.

\section{Number of investigation}

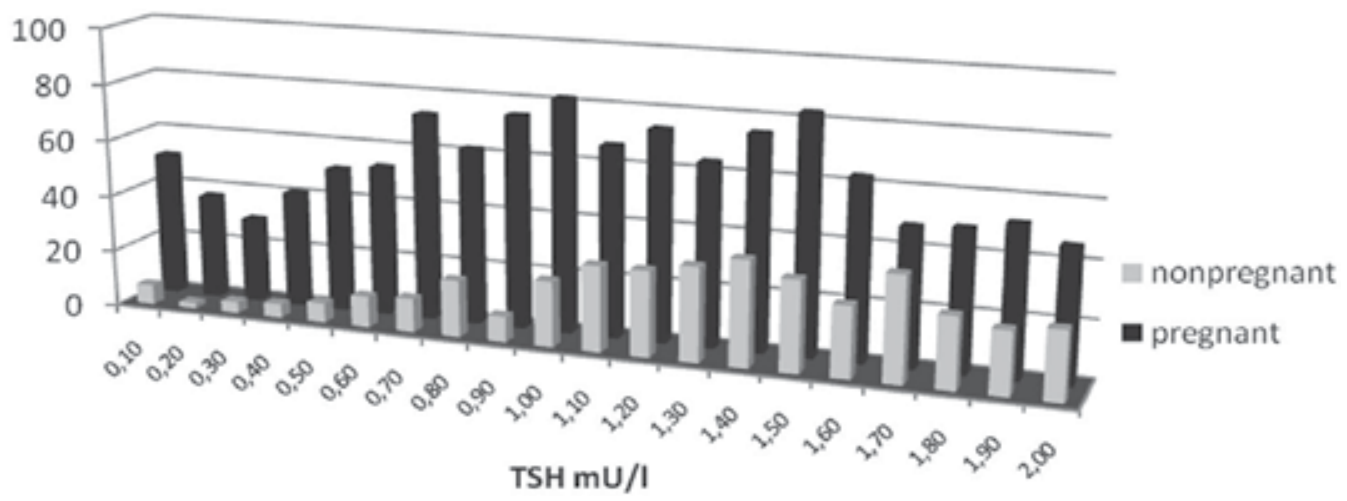

Fig. 1. Comparision TSH in group of pregnant (first trimester of pregnancy) and nonpregnant women in part with low TSH levels

In the group of pregnant women, with suppressed TSH, the average level of hCG was almost double $(\mathrm{M}=95.6 \mathrm{mg} / \mathrm{ml})$, in comparison with the group with TSH in the reference interval $(\mathrm{M}=68.9 \mathrm{mg} / \mathrm{ml})$ or with TSH $>3.67 \mathrm{mU} / 1(\mathrm{M}=62.1 \mathrm{mg} / \mathrm{ml})$. Differences between the normal and raised TSH groups in hCG levels were not significant at $p<0.050$. The other authors confirm that sub-normal serum TSH levels in the first trimester are coincident with rising hCG levels (Surks et all., 2004).

On Fig.2 is possible to see, how high is hCG in women with low TSH. (Springer et all., 2009) By using the classical reference interval for serum TSH one might misdiagnose as healthy those women who already have a slight TSH elevation and, conversely, one might suspect hyperthyroidism in normal women who have a lowered serum TSH value.

Determining FT4 is by watching the amount of biologically active hormone which is available to the organism of a pregnant woman (as well as the fetus), and is not affected by the concentration of binding proteins. Its concentration during pregnancy is partly effected by inflow of iodine and the duration of the pregnancy. Free thyroxine levels remain within the normal range during pregnancy (though total thyroxine levels are increased secondary to increased TBG). Some consider it even more informative than TSH during pregnancy (Lazarus, 2002). During the $1^{\text {st }}$ trimester, the fetus is completely dependent upon thyroxin produced by the mother. Even a small unnoticed malfunction of the thyroid gland, which doesn't have to endanger the course of the pregnancy, can affect the psychomotor 
development of the child. Early maternal hypothyroxinemia alters histogenesis and cerebral cortex cytoarchitecture of the progeny.

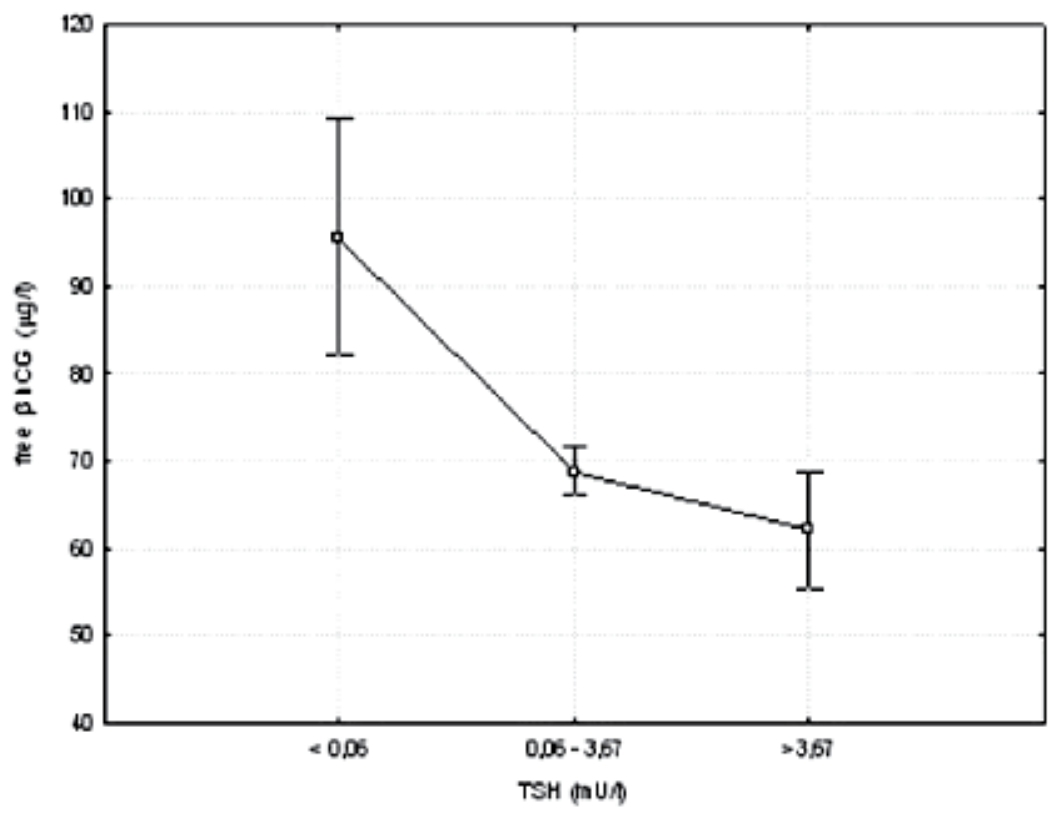

Fig. 2. Free $\beta$ hCG in groups with increasing TSH levels

Anti-TPO antibodies (TPO Ab) are markers of autoimmune process in the thyroid gland, their determination is diagnostically and prognostically important. Presence of TPO $\mathrm{Ab}$ during pregnancy also alerts to the danger of development of postpartum tyreoiditidis; about $50 \%$ of TPO Ab positive women have some thyroid dysfunction after delivery, so it is necessary to follow-up these women. The relationship between TPO Ab and TSH is not definite, despite it being known that women with high level of TSH more frequently have positive TPO $\mathrm{Ab}$.

\subsubsection{Reference intervals}

Reference intervals for different methods and manufacturer's may vary, they have been established using pools of nonpregnant normal sera and with different antibodies. Such reference ranges are not valid during pregnancy. A reference interval is the range of values of a test result for a defined population. In older references the reference interval is often designated as the reference range.

The main problem in setting of reference intervals for used laboratory markers is in case of using different immunoanalytic assays. Several factors can affect the setting of reference intervals, in particular manufacturer's methodology, euthyroid definition and iodine status. Alterations in thyroid hormone concentrations during pregnancy differed at different stage of gestation and to those of a non-pregnant state. If the non-pregnant TSH reference range was applied to pregnant women whose serum TSH concentration was within the first trimester specific reference range would be misclassified as having subclinical hyperthyroidism, or those with a TSH concentration above the first trimester specific upper reference limit would not be identified. 
Determining the reference range suitable for the $1^{\text {st }}$ trimester of pregnancy is possible by using the suggestion of the National Academy of Clinical Biochemistry (NACB) on selected samples from the population, or as $95^{\text {th }}$ percentile from the cohort of women (Demers \& Spencer, 2003).

Evaluating thyroidal function during pregnancy is difficult, considering the other differing influences of pregnancy (Dayan et all., 2002). TSH regulation is based on feedback, however during pregnancy there are also other mechanisms taking place - mainly there is suppression of TSH, presumably due to a thyroid-stimulating activity of hCG early in pregnancy when hCG levels are the highest. (Goodwin et all., 1992).

\subsubsection{Determination of own reference intervals}

TSH, TPO Ab, and FT4 were assayed by ADVIA ${ }^{\circledR}$ Centaur $^{\mathrm{TM}}$ (Siemens), with chemiluminometric detection. TSH was determined by sandwich imunoanalysis with direct chemiluminometric technology; for TPO Ab and FT4 competitive imunoanalysis with direct chemiluminometric technology was used.

Reproducibility of this method is expressed by the interassay variability. For TSH, it is 5 $7 \%$ for levels of $0.43-15.00 \mathrm{mU} / \mathrm{l}$; for TPO Ab it is $10 \%$ for the level of $70 \mathrm{kU} / 1$ and $7 \%$ for the level of $170 \mathrm{kU} / 1$. Interassay variability for FT4 is 7 - 9\% for levels $10.1-33.0 \mathrm{pmol} / 1$.

For mostly used systems were possible to use comparable TSH reference intervals, that were determined on large group of pregnant women (Springer et all., 2009). For evaluation of the reference interval, a selected group was created in accordance with the recommendations of the NACB. From the group of pregnant women $(5,520)$, all those with a history of thyroid disease were excluded; TPO $\mathrm{Ab}>60 \mathrm{kU} / 1$ (the manufacturer's cut-off) and free $\beta$ hCG higher than triple of the median $(\mathrm{Mdn}=56.6 \mu \mathrm{g} / \mathrm{l})$, in view of the suppression of TSH by a high level of hCG, were also excluded. TSH do not follow a normal distribution, data have to be normalized using log transformation. The reference interval - 95th percentile -was than determined using this log transformed data. The TSH reference interval for ADVIA:Centaur Siemens was determined to be $0.06-3.67 \mathrm{mU} / 1$.

FT4 levels fit a Gaussian distribution, so reference intervals were derived using nonparametric analyses such as the $95^{\text {th }}$ percentile. The calculated reference interval $(9.55-$ $23.0 \mathrm{pmol} / \mathrm{l})$ was almost identical to the manufacturer's $(9.8-23.1 \mathrm{pmol} / \mathrm{l})$ for all populations.

Differences in TPO Ab manufacturer's reference interval are not comparable from 0.5 to 100 kU/1 (Haddow et all., 2004; Hollowell et all., 2002; Negro et all., 2006). Reference intervals for thyroid antibody tests should be by the NACB recommendation; established from young male subjects, free from any history of thyroid disease or predisposition for any autoimmune disease (Demers \& Spencer, 2003). Establishment of decision values for thyroid antibodies in the healthy population is difficult and results are method dependent (Jensen at all., 2006). The pregnancy positivity cut-off for TPO Ab was calculated at the $95^{\text {th }}$ percentiles. From all of the women, women with a known history of thyroid disease were separated, as well as those with TSH lower than 0.1 and higher than $4.0 \mathrm{mU} / \mathrm{l}$. This interval had been used earlier for the evaluation of positive results in pregnancy; it was deduced from both specialized literature and own experience. The positivity of TPO Ab in nonpregnant individuals is about $11 \%$ (Hollowell et all., 2002); in the pregnant population it is very similar. Negro mentioned $11.7 \%$ TPO Ab positive pregnant women (Negro et all., 2006); Dossiou selected groups by age and the positivity was 10.4 and 12.6 for ages 25 and 35 years, respectively (Dossiou et all., 2008). When was used the reference interval recommended by the producer of reagents $(>60 \mathrm{kU} / \mathrm{l})$, 
in study group was $22.1 \%$ positivity. If was used the $90^{\text {th }}$ percentile $(143 \mathrm{kU} / \mathrm{l})$ as the cut-off for the group of pregnant women, was the positivity $11.2 \%$.

\subsection{Results}

The pilot project for universal screening was performed during 2009-2010 in 13 regions of the Czech Republic with the financial support of the General Insurance Company. Cooperation in 10 regions was good or suitable; 3 regions cooperated poorly and their data was not used in the first year of pilot project. In the second year were used only four laboratories for project. Thyroid examination was offered to women in the 9-11th week of pregnancy. The women with any positivity were offered immediate to endocrinological examination. Blood tests (TSH, FT4 and TPO $\mathrm{Ab}$ ) were carried out in 3577 asymptomatic pregnant women.

On Fig. 3 is showed the map of Czech Republic with selected regions. The number under town name is number of implement investigations in the pilot project, the red one are excluded regions, green number included investigations also from second part of pilot project in 2010.

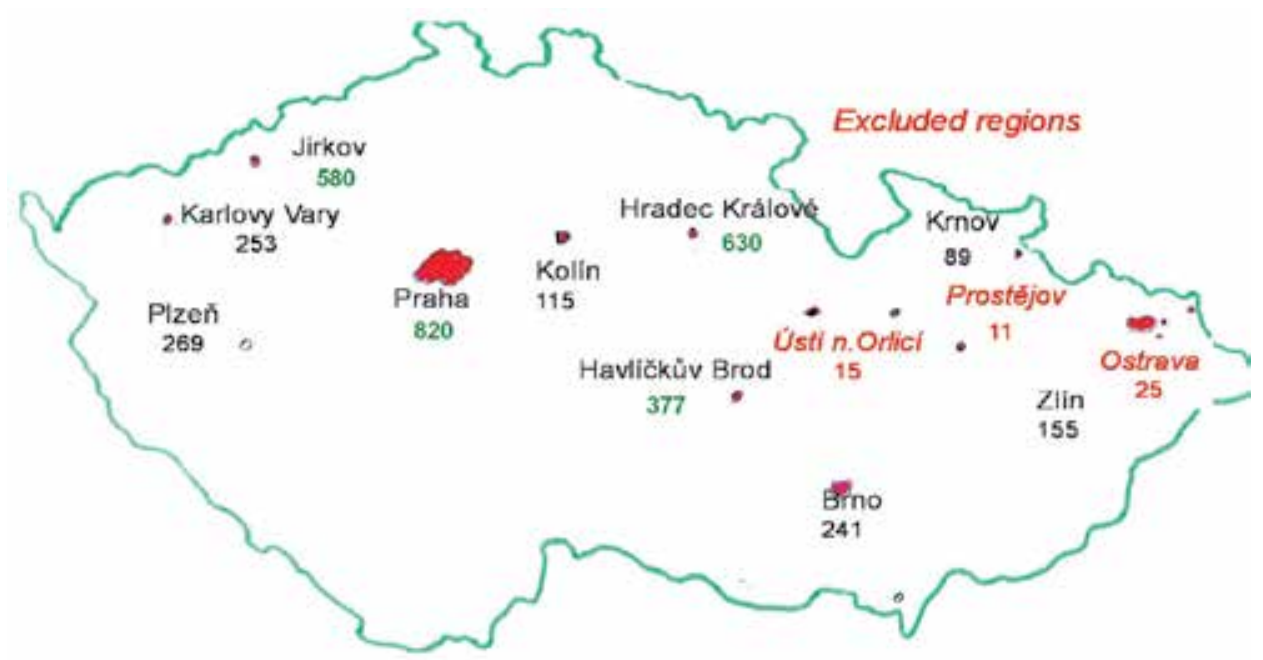

Fig. 3. The map of Czech Republic with cooperating regions. Under name of the town are number of investigations, green number indicate laboratories worked on second part of levels. The red marked regions were excluded from statistic.

There were used different analytical systems for analysis: the radio-imunoanalysis in five laboratories, chemilumino-imunoanalysis in six and electrochemilumino-imunoanalysis in two of them. Specific reference intervals for TSH, FT4, and positivity cut-off for TPO Ab during pregnancy were applied in all laboratories.

In all 3577 women investigated in pilot project were found $679(19.0 \%)$ pregnant women with some positivity.

\subsubsection{TSH}

A raised concentration of TSH was found in $7.63 \%$ of women; and a suppression of TSH was found in $3.05 \%$ of women. The prevalence of hypertyreosis in pregnant women is $1.7 \%$, and $0.4 \%$ of these women had an elevated serum FT4 level. This is similar to that reported for non- 
pregnant individuals. Low level of TSH with high FT4 level were only in $0.48 \%$, which is in concordance with previous hypotheses, as well as with Haddow study (Haddow at all., 2004). Many authors have determined the prevalence of hypothyreosis (overt and subclinical) in pregnancy and it is estimated to be $0.3-0.5 \%$ for overt hypothyroidism and $2-3 \%$ for subclinical hypothyroidism (Haddow at all., 2004). In this study there were $7.63 \%$ of pregnant women with TSH over determined own reference interval; it is evident, that no all higher TSH means hypothyreosis. Also selection of pregnant women maybe was influenced by gynaecologists, which prefer high-risk women for investigation in pilot project.. On Fig. 4 is schema with positivity in TSH levels:

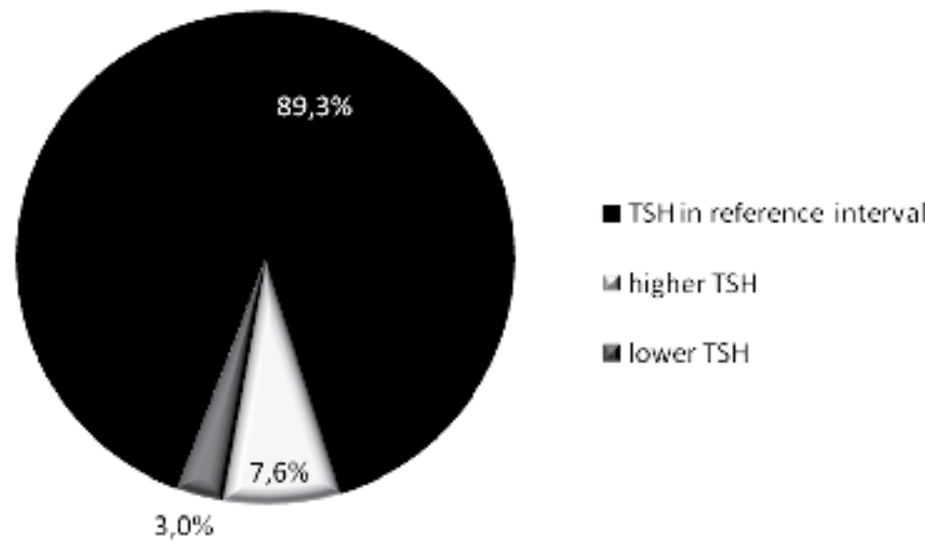

Fig. 4. Distribution of TSH levels in study group.

\subsubsection{FT4}

A raised concentration of FT4 was found in $0.48 \%$ of women; and a suppression of FT4 was found in $3.44 \%$ of women. On Fig. 5 is showed distribution of FT4 in the study group of pregnant women.

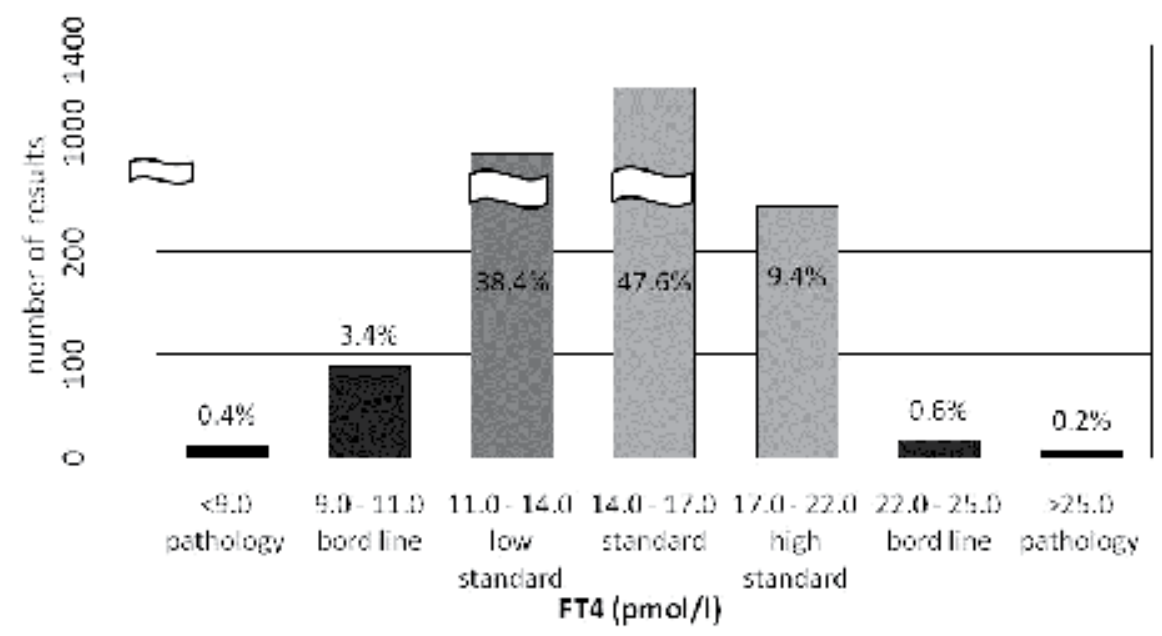

Fig. 5. Distribution of FT4 in the study cohort. 
Differences of FT4 in euthyroid women with suppressed, normal and elevated TSH were found and are showed on Fig. 6.

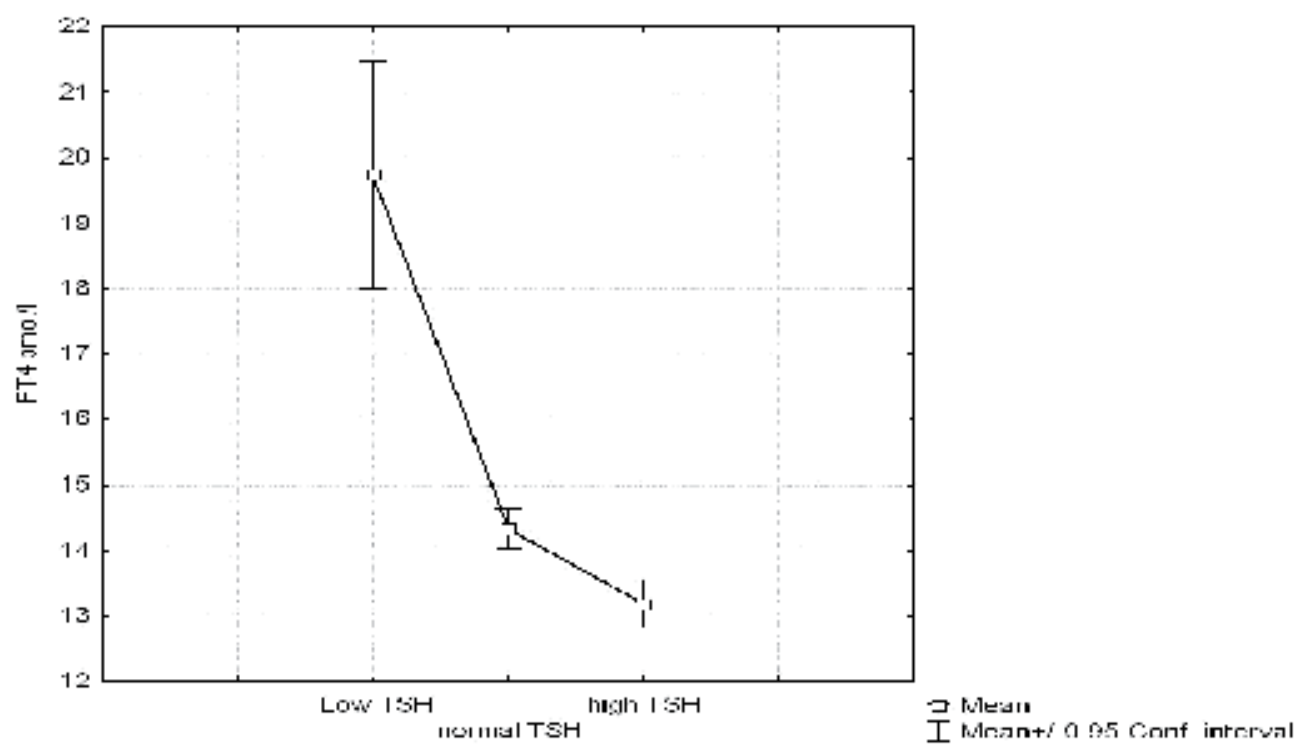

Fig. 6. FT4 in euthyroid women with suppressed, normal and elevated TSH

\subsubsection{TPO Ab}

$8.78 \%$ of pregnant women were found TPO Ab positive and there were also $5.4 \%$ of women, which had only TPO Ab positivity without another differences in TSH or FT4 levels. This distribution of results for whole study group is on Fig. 7 showed.

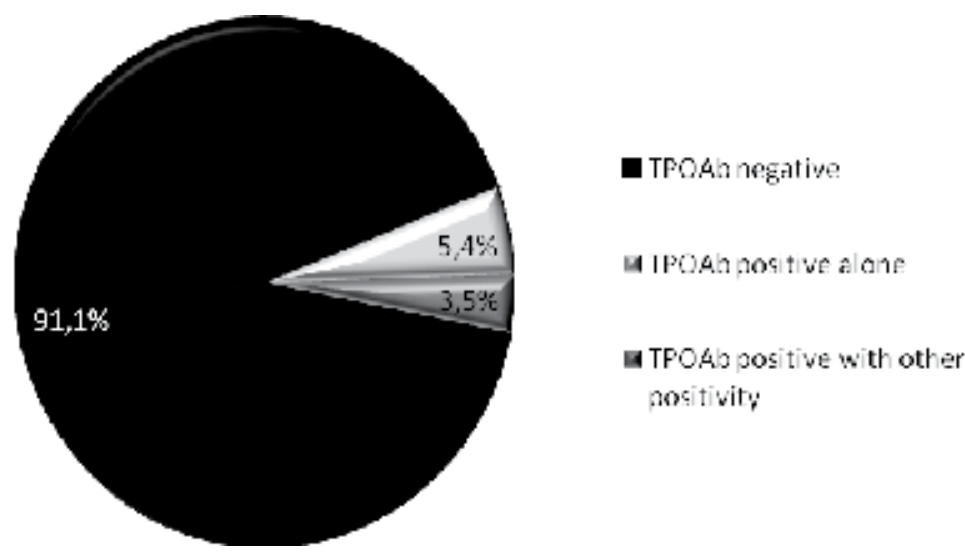

Fig. 7. TPO Ab in whole study group

\subsection{General or only high-risk pregnant women testing?}

Presently available information that supports the hypothesis that an inappropriate first trimester surge in maternal FT4, whatever the circulating TSH, would interfere with the 
development of the cerebral cortex, even if maternal euthyroidism is maintained by normal circulating T3. There is at present increasing consensus (Morreale et all., 2004) that maternal hypothyroidism, both clinical and subclinical, requires early detection and prompt treatment, because of its important negative effects for the woman, the pregnancy and the child. There also exists a positive association between the presence of thyroid antibodies and pregnancy loss with postpartum thyroiditis.

The most practical approach is to screen all pregnant women for hypothyroidism as early in pregnancy as possible (or before conception). In the case of the mother, screening would reset in early diagnosis and treatment of subclinical hypothyroidism. Unfortunately, pregnant women with subclinical hypothyroidism seem to escape early clinical detection. In Mitchel study (Mitchel \& Klein, 2004), 58\% of the hypothyroid women were unaware of their disorder, and it took a median of 5 years from the time of the pregnancy for the clinical diagnosis to be made.

Vaidya study shows that targeted thyroid function testing of only high-risk pregnant women would miss nearly one-third of women with overt/subclinical hypothyroidism during early pregnancy (Vaidya et all., 2007). In Czech Republic, case finding screening is able to disclose less than $20 \%$ of asymptomatic mild or deep hypothyroidism or women with positive TPO Ab in pregnancy (Springer et all., 2009).

\subsection{Relationship between TPO Ab and TSH, resp. FT4}

The relationship between TPO Ab and TSH is not definite, despite it being known that women with high level of TSH more frequently have positive TPO Ab. In study group, divided by serum TSH concentration, were $44.1 \%$ TPO Ab positive (in part), with TSH $>3.67$ $\mathrm{mU} / 1$ and $10.1 \%$ or $9.15 \%$ in the group with $\mathrm{TSH}<0.06 \mathrm{mU} / 1$ or $\mathrm{TSH}$ in the reference interval, as is showed on Fig. 8.

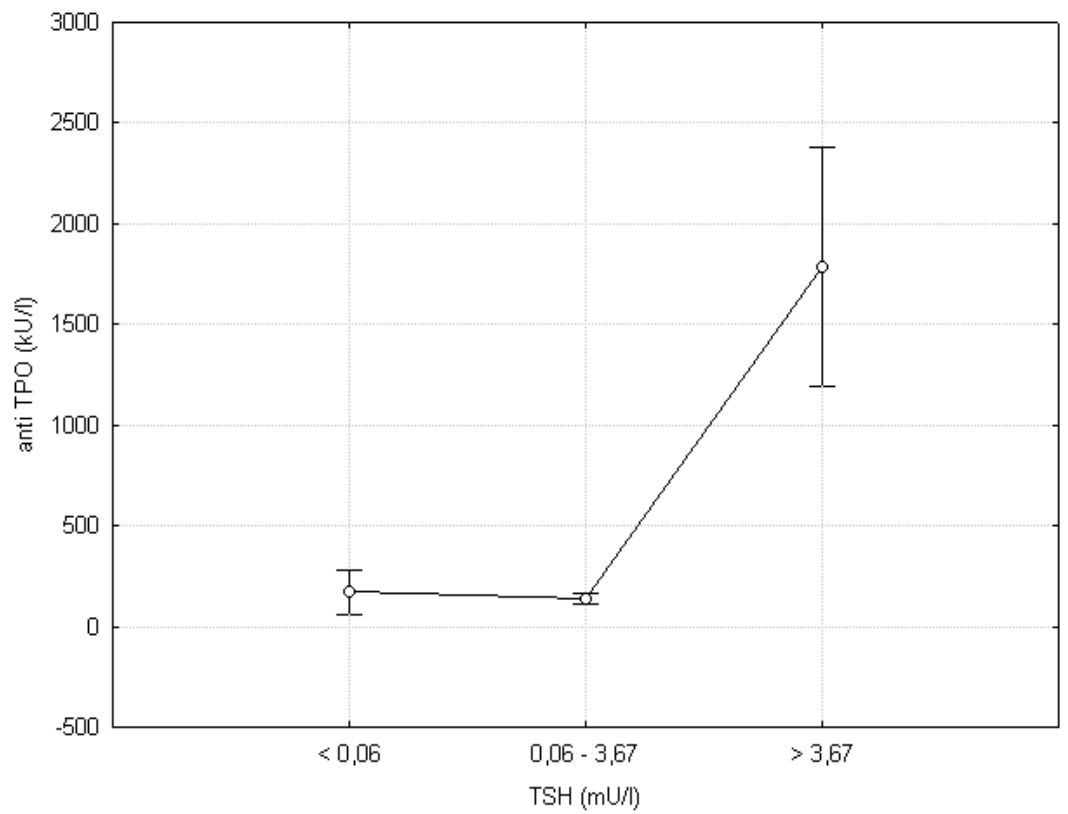

Fig. 8. TPO Ab in groups with different TSH level 
Glinoer (Glinoer et all., 1995) also documented somewhat higher TSH levels among the subpopulation of women with elevated antibody levels and these findings are confirmed in the present study.

Serum concentrations of FT4 were lower in TPO Ab positive as compared to TPO Ab negative women as is showed on Fig. 9.

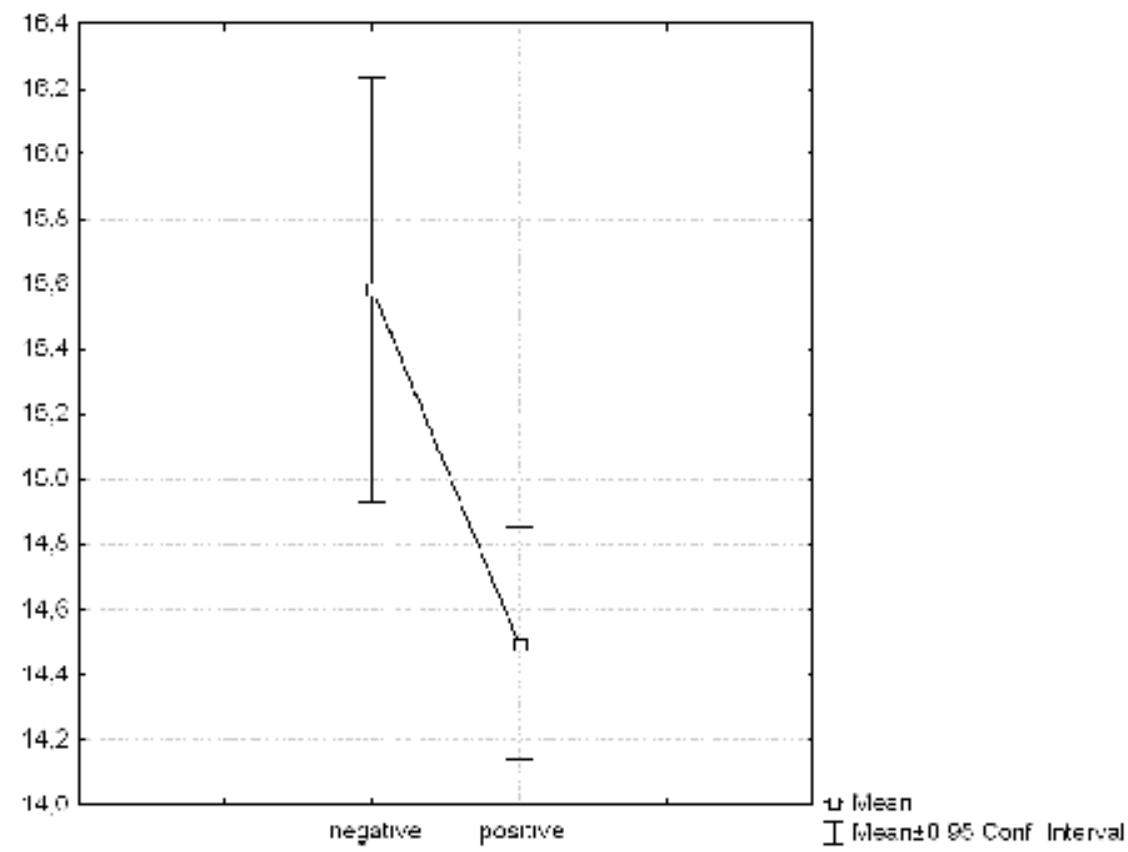

Fig. 9. Serum concentrations of FT4 in TPO Ab positive and TPO Ab negative women

\subsection{Cost effectiveness of the thyroid failure screening}

An answer to the question of screening cost-effectiveness of thyroid function in pregnancy was already presented by Dosiou (Dosiou et all., 2008). In this study is not defined costefficiency, but it is unquestioned fact that early diagnosis of thyroid disorder is cost-effective and beneficial for both mother and child.

\section{Conclusion}

The importance of maternal thyroxine for the development of the fetus brain early in pregnancy has received increasing acceptance. It has more recently become evident that maternal hypothyroxinemia results in the birth of children with decreased mental and psychomotor development.

This project proved the usefulness of universal screening of thyroid disease in pregnancy. The occurrence of pathological results in laboratory tests was 679/3577. Determination of the specific reference intervals for TSH, FT4, and TPO Ab in pregnancy is one of the basic requirements when implementing the general examination. Cooperation with gynaecologists differed, the main stumbling block was the willingness of gynaecologists to inform pregnant women about the project. 
In Czech Republic, case finding screening is able to disclose less than $20 \%$ of asymptomatic mild or deep hypothyroidism or women with positive TPO Ab in pregnancy. Investigation of combination of TSH and TPO Ab is necessary. Maternal hypothyroxinemia appears to be a much more frequent cause of deficits in the progeny than congenital hypothyroidism, for which we have successful neonatal thyroid screening programs. This study maybe will help define the impact of universal screening (TSH, FT4, TPO Ab) on the health care system.

The introduction of general screening of thyroid failure in pregnancy needs to be emphasized in public education; moreover, interdisciplinary cooperation of gynaecologist, endocrinologist and general practitioner, not to mention midwives should be improved. The other analysis would be more clearly identify the causal relationships between mild thyroid hormone deficiency and thyroid autoimmunity, on the one hand, and fetal neurological development on the other. In the meantime, physicians and obstetricians must use their own judgment about the optimal management for their individual patients.

\section{Acknowledgment}

The authors are grateful to the General Insurance Company of the Czech Republic for founging of the pilot project. The special thank belongs to all coopreating laboratories for help with blood sampling and perfekt resolving all administrative problems. Last but not least thank technicians from the Institute of Clinical Biochemistry and Laboratory Diagnostics Charles University, Prague, Czech Republic for their support in setting of reference intervals for pregnancy.

\section{References}

Abalovich, M.; Amino, N.; Barbour, L.A.; Cobin, R.H.; De Groot, L.J.; Glinoer, D.; Mandel, S.J. \& Stagnaro-Green, A. (2007) Management of Thyroid Dysfunction during Pregnancy and Postpartum: An Endocrine Society Clinical Practice Guideline. Journal of Clinical Endocrinology \& Metabolism, (August 2007), Vol.92, No 8, pp.S1 S47, ISSN 1945-7197

Casey, B.M.; Dashe, J.S.; Wells, C.E.; McIntire, D.D.; Leveno, K.J. \& Cunningham, F.G. (2006) Subclinical Hyperthyroidism and Pregnancy Outcomes. Obstetrics and Gynecology, (February 2006), Vol.107, No 2, pp. 337-341. ISSN 0029-7844

Dashe, J.S.; Casey, B.M.; Wells, C.E.; McIntire, D.D.; Byrd, E.W.; Leveno, K.J. \& Cunnigham, F.G. (2005) Thyroid-stimulating hormone in singleton and twin pregnancy: importance of gestational age-specific reference ranges. Obstetrics and Gynecology, (October 2005), Vol. 106, No 4, pp.753-757. ISSN 0029-7844

Dayan, C.M. ; Saravanan, P. \& Bayly, G. (2002) Whose normal thyroid function is betteryours or mine? Lancet (August 2002) Vol. 360, No 3, pp. 353-354.

Demers, L.M. \& Spencer, C.A. (2003) Laboratory medicine practice guidelines: laboratory support for the diagnosis and monitoring of thyroid disease. Clinical Endocrinology (February 2003) Vol. 58, No 2, pp. 138-40, ISSN 1365-2265

Dosiou, C.; Sanders, G.D; Araki, S.S. \& Crapo, L.M. (2008) Screening pregnant women for autoimmune thyroid disease: a cost-effectiveness analysis. European Journal of Endocrinology (Juny 2008), Vol. 158, No 6, pp. 841-51, ISSN: 0804-4643

Glinoer, D.; De Nayer, P.; Delange, F.; Lemone, M.; Toppet, V.; Spehl, M.; Grün, J.P.; Kinthaert, J. \& Lejeune, B. (1995) A randomized trial for the treatment of mild 
iodine deficiency during pregnancy: maternal and neonatal effects. Journal of Clinical Endocrinology \& Metabolism, (January 1995), Vol. 80, No 1, pp. 258-269, ISSN 1945-7197

Goodwin, T.M.; Montoro, M.; Mestman, J.H.; Pekary, A.E. \& Hershman, J.M. (1992) The role of chorionic gonadotropin in transient hyperthyroidism of hyperemesis gravidarum. Journal of Clinical Endocrinology \& Metabolism (November 1992), Vol. 75, No 5, pp. 1333-1337, ISSN 1945-7197

Haddow, J.E.; Palomaki, G.E.; Allan, W.C.; Williams, J.R.; Knight, G.J.; Cagnon, J.; O'Heir, C.E.; Mitchel, M.L.; Hermos, R.J.; Waisbren SE, Faix JD \& Klein RZ. (1999) Maternal thyroid deficiency during pregnancy and subsequent neuropsychological development of the child. New England Journal of Medicine, (August 1999), Vol. 341, No 8, pp.549-555, ISSN 0028-4793

Hollowell, J.G.; Staehling, N.W.; Flanders, S.; Hannon, W.H.; Gunter, E.Q.; Spencer, C.A. \& Braverman, L.E. (2002) Serum TSH, T4, and thyroid antibodies in the United States population (1988 to 1994): National Health and Nutrition Examination Survey (NHANES III). Journal of Clinical Endocrinology \& Metabolism, (February 2002), Vol. 87, No 2, pp.489-99, ISSN 1945-7197

Jensen, E.A.; Petersen, P.H.; Blaabjerg, O.; Hansen, P.S.; Brix, T.H. \& Hegedüs, L. (2006) Establishment of reference distributions and decision values for thyroid antibodies against thyroid peroxidase (TPOAb), thyroglobulin (TgAb) and the thyrotropin receptor (TRAb). Clinical Chemistry and Laboratory Medicine, (2006), Vol. 44, No 8, pp.991-998, ISSN 1434-6621

Klein, R.Z.; Sargent, J.D. \& Larsen, P.R.; (2001) Relation of severity of maternal hypothyroidism to cognitive development of offspring. Journal of Medical Screening (2001), Vol. 8, No 1, pp. 18-20, ISSN 0969-1413

Lazarus, J.H. (2002) Epidemiology and prevention of thyroid disease in pregnancy. Thyroid, (October 2002), Vol. 12, No 10, pp.861-865, ISSN 1050-7256

Lazarus, J.H. \& Premawardhana, L.D. (2005) Screening for thyroid disease in pregnancy, Journal of Clinical Pathology, (May 2005), Vol. 58, No 5, pp. 449-452. ISSN 0021-9746

Morreale de Escobar, G.; Obregon, M.J. \& Escobar del Rey, F. (2004) Role of thyroid hormone during early brain development. European Journal of Endocrinology (November 2004) Vol. 151, No 3, pp.U:25-37, ISSN: 0804-4643

Mitchell, M.L. \& Klein, R.Z. (2004) The sequelae of untreated maternal hypothyroidism. European Journal of Endocrinology (November 2004), Vol. 151, No 3, pp.U45-48. ISSN: 0804-4643

Negro, R.; Formoso, G.; Mangieri, T.; Pezzarossa, A.; Dazzi, D. \& Hassan, H. (2006) Levothyroxine Treatment in Euthyroid Pregnant Women with Autoimmune Thyroid Disease: Effects on Obstetrical Complications. Journal of Clinical Endocrinology \& Metabolism, (July 2006), Vol.91, No 7, pp. 2587-91, ISSN 1945-7197

Nicholson, W.K.; Robinson, K.A. \& Smallridge, R.C.(2006), Prevalence of postpartum thyroid dysfunction: a quantitative review. Thyroid (Juny 2006), Vol. 16, No 6, pp.573-82, ISSN 1050-7256

Pop, V.J.; Brouwers, E.P.; Vader, H.L.; Vulsma, T.; van Baar, A.L. \& de Vijlder, J.J. (2003) Maternal hypothyroxinemia during pregnancy and subsequent child development: a 3 year follow - up study. Clinical Endocrinology (September 2003), Vol. 59, No 3, pp. 282-288, ISSN 1365-2265 
Poppe, K.; Velkeniers, B. \& Glinoer, D. (2007) Thyroid disease in female reproduction. Clinical Endocrinology, (March 2007), Vol 66, No 3, pp. 309-321, ISSN 1365-2265

Premawardhana. L.D.; Parkes, A.B. John, R. Harris B \& Lazarus JH. (2004) Thyroid peroxidase antibodies in early pregnancy: utility for prediction of postpartum thyroid dysfunction and implications for screening. Thyroid (August 2004) Vol. 14, No 8, pp. 610-615. ISSN 1050-7256

Smallridge, R.C. \& Ladenson, P.W. (2001) Hypothyroidism in Pregnancy: Consequences to Neonatal Health. Journal of Clinical Endocrinology \& Metabolism (Juny 2001), Vol. 86, No 6, pp.2349-2353, ISSN 1945-7197

Springer, D.; Zima, T.; Limanova, Z. (2009) Reference intervals in evaluation of maternal thyroid fiction during the first trimester of pregnancy, European Journal of Endocrinology, (May 2009), Vol. 160, No 5, pp. 791-797, ISSN: 0804-4643

Surks, M.I.; Ortiz, E.; Daniels, G.H.; Sawin, C.T.; Col, N.F.; Cobin, R.H.; Franklyn, J.A.; Hershman, J.M.; Burman, K.D.; Denke, M.A.; Gorman, C.; Cooper, R.S. \& Weissman, N.J. (2004) Subclinical thyroid disease: scientific review and guidelines for diagnosis and management. Journal of the American Medical Association, (January 2004), Vol. 291, No 2, pp.228-38, ISSN 0098-7484

Vaidya, B.; Anthony, S.; Bilous, M.; Shields, B.; Drury, J. \& Hutchison, S. (2007) Detection of thyroid dysfunction in early pregnancy: Universal screening or targeted high risk case finding? Journal of Clinical Endocrinology \& Metabolism (January 2007), Vol. 92, No 1, pp. 203-207, ISSN 1945-7197

Zamrazil, V.; Bilek, R.; Cerovska, J. \& Delange, F. (2004) The elimination of iodine deficiency in the Czech Republic: the steps toward success. Thyroid, (January 2004) Vol. 14, No 1, pp. 49-56, ISSN 1050-7256

Zimmermann, M. \& Delange, F. (2004) Iodine supplementation of pregnant women in Europe: a review and recommendations. European Journal of Clinical Nutrition (July 2004), Vol. 58, No 7, pp. 979-84, ISSN: 0954-3007 


\title{
Adrenal Disease and Pregnancy
}

\author{
Guadalupe Guijarro de Armas \\ University Hospital of Getafe (Madrid) \\ Spain
}

\section{Introduction}

During pregnancy, maternal-endocrine regulation, as well as all their physiology, undergoes profound adaptive changes in the framework of a functional organization structured in three interrelated compartments: the mother, placenta and fetus. Many of these changes are initially induced by estradiol and progesterone produced by the corpus luteum, combined with chorionic gonadotropin. As the pregnancy progresses, steroid and peptide hormones produced by the fetoplacental unit, took over. As a result of these adaptive phenomena is achieved adequate nutritional support of the fetus, uterine quiescence is maintained during childbirth, and breastfeeding is finally possible (Schindler, 2005).

\section{Cushing's syndrome}

During normal pregnancy, serum cortisol increase gradually from the second quarter, keeping the circadian rhythm. Part of the increase in serum cortisol is due to increased estrógens and secondarily to increased cortisol binding protein (CBG), although serum free cortisol, urine and saliva can be elevated up to 2-3 times. The plasma concentration of ACTH is usually normal, although during pregnancy can be reduced or increased. There is a gradual increase in late pregnancy and during delivery (Lindsay \& Nieman, 2005). The placenta during gestation can produce CRH which is released into the maternal circulation, although this may have implications in the regulation of ACTH and cortisol secretion are not well known.

Cushing`s syndrome is uncommon during pregnancy, because hypercortisolism produces anovulation and infertility by altering androgenos and gonadotropin.

The frecuency of ACTH-independent cases is increased in pregnant as compared to non pregnant individuals. Of the approximately 136 reported cases, approximately $60 \%$ had ACTH independent Cushing's Syndrome: $44 \%$ adenoma y $11 \%$ carcinoma and the remainder a mix of primary pigmented nodular adrenal disease, ACTH independent hyperplasia and ectopic ACTH secretion. Five pregnant women with the ectopic ACTH syndrome have been reported (Guilhaume et al., 1992).

The fetus is partially protected from the hypercortisolemia because placental 11betahydroxysteroid dehydrogenase converts $85 \%$ of maternal cortisol to biologically inactive cortisone. However, untreated Cushing's syndrome has been associated with spontaneous abortion (25\%), premature delivery (50\%) and rarely, neonatal adrenal insufficiency (Aron et al., 1990). 
Maternal complications also can occur. These include hypertension in nearly $70 \%$, gestational diabetes in 25\%, myopathy, opportunistic infections, fractures, preeclampsia and rarely heart failure. Two maternal deaths have been reported (Vilar et al., 2007).

\subsection{Diagnosis}

The presence of Cushing's Syndrome during pregnancy may be masked since some of the symptoms and signs of this disorder (weight gain, hypertension, striae) can also occur in normal pregnant women. Biochemical changes during normal pregnancy can interfere with the diagnosis:

The normal pregnancy rises in ACTH and cortisol levels. The hypercortisolism of pregnancy continues to exhibit a normal circadian rhythm, though with a higher nighttime nadir; loss of diurnal rhythm is characteristic of all forms of Cushing syndrome. Salivary cortisol measurements may assist in determining this lack of diurnal response, but normal midnight levels have no been standardized for pregnancy. Urinary free cortisol levels greater than 3 times the upper limit of normal may be interpreted as indicating Cushing's syndrome in the second and third trimester. There are limited or no data using antibody based assays or mass spectrometry. Normal pregnancy is also associated with inadequate suppression of ACTH and cortisol during the overnight dexamethasone suppression test (Carr et al., 1981). ACTH levels may not reliably distinguish between pituitary and adrenal etiologies, as the levels may be normal or high in all form of Cushing syndrome, likely from placental ACTH production. When plasma ACTH levels are suppressed, preferably as measured using a two-site immunometric assay, no further biochemical testing is needed.

The high dose dexamethasone suppression test will cause $>80 \%$ suppression of serum cortisol in normal pregnancy. Patient with adrenal Cushing may be identified with this test as they don't suppress, but the test may misclassify those with Cushing disease, as three of seven cases failed to suppress in small series (Lindsay et al., 2005).

\subsection{Differential diagnosis}

Because of the persistent elevations of ACTH in pregnancy, an ACTH suppressed is not always found in independent causes of Cushing syndrome. Thus, while its measurement may be useful, lack of suppressed value does not exclude and ACTH independent cause.

There are limited data on the response to dexamethasone, $8 \mathrm{mg}$, of women with adrenal causes of Cushing's syndrome and pituitary adenomas. In general, those with and adrenal etiology do not suppress, while those with Cushing disease do suppress serum cortisol. (Barasch et al., 1988).

Because adrenal form of Cushing's syndrome are common in pregnancy, it is reasonable to perform and adrenal ultrasound to look for a mass, as well as an ACTH level and dexamethasone suppression test as an initial evaluation.

$\mathrm{CRH}$ stimulation test has been performed rarely in pregnant patients. Magnetic resonance (MRI) cannot be performed in the first trimester because of concerns about potential adverse fetal effects; during the remainder of gestation it is not commonly given with gadolinium contrast.

\subsection{Treatment}

Adrenal surgery has been performed at the 16 to 21 weeks of pregnancy without complicating the pregnancy (Buescher, 1996). It can be performed using a laparoscopic 
approach. There is no clear evidence that early treatment is more beneficial than later treatment, this is likely because treatment is generally begun late. Early second trimester surgical treatment would be optimal. For women who do no want surgery or are diagnosed later, maternal hypercortisolism can be controlled with metyrapone. Metyrapone has side effects including hypertension and preeclampsia. (Blanco et al., 2006). Ketoconazol therapy is associated with intrauterine growth retardation, but no malformation or neonatal adrenal insufficienc (Berwaerts et al., 1999). Aminoglutethamide may cause fetal masculinization and mitotane is teratogenic; both should be avoided.

Transsphenoidal surgery and pituitary radiation have both been used without complicating the pregnancy (Casson et al., 1987).

Treating the Cushing's syndrome does not reduce the frecuency of intrauterine growth restriction (about 30\%) or premature birth (about 65\%), but it does appear to prevent stillborn deliveries (about 10\% with treatment) (Buescher, 1996).

\section{Adrenal insufficiency}

The adrenal insufficiency (AI) is rare, but early diagnosis is very important to improve maternal-fetal treatment. The primary AI or Addison's disease involves adrenal cortex atrophy with response insensitivity to ACTH and angiotensin 2, which causes a deficiency of glucocorticoids and aldosterone. The secondary and tertiary AI due to lack of ACTH or CRH are secondary to hypothalamic-pituitary diseases or chronic administration of exogenous corticosteroids. The secondary and tertiary AI are not associated with mineralocorticoid deficiency (Ambrosi et al., 2003).

The prevalence of primary adrenal insufficiency in pregnancy is unknown, with a series from Norway suggesting an incidence of 1 in 3000 births from 1976 to 1987. The most common etiology for primary adrenal insufficiency is autoinmune adrenalitis, which may be associated with autoinmune polyglandular syndrome. Primary adrenal insufficiency from infections, bilateral metastatic disease, hemorraghe or infarction is uncommon. Secondary adrenal insufficiency, from pituitary neoplasm or glucocorticoid suppression of the hypothalamic-pituitary-adrenal axis is more common (Stechova, 2004).

Gestation in patients with AI should be considered high-risk pregnancy (Lindsay \& Nieman, 2005). Maternal mortality is rare today, after the introduction of hydrocortisone in 1950, as well as improved diagnosis and early treatment. When AI is not diagnosed during pregnancy, may not have negative effects to mother or fetus, indicating the transplacental passage of maternal fetal glucocorticoids. In these cases, disease appears in the postpartum.When the disease is previously known, it is necessary to adjust the dose of corticosteroids in order to avoid a default adrenal crisis defect or undesirable effects of excess treatment as hypertension and preeclampsia.

The prevalence of fetal mortality is unknown, although cases have been reported about intrauterine death, most undiagnosed in pregnant women. Intrauterine growth retardation and low birth weight are the most frequent effects in untreated mothers. The concomitance between $\mathrm{AI}$ and other autoimmune diseases (DM, lupus, anticardiolipin antibodies) increases maternal-fetal morbidity.

\subsection{Diagnosis}

Most cases are diagnosed before pregnancy. 
Adrenal insufficiency is associated with laboratory findings of hyponatremia, hyperkalemia, hypoglycemia, eosinophilia and lymphocytosis. Hiperkalemia may be absent, because of the pregnancy increase in the rennin angiotensin system (Gradden et al., 2001). Early morning plasma cortisol levels of $<3.0 \mathrm{mcg} /$ dl confirms AI, while a cortisol $>19 \mathrm{mcg} / \mathrm{dl}$ in the first or early second trimester excludes the diagnosis in a clinically stable patient. Plasma cortisol levels may fall in the normal "nonpregnant" range due to increase in CBG concentrations in the second and third trimesters, but will not be appropriately elevated for the stage of pregnancy. Appropriate pregnancy-specific cutoffs for diagnosis with the standard cosyntropin test using $250 \mathrm{mcg}$ dose have not been established. Plasma cortisol levels were $60 \%$ to $80 \%$ above nonpregnant responses in normal pregnant women tested in the second and third trimesters in one series (Nolten et al., 1978).

McKenna et al (McKenna et al., 2000) examined the 1 mcg low dose cosyntropin test for diagnosis of secondary adrenal insufficiency in women at 24-34 weeks gestational age, and found high sensitivity of diagnosis using a cutoff of $30 \mathrm{mcg} / \mathrm{dl}$. Accuracy of dosing is more difficult with this than with the standard cosyntropin test. The cosyntropin test is less sensitive to detect early secondary or tertiary forms of adrenal insufficiency. Cortisol and $\mathrm{ACTH}$ responses to $\mathrm{CRH}$ are blunted in pregnancy, making the $\mathrm{CRH}$ stimulation test unreliable for differentiating secondary and tertiary adrenal insufficiency in pregnancy. With primary AI, ACTH levels will be elevated and a level above $100 \mathrm{pg} / \mathrm{ml}$ is consistent with the diagnosis. However, ACTH will not be low with secondary forms because of the placental production of this hormone, which is nevertheless insufficient to maintain normal maternal adrenal function. ACTH values fluctuate widely, and a single value is insufficient for diagnosis. Adrenal antibodies may assist in confirming idiopathic adrenal insufficiency, as approximately $90 \%$ of patients will have 21 hydroxylase antibodies and $30 \%$ will have antibodies to 17-hydroxylase and side-chain cleavage enzymes. Aldosterone to renin ratios are low with elevated plasma rennin activity in patient with mineralocorticoid deficiency from adrenal atrophy (Symonds \& Craven, 1978).

\subsection{Treatment}

Patients with AI should be managed during pregnancy and childbirth by a multidisciplinary team that includes endocrinologist, obstetrician and an expert neurosurgeon.

\subsubsection{Glucocorticoids}

The aim is to achieve a physiological replacement dose for optimal maternal and fetal monitoring.

The most important period is the first trimester, because the symptoms may go unnoticed by the emesis of pregnancy and childbirth stress. Hydrocortisone is the glucocorticoid of choice at doses of $12-15 \mathrm{mg} / \mathrm{m} 2$ in 2 divided doses at breakfast and $1 / 3$ at lunch. It is rare to increase the dose during pregnancy.

Women must be educated on the need for treatment with parenteral hydrocortisone in cases of nausea, vomiting or intercurrent systemic disease. Prednisone or prednisolone should be avoided because Hydrocortisone is more physiological.

\subsubsection{Mineralocorticoids}

They are only required in primary AI. The most widely used on the single dose is fluorocortisona $9 \mathrm{a}$ ( 0.05 to $0.2 \mathrm{mg}$ /day). The dose is stable during pregnancy, and it can be reduced in the third trimester if there are edemas or hypertension. 


\subsubsection{Adrenal crisis}

It may appear at any time if the $\mathrm{AI}$ is not diagnosed, but it is more often during the delivery, when there is infection, preeclampsia or hemorrhage.Treatment should be started with hydrocortisone intravenous (bolus of 100 or $200 \mathrm{mg}$ and then $50-100 \mathrm{mg}$ every 6-8 hours). In women with hypoglycemia, it is necessary to administer dextrose.

After stabilization, return to oral treatment. It is not necessary to administer Mineralocorticoids in the acute phase. During delivery, the dose of glucocorticoids should be doubled at onset of labor or to administer $50 \mathrm{mg}$ of intravenous hydrocortisone. In case of caesarean, it is necessary to start treatment with hydrocortisone, $100 \mathrm{mg}$ IV every 8 hours. The oral treatment must be restarted within 48 hours.

After delivery, all women must maintain treatment with corticosteroids and with dosis of mineralocorticoids similar to the prepregnancy period.

It is not necessary to follow hypothalamic-pituitary axis in children of mothers with AI if they have been well treated during pregnancy. It can be necessary in mothers who have received supraphysiological doses.

The replacement therapy can continue during lactation. It is excreted $0.5 \%$ per liter of milk of the absorbed dose (Sidhu \& Hawkins, 1981).

\section{Primary hyperaldosteronism}

Primary hyperaldosteronism rarely has been reported in pregnancy and is most often caused by an adrenal adenoma (Okawa et al., 2002). There are reports of glucocorticoid remediable hyperaldosteronism in pregnancy (Wyckoff et al., 2000). The elevated aldosterone levels found in patients are similar to those in normal pregnant women, but the plasma rennin activity is suppressed. Moderate to severe hypertension is seen in $85 \%$, proteinuria in $52 \%$ and hypokalemia in $55 \%$, and symptoms may include headache, malaise, and muscle cramps. Placental abruption and preterm delivery are risks. Progesterone has an antimineralocorticoid effect at the renal tubules, and the hypertension and hypokalemia may ameliorate during pregnancy (Matsumoto et al., 2000).

The physiologic rise in aldosterone during pregnancy overlaps the levels seen in primary aldosteronism, making diagnosis difficult. Suppressed rennin in the setting of hyperaldosteronism, is diagnostic. Salt loading test may be used to diagnose hyperaldosteronism, but there are potential fetal risks and no normative data. If baseline and suppression testing are equivocal, or radiological scanning does not suggest unilateral disease, patients may be treated medically until delivery to allow more definitive investigations. Spironolactone, the usual nonpregnant therapy, is contraindicated in pregnancy as it cross the placenta and is a potent antiandrogenic which can cause ambiguous genitalia in a male fetus. There is no published experienced with the use during pregnancy of eplerenone, the new aldosterone receptor antagonist. Surgical therapy may be delayed until postpartum if hypertension can be controlled with agents safe in pregnancy, such as amiloride, methyldopa, labetolol, and calcium channel blockers. Potassium supplementation may be required, but as noted above, the hypokalemia may ameliorate in pregnancy because of the antikaliuretic effect of progesterone. Both hypertension and hypokalemia may exacerbate postpartum due to removal of the progesterone effect ( Nursan et al., 2009).

\section{Pheochromocytoma}

Pheochromocytoma is a rare cause of hypertension during pregnancy, with clinical features similar to those in the general population (Keely, 1998). The prevalence is estimated at 1 in 
54000 pregnancies (Botchan et al, 1995). As the uterus enlarges and an actively moving fetus compresses the neoplasm, maternal complications such as severe hypertension, hemorraghe into the neoplasm, hemodynamic collapse, myocardial infarction, cardiac arrhythmias, congestive heart failure, and cerebral hemorraghe may occur. Extra-adrenal tumours which occur in $10 \%$, such as in the organ of Zuckerkandl at the aortic bifurcation, are particularly prone to hypertensive episodes with changes in position, uterine contractions, fetal movement, and Valsalva maneuvers. Unrecognized pheochromocytoma is associated with a maternal mortality rate of $50 \%$ at induction of anesthesia or during labor (Lau et al., 1996).

There is a minimal placental transfer of catecholamines likely due to high placental concentrations of catechol-O-methyltransferase and monoamine oxidase. Adverse fetal effects such hypoxia are a result of catecholamine-induced uteroplacental vasoconstriction and placental insufficiency, and of maternal hypertension, hypotension, or vascular collapse (Saarikoski, 1974).

\subsection{Diagnosis}

Diagnosis of pheochromocytoma requires a high index of suspicion. Preconception screening of families known to have MEN 2 with RET proto-oncogene is essential. The diagnosis should be considered in pregnant women with severe or paroxysmal hypertension, particularly in the first half of pregnancy or in association with orthostatic hypotension or episodic symptoms of pallor, anxiety, headaches, palpitations, chest pain, or diaphoresis. Symptoms may occur or worsen during pregnancy because of the increased vascularity of the tumour and mechanical factors such as pressure from the expanding uterus or fetal movement (Harper et al, 1989). As in nonpregnant women, the diagnosis is usually based upon the results of 24-hour urinary fractionated metanephrines and catecholamines and plasma fractionated metanephrines. If possible, methyldopa and labetolol should be discontinued prior to the investigation as these agents may interfere with the quantification of the catecholamines. MRI is the imaging test of choice in the pregnant women. Stimulation test and 123-I-MIBG scintigraphy are not considered safe for pregnant women.

\subsection{Treatment}

Medical therapy should be iniciated with alpha adrenergic blockade (usually phenoxybenzamine) (Stenstrm \& Swolin , 1985).

Ii is started at a dose of $10 \mathrm{mg}$ twice daily, with titration until the hypertension is controlled. Placental transfer of phenoxybenzamine occurs, but is generally safe (Santeiro et al., 1996). Beta blockade is reserved for treating maternal tachycardia of arrhythmias which persist after full alpha blockade and volume repletion.

Beta blockers may be associated with fetal bradycardia and with intrauterine growth retardation, when used early in pregnancy (Chatterjee \& Parekh, 1985) All of these potential fetal risks are small compared to the risk of fetal wastage from unblocked high maternal levels of catecholamines. Hypertensive emergencies should be treated with phentolamine or nitroprusside, although the latter should be limited because of fetal cyanide toxicity.

The timing of surgical excision of the neoplasm is controversial. In the first half of pregnancy, surgical excision may proceed once adequate alpha-blockade is established, although there is a higher risk of miscarriage with first trimester surgery. In the early second trimester, abortion is less likely and the size of the uterus will nor make excision difficult. If 
the pheochromocytoma is not recognized until the second half of gestation, increasing uterine size makes surgical exploration difficult (Sarathi et al,. 2010).

Successful laparoscopic excision of a pheochromocytoma in the second trimester of pregnancy has been described (Finkensted et al, 1999).

Other options include combined cesarean delivery and tumour resection or delivery followed by tumour resection at a later date. Delivery is generally delayed until the fetus reaches sufficient maturity to reduce postpartum morbidity, providing successful medical management exists. Although successful vaginal delivery has been reported, it has been associated with higher rates of maternal mortality than caesarean section (Schenker \& Granat, 1982).

\section{Congenital Adrenal Hyperplasia (CAH)}

It occurs in a family of monogenic inherited enzymatic defects of adrenal steroid biosynthesis, with manifestations secondary to an accumulation of precursors proximal to the enzymatic deficiency. The most common form of CAH is 21-hydroxylase deficiency, seen in more than $90 \%$ of the CAH cases in pregnancy (Forest, 2004).

Classic, severe 21-hydroxylase deficiency is associated with ambiguous genitalia, and inadequate vaginal introitis, and progressive postnatal virilization including precocious adrenarche, advanced somatic development, central precocious puberty, menstrual irregularity , a reduced fertility rate, and possible salt wasting (White \& Speiser, 2000).

The spontaneous abortion rate is twice that in the normal population, and congenital anomalies are more frecuent. Conception requires adecuate glucocorticoid therapy, which then continues at stables rates during gestation, except at labor and delivery. Nonclassical 21-hydroxilase deficiency patients present with pubertal and postpubertal hirsutism and menstrual irregularity, and may have improved fertility with glucocorticoid therapy ( Krone et al., 2001).

ACTH stimulation testing to measure $17-\mathrm{OH}$ progesterone demonstrates overlap between heterozygotes for $\mathrm{CAH}$ and the normal population. Ideally CYP21 genotyping should be performed. Virilization is not seen in the female fetus with non classical 21-hydroxylase deficiency, but occurs in a fetus with classic 21-hydroxylae unless fetal adrenal androgen productions is adequately suppressed.

Dexamethasone most readily crosses the placenta as it is not bound to CBG and is not metabolize at dose of $20 \mathrm{mcg} / \mathrm{kg}$ maternal body weight per day to a maximum of $1.5 \mathrm{mg}$ daily in 3 divided doses beginning at recognition of pregnancy before the 9 th week of gestation, though lower doses are recommended by some (Coleman MA, Honour, 2004). Maternal plasma and/or urinary estriol levels reflect fetal adrenal synthesis and are monitored to assess efficacy. Maternal cortisol a DHEA-S levels will represent maternal adrenal suppression.

As only $25 \%$ of female fetuses are affected in a family with $\mathrm{CAH}$, it is important to discontinue therapy as soon as possible in the male fetus and unaffected female fetus.

Chorionic villus sampling at 9-11 weeks gestation may be used for gender determination and direct ADN analysis for the 21-hydroxilase gene CYP21.

Side effects of dexamethasone therapy are potentially significant, including excessive weight gain, sever striae with scarring, edema, irritability, gestational diabetes mellitus, hypertension, and gastrointestinal intolerance. In affected pregnancies, dexamethasone may 
be lowered to 0.75 to $1 \mathrm{mg} /$ day in the second half of pregnancy to decrease maternal side effects while avoiding fetal virilisation (Pang et al, 1990).

\section{Conclusion}

Pregnancy is a stage of life very important. It is important to recognize and to treat adrenal disease during pregnancy to avoid complications in the mother and fetus.

\section{References}

Schindler AE. Endocrinology of pregnancy: consequences foe the diagnosis and treatment of pregnancy disorders. J Steroid Biochem Mol Bio. 2005; 97:386-8.

Lindsay JR, Nieman LK. The hypothalamic-pituitary-adrenal axis in pregnancy: Challenges in disease detection and treatment. Endocr Rev. 2005; 26: 775-99.

Guilhaume B, Sanson ML, Billaund L, Bertagna X, Laudat MH, Luton JP. Cushing's Syndrome and pregnancy: etiologies and prognosis in twenty-two patients. Eur J Med. 1992; 1:83-9.

Aron DC, Schnall AM, Sheeler LR. Am J Obstet Gynecol. 1990 ; 162(1):244-52.

Vilar L, Freitas MDC, Lima LHC, et al. Cushing's syndrome in pregnancy. An overview. Arq Bras Endocrinol Metab. 2007; 51:1293.

Carr BR, Parker CR Jr, Madden JE, et al: Maternal plasma adrenocorticotropin and cortisol relationships throughout human pregnancy. Am J Obstet Gynecol. 1981; 139: 416.

Lindsay JR, Jonklaas J, Oldfield EH, Nieman LK: Cushing's syndrome during pregnancy: personal experience and review of the literature. J Clin Endocrinol Metab 90: 3077, 2005.

Barasch E, Sztern M, Spinrad S, Chayen R, Servadio C, Kaufman H, Ben Bassat M, Blum I. Pregnancy and Cushing's syndrome: example of endocrine interaction. Isr J Med Sci. 1988; 24(2):101-4.

Buescher, MA. Cushing's syndrome in pregnancy. Endocrinologist 1996; 6:357.

Blanco C, Maqueda E, Rubio JA, Rodriguez A. Cushing's syndrome during pregnancy secondary to adrenal adenoma: metyrapone treatment and laparoscopic adrenalectomy. J Endocrinol Invest. 2006;29(2):164-7.

Berwaerts J, Verhelst J, Mahler C, Abs R. Cushing's syndrome in pregnancy treated by ketoconazole: case report and review of the literature. Gynecol Endocrinol. 1999; 13: 175.

Casson IF, Davis JC, Jeffreys RV, Silas JH, Williams J, Belchetz PE. Successful management of Cushing's disease during pregnancy by transsphenoidal adenectomy. Clin Endocrinol (Oxf). 1987; 27(4):423-8.

Ambrosi B, Barbetta L, Morricone L. Diagnosis and management of Addison's disease during pregnancy. J Endocrinol Invest. 2003; 26698-702.

Stechova K, Bartaskova D, Mrstinova M, Cerny M, Snajderova M, Cinek O, et al. Pregnancy in a woman suffering from type 1 diabetes associated with Addison disease and Hashimoto Thyroiditis. Exp Clin Endocrinol Diab. 2004; 112:333-7.

Gradden C, Lawrence D, Doyle PM, et al: Uses of error: Addison's disease in pregnancy. Lancet. 2001; 357: 1197.

Sarathi V, Lila AR, Bandgar TR, et al. Pheochromocytoma and pregnancy: a rare but dangerous combination. Endocr Pract. 2010; 16: 300. 
Nolten WE, Lindheimer MD, Oparil S, et al. Desoxycorticosterone in normal pregnancy: I. sequential studies of the secretory patterns of desoxycorticosterone, aldosterone, and cortisol. Am J Obstet Gynecol. 1978; 132: 414.

Symonds EM, Craven DJ. Plasma renin and aldosterone in pregnancy complicated by adrenal insufficiency. Br J Obstet Gynaecol. 1977; 84: 191.

McKenna DS, Wittber GM, Nagaraja HN, et al. The effects of repeat doses of antenatal corticosteroids on maternal adrenal function. Am J Obstet Gynecol . 2000; 183: 669.

Sidhu RK, Hawkins DR: Prescribing in pregnancy: corticosteroids. Clin Obstet Gynaecol 8: 383, 1981.

Okawa T, Asano K, Hashimoto T, et al. Diagnosis and management of primary aldosteronism in pregnancy: case report and review of the literature. Am J Perinatol. 2002; 19: 31.

Wyckoff JA, Seely EW, Hurwitz S, et al: Glucocorticoid-remediable aldosteronism and pregnancy. Hypertension. 2000; 35: 668.

Matsumoto J, Miyake H, Isozaki T, et al. Primary aldosteronism in pregnancy. J Nippon Med Sch 2000; 67: 275.

Nursal TZ, Caliskan K, Ertorer E, Parlakgumus A, Moray G. Laparoscoptic treatment of primary hyperaldosteronism in a pregnant patient. J Can Chir. 2009; 52; 188.

Keely E. Endocrine causes of hypertension in pregnancy--when to start looking for zebras. Semin Perinatol. 1998;22(6):471-84.

Botchan A, Hauser R, Kupfermine M, et al: Pheochromocytoma in pregnancy: case report and review of the literature. Obstet Gynecol Surv 50: 321, 1995.

Lau P, Permezel M, Dawson P, et al. Phaeochromocytoma in pregnancy. Aust N Z J Obstet Gynaecol 36: 472, 1996.

Saarikoski S: Fate of noradrenaline in the human fetoplacental unit. Acta Physiol Scand 421 (Suppl): 1, 1974.

Harper MA, Murnaghan GA, Kennedy L, Hadden DR, Atkinson AB: Phaeochromocytoma in pregnancy: Five cases and a review of the literature. Br J Obstet Gynaecol 96: 594, 1989.

Stenstrm G, Swolin K. Pheochromocytoma in pregnancy. Experience of treatment with phenoxybenzamine in three patients.Acta Obstet Gynecol Scand. 1985;64(4):357-61.

Santeiro ML, Stromquist C, Wyble L. Phenoxybenzamine placental transfer during the third trimester. Ann Pharmacother . 1996;30: 1249.

Chatterjee TK, Parekh U. Phaeochromocytoma in pregnancy. Aust NZ J Obstet Gynaecol. 1985; 25: 290.

Sarathi V, Lila AR, Bandgar TR, et al. Pheochromocytoma and pregnancy: a rare but dangerous combination. Endocr Pract. 2010; 16: 300.

Finkenstedt G, Gasser RW, Hofle G, et al. Pheochromocytoma and sub-clinical Cushing's syndrome during pregnancy: Diagnosis, medical pre-treatment and cure by laparoscopic unilateral adrenalectomy. J Endocrinol Invest. 1999; 22: 551.

Schenker JG, Granat M: Phaeochromocytoma and pregnancy - An updated appraisal. Aust NZ J Obstet Gynaecol. 1982; 22: 1.

Forest MG. Recent advances in the diagnosis and management of congenital adrenal hyperplasia due to 21-hydroxylase deficiency. Hum Reprod Update. 2004; 10: 469.

White PC, Speiser PW: Congenital adrenal hyperplasia due to 21-hydroxylase deficiency. Endocr Rev. 2000; 21: 245. 
Krone N, Wachter I, Stafanidou M, Roscher AA, Schwarz HP. Mothers with congenital adrenal hyperplasia and their children: outcome of pregnancy, birth and childhood. Clin Endocrinol. 2001; 55: 523.

Coleman MA, Honour JW. Reduced maternal dexamethasone dosage for the prenatal treatment of congenital adrenal hyperplasia. BJOG. 2004; 111: 176.

Pang A, Pollack MS, Marshall RN, Immken LD. Prenatal treatment of congenital adrenal hyperplasia due to 21-hydroxylase deficiency. N Engl J Med. 1990; 322: 111. 


\section{Part 3}

Effects of Androgens 



\title{
Cardiovascular Effects of Androgens
}

\author{
Carlos Wilson, Rodrigo Maass and Manuel Estrada \\ Universidad de Chile, Facultad de Medicina, Instituto de Ciencias Biomédicas \\ Chile
}

\section{Introduction}

Androgens are the male sex hormones responsible for development of the male reproductive system. Testosterone is the main androgen, however, other circulating androgens also exist; these are dehydroepiandrosterone, androstenedione and androstenediol. In some tissues, testosterone can be converted to dihydrotestosterone by action of $5 a-$-reductase. Testosterone is also found in females, but at much lower levels than males; it can be converted into estradiol by the enzyme aromatase. Testosterone has 19 carbon atoms, and is produced from cholesterol, mainly by Leydig cells in the testes. Androgens are responsible for primary and secondary sexual characters in men, and also for the development of skeletal muscle mass and strength, erythropoiesis and bone density, amongst other functions.

The divergent effects that androgens have between sexes can be explained by differences in concentration, metabolism and receptor expressions. Male sex hormones are also known to fluctuate along the day and throughout life. Prior to puberty, testosterone level is usually low in males. However, after puberty, testosterone level increases and reaches its peak around the age of 20-25 in men. As aging occurs, testosterone levels decline.

Testosterone and its derivatives are well known for their androgenic properties and anabolic effects. These hormones direct the differentiation of organs and tissues towards the adoption of male phenotypes. Thus far, the effects of androgens on the cardiovascular system remain incompletely understood. Some studies point to increased cardiovascular risk associated with a high circulating androgen level, related to responses that lead to changes in blood pressure, ion channel activity and cardiomyocyte hypertrophy. However, other studies support a long-term cardio-protective role for these steroid hormones. Despite these differences, increasing clinical evidence supports consideration for transient use of testosterone derivatives to improve cardiovascular function.

\section{Mechanism of androgen action}

Androgens exert most their effects through the direct binding to specific intracellular receptors acting as transcriptional activators (Beato, 1989). Intracellular androgen receptors have been described in neonatal and adult cardiomyocytes (Hickson et al., 1984; Marsh et al., 1998). Genomic responses to testosterone are mediated through the intracellular androgen receptor, which is a 110-kDa protein with domains for androgen binding, nuclear localization, DNA binding, and transactivation (TD). The conserved domain structure has three major functional regions: an NH-terminal transactivation domain, a centrally located 
DNA binding domain (DBD), and a $\mathrm{COOH}$-terminal hormone-binding domain (HBD) (Figure 1). The $\mathrm{COOH}$-terminus contains an additional activation domain and a hinge region connecting the $\mathrm{HBD}$ and the $\mathrm{DBD}$. Upon ligand binding, the nuclear receptors translocate to the nucleus where they dimerize and bind to regulatory DNA sequences on target genes and activate transcription (Simental et al., 1992). Several co-regulatory proteins that bind and regulate the activity of receptors have been identified. These include both coactivators that positively regulate transcriptional effects of intracellular receptors after ligand binding and co-repressors that negatively regulate receptor activity. These effects are slow, with a latency period before onset, but they are also long lasting, remaining active for hours after hormone stimulation.

In addition to this transcriptional or genomic mode of action, increasing evidence suggests that androgens can exert rapid, non-genomic effects. The time course of these responses is not compatible with the classic genomic mechanism for the action of steroids, since they have a rapid onset without an apparent latency period. Common to these early effects is a fast increase in intracellular $\mathrm{Ca}^{2+}$ and activation of $\mathrm{Ca}^{2+}$-dependent pathways and second messenger cascades (Estrada et al., 2000, 2003). Second messenger induction by nongenomic steroid action is insensitive to inhibitors of either transcription or translation. Little is known about these non-genomic effects in cardiac cells. However, these responses involve the generation of different patterns of $\mathrm{Ca}^{2+}$ signals and also in the activation of complementary $\mathrm{Ca}^{2+}$-dependent pathways. Thus, in addition to the classical mechanism of steroid action in cardiac cells, androgens activate additional specific signal transduction pathways (Altamirano et al., 2009; Vicencio et al., 2006). An interesting hypothesis is that these second messenger cascades may ultimately serve to modulate the transcriptional activity of the intracellular androgen receptor and its associated global response. This idea of an integrated mechanism for androgen action will be discussed.

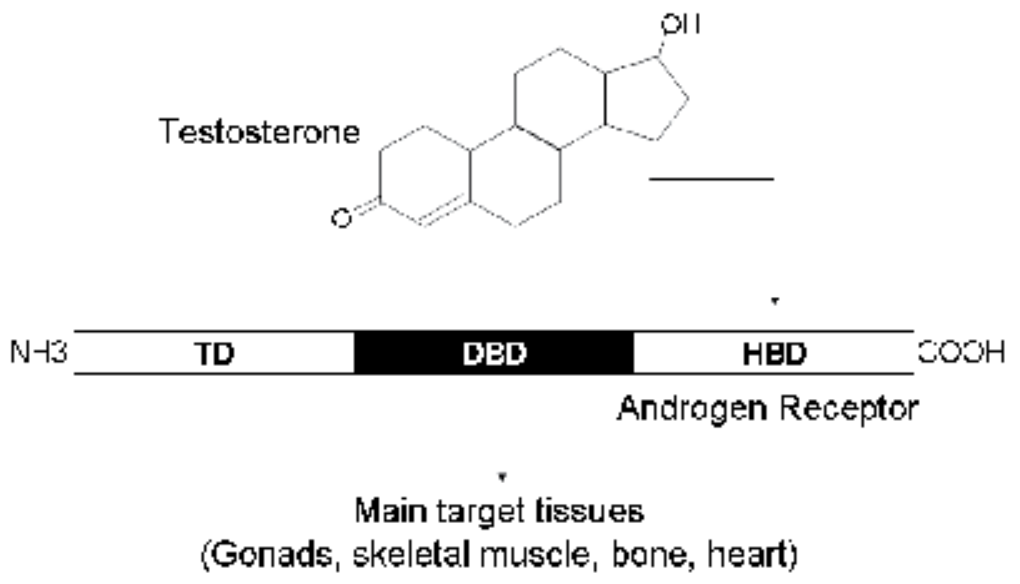

Fig. 1. Schematic representation of testosterone and the main domains of intracellular androgen receptor.

\section{Cardiovascular effects of androgens}

Androgens influence cardiac function by acting directly on the heart or by affecting the vascular system (English et al., 2001; Hayward et al., 2001; Jones et al., 2003; Kienitz \& 
Quinkler, 2008). In humans and experimental animals, anabolic steroids have been associated with an increased risk of coronary artery disease by adversely affecting the plasma lipid and lipoprotein profile, producing thrombosis and cardiac hypertrophy (Liu et al., 2003; Sullivan et al., 1998). In particular, use of elevated doses of testosterone or its synthetic cognates has been related to cardiac hypertrophy, ventricular remodelling, cardiomyopathy, myocardial infarction, and sudden cardiac death. On the other hand, with a normal steroid level, androgen actions are necessary for a range of developmental and biological processes, including maintaining the health of cardiomyocytes. Androgens might also produce additional hemodynamic effects by relaxing vascular bed, reducing after-load and rapidly increasing cardiac contractility, resulting in increased cardiac output (Liu et al., 2003). This dual androgen effect is not clear yet. Research in the field of androgens and androgen receptors signaling pathways will provide considerable understanding of the physiological and pathological roles of these hormones. These effects could be related to different concentrations of these hormones as well as to differential activation of signal transduction pathways.

Both beneficial and pathological effects of androgens are observed clinically. Patients with chronic heart failure suffer considerable morbidity as well as early mortality. They exhibit altered structure and function of cardiac and skeletal muscle and excessive activation of catabolic hormones and inflammatory cytokines (Malkin et al., 2004). Men with chronic heart failure have relatively low androgen levels, which may contribute to the pathophysiological process.

\subsection{Role of androgens in hypertension}

Hypertension is a major risk factor for developing cardiovascular disease, atherosclerosis and sudden cardiac death. Hypertension is more prevalent and occurs earlier in men than in women. Blood pressure is elevated from the onset of puberty in males, when they manifest the effects and differences of sex steroids. These differences in blood pressure between men and women are maintained until 60 years of age. Epidemiological data indicate that systolic blood pressure in men under the age of 60 years is 6-7 mm Hg higher than in women, and diastolic pressure is higher by 3-5 mm Hg (Stamler et al., 1976). In women over the age of 60 , show gradual increases of blood pressure over a period of 5 to 20 years, until hypertension is highly prevalent in women as in men. Estrogen reduction after menopause is partially responsible for this effect and experimental data indicate that the change in the estrogen/androgen ratio seems to be the cause (Akkad et al., 1997; Pripp et al., 1999).

Epidemiological studies show that androgens are important determinants of sex differences in blood pressure. An elevated level of anabolic steroids, found in anabolic abuse by high performance athletes has been associated with hypertension, cardiac remodelling and myocardial ischemia (Kienitz \& Quinkler, 2008). This suggests a direct role in the development of hypertension. However, clinical evidence shows beneficial effects of testosterone on hypertension. Observational studies in humans indicate that there is an inverse relationship between systolic pressure and the plasma level of testosterone in men. There is also higher incidence of hypertension in individuals with reduced free circulating androgen (Fogari et al., 2005). The beneficial effect of testosterone replacement has also been well documented. Accordingly, in randomized, double-blind, case-control clinical studies hormone administration was related to the reduction of vascular tone (Malkin et al., 2006). In other study, administration of testosterone significantly reduced ST segment depression 
in patients with stable angina and improved post-exercise myocardial perfusion in patients with occlusive coronary artery disease (Jaffe, 1977).

Furthermore, experimental evidences provide controversial information. In some animal models potential role for androgens in the pathogenesis of hypertension have been observed. Mice hypertension models show that castration and subsequent testosterone supplementation at high doses produce the onset of hypertension (Dubey et al., 2002). This effect is mediated by androgen receptors, as shown by the inhibitory effect of flutamide, an antagonist of the intracellular androgen receptor. However, others in vitro studies indicate a direct vasodilator effect of androgens by the activation of the nitric oxide (NO) pathway mediated by the endothelium, activation of voltage-dependent potassium channels and blockage of voltage and receptor-operated calcium channels (Jones et al., 2003, 2004).

Thus, androgens appear to be involved in the regulation of vascular tone. Aging induces a progressive reduction in the plasma testosterone levels along the years, which begins to be deleterious as aging occurs; while physiological stress produces acute diminution of androgen levels. These conditions are determinants for clinical manifestation of hypertension. Therefore, testosterone supplementation in men with low levels of androgens could be beneficial to restore altered blood pressure (Handelsman \& Liu, 2005).

\subsection{Androgens in endothelial function, atherosclerosis and heart perfusion}

Numerous clinical studies show that men exhibit higher susceptibility to atherosclerosis than pre-menopausal women. The available information indicate that the evolution of atherosclerosis is faster in males - independent of dyslipidemia or evidence of endothelial damage - than females (Kaushik et al, 2010.). However, a negative correlation between testosterone plasma level and cardiovascular disease in men has been observed (Iliescu \& Reckelhoff, 2006; Thijs et al., 2003). Testosterone deficiency affects approximately $30 \%$ of men under 30 years and as aging occurs, testosterone level decline even more, a male condition known as andropause (Handelsman \& Liu, 2005). Low androgen concentrations are strongly associated with increase in cardiovascular risks including atherogenic lipid profile, insulin resistance, obesity and prothrombotic profile (Jones et al., 2005; Kapoor et al., 2007). However, other studies indicate that testosterone increases cholesterol uptake by macrophages promoting its transformation into foam cells, which are involved in the formation of atheroma lesions (McCrohon et al., 2000). Testosterone also induces apoptosis of endothelial cells in vitro and promotes proliferation and migration of vascular smooth muscle cells, which are involved in the development of atherosclerotic lesions (Kaushik et al., 2010).

This appears to explain the faster progression of atherosclerosis occurring in men than women. However, the amount of clinical evidence suggests protective effects of androgens during atherosclerosis. For example, high to normal range of testosterone concentrations exhibit preventive role in coronary artery disease. In fact, patients with coronary artery disease show significantly lower testosterone level than patients without coronary artery disease (English et al., 2000). Animal models show similar results (Alexandersen et al., 1999). At cellular level, the mechanism for these testosterone effects involve inhibition of macrophage migration, which decrease the expression of adhesion molecules and proinflammatory cytokines such as TNFa (Malkin et al., 2004).

In addition, androgens produce direct and rapid vasodilatory effects in human coronary disease and stable angina, increasing the coronary flow between 12 and 17\% (Webb et al., 1999). This has not been free of controversy, because in isolated vessels the chronic 
treatment with testosterone produce increase in the vasoconstrictor responses to adrenergic agonists, while reduce the response to nitric oxide (Iliescu \& Reckelhoff, 2006; Malkin et al., 2006). In animal models, testosterone produces a similar effect, independent of androgen receptor. Vasodilatation occurs by inhibition of plasma membrane calcium channels and activation of potassium channel (Ding \& Stallone, 2001). However, this effect is acute and only produced in response to high doses of testosterone, so this does not appear to be an appropriate strategy for anti-ischemic treatment. But this could explain the positive effects on peripheral vascular resistance in response to acute administration of testosterone in men with heart failure, stable angina or in arteries isolated from healthy men with heart failure.

Thus, current data indicate that androgens, particularly testosterone, do not have a permissive role in the evolution of atherosclerotic lesions at the cellular level. However, testosterone diminution as in aging is associated with accelerated atherosclerosis. This occurs by increase in the expression of adhesion molecules and pro-inflammatory cytokines. Moreover, this also could be stimulated by high exogenous androgen supplementation.

\subsection{Effects of testosterone on cardiac excitability}

Gender differences are well-established in the generation of ventricular arrhythmias associated with a prolonged QT interval. This interval is used to estimate the electrocardiographic duration of ventricular action potential. Thus, women exhibit greatest risk of ventricular arrhythmias such as "torsade de pointes", a type of highly fatal polymorphic ventricular tachycardia. This clinical condition is worse in women compared with men, particularly in response to drugs that prolong the QT interval (Rautaharju et al., 2006). This has been associated with sex differences in the rate of ventricular repolarization being slower in adult women. These differences are manifested from puberty, becoming the QT interval increasingly longer until women reach adulthood. In men, once they start to drop in plasma testosterone levels gradually prolong the QT interval similar to women older than 60 (Zhou et al., 1992). Studies in experimental animals have established that testosterone levels are negatively correlated with the duration of the action potential (Pham et al., 2001) and other researchers reported that dihydrotestosterone administration in castrated male rabbits shortened QT interval (Liu et al., 2003).

This information indicates that testosterone is a regulator of sex differences in the action potential duration, ventricular repolarization and propensity to ventricular arrhythmias. In isolated cardiomyocytes has been established that testosterone increases the expression of $\beta$ adrenergic receptors, L-type calcium channel and sodium-calcium exchanger (Golden et al., 2004). Moreover, testosterone increases by $30 \%$ the density of repolarizing potassium currents, which is due to changes in both gating kinetics of the delayed rectifier potassium currents (Ikr) and shortening the duration of the QT interval (Liu et al., 2003)

Testosterone has been shown to interact directly with the NO system. Activation of this pathway induces shortening in the duration of the action potential by activating the slow component of delayed rectifier potassium current (Iks) and inhibiting L-type calcium currents (Ica,L) (Bai et al., 2004, 2005).

\section{Androgen-mediated cardiac hypertrophy}

The most striking evidence of cardiac effect of androgens is the case of highly conditioned athletes, which have died by sudden cardiac death. Post mortem examinations indicated anatomical abnormalities in the heart, known as hypertrophic cardiomyopathy (Maron et 
al., 1978, 1980). Thus, it was assumed that elevated testosterone administration induces cardiac hypertrophy.

Cardiac hypertrophy is an adaptive mechanism to enhance cardiac output in response to cardiovascular challenges. Cardiac hypertrophy is produced in response to several pathophysiological conditions, such as mechanical stretching or neuro-hormoral deregulation. This process is characterized by increases in cardiomyocyte size and protein synthesis, as well as by the re-expression of various fetal genes (Frey \& Olson, 2003; Izumo et al., 1987). At the cellular level, cardiomyocytes depend of the activation of several signalling pathways related to cell growth, which are crucial for the development of cardiac hypertrophy. These pathways involve both androgen receptors as well as intracellular signalling pathways.

\subsection{Androgen receptor in hypertrophy}

Cellular effects of testosterone depend on activation of androgen receptor, which is localized in cytoplasm and acts as a transcriptional factor when it binds testosterone. Marsh et al. have shown that androgens produce cardiac hypertrophy by a direct, receptor-specific mechanism (Marsh et al., 1998). They have also revealed that androgens regulate functional expression of an L-type calcium channel in isolated rat ventricular cardiomyocytes, leading to a modulation of cardiac performance in males. Li et al. reported that either castration or administration of flutamide, an androgen receptor antagonist, markedly attenuated cardiac hypertrophy and fibrosis in guanylyl cyclase-A knock-out male mice (Li et al., 2004). In baroreceptor-denervated rats, left ventricular hypertrophy is gender-dependent and elevated testosterone stimulates cardiac hypertrophy (Cabral et al., 1988a, 1988b). Moreover, in vitro studies provide evidence that androgens induce hypertrophic growth in cultured cardiomyocytes, suggesting that the growth promoting effect is direct (Marsh et al., 1998). The hypertrophic effects of testosterone are associated with increased protein synthesis mediated by the androgen receptor and specific nuclear coactivators related to cell growth (Hickson et al., 1984).

\subsection{Intracellular signaling pathways}

Pro-hypertrophy stimuli activate diverse intracellular signaling pathways. Activation of these pathways by androgens could lead to long-term cellular effects by activation of cotranscriptional modulators. Induction of multiple signaling pathways in cardiac hypertrophy has been described as follows:

\section{$\mathrm{Ca}^{+2} /$ Calcineurin/NFAT pathway}

Calcium ion $\left(\mathrm{Ca}^{+2}\right)$ is one of the most diverse and important intracellular second messenger as well as a key element in the excitation-contraction coupling of cardiac muscle. $\mathrm{Ca}^{+2}$ has been related to cardiac hypertrophy, because of its ability to promote the activation of the protein phosphatase calcineurin through establishment of $\mathrm{Ca}^{+2} /$ calmodulin complex (Heineke \& Molkentin, 2006). Calcineurin promotes the translocation of the nuclear factor of activated T cells (NFAT) from cytoplasm to nucleus. NFAT family proteins are responsible for the expression of c-fos, c-jun and c-myc, early fetal genes; which are expressed during fetal development. These are silenced in adult stages and then re-expressed during cardiac hypertrophy, reason why they are considered as hypertrophic markers (Frey \& Olson, 2002, 2003; Heineke \& Molkentin, 2006).

\section{PI3K/Akt/GSK3- $\boldsymbol{\beta}$ pathway}

Another cellular pathway involved in cardiac hypertrophy is PI3-K (Phosphoinositide 3kinase)/Akt proteins. This signalling pathway has been related to cell survival and 
proliferation in almost all cell types. However, the up-regulation of the pathway by several stimuli induces cardiac hypertrophy. One of the most common downstream targets of Akt is the protein kinase GSK3- $\beta$ (Glycogen Synthase Kinase 3- $\beta$ ) (Antos et al., 2002). Activated GSK3- $\beta$ phosphorylates several members of NFAT family, which promotes their translocation from nucleus to cytoplasm. Akt phosphorylates and inhibits GSK3- $\beta$, which increases the residence of NFAT in the nucleus. Also, Akt has the ability to phosphorylate the protein mTOR (mammalian target of rapamycin), another downstream target of PI3K/Akt pathway. In cardiac cells, protein synthesis is highly regulated by mTOR, which stimulates protein translation and ribosome biosynthesis (Proud, 2004). mTOR lies upstream of critical translation regulators such as the 40S ribosomal protein S6 kinase 1 (S6K1) and the eukaryotic initiation factor $4 \mathrm{E}-$ binding protein 1 (4E-BP1). Activation of the mTOR pathway is a critical step to induce cardiac hypertrophy in vitro (Altamirano et al., 2009; Takano et al., 1996) and in vivo (Shioi et al., 2003).

\section{G-protein-coupled receptors pathway}

Plasma membrane G-protein G-protein-coupled receptors (GPCR) are crucial for cardiac function and hypertrophic growth. Both Gas and Gaq are sufficient to produce cardiac hypertrophy. Gas induces the synthesis of cAMP and PKA activation, which could induce hypertrophy. Gaq promotes the activation of the protein phopholipase $\mathrm{C}$ (PLC) and $\mathrm{IP}_{3}$ production, which induces intracellular $\mathrm{Ca}^{+2}$ oscillations and hence, the activation of different proteins responsible of cardiac hypertrophy, such as calcineurin (Heineke \& Molkentin, 2006).

These signalling pathways are related to the hypertrophic growth of cardiomyocytes. It has been described that testosterone induces intracellular $\mathrm{Ca}^{2+}$ increase through a nongenomic action mechanism, as we discussed earlier in this chapter. Studies in cultured cardiomyocytes show that through a nongenomic mechanism, testosterone is implicated in the activation of a membrane receptor coupled to a Gaq protein, thus resulting in the production of $\mathrm{IP}_{3}$ and $\mathrm{Ca}^{+2}$ release from endoplasmic reticulum (Vicencio et al., 2006). Then, calcium oscillations induce the activation of the mitogen-activated protein kinase ERK 1/2, which in turns phosphorylates mTOR, promoting hypertrophic cardiac growth (Altamirano et al., 2009).

Aside from classical action mechanism for testosterone, non-classical effects also are implicated in cardiac hypertrophy development has been described. The establishment of testosterone-androgen receptor complex acts as a transcriptional factor for the expression of different genes and proteins necessary for protein synthesis, energy production and cell growth, which are crucial for hypertrophic growth.

\subsection{Cardiac remodelling}

Cardiac remodelling involves changes in the structure, mass and function of the heart, mainly due to increase in the number of myofibrils or cardiomyocyte hypertrophy. Proliferation of cardiac fibroblasts and consequent increase in the extracellular matrix is called cardiac fibrosis. The balance between synthesis and degradation of different collagen types determine the content of extracellular matrix proteins. Cardiac fibrosis increases the stiffness of the heart chambers, which produce high end diastolic pressure. If this event is persistent, leads to progressive and irreversible cardiac damage and heart failure. Controversial information exists about the role of sex hormones on cardiac remodelling during cardiac hypertrophy, including fibrosis. However, these differences are manifested 
as gender differences in cardiac remodelling. Heart size of men is bigger than women, even when is corrected for body weight. Men also have higher incidence of fibrosis; however direct effects of androgens are not clear. The increase in cardiac mass is higher in men from puberty and has been shown that estrogens have preventive effects on cardiac hypertrophy (Weinberg et al., 1999). In castrated mice, administration of androgen receptor antagonists does not abolish the sex differences in heart size or cardiac fibrosis (Li et al, 2004), suggesting that androgens are not the only determinants for these differences. Negative consequences of fibrosis are mediated mainly by local effect of the renin-angiotensin system. Angiotensin II regulates differentiation and proliferation of ventricular fibroblasts and synthesis of extracellular matrix, which consist mainly of collagen type I and III (Krenning et al., 2010). The synthesis of collagen type I and III by fibroblasts is stimulated by TGF- $\beta 1$ and inhibited by androgens (Ikeda et al., 2005). Cardiac fibroblasts express androgen receptor, which suggest a role for androgens during cardiac remodelling. Experimental evidence in androgen receptor knockout (ARKO) mice show reduced ventricular volume and wall thickness, but no differences in blood pressure or heart rate as compared with normal animals (Ikeda et al., 2005). It has also been demonstrated that dihydrotestosterone increase atrial natriuretic peptide (ANP) secretion from neonatal rat cardiomyocytes (Marsh et al., 1998). Furthermore, ARKO mice show a significant reduction in ANP gene transcription, resulting in increased cardiac fibrosis. On the other hand, testosterone has been shown to increase the amount of collagen measured around coronary blood vessels contributing to fibrosis in male hypertensive rats independent of the reninangiotensin system. Cavasin et al. (2006) have determined that high testosterone levels enhance acute myocardial inflammation, adversely affecting myocardial healing and early remodelling (Cavasin et al., 2006). Even when the evidence is still controversial, androgens show a protective role on cardiac remodelling and protect the heart from maladaptive fibrosis, preventing the deleterious effects of increased pre- and after-load induced by angiotensin II.

\section{Cardiac metabolism}

Normal heart requires a continuous supply of energy to maintain muscle contraction as well as hemodynamic adaptation, survival, growth and metabolism. Neuro-hormonal activation is an important input for cardiovascular response to metabolic demands. Although initially adaptive, neuro-hormonal activation together with metabolic alterations has deleterious effects on cardiovascular system.

In the heart muscle, ATP production is crucial for all cellular and contractile process. In the adult heart, ATP comes mainly from the $\beta$-oxidation of fatty acids, an oxygen dependent process. The $10-40 \%$ remaining come from glucose degradation through glycolysis, an oxygen independent process (Neglia et al., 2007; Stanley et al., 2005).

$\beta$-oxidation depends upon fatty acids uptake, which occurs through different fatty acid translocases located in the plasma membrane, like CD36 protein. Fatty acids must be transported to the mitochondria for $\beta$-oxidation, which occurs through the enzyme carinitine palmitoyl transferase-1 (CPT-1). Once inside mitochondria, fatty acids are oxidized to produce acetil-CoA, which will be incorporated into Krebs cycle for NADH, $\mathrm{FADH}_{2}$ and $\mathrm{CO}_{2}$ production. These intermediates provide oxidative power during the oxidative phosphorylation in mitochondria, where ATP is finally produced by ATP synthase complex V. 
On the other hand, glycolysis requires glucose uptake, which occurs through the glucose transporters 1 and 4 (GLUT1 and GLUT4), the main glucose transporters in cardiac cells. Once inside the cell, the enzymes hexokinase and phosphofructokinase, the glycolysis pacemaker enzyme, lead the conversion of glucose to pyruvate. Through this process 2 ATP molecules are generated from each glucose molecule incorporated.

However, the heart muscle is able to modify the ratio between $\beta$-oxidation and glycolysis in response to pro-hypertrophic agents (Stanley et al., 2005). For example, cardiac hypertrophy due to pressure overload is accompanied of a reduction in $\beta$-oxidation and an increase in the glycolytic rate as a compensatory mechanism that improves ATP production in the heart muscle (van der Vusse et al., 2000, 2002). In contrast, individuals with uncompensated diabetes usually develop a different cardiac hypertrophy, known as diabetic cardiomyopathy. Since diabetic patients are not able to metabolize glucose, diabetic cardiomyopathy is characterized by an increase in the fatty acids assimilation by cardiac cells, which carry cardiac lipotoxicity (van der Vusse et al., 2000).

During heart failure, cardiac muscle is not able to produce enough ATP for cardiac contraction, resulting in poor contractile performance. It is common to observe heart failure in pathologies associated to bad glucose handling for ATP production, as insulin resistance and diabetes. Metabolic syndrome, which comprehends both pathologies, has been correlated with low testosterone blood levels (Saad \& Gooren, 2009, 2011). It has been recently postulated that decrease in testosterone is a link between metabolic syndrome and heart failure. Clinical trials have demonstrated that the administration of testosterone at physiological concentrations improved insulin sensitivity, reduced glycaemia and central obesity, and heart failure progression in men suffering metabolic syndrome (Cook \& Romashkan, 2011). In addition to clinical trials, there are new studies related to testosterone effects on glucose metabolism. It has been described that testosterone is necessary to maintenance insulin and glucose concentration in blood. Recent reports have shown an important role for testosterone in the mobilization of glucose transporter GLUT4 to the plasma membrane in skeletal muscle, liver and fat tissue (Muthusamy et al., 2007, 2009).

In spite, elevated testosterone administration in humans is usually associated with the development of cardiac hypertrophy and heart failure; there are several studies that examine the relationship between the testosterone supplementation and heart failure with non positive correlation between them. Nowadays, several clinical trials lead to propose that testosterone supplementation at physiological doses could be a treatment for men with metabolic syndrome and heart failure (Pugh et al., 2000). The effect of testosterone as a metabolic modulator could improve insulin sensitivity and glucose uptake in the heart, which could lead to an increase in ATP production when cardiac output increases. However, evidences about the metabolic properties of testosterone on heart muscle come from observational studies. Research on the molecular mechanisms implicated in the metabolic testosterone actions is required.

\section{Integrated model for androgen action}

Androgens diffuse across plasma membrane due to their lipophilic nature. Once inside the cell, they are recognized by the cytosolic androgen receptor, which forms a complex with its ligand. This complex works as a transcription factor, which translocates to cell nucleus, binds to DNA and promotes the activation of several genes (Beato, 1989). This is called the 
classic or genomic androgen response pathway. On the other hand, it has been reported that androgens, exert a rapid, non-genomic effect mediated by a putative plasma membrane receptor. Its activation implicates participation of kinases, intracellular calcium oscillations and transcription factor activation, among other fast events.

Cardiomyocytes are terminally differentiated cells. Cardiac hypertrophy is characterized by an increase in cell size and protein synthesis and reactivation of a fetal gene program. Emerging evidence indicate that androgen action involves a crosstalk between genomic and nongenomic mechanisms. These could imply a two-step process, where both non-genomic and genomic effects occur sequentially (Figure 2). First, fast effects would be generated at the plasma membrane level with second messenger participation. Second, there would be gene activation; the pathways used by each cell type could provide specificity to the signal through a cooperative mechanism, which can act in a concerted form.

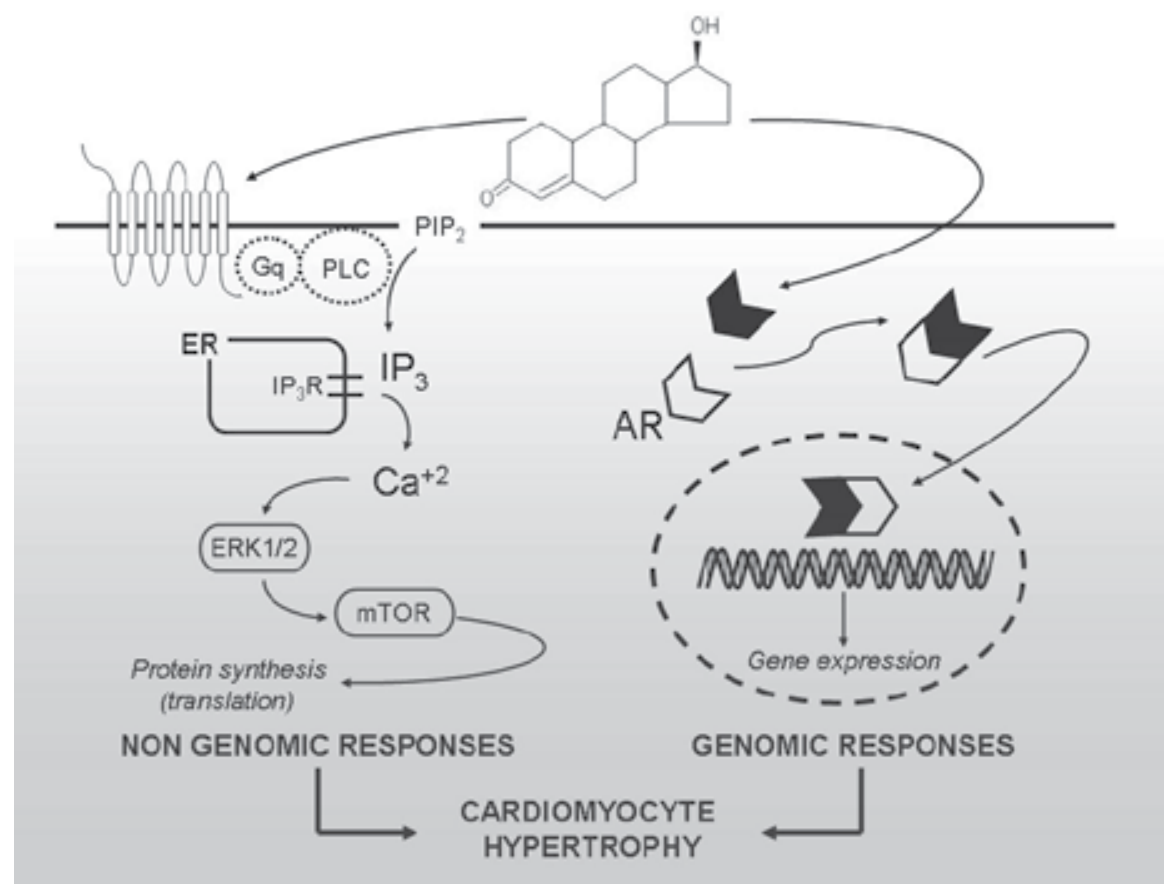

Fig. 2. Integrated mechanism for testosterone effects in cardiomyocytes. In cardiomyocytes, testosterone activates plasma membrane androgen receptors coupled to heterotrimeric $\mathrm{Gq}$ protein. $\mathrm{G} \beta \gamma$ dimers activate phospholipase $\mathrm{C}$ (PLC), which locally produces inositol $\mathrm{IP}_{3}$ thus activating $\mathrm{IP}_{3}$ receptors $\left(\mathrm{IP}_{3} \mathrm{R}\right)$. The consequent $\mathrm{Ca}^{2+}$ increase leads to the activation of several pathways, including the MEK/ERK/mTOR axis. These responses combined induce a series of genomic changes that lead to increased gene expression and increased protein synthesis, ultimately leading to cardiac hypertrophy.

While studying these hypertrophy effects on cardiomyocytes, our laboratory determined that testosterone uses a cooperative mechanism between the genomic and nongenomic pathways to produce the hypertrophic growth of cardiac cells. Thus, with normal levels of androgens the interactions among signaling pathways lead to the maintained health of cardiac cells, whereas high doses recruit additional signals which are hypertrophic. As 
depicted in Figure 2, testosterone activates a plasma membrane G-protein coupled receptor, a signaling pathway that results in a nongenomic mechanism. Activation of this pathway facilitates the hydrolysis of phosphatidylinositol 4,5-bisphosphate by phospholipase C, thereby generating diacylglycerol and $\mathrm{IP}_{3} . \mathrm{IP}_{3}$ mediates opening of $\mathrm{IP}_{3}$ receptors in the sarcoplasmatic reticulum, which in turn produce rapid (1-5 min) $\mathrm{Ca}^{2+}$ release (Vicencio et al., 2006). Similar effects of testosterone have been identified in T-cells, skeletal muscle and neuroblastoma cells (Benten et al., 1999; Estrada et al., 2003, 2006). In cardiomyocytes, nongenomic signals activate the extracellular signal-regulated kinase (ERK) and the mTOR pathways. Activation of $\mathrm{Ca}^{2+} / \mathrm{ERK} / \mathrm{mTOR}$ axis is independent of androgen receptor.

The anabolic properties of testosterone indicate that this hormone regulate multiple genes involved in growth and metabolism. Traditionally, ligand-dependent androgen receptors act on DNA within the nucleus and in this compartment there is cross-talk among the nuclear receptors and cytosolic signaling. We have determined that testosterone induce a hypertrophic pattern in cardiomyocytes, evaluated as increase in the expression of fetal proteins, cardiomyocyte size, and protein synthesis. Hypertrophy effects of testosterone were blocked by either inhibition of mTOR or androgen receptor (Altamirano et al., 2009). We propose that cell growth produced by androgens require both androgen receptor activity and translation control through mTOR signaling pathway. Thus, both mTOR pathway and androgen receptor could control protein synthesis by a coordinated mechanism, where mTOR regulates translation and the intracellular androgen receptor regulates gene expression.

\section{Perspective}

The role of sex steroid hormones in modulating cardiovascular function is of the highest importance, given that androgen deficiency is strongly associated with common medical conditions including metabolic syndrome, obesity, diabetes, hypertension and atherosclerosis. However, cardiovascular side effects of high doses of anabolic/androgen steroid reduce its actual therapeutic use. Research in this field is necessary to know the real cardiovascular effects of androgens and to elaborate future optimal therapeutic replacement protocols.

\section{Acknowledgment}

This work was supported by FONDECYT grant 1090276.

\section{References}

Akkad, A. A.; Halligan, A. W.; Abrams, K.; \& al-Azzawi, F. (1997). Differing responses in blood pressure over 24 hours in normotensive women receiving oral or transdermal estrogen replacement therapy. Obstet Gynecol, 89, 97-103.

Alexandersen, P.; Haarbo, J.; Byrjalsen, I.; Lawaetz, H.; \& Christiansen, C. (1999). Natural androgens inhibit male atherosclerosis: a study in castrated, cholesterol-fed rabbits. Circ Res, 84, 813-819.

Altamirano, F.; Oyarce, C.; Silva, P.; Toyos, M.; Wilson, C.; Lavandero, S.; Uhlen, P.; \& Estrada, M. (2009). Testosterone induces cardiomyocyte hypertrophy through mammalian target of rapamycin complex 1 pathway. J Endocrinol 202, 299-307. 
Antos, C. L.; McKinsey, T. A.; Frey, N.; Kutschke, W.; McAnally, J.; Shelton, J. M.; Richardson, J. A.; Hill, J. A. \& Olson, E. N. (2002). Activated glycogen synthase-3 beta suppresses cardiac hypertrophy in vivo. Proc Natl Acad Sci U S A, 99, 907-912.

Bai, C. X.; Namekata, I.; Kurokawa, J.; Tanaka, H.; Shigenobu, K, \& Furukawa, T. (2005). Role of nitric oxide in $\mathrm{Ca}^{2+}$ sensitivity of the slowly activating delayed rectifier $\mathrm{K}+$ current in cardiac myocytes. Circ Res, 96, 64-72.

Bai, C. X.; Takahashi, K.; Masumiya, H.; Sawanobori, T.; \& Furukawa, T. (2004). Nitric oxidedependent modulation of the delayed rectifier $\mathrm{K}+$ current and the L-type $\mathrm{Ca}^{2+}$ current by ginsenoside Re, an ingredient of Panax ginseng, in guinea-pig cardiomyocytes. Br J Pharmacol, 142, 567-575.

Beato, M. (1989). Gene regulation by steroid hormones. Cell, 56, 335-44.

Benten, W. P.; Lieberherr, M.; Giese, G.; Wrehlke, C.; Stamm, O.; Sekeris, C. E.; Mossmann, H.; \& Wunderlich, F. (1999). Functional testosterone receptors in plasma membranes of T cells. FASEB J, 13, 123-133.

Cabral, A. M.; Antonio, A.; Moyses, M. R.; \& Vasquez, E. C. (1988a). Left ventricular hypertrophy differences between male and female renovascular hypertensive rats. Braz J Med Biol Res, 21, 633-635.

Cabral, A. M.; Vasquez, E. C.; Moyses, M. R.; \& Antonio, A. (1988b). Sex hormone modulation of ventricular hypertrophy in sinoaortic denervated rats. Hypertension, 11, 193-197.

Cavasin, M. A.; Tao, Z. Y.; Yu, A. L.; \& Yang, X. P. (2006). Testosterone enhances early cardiac remodeling after myocardial infarction, causing rupture and degrading cardiac function. Am J Physiol Heart Circ Physiol, 290, H2043-2050.

Cook, N. L.; \& Romashkan, S. (2011). Why do we need a trial on the effects of testosterone therapy in older men? Clin Pharmacol Ther, 89, 29-31.

Ding, A. Q.; \& Stallone, J. N. (2001). Testosterone-induced relaxation of rat aorta is androgen structure specific and involves $\mathrm{K}+$ channel activation. J Appl Physiol, 91, 2742-2750.

Dubey, R. K.; Oparil, S.; Imthurn, B.; \& Jackson, E. K. (2002). Sex hormones and hypertension. Cardiovasc Res, 53, 688-708.

English, K. M.; Jones, R. D.; Jones, T. H.; Morice, A. H.; \& Channer, K. S. (2001). Gender differences in the vasomotor effects of different steroid hormones in rat pulmonary and coronary arteries. Horm Metab Res, 33, 645-652.

English, K. M.; Mandour, O.; Steeds, R. P.; Diver, M. J.; Jones, T. H.; \& Channer, K. S. (2000). Men with coronary artery disease have lower levels of androgens than men with normal coronary angiograms. Eur Heart J, 21, 890-894.

Estrada, M.; Espinosa, A.; Muller, M.; \& Jaimovich, E. (2003). Testosterone stimulates intracellular calcium release and mitogen-activated protein kinases via a $G$ proteincoupled receptor in skeletal muscle cells. Endocrinology, 144, 3586-3597.

Estrada, M.; Liberona, J. L.; Miranda, M.; \& Jaimovich, E. (2000). Aldosterone- and testosterone-mediated intracellular calcium response in skeletal muscle cell cultures. Am J Physiol Endocrinol Metab, 279, E132-139.

Estrada, M.; Uhlen, P.; \& Ehrlich, B. E. (2006). Ca2+ oscillations induced by testosterone enhance neurite outgrowth. J Cell Sci, 119, 733-743. 
Fogari, R.; Preti, P.; Zoppi, A.; Fogari, E.; Rinaldi, A.; Corradi, L.; \& Mugellini, A. (2005). Serum testosterone levels and arterial blood pressure in the elderly. Hypertens Res, $28,625-630$.

Frey, N.; \& Olson, E. N. (2002). Modulating cardiac hypertrophy by manipulating myocardial lipid metabolism? Circulation, 105, 1152-1154.

Frey, N.; \& Olson, E. N. (2003). Cardiac hypertrophy: the good, the bad, and the ugly. Annu Rev Physiol, 65, 45-79.

Golden, K. L.; Marsh, J. D.; \& Jiang, Y. (2004). Testosterone regulates mRNA levels of calcium regulatory proteins in cardiac myocytes. Horm Metab Res 36, 197-202.

Handelsman, D. J. and Liu, P. Y. (2005). Andropause: invention, prevention, rejuvenation. Trends Endocrinol Metab, 16, 39-45.

Hayward, C. S.; Webb, C. M.; \& Collins, P. (2001). Effect of sex hormones on cardiac mass. Lancet, 357, 1354-1356.

Heineke, J.; \& Molkentin, J. D. (2006). Regulation of cardiac hypertrophy by intracellular signalling pathways. Nat Rev Mol Cell Biol, 7, 589-600.

Hickson, R. C.; Galassi, T. M.; Kurowski, T. T.; Daniels, D. G.; \& Chatterton, R. T.; Jr. (1984). Androgen and glucocorticoid mechanisms in exercise-induced cardiac hypertrophy. Am J Physiol, 246, H761-767.

Ikeda, Y.; Aihara, K.; Sato, T.; Akaike, M.; Yoshizumi, M.; Suzaki, Y.; Izawa, Y.; Fujimura, M.; Hashizume, S.; Kato, M. et al. (2005). Androgen receptor gene knockout male mice exhibit impaired cardiac growth and exacerbation of angiotensin II-induced cardiac fibrosis. J Biol Chem, 280, 29661-29666.

Iliescu, R.; \& Reckelhoff, J. F. (2006). Testosterone and vascular reactivity. Clin Sci (Lond), 111, 251-252.

Izumo, S.; Lompre, A. M.; Matsuoka, R.; Koren, G.; Schwartz, K.; Nadal-Ginard, B.; \& Mahdavi, V. (1987). Myosin heavy chain messenger RNA and protein isoform transitions during cardiac hypertrophy. Interaction between hemodynamic and thyroid hormone-induced signals. J Clin Invest, 79, 970-977.

Jaffe, M. D. (1977). Effect of testosterone cypionate on postexercise ST segment depression. Br Heart J, 39, 1217-1222.

Jones, R. D.; Hugh Jones, T.; \& Channer, K. S. (2004). The influence of testosterone upon vascular reactivity. Eur J Endocrinol, 151, 29-37.

Jones, R. D.; Nettleship, J. E.; Kapoor, D.; Jones, H. T.; \& Channer, K. S. (2005). Testosterone and atherosclerosis in aging men: purported association and clinical implications. Am J Cardiovasc Drugs, 5, 141-154.

Jones, R. D.; Pugh, P. J.; Jones, T. H.; \& Channer, K. S. (2003). The vasodilatory action of testosterone: a potassium-channel opening or a calcium antagonistic action? $\mathrm{Br} \mathrm{J}$ Pharmacol, 138, 733-744.

Kapoor, D.; Aldred, H.; Clark, S.; Channer, K. S.; \& Jones, T. H. (2007). Clinical and biochemical assessment of hypogonadism in men with type 2 diabetes: correlations with bioavailable testosterone and visceral adiposity. Diabetes Care, 30, 911-917.

Kaushik, M.; Sontineni, S. P.; \& Hunter, C. (2010). Cardiovascular disease and androgens: a review. Int J Cardiol, 142, 8-14.

Kienitz, T.; \& Quinkler, M. (2008). Testosterone and blood pressure regulation. Kidney Blood Press Res, 31, 71-79. 
Krenning, G.; Zeisberg, E. M.; \& Kalluri, R. (2010) The origin of fibroblasts and mechanism of cardiac fibrosis. J Cell Physiol, 225, 631-637.

Li, Y.; Kishimoto, I.; Saito, Y.; Harada, M.; Kuwahara, K.; Izumi, T.; Hamanaka, I.; Takahashi, N.; Kawakami, R.; Tanimoto, K. et al. (2004). Androgen contributes to gender-related cardiac hypertrophy and fibrosis in mice lacking the gene encoding guanylyl cyclase-A. Endocrinology, 145, 951-958.

Liu, P. Y.; Death, A. K.; \& Handelsman, D. J. (2003). Androgens and cardiovascular disease. Endocr Rev, 24, 313-340.

Liu, X. K.; Katchman, A.; Whitfield, B. H.; Wan, G.; Janowski, E. M.; Woosley, R. L. \& Ebert, S. N. (2003). In vivo androgen treatment shortens the QT interval and increases the densities of inward and delayed rectifier potassium currents in orchiectomized male rabbits. Cardiovasc Res, 57, 28-36.

Malkin, C. J.; Pugh, P. J.; Jones, R. D.; Kapoor, D.; Channer, K. S.; \& Jones, T. H. (2004). The effect of testosterone replacement on endogenous inflammatory cytokines and lipid profiles in hypogonadal men. J Clin Endocrinol Metab, 89, 3313-3318.

Malkin, C. J.; Pugh, P. J.; West, J. N.; van Beek, E. J.; Jones, T. H.; \& Channer, K. S. (2006). Testosterone therapy in men with moderate severity heart failure: a double-blind randomized placebo controlled trial. Eur Heart J, 27, 57-64.

Maron, B. J.; Roberts, W. C.; Edwards, J. E.; McAllister, H. A.; Jr.; Foley, D. D.; \& Epstein, S. E. (1978). Sudden death in patients with hypertrophic cardiomyopathy: characterization of 26 patients with functional limitation. Am J Cardiol, 41, 803-810.

Maron, B. J.; Roberts, W. C.; McAllister, H. A.; Rosing, D. R.; \& Epstein, S. E. (1980). Sudden death in young athletes. Circulation, 62, 218-229.

Marsh, J. D.; Lehmann, M. H.; Ritchie, R. H.; Gwathmey, J. K.; Green, G. E.; \& Schiebinger, R. J. (1998). Androgen receptors mediate hypertrophy in cardiac myocytes. Circulation, 98, 256-261.

McCrohon, J. A.; Death, A. K.; Nakhla, S.; Jessup, W.; Handelsman, D. J.; Stanley, K. K.; \& Celermajer, D. S. (2000). Androgen receptor expression is greater in macrophages from male than from female donors. A sex difference with implications for atherogenesis. Circulation, 101, 224-226.

Muthusamy, T.; Dhevika, S.; Murugesan, P.; \& Balasubramanian, K. (2007). Testosterone deficiency impairs glucose oxidation through defective insulin and its receptor gene expression in target tissues of adult male rats. Life Sci, 81, 534-542.

Muthusamy, T.; Murugesan, P.; \& Balasubramanian, K. (2009). Sex steroids deficiency impairs glucose transporter 4 expression and its translocation through defective Akt phosphorylation in target tissues of adult male rat. Metabolism, 58, 1581-1592.

Neglia, D.; De Caterina, A.; Marraccini, P.; Natali, A.; Ciardetti, M.; Vecoli, C.; Gastaldelli, A.; Ciociaro, D.; Pellegrini, P.; Testa, R. et al. (2007). Impaired myocardial metabolic reserve and substrate selection flexibility during stress in patients with idiopathic dilated cardiomyopathy. Am J Physiol Heart Circ Physiol, 293, H3270-3278.

Pham, T. V.; Sosunov, E. A.; Gainullin, R. Z.; Danilo, P.; Jr.; \& Rosen, M. R. (2001). Impact of sex and gonadal steroids on prolongation of ventricular repolarization and arrhythmias induced by I(K)-blocking drugs. Circulation, 103, 2207-2212.

Pripp, U.; Hall, G.; Csemiczky, G.; Eksborg, S.; Landgren, B. M.; \& Schenck-Gustafsson, K. (1999). A randomized trial on effects of hormone therapy on ambulatory blood 
pressure and lipoprotein levels in women with coronary artery disease. J Hypertens, $17,1379-1386$.

Proud, C. G. (2004). Ras, PI3-kinase and mTOR signaling in cardiac hypertrophy. Cardiovasc Res, 63, 403-413.

Pugh, P. J.; English, K. M.; Jones, T. H.; \& Channer, K. S. (2000). Testosterone: a natural tonic for the failing heart? QJM, 93, 689-694.

Rautaharju, P. M.; Prineas, R. J.; Kadish, A.; Larson, J. C.; Hsia, J.; \& Lund, B. (2006). Normal standards for QT and QT subintervals derived from a large ethnically diverse population of women aged 50 to 79 years (the Women's Health Initiative [WHI]). Am J Cardiol, 97, 730-737.

Saad, F.; \& Gooren, L. (2009). The role of testosterone in the metabolic syndrome: a review. J Steroid Biochem Mol Biol, 114, 40-3.

Saad, F, \& Gooren, L. J. (2011). The role of testosterone in the etiology and treatment of obesity, the metabolic syndrome, and diabetes mellitus type 2. J Obes, 2011.

Shioi, T.; McMullen, J. R.; Tarnavski, O.; Converso, K.; Sherwood, M. C.; Manning, W. J.; \& Izumo, S. (2003). Rapamycin attenuates load-induced cardiac hypertrophy in mice. Circulation, 107, 1664-1670.

Simental, J. A.; Sar, M.; \& Wilson, E. M. (1992). Domain functions of the androgen receptor. J Steroid Biochem Mol Biol, 43, 37-41.

Stamler, J.; Stamler, R.; Riedlinger, W. F.; Algera, G.; \& Roberts, R. H. (1976). Hypertension screening of 1 million Americans. Community Hypertension Evaluation Clinic (CHEC) program, 1973 through 1975. JAMA, 235, 2299-2306.

Stanley, W. C.; Recchia, F. A.; \& Lopaschuk, G. D. (2005). Myocardial substrate metabolism in the normal and failing heart. Physiol Rev, 85, 1093-1129.

Sullivan, M. L.; Martinez, C. M.; Gennis, P.; \& Gallagher, E. J. (1998). The cardiac toxicity of anabolic steroids. Prog Cardiovasc Dis, 41, 1-15.

Takano, H.; Komuro, I.; Zou, Y.; Kudoh, S.; Yamazaki, T.; \& Yazaki, Y. (1996). Activation of p70 S6 protein kinase is necessary for angiotensin II-induced hypertrophy in neonatal rat cardiac myocytes. FEBS Lett, 379, 255-259.

Thijs, L.; Fagard, R.; Forette, F.; Nawrot, T.; \& Staessen, J. A. (2003). Are low dehydroepiandrosterone sulphate levels predictive for cardiovascular diseases? A review of prospective and retrospective studies. Acta Cardiol, 58, 403-410.

van der Vusse, G. J.; van Bilsen, M.; \& Glatz, J. F. (2000). Cardiac fatty acid uptake and transport in health and disease. Cardiovasc Res, 45, 279-293.

van der Vusse, G. J.; van Bilsen, M.; Glatz, J. F.; Hasselbaink, D. M.; \& Luiken, J. J. (2002). Critical steps in cellular fatty acid uptake and utilization. Mol Cell Biochem, 239, 915.

Vicencio, J. M.; Ibarra, C.; Estrada, M.; Chiong, M.; Soto, D.; Parra, V.; Diaz-Araya, G.; Jaimovich, E.; \& Lavandero, S. (2006). Testosterone induces an intracellular calcium increase by a nongenomic mechanism in cultured rat cardiac myocytes. Endocrinology, 147, 1386-1395.

Webb, C. M.; McNeill, J. G.; Hayward, C. S.; de Zeigler, D.; \& Collins, P. (1999). Effects of testosterone on coronary vasomotor regulation in men with coronary heart disease. Circulation, 100, 1690-1696. 
Weinberg, E. O.; Thienelt, C. D.; Katz, S. E.; Bartunek, J.; Tajima, M.; Rohrbach, S.; Douglas, P. S.; \& Lorell, B. H. (1999). Gender differences in molecular remodeling in pressure overload hypertrophy. J Am Coll Cardiol, 34, 264-273.

Zhou, S. H.; Wong, S.; Rautaharju, P. M.; Karnik, N.; \& Calhoun, H. P. (1992). Should the JT rather than the QT interval be used to detect prolongation of ventricular repolarization? An assessment in normal conduction and in ventricular conduction defects. J Electrocardiol, 25 Suppl, 131-136. 


\title{
Testosterone Therapy and the Heart
}

\author{
Güzin Fidan Yaylalı and Yalın Tolga Yaylalı \\ Pamukkale University \\ Turkey
}

\section{Introduction}

Testosterone (T) therapy has been offered to men who have low $\mathrm{T}$ levels, who are symptomatic with classical androgen deficiency syndromes, to induce and maintain secondary sex characteristics and to improve muscle mass and strength, bone mineral density, their sexual function, and sense of well-being. Hypogonadism is a clinical syndrome that is caused by inability of the testis to produce physiological levels of $\mathrm{T}$ in men. The age-related reduction in $\mathrm{T}$ levels is a result of defects in both hypothalamic-pituitary and testicular function. A diagnosis of androgen deficiency should be made only when low serum $\mathrm{T}$ and consistent symptoms and signs are encountered in men. It is not recommended to offer $\mathrm{T}$ therapy to all older men with low $\mathrm{T}$ level. A decision should be made on an individualized basis for older men with clinically significant symptoms of androgen deficiency and consistently low T level. Hyperandrogenemia in women and hypoandrogenemia in men are associated with increased risk of coronary artery disease. In addition, these states are associated with insulin resistance, visceral obesity, elevated triglycerides, low high-density lipoprotein (HDL) cholesterol, lowdensitylipoprotein (LDL) cholesterol and plasminogen activator inhibitor (PAI-1). These gender differences and confounders make the exact role of endogenous androgens in atherosclerosis unclear. In contrast, exogenous androgens exert both apparently beneficial and deleterious effects on cardiovascular risk factors by reducing serum levels of PAI-1 (apparently deleterious), HDL-C, insulin, leptin, lipoprotein(a), visceral fat mass (apparently beneficial), and fibrinogen in women as well as men. Androgen-induced reduction in circulating HDL-C levels should not reflexively be considered to be pro-atherogenic, because it may show increased reverse cholesterol transport instead. Short-term use of supraphysiological doses of exogenous $\mathrm{T}$ can decrease the severity and frequency of angina pectoris and reverse the electrocardiographic signs of myocardial ischaemia; yet long-term effects have not been determined. Nonetheless, the effects of pharmacological doses of androgens particularly on flow-mediated dilatation and arterial compliance must be interpreted with caution, since in addition at physiological concentrations detrimental effects, neutral, and beneficial effects on vascular reactivity can be observed. Testosterone induces an anti-atherogenic effect by facilitating efflux of cellular cholesterol to HDL and induces pro-atherogenic effects on macrophage function by increasing the uptake of modified lipoproteins.

\section{Endogenous $T$ and CAD morbiditylmortalitiy}

In half of cross-sectional studies [Wu and Eckardstein 2003; Alexandersen et al 1996], serum levels of $\mathrm{T}$ were lower in patients with CAD than healthy controls. The other half of the 
studies demontrated no difference in T levels when cases and controls are compared. In none of the studies, high levels of $\mathrm{T}$ were seen in patients with CAD. In all the studies, an inverse association was found between CAD and levels of free T [Wu and Eckardstein 2003; Alexandersen et al 1996]. None of six longitudinal studies revealed any significant association between the future risk of CAD events and serum levels of $\mathrm{T}$ in men [Wu and Eckardstein, 2003; Alexandersen et al., 1996].

European Prospective Investigation into Cancer in Norfolk Study demonstrated that serum levels of $\mathrm{T}$ at baseline were inversely associated with cardiovascular mortality and all-cause mortality in men aged 40-79 with no history of cancer or cardiovascular disease (Khaw et al., 2007). This risk association persisted after correction for traditional cardiovascular risk factors, indicating that the benefit may involve additional pathways. Also, other studies have showed the association between low testosterone and cardiovascular disease and increased mortality (English et al., 2000; Shores et al., 2006). Thus, increasing research on the clinical implications of physiological decline in androgens with aging has led to rekindled interest in the potentially cardioprotective role of $\mathrm{T}$. Abuse of $\mathrm{T}$ is associated with increased risk of cardiovascular disease and sudden death, yet higher $\mathrm{T}$ serum levels within the physiological range have been associated with a more favourable cardio-metabolic risk profile. In contrast, low $\mathrm{T}$ serum levels have been associated with elevated triglyceride and low high-density-lipoprotein-cholesterol levels, glucose intolerance, diabetes, and central obesity (Kapoor et al., 2005; Tong et al., 2005; Wu and Eckardstein, 2003). This is in part because of the increased triglyceride and lipoprotein lipase uptake by adipocytes, causing central obesity and insulin resistance. The central obesity leads to increased peripheral conversion of $\mathrm{T}$ to estradiol by aromatase activity, further worsening this vicious cycle. Decreased serum levels of $\mathrm{T}$ are associated with a pro-inflammatory state with raised levels of inflammatory mediators like TNF-a and IL-1b, which can be improved with T substitution (Malkin et al., 2004).

Besides its pro-atherogenic effects by altered lipid profile and insulin resistance, $\mathrm{T}$ has also direct effects on the vasculature. $T$ causes coronary vasodilation and improves chronic stable angina in men (English et al., 2000). Androgen receptors have been found in the myocardium and may exert some of the effects of $\mathrm{T}$ on the cardiac remodeling and renin-angiotensinaldosterone system. $\mathrm{T}$ and other anabolic hormone deficiencies are associated with the severity of heart failure and increased mortality (Jankowska et al., 2006). T augments expression of heat shock protein 70 in cardiac myocytes, through which it may play an important role in preconditioning and protection against cardiac ischemia (Liu et al., 2006).

Studies that demonstrated an association between low serum $\mathrm{T}$ levels and raised cardiovascular mortality in general excluded patients at high risk for cardiovascular disease or those with established cardiovascular disease. This association whether applies to subjects with established cardiovascular disease has not been defined. In a study of 930 men with angiographically proven coronary disease that were followed up for a mean duration of 7 years, a high prevalence of low $\mathrm{T}$ at baseline ranging from 17 to $24 \%$ was seen. Decreased serum $\mathrm{T}$ levels as defined by baseline serum $\mathrm{T}$ levels of $<2.6 \mathrm{nmol} / 1$ were an independent predictor of vascular and all-cause mortality (Malkin et al., 2010). In a recent study, Ruige et al. (Ruige et al., 2010) have reviewed the literature on serum T levels and overall mortality up to 2009 . They demonstrated an excess mortality in elderly men (>70 years of age) who have a reduced T, which has been especially marked in studies since 2007. It is important to consider the limitations of observational studies in showing the associations between coronary artery disease (CAD) and serum levels of endogenous androgens. These 
studies have had extremely variable CAD endpoints (e.g., ultrasound- or postmortem- based diagnosis, unspecified cardiac events, morbid conditions such as myocardial infarction [MI] and angina, mortality, and the performance of angiography), heterogeneous study populations, and variable selection criteria. For instance, most CAD patients have been taking medications and have changed their lifestyle, factors which could affect them compared to controls. In some studies, allocation of poorly matched controls may be problematic in analysis. Among patients, the time interval from MI to sampling changed from 3 months to several years and has not been always standardized for diurnal rhythm of hormone levels. Also, in most of the studies, no adjustment has been made for confounding factors. For instance, the diagnoses of hyperandrogenemia in women and hypoandrogenemia in men were confounded by accompanying concurrent metabolic disorders, such as insulin resistance, obesity, impaired fibrinolysis, and dyslipidemia, which are frequently seen in chronic diseases, including CAD and lower serum levels of T (Eckardstein \& Wu, 2003).

\section{Exogenous $\mathrm{T}$ in cardiovascular disease}

The long-term effects of exogenous $\mathrm{T}$ on incidence of coronary events have not been determined. However, few small studies demonstrated that therapeutic doses of $\mathrm{T}$ decreased the severity and frequency of angina pectoris and reversed electrocardiographic signs of myocardial ischemia. Webb et al. [Webb et al 1999] demonstrated that a single intravenous (IV) bolus of $2.3 \mathrm{mg} \mathrm{T}$ prolonged time to 1-mm ST segment depression by 66 seconds in 14 men with low plasma T levels and CAD. The plasma levels of T increased from 5.2 to $117 \mathrm{nmol} / \mathrm{l}$, suggesting that this is a pharmacological action on the coronary vessels. These acute, direct pharmacological effects of $\mathrm{T}$ have been further investigated during coronary angiography. Administration of $\mathrm{T}$ over a 3-min period into the coronary arteries of 13 men with the diagnosis of CAD during coronary angiography at supra-physiological doses of $8 \mathrm{lmol} / \mathrm{l}$, but not at the physiological doses of $8 \mathrm{nmol} / \mathrm{l}$, cause coronary vessel diameter and blood flow to increase significantly at all four doses of $\mathrm{T}$ tested. These results have been also confirmed by a similar study of 14 men with CAD [Rosano ET 1999].

$\mathrm{T}$ has been employed at either pharmacological doses to exert selective effects on haematopoeitic marrow, muscle, bone, or other salutary effects in men with various chronic diseases (Handelsman, 2005; Liu, 2004) or at physiological doses as androgen replacement therapy for men with disorders of the hypothalamo-pituitary-testicular axis (Handelsman, 2005; Zitzmann \& Nieschlag, 2000). Randomized placebo-controlled studies demonstrated that $\mathrm{T}$ employed to patients with chronic heart failure decreases systemic vascular resistance and improves both overall exercise capacity and cardiac output (Malkin et al., 2006; Pugh et al., 2003, 2004). Yet, effects on objective echocardiographic findings were little, suggesting that improvements could have been indirect through enhanced exercise endurance resulting from skeletal muscle or psychological effects. The effects of androgens on undamaged and damaged myocardium might be variable. One randomized placebo-controlled study demonstrated no deleterious effects on cardiac structure or function in 16 athletes after 8 weeks of $200 \mathrm{mg}$ nandrolone decanoate injections (Hartgens et al., 2003). Likewise, the effects of testosterone have not been tested to determine whether androgen activation by aromatization to estradiol and/or amplification by 5 a reduction influences effects of androgens on cardiac function. Routine echocardiographic evaluation used in the above studies may not have sufficient sensitivity to determine subtle changes of myocardial function seen with drugs including androgens. 
Androgens might exert cardiac effects through indirect mechanisms like in blood vessel disorders such as atherosclerosis, increased erythropoiesis, hyperviscosity, haematocrit, and hypertension. In addition, androgens might exert direct effects on cardiac muscle and its function by the androgen receptor expressed in cardiac muscle. In vitro studies of nonhuman cardiac myocytes demonstrated that $\mathrm{T}$ can decrease peak shortening times and action potential duration (hence altering repolarization) (Kimura et al., 1993). The direct effects of androgens on cardiac muscle have been less investigated (Sader et al., 2001). They are mostly based on case reports of cardiomyopathy in some androgen abusers on postmortem examinations (Sullivan et al., 1998). Some studies of anabolic steroid abuse indicate that androgen abuse in athletes may cause left ventricular hypertrophy, which may persist afterwards. Yet, several important limitations should be mentioned such as the lack of randomization, the confounding role of strength training, and self-selection. A study of testosterone and nandrolone (Chung et al., 2007) employed for 4 weeks demonstrated no adverse effects of androgens on non-invasive measures of cardiac function, which is consistent with a previous study using nandrolone for 8 weeks (Hartgens et al., 2003). Despite these promising findings during short-term use, longer studies would be necessary to show the maintenance of such a safety profile for long term. Retrospective data of over 2000 elite athletes from the East German national sports doping program, who were taking high dose synthetic androgens and were regularly monitored medically showed no cardiovascular complications. However, hepatic and other complications were frequently reported (Franke \& Berendonk, 1997).

Previous work suggests that $\mathrm{T}$ may relieve symptoms in patients with angina pectoris and resolves post-exercise ST-segment depression in patients suffering from angina (Jaffe, 1977). Jaffe et al. (Jaffe, 1977) demonstrated that intramuscular T injection for 4 to 8 weeks in 50 men, who had ST-segment depression after exercise, improved post-exercise ST-segment depression, compared with placebo. This work did not study mechanisms by which $\mathrm{T}$ reduced ST-segment depression. Although early studies suggested beneficial effects of $\mathrm{T}$ in patients with angina, these studies were not placebo-controlled, were not randomized and the diagnosis of coronary artery disease was not angiographically established. Furthermore, the study by Jaffe (Jaffe, 1977) investigated the effect of T only on post-exercise ST-segment depression. It did not provide any information on hemodynamic parameters and the time course of ST-segment depression. Furthermore, not all previous studies in patients with angina pectoris have used pure $\mathrm{T}$ and therefore have not investigated the effect of $\mathrm{T}$ by itself on cardiovascular physiology. Yue et al. (Yue et al., 1995) demonstrated that T exerts endothelium independent dilatation of isolated rabbit aorta and coronary artery. The authors indicated that this may depend on an effect of $\mathrm{T}$ on potassium channels and potassium conductance but not on ATP-sensitive potassium channels, and they demonstrated that this effect is neither mediated by a classic hormonal receptor nor is sexdependent (Yue et al., 1995). Experimental evidence indicates that $\mathrm{T}$ may have a potential beneficial effect on myocardial ischemia by playing a role in the regulation of coronary artery tone.

Mechanisms of action proposed for the effects of $\mathrm{T}$ were vasodilation of coronary arteries or their collaterals and an increase in hemoglobin levels which improves oxygen-carrying capacity of blood. Yet, the vasoactive properties of T have not been reported until recently. The time elapsed to 1-mm ST-segment depression was reported to be prolonged after intravenous infusion of $\mathrm{T}$. This indicates an acute anti-ischemic effect of $\mathrm{T}$. The increase in heart rate- blood pressure product and heart rate shown either at 1-mm ST-segment depression or at peak exercise may suggest a direct vasodilator effect of $\mathrm{T}$ on coronary circulation. However, heart rate and blood pressure at rest were similar before and after $\mathrm{T}$ 
employment. This suggests that a peripheral effect of $\mathrm{T}$ may not determine its anti-ischemic effect. The prolongation of time to 1-mm ST-segment depression observed is similar to that observed in women after acute employment of $17 \mathrm{~b}$ estradiol, suggesting a similar effect of sex hormones in men and women (Rosano et al., 1993). Collins et al. (Collins et al., 1995) indeed demonstrated that intracoronary infusion of $17 \mathrm{~b}$-estradiol restores endothelium dependent vasodilatation in women but not in men, indicating a specific role of sex hormones on the cardiovascular system. The anti-ischemic effect of $\mathrm{T}$ reported might explain the cardio-protective effect of $\mathrm{T}$ substitution in men with hypotestosteronemia. In the present study, mostly the patients with lower testosterone benefited from testosterone employment (Rosano et al., 1999).

A recent study has shown that ventricular functions are normal in men with idiopathic hypogonadotropic hypogonadism $(\mathrm{IHH})$ and substitutive therapy has no effects on ventricular functions, however it may increase peak pulmonary artery pressure (PAP) in small amounts (Yaylali et al., 2010). This finding is in line with previous studies demonstrating normal left ventricular functions in IHH men (Baysan et al., 2007; Celik et al., 2001; Hartgens et al., 2003). In addition, substitutive therapy had no effects on RV systolic or diastolic functions. This study found no evidence of clinically significant effects of the use of substitutive therapy on ventricular functions in the short term. However, substitutive therapy may increase PAP in small amounts which may be related to its vasoactive properties in the pulmonary vasculature. The younger normal even testosterone deplete heart is a totally different state than the diseased atherosclerotic or failing older heart. In this respect previous studies examined the effects of exogenous testosterone on the hearts of older men which were already affected by atherosclerosis or syndrome of heart failure. In contrast, this study investigated the ventricular functions in much younger hearts with no evidence of atherosclerosis or heart failure before and after substitutive therapy.

It has been shown that 12 weeks of treatment with $\mathrm{T}$ in men with CHF was well tolerated, safe, and led to significant improvements in symptoms and physical capacity. Larger clinical trials are needed to evaluate the mechanism of action of $\mathrm{T}$, beneficial effect and confirmation of its safety in selected patients (Lellamo et al., 2010).

\section{Effects of T on cardiovascular risk factors}

Several cross-sectional population studies have demonstrated statistically significant correlations between various cardiovascular risk factors and plasma levels of $\mathrm{T}$, however the correlations were opposite in women and men. The plasma T levels in men were frequently found to have positive correlations with serum levels of HDL $-\mathrm{C}$ and have inverse correlations with plasma levels of low-density lipoprotein cholesterol (LDL-C), triglycerides, fibrinogen, total cholesterol, and PAI-1 (Hergenc et al., 1999; Tchernof et al., 1996; Tsai et al., 2000). Yet, serum levels of $T$ were found to have even stronger inverse correlations with BMI, waist-hip ratio (WHR), waist circumference, amount of visceral fat, insulin, serum levels of leptin, and free fatty acids. The correlations of $\mathrm{T}$ with the cardiovascular-disease risk factors except visceral fat and insulin lost their statistical significance after adjustment for obesity and insulin resistance (Hergenc et al., 1999; Tchernof et al., 1996; Tsai et al., 2000). These findings suggest that a low serum level of $\mathrm{T}$ is a component of the metabolic syndrome in eugonadal men, which is a cluster of cardiovascular risk factors such as obesity, hypertriglyceridemia, glucose intolerance or overt type 2 diabetes mellitus, low HDL-C, and arterial hypertension. Metabolic syndrome is considered a procoagulatory and an anti-fibrinolytic state. And insulin resistance plays an important role in its etiology. Thus, 
the frequent association of high $\mathrm{T}$ levels with a more favorable cardiovascular risk factor profile in men perhaps does not reflect direct regulatory effects of $T$ on lipoprotein metabolism and the hemostatic system. Some studies demonstrated the loss of these associations when serum levels of free $\mathrm{T}$ were used to correlate with lipids and other cardiovascular-disease risk factors instead of serum levels of total $\mathrm{T}$ were used. In agreement with these findings, a reduced number of CAG repeats in the androgen receptor, which facilitates its binding to $\mathrm{T}$, was associated with decreased levels of leptin, HDL-C, BMI, and low body fat mass (Zitzmann et al., 2001, 2003). One reason for the discrepancy between the associations of endogenous $\mathrm{T}$ and the biological effects with various cardiovascular risk factors is the inhibitory effect of insulin on the production of SHBG so that insulin resistance results in low levels of SHBG and low levels of total T as a result.

The association between increased risk of coronary artery disease and plasma testosterone levels has been attributed in part to the unfavorable effect of $\mathrm{T}$ on fibrinolysis and HDL cholesterol (Glueck et al., 1993; Jones et al., 1989; Sorva et al., 1988). Plasma levels of HDL cholesterol are higher in women than in men, and some studies indicate that $\mathrm{T}$ substitution in men causes a decrease in plasma levels of HDL cholesterol (Jones et al., 1989; Sorva et al., 1988). Glueck et al. (Glueck et al., 1993) demonstrated that $\mathrm{T}$ correlates with tissue plasminogen activator, the major stimulator of fibrinolysis positively, and with fibrinogen and plasminogen activator inhibitor inversely. However, recent studies have demonstrated that 2month therapy with testosterone undecanoate had a beneficial effect on lipoprotein profiles in older men (Uyanik et al., 1997). Although there might be an effect of plasma T levels on prothrombotic state, yet there is no epidemiological evidence showing an association between coronary artery disease and high testosterone levels (Uyanik et al., 1997).

\section{Effects of androgens on vascular reactivity}

$\mathrm{T}$ can exert vasodilatation or vasoconstriction via endothelium-independent or endothelium-dependent mechanisms and by genomic or non-genomic modes of action. The variation in these findings appears to be due to differences in concomitant disease, species, gender, and, most importantly, the dosage of $\mathrm{T}$ given. The significant reduction in nitrateinduced (and hence endothelium-independent) dilatation of the brachial arteries in femaleto-male transsexuals taking high-dose androgens indicate these possible adverse effects associated with use of $\mathrm{T}$ (McCredie et al., 1998). In another study, castrated patients with prostate cancer had a greater flow-induced (i.e., endothelium-dependent) dilatation of brachial arteries compared to controls; however, the degree of nitroglycerin induced endothelium dependent vasodilatation did not differ between the two groups (Herman et al., 1997). In a study of 110 healthy men, a positive association between endotheliumdependent as well as endothelial-independent vasodilatation and the numbers of CAG repeats in exon 1 of the androgen receptor gene was observed. Therefore, the greater the sensitivity to $\mathrm{T}$, the less brachial arteries dilate in response to either administration of nitrate or increased blood flow (Zitzmann et al., 2001). In contrast to these studies, IV administration of $\mathrm{T}$ in acute interventional studies to male patients with CAD showed apparently beneficial vasodilatory effects of $\mathrm{T}$. Likewise, most in vitro studies with animal vessels and in vivo studies in monkeys and dogs of both sexes indicate that $\mathrm{T}$ induces beneficial effects on vascular reactivity. Intracoronary injections of acetylcholine caused a significant endothelium-dependent vasodilatation in ovariectomized female cynomolgus monkeys treated with $\mathrm{T}$ for 2 years compared to untreated animals. In contrast, endothelium-independent vasodilatation occurred in the two groups normally (Adams et 
al., 1995). In dogs, $\mathrm{T}$ induced vasodilatation of coronary arteries by both endotheliumdependent and -independent mechanisms (Chou et al., 1996; Costarella et al., 1996). In addition, the results of studies with isolated aortas and/or rings of coronary arteries from pigs, rats, and rabbits showed that $\mathrm{T}$ administration improved both endotheliumindependent and/or endothelium-dependent vascular responsiveness in both sexes (Chou et al., 1996; Costarella et al., 1996; Yue et al., 1995). Yet, it must be noted that all these studies used supra-physiological doses of $\mathrm{T}$ in the micro-molar range. Teoh et al. (Teoh et al., 2000) demonstrated a direct vasodilatory effect of $\mathrm{T}$ on porcine coronary artery rings when given at micro-molar concentrations. But no direct effect was observed when $\mathrm{T}$ given at nanomolar concentrations. In contrast, physiological doses of T reduced the vasodilatory effects of calcium ionophores and bradykinin. Likewise, $\mathrm{T}$ impaired endothelium-dependent relaxation of aortic rings from rabbits that were either exposed to tobacco smoke or that were either made hypercholesterolemic. In addition, $\mathrm{T}$ inhibited the adenosine-mediated vasodilatation of rat coronary arteries (Ceballos et al., 1999; Farhat et al., 1995; Hutchison et al., 1997). The molecular and cellular mechanisms by which $\mathrm{E} 2$ and $\mathrm{T}$ regulate vascular tone are not well known. Evidence for and against endothelium-dependent or endotheliumindependent mechanisms has been found. Some studies indicate endothelial nitric oxide involvement (Chou et al., 1996; Costarella et al., 1996; Geary et al., 2000). The nitric oxide synthase inhibitor L-NMMA inhibited T-induced vasodilatation in the aortas of rats, the coronary arteries of dogs, and the cerebral arteries of rats. Yet, another study demonstrated no effect of L-NMMA on T-induced vasodilatation of rabbit coronary arteries and aortas (Yue et al., 1995). Likewise, Hishikawa et al. (Hishikawa et al., 1995) demonstrated that E2 but not $\mathrm{T}$ stimulated in vitro expression of nitric oxide synthase in human aortic endothelial cells. It has been observed that $\mathrm{T}$ increases the response of coronary arteries to prostaglandin F2a (Farhat et al., 1995). Also, dihydro-T increases the density of thromboxane receptors in rats and guinea pigs (Masuda et al., 1995). Yet, results of some in vitro and in vivo animal studies suggest that pretreatment with the prostaglandin synthesis inhibitor indomethacin induced no effect on T-induced vasodilatation. The role of eicosanoids in mediating the actions of $\mathrm{T}$ on the arterial wall still remains controversial. It is unknown whether $\mathrm{T}$ regulates vasoreactivity by either non-genomic or genomic effects or both. Androgen receptor expression has been determined in rat endothelial cells and aortic smooth muscle cells. In human arterial cells expression of the androgen receptors has not been directly demonstrated. However, the association of endothelium-independent and endotheliumdependent vasoreactivity with the CAG repeat polymorphism in the androgen receptor suggests some indirect evidence for the expression of the androgen receptor on vascular smooth muscle cells and endothelial cells, respectively (Zitzmann et al., 2003). Also, steroid hormones can regulate vascular tone by modulation of cell membrane channels (e.g., voltage-dependent, ATP-sensitive, and calcium-activated potassium channels) and by nongenomic mechanisms that involve plasma membrane steroid receptors. Several observations indicate that $\mathrm{T}$, especially at supra-physiological doses, modulates vascular tone via its secondary metabolites (e.g., E2) and/or non-genomic modes of action. Flutamide or cyproterone acetate, the androgen receptor antagonists did not reduce the effects of $\mathrm{T}$ on pig or rabbit coronary arteries (Teoh et al., 2000). The expression of aromatase in vascular endothelial cells (Harada et al., 1999) increases the possibility that T can be converted to E2 and T induces its vasoactive effects through stimulation of the estrogen receptors. Yet, neither the estrogenreceptor antagonist ICI 182,780 nor the aromatase inhibitor aminogluthemide prevented the Tinduced vasodilatation (Chou et al., 1996). Barium chloride decreased the T-induced 
vasorelaxation of rabbit coronary arteries and aortas, indicating that $\mathrm{T}$ modulates the opening of potassium channels in vascular smooth muscle cells.

\section{Conclusion}

The clinical picture of male hypogonadism carries a significant morbidity. After a careful diagnostic evaluation to identify the underlying cause of hypogonadism, substitutive therapy may be instituted after examining benefit to risk ratio for an individual patient. The clinician has a choice among different $\mathrm{T}$ preparations, tailoring pharmacokinetics and route of employment to the patient. Long-term effects of substitutive therapy on the cardiovascular system still remain unclear. Published data mostly consists of small, observational studies with no clear definition of outcome. We still lack large randomized controlled studies investigating the relationship between substitutive therapy and cardiovascular risk, although androgen replacement therapy has been found to have beneficial effects on bone density, body composition, metabolism, and muscle strength in hypogonadal men. The effects of physiological doses of $\mathrm{T}$ on the lipid profile remain to be fully defined and the risk of not replacing $\mathrm{T}$ in the deficient men also remains unclear. Firstly, we might think that $\mathrm{T}$ and cardiovascular disease are clearly related, but the intricacies of the relationship are much more complex. As the role of androgens in cardiovascular system becomes clearer in the future, we may find out the mechanisms that play a role in the observed sex differences in the incidence of coronary artery disease in the middle-aged population.

\section{References}

Adams M.R., Williams J.K., \& Kaplan J.R (1995). Effects of androgens on coronary artery atherosclerosis and atherosclerosis-related impairent of vascular responsiveness. Arterioscler. Thromb. Vasc. Biol, Vol.15, No.5 (May 1995), pp. 562-570, ISSN 1079-5642.

Alexandersen, P., Haarbo J., \& Christiansen C. (1996). The relationship of natural androgens to coronary heart disease in males: a review. Atherosclerosis, Vol. 125, No.1, (August 1996), pp. 1-13, ISSN 0021-9150.

Baysan O, Bolu E, Uzun M, Kilicaslan F, Erinc K, Pinar M, Hasimi A, Yokusoglu M, Genc C, Yelamanchili P, Karaeren H, \& Isik E.. (2007). Left ventricular function in male patients with secondary hypogonadism. Echocardiography, Vol.24, No.3, (March 2007), pp.222-7. ISSN 0742-2822.

Ceballos G., Figueroa L., Rubio I., Gallo G., Garcia A., Martinez A., Yanez R., Perez J., Morato T., \& Chamorro G. (1999) Acute and nongenomic effects of testosterone on isolated and perfused rat heart, J. Cardiovasc. Pharmacol., Vol.33, No.5, (May 1999), pp.691-697, ISSN: 0160-2446.

Celik S., Erdol C., Erem C., Baykan M., Gokce M., \& Durmus I. (2001). Echocardiographic evaluation in patients with hypogonadotropic hypogonadism. J Reprod Med, Vol.46, No.8, (August 2001), pp.709-11, ISSN: 0024-7758.

Chou T.M., Sudhir K., Hutchison S.J., Ko E., Amidon T.M., Collins P., Chatterjee K. (1994). Testosterone induces dilatation of canine coronary conductance and resistance arteries in vivo. Circulation, Vol.94, No.10, (November 1996), pp. 2614-2619, ISSN 0009-7322.

Chung T., Kelleher S., Liu P.Y., Conway A.J., Kritharides L., \& Handelsman D.J. (2007). Effects of testosterone and nandrolone on cardiac function: a randomized, 
placebo-controlled study.Clin Endocrinol (Oxf), Vol.66, No.2, (February 2007), pp.235-45, ISSN 0300-0664.

Collins P., Rosano G.M.C., Sarrel P.M., Ulrich L., Adamopoulos S., Beale C.M., McNeil J., \& Poole-Wilson P.A. (1995). 17b-Estradiol attenuates acetylcholineinduced coronary arterial constriction in women but not men with coronary heart disease. Circulation, Vol.92, No.11, (July 1995), pp.24 -30, ISSN 0009-7322.

Costarella C.E., Stallone J.N., Rutecki G.W., \& Whittier F.C. (1996). Testosterone causes direct relaxation of rat thoracic aorta. J. Pharmacol. Exp. Ther, Vol.277, No.1, (April 1996), pp. 34-39, ISSN 0022-3565.

Eckardstein A., \& Wu F.C. (2003). Testosterone and atherosclerosis. Growth Horm IGF Res,. Vol.13, No.Suppl A, (August 2003), pp.S72-84, ISSN:1096-6374.

English K.M., Steeds R.P., Jones T.H., Diver M.J., \& Channer K.S. (2000). Low-dose transdermal testosterone therapy improves angina threshold in men with chronic stable angina: A randomized, double-blind, placebo-controlled study. Circulation, Vol.102, No.16, (October 2000), pp.1906-11, ISSN 0009-7322.

English KM, Mandour O, Steeds RP, Diver MJ, Jones TH, \& Channer KS. (2000). Men with coronary artery disease have lower levels of testosterone than those with normal coronary angiograms. Eur Heart J, Vol.21, No.11, (June 2000), pp.890-4, ISSN 0195$668 X$.

Farhat M.Y., Wolfe R., Vargas R., Foegh M.L., \& Ramwell P.W. (1995). Effect of testosterone treatment on vasoconstrictor response to left anterior descending coronary artery in male and female pigs. J. Cardiovasc. Pharmacol., Vol.25, No.3, (March 1995), pp.495-500, ISSN: 0160-2446.

Franke, W.W. \& Berendonk, B. (1997). Hormonal doping and androgenization of athletes: a secret program of the German Democratic Republic government. Clinical Chemistry, Vol.43, No.7, (July 1997), pp.1262-1279, ISSN 0009-9147.

Geary G.G., Krause D.N., \& Duckles S.P. (2000). Gonadal hormones affect diameter of male rat cerebral arteries through endotheliumdependent mechanisms. Am. J. Physiol. Heart Circ. Physiol, Vol.279, No.2, (August 2000), pp.H610-618, ISSN 0363-6135.

Glueck C.J., Glueck H.I., Stroop D., Speirs J, Hamer T, \& Tracy T. (1993). Endogenous testosterone, fibrinolysis and coronary heart disease risk in hyperlipidemic men. $J$ Lab Clin Med, Vol.122, No.4, (October 1993), pp.412-420, ISSN 0022-2143.

Handelsman, D.J. (2005). Androgen action and pharmacologic uses. In: Endocrinology, L.J. Degroot, J.L. Jameson, (Eds.), 3121-3138, Elsevier Saunders, Philadelphia, PA.

Harada N., Sasano H., Murakami H., Ohkuma T., Nagura H., \& Takagi Y. (1999) Localized expression of aromatase in human vascular tissue. Circ. Res, Vol.84, No.11, (June 1999), pp.1285-1291, ISSN ISSN 0009-7330.

Hartgens F., Cheriex E.C. \& Kuipers H. (2003). Prospective echocardiographic assessment of androgenic-anabolic steroids effects on cardiac structure and function in strength athletes. International Journal of Sports Medicine, Vol.24, No.5, (July 2003), pp.344-351, ISSN 0172-4622.

Hergenc G., Schulte H., Assmann G., \& von Eckardstein A. (1999). Associations of obesity markers, insulin, and sex hormones with HDL-cholesterol levels in Turkish and German individuals, Atherosclerosis, Vol.145, No.1 (July 1999), pp. 147-156, ISSN 0021-9150. 
Herman S.M., Robinson J.T.C., McCredie R.J., Adams M.R., Boyer M.J., Celermajer D.S. (1997). Androgen deprivation is associated with enhanced endotheliumdependent dilatation in adult men. Arterioscler. Thromb. Vasc. Biol, Vol.17, No.10, (October 1997), pp. 2004-2009, ISSN 1079-5642.

Hishikawa K., Nakaki T., Marumo T., Suzuki H., Kato R., \& Saruta T. (1995). Up regulation of nitric oxide synthase by estradiol in human aortic endothelial cells. FEBS Lett, Vol.360, No.3, (March 1995), pp.291-295, ISSN: 0014-5793.

Hutchison S.J., Sudhir K., Chou T.M., Sievers R.E., Zu B.Q., Sun Y.P., Deedwania P.C., Glantz S.A., Parmely W.W., \& Chatterjee K. (1997). Testosterone worsens endothelial dysfunction associated with hypercholesterolemia and environmental tobacco smoke exposure in male rabbit aorta. J. Am. Coll. Cardiol, Vol.29, No.4, (March 1997), pp.800-807, ISSN 0735-1097.

Iellamo F., Volterrani M., Caminiti G., Karam R., Massaro R., Fini M., Collins P., \& Rosano G.M. (2010). Testosterone therapy in women with chronic heart failure: a pilot double-blind, randomized, placebo -controlled study. J Am Coll Cardiol, Vol.56, No.16, (October 2010), pp.1310-6, ISSN 0735-1097.

Jaffe M.D. (1977). Effect of testosterone cypionate on postexercise ST segment depression. Br Heart J, Vol.39, No.11, (November 1977), pp.1217-1222, ISSN 0007-0769.

Jankowska EA, Biel B, Majda J, Szklarska A, Lopuszanska M, Medras M, Anker SD, Banasiak W, Poole-Wilson PA, \& Ponikowski P. Anabolic deficiency in men with chronic heart failure: prevalence and detrimental impact on survival. Circulation, Vol.114, No.17, (October 2006), pp.1829-37, ISSN 0009-7322.

Jones D.B., Higgins B., Billet J.S., Price W.H., Edwards C.R., Beastall G.H., Sheperd J., Sweeting V.M., Horn D.B., \& Wenham P.R. (1989). The effect of testosterone replacement on plasma lipids and apolipoproteins. Eur J Clin Invest, Vol.19, No.5, (October 1989), pp.438-441, ISSN 0014-2972.

Kapoor D., Malkin C.J., Channer K.S., \& Jones T.H. (2005). Androgens, insulin resistance and vascular disease in men. Clin Endocrinol (Oxf), Vol.63, No.3, (September 2005), pp.239-50, ISSN 0300-0664.

Khaw K.T., Dowsett M., Folkerd E., Bingham S, Wareham N, Luben R, Welch A, \& Day N. (2007). Endogenous testosterone and mortality due to all causes, cardiovascular disease, and cancer in men: European prospective investigation into cancer in Norfolk (EPICNorfolk) Prospective Population Study. Circulation, Vol.116, No.23, (December 2007), pp.2694-701, ISSN 0009-7322.

Kimura, N., Mizokami, A., Oonuma, T., Sasano, H. \& Nagura, H. (1993) Immunocytochemical localization of androgen receptor with polyclonal antibody in paraffin-embedded human tissues. Journal of Histochemistry and Cytochemistry, Vol.41, No.5, (May 1993), pp.671-678, ISSN 1551-5044.

Liu J., Tsang S., \& Wong T.M. (2006). Testosterone is required for delayed cardioprotection and enhanced heat shock protein 70 expression induced by preconditioning. Endocrinology, Vol.147, No.10, (October 2006), pp.4569-77, ISSN: 0013-7227.

Liu, P.Y. \& Handelsman, D.J. (2004) Androgen therapy in nongonadal disease. In: Testosterone: Action, Deficiency and Substitution, E. Nieschlag, H.M. Behre, (Eds.), 445-495, Springer-Verlag, Berlin. 
Malkin C.J., Pugh P.J., Jones R.D., Kapoor D., Channer K.S., \& Jones T.H. (2004). The effect of testosterone replacement on endogenous inflammatory cytokines and lipid profiles in hypogonadal men. J Clin Endocrinol Metab, Vol.89, No.7, (July 2004), pp.3313-18, ISSN 0021-972X.

Malkin, C.J., Pugh, P.J., West, J.N., van Beek, E.J., Jones, T.H. \& Channer, K.S. (2006) Testosterone therapy in men with moderate severity heart failure: a double-blind randomized placebo controlled trial. European Heart Journal, Vol.27, No.1, (January 2006), pp.57-64, ISSN 0195-668X.

Malkin C.J., Pugh P.J., Morris P.D., Asif S., Jones T.H., \& Channer K.S. (2010). Low serum testosterone and increased mortality in men with coronary heart disease. Heart, Vol.96, No.22, (November 2010), pp.1821-5, ISSN: 1355-6037.

Masuda A., Mathur A., \& Halushka P.V. (1995). Testosterone increases thromboxane A2 receptors in cultured rat smooth muscle cells. Circ. Res, Vol.69, No.3, (September 1995), pp.638-643, ISSN 0009-7330.

McCredie R.C., McCrohon J.A., Turner L., Griffiths K.A., Handelsman D.J:, \& Celermajer D.S. (1998). Vascular reactivity is impaired in genetic females taking high-dose androgens. J. Am. Coll. Cardiol., Vol.32, No.5, (November 1998), pp. 1331-1335, ISSN 0735-1097.

Pugh, P.J., Jones, T.H. \& Channer, K.S. (2003) Acute haemodynamic effects of testosterone in men with chronic heart failure. European Heart Journal, Vol.24, No.10, (May 2003), pp.909-915, ISSN 0195-668X.

Pugh, P.J., Jones, R.D., West, J.N., Jones, T.H. \& Channer, K.S. (2004) Testosterone treatment for men with chronic heart failure. Heart, Vol.90, No.4, (April 2004), pp.446-447, ISSN 1355-6037.

Rosano G.M.C., Sarrel P.M., Poole-Wilson P.A., \& Collins P. (1993). Beneficial effect of oestrogen on exercise-induced myocardial ischaemia in women with coronary artery disease. Lancet, Vol.342, No.8864, (July 1993), pp.133-136, ISSN: 0140-6736.

Rosano G.M., Leonardo F., Pagnotta P., Pellicia F., Panina G., Cerquetani E., Monica P.L., Bonfigli B., Volpe M., \& Chierchia S.L. (1999). Acute anti-ischemic effect of testosterone in men with coronary artery disease. Circulation, Vol. 99, No.13, (April 1999), pp. 1666-1670, ISSN 0009-7322.

Ruige J.B., Mahmoud A.M., De Bacquer D., \& Kaufman J.M. (2010). Endogenous testosterone and cardiovascular disease in healthy men: a meta-analysis. Heart, (December 2010) [Epub ahead of print].

Sader, M.A., Griffiths, K.A., McCredie, R.J., Handelsman, D.J. \& Celermajer, D.S. (2001). Androgenic anabolic steroids and arterial structure and function in male bodybuilders. Journal of the American College of Cardiology, Vol.37, No.1, (January 2001), pp.224-230, ISSN 0735-1097.

Shores M.M., Matsumoto A.M., Sloan K.L., \& Kivlahan D.R. (2006). Low serum testosterone and mortality in male veterans. Arch Intern Med, Vol.166, No.15, (August 2006), pp.1660-5, ISSN 0003-9926.

Sorva R., Kuusi T., Taskinen M.R., Perheentupa J., \& Nikkila E.A. (1988) Testosterone substitution increases the activity of lipoprotein lipase and hepatic lipase in hypogonadal males. Atherosclerosis, Vol.69, No.2-3, (February 1988), pp.191-197, ISSN 0021-9150. 
Sullivan, M.L., Martinez, C.M., Gennis, P. \& Gallagher, E.J. (1998) The cardiac toxicity of anabolic steroids. Progress in Cardiovascular Diseases, Vol.41, No.1, (July-August 1998), pp.1-15, ISSN 0033-0620.

Tchernof A., Labrie F., Belanger A., \& Despres J.P. (1996). Obesity and metabolic complications: contribution of dehydroepiandrosterone and other steroid hormones, J. Endocrinol., Vol.150, No.Suppl., (Sep 1996), pp. S155-164, ISSN 0022-0795.

Teoh H., Quan A., Leung S.W., \& Man R.Y. (2000). Differential effects of 17-beta-estradiol and testosterone on the contractile responses of porcine coronary arteries. $\mathrm{Br} . \mathrm{J}$. Pharmacol., Vol.129, No.7, (April 2000), pp.1301-1308, ISSN 0007-1188.

Tong P.C., Ho C.S., Yeung V.F., Ng M.C., So W.Y., Ozaki R., Ko G.T., Ma R.C., Poon E., Chan N.N., Lam C.W., \& Chan J.C. (2005). Association of testosterone, insulin-like growth factor-I, and C-reactive protein with metabolic syndrome in Chinese middle-aged men with a family history of type 2 diabetes. J Clin Endocrinol Metab, Vol.90, No.12, (December 2005), pp.6418-23, ISSN 0021-972X.

Tsai E.C., Boyko E.J., Leonetti D.L., \& Fujimoto W.Y. (2000). Low serum testosterone level as a predictor of increased visceral fat in Japanese-American men. Int. J. Obes. Relat. Metab. Disord. Vol.24, No.4, (April 2000), pp. 485-491.

Uyanik B.S., Ari Z., Gumus B., Yigitoglu M.R., Arslan T. (1997). Beneficial effects of testosterone undecanoate on the lipoprotein profiles in healthy elderly men: a placebo controlled study. Jpn Heart J, Vol.38, No.1, (January 1997), pp.73- 82, ISSN: 0021-4868.

Webb C.M., Adamson D.L., Zeigler D., \& Collins P. (1999). Effect of acute testosterone on myocardial ischemia in men with coronary artery disease. Am. J. Cardiol, Vol. 83, No.3, (Feb 1999), pp. 437-439, ISSN 0002-9149.

Wu, F.C.W. \& von Eckardstein, A. (2003). Androgens and coronary artery disease. Endocr. Rev., Vol.24, No.2, (April 2003), pp. 183-217, ISSN 0163-769X.

Yaylali Y.T., Yaylali G.F., Akin F., Susam I., \& Bastemir M. (2010). Effects of Substitutive Therapy on Right Ventricular Systolic and Diastolic Functions in Patients with Idiopathic Hypogonadotropic Hypogonadism. J Endocrinol Invest, (September 2010), [Epub ahead of print].

Yue P., Chatterjee K., Beale C., Poole-Wilson P.A., \& Collins P. (1995). Testosterone relaxes rabbit coronary arteries and aorta. Circulation, Vol.91, No.4, (February 1995), pp. 1154-1160, ISSN 0009-7322.

Zitzmann M. \& Nieschlag E. (2000). Hormone substitution in male hypogonadism. Molecular and Cellular Endocrinology, Vol.161, No.1-2, (March 2000), pp.73-88, ISSN: 0303-7207.

Zitzmann M., Brune M., Kornmann B., Gromoll J., von Eckardstein S., von Eckardstein A., \& Nieschlag E. (2001). The CAG repeat polymorphism in the androgen receptor gene affects high density lipoprotein cholesterol and arterial vasoreactivity. J. Clin. Endocrinol. Metab, Vol.86, No.10, (October 2001), pp. 4867-4873, ISSN 0021-972X.

Zitzmann M., Gromoll J., von Eckardstein A., \& Nieschlag E. (2003),.The CAG repeat polymorphism in the androgen receptor gene modulates body fat mass and serum levels of leptin and insulin in men. Diabetologia Vol.46, No.1, (January 2003), pp. 31-39, ISSN 0012-186X. 


\title{
Androgens and Vascular Function
}

\author{
Mercedes Ferrer \\ Departamento de Fisiología, Facultad de Medicina, Universidad Autónoma de Madrid \\ and Instituto de Investigación Sanitaria IdiPAZ \\ Spain
}

\section{Introduction}

It is widely recognized that vascular function is modulated by the endocrine system. So it is known that hormones as aldosterone, renin-angiotensin II system, thyroids hormones, oxitocine, ghrelin, vasopressine, etc exert action on the vascular tone (Axelband et al., 2011; Nguyen \& Touyz, 2011; Szmydynger-Chodobska et al., 2011; Tesauro et al., 2010;). Regarding sex hormones, epidemiological studies have demonstrated that there is a gender difference in the morbidity associated with hypertension and that there is an increased prevalence of cardiovascular diseases in postmenopausal women (Leung et al., 2007; Teede, 2007). Simultaneously, androgens had been associated with an increased risk of cardiovascular disease, but recent studies have explored protective effects of androgens in males (Jones, 2010; Traish and Kypreos, 2011). For example, it has been demonstrated that men with coronary artery disease have decreased levels of testosterone, which were conversely correlated to the degree of coronary artery narrowing (Saad et al., 2008). Likewise, lower testosterone, predicted incident stroke and transient ischemic attack in older men (BragaBasaria, 2006). In general terms, it seems to be demonstrated that men with cardiovascular disease had lower levels of testosterone, and what is more important, new emerging evidence points to androgen deficiency more likely to be associated with cardiovascular diseases than gender per se (Traish \& Kypreos, 2011). Testosterone deficiency alters carbohydrate, lipid and protein metabolism, this contributing to oxidative stress, endothelial dysfunction and increased production of pro-inflammatory factors, promoting alterations on vascular function. Among the alterations induced by testosterone deficiency are the loss of muscle mass and strength, increasing visceral fat mass, reduced libido, erectile dysfunction, increased osteoporosis, lethargy, lack of energy, and changes in mood. In addition, testosterone deficiency has been associated with increased risk of metabolic syndrome, type 2 diabetes, obesity, insulin resistance and atherosclerosis (Jones \& Saad, 2009; Kapoor et al., 2005).

Most of results obtained about that effects have been obtained from patients with prostate cancer subjected to androgen deprivation therapy. This therapy improves cancer related symptoms and quality of life (Bain, 2010), but shows side effects as sexual dysfunction, decreased lean body mass, decreased quality of life, osteoporosis, and detrimental changes in metabolic status (Basaria \& Dobs, 2001; Chodak et al., 2002; Smith et al., 2002). Increased insulin levels and insulin resistance and increased prevalence of fasting hyperglycemia and hypertriglyceridemia have also been observed in men with prostate cancer treated with 
androgen deprivation therapy (Braga-Bassaria et al., 2006; Keating et al., 2006). This type of therapy provides an invaluable method to correlate vascular alteration and sex hormone status. However, at mechanistic level the animal models are of valuable interest. In this sense our research group has been focused on analyzing the effects produced by the loss of gonadal function on vascular reactivity, as well as some of the underlaying mechanisms.

Vascular tone is regulated by several mechanisms in which nitric oxide (NO) plays an important role. $\mathrm{NO}$ is formed through several NO synthases (NOS), i.e., endothelial NOS (eNOS), inducible (iNOS), and neuronal (nNOS). Independently from the source of NO, one of the major downstream events occurring after NO release is an increase in cGMP formation through soluble guanylate cyclase stimulation, and the subsequent activation of cGMPdependent protein kinase (PKG) (Murad, 1997). PKG contributes to reduce the intracellular calcium concentration through a wide spectrum of PKG substrates, leading to vasodilation (Lincoln et al., 2001; Munzel et al., 2003). In addition, NO (Bolotina et al., 1994) and cGMP (Ferrer et al., 1995) can induce membrane hyperpolarization and subsequent relaxation.

Concerning NO, and independently from the NO-activated signalling pathway, it is important to take into account that vascular function of endothelial NO depends on its bioavailability, which is determined by the rate of NO production and by its scavenging by superoxide anion. Therefore, the elimination of superoxide anion within the vessel wall is fundamental and it is performed by superoxide dismutases (SODs) (Wolin, 2002). It is well understood that alterations of different steps along the NO pathway determine its effect on the vascular tone. Vascular tone is also regulated by prostanoids originated by arachidonic acid metabolism through the cyclooxygenase (COX) pathway (Henrion et al., 1997). One of the best studied prostanoids is thromboxane $\mathrm{A}_{2}\left(\mathrm{TXA}_{2}\right)$ which has been implicated as mediator in diseases such as myocardial infarction and hypertension (FitzGerald et al., 1987). Additionally, the role of COX derivatives other than TXA $A_{2}$, such as prostaglandin (PG) $\mathrm{F}_{2 \alpha}$ and $\mathrm{PGE}_{2}$, or $\mathrm{PGI}_{2}$ which can induce a vasoconstrictor or vasodilator response is the subject of numerous studies (Blanco-Rivero et al., 2005; Félétou \& Vanhoutte, 2006) since they could also participate in vascular dysfunction.

On the other hand, proteins kinases are important regulators of different cell signalling pathways. Among different proteins kinases, PKC merits special attention since it is able to regulate the activity of different enzymes such as NOS and COX-2 (Kim et al., 2008; Shanmugam et al., 2004). In turn, PKC can be activated by different reactive oxygen species. At this point, it is important to note that sex hormones possesses antioxidant properties, and the loss of gonadal function can induce oxidative stress and, in turn triggers modulatory actions in different cell signalling pathways that are working simultaneously to ensure the optimal response of the vessel to different stimuli.

For this, this chapter will review how the loss of gonadal function modifies the release and function of different mediators, such as reactive oxygen species, nitric oxide and prostanoids, and their functional involvement in the reactivity of aorta and mesenteric artery of the male rats. Future studies in the research field of androgens on cell signaling pathways will be commented, since they will be of important interest to implement therapeutic strategies that could improve vascular function.

\section{Androgens and nitric oxide}

The functional role of $\mathrm{NO}$ in vascular tone regulation has been widely reported (Furchgott \& Zawadzki, 1980; Toda \& Okamura, 2003; Vanhoutte 1996). NO is formed through several 
NO synthases (NOS), i.e, endothelial NOS (eNOS), inducible (iNOS) and neuronal (nNOS) (Förstermann et al., 1991). Most of the studies about the effects of androgens on vascular function have been focused on analyzing the interaction between androgens and endothelial NO (Tep-areenan et al., 20043; Jones et al., 2004). More specifically, most studies have been focused on analyzing the effects of androgenic derivatives on different aspects of the NO system, such us eNOS expression, NO release or NO vasodilator effect (Ceballos et al., 1999; Hutchison et al., 1997; Teoh et al., 2000). However, few studies exist about the specific effect of endogenous male sex hormones on these aspects referred to endothelial or neuronal NO when they are simultaneously studied. Our data were obtained from aorta and mesenteric artery from intact and orchidectomized male Sprague-Dawley rats (6 months old), and seem not to be related to haemodynamic changes, since orchidectomy did not modify blood pressure $(137 \pm 5.8 \mathrm{~mm} \mathrm{Hg}$ in control rats and of $145 \pm 6.2 \mathrm{~mm} \mathrm{Hg}$ in orchidectomized rats; $p$ $>0.05)$. Moreover, the results on vascular function would have to be androgen-related, as confirmed by the decreased testosterone levels (control: $2404 \pm 323 \mathrm{pg} / \mathrm{mL}$; orchidectomized: $220 \pm 49 \mathrm{pg} / \mathrm{mL} ; \mathrm{n}=6 ; p<0.001$ ).

The reported effects of androgens on NO release are contradictory. Testosterone impairs relaxation and worsens endothelial dysfunction in male rabbits (Hutchison et al., 1997). However, it has also been reported that testosterone or its derivatives increase eNOS (Liu \& Dillon, 2002; Weiner et al., 1994) and nNOS activity in the central nervous system of guinea pig (Weiner et al., 1994) and mouse (Scordalakes et al., 2002). Nevertheless, to our knowledge, we showed first evidence on the effect of endogenous male sex hormones on the nNOS/eNOS expression and nNOS-/eNOS-derived NO release in vascular tissues (Martin et al., 2005; Blanco-Rivero et al., 2007).

\subsection{Neuronal nitric oxide}

The analysis of the expression of nNOS, by Western blot, showed that it was higher in segments from control rats than from orchidectomized rats (Martín et al., 2005). The NO release was quantified by measuring nitrite production and also the fluorescence emitted by DAF-2, and the results showed that electrical field stimulation EFS-induced NO release was similar in segments from both control and orchidectomized rats. The measured NO release seems to come from nerve endings, since preincubation with tetrodotoxin abolished the nitrite release in endothelial-denuded segments from both groups of rats. This result indicates that male sex hormones apparently do not modulate nNOS-derived NO release, in contrast to our observations with female sex hormones in which we found that the loss of these hormones provoked by ovariectomy increased nNOS-derived NO release (Minoves et al., 2002).

To study the involvement of neuronal or endothelial NO on vasomotor responses, EFS induced contractile responses in endothelium-denuded mesenteric segments were analyzed by using vascular reactivity technique (Nielsen \& Owman, 1971). The contractile response induced by EFS were practically abolished by tetrodotoxin and markedly reduced by phentolamine, the respective blockers for nerve impulse propagation and $\alpha$-adrenoceptors in arteries from both control and orchidectomized rats. Therefore, these responses appear to be mediated by noradrenaline (NA) release from adrenergic nerve terminals and the subsequent activation of $\alpha$-adrenoceptors in both experimental hormonal conditions, as has been described in other rat strains (Ferrer et al., 2000; 2001).

The present results show that vasoconstrictor response to $\mathrm{KCl}$ and exogenous NA are diminished in segments from orchidectomized male rats, which is in agreement with most studies demonstrating that testosterone treatment enhanced the action of several contractile 
agents (Baker et al., 1978; Calderone et al., 2002; Greenberg et al, 1974). However, the responses induced by EFS was similar in both groups of rats Fig. 1 which would suggest that EFS increased the release of a vasoconstrictor factor, that could be the NA release from adrenergic endings in segments from orchidectomized animals.

Concerning this point, most studies have been performed in the central nervous system and, conflicting results exist. Thus, a decrease (Guan \&Dluzen, 1991; Holmquist et al., 1994), an increase (Shan \& Dluzen, 2002; Siddiqui \& Shah, 1997) and no modification (Agostini et al., 1981; Chen et al., 1999) of NA release have been reported in orchidectomized male animals. In a later study we demonstrated that the NA release was not modified by orchidectomy (Blanco-Rivero et al., 2006).

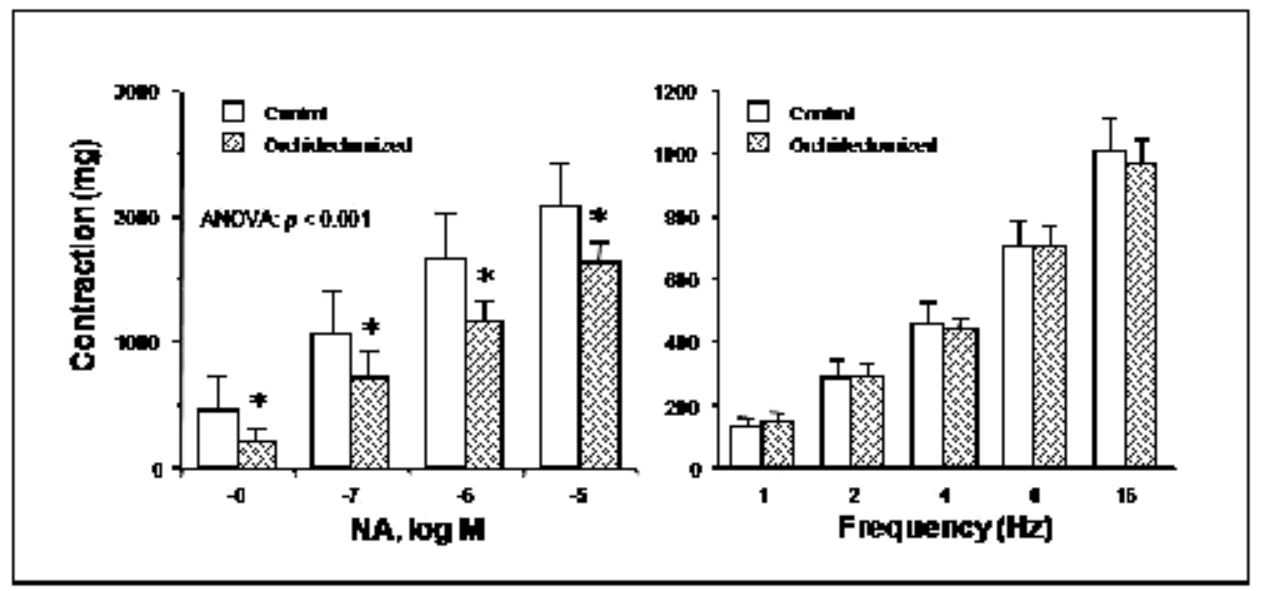

Fig. 1. Contractile response induced by cumulative concentration-response curves to noradrenaline (NA) and by frequency-response curves in denuded mesenteric arteries from control and orchidectomized rats. Results (means \pm SEM) are expressed in milligram. Number of animals: 25-30. * $p<0.01$ compared with control rats (from Martín et al., 2005).

Since sex hormone modulation of the calcitonin gene related peptide (CGRP) system has been described (Sun et al., 2001), and that the CGRP, the essential neurotransmitter in sensory nerves (Kawasaki et al., 1988), had been proposed to play a role in vascular tone regulation, the participation of sensory innervation in the vasomotor response to EFS was assessed by the use of capsaicin, which selectively depletes the sensory nerves of the neurotransmitter (Li \& Duckles, 1992). Capsaicin did not have a significant effect on the vasomotor response to either EFS or exogenous NA in mesenteric arteries from control and orchidectomized rats (data not shown), indicating that sensory innervation does not modulate the vasomotor response to EFS in our experimental conditions. Sun et al., (2001) analyzed how orchidectomy modulates CGRP release, while we analyzed the functional involvement of the sensory innervation in the response to EFS without separately studying CGRP release and/or response.

The NOS inhibitor L-NAME increased the vasoconstrictor response to EFS in segments from both control and orchidectomized rats. The fact that the endothelium was removed and that AMT, an inhibitor of iNOS (Ferrer et al., 2000; Ishikawa \& Quock, 2003; Tracey et al., 1995), did not modify the response induced by EFS in segments from both rat groups, reinforced the neuronal origin for the NO release. 


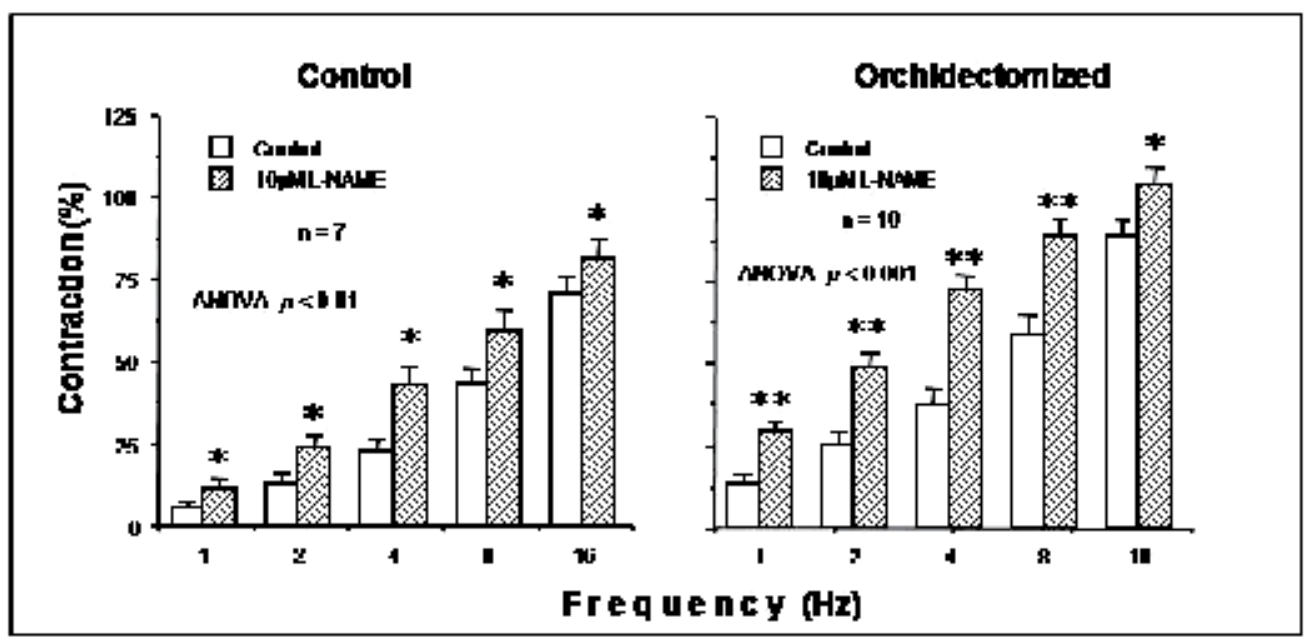

Fig. 2. Effect of L-NAME on the frequency-response curves performed in mesenteric arteries from control and orqchidectomized rats. Results are expressed as a percentage of a previous tone with $75 \mathrm{mM} \mathrm{KCl}$. n, number of animals; ${ }^{*} p<0.05$; ${ }^{* *} p<0.01$ compared with control rats (from Martín et al., 2005).

The greater response to EFS in the presence of L-NAME in segments from orchidectomized animals compared with the response obtained in segments from control rats Fig. 2 indicated differences in steps downstream from neuronal NO release, that will be considered later.

The reported effects of androgens on NO release are contradictory. Testosterone impairs relaxation and worsens endothelial dysfunction in male rabbits (Hutchison et al., 1997). However, it has also been reported that testosterone or its derivatives increase eNOS (Liu \& Dillon, 2002; Weiner et al., 1994) and nNOS activity in the central nervous system of guinea pig (Weiner et al., 1994) and mouse (Scordalakes et al., 2002). Nevertheless, to our knowledge, there is no experimental evidence on the effect of male sex hormones on the nNOS expression and nNOS-derived NO release in vascular tissues. Therefore, we analysed the expression of nNOS by western blot, and found it was higher in segments from control rats than from orchidectomized rats. We also quantified the NO release induced by EFS in segments from both groups of rats by measuring nitrite production and the fluorescence emitted by DAF-2, and the results showed that the EFS-induced NO release was similar in segments from both control and orchidectomized rats.

\subsection{Endothelial nitric oxide}

The eNOS expression in aorta and mesenteric artery showed that not was modified by orchidectomy (Blanco-Rivero et al., 2007; Martorell et al., 2008), in contrast to that observed in endothelial-denuded mesenteric artery (Martín et al., 2005), which indicates that endogenous male sex hormones act in a different manner depending on the target protein. Additionally, these results also indicate that effects induced by endogenous hormones are quite different from those induced by exogenous hormones, since it has been reported that androgenic derivatives can increase (Simoncini et al., 2003), decrease (Chatrath et al., 2003) or not affect (McNeill et al., 1999) eNOS expression.

Regarding eNOS activity, androgen-induced increase (Liu \& Dillon, 2002; Simoncini et al., 2003) and decrease (Mukherjee et al., 2001) have both been reported. Others researchers have 
demonstrated that androgens increased (Orshal \& Khalil, 2004; Wynne \& Khalil, 2003) and decreased (Ba et al., 2001; Gonzales et al., 2004) the vasodilator effect of endothelial NO. In our experimental rat model, we have found that the release of endothelial $\mathrm{NO}$ was not modified by orchidectomy, either in mesenteric artery (Blanco-Rivero et al., 2007) or aorta (Blanco-Rivero et al., 2006). However, orchidectomy reduced the endothelium-dependent vasodilator response induced by Acetylcholine (Ach) in mesenteric artery while increased in rat aorta (Fig. 3).

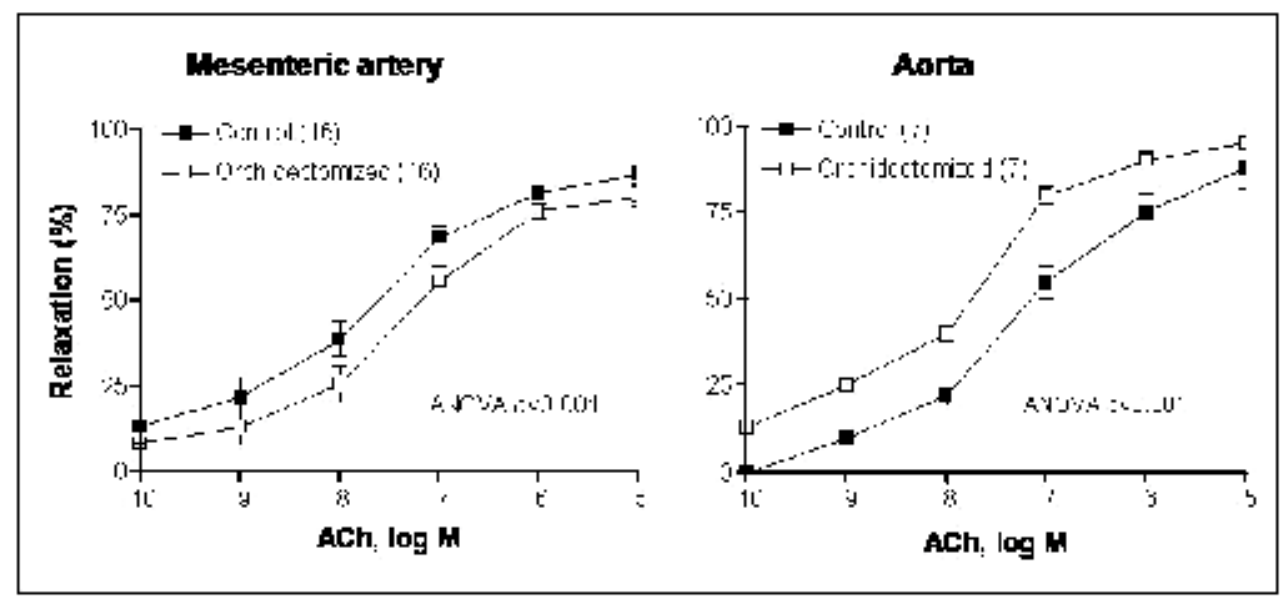

Fig. 3. Concentration-response curve to acetylcholine (ACh) in mesenteric artery and aortic segments from control and orchidectomized rats. Results are expressed as a percentage of a previous tone with noradrenaline. Number of animals is indicated in parentheses (from Blanco-Rivero et al., 2007; Ferrer et al., 1999).

These results could indicate that orchidectomy, depending on the vessel, may alter the sensitivity to $\mathrm{NO}$ and/or the release of factors other than $\mathrm{NO}$, that will be revised in the next sections.

\section{Androgens and production of reactive oxygen species}

Reactive oxygen species are involved in metabolising NO (Gryglewski et al. 1986, Ferrer et al. 2000, 2001) and it has been reported that can induce oxidative processes associated with cardiovascular disorders (Harrison 1994; Munzel et al., 1997). Among all the reactive oxygen species, superoxide anion plays a critical role since it is a source of many other reactive oxygen intermediates (Beckman \& Koppenol, 1996). Therefore, both production and removal of superoxide anion are important contributors to the maintenance of appropriated levels of this oxygen species. Since several studies have demonstrated androgens antioxidants properties of androgens (Békési et al., 2000; Yorek et al., 2002), the effect of the orchidectomy on the production of superoxide anion was analyzed, by measuring the lucigenin chemiluminescence (control =117 $\pm 43 \mathrm{U} / \mathrm{mg} / \mathrm{min}, \mathrm{n}=5$; orchidectomized $=546 \pm 58 \mathrm{U} / \mathrm{mg} / \mathrm{min}, \mathrm{n}=5 ; \mathrm{p}<0.001$ ). A similar result was obtained with acetylcholine-induced superoxide anion in aortas from the same animals (control: $34.7 \pm 5.6 \mathrm{U} / \mathrm{mg} / \mathrm{min}, \mathrm{n}=4$; orchidectomized: $132.8 \pm 3.2, \mathrm{n}=4$; $\mathrm{p}<$ 0.001). These results agree with previous studies showing the antioxidants properties of androgens (Békési et al., 2000; Yorek et al., 2002). The elimination of superoxide anion within the vessels is fundamental since this oxygen specie can reduce the NO bioavailability. 
Within the vessel wall, SODs transform superoxide anion to hydrogen peroxide (Oury et al., 1996, Price et al., 2000, Muzykantov, 2001). Although three SOD isoforms have been identified: cytosolic $\mathrm{Cu} / \mathrm{ZnSOD}$, mitochondrial MnSOD, and extracellular ecSOD -which is also $\mathrm{Cu} / \mathrm{Zn}$ dependent (Strehlow et al., 2003), we have focused on analyzing the participation of $\mathrm{Cu} / \mathrm{ZnSOD}$ since it is the predominant isoform in peripheral vessels (Namgaladze et al., 2005), and this enzyme therefore plays a crucial role in the pathogenesis of vascular dysfunction (Wolin, 2002). We analyzed the expression and activity of SODs because there was no information about modulation of these enzymes by endogenous male sex hormones. We found that both the expression and activity of $\mathrm{Cu} / \mathrm{ZnSOD}$ were increased in aortic segments from orchidectomized rats (Fig. 4). These results were in line with other studies that described an increased expression and/or activity of SOD in cardiovascular pathologies, in which superoxide anion overproduction exists (Kobayashi et al., 2002, Tanaka et al., 2005).

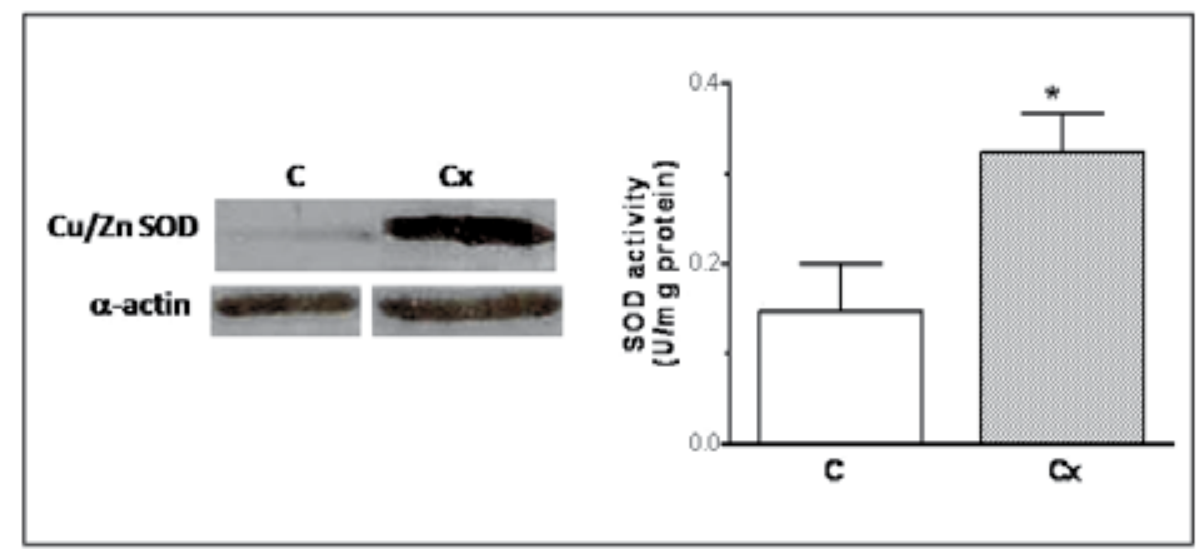

Fig. 4. Representative western blot for $\mathrm{Cu} / \mathrm{ZnSOD}$ and) $\alpha$-actin expression and SOD activity in aortic segments from control (C) and from orchidectomized (Cx) rats (from Blanco-Rivero et al., 2006).

In addition, these results indicated that the increases in both expression and activity of $\mathrm{Cu} / \mathrm{ZnSOD}$ could be a compensatory mechanism to eliminate the elevated superoxide anion formation induced by orchidectomy in male rats. On the other hand, additional mechanisms may exist to try to maintain vasodilator function. One of these mechanisms could be the activation of calcium-dependent potassium channels by superoxide anion (Ferrer et al., 1999). In that report, we confirmed that the calcium dependent potassium channels $\left(\mathrm{K}_{\mathrm{Ca}}\right)$ activation was specifically induced by superoxide anion, since the NO synthesis was inhibited.

However, the vascular response depends on the vascular bed analyzed. For example, in mesenteric artery from orchidectomized rats, the vascular ROS-induced relaxation was due to the production of peroxynitrite and hydrogen peroxide $\mathrm{H}_{2} \mathrm{O}_{2}$. The increased formation of peroxynitrite in arteries from orchidectomized rats was studied by immunohistochemical localization and was reinforced by functional analysis on vasodilator response induced by sodium nitroprusside (SNP):

The presence of SOD increased the response to SNP in segments from orchidectomized rats which could be mediated through the decreased peroxynitrite formation by removing superoxide anion, and the simultaneous increased of $\mathrm{H}_{2} \mathrm{O}_{2}$ formation, which exert 
vasodilator action (Martín et al., 2005; Rubanyi \& Vanhoutte, 1986; Wei et al., 1996). The simultaneous incubation of arteries with SOD and catalase reversed the vasodilator response to SNP, indicating that the $\mathrm{H}_{2} \mathrm{O}_{2}$ synthesized in the presence of SOD, would participate in that vasodilator effect, when the formation of peroxynitrite is inhibited (Fig. 5).

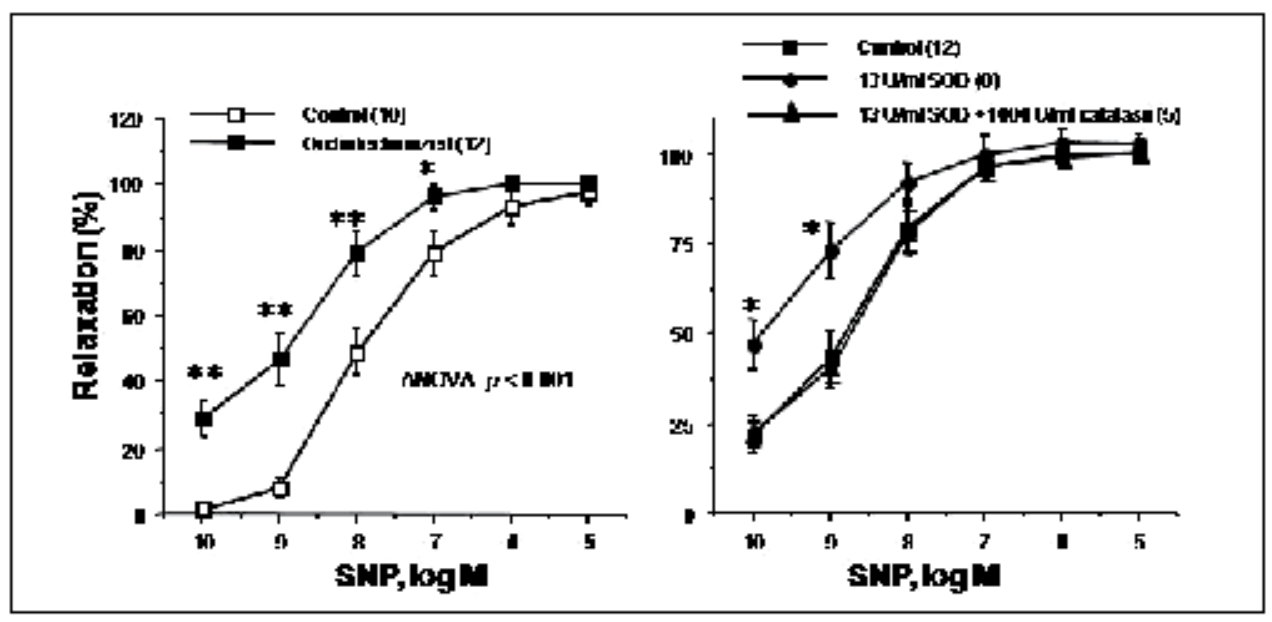

Fig. 5. Effect of orchidectomy, and effect of superoxide dismutase (SOD) and SOD plus catalase on the concentration-response curves to sodium nitroprusside (SNP) in mesenteric artery segments from orchidectomized rats. Results are expressed as a percentage of the inhibition of contraction induced by noradrenaline. Number of animals is indicated in parentheses. * $p<0.01$ compared with control (from Martín et al., 2005).

At this point, it has been discussed that the loss of male sex hormones did not modify:

(1) the nNOS-derived NO release induced by EFS although it did increase the NO metabolism through superoxide anion and peroxynitrite generation; however, the functional role of the nNOS-derived NO release was more pronounced in arteries from orchidectomized animals, due to products generated from the NO metabolism, such as peroxynitrite and hydrogen peroxide, that seem to be able to compensate for the loss of NO bioavailability, probably through their direct vasodilator effect,

(2) the eNOS-derived NO release induced by Ach in both aorta and mesenteric artery; however the functional role of the endothelial $\mathrm{NO}$ release seem to be different in both arteries: Ach-induced relaxation is totally dependent of NO because the Ach-induced relaxation is inhibited when the synthesis of NO is blocked (Blanco-Rivero et al., 2007), as occur in aorta from control rats, while in aorta from orchidectomized rats important relaxation exist even after NO synthesis was blocked (Ferrer et al., 1999).

These differences could be due to the existence of regulatory mechanisms turned on by the loss of gonadal function that include, at least, prostanoids production.

\section{Androgens and prostanoids}

Endothelial cells also release vasoconstrictor and vasodilator prostanoids, originated from the arachidonic acid metabolism through the cyclooxygenase (COX) pathway, to regulate vascular tone (Blanco-Rivero et al., 2005; Feletou \& Vanhoutte, 2006; Henrion et al., 1997). 
Two major isoforms of COX exist: COX-1 is expressed constitutively and is usually abundant in all animal and human endothelial cells, whereas endothelial COX-2 is induced mainly during inflammatory responses in nearly all animals. Depending on the vessel studied and the agonist used to activate cells, different prostanoids can be released and contribute to vasomotor response depending on the prostanoid receptor that result activated. Among all the prostanoids, one of the most studied is thromboxane $\mathrm{A}_{2}\left(\mathrm{TXA}_{2}\right)$, which has been implicated as a mediator in diseases such as myocardial infarction, hypertension, stroke and bronchial asthma (FitzGerald et al., 1987; Narumiya et al., 1999; Noll\& Luscher, 1998). However, little information is available on the effect of androgens on vascular effects of endogenous $\mathrm{TXA}_{2}$. Thus, orchidectomy has been reported to either decrease (Gonzales et al., 2005) or not modify (Blanco-Rivero et al., 2006) TXA 2 synthase expression. Likewise, the contractile effect induced by the TXA 2 mimetic, U-46619, was not modified by orchidectomy in mesenteric (Blanco-Rivero et al., 2006) and cerebral (Gonzales et al., 2005) rat arteries.

On the other hand, the role of COX-derivates, other than $\mathrm{TXA}_{2}$, such as prostaglandin (PG) $\mathrm{I}_{2}, \mathrm{PGF}_{2 \alpha}$ and $\mathrm{PGE}_{2}$, which can act as vasoconstrictors under certain pathological conditions, is the objective of numerous studies (Félétou et al., 2010; Gluais et al., 2005; Rapoport \& Williams, 1996). However, to the best of our knowledge studies analyzing the effect of endogenous male sex hormones in the involvement of these prostanoids in vascular function were lacking, and therefore this was one of our objectives. As above commented, we have previously demonstrated that EFS induced similar contractile response (Fig.1) in mesenteric arteries from control and orchidectomized rats, responses that appear to be mediated by NA release from adrenergic nerve terminals and the subsequent activation of $\alpha$-adrenoceptors (Martín et al., 2005); in addition, we found that the contractile response to exogenous NA was decreased by orchidectomy, suggesting the EFS could increase NA release in arteries from orchidectomized rats; however, we later demonstrated the EFSinduced NA release was not modified by orchidectomy (Blanco-Rivero et al., 2006) which indicated that other vasoconstrictor factors could be released when the artery was electrically stimulated. We observed that the EFS induced a greater $\mathrm{TXA}_{2}$ formation in arteries from orchidectomized than control rats, which was in line with other reports showing increased TXA 2 release after activation of muscarinic (Blanco-Rivero et al., 2007) or $\alpha_{2}$-adrenoceptors (Blanco-Rivero et al., 2006), and it confirmed the endothelial and smooth muscle cells as sources of TXA $\mathrm{T}_{2}$ production. The increased $\mathrm{TXA}_{2}$ release could be the contractile factor that was released when the artery is electrically stimulated, and explains the non modification of the EFS-induced response in arteries from control and orchidectomized rats, in spite of the fact that the NA response was diminished in arteries from the latter animals.

It has been previously reported that prostanoids other than $\mathrm{TXA}_{2}$, i.e. prostaglandin (PG) $\mathrm{I}_{2}$ increased neuronal NO release (Ferrer et al., 2004) and taking into account that in our experimental conditions the main neurotransmitters involved in that response elicited by EFS were NO and NA, we investigated the regulation of the NA and NO release and function by $\mathrm{TXA}_{2}$. We observed that in arteries from control rats, the $\mathrm{TXA}_{2}$ synthesis inhibition, with furegrelate, increased the neuronal NO release, which was in line with reports describing an inhibitory effect of $\mathrm{TXA}_{2}$ on inducible (Yamada et al., 2003) and endothelial (Miyamoto et al., 2007) NO release. The vasodilator response induced by the NO donor, sodium nitroprusside was also increased by furegrelate. Concerning the effects of $\mathrm{TXA}_{2}$ on NA release, inhibition (Nishihara et al., 2000) or non-modification (Rump \& 
Schollmeyer, 1989) have been reported. In our experimental model, the inhibition of TXA synthesis did not modify either NA release or its vasomotor effect, which indicated that endogenous $\mathrm{TXA}_{2}$ did not alter the function of sympathetic innervations on arteries from control rats. By contrast, in arteries from orchidectomized rats, endogenous $\mathrm{TXA}_{2}$ did not regulate either the release/function of neuronal $\mathrm{NO}$ or NA. The results obtained in mesenteric arteries from control animals explain the decreased EFS-induced response in the presence of furegrelate; however, did not explain the unaltered EFS-induced response in arteries from orchidectomized rats, since to remove a constrictor substance a decreased in EFS-induced vasoconstriction would be expected. Since cross-talk between $\mathrm{TXA}_{2}$ and $\mathrm{PGI}_{2}$ has been reported (Cheng et al., 2002; Martorell et al., 2008) and joint increases in $\mathrm{PGI}_{2}$ and $\mathrm{TXA}_{2}$ synthesis have been shown in pathological conditions (Caughey et al., 2001; FitzGerald, 1991), the effect of $\mathrm{TXA}_{2}$ on $\mathrm{PGI}_{2}$ production was analyzed, as well as, its dependence of the hormonal status. We observed that the inhibition of endogenous synthesis of $\mathrm{TXA}_{2}$ did not modify the release of $\mathrm{PGI}_{2}$ in arteries from control rats, while it did greatly increase $\mathrm{PGI}_{2}$ release in arteries from orchidectomized rats, which could work as a contractile factor after activation of $\mathrm{TXA}_{2}$ receptors. Taking together these results, the loss of gonadal function in male rats increased the non-endothelial $\mathrm{TXA}_{2}$ release in mesenteric arteries, and regulates the EFS-induced response through different mechanisms.

As previously commented, orchidectomy increased the TXA 2 release in endothelial-intact mesenteric arteries (Blanco-Rivero et al., 2006; 2007). Similar effect was also observed in aorta segments from comparable animals (Martorell et al., 2008), however, in this case the relaxation to ACh was increased. Based on this result, the level of expression of COX-2 as well as the production of prostanoids derived from COX-2 other than $\mathrm{TXA}_{2}$ was investigated. We found that COX-2 expression, in contrast to observations in mesenteric artery (Blanco-Rivero et al., 2006), was increased in aortas from orchidectomized rats indicating that endogenous male sex hormones act differently depending on the specific vessel. Our results also show that, in aorta from orchidectomized rats, COX-2 derivatives could also be increased and play a role in the regulation of vascular function. To test this hypothesis, we analyzed the effect of the COX-2 inhibitor NS-398 on the ACh-induced response. In contrast to our assumptions, we found that NS-398 did not modify the AChinduced relaxation in either group of rats, apparently indicating the lack of participation of COX-2 derived products in the ACh response, probably due to the equilibrium between the inhibition of prostanoids formation and phosphodiesterase inhibition (Klein et al., 2007), which allowed us to speculate that the contribution of different prostanoids to the vasodilator response mediated by $\mathrm{ACh}$ could be regulated by endogenous male sex hormones.

Once we had established that orchidectomy increased $\mathrm{TXA}_{2}$ release, we analyzed the possible role of this prostanoid in the response to ACh by analyzing the effect of the TXA2 synthase inhibitor, furegrelate, and the TP receptor antagonist, SQ29,548, on the vasodilator response to $\mathrm{ACh}$. We observed that neither substance had any effect on the ACh-induced response in arteries from control animals, indicating that $\mathrm{TXA}_{2}$ did not participate in that response, in agreement with reports in other rat strains (Gluais et al., 2005; Rapoport \& Williams, 1996). However, in arteries from orchidectomized rats, furegrelate enhanced the vasodilator response to $\mathrm{ACh}$, showing a functional involvement of TXA $\mathrm{A}_{2}$ The fact that the contractile response to the TXA 2 mimetic U-46619 was similar in arteries from control and orchidectomized rats demonstrated that sensitivity to TXA2 is not modified by orchidectomy, which agrees with reports in cerebral (Gonzales et al., 2005) and mesenteric 
(Blanco-Rivero et al., 2006) arteries; additionally, it also shows that differences in the TXA involvement in the ACh-response are due to increased synthesis rather than increased sensitivity to TXA 2 . However, the incubation with SQ29,548 did not affect the ACh-induced relaxation, which seems to contradict the results obtained with furegrelate. However, since interactions among different prostanoids have been reported (Bachschmid et al., 2005; Cheng et al., 2002), it is possible to hypothesize that when TXA $\mathrm{T}_{2}$ synthesis is inhibited, the production of other prostanoids, which counterbalance the TXA $\mathrm{T}_{2}$ effect, could be increased. Therefore, we investigated the effect of inhibiting $\mathrm{PGI}_{2}$ synthesis (with $\mathrm{TCP}$ ) on the AChinduced response, observing that it decreased the vasodilator response to $\mathrm{ACh}$ to a greater extent in arteries from orchidectomized than in those of control rats, which would indicate a greater involvement of this vasodilator prostanoid in the former arteries. Therefore, the release and vasomotor effect of $\mathrm{PGI}_{2}$ was investigated. The $\mathrm{ACh}$-induced $\mathrm{PGI}_{2}$ release was increased in arteries from orchidectomized rats, probably due to the superoxide anion overproduction observed in aortas from orchidectomized rats (Blanco-Rivero et al., 2006), supporting the concept of redox regulation of vascular prostanoid synthesis proposed by Bachschmid et al. (2005). Moreover, the increased production of $\mathrm{PGI}_{2}$ is in line with that reported in human syndromes involving platelet activation in which $\mathrm{PGI}_{2}$ biosynthesis is elevated along with TXA 2 (Caughey et al., 2001; FitzGerald, 1991). It is known that $\mathrm{PGI}_{2}$ can induce both vasodilation, through activation of prostacyclin receptors (IP) and thereby increasing cyclic-AMP, and vasoconstriction through activation of TP receptors (BlancoRivero et al., 2005). In the present study, we found that exogenous $\mathrm{PGI}_{2}$ induced relaxation in rat aorta, and that it was decreased in arteries from orchidectomized rats, which could be due to differences in the expression of IP receptors rather than differences in cell signalling operating after receptor activation; we have observed that the relaxation induced by the activator of adenylate cyclase, forskolin, was similar in arteries from control and orchidectomized rats (unpublished data).

Since considerable evidence exists for cross-talk between the TXA 2 and $\mathrm{PGI}_{2}$ systems (Cheng et al., 2002), we analyzed the functional effect of inhibiting the synthesis of both prostanoids. We observed that co-incubation of arteries with TCP plus furegrelate, or TCP plus SQ29,548, reversed the decreased response to $\mathrm{ACh}$ caused by TCP in arteries from control rats, showing the existence of a balance between $\mathrm{TXA}_{2}$ and $\mathrm{PGI}_{2}$ in these arteries. However, in arteries from orchidectomized rats, the co-incubation with TCP plus furegrelate did not modify the decreased $\mathrm{ACh}$ response caused by TCP, indicating the participation of prostanoids other than $\mathrm{PGI}_{2}$ and $\mathrm{TXA}_{2}$ that could induce contraction. Moreover, these prostanoids would activate TP receptors since co-incubation with TCP and SQ29,548 completely reversed the decrease in the ACh response induced by TCP.

Among COX-2 derivatives, other than $\mathrm{TXA}_{2}$ and $\mathrm{PGI}_{2}$, that can activate $\mathrm{TP}$ receptors, $\mathrm{PGE}_{2}$ is the most plausible candidate (Gluais et al., 2005; Blanco-Rivero et al., 2007) since the AChinduced $\mathrm{PGF}_{2 \alpha}$ production and its vasoconstrictor effect were both very limited. Therefore, we investigated the ACh-induced $\mathrm{PGE}_{2}$ release, as well as its vasoconstrictor effect. We found that both $\mathrm{ACh}$-induced $\mathrm{PGE}_{2}$ production and $\mathrm{PGE}_{2}$-induced vasoconstrictor response were greater in arteries from orchidectomized than in those of control rats. Consequently, the ACh-induced $\mathrm{PGE}_{2}$ release, under inhibited synthesis of $\mathrm{TXA}_{2}$ and $\mathrm{PGI}_{2}$, was analyzed. We found the ACh-induced $\mathrm{PGE}_{2}$ production further increased, probably as a consequence of increased $\mathrm{PGH}_{2}$ production and subsequent transformation into $\mathrm{PGE}_{2}$ (Frein et al., 2005); and, what is more important, the $\mathrm{PGE}_{2}$ increase was more pronounced in arteries from orchidectomized than in those of control rats. 


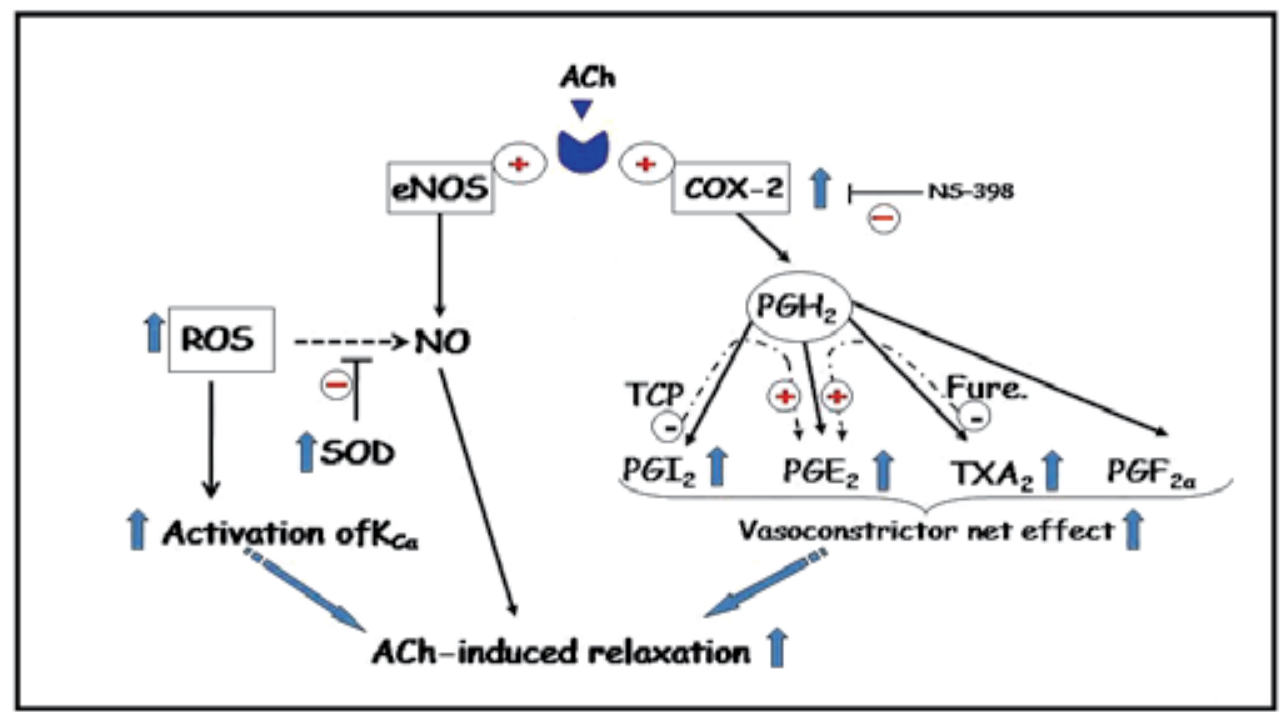

Fig. 6. Scheme showing the effect of orchidectomy on different mechanisms involved in the ACh-induced relaxation (see text for explanation).

This finding confirms our hypothesis that when the synthesis of $\mathrm{PGI}_{2}$ and $\mathrm{TXA}_{2}$ was inhibited, the release of $\mathrm{PGE}_{2}$ was increased in arteries from orchidectomized rats, but raises the question as to why the $\mathrm{PGE}_{2}$ produced in the presence of TCP plus furegrelate did not affect the AChinduced relaxation in arteries from control animals. The possible explanation could be that the $\mathrm{PGE}_{2}$ release was not sufficient to induce a vasomotor effect and/or the $\mathrm{PGE}_{2}$-induced contraction in arteries from control rats was diminished as a consequence of different expression of EP receptor subtypes. By itself, this finding is of physiological relevance, since $\mathrm{PGE}_{2}$ release and the vasoconstrictor effect are both increased in orchidectomized animals. In summary, in rat aorta orchidectomy enhances COX-2 expression, and induces an imbalance in the production and function of vasodilator and vasoconstrictor prostanoids, in such a way that the vasoconstrictor prostanoids predominate in the latter group. Additionally, we have previously reported a decreased NO bioavailability in aorta from orchidectomized rats (Blanco-Rivero et al., 2006) that would also counteract the vasodilator response to ACh. However, despite these findings, the vasodilator response to ACh is increased in aorta from orchidectomized rats, probably as a consequence of compensatory mechanisms, such as the activation of $\mathrm{K}_{\mathrm{Ca}}$ channels by superoxide anion, the formation of which is increased in orchidectomized rats (Ferrer et al., 1999) (Fig. 6).

\section{Androgens and NO release, oxidative stress and protein kinase $\mathrm{C}$ interactions}

The results described above point to that orchidectomy increases the oxidative stress through superoxide anion formation, but in contrast to that expected, without modifying the NO release. What is the mechanism underlying this effect?.

In several types of vascular diseases, protein kinase $C$ (PKC) activation is involved in the induction of oxidative stress through the increased expression and activity of NADPH oxidase and the eNOS uncoupling (Hadi \& Swaidi, 2007; Vanhoutte, 2001). But increased 
of PKC activity by different reactive oxygen species has been also reported (Balafanova et al., 2002; Bapat et al., 2001; Oeckler \& Wolin, 2000). PKC is a ubiquitous enzyme that was originally described as calcium-activated, phospholipid-dependent protein kinase. Molecular cloning and biochemical analysis have revealed a family of PKC subspecies with closely related structures (Newton, 1995; Nishizuka, 1992). The activity of these proteins is critical for signal transduction of a wide range of biological responses (Chen, 2003; Nishizuka, 1984). The pathways through PKC exerts its vascular effects include actions on ion channels, cytoskeleton and cell adhesion proteins, transcription factors, other kinases and other proteins (Spitaler \& Cantrell, 2004; Ward et al., 2004). The participation of PKC in vascular smooth muscle contraction is well established (Khalil \& van Breemen, 1988; Salamanca \& Khalil, 2005); in addition, different investigations have also reveal that PKC can phosphorylate nNOS in the central nervous system leading to an increase (Nakane et al., 1991; Okada, 1995) or a decrease (Bredt et al., 1992; Dawson et al., 1993) in neuronal NO production.

On the other hand, influence of gender on PKC activity and expression had been studied (Kanashiro \& Khalil, 2001). In that work, the authors observed a gender-specific reduction in vascular smooth muscle reactivity in female rats with intact gonadal function compared with males, that was associated with a reduction in the expression and activity of different $\alpha-, \delta$-, and $\zeta$-PKC isoforms; they also proposed that gender-specific differences in vascular reactivity and PKC activity were possible related to endogenous estrogen. However, little information is available on the specific effect of endogenous male sex hormones on PKC activity in vascular tissues.

As described in the section corresponding to neuronal NO release, we observed that the neuronal NO release was not modified by orchidectomy although the nNOS expression was diminished, which indicated that $\mathrm{nNOS}$ activity could be increased; regarding regulation of nNOS by male sex hormones both increase (Simoncini et al., 2003; Weiner et al., 1994) or decrease (Reynoso et al., 2002; Singh et al., 2000) have been reported. Since in our experimental model, orchidectomy induced an increased oxidative stress, we analyzed the possible differences in PKC activity as well as its involvement in neuronal NO release.

We observed that orchidectomy increased PKC activity in rat mesenteric arteries (BlancoRivero et al., 2005), in contrast to the results obtained in aorta from Wistar-Kyoto rats (Kanashiro \& Khalil, 2001); this discrepancy could be due to differences in the artery analyzed, since it has been described different enzyme properties and function in the same blood vessels from different species and in different vessels from the same species (Liou \& Morgan, 1994; Kanashiro \& Khalil, 1988;Khalil etal., 1992). However, the fact that PKC was increased by orchidectomy is not totally surprising, since orchidectomy increased the formation of superoxide anion and peroxynitrite that has been described to act in cell signalling pathways, for instance, increased PKC activity (Balafanova et al., 2002; Bapat et al., 2001; Oeckler \& Wolin, 2000).

The regulatory effect of PKC on nNOS activity in arteries from the orchidectomized and the control animals was analyzed by using DAF-2 as fluorescence probe to measure the modification in basal and EFS-induced NO release. The results showed that the PKC activator PDBu (Abdel-Latif, 1986; Nishizuka, 1984) induced a greater increase in EFSinduced NO release in arteries from control than from orchidectomized animals, while the PKC inhibitor, calphostin C (Kobayashi et al., 1989), induced a stronger decrease in arteries from the control than the orchidectomized animals (Fig. 7). 


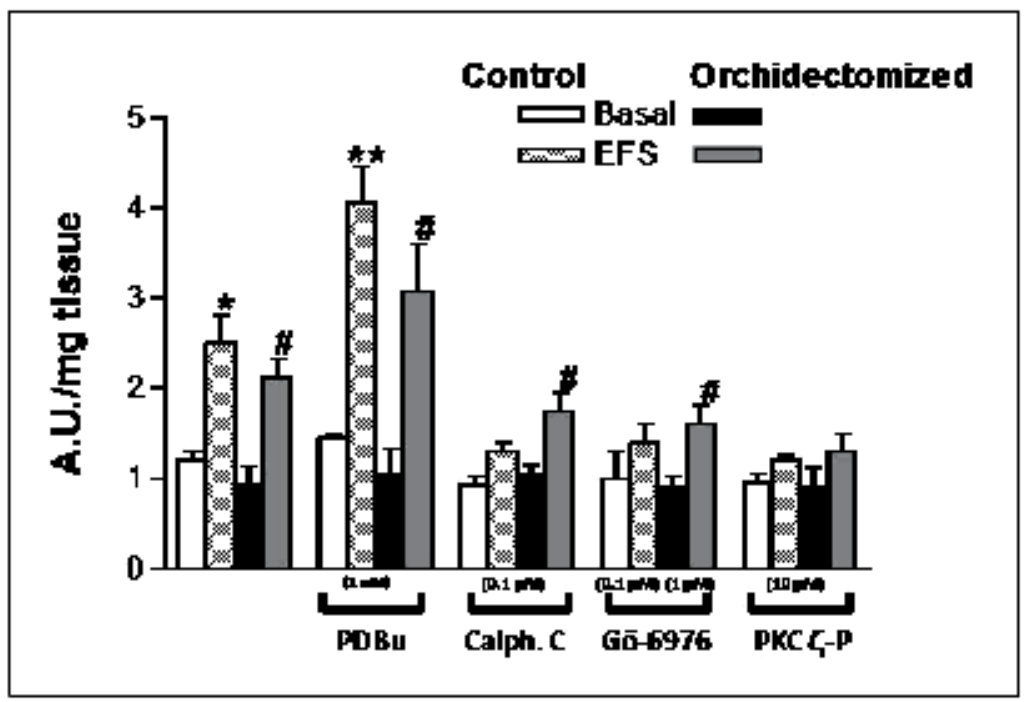

Fig. 7. Effect of PDBu, calphostin, Gö-6976 or PKC $\zeta-P I$ on the basal-and EFS-induced NO release in mesenteric arteries from control and orchidectomized rats. Results are expressed as arbitrary units (AU). Number of animals $=4-7 .{ }^{*} p<0.05,{ }^{* *} p<0.01$ vs the respective basal NO release from control rats; $\# p<0.05$ vs the respective basal NO release from orchidectomized rats (from Blanco-Rivero et al., 2005).

These results indicate that PKC is involved in nNOS activation in arteries from both control and orchidectomized rats. Because the degree of PKC activation is already greater in arteries from orchidectomized rats, PDBu and calphostin $\mathrm{C}$ showed less ability to respectively increase or diminish NO release in arteries from orchidectomized than from control rats. Conventional and novel PKC isoforms are dependent on dyacylglycerol (DAG) (Ward et al., 2004) and, since we use the pharmacological mimetic of DAG, PDBu, we stimulate both isoforms. Although selective inhibitors for these isoforms do not exist (Davies et al., 2000) it has been reported that certain compounds, such as the indolocarbazole Gö6976, are partially selective for conventional over the novel and atypical isoforms (Martiny-Baron et al., 1993; Ward et al., 2004). Consequently, we tested the effect of this inhibitor on nNOS activity, and observed that a concentration of $0.1 \mu \mathrm{M}$ Gö6976 inhibited the EFS-induced neuronal NO release in arteries from control arteries while it did not affect the neuronal NO release in arteries from orchidectomized rats. A higher Gö6976 concentration $(1 \mu \mathrm{M})$ was used but it only decreased the EFS-induced NO release in arteries from orchidectomized rats. All these results support the assumption that nNOS seems to be much more activated by PKC, and probably the conventional PKC isoforms, in arteries from the orchidectomized than from the control rats.

Since the atypical PKC $\zeta$ isoform has been described in vascular smooth muscle as modulating vascular responses to different agents (Cogolludo et al., 2003; De Witt et al., 2001), the effect of this isoform on nNOS activity was analyzed. We found that PKC decreased EFS-induced NO release to a similar extent in arteries from control and orchidectomized animals. This result indicates that PKC $\zeta$ isoform involvement in the regulation of neuronal NO release occurs and that this involvement is not modulated by endogenous male sex hormones. 
Regarding endothelial NO release, it has been previously described that orchidectomy did not modify the Ach-stimulated endothelial NO release, despite the increased production of superoxide anion. Based on the results obtained about PKC regulation of nNOS activity, the action of PKC activation or inhibition on eNOS activity was also investigated in arteries from orchidectomized and control animals. The results obtained showed that neither the PKC activator, PDBu (Nishizuka, 1984), nor the PKC inhibitor, calphostin C (Kobayashi et al. 1989), modified ACh-induced NO release in arteries from control animals. In contrast, in arteries from orchidectomized rats, PKC activation increased the basal and the AChinduced NO release while PKC inhibition more strongly decreased both basal and AChinduced NO release (Fig. 8).

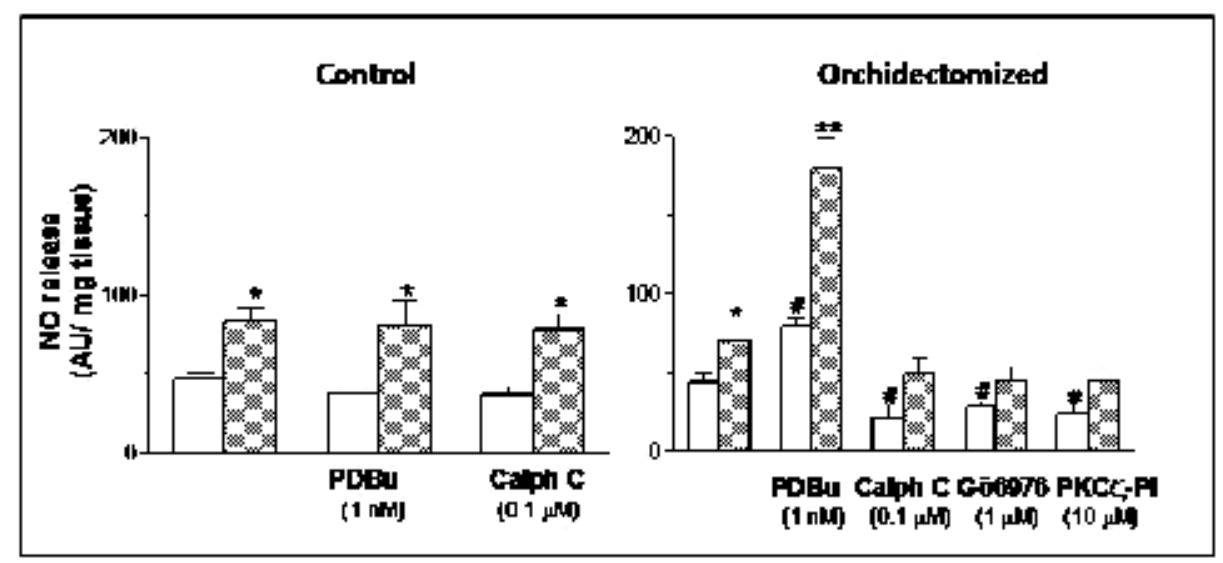

Fig. 8. Effect of PDBu, calphostin, Gö-6976 or PKC Ach - (dashed columns) induced NO release in mesenteric arteries from control and orchidectomized rats. Results are expressed as arbitrary units (AU). Number of animals $=8$. ${ }^{*} p<0.05$ vs the respective basal NO release; $\# p<0.05$ vs basal NO release in non treated arteries (from Blanco-Rivero et al., 2007).

These results indicate that PKC participates in eNOS activity only in arteries from orchidectomized rats, and also seem to indicate that PKC apparently did not regulate eNOS activity in arteries from control animals, which contrast with the results reported with nNOS (Blanco-Rivero et al., 2005) in which we observed an nNOS activity modulation by PKC. In this respect, it is possible to speculate that very subtle differences could exist in the modulation of NOS isoforms. In this regard, it is important to keep in mind that regulatory mechanisms other than PKC could be working on eNOS, including different redox conditions (Polytarchou \& Papadimitriou, 2005), phosphatases activity (Fleming et al., 2001) and/or other kinases (Ferrer et al., 2004) that, in their turn, regulate the intracellular environment and function. Additionally, since the pharmacological mimic of dyacylglycerol, $\mathrm{PDBu}$, stimulate conventional and novel PKC isoforms (Ward et al., 2004) and since calphostin C is a non specific PKC inhibitor, we tested the effect of the PKC inhibitor Gö6976, which is partially selective for conventional over novel and atypical PKC isoforms (Martiny-Baron et al., 1993, Ward et al., 2004). We observed that this inhibitor also decreased basal and ACh-induced $\mathrm{NO}$ in arteries from orchidectomized rats, indicating the involvement of the conventional PKC isoforms in endothelial NO regulation. Since the 
atypical PKC $\zeta$ isoform has been reported to modulate vascular responses (Damron et al., 1998, De Witt et al., 2001, Cogolludo et al., 2003) and neuronal NO release (Blanco-Rivero et al., 2005), we also tested the possible involvement of this isoform in endothelial NO release. The fact that PKC $\zeta$-PI decreased the basal and ACh-induced NO release showed the participation of this isoform. Moreover, since the three PKC inhibitors that we used, calphostin C, Gö6976 and PKC $\zeta$-PI, diminished both basal and ACh-induced NO release, it seems that eNOS, like nNOS (Blanco-Rivero et al., 2005), would have already been activated by PKC in arteries from orchidectomized rats.

These results show that PKC activity is enhanced in mesenteric arteries from orchidectomized rats, and this increase would be responsible for the higher nNOS and eNOS activity.

\section{Conclusions}

Orchidectomy alters different cell signalling pathways that are involved in vascular tone regulation. Orchidectomy increases: (i) the formation of superoxide anion and peroxynitrite; (ii) the activity of PKC; and (iii) the expression of COX-2, the production of prostanoids derived from COX-2, as well as their vasoconstrictor effect. These aspects seem to be physiologically relevant, since the balance between vasodilator/vasoconstrictor prostanoids is lost in favour of vasoconstrictor substances in arteries from orchidectomized rats. This situation could indicate a disadvantage in cardiovascular function in the absence of male sex hormones, thereby suggesting that testosterone has a beneficial influence on the vasculature. However, in the animals used in our study (6 months old) several compensatory mechanisms are working: reactive oxygen species are able to induce relaxation; PKC positively regulates nNOS and eNOS activity ensuring the maintenance of NO release; the activity and expression of SOD are increased in an attempt to compensate for the increased superoxide anion production. This intriguing information makes it essential to perform studies in vascular function taking into account different cell signalling pathways that are working simultaneously. Future studies in the research field of androgens on cell signaling pathways are needed, since they will be of important interest to implement therapeutic strategies that could improve vascular function.

\section{Acknowledgements}

This work was supported by grant from Fondo de Investigaciones Sanitarias (PI08831).

\section{References}

Abdel-Latif A.A. (1986). Calcium mobilizing receptors, polyphosphoinositides, and the generation of second messengers. Pharmacol Rev 38: 227-272.

Agostini M.C., Borda E.S., Gimeno M.F. et al. (1981). Differences in the effects of acetylcholine on the vas deferens from normal and castrated rats. A participation of adrenergic mechanisms. Arch Int Pharmacodyn Ther 250: 212-220.

Axelband F., Dias J., Ferrão F.M. et al. (2011). M. Nongenomic signaling pathways triggered by thyroid hormones and their metabolite 3-iodothyronamine on the cardiovascular system. J Cell Physiol 226:21-28. 
Ba Z.F., Wang P., Koo D.J. et al. (2001). Attenuation of vascular endothelial dysfunction by testosterone receptor blockade after trauma and hemorrhagic shock. Archives of Surgery 136: 1158-63.

Balafanova Z., Bolli R., Zhang J. et al. (2002). Nitric oxide (NO) induces nitration of protein kinase Cepsilon (PKCepsilon), facilitating PKCepsilon translocation via enhanced PKCepsilon -RACK2 interactions: a novel mechanism of no-triggered activation of PKCepsilon. J Biol Chem 277: 15021-7.

Bain J. (2020). Testosterone and the aging male: to treat or not to treat? Maturitas 66: 16-22.

Baker P.J., Ramey E.R. \& Ramwell P.W. (1978). Androgen-mediated sex differences of cardiovascular responses in rats. Am J Physiol 235: H242-246.

Bapat S., Verkleij A. \& Post J.A. (2001). Peroxynitrite activates mitogen-activated protein kinase (MAPK) via MEK-independent pathway: a role for protein kinase C. FEBS Lett 499: 21-6.

Barud W. Palusinski R., Beltkowski J. et al. (2002). Inverse relationship between total testosterone and anti-oxidized low-density lipoprotein antibody levels in ageing males. Atherosclerosis 164:282-288.

Basaria S. \& Dobs A.S. (2001) Hypogonadism and androgen replacement therapy in elderly men. Am J Med 110: 563-572.

Bachschmid M., Schildknecht S. \& Ullrich V. (2005). Redox regulation of vascular prostanoid synthesis by the nitric oxide-superoxide system. Biochem Biophys Res Commun 338:536-542.

Békési G., Kakucs R., Várvíró S. et al. (2000). In vitro effects of different steroid hormones on superoxide anion production of human neutrophil granulocytes. Steroids 65: 889894.

Blanco-Rivero J., Balfagón G. \& Ferrer M. (2005). Male castration increases neuronal nitric oxide synthase activity in the rat mesenteric artery through protein kinase $\mathrm{C}$ activation. Journal of Vascular Research 42: 526-534.

Blanco-Rivero J., Balfagón G. \& Ferrer M. (2005). Orchidectomy modulates $\alpha 2$-adrenoceptor reactivity in rat mesenteric artery through increased thromboxane $A_{2}$ formation. Journal of Vascular Research 43: 101-108.

Blanco-Rivero J., Cachofeiro V., Lahera V. et al. (2005). Participation of prostacyclin in endothelial dysfunction induced by aldosterone in normotensive and hypertensive rats. Hipertension 46:107-12.

Blanco-Rivero J., Sagredo A., Balfagón G. \& Ferrer M. (2006). Orchidectomy increases expression and activity of $\mathrm{Cu} / \mathrm{Zn}$-superoxide dismutase, while decreases endothelial nitric oxide bioavailability. J Endocrinol 190: 771-778.

Blanco-Rivero J., Sagredo A., Balfagón G. \& Ferrer M. (2007). Protein kinase C activation increases endothelial nitric oxide release in mesenteric arteries from orchidectomized rats. J Endocrinol 192: 189-197.

Blanco-Rivero J., Márquez-Rodas I., Xavier F. et al. (2007). Long-term fenofibrate treatment impairs endothelium-dependent dilation to acetylcholine by altering cyclooxygenase pathway. Cardiovas Res 75:398-340.

Bolotina V.M., Najibi S., Palacino J.J. et al. (1994). Nitric oxide directly activates calciumdependent potassium channels in vascular smooth muscle. Nature 368: 850-853. 
Braga-Basaria M., Dobs A.S., Muller D.C. et al. (2006). Metabolic syndrome in men with prostate cancer undergoing long-term androgen-deprivation therapy. J Clin Oncol 24: 3979-3983.

Bredt D.S., Ferris C.D. \& Snyder S.H. (1992). Nitric oxide synthase regulatory sites. Phosphorylation by cyclic AMP-dependent protein kinase, protein kinase $\mathrm{C}$ and calcium/calmodulin protein kinase; identification of flavin and calmodulin binding sites. J Biol Chem 267: 10976-10981.

Calderone V., Baragatti B., Breschi M.C. et al. (2002). Hormonal influence on the release of endothelial nitric oxide: gender related dimorphic sensitivity of rat aorta for noradrenaline. J Pharm Pharmacol 54: 523-528.

Caughey G.E., Cleland L.G., Gamble J.R. \& James M.J. (2001) Up-regulation of endothelial cyclooxygenase- 2 and prostanoid synthesis by platelets. Role of thromboxane A2. J Biol Chem 276: 37839-37845.

Ceballos G., Figueroa L., Rubio I. et al. (1999). Acute and nongenomic effect of testosterone on isolate and perfused rat heart. J Cardiovasc Pharmacol 33: 691-697.

Chatrath R., Ronningen K.L., Severson S.R. et al. (2003). Endothelium-dependent responses in coronary arteries are changed with puberty in male pigs. Am J Physiol 285: H1168-1176.

Chen D.C., Duckles S.P. \& Krause D.N. (1999). Postjunctional a2-adrenoceptors in the rat tail artery: effect of sex and castration. Eur J Pharmacol 372: 247-252.

Chen G.X. (2003). Selective protein kinase C inhibitors and their applications. Curr Drug Targets Cardiovasc Haematol Disord 3: 301-307.

Cheng Y., Austin S.C., Rocca B. et al. (2002). Role of prostacyclin in the cardiovascular response to thromboxane A2. Science 296 539-541.

Chodak G.W., Keane T. \& Klotz L. (2002) Critical evaluation of hormonal therapy for carcinoma of the prostate. Urology 60: 201-208.

Cogolludo A., Moreno L., Bosca L. et al. (2003). Thromboxane $\alpha_{2}$-induced inhibition of voltage-gated $\mathrm{K}+$ channels and pulmonary vasoconstriction: role of protein kinase Czeta. Circ Res 93: 656-63.

Damron D.S., Nadim H.S., Hong S.J. et al. (1998). Intracellular translocation of PKC isoforms in canine pulmonary artery smooth muscle cells by ANG II. Am J Physiol 274: L278288.

Davies S.P., Reddy H., Caivano M. \& Cohen P. (2000). Specificity and mechanism of action of some commonly used protein kinase inhibitors. Biochem J 351:95-105.

Dawson T.M., Steiner J.P., Dawson V.L. et al. (1993). Inmunosuppressant FK506 enhances phosphorylation of nitric oxide synthase and protects against glutamate neurotoxicity. Proc Natl Acad Sci 90: 9808-9812.

De Witt B.J., Kaye A., Ibrahim I.N. et al. (2001). Effects of PKC isozyme inhibitors on constrictor responses in the feline pulmonary vascular bed. Am J Physiol 280: L5057.

Duckles S.P. \& Miller V.M. (2010). Hormonal modulation of endothelial NO production. Eur J Physiol 459: 841-851.

Félétou M., Köhler R. \& Vanhoutte P.M. (2010). Endothelium-derived vasoactive factors and hypertension: possible roles in pathogenesis and as treatment targets. Curr Hypertens Rep 12: 267-275. 
Félétou M. \& Vanhoutte P.M. (2006). Endothelial dysfunction: a multifaceted disorder. Am J Physiol Heart Circ Physiol 291: 985-1002.

Ferrer M., Alonso M.J., Salaices M. et al. (2000). Increase in neurogenic nitric oxide metabolism by endothelin-1 in mesenteric arteries from hypertensive rats. $J$ Cardiovasc Pharmacol 36: 541-547.

Ferrer M., Alonso M.J., Salaices M. et al. (2001). Angiotensin II increases neurogenic nitric oxide metabolism in mesenteric arteries from hypertensive rats. Life Sci 68: 11691179.

Ferrer M., Encabo A., Conde M.V. et al. (1995). Heterogeneity of endothelium-dependent mechanisms in different rabbit arteries. J Vasc Res 32: 339-46.

Ferrer M., Marín J. \& Balfagón G. (2000). Diabetes alters neuronal nitric oxide release from rat mesenteric arteries. Role of protein kinase C. Life Sci. 66:337-345.

Ferrer M., Tejera N., Marín J. et al. (1999). Androgen deprivation facilitates acetylcholineinduced relaxation by superoxide anion generation. Clin Sci 140: 1861-1868.

Ferrer M., Salaices M. \& Balfagón G. (2004). Endogenous prostacyclin increases neuronal nitric oxide release in mesenteric artery from spontaneously hypertensive rats. Eur J Pharmacol 506: 151-156.

FitzGerald G.A. (1991). Mechanisms of platelet activation: thromboxane A2 as an amplifying signal for other agonists. Am J Cardiol 68: 11-15.

FitzGerald G.A., Healy C. \& Daugherty J. (1987). Thromboxane A2 biosynthesis in human disease. Fed Proc 46:154-8.

Fleming I., Fisslthaler B., Dimmeler S. et al. (2001). Phosphorylation of $\operatorname{Thr}(495)$ regulates $\mathrm{Ca}(2+) /$ calmodulin-dependent endothelial nitric oxide synthase activity. Circ Res 88: E68-75.

Förstermann U., Pollock J.S., Schmint H.H.H.W. et al. (1991). Calmodulin-dependent endothelium-derivaded relaxing factor/nitric oxide synthase activity is present in the particulate and cytosolic fractions of bovine aortic endothelium cells. Proc Nat Acad Sci 88: 1788-1792.

Frein D., Schildknecht S., Bachschmid M. et al. (2005). Redox regulation: a new challenge for pharmacology. Biochem Pharmacol 70:811-823.

Furchgott R.F. \& Zawadzki J.V. (1980). The obligatory role of endothelial cells in the relaxation of arterial smooth muscle by acetylcholine. Nature 288: 373-376.

Gluais P., Lonchampt M., Morrow J.D. et al. (2005). Acetylcholine-induced endotheliumdependent contractions in the SHR aorta: the Janus face of prostacyclin. $\mathrm{Br} \mathrm{J}$ Pharmacol 146: 834-45.

Gonzales R.J., Ghaffari A.A., Duckles S.P. et al. (2005). Testosterone treatment increases thromboxane function in rat cerebral arteries. Am J Physiol Heart Circ Physiol 289: $578-85$.

Gonzales R.J., Krause D.N. \& Duckles S.P. (2004). Testosterone suppresses endotheliumdependent dilation of rat middle cerebral arteries. Am J Physiol 286: H552-H560.

Greenberg S., George W.R., Kadowitz P.J. et al. (1974). Androgen-induced enhancement of vascular reactivity. Can J Physiol Pharmacol 52: 14-22.

Gryglewski R.J., Palmer R.M.J. \& Moncada S. (1986). Superoxide anion is involved in the breakdown of endothelium-derived vascular relaxing factor. Nature 320: 454-456.

Guan X.B. \& Dluzen D. (1991). Castration reduces potassium-stimulated norepinephrine release from superfused olfactory bulbs of male rats. Brain Res 568: 147-151. 
Harrison D.G. (1994). Endothelial dysfunction in atherosclerosis. Basic Res Cardiol 89: 87-102. Henrion D., Dechaux E., Dowell F.J. et al. (1994). Alteration of flow-induced dilatation in mesenteric resistance arteries of L-NAME treated rats and its partial association with induction of cyclo-oxygenase-2. Br J Pharmacol 121:83-90

Holmquist F., Persson K., Bodker A. et al. (1994). Some pre- and postjunctional effects of castration in rabbit isolated corpus cavernosum and urethra. J Urol 152: 1011-1016.

Hutchison S.J., Sudhir K., Chou T.M. et al. (1997). Testosterone worsens endothelial dysfunction associated with hypercholesterolemia and environmental tobacco smoke exposure in male rabbit aorta. J Am Coll Cardiol 29: 800-807.

Ishikawa M. \& Quock R.M. (2003). Role of nitric-oxide synthase isoforms in nitrous oxide antinociception in mice. J Pharmacol Exp Ther 306: 484-489.

Jones R.D., Jones H.T. \& Channer K.S. (2004). The influence of testosterone upon vascular reactivity. Eur J Endocrinol 151: 29-37.

Jones T.H. (2010). Testosterone deficiency: a risk factor for cardiovascular disease? Trends Endocrinol Metab 21: 496-503.

Jones T.H. \& Saad F. (2009). The effects of testorene on risk factors for, and the mediators of, the atherosclerotic process. Atherosclerosis 207: 318-327.

Kapoor D., Malkin C.J. Channer K.S. et al. (2005). Androgens, insulin resistance and vascular disease in men. Clin Endocrinol 63: 239-250.

Kanashiro C.A. \& Khalil R.A. (2001). Gender-related distinctions in protein kinase C activity in rat vascular smooth muscle. Am J Physiol 280: C34-C45.

Kawasaki H., Takasaki K., Saito A. et al. (1988). Calcitonin gene-related peptide acts as a novel vasodilator neurotransmitter in mesenteric resistance vessels of the rat. Nature 335: 164-167.

Keating N.L., O'Malley A.J. \& Smith M.R. (2006). Diabetes and cardiovascular disease during androgen deprivation therapy for prostate cancer. J Clin Oncol 24: 4448-4456.

Khalil R.A. \& van Breemen C. (1988). Sustained contraction of vascular smooth muscle: calcium influx or C-kinase activation?. J Pharmacol Exp Ther 244: 537-542.

Kim E.J., Raval A.P. \& Perez-Pinzon M.A. (2008). Preconditioning mediated by sublethal oxygen-glucose deprivation-induced cyclooxygenase-2 expression via the signal transducers and activators of transcription 3 phosphorylation. J Cereb Blood Flow Metab 28: 1329-1340.

Klein T., Eltze M., Grebe T. et al. (2007). Celecoxib dilates guinea-pig coronaries and aortic rings and amplifies NO/cGMP signaling by PDE5 inhibition. Cardiovasc Res 75: 390397.

Kobayashi E., Nakano H., Morimoto \& Tamaoki T. (1989). Calphostin C (UCN-1028C), a novel microbial compound is a highly potent and specific inhibitor of protein kinase C. Biochem Biophys Res Commun 159: 548-553.

Kobayashi S., Inoue N., Azumi H. et al. (2002). Expressional change of the vascular antioxidant system in atherosclerotic coronary arteries. Arterioscler Thromb Vasc Biol 9: 184-190.

Li Y.J. Duckles\& S.P. (1992). Effect of endothelium on the actions of sympathetic and sensory nerves in the perfused rat mesentery. Eur J Pharmacol 210: 23-40.

Lincoln T.M., Dey N. \& Sellak H. (2001). cGMP-dependent protein kinase signaling mechanisms in smooth muscle: from the regulation of tone to gene expression. $J$ Appl Physiol 91: 1421-1430. 
Liu D. \& Dillon J.S. (2002). Dehydroepiandrosterone activates endothelial cell nitric-oxide synthase by a specific plasma membrane receptor coupled to G alpha (i2,3), J Biol Chem $277: 21379-21388$.

Martín M.C., Balfagón G., Minoves N. \& Ferrer M. (2005). Androgen deprivation increases neuronal nitric oxide metabolism and its vasodilator effect in rat mesenteric arteries. Nitric Oxide: Biology and Chemistry 12: 163-176.

Martiny-Baron G., Kazanietz M.G., Mischak H. et al. (1993). Selective inhibition of protein kinase C isozymes by the indolocarbazole Gö6976. J Biol Chem 268:9194-7.

McNeill A.M., Kim N., Duckles S.P. et al. (1999). Chronic estrogen treatment increases levels of endothelial nitric oxide synthase protein in rat cerebral microvessels. Stroke 30: 2186-2190.

Minoves N., Balfagón G. \& Ferrer M. (2002). Role of female sex hormones in neuronal nitric oxide release and metabolism in rat mesenteric arteries. Clin Sci 103: 239-247.

Mukherjee S., Coaxum S.D., Maleque M. et al. (2001). Effects of oxidized low density lipoprotein on nitric oxide synthetase and protein kinase $\mathrm{C}$ activities in bovine endothelial cells. Cell Mol Biol 47: 1051-1058.

Munzel T., Heitzer T. \& Harrison D.G. (1997). The physiology and pathophysiology of the nitric oxide/superoxide system. Herz 22:158-172.

Murad F. (1997). What are the molecular mechanisms for the antiproliferative effects of nitric oxide and cGMP in vascular smooth muscle? Circulation 95: 1101-1103.

Muzykantov V.R. (2001). Targeting of superoxide dismutase and catalase to vascular endothelium. J Controlled Release 71: 1-21.

Miyamoto A., Hashiguchi. Y, Obi T. et al. (2007). Ibuprofen or ozagrel increases NO release and 1-nitro arginine induces TXA(2) release from cultured porcine basilar arterial endothelial cells. Vasc Pharmacol 46. 85-90.

Nakane M., Mitchell J., Forstermann U. \& Murad F. (1991). Phosphorylation by calcium calmodulin-dependent protein kinase II and protein kinase C modulates the activity of nitric oxide synthase. Biochem Biophys Res Commun 180: 1396-1402.

Namgaladze D., Shcherbyna I., Kienhofer J. et al. (2005). Superoxide targets calcineurin signaling in vascular endothelium. Biochem BiophysRes Commun 334: 1061-1067.

Narumiya S., Sugimoto Y. \& Ushikubi F. (1999). Prostanoid receptors: structures, properties, and functions. Physiol Rev 79:1193-226.

Newton AC. (1995). Protein kinase C: structure, function and regulation. J Biol Chem 270: 28495-28498.

Nielsen K.C. \& Owman C. (1971). Contractile response and amine receptor mechanism in isolated middle cerebral artery of the cat. Brain Res 27: 25-32.

Nishihara M., Yokotani K., Inoue S. \& Osumi Y. (2000). U-46619, a selective thromboxane A2 mimetic, inhibits the release of endogenous noradrenaline from the rat hippocampus in vitro. Jpn J Pharmacol 82: 226-231.

Nishizuka Y. (1992). Intracellular signaling by hydrolysis of phospholipids and activation of PKC. Science 258: 607-614.

Nishizuka Y. (1984). The role of protein kinase C in cell surface signal transduction and tumour promotion. Nature 308: 693-698.

Nguyen Dinh Cat A \& Touyz RM. (2011) Cell Signaling of Angiotensin II on Vascular Tone: Novel Mechanisms. Curr Hypertens Rep 13:122-128. 
Noll G. \& Luscher T.F. (1998). The endothelium in acute coronary syndromes. Eur Heart J 19: C30-C38.

Oeckler R.A. \& Wolin M.S. (2000). New concepts in vascular nitric oxide signalling. Curr Atheroscler 2: 437-444.

Okada D. (1992). Two pathways of cyclic GMP production through glutamate receptormediated nitric oxide synthesis. J Neurochem 59: 1203-1210.

Okada D. (1995). Protein kinase C modulates calcium sensitivity of nitric oxide synthase in cerebellar slices. J Neurochem 64: 1298-1304.

Onoue S., Endo K., Yajima T. et al. (2002). Pituitary adenylate cyclase activating polypeptide regulates the basal production of nitric oxide in PC12 cells. Life Sci 71: 205-214.

Orshal J.M. \& Khalil R.A. (2004). Gender, sex hormones and vascular tone. Am J Physiol 286: R233-R249.

Oury T.D., Day B.J. \& Crapo J.D. (1996). Extracellular superoxide dismutase: a regulator of nitric oxide bioavailability. Laboratory Investigation 75: 617-36.

Polytarchou C. \& Papadimitriou E. (2005). Antioxidans inhibit human endothelial cell functions through down-regulation of endothelial nitric oxide synthase activity. Eur J Pharmacol 510: 1-38.

Price D.T., Vita J.A. \& Keaney J.F.Jr. (2000). Redox control of vascular nitric oxide bioavailability. Antioxidants \& Redox Signaling 2: 919-935.

Rapoport R.M. \& Williams S.P. (1996). Role of prostaglandins in acetylcholine-induced contraction of aorta from spontaneously hypertensive and Wistar-Kyoto rats. Hypertension 28: 64-75.

Reynoso R., Mohn C., Retory V. et al. (2002). Changes in the effect of testosterone on hypothalamic nitric oxide synthetase during sexual maturation. Its relationship with GnRH release. Neuroendocrinol Lett 23: 101-4.

Rubanyi G.M. \& Vanhoutte P.M. (1986). Oxygen-derived free radicals, endothelium, and responsiveness of vascular smooth muscle. Am J Physiol 120: H815-H821.

Rump L.C. \& Schollmeyer P. (1989). Effects of endogenous and synthetic prostanoids, the thromboxane A2 receptor agonist U-46619 and arachidonic acid on [3H]noradrenaline release and vascular tone in rat isolated kidney. $\mathrm{Br} J$ Pharmacol 97: 819-828.

Saad F., Gooren L.J., Haider A. et al. (2008). A dose-response study of testosterone on sexual dysfunction and features of the metabolic syndrome using testosterone gel and parenteral testosterone undecanoate. J Androl 29: 102-105.

Scordalakes E.M., Imwalle D.B. \& Rissman E.F. (2002). Oestrogen's masculine side: medition of mating in male mice. Reproduction 124: 331-338.

Shang Y. \& Dluzen D.E. (2002). Castration increases nisoxetine-evoked norepinephrine levels in vivo within the olfactory bulb of male rats. Neurosci Lett 328: 81-84.

Shanmugam N., Gaw-Gonzalo I.T. \& Natarajam R. (2004). Molecular mechanisms of high glucose-induced cyclooxygenase-2 expression in monocytes. Diabetes 53: 795-802.

Siddiqui A. \& Shah B.H. (1997). Neonatal androgen manipulation differentially affects the development of monoamine systems in rat cerebral cortex, amygdale and hypothalamus. Dev Brain Res 98: 247-252.

Simon D., Charles M.A., Nahoul K. et al., (1997). Association between plasma testosterone and cardiovascular risk factors in healthy adult men: the telecom study. J Clin Endocrinol Metab 82: 682-689. 
Simoncini T., Mannella P., Fornari L. et al. (2003). Dehydroepiandrosterone modulates endotelial nitric oxide synthesis via direct genomic and nongenomic mechanisms. Endocrinology 144: 3449-55.

Singh .R, Pervin S., Shryne J. et al. (2000). Castration increases and androgens decrease nitric oxide synthase activity in the brain: physiologic implications. Proc Natl Acad Sci 97: 3672-7.

Smith M.R., Finkelstein J.S., McGovern F.J. et al. (2002). Changes in body composition during androgen deprivation therapy for prostate cancer. J Clin Endocrinol Metab 87: 599603.

Spitaler M. \& Cantrell D.A. (2004). Protein kinase C and beyond. Nature Immunol 5:785-790.

Strehlow K., Rotter S., Wassmann S. et al. (2003). Modulation of antioxidant enzyme expression and function by estrogen. Circ Res 93: 170-177.

Sun C., Chen M., Mao J. et al. (2001). Biphasic effects of orchidectomy on calcitonin generelated peptide synthesis and release. Neuroreport 12: 3497-3502.

Szmydynger-Chodobska J., Zink B.J. \& Chodobski A. (2011) Multiple sites of vasopressin synthesis in the injured brain. J Cereb Blood Flow Metab 31:47-51.

Tanaka M., Umemoto S., Kawahara S. et al. (2005). Angiotensin II type 1 receptor antagonist and angiotensin-converting enzyme inhibitor altered the activation of $\mathrm{Cu} / \mathrm{Zn}$ containing superoxide dismutase in the heart of stroke-prone spontaneously hypertensive rats. Hypertens Res 28: 67-77.

Teoh H., Quan A. \& Man R.Y. (2000). Acute impairment of relaxation by low levels of testosterone in porcine coronary arteries. CardiovascRes 45: 1010-1018.

Tep-areenan P., Kendall D.A. \& Randal M.D. (2003). Mechanisms of vasorelaxation to testosterone in the rat aorta. Eur J Pharmacol 465: 125-132.

Tesauro M., Schinzari F., Caramanti M. et al. (2010). Cardiovascular and metabolic effects of ghrelin. Curr Diabetes Rev 6:228-35.

Toda N. \& Okamura T. (2003). The pharmacology of nitric oxide in the peripheral nervous system of blood vessels. Pharmacol Rev 55:271-324.

Tracey W.R., Nakane M., Basha F. et al. (1995). In vivo pharmacological evaluation of two novel type II (inducible) nitric oxide synthase inhibitors. Can J Physiol Pharmacol 73: 665-669.

Traish A.M. \& Kypreos K.E. (2011). Testosterone and cardiovascular disease: an old idea with modern clinical implications. Atherosclerosis 214:244-248.

Vanhoutte P.M. (1996). Endothelium-dependent responses in congestive heart failure. J Mol Cell Cardiol 28: 2233-2240.

Villablanca A.C., Jayachandran M. \& Banka C. (2010). Atherosclerosis and sex hormones: current concepts. Clin Sci 119:493-513.

Ward J.P.T., Knock G.A., Snetkov V.A. \& Aaronson P.I. (2004). Protein kinases in vascular smooth muscle tone -role in the pulmonary vasculature and hypoxic pulmonary vasoconstriction. Pharmacol Ther 104: 207-231.

Wei E.P., Kontos H.A. \& Beckman J.S. (1996). Mechanisms of cerebral vasodilation by superoxide, hydrogen peroxide, and peroxynitrite. Am J. Physiol 271: H1262-H1266.

Weiner I., Lizasoain S.A., Baylis R.G. et al. (1994). Induction of calcium-dependent nitric oxide synthases by sex hormones. Proc Natl Acad Sci 91: 5212-5216.

Wolin M.S. (2002). Interaction of oxidants with vascular signaling system. Arterioscler Thromb Vasc Biol 20: 1430-1442. 
Wynne F.L. \& Khalil R.A. (2003). Testosterone and coronary vascular tone: implications in coronary artery disease. J Endocrinol Invest 26: 181-186.

Yamada T., Fujino T., Yuhki K. et al. (2003). Thromboxane A2 regulates vascular tone via its inhibitory effect on the expression of inducible nitric oxide synthase. Circulation 108: 2381-2386.

Yorek M.A., Coppey L.J., Gellett J.S. et al. (2002). Effect of treatment of diabetic rats with dehydroepiandrosterone on vascular and neural function. Am J Physiol 283: 10671075. 


\title{
Orchidectomy Upregulates While Testosterone Treatment Downregulates the Expression of Ornithine Aminotransferase Gene in the Mouse Kidney
}

\author{
Olivier Levillain, Cyril Dégletagne, \\ Dominique Letexier and Henri Déchaud ${ }^{1}$ \\ University Claude Bernard Lyon 1, UMR 5123 CNRS \\ 1 University Claude Bernard Lyon 1, U1060 INSERM
}

France

\section{Introduction}

Ornithine aminotransferase (L-ornithine: 2-oxoacid aminotransferase, OAT, EC 2.6.1.13) plays crucial physiological roles in amino acid metabolism because this enzyme is at the crossroad of several pathways including those of L-arginine, L-ornithine, L-glutamate, Lglutamine, and L-proline. Specifically, OAT catalyzes the transamination of L-ornithine in the presence of $\alpha$-ketoglutarate to produce one molecule of L-glutamate and the unstable compound glutamate- $\gamma$-semialdehyde that is spontaneously converted into $\Delta^{1}$-pyrroline-5carboxylate. This latter molecule is further metabolized by the enzyme pyrroline-5carboxylate dehydrogenase into a second molecule of L-glutamate (Wakabayashi, 2004). The enzyme is expressed in many mammalian tissues including the liver, the kidney, and the intestine which exhibit the highest OAT activities (Peraino \& Pitot, 1963; Herzfeld \& Knox, 1968; Sanada et al., 1970; Kasahara et al., 1986; Alonso \& Rubio, 1989; Levillain et al., 2007; Ventura et al., 2009). These enzymes may not only display diverse tissue-specific physiological roles, but demonstrate marked sexual differences in expression and activity.

In rat kidneys, estrogen dramatically increased the expression of OAT and is responsible for the higher levels of OAT in female than in male rat kidney (Herzfeld \& Knox, 1968; Lyons \& Pitot, 1977; Mueckler \& Pitot, 1983; Mueckler et al., 1984; Levillain et al., 2004). The presence of thyroid hormone is required for estrogen induction. These hormones exert a synergistic effect on the expression of OAT gene (Mueckler \& Pitot, 1983). The expression of OAT gene during the rat postnatal development strongly supports the sexual dimorphism of OAT in kidney, but not in liver (Herzfeld \& Knox, 1968; Herzfeld \& Greengard, 1969). Taken together, the expression of OAT gene in the female rat kidney is naturally upregulated in the presence of estrogen.

The expression of OAT gene in the mouse kidney has been reported by different authors who independently measured OAT mRNA and protein levels or OAT activity (Alonso \& Rubio, 1989; Natesan \& Reddy, 2001; Yu et al., 2003; Levillain et al., 2005; ManteuffelCymborowska et al., 2005; Levillain et al., 2007; Ventura et al., 2009). Strong evidences 
support a marked sexual dimorphism in the expression of OAT gene in the mouse kidney with three-fold higher levels in females than in males. A detailed study of the renal expression of OAT gene during the postnatal development of male and female mice revealed that puberty is the starter responsible for this sexual dimorphism (Levillain et al., 2007). In addition, the level of OAT protein has been inversely correlated with the plasma level of testosterone (Levillain et al., 2005).

The present study was designed to explore the mechanismes involved in the sexual dimorphism of the expression of OAT gene in the mouse kidney. We shall determine by in vivo studies at which level testosterone regulates the expression of OAT gene. To answer this question, male mice were subjected to orchidectomy and testosterone replacement. The renal expression of OAT gene was analyzed at the transcriptional, translational, and posttranslational levels. The possible involvement of the eukaryotic initiation factor eIF4-E in the control of OAT gene expression was analyzed. We also explored the delay required for testosterone to induce a decrease in the expression of OAT gene in orchidectomized mice. For this, a time-course study was performed over a period of $32 \mathrm{hrs}$ following a single injection of testosterone to castrated male mice. Finally, to explain the physiological role of testosterone on the expression of OAT specifically in the mouse kidney, we searched to identify androgen response elements (ARE) in the promoter of the murine OAT gene.

\section{Material and methods}

\subsection{Animals and treatment}

Eight- to nine-week-old adult male (35-40 g body weight) OF-1 Swiss (IOPS Caw) mice, from either Charles River Laboratories (L'Arbresle-sur-Orge, France) or Janvier (Le Genestsaint-Isle, France) had free access to tap water and standard food (2018 Teklad Global 18\% Protein Rodent Diet, Harlan, Gannat, France). Animals were housed in a controlled environment maintained at $21 \pm 1^{\circ} \mathrm{C}$ with a 12-h light, 12-h dark cycle, lights on at $0600 \mathrm{~h}$.

Twenty-four thirty-day-old male mice were subdivided into four groups of six mice: nonoperated (group I, control), sham-operated (group II) and two groups of orchidectomized mice. Eleven days later (i.e. 41 days after birth), mice of groups I, II, and III were sacrified, whereas mice of group IV were sacrified seven days latter (i.e. 18 days after orchidectomy).

Twenty-four thirty-day-old male mice were subdivided into four groups of six mice: shamoperated (group V, control), 11-day orchidectomized (group VI), 11-day orchidectomized treated with sesame oil (group VII), and 11-day orchidectomized treated with testosterone + sesame oil (group VIII). Mice subjected to oil or testosterone treatment were injected subcutaneously with $150 \mu \mathrm{L}$ vehicule or testosterone propionate $(3.1 \mathrm{mg} / \mathrm{mL}$ in sesame oil, i.e. approximately $15 \mu \mathrm{g} / \mathrm{g}$ BW or $0.55 \mathrm{mg}$ per mouse). All mice were sacrified forty-eight hrs after the treatment.

Twenty thirty-day-old male mice were subjected to orchidectomy (11-day) and subdivided into five groups of four mice: 11-day orchidectomized (group IX, control) and four groups of mice treated with testosterone as described above $(0.55 \mathrm{mg}$ per mouse). Mice were sacrified $8 \mathrm{hrs}$ (group X), $24 \mathrm{hrs}$ (group XI), 28 hrs (group XII), or 32 hrs (group XIII) after the treatment (Fig. 1). For these three protocols, half of the mice were purchased from Charles River Laboratories and the other from Janvier. Mice were equally distributed in the different experimental groups. Orchidectomy was carried out by the suppliers. Mice were anesthetized (ip) using $0.1 \mathrm{~mL} / 30 \mathrm{~g}$ BW pentobarbital sodium (Nembutal 6\%, Clin Midy, Paris, France) diluted $1: 2$ in $0.9 \% \mathrm{NaCl}$ solution. 


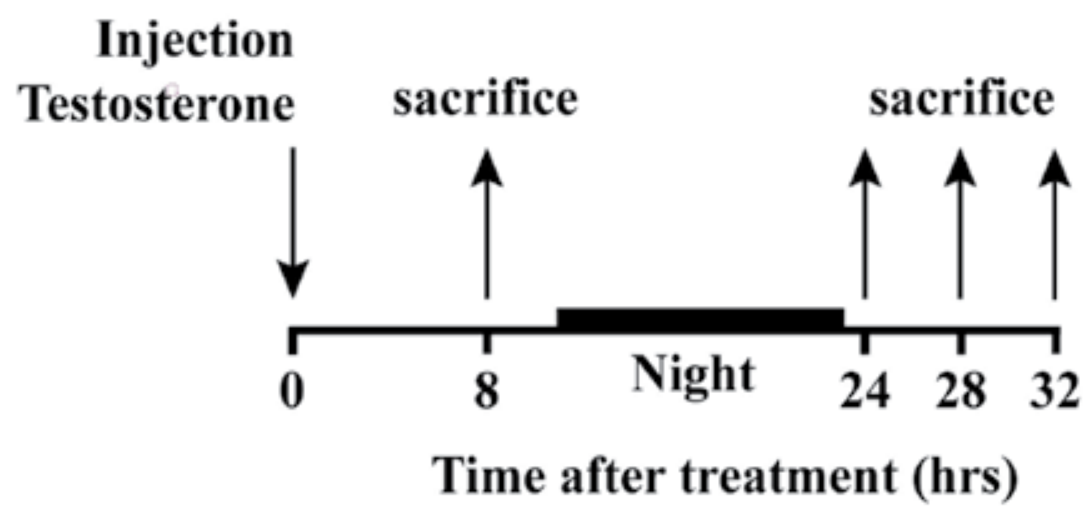

Fig. 1. Schema of the time-course study of testosterone effect on the expression of OAT gene.

Animal care complied with French regulations for the protection of animals used for experimental and other scientific purposes and with European Community regulations (Council of Europe $N^{\circ} 123$, Strasbourg, 1985). The author (O. Levillain) is authorized by the "Direction Départementale des Services Vétérinaires" (authorization no. 69-33 and 69266391) and the local Animal Care Committee to use animals for these experiments (authorization no. 299 revised and no. BH 2009-15).

\subsection{Sampling of kidneys and blood}

The renal pedicle of each kidney was clamped and the kidney was rapidly removed, decapsulated; the blood contained in each kidney was removed with blotting paper (freeblood). The kidney was placed in a sterilized Eppendorf tube, frozen, and conserved at $-80^{\circ} \mathrm{C}$.

Blood was collected in the vena cava of all mice with a 25-gauge needle (Neolus, VWR, Limonest, France) mounted on a 1-mL syringe (Terumo, VWR) prealably heparinized (Heparin, Roche, Meylan, France). Blood was immediately transferred in a cold BD Vacutainer tube, centrifuged at $4,000 \times \mathrm{g}$ for $20 \mathrm{~min}$ at $4^{\circ} \mathrm{C}$. Plasma was frozen and stored in liquid nitrogen until testosterone and corticosterone measurement.

\subsection{RNA extraction and semiquantitative RT-PCR}

The steady state levels of OAT and cyclophilin A transcripts were estimated by semiquantitative polymerase chain reaction (PCR) and quantitative PCR (qPCR) as described further in the text.

\subsubsection{RNA extraction}

Total RNA was extracted from whole kidney by using Trizol ${ }^{\circledR}$ according to the supplier's procedure. Briefly, kidneys were mixed in the proportion of $150 \mathrm{mg}$ tissue per $1 \mathrm{~mL}$ Trizol ${ }^{\circledR}$ at $4^{\circ} \mathrm{C}$ with a Ultra-Turrax T10 (VWR, Fontenay-sous-Bois, France). RNAs were extracted with chloroform, purified by isopropanol precipitation, and washed with $70 \%$ ethanol. RNA pellets were resuspended in sterilized water (Eurobio, Courtaboeuf, France) and stored 
frozen $\left(-80^{\circ} \mathrm{C}\right)$. RNA concentration was determined from the absorbance at $260 \mathrm{~nm}$ and RNA purity the absorbance ratio at 260 and $280 \mathrm{~nm}($ ratio $\approx 2)$ using a BioPhotometer (Eppendorf France S.A.R.L., Le Pecq, France). RNA integrity was checked by electrophoresis on 1\% agarose gel (Eurobio).

\subsubsection{Reverse transcription}

Total RNA $(1 \mu \mathrm{g})$ was denatured for $5 \mathrm{~min}$ at $65^{\circ} \mathrm{C}$ and mRNAs were reverse-transcripted $\left(60 \mathrm{~min}\right.$ at $37^{\circ} \mathrm{C}$ ) in $25 \mu \mathrm{L}$ final volume containing $5 \mu \mathrm{L}$ of M-MLV RT 5X buffer, $100 \mathrm{U}$ moloney murine leukemia virus reverse transcriptase (Invitrogen, France), 15 nmoles of deoxynucleotide triphosphate and $1 \mu \mathrm{g}$ oligo dT (PCR) or $100 \mathrm{ng}$ random primer (qPCR, Invitrogen). After RT, inactivation step was $15 \mathrm{~min}$ at $70^{\circ} \mathrm{C}$. RT products were frozen $\left(-30^{\circ} \mathrm{C}\right)$.

\subsubsection{Polymerase chain reaction for PCR}

The cDNA from $2.5 \mu \mathrm{L}$ of RT product were amplified by PCR in $47.5 \mu \mathrm{L}$ of PCR mixture containing $5 \mu \mathrm{L}$ of $10 X$ Taq PCR buffer, 100 nmoles $\mathrm{MgCl}_{2}, 15$ nmoles of deoxynucleoside triphosphate (Promega), 2.5 U Taq DNA polymerase, 15 pmoles corresponding to forward and reverse primers. Gene-specific oligonucleotide primers (20-22 nucleotides) were selected from the cDNA sequences of mouse OAT and rat cyclophilin A. Forward and reverse primers were designed using Primer3 software (v. 0.4.0) (http://frodo.wi.mit.edu/primer3/) and are shown in Table 1. Sequence identity between rat and mouse cyclophilin A was $91 \%$ for forward primer and $95 \%$ for reverse primer. The PCR program consisted of a denaturation step $\left(2 \mathrm{~min}\right.$ at $\left.94^{\circ} \mathrm{C}\right), \mathrm{X}$ cycles (see Table 1$)$ and a final elongation step $\left(10 \mathrm{~min}\right.$ at $\left.72^{\circ} \mathrm{C}\right)$. Each cycle included denaturation $\left(1 \mathrm{~min}\right.$ at $\left.94^{\circ} \mathrm{C}\right)$, primer annealing $\left(1 \mathrm{~min}\right.$ at $\left.60^{\circ} \mathrm{C}\right)$, and elongation $\left(1 \mathrm{~min}\right.$ at $\left.72^{\circ} \mathrm{C}\right)$. Preliminary experiments were performed to determine the linear range of PCR amplication for each target mRNA. RT and PCR reactions were performed using a thermocycler (Mastercycler ${ }^{\circledR}$ Personal, Eppendorf, Le Pecq, France).

\begin{tabular}{|c|c|c|c|c|c|}
\hline Gene & $\begin{array}{l}\text { Accession } \\
\text { number }\end{array}$ & Primer & Sequences $\left(5^{\prime}->3^{\prime}\right)$ & $\begin{array}{c}\text { PCR } \\
\text { product size }(\mathrm{pb})\end{array}$ & \begin{tabular}{|c|} 
Cycle \\
number
\end{tabular} \\
\hline \multirow[t]{2}{*}{ OAT } & \multirow[t]{2}{*}{ NM_016978.2 } & Forward & TCCAGGATACCTGACGGGAGTT & \multirow[t]{2}{*}{330} & \multirow[t]{2}{*}{27} \\
\hline & & Reverse & ATCTTGTCTGCGTTTTCAGCAA & & \\
\hline \multirow[t]{2}{*}{ eIF4-E } & \multirow[t]{2}{*}{ NM_007917.3 } & Forward & AGCAGAGTGGACTGCACTGA & \multirow[t]{2}{*}{394} & \multirow[t]{2}{*}{27} \\
\hline & & Reverse & GCAAGGACAATGCTGTGAAA & & \\
\hline \multirow[t]{2}{*}{ Cyclophilin A } & \multirow[t]{2}{*}{ NM_017101 } & Forward & GTGGCAAGTCCATCTACGGAG & \multirow[t]{2}{*}{265} & \multirow[t]{2}{*}{24} \\
\hline & & Reverse & CCACAGTCGGAGATGGTGATC & & \\
\hline
\end{tabular}

Abbreviation: ornithine aminotransferase (OAT) and eukaryotic initiation factor eIF4-E (eIF4-E).

Table 1. Gene-specific sequences of PCR primers, predicted PCR products, and parameters for PCR analyses

\subsubsection{Quantification of RT-PCR products}

Fourteen $\mu \mathrm{L}$ of each PCR products containing $14 \%$ of a gel loading buffer (Blue juice 10X) were separated by electrophoresis on a $4 \%(\mathrm{w} / \mathrm{v})$ agarose (Eurobio) gel prestained with 
$0.01 \%$ ethidium bromide. For quantitation of band intensities, pictures were taken with a Camera DC120 (Kodak) and intensities of the bands were determined with Kodak Digital Science 1D 2.0 (Kodak Scientific Imaging System). The housekeeping rat cyclophilin A gene was used as an internal control to normalize the target gene expression as previously reported (Bitoun et al., 2001).

\subsubsection{Polymerase chain reaction for $\mathrm{qPCR}$}

Real-time PCR was performed in a MyiQ thermal cycler (Bio-Rad, Marnes La Coquette, France) using IQ SYBR Green Supermix (Bio-Rad). Primers specific to the mouse sequence of OAT and HPRT were designed using Primer3 software. The following qPCR conditions were used: $3 \mathrm{~min}$ at $95^{\circ} \mathrm{C}$, followed by 40 cycles of denaturation for $10 \mathrm{~s}$ at $95^{\circ} \mathrm{C}$ and annealing/extension for $45 \mathrm{~s}$ at $60^{\circ} \mathrm{C}$, according to the manufacturer's instructions. All samples were run in duplicate along with dilutions of known amounts of target sequence to quantify the initial cDNA copy number (Concentration $=$ Efficiency $\Delta \mathrm{Ct}$ ). The results are expressed as the ratio of the target gene over HPRT mRNA concentration which was verified to exhibit non-significant variation between the different groups of cDNAs.

\begin{tabular}{|c|c|c|c|c|}
\hline Gene & $\begin{array}{c}\text { Accession } \\
\text { number }\end{array}$ & Primer & Sequences $\left(5^{\prime}->3^{\prime}\right)$ & $\begin{array}{c}\text { qPCR } \\
\text { product size }(\mathrm{pb})\end{array}$ \\
\hline OAT & NM_016978.2 & $\begin{array}{r}\text { Forward } \\
\text { Reverse }\end{array}$ & $\begin{array}{r}\text { GGGCTCTTGTGAAACTCTGC } \\
\text { AGATGGGTCCGTTTCTCCTT }\end{array}$ & 195 \\
HPRT & NM_013556 & $\begin{array}{r}\text { Forward } \\
\text { GTAATGATCAGTCAACGGGGGAC }\end{array}$ & 177 \\
& & Reverse & CCAGCAAGCTTGCAACCTTAACCA & \\
\hline
\end{tabular}

Abbreviation: ornithine aminotransferase (OAT) and hypoxanthine guanine phosphoribosyl transferase (HPRT).

Table 2. Gene-specific sequences of PCR primers and predicted PCR products for qPCR analyses.

\subsection{Protein extraction and western blot}

Frozen kidneys were mixed at $4^{\circ} \mathrm{C}$ with a Turrax homogenizer at $100 \mathrm{mg}$ frozen tissue per 2 $\mathrm{mL}$ of lysing buffer containing protease inhibitor (Laemmli, 1970). After centrifugation, the concentration of soluble proteins was determined using the Bradford protein assay (Bradford, 1976). Fifty or $100 \mu \mathrm{g}$ samples of soluble proteins were subjected to $10 \%$ PAGE containing $0.1 \%$ SDS using 6 Watts per gel. Protein transfer and equal loading of proteins were visualized on the membranes with Ponceau $S$ solution. Blocked immunoblots were incubated with primary polyclonal rabbit antibodies raised against rat/mouse-OAT (dilution 1:1,000), rat-aldose reductase (AR; EC 1.1.1.21, dilution 1:3,000) (Lambert-Langlais et al, 2009), and monoclonal mouse $\beta$-actin (dilution 1:2,000) and glyceraldehyde-3-phosphate dehydrogenase (G3PDH; EC 1.2.1.12, dilution 1:170) antibodies, and then with a peroxidase-conjugated anti-rabbit or antimouse IgG secondary antibodies (dilution 1:10,000) as previously described (Levillain et al., 2004, 2005). Antibody binding was revealed using chemiluminescence (ECL) Western Blotting Kit. Details for ECL detection and quantitation of the bands have been mentioned earlier (Levillain et al., 2004, 2005). 


\subsection{Measurement of OAT activity}

OAT activity was measured in whole kidneys. Samples were mixed at $4^{\circ} \mathrm{C}$ with a Turrax homogenizer in a buffer ( $0.33 \mathrm{M}$ sucrose, $5 \mathrm{mM}$ HEPES, $1 \mathrm{mM}$ EGTA, $1 \mathrm{mM}$ DTT, and $0.5 \%$ Triton $\mathrm{X} \mathrm{100)}$. Homogenates were centrifuged $21,000 \times \mathrm{g}$ for $10 \mathrm{~min}$ at $4^{\circ} \mathrm{C}$. The protein concentration was determined on the supernatant using the Bradford protein assay. OAT activity was determined using the enzyme assay previously described (Herzfeld \& Knox, 1968; Peraino \& Pitot, 1963). Briefly, the supernatant was incubated with a buffer composed of $75 \mathrm{mM}$ potassium phosphate $\mathrm{pH} 8.0,20 \mathrm{mM}$ L-ornithine, $0.45 \mathrm{mM}$ pyridoxal phosphate, 5 $\mathrm{mM} \alpha$-aminobenzaldehyde, and $3.75 \mathrm{mM} \alpha$-keto-glutarate for 15 or $30 \mathrm{~min}$ at $37^{\circ} \mathrm{C}$. Blanks did not contain $\alpha$-keto-glutarate. The reaction was stopped by adding trichloroacetic acid $40 \%$. Samples were centrifuged $21,000 \times g$ for $3 \mathrm{~min}$ at $4^{\circ} \mathrm{C}$ and absorbance was measured on the clear supernatant at $440 \mathrm{~nm}$ on a Hitachi U-1100 spectophotometer (Meylan, France). Duplicate or triplicate samples and blanks were performed for all experiments.

\subsection{Determination of testosterone and corticosterone levels}

Testosterone was measured by radioimmunoassay after extraction by organic solvant and partition chromatography of the plasma samples as previously described (Dechaud et al, 1989). Corticosterone concentration was measured, after diethylether extraction, by radioimmunoassay using 1,2,6,7 [3H]-corticosterone and rabbit anti-corticosterone polyclonal antibody (Filipski et al, 2002).

\subsection{Calculations and statistical analyses}

The calculations were as follows: for each group of mice and for each protein, the mean intensity optical densitometry (IOD) of the bands was calculated. The mean IOD of the untreated (group I) and sham-operated (group V) mice were used as a reference (control). For each mouse, the IOD value of a given protein was divided by the mean IOD value of the control group. Consequently, this ratio value is 1 in each control group. Then, these ratios were related to those of $\beta$-actin and/or G3PDH.

OAT activity was expressed in absorbance per $15 \mathrm{~min}$ per $\mathrm{mg}$ soluble protein because we were unable to find a supplier to buy P5C as standart to convert the absorbance of P5C into molar unit. Depending on the material used or the physiological interest of expressing the data in other units, OAT activity is expressed in absorbance per $15 \mathrm{~min}$ per mg soluble proteins.

Results are expressed as means \pm SE. Non-parametric statistical tests were used to analyze the data. Where appropriate, statistical differences were assessed using the Kruskal-Wallis test at level significance of $95 \%$ and this test was followed by the U-Mann-Whitney test at level significance of $95 \%$ (StatView SE+Gr). For correlation analyses, the correlation coefficient $r^{2}$ was calculated with Microsoft Excel, and $P$ was determined from tables at the $95 \%$ level of significance.

\subsection{Chemicals}

Salts and most chemicals, Ponceau S solution, secondary anti-IgG antibodies, Kodak X-MAT film were purchased from Sigma ( $S^{t}$ Quentin Fallavier, France). Protease inhibitor cocktail were purchased from Boehringer Mannhein (Strasbourg, France). Agarose Seakem GTG was purchased from TEBU (Le Perray-en-Yvelines, France). ECL Western Blotting Kits, and ImagerMaster Total Lab v2.01 program were purchased from Amersham (Buckinghamshire, UK). 


\section{Results}

\subsection{Technical verifications}

\subsubsection{Semiquantitative RT-PCR}

To quantify the levels of OAT and cyclophilin A mRNA by RT-PCR, we determined the appropriate number of amplification cycles to remain in the exponential phase of the amplification process and avoid saturation (Table 1). For each mRNA studied a single RTPCR product was obtained. The amplified RT-PCR products were of the expected size (Table 1). The level of the mRNA of a housekeeping gene (cyclophilin A) did not vary significantly in our experimental conditions (data not shown).

\subsubsection{OAT activity assay}

The renal cortex of male and female mice was dissected and prepared to quantify OAT activity. To determine the conditions for assay of OAT activity, the incubation time was tested every $5 \mathrm{~min}$ up to $30 \mathrm{~min}$ and the protein concentration varied from 0 to $400 \mu \mathrm{g}$ per sample. OAT activity increased linearly with the concentration of soluble proteins up to $400 \mu \mathrm{g}$ in male mouse cortex and $300 \mu \mathrm{g}$ in that of the female when the incubation time was fixed at $30 \mathrm{~min}$ (Fig.2 left, male: $\mathrm{r}^{2}=0.99809$ and female: $\mathrm{r}^{2}=0.99583, P<0.01$ ). OAT activity increased linearly in proportion with the incubation time up to $30 \mathrm{~min}$ when the concentration of soluble proteins was fixed at $140 \mu \mathrm{g}$ in both male and female mice (Fig. 2 right, male: $\mathrm{r}^{2}=0.99352$ and female: $\mathrm{r}^{2}=0.9972, P<0.01$ ). Constantly, OAT activity was more than three-fold higher in female than in male mouse kidney. The sex-differential OAT activity found in the present results is in good agreement with published data (Levillain et al., 2007; Ventura et al. 2009).
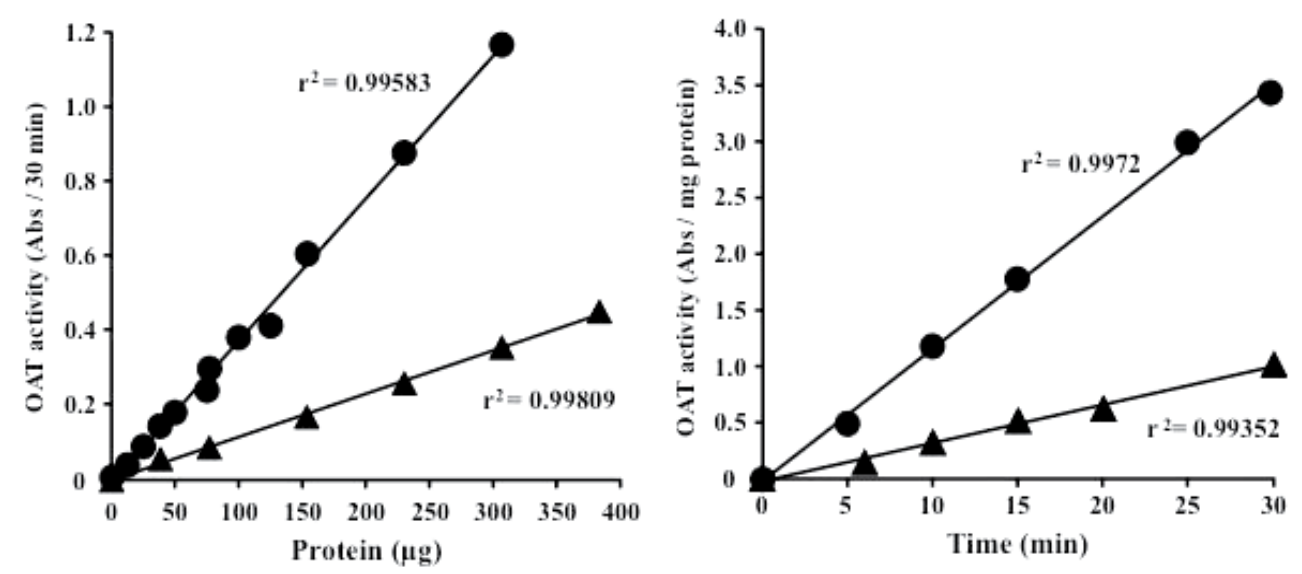

Fig. 2. Technical verifications to determine the conditions for OAT assay.

Closed circles: female mouse kidney and closed triangles: male mouse kidney. In all cases, the coefficient of correlation was statistically significant $(P<0.01$ or less).

\subsection{Influence of orchidectomy on the expression of OAT gene}

A complete analysis of the expression of OAT gene in the mouse kidney was undertaken by analyzing the levels of mRNA and protein, and measuring OAT activity. The level of OAT 
mRNA, protein, and enzyme activity did not differ between control and sham-operated male mice. Surgery did not affect the expression of OAT gene in the mouse kidney (Fig. 3). In contrast, orchidectomy provoked a sharp increase in OAT mRNA, protein, and enzyme activity. In details, in castrated mice killed 11 day after the surgery, the level of OAT mRNA, OAT protein, and OAT activity were increased by 3.95-fold (Kruskal-Wallis, $P<0.035$ followed by Mann Whitney, $P<0.0495)$, 2.13-fold (Kruskal-Wallis, $P<0.0004$ followed by Mann Whitney, $P<0.0039$ ), and 2.27-fold (Kruskal-Wallis, $P<0.018$ followed by Mann Whitney, $P<0.05$ ), respectively as compared to the sham-operated mice (Fig. 3). When orchidectomized mice were killed 18 days after the operation, OAT gene remained still highly expressed, nevertheless, its expression had a tendancy to be higher than at day 11 . The level of OAT mRNA was 4.44-fold higher than that of the sham-operated mice (Mann Whitney, $P<0.0495)$, but did not differ from that of the mice killed on day 11. Similarly, the mean value of OAT protein was higher on day 18 than on day 11, but it did not reach the statistical level of significance $(P<0.0547)$. In contrast, OAT activity was significantly higher on day 18 than day 11 as compared to the sham-operated mice (Mann Whitney, $P<0.0495$ ). The level of OAT mRNA was quantitated either by RT-PCR (Fig. 3) or by q-PCR (Fig. 4). The two methods gave similar results and patterns (Figs. 3 and 4). Different house-keeping genes were used to prove that the effect of castration were independent of the gene of reference. Orchidectomy provoked a 4.9- and 4.7-fold increase in the level of OAT mRNA in $11 \mathrm{~d}$ - and $18 \mathrm{~d}$-castrated mice as compared to the sham-operated male mice. (Fig. 4; KruskalWallis, $P<0.0001$ followed by Mann Whitney, $P<0.0027$ or less in both cases).
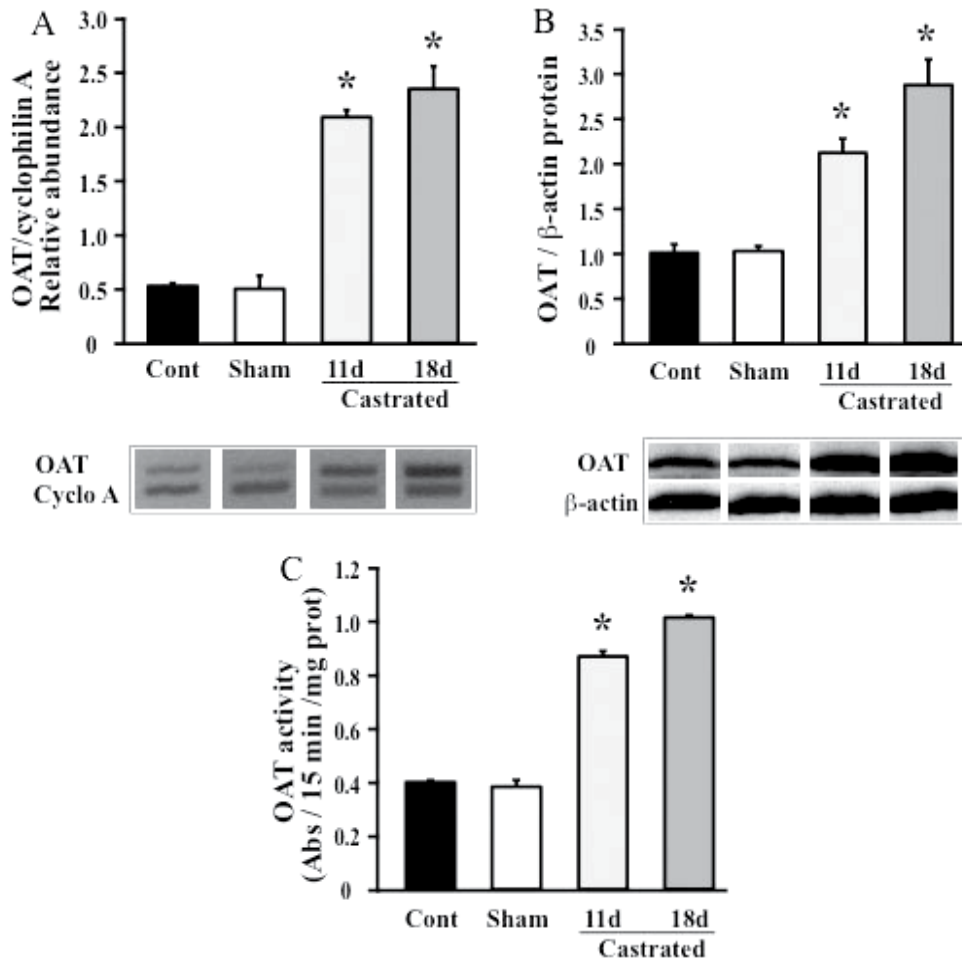

Fig. 3. Effect of orchidectomy on the expression of ornithine aminotransferase gene in the mouse kidney. 
The values are expressed as means \pm SE. A: The level of OAT mRNA were analyzed by semiquantitative RT-PCR. The amplified cDNAs were separated by agarose-gel electrophoresis. Band intensities were quantified and reported relative to the cyclophilin A band $(n=3$ mice per group). B: Immunoblot assessing the abundance of OAT and $\beta$-actin proteins in mouse kidneys. Immunoblots were loaded with samples of $100 \mu \mathrm{g}$ soluble proteins $(\mathrm{n}=6$ mice per group). $\beta$-actin was used as control of protein loading and transfer. C: OAT activity was measured in mouse kidneys ( $n=4,3,3,3$ mice per group, respectively). To simplify the Figure, a representative RT-PCR or immunoblot that corresponds to one mouse from each group was shown. Abbreviations: control (Cont), sham-operated (Sham), and 11- and 18-day orchidectomized mice (11d and 18d, respectively), cyclophilin A (Cyclo A), ornithine aminotransferase (OAT), and absorbance (Abs). Differences between groups were statistically analyzed by Kruskal-Wallis test and followed by Mann-Whitney test. ${ }^{*}, P<0.05$ or less.

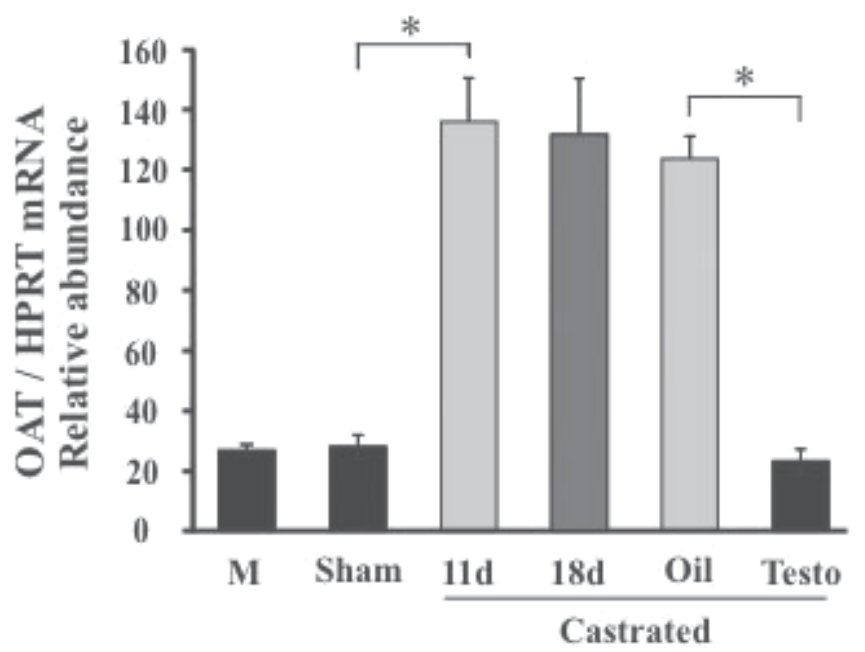

Fig. 4. Relative levels of ornithine aminotransferase mRNA in mouse kidneys.

The values are expressed as means \pm SE. The relative mRNA levels of OAT were determined by qPCR in the kidneys of male (M), sham-operated (Sham), 11- and 18-day orchidectomized mice (11d and 18d, respectively), castrated mice treated with oil as solvant (Oil), and castrated mice supplemented with testosterone dissolved in oil (Testo). Abbreviations: ornithine aminotransferase (OAT), and hypoxanthine guanine phosphoribosyl transferase (HPRT). Differences between groups were statistically analyzed by Kruskal-Wallis test $(P<0.0001)$ and followed by Mann-Whitney test. ${ }^{*}, P<0.0039$ or less. Number of mice used: $11,6,9,7,6$, and 6, respectively.

\subsection{Influence of testosterone on the expression of OAT gene}

Given that orchidectomy provoked a sharp increase in the expression of OAT gene in the mouse kidney, we hypothesized that androgens control and down-regulate the expression of this gene. To verify our hypothesis, castrated male mice were subjected to testosteronetreatment. An additional group of castrated mice was subjected to sesame oil-treatment inasmuch as oil was used as a solvant to dissolve testosterone. The expression of OAT gene was analyzed at the transcriptional and traductional levels and OAT activity was measured. In 
this new study, our results confirmed that castration of male mice provoked an overexpression of OAT gene (Fig. 5). The levels of OAT mRNA, protein, and enzyme activity were increased and strongly resemble those presented in Figure 3. However, the level of OAT mRNA was increased only by two-fold in kidneys of castrated mice of the second study, (Fig. 5) as compared to four-fold for the first study (Fig. 3). In kidneys of castrated mice treated with a single injection of sesame oil, the level of OAT mRNA, protein, and OAT activity did not differ from those of the castrated mice (Fig. 5). In contrast, a single injection of a physiological dose of testosterone decreased by 2-fold the level of OAT mRNA (Kruskal-Wallis, $P<0.036$ followed by Mann Whitney, $P<0.0495$ ), OAT protein by 1.58 -fold (Kruskal-Wallis, $P<0.032$ followed by Mann Whitney, $P<0.05$ ), and OAT activity by 1.62 -fold (Kruskal-Wallis, $P<0.0045$ followed by Mann Whitney, $P<0.0209$ ) (Fig. 5). The level of OAT mRNA was also quantitated either by RT-PCR (Fig. 5) or by q-PCR (Fig. 4). Different house-keeping genes were used to prove that the effect of castration were independent of the gene of reference. Again, the same pattern was found with the two methods (Figs. 4 and 5). Oil-treatment had no effect whereas testosterone-treatment provoked a 5.3-fold decrease in the level of OAT mRNA as compared to oil-treated mice. (Fig. 5; Kruskal-Wallis, $P<0.0001$ followed by Mann Whitney, $P<0.0039$ ). The plasma levels of corticosterone had a tendancy to increase after orchidectomy and decrease in testosterone-treated mice. Unfortunately, the difference did not reach statistical significance (Kruskal-Wallis, $P<0.2435$ ). The plasma level of corticosterone were inversely correlated with those of testosterone (Fig. 5 and Levillain et al. 2005).
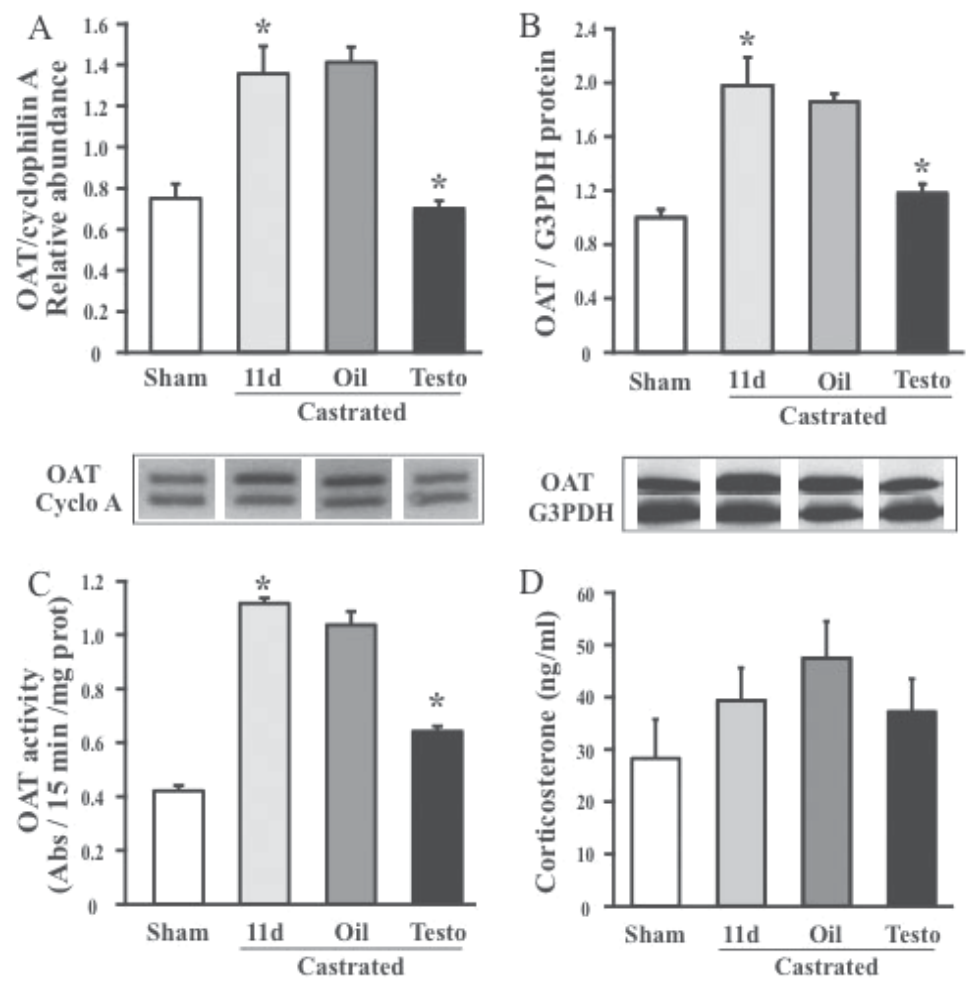

Fig. 5. Effect of testosterone treatment on the expression of ornithine aminotransferase gene in the mouse kidney. 
The values are expressed as means \pm SE. A: The level of OAT mRNA were analyzed by semi-quantitative RT-PCR. The amplified cDNAs were separated by agarose-gel electrophoresis. Band intensities were quantified and reported relative to the cyclophilin A band ( $\mathrm{n}=3$ mice per group). B: Immunoblot assessing the abundance of OAT and G3PDH proteins in mouse kidneys. Immunoblots were loaded with samples of $100 \mu \mathrm{g}$ soluble proteins ( $\mathrm{n}=3$ mice per group). G3PDH was used as as control of protein loading and transfer. C: OAT activity was measured in mouse kidneys ( $n=4$ mice per group). D: Plasma levels of corticosterone ( $\mathrm{n}=9,10,10$, and 9 mice, respectively). To simplify the Figure, a representative RT-PCR or immunoblot that corresponds to one mouse from each group was shown. Abbreviations: sham-operated (Sham), and 11-day orchidectomized mice (11d), cyclophilin A (Cyclo A), ornithine aminotransferase (OAT), G3PDH (glyceraldehyde-3phosphate dehydrogenase), Testo (oil + testosterone), and absorbance (Abs). Differences between groups were statistically analyzed by Kruskal-Wallis test and followed by MannWhitney test. ${ }^{*}, P<0.05$ or less.

\subsection{Influence of testosterone on the expression of elF4-E gene}

The eukaryotic initiation factor eIF4-E has been reported to be rate-limiting for OAT translation (Fagan et al., 1991). We analyzed whether the level of eIF4-E mRNA was altered by orchidectomy and testosterone replacement. Our data show that, in the mouse kidney, the level of eIF4-E mRNA had a tendancy to be decreased by orchidectomy and enhanced by testosterone replacement. Nevertheless, the difference did not reach statistical significance (Fig. 6, Kruskal-Wallis, $P<0.1574$ ).

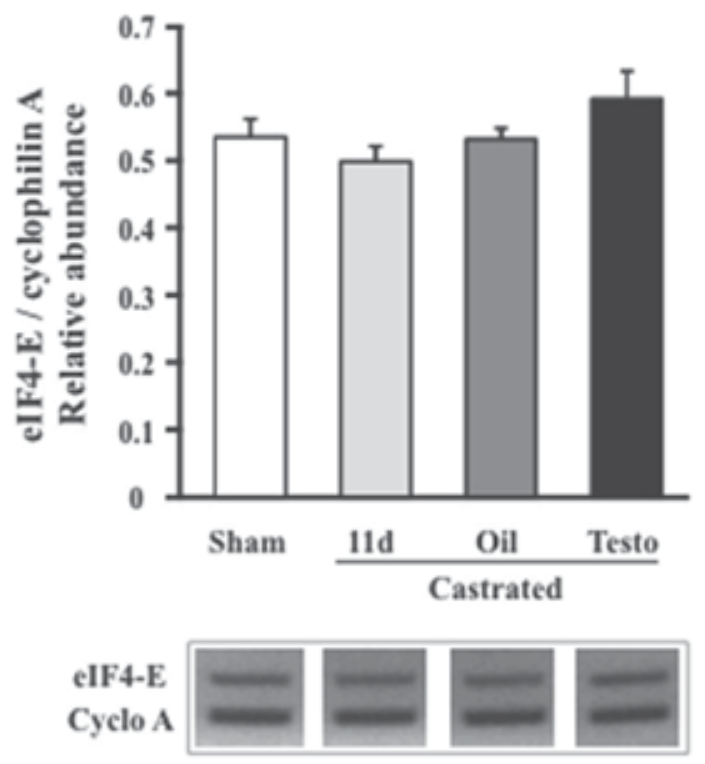

Fig. 6. Effect of testosterone treatment on the expression of eIF4-E gene in the mouse kidney.

The values are expressed as means \pm SE. The levels of eIF4-E mRNA were analyzed by semiquantitative RT-PCR. The amplified cDNAs were separated by agarose-gel electrophoresis. Band intensities were quantified and reported relative to the cyclophilin A band ( $n=3$ mice 
per group). To simplify the Figure, a representative RT-PCR that corresponds to one mouse from each group was shown. Abbreviations: sham-operated (Sham), and 11-day orchidectomized mice (11d), cyclophilin A (Cyclo A), eukaryotic initiation factor eIF4-E (eIF4-E), and oil + testosterone (Testo). Differences between groups were statistically analyzed by Kruskal-Wallis test, $P=0.1574$.

\subsection{Time course changes in the expression of OAT gene}

This experiment was performed to determine the delay requested for testosterone to downregulate the expression of OAT gene in the mouse kidney. The time-course effect of testosterone on the expression of OAT gene was analyzed at the transcriptional and posttranslational levels 8, 24, 28, and 32 hrs following hormone administration. Eight hours following testosterone treatment, the level of OAT mRNA was reduced by $8 \%$, but did not reach statistical significance (Fig. 7A). In contrast, 24, 28, and $32 \mathrm{hrs}$ after testosterone replacement, the renal levels of OAT mRNA were decreased by $45 \%, 40 \%$, and $36 \%$, respectively (Kruskal-Wallis $P<0.0028$ followed by Mann Whitney, $P<0.0209$ for each case). The pattern of OAT activity along this time-course study strongly resembled that of OAT mRNA except that the decrease in OAT activity was about 2-fold lower than that of OAT mRNA (Fig. 7B). Indeed, 24, 28, and $32 \mathrm{hrs}$ after testosterone administration, OAT activities were decreased by $20 \%, 21 \%$, and $23 \%$, respectively (Kruskal-Wallis $P<0.0071$ followed by Mann Whitney, $P<0.0209$ for each case). The efficiency of the hormonal treatment was checked by measuring testosteronemia. Our results show that testosteronemia was very high $8 \mathrm{hrs}$ after a single injection of the hormone and regularly decreased over the experimental period. Thirty-two hours after the treatment, testosteronemia was about 2-fold higher than the physiological concentration of testosterone reported for control male mice (Levillain et al., 2007). Corticosteronemia were quantified in the same mice to determine whether testosteronemia modified the plasma level of corticosterone. A high concentration of corticosterone was detected $8 \mathrm{hrs}$ after testosterone treatment (Fig. 7C). One day later (24 and $28 \mathrm{hrs}$ ), the plasma level of corticosterone were decreased by 3 -fold whereas at 32 hrs, it increased again by 2-fold (Fig. 7D). Unfortunately, given that it was impossible to have access to the animal room during the night, no mice could be sampled during the dark period.

\section{Discussion}

OAT plays a pivotal role in the intermediary metabolism because this enzyme is at the crossroad of several pathways. OAT controls the production of glutamate and ornithine, competes with the polyamine pathway, and may be a source of carbon for the renal gluconeogenesis. These pathways are essential for many physiological roles including growth and energy supply. Several reports clearly documented the hormonal regulation of OAT gene in the rat liver and kidney. In this species, the renal expression of OAT gene is upregulated by estrogens and triiodothyronine (Herzfeld \& Knox, 1968; Lyons \& Pitot, 1977; Mueckler \& Pitot, 1983; Mueckler et al., 1984). During the post-natal development of the rat kidney, the sexual dimorphism of the expression of OAT gene increased in parallel with the endogenous synthesis of estrogens (Herzfeld \& Knox, 1968). In contrast, testosterone affected OAT activity neither in liver nor in kidneys of male and female rats (Herzfeld \& Knox, 1968). The authors concluded that estrogen naturally control and upregulate the expression of OAT 

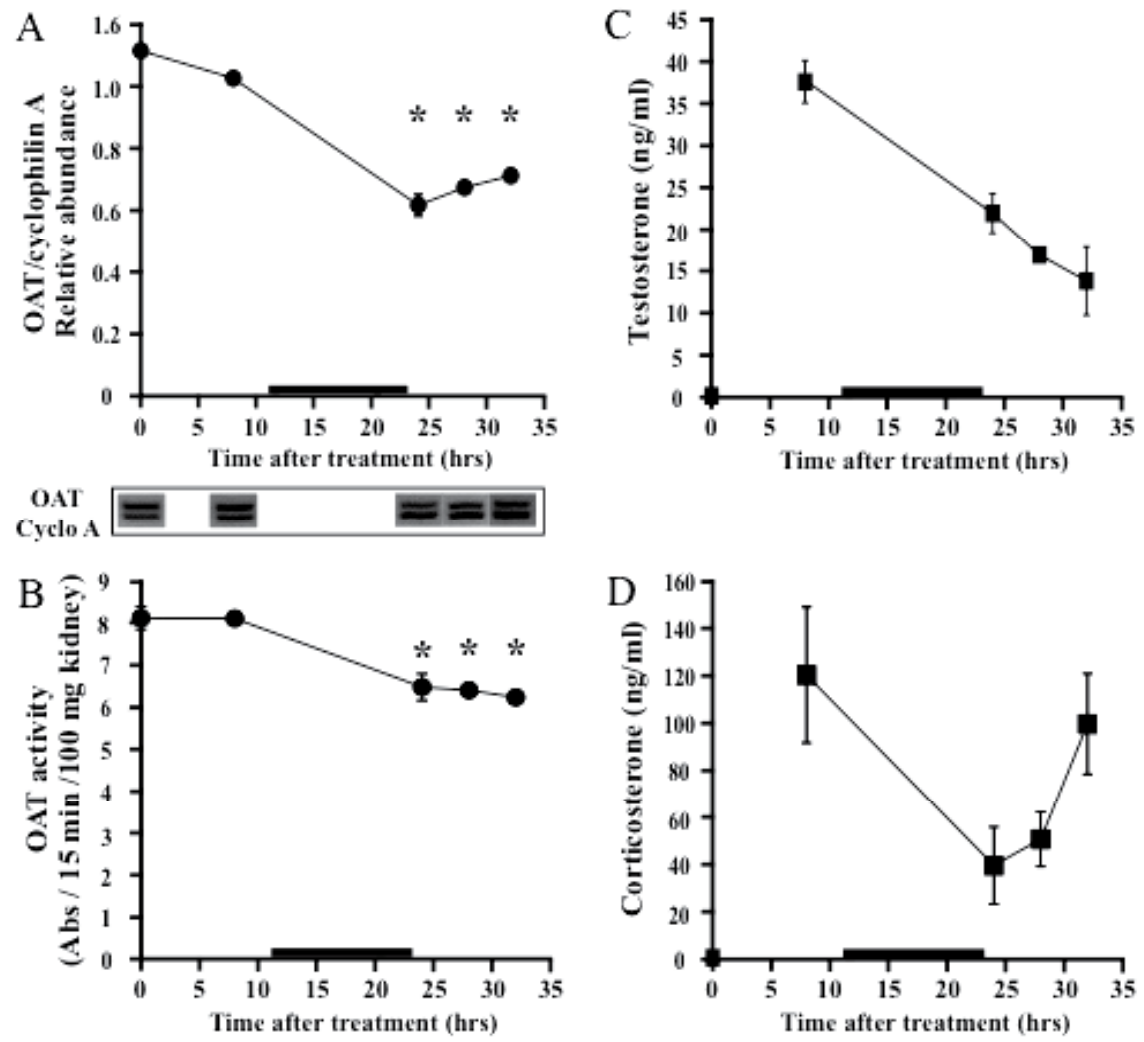

Fig. 7. Time course effect of testosterone on the expression of ornithine aminotransferase gene in the mouse kidney. A single dose of testosterone was injected to castrated-male mice. Mice were killed 8, 24, 28, and $32 \mathrm{hrs}$ after the hormonal-treatment. Untreated castrated mice were used as controls. The values are expressed as means $\pm S E,(n=4$ mice per group). A: The level of OAT mRNA were analyzed by semi-quantitative RT-PCR. The amplified cDNAs were separated by agarose-gel electrophoresis. Band intensities were quantified and reported relative to the cyclophilin A band. To simplify the Figure, a representative RT-PCR that corresponds to one mouse from each group was shown. B: OAT activity was measured in mouse kidneys. C: Plasma levels of corticosterone. D: Plasma levels of testosterone. The black bar represents the dark period (night). Differences between groups were statistically analyzed by Kruskal-Wallis test and followed by Mann-Whitney test. ${ }^{*}, \mathrm{P}<0.0209$ in all cases.

gene in the female rat kidney. As reported for the rats, the mouse kidney also exhibits a sexual dimorphism in the expression of OAT gene. Although the hormonal regulation of this gene has been poorly studied in both liver and kidney of male and female mice, it has been clearly shown that the endogenous production of testosterone was responsible for a decrease in the renal expression of OAT gene (Levillain et al., 2007). Interestingly, in contrast to the rats, ovariectomy altered neither the level of OAT protein nor OAT activity in the murine kidney (Levillain et al., 2007). Estrogens do not control the renal expression of OAT in the mouse kidney. Consequently, testosterone naturally controls and down-regulates the expression of 
OAT gene in the male mouse kidney. Furthermore, orchidectomy completely abolished the sexual dimorphism of the renal expression of OAT gene (Levillain et al., 2007). The present findings confirm these statements. Moreover, our results show that testosterone negatively regulated the expression of OAT gene at the transcriptional level. Indeed, the levels of OAT mRNA, protein, and enzyme activity were markedly increased following castration. The castrated male mice were killed either 11 days or 18 days after the surgery to completely deplete the endogenous pool of testosterone. Plasma testosterone levels showed that all mice were testosterone-free as soon as 11 days after castration (Levillain et al., 2005).

To further explore the mechanismes involved in the regulation of OAT gene by testosterone in the mouse kidney, experiments were conducted to test the consequence of testosterone replacement on the expression of OAT gene at the transcriptional, translational, and posttranslational levels. The dose of testosterone injected was calculated to reach a physiological plasma level of testosterone. The efficiency of testosterone to lower the level of OAT mRNA in the mouse kidney was confirmed. These results demonstrate that testosterone regulates OAT gene expression at the transcriptional level. The regulation of OAT gene at the transcriptional level has been also reported in the rat tissues (Mueckler \& Pitot, 1983; Mueckler et al., 1983, 1984). The levels of OAT protein and OAT activity were also diminished by a single injection of testosterone, however, this decrease was less pronounced than that of OAT mRNA. This difference may be explained by the long half-life of OAT protein. The half-life of OAT protein is estimated at about $48 \mathrm{hrs}$ (Ip et al., 1974). The timecourse study of the effect of testosterone on the expression of OAT gene in castrated male mice also supports this timeline with the level of OAT mRNA decreasing more rapidly than OAT activity. This experiment also revealed a lag-time of $8 \mathrm{hrs}$ or more from testosterone administration before detecting significant changes in the level of OAT mRNA. Similar results were observed with injection of testosterone to female mice (paper in preparation). This delay from administration to mRNA expression suggests that several genomic and/or non-genomic events may take place in the signaling cascade of testosterone (Heinlein \& Chang, 2002). One hypothesis is that a target molecule such as the eukaryotic initiation factor eIF4-E is rate-limiting for OAT translation (Fagan et al., 1991). However, in our expriments, the level of eIF4-E mRNA was altered neither by orchidectomy nor by testosterone replacement.

In order to explain a direct genomic action of testosterone, an attempt was made to identify ARE on the promoter of the mouse OAT gene. We carried out an in silico search for homology to the consensus ARE motifs by selecting either the left half-site 5'-AGAACA-3' or the right half-site 5'-TGTTCT-3' motifs by search computational using MatInspector (http://www.genomatix.de/) (Beato et al., 1989; Fabre et al., 1994; Roche et al., 1992; Wang et al., 2007; Merkulov \& Merkulova, 2009). Several ARE (5'-AGAACAnnnTGTTCT-3') and glucocorticoid responsive element (GRE, 5'-GGTACAnnnTGTTCT-3') which share the same sequence 5'-TGTTCT-3' (Nelson et al., 1999, Verrijdt et al., 2003) were identified on the promoter of the mouse OAT gene. Interestingly, four GRE have been found in the human OAT gene (Zintz \& Inana, 1990). Further experiments will be required to determine the functionality of these elements in response to hormone administration.

Recently, it has been reported that, in Swiss CD1 mice, sex hormones influence the weight of the adrenal gland and the plasma level of corticosterone (Bastida et al, 2007). Indeed, the weight of the female adrenal gland was 2.8-fold higher than that of the male (Bastida et al, 2007). Orchidectomy enhanced the weight of the male adrenal gland by 2.1-fold whereas 
testosterone treatment decreased by 2.6-fold the weight of the female adrenal gland which did not differ from that of the control male adrenal gland (Bastida et al, 2007). The plasma level of corticosterone was 2.8-fold higher in the females as compared to the males (Bastida et al, 2007). These results led us to hypothesize that testosterone may control the plasma level of corticosterone which may secondarily regulate the expression of OAT gene in the mouse kidney. For this reason the plasma level of corticosterone were measured in the different groups of mice. Our results did show a trend for the plasma levels of corticosterone to be higher in orchidectomized mice than in untreated male mice and in castrated male mice treated with testosterone, however, with a low sample number and high standard error the difference did not reach statistical significance. Contrarily, when analyzing the time course effect of testosterone $8 \mathrm{hrs}$ after the hormonal treatment the plasma level of corticosterone and testosterone were both very high suggesting that testosterone does not control the rate of synthesis and release of corticosterone. The presence of GRE and ARE in the promoter of the mouse OAT gene offers new insight on the hormonal regulation of this gene. Further experiments utilizing male mice subjected to both orchidectomy and adrenalectomy may afford a model to resolve this point.

Hormonal regulation of OAT gene by steroids can impact human disease model, such as prostate cancer $(\mathrm{PCa})$. Androgen receptor (AR) targets have been recently identified in a model of androgen-dependent (LNCaP) and a model of castrate-resistant (C4-2B) human PCa cell lines (Jariwala et al., 2007) with OAT expressed at a higher level in the castrate resistant (C4-2B) cells. Expression of OAT was repressed by siRNA in C4-2B cells demonstrating that OAT was an AR regulated gene, although it did not respond to dihydrotestosterone (DHT). Furthermore, the expression of OAT was analyzed in primary PCa tumors and primary PCa tumors after 3 months of androgen ablation therapy. OAT appears to be negatively regulated by the AR in vivo.

In conclusion, in the mouse kidney, testosterone down-regulates the expression OAT gene at the transcriptional level. This finding may have interesting consequences for human diseases as reported for prostate cancer.

\section{Acknowledgements}

The authors are indebted to Dr Joseph Satriano, Department of Medicine, University of California, San Diego, and Veterans Administration San Diego Healthcare System, La Jolla, California, USA for reading and improving the paper.

\section{References}

Alonso, E. \& Rubio, V. (1989). Participation of ornithine aminotransferase in the synthesis and catabolism of ornithine in mice. Biochemical Journal, Vol.259, No.1, pp. 131-138, ISSN 0264-6021

Bastida, C.M.; Cremades, A.; Castells, M.T.; Lopez-Contreras, A.J.; Lopez-Garcia, C.; Sanchez-Mas, J. \& Penafiel, R. (2007). Sexual dimorphism of ornithine decarboxylase in the mouse adrenal: influence of polyamine deprivation on catecholamine and corticoid levels. American Journal of Physiology - Endocrinology and Metabolism, Vol.292, No.4, pp. E1010-1017, ISSN 0193-1849 
Beato, M.; Chalepakis, G.; Schauer, M. \& Slater, E.P. (1989). DNA regulatory elements for steroid hormones. Journal of Steroid Biochemistry, Vol.32, No.5, pp 737-747, ISSN 0022-4731

Bitoun, M.; Levillain, O. \& Tappaz, M. (2001). Gene expression of the taurine transporter and taurine biosynthetic enzymes in rat kidney after antidiuresis and salt loading. Pflügers Archiv - European Journal of Physiology, Vol.442, No.1, pp. 87-95, ISSN 00316768

Bradford, M.M. (1976). A rapid and sensitive method for the quantitation of microgram quantities of protein utilizing the principle of protein-dye binding. Analytical Biochemistry, Vol.72, pp. 248-254, ISSN 0003-2697

Déchaud, H.; Lejeune, H.; Garoscio-Cholet, M.; Mallein, R. \& Pugeat, M. (1989). Radioimmunoassay of testosterone not bound to sex-steroid-binding protein in plasma. Clinical chemistry, Vol.35, No.8, pp. 1609-1614, ISSN 0009-9147.

Fabre, S.; Manin, M.; Pailhoux, E.; Veyssiere, G. \& Jean, C. (1994). Identification of a functional androgen response element in the promoter of the gene for the androgen-regulated aldose reductase-like protein specific to the mouse vas deferens. The Journal of Biological Chemistry, Vol.269, No.8, pp 5857-5864, ISSN 00219258

Fagan, R.J.; Karatzas, A.L.; Sonenberg, N. \& Rozen, R. (1991). Translational control of ornithine aminotransferase. Modulation by initiation factor eIF-4E. The Journal of Biological Chemistry, Vol.266, No.25, pp 16518-16523, ISSN 0021-9258

Filipski, E.; King, V.M.; Li, X.; Granda, T.G.; Mormont, M.C.; Liu, X.; Claustrat, B.; Hastings, M.H. \& Levi, F. (2002). Host circadian clock as a control point in tumor progression. Journal of the National Cancer Institute, Vol.94, No.9, pp. 690-697, ISSN 0027-8874

Heinlein, C.A. \& Chang, C. (2002). The roles of androgen receptors and androgen-binding proteins in nongenomic androgen actions. Molecular Endocrinology Vol.16, No.10, pp 2181-2187, ISSN 0888-8809

Herzfeld, A. \& Knox, W.E. (1968). The properties, developmental formation, and estrogen induction of ornithine aminotransferase in rat tissues. The Journal of Biological Chemistry, Vol.243, No.12, pp. 3327-3332, ISSN 0021-9258

Herzfeld, A. \& Greengard, O. (1969). Endocrine modification of the developmental formation of ornithine aminotransferase in rat tissues. The Journal of Biological Chemistry, Vol.244, No. 18, pp. 4894-4898, ISSN 0021-9258

Ip, M.M.; Chee, P.Y. \& Swick, R.W. (1974). Turnover of hepatic mitochondrial ornithine aminotransferase and cytochrome oxidase using (14C)carbonate as tracer. Biochimica et Biophysica Acta, Vol.354, No.1, pp 29-38, ISSN 0006-3002

Jariwala, U.; Prescott, J.; Jia, L.; Barski, A.; Pregizer, S.; Cogan, J.P.; Arasheben, A.; Tilley, W.D.; Scher, H.I.; Gerald, W.L.; Buchanan, G.; Coetzee, G.A. \& Frenkel, B. (2007). Identification of novel androgen receptor target genes in prostate cancer. Molecular Cancer, Vol.6, No.6, pp 39, ISSN 1476-4598

Kasahara, M.; Matsuzawa, T.; Kokubo, M.; Gushiken, Y.; Tashiro, K.; Koide, T.; Watanabe, H. \& Katunuma, N. (1986). Immunohistochemical localisation of ornithine aminotransferase in normal rat tissues by Fab'horseradish peroxidase conjugates. The Journal of Histochemistry and Cytochemistry, Vol.34, No.11, pp 1385-1388, ISSN 0022-1554 
Laemmli, UK. (1970). Cleavage of structural proteins during the assembly of the head of bacteriophage T4. Nature, Vol.227, No.5259, pp 680-685, ISSN 0028-0836

Lambert-Langlais, S.; Pointud, J.C.; Lefrancois-Martinez, A.M.; Volat, F.; Manin, M.; Coudore, F.; Val, P.; Sahut-Barnola, I.; Ragazzon, B.; Louiset, E.; Delarue, C.; Lefebvre, H.; Urade, Y. \& Martinez, A. (2009). Aldo keto reductase 1B7 and prostaglandin F2alpha are regulators of adrenal endocrine functions. PLoS One, Vol.4, No.10, pp e7309, ISSN 1932-6203.

Levillain, O.; Hus-Citharel, A.; Garvi, S.; Peyrol, S.; Reymond, I.; Mutin, M. \& Morel, F. (2004). Ornithine metabolism in male and female rat kidney: mitochondrial expression of ornithine aminotransferase and arginase II. American Journal of Physiology - Renal Physiology, Vol.286, No.4, pp F727-F738, ISSN 0363-6127

Levillain, O.; Diaz, J-J.; Blanchard, O. \& Dechaud, H. (2005). Testosterone down-regulates ornithine aminotransferase gene and up-regulates arginase II and ornithine decarboxylase genes for polyamines synthesis in the murine kidney. Endocrinology, Vol.146, No.2, pp 950-959, ISSN 0013-7227

Levillain, O.; Ventura, G.; Dechaud, H.; Hobeika, M.; Meseguer, A.; Moinard, C. \& Cynober, L. (2007). Sex-differential expression of ornithine aminotransferase in the mouse kidney. American Journal of Physiology - Renal Physiology, Vol.292, No.3, pp F10161027, ISSN 0363-6127

Lyons, R.T. \& Pitot, H.C. (1977). Hormonal regulation of ornithine aminotransferase biosynthesis in rat liver and kidney. Archives of Biochemistry and Biophysics, Vol.180, No.2, pp 472-479, ISSN 0003-9861

Manteuffel-Cymborowska, M.; Chmurzynska, W.; Peska, M. \& Grzelakowska-Sztabert, B. (1995). Arginine and ornithine metabolizing enzymes in testosterone-induced hypertrophic mouse kidney. The International Journal of Biochemistry E Cell Biology, Vol.27, No.3, pp 287-295, ISSN 1357-2725

Merkulov, V.M. \& Merkulova, T.I. (2009). Structural variants of glucocorticoid receptor binding sites and different versions of positive glucocorticoid responsive elements: Analysis of GR-TRRD database. The Journal of Steroid Biochemistry and Molecular Biology, Vol.115, No.1-2, pp 1-8, ISSN 1879-1220

Mueckler, M.M. \& Pitot, H.C. (1983). Regulation of ornithine aminotransferase mRNA levels in rat kidney by estrogen and thyroid hormone. The Journal of Biological Chemistry, Vol.258, No.3 , pp 1781-1784, ISSN 0021-9258

Mueckler, M.M.; Moran, S. \& Pitot, H.C. (1984). Transcriptional control of ornithine aminotransferase synthesis in rat kidney by estrogen and thyroid hormone. The Journal of Biological Chemistry, Vol.259, No.4, pp 2302-2305, ISSN 0021-9258

Natesan, S. \& Reddy, S.R. (2001). Compensatory changes in enzymes of arginine metabolism during renal hypertrophy in mice. Comparative Biochemistry and Physiology Part B, Biochemistry \& Molecular Biology, Vol.130, No.4, pp 585-595, ISSN 1096-4959

Nelson, C.C.; Hendy, S.C.; Shukin, R.J.; Cheng, H.; Bruchovsky, N.; Koop, B.F. \& Rennie, P.S. (1999). Determinants of DNA sequence specificity of the androgen, progesterone, and glucocorticoid receptors: evidence for differential steroid receptor response elements. Molecular Endocrinology, Vol.13, No.12, pp 2090-2107, ISSN 0888-8809

Peraino, C. \& Pitot, H.C. (1963). Ornithine- $\delta$-transaminase in the rat. I. Assay and some general properties. Biochimica et Biophysica Acta, Vol.73, pp 222-231, ISSN 0006-3002 
Roche, P.J.; Hoare, S.A. \& Parker, M.G. (1992). A consensus DNA-binding site for the androgen receptor. Molecular Endocrinology Vol.6, No.12, pp 2229-2235, ISSN 08888809

Sanada, Y.; Suemori, I. \& Katunuma, N. (1970). Properties of ornithine aminotransferase from rat liver, kidney and small intestine. Biochimica et Biophysica Acta, Vol.220, No.1, pp 42-50, ISSN 0006-3002

Ventura, G.; De Bandt, J.P.; Segaud, F.; Perret, C.; Robic, D.; Levillain, O.; Le Plenier, S.; Godard, C.; Cynober, L. \& Moinard, C. (2009). Overexpression of ornithine aminotransferase: consequences on amino acid homeostasis. The British Journal of Nutrition, Vol.101, No.6, pp 843-851, ISSN 1475-2662

Verrijdt, G.; Haelens, A. \& Claessens, F. (2003). Selective DNA recognition by the androgen receptor as a mechanism for hormone-specific regulation of gene expression. Molecular Genetics and Metabolism, Vol.78, No. 3, pp 175-185, ISSN 1096-7192

Wakabayashi, Y. (2004). The glutamate crossway. In: Metabolic \& Therapeutic Aspects of Amino Acids in Clinical Nutrition, L. Cynober, (Ed.), pp. 135-152, Taylor \& Francis CRC Press, ISBN 0-8493-1382-1, Boca Raton, USA

Wang, Q.; Li, W.; Liu, X.S.; Carroll, J.S.; Janne, O.A.; Keeton, E.K.; Chinnaiyan, A.M.; Pienta, K.J. \& Brown, M. (2007). A hierarchical network of transcription factors governs androgen receptor-dependent prostate cancer growth. Molecular Cell, Vol.27, No.3, pp 380-392, ISSN 0021-9258

Yu, H.; Yoo, P.K.; Aguirre, C.C.; Tsoa, R.W.; Kern, R.M.; Grody, W.W.; Cederbaum, S.D. \& Iyer, R.K. (2003). Widespread expression of arginase I in mouse tissues. Biochemical and physiological implications. The Journal of Histochemistry and Cytochemistry Vol.51, No.9, pp 1151-1160, ISSN 0022-1554

Zintz, C.B. \& Inana, G. (1990). Analysis of the human ornithine aminotransferase gene family. Experimental Eye Research, Vol.50, No.6, pp 759-770, ISSN 0014-4835 


\section{Part 4}

\section{Insulinomas}





\title{
Diagnosis and Treatment of Insulinomas in the Adults
}

\author{
D. Vezzosi et al. ${ }^{*}$ \\ Department of Endocrinology, CHU Larrey, Toulouse \\ France
}

\section{Introduction}

Insulinomas are rare endocrine tumours developed from pancreatic beta cells. Their incidence is about 1 in 250,000 patient-years (Cryer 2008) (0.396 per 100,000 person-years for two decades, 1967-1986) (Service et al. 1991). The median age at surgical diagnosis was found to be 47 years ( 8 to 82 ), $59 \%$ being female patients. In a series of 33 patients, the age at the time of diagnosis was $57+/-16$ years (mean +/- SD) (range: 18-85 years) and 66\% were female patients (Vezzosi et al. 2007). 90\% of insulinomas are single, benign and sporadic tumours that are located in the pancreas. The diagnostic and therapeutic strategy of benign sporadic insulinomas has been now established by a recent expert consensus (Cryer et al. 2009). However, some issues remain unaddressed regarding the diagnosis and the treatment of insulinomas. More rarely, in about $10 \%$ of insulinoma patients, the insulinoma is part of MEN-1. Such patients often present with multiple insulinomas and other secreting or non-secreting endocrine tumours. Finally, a particular condition is malignant insulinoma, also found in about $10 \%$ of insulinoma patients. There are no recommendations regarding the particular conditions represented by insulinomas in MEN-1 and malignant insulinomas.

The aim of this chapter is to give an updated and detailed view of the medical management of adult patients with insulinoma regarding the diagnosis (diagnosis of hypoglycemia related to endogenous hyperinsulinism, differential diagnosis, topographic assessment) and the treatment (surgery, medical therapies), including the therapeutic strategy and the possibilities of long-term medical treatment in inoperable patients. The first part of the chapter will be focused on the most frequent case, i.e. single benign sporadic insulinoma. The remaining parts of the chapter will deal with specific issues and concerns regarding malignant insulinomas, insulinomas in genetic disorders, and the rare cases of nesidioblastosis in the adults.

\footnotetext{
${ }^{*}$ D. Vezzosi ${ }^{1}$, A. Bennet ${ }^{1}$, J.C. Maiza ${ }^{1}$, A. Buffet ${ }^{1}$, S. Grunenwald ${ }^{1}$, J. Fauvel${ }^{2}$, F. Courbon 3 , P. Otal ${ }^{4}$, N. Carrere $^{5}$ and $\mathrm{Ph}$. Caron ${ }^{1}$

${ }^{1}$ Department of Endocrinology and Metabolic Diseases, CHU Larrey,

${ }^{2}$ Laboratory of Biochemistry, IFB, CHU Purpan,

${ }^{3}$ Department of Nuclear Medicine, CHU Rangueil,

${ }^{4}$ Department of Radiology, CHU Rangueil,

${ }^{5}$ Department of Surgery, CHU Purpan, Toulouse, France.
} 


\section{Single benign sporadic insulinomas}

\subsection{Diagnosis of hypoglycaemia related to endogenous hyperinsulinism}

\subsubsection{Clinical symptoms of insulinomas}

The clinical symptoms of insulinomas are heterogeneous and may differ among the patients. There is no specific clinical symptom. Hypoglycaemia results in autonomic and neuroglycopenic symptoms. Autonomic symptoms comprise adrenergic symptoms, such as palpitations and tremor, and cholinergic symptoms, with sweating, hunger, sometimes paresthesias. Neuroglycopenic symptoms comprise severe weakness, and many psychiatric and neurological manifestations, the most commonly reported being behavioural changes, confusion, agitation or slow reaction patterns, blurred vision, and finally seizures, transient loss of consciousness or hypoglycaemic coma. Hypoglycaemic coma is typically sudden, with agitation, sometimes pyramidal signs, and hypothermia; it may be profound and prolonged and therefore may be a cause of neurologic and cognitive sequelae and may occasionally lead to brain death. The combination of autonomic and moderate neuroglycopenic symptoms strongly suggests the diagnosis of hypoglycaemia. However, in insulinoma patients, autonomic symptoms may often be lacking. Neuroglycopenic symptoms are more specific of hypoglycemia related to insulinoma, but may be mild, or more often misleading. Therefore measurement of plasma glucose concentrations should be recommended in all patients with such symptoms, either in a patient without any known neurological or psychiatric disorder, or in a patient in whom such disorder had been previously controlled. Hypoglycaemic spells typically occur suddenly after a period of fast, several hours after the last meal, or after physical exercise. Some of them have been reported to occur within the hours following a meal or without any relationship with meal time, so that symptoms occurring in non fasting patients cannot rule out the diagnosis of insulinoma. In a series of 214 insulinoma patients with a reliable clinical history, symptoms of hypoglycaemia were reported exclusively in the fasting state in $73 \%$, postprandial state in $6 \%$, and both fasting and postprandial state in $21 \%$ (Placzkowski et al. 2009). Weight gain is found only in $25 \%$ of patients.

Rapid (or rarely delayed) resolution of symptoms after glucose administration is part of Whipple's triad, which makes the diagnosis of hypoglycaemia when it has been assessed reliably; the triad comprises clinical symptoms of hypoglycaemia, the finding of a low plasma glucose concentration at the time of clinical symptoms, and subsiding of clinical symptoms after glucose administration.

In rare pregnant patients with insulinoma, symptoms may resemble those of emesis in early pregnancy and may subside in late pregnancy as a consequence of insulin resistance, then are unmasked after delivery (Diaz et al. 2008), as reported in a patient who presented with coma and clonic seizures 14 hours after delivery (Christiansen \& Vestergaard 2008).

\subsubsection{Biological diagnosis of insulinomas}

\section{Plasma glucose concentrations}

Since the clinical symptoms lack diagnostic specificity, measurement of plasma concentration of glucose is mandatory (ideally at the time of occurrence of clinical symptoms) and must be performed in venous blood samples with a reliable laboratory method. In order to avoid pseudohypoglycaemia, i.e. a consequence of glucose metabolism by blood cells in the tube containing the blood sample, the blood sample should be collected in a tube with a glycolysis inhibitor $(\mathrm{NaF})$. Glucose concentrations are measured using reference method with hexokinase. 
The threshold to define hypoglycemia remains controversial. According to recent expert recommendations (Cryer et al. 2009) a $0.55 \mathrm{~g} / \mathrm{L}$ threshold must be selected. However, the glycaemic threshold that can cause clinical symptoms is very different among individuals, and a plasma concentration of glucose below $0.7 \mathrm{~g} / \mathrm{L}$ at the time of clinical symptoms is thought be enough, if the other criteria of Whipple's triad are fulfilled, to warrant further investigation. A plasma glucose concentration above $0.7 \mathrm{~g} / \mathrm{L}$ during a symptomatic episode indicates that those symptoms are not the result of hypoglycaemia.

Since even values below $0.55 \mathrm{~g} / \mathrm{L}$ can be found in some healthy individuals, it is also recommended by the expert consensus that such levels be taken into account for further evaluation only in patients who had presented Whipple's triad. On the other hand, very rare insulinoma patients were found to be asymptomatic and did not fulfil Whipple's triad. Among our patients (Vezzosi et al. 2007), the diagnosis of insulinoma was made on the basis of repeated plasma glucose concentrations of $0.40-0.55 \mathrm{~g} / 1$ after overnight fasts in one patient, though she never described any clinical symptom. In many insulinoma patients, the glycaemic threshold for clinical symptoms is shifted to very low glucose levels, so that they may be asymptomatic at the time of plasma glucose concentrations below 0.55 and even 0.45 $\mathrm{g} / \mathrm{L}$; most of these patients experienced some clinical symptoms suggestive of hypoglycaemia, but even if they present with fasting glucose levels below $0.55 \mathrm{~g} / \mathrm{L}$, Whipple's triad has not been assessed in most of them, and awaiting Whipple's triad to be fulfilled would make the diagnosis be delayed. The finding of a spontaneous plasma glucose concentration below $0.55 \mathrm{~g} / \mathrm{L}$ is rare in normal subjects; during a 72-hour fast test, plasma glucose concentrations do not reach values below $0.45 \mathrm{~g} / \mathrm{L}$ in most controls, and do not drop below $0.4 \mathrm{~g} / \mathrm{L}$ in controls (Vezzosi et al. 2007). Therefore we think that patients with spontaneous plasma glucose concentrations below $0.55 \mathrm{~g} / \mathrm{L}$ warrant further investigation, even when they do not fulfil all the criteria of Whipple's triad, and that such evaluation is mandatory in patients with plasma concentrations below $0.45 \mathrm{~g} / \mathrm{L}$, provided that plasma glucose concentration has been measured reliably in a venous sample.

Confirmation of hypoglycaemia in a venous sample is the first requirement for the biological diagnosis of insulinoma.

If a venous sample cannot be collected when hypoglycaemia occurs spontaneously, a 72 hour-fast test is to be performed.

A detailed protocol for the fast test has first been described by the Mayo Clinic group (Service 1995)(Service 1999) and more recently by an expert consensus (Cryer et al. 2009). The patient is allowed to drink calorie-free beverages. Samples are to be collected every 6 hours until the plasma glucose concentration is less than $0.6 \mathrm{~g} / \mathrm{L}$ if the patient remains asymptomatic, then the frequency of sampling is increased (every 1 or 2 hours). Serum insulin, C-peptide, proinsulin and beta-hydroxy-butyrate are to be measured in all the samples taken at the time when plasma glucose concentration drops below $0.6 \mathrm{~g} / \mathrm{L}$. At the end of the fast test, a sample is collected to measure oral hypoglycaemic agents; a glucagon test (1.0 mg intravenously) has also been recommended. Insulin antibodies should also be measured.

The criteria used to decide to stop the fast test before 72 hours have been modified recently. According to previous recommendations (Service 1995), the fast test is to be stopped if the patient has symptomatic hypoglycaemia with a plasma glucose concentration of $0.45 \mathrm{~g} / 1$ or less, or if the plasma glucose concentration drops below $0.4 \mathrm{~g} / \mathrm{L}$. According to the recent recommendations (Cryer et al. 2009) the fast test can be stopped: 1) when Whipple's triad is observed; 2) when plasma glucose concentrations drop below $0.55 \mathrm{~g} / \mathrm{L}$ in a patient who had previously experienced Whipple's triad; 3) if plasma beta-hydroxy-butyrate levels rise above $2.7 \mathrm{mmol} / \mathrm{L}$. 
Awaiting that plasma glucose concentrations drop below $0.45 \mathrm{~g} / \mathrm{L}$ in an asymptomatic patient to stop the fast test, instead of stopping the fast when plasma glucose is $0.46-0.54$ $\mathrm{g} / \mathrm{L}$, leads to an improvement in diagnostic specificity regarding the diagnosis of a hypoglycaemic disorder. In our own data, out of 67 controls, 31 reached glucose plasma concentrations of $0.46-0.54 \mathrm{~g} / \mathrm{L}$ during a 72-hour fast test, and only 4 reached values within the $0.40-0.45 \mathrm{~g} / \mathrm{L}$ range $(0.41-0.43 \mathrm{~g} / \mathrm{L})$ after 24 hours of fast. No control subject reached plasma glucose concentrations below $0.4 \mathrm{~g} / \mathrm{L}$. Among 55 patients who were diagnosed to have insulinoma in our institution between 1997 and 2010, and who underwent a fast test, only one patient reached a plasma glucose concentration below 0.55 $\mathrm{g} / \mathrm{L}(0.53 \mathrm{~g} / \mathrm{L})$ without further decrease in glucose concentration, and all the other patients who had a positive fast test reached glucose concentrations below $0.45 \mathrm{~g} / \mathrm{L}$; the fast test was negative in one patient. In addition, using a $0.45 \mathrm{~g} / \mathrm{L}$ glucose level threshold increases the diagnostic specificity of concomitant serum insulin, C-peptide and proinsulin levels for the diagnosis of insulinoma (see below). Therefore we think that if the patient remains asymptomatic, the fast test is to be prolonged at least until reaching plasma glucose concentrations below $0.45 \mathrm{~g} / \mathrm{L}$, the diagnostic specificity being about $100 \%$ if such levels are reached.

In most insulinoma patients such plasma glucose concentrations are reached within the first 48 hours of the test (Hirshberg et al. 2000; Vezzosi et al. 2007), though the 72 hour-fast test was reported to be necessary to provide a clear diagnostic conclusion in a few patients (Service 1999; Service \& Natt 2000). Moreover, additional criteria for the diagnosis of insulinoma using proinsulin and beta-hydroxy-butyrate levels and plasma glucose response to intravenous glucagon were established during a 72-hour (not 48-hour) fast test for patients who did not reach plasma glucose concentrations below 0.45 or $0.55 \mathrm{~g} / \mathrm{L}$. Thus in most patients the test to be performed is the classical 72 hour-test. However, 48 hours of fast test are enough to provide diagnostic evidence in almost all insulinoma patients who have a positive fast test.

In the patients who experience symptoms of hypoglycemia only within the hours following a meal, a meal test is to be performed with serial measurement of plasma concentrations of glucose, insulin, C-peptide and proinsulin during the 5 hours following the ingestion of a standardized meal. A mixed meal similar to that which the patient reports to have caused the clinical symptoms is to be used, or a commercial formula mixed meal. Samples should be collected every 30 minutes and those collected for insulin, C-peptide and proinsulin measurement should be sent for analysis only if the sample has been taken at the time when plasma glucose concentration was found to be below $0.6 \mathrm{~g} / \mathrm{L}$. Measurement of oral hypoglycaemic agents and anti-insulin antibodies must also be performed if Whipple's triad is demonstrated (Cryer et al. 2009). Post-prandial hypoglycaemia without fasting hypoglycaemia is now known to occur in some insulinoma patients $(6 \%$ according to Placzkowski et al. 2009) and in patients with noninsulinoma pancreatogenous hypoglycaemia (Service et al. 1999), a syndrome which is part of nesidioblastosis (see below). Others have reported false negative tests in insulinoma patients who are correctly diagnosed after a meal test or oral glucose tolerance test (Sjoberg \& Kidd 1992) (Izumiyama et al. 2006; Kar et al. 2006). A mixed meal test was shown to be preferable to the oral glucose tolerance test (Hogan et al. 1983), so that only the meal test was recommended in the 2009 expert consensus.

The next requirement for the diagnosis of insulinoma is to provide evidence for inappropriate insulin secretion at the time of hypoglycaemia. 


\section{Criteria for inappropriate insulin secretion (hypoglycaemia related to endogenous hyperinsulinism)}

According to the expert consensus, the diagnosis of hypoglycaemia related to endogenous hyperinsulinism can be made when serum insulin concentration is equal to or greater than 3 $\mathrm{mIU} / \mathrm{L}$, serum C-peptide concentration is equal to or greater than $0.6 \mathrm{ng} / \mathrm{mL}(0.2 \mathrm{nmol} / \mathrm{L})$, and serum proinsulin concentration is equal to or greater than $5 \mathrm{pmol} / \mathrm{L}$ at the time of hypoglycaemia, with venous plasma glucose concentrations less than $0.55 \mathrm{~g} / \mathrm{L}$. During a fast test, beta-hydroxy-butyrate levels of $2.7 \mathrm{mmol} / \mathrm{L}$ or less and an increase in plasma glucose of at least $0.25 \mathrm{~g} / \mathrm{L}$ after intravenous glucagon indicate mediation of hypoglycaemia by insulin.

\section{Insulin}

Serum insulin concentrations can be artifactually modified by haemolysis, heterophilic antibodies, and endogenous anti-insulin antibodies. Red cells contain an insulin-degrading enzyme which may lead to underestimation of the actual insulin concentrations on haemolysed samples. Most insulin assays are calibrated against the standard IRP 66/304 preparation, and the new $83 / 500$ standard is not yet used by all insulin assays. As a consequence of the differences between the standards and the methods employed, the conversion factor from $\mathrm{mIU} / \mathrm{L}$ to $\mathrm{pmol} / \mathrm{L}$ varies from 6.0 to 7.5. In the 2009 expert consensus, the threshold of $3 \mathrm{mIU} / \mathrm{L}$ is equal to $18 \mathrm{pmol} / \mathrm{L}$.

Insulin concentrations had been measured for long with non-specific assays that yielded cross-reactions with proinsulin. The insulin assays that are now in use have negligible crossreaction with proinsulin. Though the $3 \mathrm{mIU} / \mathrm{L}$ threshold (which replaces a $6 \mathrm{mIU} / 1$ threshold previously established with less specific insulin assays) was established for insulin-specific assays, it is known now that the finding of low insulin levels with such assays cannot rule out the diagnosis of insulinoma (Vezzosi et al. 2003). 11-35\% patients with insulinoma were found to have insulin levels below the recommended diagnostic threshold $(3 \mathrm{mIU} / \mathrm{L})$ at the time of hypoglycemia when insulin was measured with insulinspecific assays, the percentage of values below $3 \mathrm{mIU} / \mathrm{L}$ depending on the assay employed (Vezzosi et al. 2007). On the other hand, while the specificity of the $3 \mathrm{mIU} / \mathrm{L}$ threshold was found to be $100 \%$ with a plasma glucose concentration threshold of $0.45 \mathrm{~g} / \mathrm{L}$ for the diagnosis of hypoglycaemia related to endogenous hyperinsulinism, it was lowered to $87 \%$ for glucose levels ranging from 0.46 to $0.54 \mathrm{~g} / \mathrm{L}$ (personal data). The sensitivity and specificity for serum insulin concentrations with a threshold level of at least $3 \mathrm{mIU} / 1$ at the time of plasma glucose concentrations below $0.6 \mathrm{~g} / \mathrm{L}$ were found to be $93 \%$ and $95 \%$, respectively (Placzkowski et al. 2009).

\section{C-peptide}

C-peptide and proinsulin levels at the time of hypoglycemia have better diagnostic accuracy than insulin levels. C-peptide assays are calibrated against the $1^{\text {st }}$ standard IRP 84/510 (WHO). According to the expert consensus (Cryer et al. 2009), serum C-peptide levels of at least $0.6 \mathrm{ng} / \mathrm{mL}$ concomitant with plasma glucose concentrations below $0.55 \mathrm{~g} / 1$ are one of the criteria that make the diagnosis of hypoglycaemia related to endogenous hyperinsulinism. In 33 patients who reached plasma glucose concentrations below $0.45 \mathrm{~g} / \mathrm{L}$ during a fast test, all insulinoma patients had C-peptide levels above $0.6 \mathrm{ng} / \mathrm{mL}$, and only one patient who had previously been treated by left-sided pancreatectomy for nesidioblastosis and who had recurrent hypoglycaemia did not reach the $0.6 \mathrm{ng} / \mathrm{mL}$ threshold at the time of hypoglycaemia below $0.45 \mathrm{~g} / \mathrm{L}$ (Vezzosi et al. 2007). The diagnostic accuracy is improved when blood glucose levels drop below $0.45 \mathrm{~g} / \mathrm{L}$ : for such blood glucose levels, the sensitivity 
and specificity of C-peptide (with a threshold of $0.6 \mathrm{ng} / \mathrm{mL}$ ) are close to $100 \%$, whereas we observed a false positive rate of $9 \%$ for C-peptide for concomitant plasma glucose concentrations of $0.46-0.54 \mathrm{~g} / \mathrm{L}$ (personal data). It had been previously shown that for the 0.50 $0.60 \mathrm{~g} / \mathrm{L}$ (O’Brien et al.1993) or $0.45-0.60 \mathrm{~g} / \mathrm{L}$ (Vezzosi et al. 2007) range for plasma glucose concentrations, there was a considerable overlap between patients and controls regarding Cpeptide levels. In the study by Placzowski et al. the sensitivity of the $0.6 \mathrm{ng} / \mathrm{mL}$ threshold for the diagnosis of insulinoma is $100 \%$ if concomitant plasma glucose is below $0.6 \mathrm{~g} / \mathrm{L}$, while its specificity is $60 \%$ for concomitant glucose levels below $0.6 \mathrm{~g} / \mathrm{L}$ and $78 \%$ for concomitant glucose levels of $0.5 \mathrm{~g} / 1$ or less (Placzkowski et al. 2009). This argues for prolonging the fast test until a glucose level of $0.45 \mathrm{~g} / \mathrm{L}$ or less is reached.

\section{Proinsulin}

A high proportion of proinsulin is known to be secreted by insulinomas. Intact proinsulin enzymatic processing leads to split 32,33 proinsulin or split 65,66 proinsulin, then to des31,32-proinsulin (the molecule with the highest serum concentration) and des-64,65proinsulin and finally to insulin and C-peptide. Proinsulin assays may measure either intact proinsulin (most of them measuring both intact proinsulin and des-64,65-proinsulin) or "total proinsulin" (i.e. intact proinsulin and the other molecules, mostly des-31,32proinsulin). Therefore the results depend strongly on the method employed. In addition, proinsulin should be measured in serum samples, since results observed in plasma samples may be different (and higher).

According to the 2009 consensus (Cryer et al. 2009), proinsulin levels of at least 5 pmol/L concomitant with plasma glucose concentrations below $0.55 \mathrm{~g} / \mathrm{L}$ are one of the criteria that make the diagnosis of hypoglycaemia related to endogenous hyperinsulinism. Whether this $5 \mathrm{pmol} / \mathrm{L}$ threshold refers to assays measuring "total proinsulin" or "intact proinsulin", or to a specific assay, has not been specified. We used the Human Proinsulin RIA kit (Linco Research), which measures "total proinsulin" (in fact intact proinsulin and des-31,32-proinsulin, the cross-reactions with des-64,65-proinsulin, insulin and C-peptide being $<0.1 \%$ ), to measure proinsulin in 33 patients with hypoglycaemia related to endogenous hyperinsulinism and 67 controls who underwent a 72-hour fast test. $100 \%$ sensitivity and specificity were found using a $5 \mathrm{pmol} / \mathrm{L}$ threshold for serum proinsulin and a $0.45 \mathrm{~g} / 1$ threshold for plasma glucose concentration (Vezzosi et al. 2007). The specificity would have been much lowered if the $5 \mathrm{pmol} / \mathrm{L}$ threshold had been applied to the $0.46-0.54 \mathrm{~g} / \mathrm{L}$ range for plasma glucose concentrations: 9 out of 31 control subjects $(29 \%)$ who reached this range of plasma glucose concentrations during the prolonged fast were found to have proinsulin levels above $5 \mathrm{pmol} / \mathrm{L}$ (personal data). For this threshold of $5 \mathrm{pmol} / \mathrm{L}$, Placzowski et al reported a 100\%-sensitivity for the diagnosis with plasma glucose concentrations below $0.6 \mathrm{~g} / \mathrm{L}$, whereas the specificity was only $68 \%$ and $78 \%$ with glucose levels below $0.6 \mathrm{~g} / \mathrm{L}$ and below $0.5 \mathrm{~g} / \mathrm{L}$, respectively (Placzkowski et al. 2009). This also argues for prolonging the fast test until a glucose level of $0.45 \mathrm{~g} / \mathrm{L}$ or less is reached.

In addition, serum proinsulin levels above 22 pmol/L can make the diagnosis of hypoglycaemia related to endogenous hyperinsulinism when concomitant plasma glucose concentration is below $0.6 \mathrm{~g} / \mathrm{L}$ with $74 \%$ sensitivity and $100 \%$ specificity. Moreover, in nonobese subjects (body mass index less than $30 \mathrm{~kg} / \mathrm{m} 2$ ) the diagnostic specificity of a 22 $\mathrm{pmol} / \mathrm{L}$ for serum proinsulin levels measured after an overnight fast was found to be $100 \%$, while its sensitivity was $70 \%$, with concomitant low or normal plasma glucose 
concentrations (Vezzosi et al. 2007). This $22 \mathrm{pmol} / \mathrm{L}(0.2 \mathrm{ng} / \mathrm{mL})$ threshold for proinsulin had been previously reported by Hirshberg et al. (Hirshberg et al. 2000). In obese or insulinresistant subjects, proinsulin levels after an overnight fast exceeding $22 \mathrm{pmol} / \mathrm{L}$ do not make the diagnosis of insulinoma: in a group of 110 obese subjects who did not present with glycaemic disorders, 23 (21\%) had proinsulin levels above 22 pmol/L after an overnight fast (Vezzosi et al. 2007). In conclusion, serum proinsulin levels after an overnight fast below 22 $\mathrm{pmol} / \mathrm{L}$ do not rule out the diagnosis of insulinoma, while if they are above $22 \mathrm{pmol} / \mathrm{L}$ in a non-obese, non-insulin-resistant subject they should lead to a high suspicion of insulinoma, but to date, this can be used as a diagnostic criterion only if plasma glucose levels do not exceed $0.6 \mathrm{~g} / \mathrm{L}$.

There are some limitations regarding the insulin, C-peptide and proinsulin threshold levels for the diagnosis of hypoglycaemia related to endogenous hyperinsulinism.

The recommended diagnostic thresholds for serum insulin, C-peptide and proinsulin levels are known to be valid only in patients with normal liver and renal function, and there is no study regarding their validity in patients who have concurrent endocrine disorders liable to modify insulin resistance or sensitivity and glucose counter-regulation. In addition, there is no specific study regarding their validity for the diagnosis of recurrence of insulinoma after partial pancreatectomy.

In 33 patients with hypoglycaemia related to endogenous hyperinsulinism, the only patient who did not present with a C-peptide level of at least $0.6 \mathrm{ng} / \mathrm{mL}$ at the time of hypoglycaemia below $0.45 \mathrm{~g} / 1$ during a fast test was a patient who had recurrence of nesidioblastosis one year after undergoing left-sided pancreatectomy; we speculated that a lower glucagon production could explain why severe hypoglycaemia was associated with lower insulin and C-peptide levels than in the other patients (Vezzosi et al. 2007). In addition, three of our patients with malignant insulinomas, in whom total remission had been initially achieved by partial pancreatectomy, did not fulfil the criteria for C-peptide levels when they were found to have recurrence of tumour-induced hypoglycaemia (personal data).

Insulin clearance takes place in the liver ( $50 \%$ of portal insulin is cleared by the liver) and in the kidney (50\% of peripheral insulin removal) both by diffusion and receptor-mediated transport, the major route of clearance being receptor-mediated degradation by the renal tubular epithelial cells; the kidney also removes $70 \%$ of C-peptide by renal filtration. Therefore, measuring insulin and C-peptide levels in patients with severe renal insufficiency is not helpful; in such patients it has been recommended to use beta-hydroxy-butyrate levels and glucose response to glucagon at the end of a fast test to provide evidence for insulinmediated hypoglycaemia (Basu et al. 2002).

\section{Beta-hydroxy-butyrate}

Another valuable tool for the diagnosis of insulinomas is measurement of plasma betahydroxy-butyrate level during the fast test. Insulin is known to suppress ketogenesis. According to the 2009 consensus (Cryer et al. 2009), during a fast test, beta-hydroxy-butyrate levels of $2.7 \mathrm{mmol} / \mathrm{L}$ or less indicate mediation of hypoglycaemia by insulin.

A progressive rise in beta-hydroxy-butyrate levels during the fast test was found to rule out insulinomas (Service \& O'Brien 2005). A plasma level of beta-hydroxy-butyrate exceeding $2.7 \mathrm{mmol} / \mathrm{L}$ was found to rule out the diagnosis of insulinoma when blood glucose levels were $0.50-0.60 \mathrm{~g} / \mathrm{L}$ during a 72 -hour fast test with both sensitivity and specificity close to 
$100 \%$ (O'Brien et al. 1993). There is no study specifying the validity of this criterion for another range of plasma glucose concentrations. Placzowski et al. reported $100 \%$ sensitivity and specificity for the diagnosis of insulinoma with beta-hydroxy-butyrate levels of 2.7 $\mathrm{mmol} / \mathrm{L}$ or less during a fast test with concomitant plasma glucose concentrations below 0.6 $\mathrm{g} / \mathrm{L}$ or below $0.5 \mathrm{~g} / \mathrm{L}$ (Placzkowski et al. 2009), but the results are not detailed. There are two case reports of insulinoma patients with false negative results of beta-hydroxy-butyrate levels: an 80-year-old female patient with plasma glucose concentrations of $0.48 \mathrm{~g} / \mathrm{L}(2.7$ $\mathrm{mmol} / \mathrm{L})$, serum C-peptide of $0.93 \mathrm{ng} / \mathrm{mL}(0.31 \mathrm{nmol} / \mathrm{L})$ and beta-hydroxy-butyrate levels of $3.0 \mathrm{mmol} / \mathrm{L}$ after 72 hours of fast (Wiesli et al. 2004b) and a 49-year-old man with plasma glucose concentrations of $0.32 \mathrm{~g} / \mathrm{L}$, serum C-peptide levels of $1.2 \mathrm{ng} / \mathrm{mL}$, and betahydroxy-butyrate levels of $3.2 \mathrm{mmol} / \mathrm{L}$ (Soh \& Kek 2010). Among our patients (Vezzosi et al. 2007), one patient with a malignant insulinoma was found to have, during a fast test, plasma glucose concentrations of $0.36 \mathrm{~g} / \mathrm{L}$, serum C-peptide levels of $1.7 \mathrm{ng} / \mathrm{mL}$, plasma proinsulin levels of $37 \mathrm{pmol} / \mathrm{L}$ (which led to the unequivocal diagnosis of inappropriate insulin secretion) and plasma beta-hydroxy-butyrate levels of $3.8 \mathrm{mmol} / \mathrm{L}$. We hypothesized that severe hypoglycaemia below $0.45 \mathrm{~g} / \mathrm{L}$ could result in a greater secretion of counterregulatory hormones thereby leading to an increase in beta-hydroxy-butyrate levels; lipolysis may escape the inhibitory effect of insulin during hyperinsulinic hypoglycaemia (Lucidi et al. 2010). However we observed a patient with a malignant insulinoma whose lowest plasma glucose concentration during a 72 hour-fast test was $0.53 \mathrm{~g} / \mathrm{L}$ after 58 hours of fast, with concomitant serum levels of insulin, C-peptide and proinsulin of $13 \mathrm{mIU} / \mathrm{L}, 2.4 \mathrm{ng} / \mathrm{mL}$, and $36 \mathrm{pmol} / \mathrm{L}$ (which gave diagnostic evidence), respectively, and plasma beta-hydroxy-butyrate levels above $2.7 \mathrm{mmol} / \mathrm{L}$. At the end of the 72 hour-fast test, beta-hydoxy-butyrate levels reached the value of $7.0 \mathrm{mmol} / \mathrm{L}$ in this patient, with concomitant concentrations of $0.68 \mathrm{~g} / \mathrm{L}$ for plasma glucose, $4.0 \mathrm{mIU} / \mathrm{L}$ for serum insulin, $1.2 \mathrm{ng} / \mathrm{mL}$ for serum C-peptide and 25 $\mathrm{pmol} / \mathrm{L}$ for serum proinsulin (personal data).

In conclusion, though being very valuable, the threshold of $2.7 \mathrm{mmol} / \mathrm{L}$ or less for betahydroxy-butyrate levels does not yield $100 \%$ sensitivity and specificity. Based on the observed results there are several caveats: 1 ) beta-hydroxy-butyrate levels may lose part of their diagnostic accuracy when plasma glucose concentrations are below $0.45 \mathrm{~g} / \mathrm{L}$ and are of minor interest for this range of glucose levels; 2) proinsulin levels must be taken into account before ruling out the diagnosis of insulinoma in patients whose plasma glucose concentrations are within the $0.45-0.60 \mathrm{~g} / \mathrm{L}$ range even when plasma beta-hydroxy-butyrate levels reach values above $2.7 \mathrm{mmol} / \mathrm{L}$; 3) patients with recurrent insulinoma or nesidioblastosis after partial pancreatectomy may not fulfil the usual diagnostic criteria for insulin-mediated hypoglycaemia during the fast test. Whether a disruption in the progressive elevation of beta-hydroxy-butyrate levels concomitant with lower glucose levels during the fast test (with an insulin secretory burst) should lead to suspicion of insulinoma remains to be determined.

\section{Glucagon test}

According to the 2009 expert consensus (Cryer et al. 2009) an increase in plasma glucose of at least $25 \mathrm{mg} / \mathrm{dL}(0.25 \mathrm{~g} / \mathrm{L}, 1.4 \mathrm{mmol} / \mathrm{L})$ after intravenous glucagon indicate mediation of hypoglycaemia by insulin. This refers to the evaluation protocol established by the Mayo Clinic group (O'Brien et al. 1993) : the glucagon test is performed at the end of a prolonged fast test, i.e. either at the time of occurrence of symptomatic hypoglycaemia with concomitant 
plasma glucose concentrations of $0.45 \mathrm{~g} / \mathrm{L}(2.5 \mathrm{mmol} / \mathrm{L})$ or less, or after 72 hours of fast: plasma glucose responses to the intravenous injection of $1 \mathrm{mg}$ glucagon are measured at 10 min-intervals for $30 \mathrm{~min}$. Under these conditions, plasma glucose response to glucagon was found to be higher in insulinoma patients than in controls with a range of maximal increase in plasma glucose concentrations of 1.4-5.4 mmol/L in insulinoma patients and of 0.1-1.3 $\mathrm{mmol} / \mathrm{L}$ in controls, as a consequence of a lesser depletion of hepatic glycogen in insulinoma patients during the fast, which is related to the higher insulin secretion in the patients. This allowed a clear distinction between patients and controls who has reached plasma glucose concentrations below $3.3 \mathrm{mmol} / \mathrm{L}(0.6 \mathrm{~g} / \mathrm{L})$ during the fast test (O'Brien et al. 1993).

On the other hand, the glucagon test has long been known to be a provocative test in insulinoma patients: glucagon may trigger severe hypoglycaemia related to insulin secretion in insulinoma patients. This provocative test was found to be helpful for the diagnosis of insulinoma in patients with a negative fast test (Wiesli et al. 2004b; Soh \& Kek 2010).

\section{Other diagnostic criteria for hypoglycaemia related to endogenous hyperinsulinism}

* Regarding the various tests employed in the evaluation of a patient with suspected hypoglycaemic disorder, only the fast test, with a glucagon test at its termination, in patients with symptoms of fasting hypoglycaemia, and the mixed meal test in patients with postprandial hypoglycaemia are recommended by the 2009 expert consensus (Cryer et al. 2009).

\# Physical exercise is known to result in hypoglycaemia in many insulinoma patients. A physical exercise was found to be necessary in some insulinoma patients to make the correct diagnosis (Jarhult et al. 1981). The percentage of patients with negative fast test and meal test who could be diagnosed to have insulinoma by a physical exercise test remains to be established. In selected patients a "physical exercise test" under medical supervision, with at least serial measurements of plasma glucose and serum insulin, C-peptide and proinsulin could be considered.

\# Cohn's diet (1200 kcal with $50 \mathrm{~g}$ of carbohydrates followed by a 36 hour-fast) is no more in use and has been replaced by the 72 hour-fast test.

\# The oral glucose tolerance test was found to be of interest in patients with a negative fast test (Wiesli et al. 2004b) (Kar et al. 2006), but it was shown to be less accurate than the mixed meal test (Hogan et al. 1983) and is not recommended by the 2009 expert consensus (Cryer et al. 2009). 10\% of healthy persons were reported to have a plasma glucose nadir less than $0.5 \mathrm{~g} / \mathrm{L}$ during this test while being asymptomatic and without presenting with Whipple's triad (Lev-Ran \& Anderson 1981). Whether such subjects may have some subtle abnormality regarding glucose regulation may still be debated, but this test was not considered as a tool to provide diagnostic evidence for a hypoglycaemic disorder.

\# The C-peptide suppression test by insulin-induced hypoglycaemia may give results that do not clearly distinguish all patients from controls, and its interpretation may be difficult, since the results depend on several parameters including gender and body mass index (Service et al. 1992). A more sophisticated C-peptide suppression test, combined with the euglycaemic clamp, was successfully employed for the diagnosis of insulinoma, but it cannot be recommended for clinical practice (Gin et al. 1987).

* Regarding the diagnostic criteria for inappropriate insulin secretion, previously employed ratios (insulin/glucose ratio, Turner's index) are no more in use and do not bring greater diagnostic accuracy than the presently-used criteria (Vezzosi et al. 2007) (Service 1995). Though insulinoma secrete a high proportion of proinsulin, the proinsulin/insulin ratio 
does not bring more valuable information than proinsulin levels for the diagnosis of insulinoma (Vezzosi et al. 2007).

\subsection{Differential diagnosis}

\subsubsection{Evaluation of the patient}

In an adult patient clinically otherwise healthy who presents with severe hypoglycemia, the diagnosis of insulinoma must be considered as very likely, provided that the patient does not use insulin or other hypoglycaemic agents.

Apart from "reactive functional hypoglycaemia"(see below), which is a controversial and heterogeneous medical entity without actual hypoglycaemia below $0.55 \mathrm{~g} / \mathrm{L}$, other actual causes of hypoglycaemia are often observed in patients presenting with other clinical symptoms related to their disease: alcohol ingestion, critically ill patients or septicemia, severe prolonged undernutrition, liver or renal deficiency, adrenal insufficiency, hypopituitarism, IGF-II or pro-IGF-II secreting tumours, or very rare patients with other tumour secretion (IGF-I, GLP1 and somatostatin).

Thus the first step is to record carefully the history of the patient including exposure to any medication, and the possible access to hypoglycaemic agents, and to perform a clinical physical examination.

Then the causes of hypoglycaemia are identified mainly on the basis of insulin, C-peptide and proinsulin levels at the time of hypoglycaemia. Additional biological evaluation comprises measurement of oral hypoglycaemic agents (at the time of hypoglycaemia) and anti-insulin antibodies (at any time) in plasma samples in patients who are found to have insulin-mediated hypoglycaemia. Other plasma measurements will be made if there is clinical presumption of a specific disease, for instance diseases known to lead to hypoglycaemia mediated by IGF-II or incompletely processed IGF-II ("big IGF-II"), exceptionally IGF-I. Finally, according to the 2009 expert consensus (Cryer et al. 2009), "a test of adrenocortical function is reasonable".

\subsubsection{Reactive "functional hypoglycaemia"}

Reactive "functional hypoglycaemia" is a controversial entity, and its existence is still debated. The first definition of "reactive functional hypoglycaemia" had been based on the belief that hypoglycaemic disorders could be divided into disorders responsible for fasting hypoglycaemia (mainly insulinoma) and disorders responsible for reactive hypoglycaemia (mainly "functional hypoglycaemia"). It is now known that many organic disorders may result both in fasting and/or reactive hypoglycaemia. However, many patients present with dizziness or minor autonomic symptoms within the hours following a meal, and most of them do not meet the criteria for actual hypoglycaemia, i.e. they do not have actually low plasma glucose levels below $0.55 \mathrm{~g} / \mathrm{L}$, and do not necessarily fulfil Whipple's triad. The socalled "reactive functional hypoglycaemia" may be the only likely diagnosis for some of these patients, but glucose levels do not drop below $0.55 \mathrm{~g} / \mathrm{L}$, and it cannot be responsible for symptoms of neuroglycopenia. It could reflect various mechanisms: 1) rapid changes in plasma glucose concentrations after ingestion of nutrients with a high glycaemic index; 2) a plasma glucose threshold for autonomic symptoms higher than that of other subjects 3) various reactions after ingestion of nutrients, including mechanisms differing from changes in plasma glucose levels. The patients are asked to reduce their intake of simple carbohydrates while increasing that of complex carbohydrates, and to divide their daily 
nutrient intake into three meals and two or three snacks. Repeated symptoms suggesting hypoglycaemia despite correct nutrition warrant further investigation.

Actual reactive insulin-mediated hypoglycaemia is observed in patients with dumping syndrome (see below, causes of hypoglycaemia differing from insulinomas), and this must be distinguished from "reactive functional hypoglycaemia".

\subsubsection{Causes of hypoglycaemia differing from insulinomas}

\section{Medications known to be used by the patient}

The first step of any evaluation is to check whether some of the medications ordered to the patient can cause hypoglycaemia. Insulin, insulin analogues or insulin secretagogues (sulfonylureas, glinides) are the most common causes of hypoglycaemia. Some patients may be mistaken and accidentally take inappropriate doses of medications, or undergo concurrent disorders that increase the bioavailability of the drug. Though metformin cannot induce hypoglycaemia, as confirmed by the expert consensus (Cryer et al. 2009), it has been reported to cause severe hypoglycaemia in the 1995 UK prospective diabetes study (Cryer et al. 2009) and in an elderly patient (Zitzmann et al. 2002). Thiazolidine-diones, alphaglucosidase inhibitors, GLP1-receptor agonists and dipeptidyl peptidase IV inhibitors do not induce hypoglycaemia themselves but increase the risk of hypoglycaemia when combined with an insulin secretagogue or insulin. Other medications are known to be liable to induce hypoglycaemia, mostly in aged patients and patients with associated diseases, or combination of treatments, or renal failure. Miscellaneous mechanisms may be involved: increased insulin release, reduced insulin clearance, interference with glucose metabolism, liver or renal toxicity (Ben Salem et al. 2011).

A list of the most commonly employed medications liable to induce hypoglycaemia has been given in the 2009 consensus (Cryer et al. 2009): some of them are associated with a risk of hypoglycaemia with moderate quality of evidence: cibenzoline, gatifloxacin, pentamidine, quinine, indomethacin. Other medications are involved with a lesser quality of evidence. The most commonly reported offending drugs appeared to be quinolones, pentamidine, quinine, beta blockers, angiotensin-converting enzyme agents, and IGF (Murad et al. 2009). Salicylates in large doses (4-6 g/day) may produce rarely hypoglycaemia in adults, and more often in children, by reducing basal glucose production and possibly increasing sensitivity to insulin (Cryer 2008). Disopyramide (Marks \& Teale 1999), non-steroid anti-inflammatory drugs, analgesics, antidepressants (Ben Salem et al. 2011) and antifungal agents (Lionakis et al. 2008) have been reported to induce hypoglycaemia. However hypoglycaemia appears to be rare with such medications, unless employed in combination with other medications or in patients with underlying diseases. Recently tyrosine kinase inhibitors were found to decrease plasma glucose concentrations (Agostino et al. 2010). Patients with huge non functional endocrine tumours and multiple liver metastases may be at risk of developing hypoglycaemia when treated by long-acting somatostatin analogues, as a result of reduced glucagon and GH secretion, impairment of hepatic glucose output and delay in intestinal absorption of carbohydrates (Unek et al. 2009).

\section{Patient with known or obvious acute or chronic disorder}

In such patients the diagnosis is often clinically obvious. Concurrent intake of hypoglycaemic agents must always be screened for, and in patients without any treatment 
with insulin secretagogues, measurement of insulin, C-peptide, proinsulin and (whenever possible) beta-hydroxy-butyrate levels at the time of hypoglycaemia below $0.55 \mathrm{~g} / \mathrm{L}$ will generally rule out insulin-mediated hypoglycaemia, unless the underlying disorder (especially in renal failure and acute liver failure) is liable to alter insulin, C-peptide and proinsulin metabolic processing and clearance.

\begin{abstract}
Alcohol
Alcohol ingestion is known to cause hypoglycaemia. Serum insulin and C-peptide are appropriately low during episodes of alcohol-induced hypoglycaemia (Marks \& Teale 1999). Ethanol inhibits gluconeogenesis (Cryer 2008) and hormonal counterregulation to hypoglycaemia (Marks \& Teale 1999; Cryer 2008), and can exert influences on pancreatic microcirculation, resulting in a massive redistribution of blood flow from the exocrine into the endocrine part of the pancreas, augmenting late-phase insulin secretion (Huang \& Sjoholm 2008). In patients presenting in coma from alcohol-induced hypoglycaemia, recovery after glucose injection is immediate, with no relapse if there is no concurrent cause of hypoglycaemia; recovery is delayed when brain swelling has occurred, which requires specific treatment. Glucagon is not recommended (Marks \& Teale 1999). Alcoholinduced hypoglycaemia typically occurs after a binge of alcohol consumption within 6 to 36 hours generally in a patient who presents glycogen depletion, and ethanol is measurable in blood but poorly correlates with glucose levels; it may also be a late feature of alcoholic keto-acidosis and ethanol may be undetectable in blood samples (Marks \& Teale 1999).
\end{abstract}

\title{
Acute hepatic failure
}

Acute hepatic failure, with massive and rapid liver destruction, rather than common forms of cirrhosis and hepatitis, can lead to severe hypoglycaemia. Massive destruction of the liver tissue and defective glucose storage in extrahepatic organs are thought to be the main mechanisms, but non-insulin hypoglycaemic factors secreted by the damaged liver might be involved, since reversal of fulminant hepatitis-associated hypoglycaemia was observed at the anhepatic stage of liver transplantation (Ilan et al. 1996).

\section{Renal failure}

Hypoglycaemia is not rare in renal failure and its pathogenesis involves generally several mechanisms (Arem 1989; Basu et al. 2002). Mechanisms directly related to renal failure are involved: reduced renal gluconeogenesis, impaired renal insulin degradation and clearance. Additional mechanisms may be involved, such as medications, sepsis, poor nutrition with deficiency of precursors of gluconeogenesis, impaired glycogenolysis, defective counterregulation with frequent autonomic dysfunction, concurrent disorders such as concomitant liver disease, congestive heart failure, or an associated endocrine deficiency. In patients undergoing haemodialysis a particular mechanism is postdialysis glucose-induced hyperinsulinemia, caused by a high glucose content in the dialysate (Arem 1989; Basu et al. 2002). On the other hand dialysis with glucose-free solution results in frequent hypoglycaemia, whereas using glucose-added dialysis solution at $90 \mathrm{mg} / \mathrm{dL}$ was found to reduce the number and severity of hypoglycaemic episodes (Burmeister et al. 2007). Since clearance of insulin, C-peptide and proinsulin is impaired in renal failure, beta-hydroxybutyrate during a fast test and glucose response to glucagon were reported to be the best biological parameters for the differential diagnosis of insulinoma in patients with renal failure (Basu et al. 2002). 


\section{Heart failure}

Hypoglycaemia has been occasionally reported in patients with congestive heart failure. Its pathogenesis is unknown, probably multifactorial, and may involve inhibited gluconeogenesis (Cryer 2008).

\section{Inanition}

Inanition related hypoglycaemia, with low insulin, C-peptide and proinsulin levels has been found in some patients with very severe malnutrition, such as patients with very severe chronic anorexia nervosa (Rich et al. 1990; Yanai et al. 2008). The occurrence of inanitionrelated severe hypoglycaemia in a patient with anorexia nervosa is thought to imply a grave prognosis (Rich et al. 1990).

\section{Adrenal or pituitary failure}

Adrenal and/or pituitary failure does not result in plasma glucose concentrations below $0.55 \mathrm{~g} / \mathrm{L}$ unless associated with other disorders or hypoglycaemic medications. Plasma glucose concentrations of $0.6 \mathrm{~g} / \mathrm{L}$ may be found in such patients, and are often associated with hyponatremia and/or typical clinical symptoms of the disease. As stated in the 2009 expert consensus (Cryer et al. 2009), adrenocortical failure without associated conditions is unlikely to induce hypoglycaemia below $0.55 \mathrm{~g} / \mathrm{L}$, and a low cortisol level at the time of hypoglycaemia may be the consequence of a lower glycaemic threshold to stimulate cortisol in patients with recurrent hypoglycaemia without adrenal failure.

\section{Other causes}

\section{Low insulin, C-peptide and proinsulin levels}

* Hypoglycaemia related to non-insulin secreting tumours : IGF-II and precursors ("big IGF-IIs")

If insulin, C-peptide and proinsulin levels are low at the time of hypoglycemia, the diagnosis of non pancreatic IGF-II (or pro-IGF-II) -secreting tumour must be considered. However, one must bear in mind that rare insulin-specific assays may not be able to identify insulin analogues (see below, "factitious hypoglycaemia"). Patients with IGF-II secreting tumours have low IGF-I levels and increased IGF-II/IGF-I ratios, which are pathognomonic of the diagnosis. IGF-II precursors ("big IGF-IIs") do not complex normally with IGFBPs, thus can reach more readily target tissues, which is thought to be the mechanism of hypoglycaemia in most patients. Enhanced mRNA expression of IGF-II and defective expression of prohormone convertase 4, a potential protease responsible for IGF-II precursor processing, were found in a patient with pleural solitary fibrous tumour (Tani et al. 2008). Glucose consumption is also thought to be a mechanism of hypoglycaemia in such tumours, and could be the major mechanism in some patients without evidence for IGF-II secretion, in whom PET-scan with 18-Fluoro-deoxy-glucose showed preferential tumour glucose uptake (Habra et al. 2010). Most IGF-II secreting tumours are large tumours that can be found on clinical examination or chest X-ray. IGF-II related hypoglycaemia is well known in patients with pleural solitary fibrous tumour (Doege-Potter syndrome). Solitary fibrous tumour is a rare mesenchymal neoplasm composed of CD34-positive fibroblastic cells; it can be either pleural or extrapleural, with abdominal locations, of whom one was found to grow in the bladder (Bruzzone et al. 2010). IGF-II secreting mesenchymal neoplasms are numerous, and also comprise synovial sarcomas, myxoid liposarcomas, GISTs, malignant peripheral nerve sheath tumours, chondrosarcomas, undifferentiated pleomorphic sarcomas, Ewing's 
sarcomas and tenosynovial giant cell tumours (Steigen et al. 2009) . We observed hypoglycaemia with suppressed insulin, C-peptide and proinsulin levels and high pro-IGFII levels in a patient with a malignant meningioma and lung and pleural metastases (unpublished observation). Rare cases of adrenocortical carcinomas have also been reported to be responsible for hypoglycaemia (Cryer 2008). One exceptional patient with an islet-cell tumour of the pancreas was reported to have IGF-II-related hypoglycaemia (Chung et al. 2008).

* Other tumours (non-insulin, non-IGF-II secreting tumours)

Exceptionally, tumour-induced hypoglycaemia was found to be related to hormone secretions that differed from insulin or IGF-II: IGF-I, in a metastasizing undifferentiated large-cell carcinoma of the lung (Nauck et al. 2007), somatostatin in an ovarian teratoma (Gregersen et al. 2002). The latter patient had alternate episodes of hyper- and hypoglycaemia, with only reactive post-prandial hypoglycaemia and a negative fast test; insulin levels were low at the time of hyperglycaemia, and were not reported at the time of hypoglycaemia. It was hypothesized that somatostatin led to suppression of glucagon secretion to a greater extent than that of insulin secretion in the post-prandial period, thereby leading to reactive hypoglycaemia. Another ovarian tumour was reported to induce hypoglycaemia by secreting GLP-1 and somatostatin (see below).

\section{High insulin levels with low C-peptide and proinsulin levels}

* Factitious hypoglycaemia related to insulin and insulin analogues

In clinical practice, the finding of high insulin levels with concomitant low C-peptide and proinsulin levels is almost specific of the diagnosis of surreptitious insulin injections (Grunberger et al. 1988). It must be known that some insulin-specific assays may not be able to identify insulin analogues (Sapin 2003; Neal \& Han 2008); insulin assays that can identify the presence of insulin analogues are to be preferred.

* Anti-insulin receptor antibodies

Such antibodies were found mostly in patients with immunity disorders, either before or after the use of medications like methimazole (Redmon \& Nuttall 1999). Many of these patients have type B insulin resistance and diabetes mellitus, but some of them develop hypoglycaemia. Anti-insulin receptor antibodies bind to the insulin receptor, may mimic insulin action and cause fasting hypoglycaemia; also, they may inhibit insulin binding thereby inhibiting insulin clearance and increasing insulin levels, while the resulting hypoglycaemia suppresses beta-cell secretion and C-peptide levels (Taylor et al. 1989). Spontaneous remissions and improvement after glucocorticoid treatment have been reported (Taylor et al. 1989).

* Insulin receptor mutation

Exceptionally patients may present an insulin receptor mutation, which is transmitted as an autosomal dominant trait, and delays insulin clearance, resulting in hypoglycaemia with inappropriate insulin levels after an overnight fast, and low C-peptide levels, with increased insulin/C-peptide ratio (Hojlund et al. 2004), or reactive insulin-mediated hypoglycaemia; in such patients the fast test is positive for hypoglycaemia $(<0.4 \mathrm{~g} / \mathrm{L})$, but insulin, C-peptide and proinsulin are suppressed during a prolonged fast. This disease can be considered to be one of the established genetic causes of nesidioblastosis (see below). 


\section{High insulin, C-peptide and proinsulin levels}

If insulin, C-peptide and proinsulin levels are elevated at the time of hypoglycemia, insulinoma is the most likely diagnosis. One must remind that some insulinoma patients do not have elevated insulin levels when insulin is measured with insulin-specific assays (Vezzosi et al. 2003). When an insulinoma is not found by imaging techniques, two very different diagnoses must be suspected: factitious hypoglycemia related to sulfonylurea or glinide, or nesidioblastosis, which is rare in adult patients. Exceptionally, anti-insulin antibodies and extra-pancreatic non-islet cell insulin-secreting tumours may also be found; sometimes a genetic metabolic disorder which has been overlooked at a younger age may be diagnosed in an adult patient. Finally, a particular condition is reactive insulin-mediated hypoglycaemia in patients with dumping syndrome; some of these patients were reported to have post-gastric bypass nesidioblastosis.

* Factitious hypoglycaemia related to sulfonylureas or glinides

A plasma sample must be collected to measure oral hypoglycaemic agents (ideally all available sulfonylureas and glinides) with specific methods at the time of symptomatic hypoglycaemia. This is the only way to distinguish factitious (or accidental) hypoglycaemia related to insulin secretagogues from the endogenous abnormal insulin secretion observed in patients with insulinomas and nesidioblastosis. The diagnosis is generally suspected in patients whose relatives are diabetic or health professionals, but it may be very difficult (Hirshberg et al. 2001).

\section{* Anti-insulin antibodies}

Anti-insulin antibodies responsible for hyperinsulinaemic hypoglycaemia have been rarely found (Taylor et al. 1989; Redmon \& Nuttall 1999) generally in patients with autoimmune disorders who developed such antibodies spontaneously or a few weeks after specific treatments for autoimmune diseases, especially medications with a sulphydryl group, or in very rare cases of myeloma (Halsall et al. 2007). Anti-insulin antibodies must be measured in patients with hypoglycaemia related to endogenous hyperinsulinism, not necessarily during hypoglycaemia (Cryer et al. 2009). Insulin levels are often very high, partly as a consequence of an interference in the insulin assay by the anti-insulin antibody. Most patients have reactive hypoglycaemia, which could be a consequence of meal-induced exaggerated insulin secretion, overcoming the buffering effect of the antibody (Taylor et al. 1989); however some patients also have fasting hypoglycaemia (Basu et al. 2005). The natural course is not predictable, some patients may be controlled by frequent meals and many experienced remission some months after the withdrawal of the drug responsible for the onset of the disorder, but others required glucocorticoids or even plasmapheresis.

* Non islet cell insulin -secreting tumours and GLP-1 secreting tumour

Non islet cell insulin-secreting tumours are quite exceptional. They must be distinguished from "ectopic insulinomas" which are extrapancreatic islet-cell tumours located in the proximity of the pancreas. Insulin-mediated hypoglycaemia has been reported in the following tumours : a small cell carcinoma of the cervix (Seckl et al. 1999), a neuroectodermal brain tumour (Nakamura et al. 2001), and a neuroendocrine carcinoma of the gallbladder (Ahn et al. 2007).

Todd et al reported a GLP-1 and somatostatin-secreting ovarian tumour (Todd et al. 2003). The patient had alternate episodes of hyper- and hypoglycaemia, with a negative fast test. 
Insulin-mediated hypoglycaemia was thought to be a consequence of GLP-1 and somatostatin secretion; since the effects of GLP-1 on insulin secretion are dependent on glucose levels, the inhibitory effects of somatostatin on glucagon secretion may have played a role in inducing reactive hypoglycaemia.

* Genetic metabolic disorders

Some patients with hypoglycaemia related to metabolic genetic disorders may occasionally be diagnosed to have such disorders when they are adults. Some of these disorders can be considered as possible causes of nesidioblastosis (Christesen et al. 2008; Palladino \& Stanley 2011) (Flanagan et al. 2011b) (Flanagan et al. 2011a) (see last section of this chapter): 1) physical exercise-induced hypoglycaemia caused by failed silencing of monocarboxylate transporter 1 in pancreatic beta cells; 2) patients with mostly post-prandial (but also fasting) symptoms of hypoglycaemia in mutations of insulin receptor (see above), activating mutation of glucokinase with some patients diagnosed only as adults (Christesen et al. 2008), and hyperinsulinism-hyperammonemia syndrome due to activating mutations of glutamate dehydrogenase; 3 ) patients with mostly fasting (and also post-prandial) hypoglycaemia due to mutations in the genes of the subunits of K-ATP channel (ABCC8, KCNJ11) and mutations of 3 hydroxy-acyl-CoA dehydrogenase (HADH) gene. Among 79 patients admitted in our department between 1990 and 2010 for organic causes of hypoglycaemia (69 of them with insulinomas) only one had hyperinsulinism-hyperammonemia syndrome (diagnosed at the age of 30), with an activating mutation of glutamate dehydrogenase, and another one had two heterozygous mutations of the ABCC8 gene (diagnosed at the age of 47). Both patients had been treated since early childhood for epilepsy.

Other patients may present with other metabolic disorders such as disorders of the glycogen metabolic pathway. Some patients with almost asymptomatic forms of glycogen storage disease type Ia may develop hepatocellular adenomas and carcinomas as adults (Cassiman et al. 2010).

A detailed review of these genetic disorders in childhood has been made by Palladino (Palladino et al. 2008).

* Reactive hypoglycaemia in patients with dumping syndrome

Postprandial hypoglycaemia caused by rapid emptying of the gastric remnant has long been known to be a possible complication of gastric resection; it is associated with various symptoms, including symptoms unrelated to hypoglycaemia, which are termed dumping syndrome. Many, but not all patients with post-gastric bypass were found to have reactive severe insulin-mediated hypoglycaemia a few months or years after bypass surgery. Continuous glucose monitoring can be a useful tool to identify hypoglycaemia in patients after bariatric surgery (Hanaire et al. 2010). The abnormal insulin responses to intraarterial calcium injection and the histopathological findings in 6 patients, compared to pancreata from patients with pancreatic cancer, led to the conclusion than such patients might have gastric bypass-induced nesidioblastosis (Service \& O'Brien 2005) (see below). This conclusion was challenged, since Meier JJ et al. did not confirm the histopathological diagnosis of nesidioblastosis in the 6 patients, when compared to pancreata collected at autopsy; they only observed a greater beta-cell nuclear diameter than in controls, and this nuclear diameter was positively correlated with BMI, if the BMI used for the patients in the correlation was the BMI observed prior to bypass surgery (Meier et al. 2006). Goldfine AB et al reported increased GLP-1 levels after a liquid mixed-meal in patients who had postgastric bypass surgery hypoglycaemia, in comparison with those who did not have 
hypoglycaemia (Goldfine et al. 2007). GLP-1 is thought to be unable to induce hypoglycaemia in patients with normal beta cells, but high GLP-1 levels might override glucose-dependency and cause hypoglycaemia (Toft-Nielsen et al. 1998). The degree of postprandial GLP-1-induced glucagon suppression (which is also dependent on glucose, GLP-2 and GIP levels) might play a role in the resulting post-prandial glucose levels. Insulinmediated hypoglycaemia after gastric bypass surgery is not associated with overexpression of GLP-1 receptor in islets (Reubi et al. 2010). McLaughlin et al reported immediate reversal of reactive hypoglycaemia by feeding a patient with Roux-en-Y gastric bypass through a gastrostomy tube, which argued against a structural pancreatic abnormality in this patient and provided major evidence for a functional dysregulation of post-prandial insulin secretion in patients with gastric bypass-induced hypoglycaemia (McLaughlin et al. 2010). Nevertheless such patients often require insulin-suppressing treatments (diazoxide, calcium channel blockers, somatostatin agonists) (Tack et al. 2009) (Vella \& Service 2007). Acarbose, which delays absorption of simple carbohydrates and may reduce GLP-1 secretion, was successfully employed (in combination with dietary advices) (Tack et al. 2009; Hanaire et al. 2010) but it was found relatively ineffective by others (Vella \& Service 2007). A patient who had dumping syndrome after partial gastric resection was finally admitted in our department, 20 years after gastric surgery, for severe reactive insulin-mediated hypoglycaemia, with a negative fast test, and normal pancreas on CT-scan; hypoglycaemia was controlled by diazoxide, not by octreotide. Partial (distal) pancreatectomy has been performed to control hypoglycaemia in some of these patients, as in patients with nesidioblastosis. Since insulinomas may present with GIP and/or GLP1 receptors, occurrence of insulin-mediated hypoglycaemia after bypass surgery or gastrectomy can be caused by an insulinoma. Radiological evaluation is of course mandatory in such patients.

\subsection{Topographic assessment}

The topographic assessment of an insulinoma must be performed only after the biological diagnosis of hypoglycemia related to inappropriate insulin secretion has been confirmed. Insulinomas are generally thought to be difficult to localize due to their small size. Intraoperative palpation and ultrasound examination of the pancreas had been thought to be the best methods to detect insulinomas. Using such methods intra-operatively remains mandatory, but to date careful radiological examination must be performed to localize insulinomas before surgery in order to avoid failure of surgery to cure the disease and reoperations. The imaging techniques now in use have greatly improved, so that most insulinomas are detected preoperatively.

High definition multidetector helical CT-scans have become widely available since the early 2000s, so that CT-scan is now again the first examination that must be performed to localize insulinomas. Multidetector CT-scan allows optimization of the scan protocols (with very rapid scan times reducing movement artefacts), and arterial and portal venous phase images on thin-sections. A meticulous technique is mandatory and detailed recommendations have been made regarding the examination procedure (Rockall \& Reznek 2007) (Sundin et al. 2009). Most insulinomas are small, isodense with the pancreas on pre-contrast images, then hypervascular on arterial phase images, but sometimes are more easily detected on portal venous phase images. More rarely, the tumours are hyperdense to the pancreas, or have nodular calcification, or appear hypovascular, cystic or hypodense after injection of contrast medium. Exceptionally, ectopic insulinomas are located in the proximity of the pancreas or 
of the liver. While the sensitivity of non helical CT had been $29 \%$, with multidectector helical CT-scan a meticulous technique can result in $94 \%$ sensitivity (Rockall \& Reznek 2007). CTscan can show metastases (see below, malignant insulinomas)

MRI is often complementary to $\mathrm{CT}$, in order to confirm a suspected lesion on CT, or to search for a tumour that CT-scan has not been able to localize; combining both methods (CT and MRI) improves the accuracy for detection of insulinomas. Detailed technical information has been provided (Rockall \& Reznek 2007). Temporal resolution and spatial resolution are greater with CT than with MRI, but MRI allows high resolution contrastenhanced imaging. Pancreatic endocrine tumours generally appear hypo-intense on T1weighted sequences and hyperintense on T2-weighted sequences. On pre-contrast imaging, fat suppressed T1 and fat saturation T2 may improve visualization of the tumours, which appear of low intensity on T1 and have a bright T2 signal. There is a marked homogeneous enhancement after injection of gadolinium, which may in some cases render the lowintensity tumour isointense and less detectable (Rockall \& Reznek 2007). The sensitivity of MRI for detection of pancreatic endocrine tumours was first reported to be less than that of CT, but is now similar to that of CT: a sensitivity of up to $94 \%$ has now been reported (Thoeni et al. 2000). MRI has also proven very helpful in the diagnosis of hepatic metastases of malignant insulinomas (see below, malignant insulinomas).

Trans-abdominal ultrasound examination is traditionally thought to be of low sensitivity to detect pancreatic endocrine tumours like insulinomas: the sensitivity was as low as $20 \%$ in the series reported in the 1990s, with a maximum of 66-80\% (Grant 1999). Insulinomas generally appear as small hypoechoic solid masses. The limitations of ultrasound examination are related to body habitus and tumour size; also, the presence of bowel obscures the left upper quadrant, and insulinomas located in the body and the tail of the pancreas may be difficult to visualize. Water intake by the patient allows to use the stomach as an acoustic window and may improve the detection. A sensitivity of up to $79.3 \%$ has been reported with recent material for transabdominal ultrasound (Oshikawa et al. 2002) (Rockall \& Reznek 2007).

More recently, contrast-enhanced ultrasonography has been reported to detect insulinomas in a high number of patients. Very promising results were found by An L et al (An et al. 2010), who reported the results obtained with a second-generation sonographic contrast agent (SonoVue) in 31 patients with hypoglycaemia related to endogenous hyperinsulinism, among whom 27 had a solitary insulinoma, 3 had multiple insulinomas, and 1 had no definite tumour during laparoscopic evaluation. The results of contrast-enhanced ultrasonography were in agreement with surgical findings except in three patients: one solitary tumour had been localized in the head of the pancreas and was found in the duodenum ligament; one tumour had been visualized whereas no tumour was found during surgery; in the patient with 6 insulinomas, only 2 tumours had been visualized. Thus the diagnostic sensitivity and localization specificity were $33(89.2 \%)$ and $32(86.5 \%)$ of 37 surgically verified insulinomas, respectively. The enhancement pattern of insulinoma was fast wash-in and slow wash-out. The insulinomas displayed homogeneous hypervascularity in the earlier arterial phase and had still a hyperenhancing pattern in the late phase. This ultrasound non invasive examination could probably be developed in the next years.

Endoscopic ultrasound has been reported to be the reference method to localize insulinomas in the 1990s: it allows to use a high frequency US probe in close proximity to the pancreas, and in expert hands its sensitivity has been shown to be 79-100\% (Rosch et al. 1992) (McLean \& Fairclough 2005). It may show very small tumours (about $3 \mathrm{~mm}$ in size) in the head of the 
pancreas, such tumours being impalpable at surgery. A lower sensitivity for pancreatic tail lesions (37-50\%) has been reported (Ardengh et al. 2000). Pancreatic nodularities may be mistaken for insulinomas (Kann et al. 2003). Endoscopic ultrasound is an invasive method, which requires sedation, and its results are operator-dependent. Therefore it is now a second-line examination after conventional imaging. Even if recent CT-scan techniques lead to localization of most insulinomas, endoscopic ultrasound still brings the advantage of making a better evaluation of the lesions (especially if they are multiple, as often in MEN-1) and of their proximity with pancreatic ducts and vessels, and it also enables the operator to make biopsies.

Intra-operative ultrasound is mandatory during surgery of insulinomas in order to localize impalpable tumours. High-frequency intra-operative ultrasound has been shown in expert hands to improve detection of small tumours in the pancreatic head and multiple pancreatic lesions to up to 97\% (Grant 1988) (Grant 1999). Intra-operative ultrasound examination of the pancreas is also mandatory (using a specific material) during laparoscopic surgery of insulinomas. Despite the high sensitivity of intra-operative ultrasound, a thorough preoperative examination is necessary to localize insulinomas, in order to maximize the chance for a successful initial resection, minimize the risk of re-operation with its possible morbidity, help in the choice of the surgical technique and make laparoscopic surgery easier when it appears to be the possible choice to remove the insulinoma.

Nuclear imaging of insulinomas is also possible. One of the first functional imaging method was based on the fact that most endocrine tumours display somatostatin receptors, which led to the use of Octreoscan* scintigraphy (111In-DTPA-octreotide). On the other hand, sst2A receptors were found in only about $66 \%$ of insulinomas (Reubi \& Waser 2003). Recommendations have been made regarding the protocol (Balon et al. 2001; Bombardieri et al. 2003). Because of competition of the somatostatin analogues at the receptor site, somatostatin analogue treatment should be withdrawn before performing Octreoscan scintigraphy, though there are contradictory data (Dörr et al. 1993). The sensitivity for tumour detection is poor in patients with insulinomas (20-50\%) (Krenning et al. 1993) in comparison with other endocrine tumours. However it was $80 \%$ in a series of 14 insulinoma patients with the use of SPECT (single-photon emission computed tomography) and an injected activity of $250 \mathrm{MBq}$ of Octreoscan instead of the commonly recommended activity of 150-200 MBq (Schillaci et al. 2000). We only found a $24 \%$ sensitivity and neither pre-treatment with octreotide nor the lack of expression of sst2A receptors could account for all the negative scans (Vezzosi et al. 2005). In our experience, Octreoscan scintigraphy proved to be useful in a patient with an ectopic insulinoma, which was located about $2 \mathrm{~cm}$ below the body of the pancreas. Using the same technique for Octreoscan scintigraphy, $89.1 \%$ of non-insulinoma well-differentiated digestive endocrine tumours were detected in our centre. Small tumours cannot be detected by Octreoscan scintigraphy (Dromain et al. 2005). Octreoscan displays a lower affinity for sst2 receptors than octreotide (Reubi et al. 2000). Specific problems of imaging techniques may play a role in this low detection of insulinomas, even in sst2-positive insulinomas (Vezzosi et al. 2005). Octreoscan scintigraphy may help in localizing metastases, but MRI is better than Octreoscan scintigraphy for detection of liver metastases of endocrine tumours (Dromain et al. 2005). To date, the systematic use of Octreoscan scintigraphy in insulinoma patients is questionable.

Positron emission tomography (PET) with 18-F-labelled deoxy-glucose (FDG) has not proven advantageous for imaging endocrine tumours with the exception of poorly 
differentiated, highly proliferative tumours (Pasquali et al. 1998; Sundin et al. 2009). The unstable glucose levels in insulinoma patients may also increase the difficulties.

Since pancreatic endocrine tumours are part of the APUDomas because of their ability for amine precursor uptake and decarboxylation through the action of aromatic amino acid decarboxylase, 18F-labelled-DOPA was also employed as a tracer. The first results in 10 patients with hyperinsulinemic hypoglycaemia were very encouraging. The pancreatic lesion was localized in $9 / 10$ patients with subsequent confirmation by histological analysis (Kauhanen et al. 2007). The following studies did not confirm these results. A $27 \%$ sensitivity was reported for detection of pancreatic endocrine tumours (Montravers et al. 2009). In six patients with hyperinsulinemic hypoglycaemia (4 solitary insulinomas, 1 diffuse beta-cell hyperplasia, 1 malignant insulinoma), F-DOPA-PET was positive in only one case and it underestimated the extent of the disease in the malignant insulinoma with liver metastases (Tessonnier et al. 2010). More data are necessary to conclude, but to date F-DOPA PET does not appear to be a major help in managing pancreatic endocrine tumours.

The first results achieved with a radiolabelled GLP-1 analogue seem promising. Insulinomas were reported to be characterized by a very high incidence of GLP-1 receptors, these receptors being expressed in a particularly high density (Reubi \& Waser 2003). A radiolabelled GLP-1 analogue (111In-DOTA-exendin-4) was employed in 6 patients (5 with pancreatic insulinomas, 1 with an extrapancreatic insulinoma). Scintigraphy with GLP-1 analogue correctly localized the insulinoma in all 6 patients, while CT-scan was positive in 1, MRI-scan in 1 and endoscopic ultrasound in 4. Four patients had an intense uptake 4 hours after injection, and the other 2 patients showed demarcation between tumour and kidney only at late scans 3-7 days after injection (Christ et al. 2009). Interestingly, while exendin-4 does not induce hypoglycaemia in normal subjects, the insulinoma patients experienced a decrease in plasma glucose levels, with a nadir $40 \mathrm{~min}$ after injection, and an exogenous glucose infusion was necessary in 3 patients (for a maximum of $120 \mathrm{~min}$ ), so that scintigraphy with radiolabelled exendin-4 appears to be also a provocative test in some insulinoma patients, and plasma glucose levels must be monitored after injection.

Finally trans-hepatic pancreatic venous sampling, to screen for an insulin concentration gradient, or calcium injection after selective catheterization of the arteries supplying the pancreas combined with measurement of insulin levels in the right hepatic vein can be used in difficult cases. The latter method was first described by Doppman et al (Doppman et al. 1993). A recent report by an expert team has evaluated the diagnostic accuracy of this technique (Guettier et al. 2009). A 2-fold or greater step-up in the right hepatic vein insulin concentration from baseline at times 20,40 or 60 seconds after injection was considered to be positive. When a positive response was found at more than one injection site, the dominant site was used to predict tumour localization. In the absence of anatomical variants, a positive response to calcium injection in the gastroduodenal artery or superior mesenteric artery predicts a head-neck tumour, a positive response to the injection into the proximal splenic or the midsplenic artery predicts a body-tail tumour, and a response to calcium injection into the proper hepatic artery represents liver metastases. In 45 patients with surgically proven insulinomas, $38(84 \%)$ localized to the correct region; in 5/45 (11\%) the result was falsely negative, and $2 / 45(4 \%)$ had false-positive localizations. Thus in expert hands selective intra-arterial calcium stimulation is a valuable tool to localize insulinomas when conventional imaging is negative. However, as pointed out by the expert group 
(Guettier et al. 2009), there are several caveats, because this technique is based on the following 3 assumptions: 1) a 2-fold insulin increase is pathological; 2) normal beta cells do not show a positive response to calcium injection; 3 ) insulinomas always respond to calcium injection. All 3 assumptions can be challenged on the basis of the available data. According to Guettier's report, there was no explanation for 3 false-negative cases of insulinomas. A 2fold increase in insulin levels was found in two or more vessels in 24 of 45 cases, which could suggest that some normal pancreatic areas respond to calcium injection, as already reported by Wiesli (Wiesli et al. 2004a), who recommended that only a 5-fold increase should be considered as a positive response if insulin levels are measured with an insulinspecific assay. This invasive test should probably be a last-line investigation in patients with hypoglycaemia related to endogenous hyperinsulinism that cannot be controlled easily by a medical treatment. Within the last 10 years, we used this method according to the modified protocol described by O'Shea (O'Shea et al. 1996) in only two patients, who were finally found to have nesidioblastosis (with two heterozygous mutations in the ABCC8 gene in one patient) with false positive "pseudo-insulinoma" results.

A recent study (Druce et al. 2010) compared the diagnostic accuracy of most methods employed to localize insulinomas in the years 1990-2009 in 36 patients, among whom 30 were treated by surgery. Among these 30 patients, 25 had CT and 28 had MRI with successful localization in $16(64 \%)$ and 21 (75\%) by CT and MRI, respectively. Together this led to $80 \%$ of successful localizations. Radiolabelled octreotide scanning was positive in 10 out of 20 cases (50\%). Endoscopic ultrasound identified 17 tumours in 26 patients $(65.4 \%) .27$ patients had selective intra-arterial calcium stimulation: 6 (22\%) did not localize, 17 (63\%) were correctly localized, and $4(15 \%)$ gave discordant or confusing results. Thus combination of CT and MRI predicts tumour localization with high accuracy, Octreoscan and endoscopic ultrasound are less helpful but could be valuable in selected cases, and calcium stimulation may provide an additional functional perspective.

In most patients, by now, multidetector CT-scan (with trans-abdominal ultrasound and/or MRI as complementary techniques) employed by an experienced radiologist will localize insulinomas, and must be considered as a first-line examination, while contrast-enhanced ultrasound needs further evaluation.

\subsection{Treatment}

\subsubsection{Surgery}

Surgery remains the only curative treatment of insulinomas. Long-term remission can be achieved by surgery in $95 \%$ of patients according to a recent study (Zhao et al. 2011). Two different types of surgery can be performed : minimal resection i.e. either tumour enucleation whenever it is possible or central pancreatectomy, or a more extended resection, i.e. left-sided pancreatectomy or pancreatico-duodenectomy. The type of surgery depends on the size and the location of the tumour and of its proximity with specific anatomical structures (pancreatic duct, vessels, adjacent organs). The improvement in the pre-operative imaging techniques enables the surgeon to have an accurate pre-operative topographic assessment and to decide the surgical approach pre-operatively. However intra-operative bidigital palpation and ultrasound remain valuable (Fendrich et al. 2009).

Whenever it is possible, tumour enucleation is to be chosen (Crippa et al. 2007). It allows to cure the patient in most cases with minimized risks of post-operative pancreatic exocrine deficiency and diabetes mellitus. It must be performed only to remove small tumours on the surface of the pancreas, with a distance of more than 2-3 mm between the 
tumour and the pancreatic duct (Finlayson \& Clark 2004). Providing that the tumour present with the above mentioned characteristics, and that surgery is performed by experienced surgeons, the risk of pancreatic fistula is not higher than that observed in larger resections of the pancreas (Kooby et al. 2008). When tumour enucleation is not possible, central pancreatectomy for a tumour in the pancreatic neck or adjacent body is preferred by several groups (Muller et al. 2006; Crippa et al. 2007; Zhao et al. 2011), in order to preserve a functional pancreatic gland, and to reduce the risks of post-operative pancreatic exocrine deficiency and diabetes mellitus (Crippa et al. 2007; Hirono et al. 2009). A larger pancreatic resection, i.e. left-sided pancreatectomy, ideally spleenpreserving, or pancreatico-duodenectomy, is preferred when the insulinoma is in close proximity to the pancreatic duct in order to lower the risk of pancreatic fistula (Carrere et al. 2007; Nikfarjam et al. 2008). If a plane between the tumour capsule and the pancreatic parenchyma cannot be easily identified, resection is indicated instead of enucleation (Fendrich et al. 2009). A large resection is also preferable for big invasive insulinomas that are suspected to be malignant.

When enucleation is possible, or even when left-sided pancreatectomy is to be performed, laparoscopy is now employed (Crippa et al. 2007). It reduces the duration of the stay in the hospital and improves the post-operative quality of life (Zhao et al. 2011). It must be performed only by experienced surgeons. It can be employed only if the insulinoma has been accurately localized preoperatively. It does not allow intra-operative bi-digital palpation of the pancreas. Laparoscopic ultrasound can be now performed in many expert centres and can localize the insulinoma and evaluate its proximity with the pancreatic duct and the possibility of performing tumour enucleation.

When no insulinoma was found intra-operatively, blind distal pancreatectomy had been recommended several years ago, but to date, such procedure must not be performed (Hirshberg et al. 2002), due to its short-term and long-term morbidity and its frequent failure to achieve a cure of the disease. If no insulinoma is found, it is recommended to stop the operation, then to perform new investigations in order to localize the insulinoma, including invasive techniques.

Morbidity and mortality depend on the type of surgery. Mortality is almost $0 \%$ for enucleation, but may reach $1-2 \%$ for left-sided pancreatectomy and up to $4-5 \%$ for pancreaticoduodenectomy. The most frequent short-term complication of pancreatic surgery is pancreatic fistula. Pancreatic fistulae are more frequent after enucleation or left-sided pancreatectomy, but their consequences are more severe after pancreaticoduodenectomy, due to infectious or haemorrhagic complications. They occur globally in 3-60\% of cases, depending on the definition (Pannegeon et al. 2006; Yoshioka et al. 2010; Zhao et al. 2011). Most of them are asymptomatic and no additional treatment is necessary. The clinical prevalence of pancreatic fistulae is about $14 \%$ (Zhao et al. 2011). Other complications are intra-abdominal abscess $(6.6 \%)$, pulmonary infections $(3.7 \%)$, wound infection $(2.5 \%)$, delayed gastric emptying $(2.2 \%)$, abdominal bleeding $(1.3 \%)$ acute pancreatitis $(0.6 \%)$ and pulmonary embolism (0.6\%) (Zhao et al. 2011). Long-term complications also depend on the type of surgery. Pancreatic exocrine deficiency and diabetes mellitus almost never occur after enucleation or central pancreatectomy. Pancreaticoduodenectomy results in exocrine pancreatic deficiency in $60 \%$ of cases, and left-sided pancreatectomy may lead to $5-10 \%$ diabetes mellitus. Therefore, limited pancreatic resection such as tumour enucleation or central pancreatectomy are preferred whenever they are technically possible. 


\subsubsection{Medical treatment}

A medical treatment must be given to insulinoma patients in order to control the hypoglycaemia while the patient is awaiting surgery. A long-term medical treatment is given only if surgery is technically impossible or contra-indicated.

In some patients a medical treatment can result in controlling the hypoglycaemia. Evaluation of the occurrence of hypoglycaemia could probably be improved by continuous glucose monitoring (Munir et al. 2008). However sudden occurrence of severe hypoglycaemic spells cannot be ruled out, so that even if medications seem to be effective, surgery must not be delayed or cancelled when a surgical cure is possible. Dietary advice is useful but generally not sufficient to avoid hypoglycaemia. The patient must be advised regarding the symptoms suggesting hypoglycaemia, and what must be done when such symptoms occur. Self monitoring of glucose levels is recommended in order to detect asymptomatic episodes of hypoglycaemia and to prevent occurrence of hypoglycaemic spells, by treating asymptomatic abnormal lowering of glucose levels. The patients should be advised regarding everyday personal safety, to avoid possible consequences of dizziness and loss of consciousness.

Diazoxide (a benzothiazide) allows direct suppression of insulin secretion by beta cells through its effect on K-ATP channel. It stimulates hepatic gluconeogenesis and lowers glucose utilization by muscle cells (Altszuler et al. 1977). It can be given bid or tid at a total daily dose of $150-400 \mathrm{mg}$ in most cases. It can control symptomatic hypoglycaemia in 50$60 \%$ of the patients (Stefanini et al. 1974). Adverse effects have been reported in about half of the patients. They comprise mainly fluid retention with oedemas, hypokalemia, digestive intolerance with nausea, cutaneous rashes and hirsutism. Diuretics may be added to treatment with diazoxide in order to control oedemas, and thiazides are known to potentiate the anti-hypoglycemic effects of diazoxide, but may induce electrolytic disorders or cause worsening of hypokalemia.

Somatostatin analogues can achieve normalization of plasma glucose levels in $50-60 \%$ of the patients (Vezzosi et al. 2008). There are only few adverse effects, mostly digestive intolerance with diarrhoea and steatorrhea. We did not observe a tachyphylaxis phenomenon when using somatostatin analogues in insulinoma patients. The dose of octreotide that was found to control the hypoglycaemia had to be determined on an individual basis, since the doses varied between 50 and $2000 \mu \mathrm{g}$ per day. Somatostatin analogues inhibit insulin secretion mainly through their effects on sst2A and sst5 receptors, which were found in $70 \%$ of insulinomas (Bertherat et al. 2003). A short $100 \mu \mathrm{g}$ octreotide test, not Octreoscan uptake, was predictive of the long-term efficacy of octreotide treatment on hypoglycaemia. This could be explained by the differing affinities of Octreoscan and octreotide for sst2 receptor (Reubi et al. 2000; Vezzosi et al. 2008). Worsening of hypoglycaemia after administration of somatostatin analogues has been reported (Healy et al. 2007). Such phenomenon could be explained by glucagon suppression by somatostatin analogues. It has not been observed in all series (Vezzosi et al. 2008).

Glucocorticoids may be used to normalize plasma glucose levels in insulinoma patients (Novotny et al. 2005). They decrease insulin secretion and increase peripheral insulin resistance. They are associated with several well-known adverse effects and they cannot be recommended as a first-line medication or for long-term use. Other medications have been employed with variable results, e.g. calcium channel blockers like verapamil (Stehouwer et al. 1989), and also phenytoin and propanolol. To date, m-TOR inhibitors have only been used in metastatic malignant insulinomas (see below). 


\section{Particular conditions}

\subsection{Malignant insulinomas}

Malignant insulinomas represent 5-10\% of insulinomas (Danforth et al. 1984; Service et al. 1991). The clinical and biological diagnostic criteria of insulinoma do not differ from those of benign insulinomas. On the other hand, there are specific issues in malignant insulinomas, regarding the diagnosis of malignancy, and the therapeutic management.

The histological diagnosis of malignancy is difficult. The only definite basis is the presence of a metastasis.

In clinical practice, a malignant insulinoma is generally a single large $(>4 \mathrm{~cm})$ tumour. In most cases there are synchronous metastases, which allow to make the diagnosis of malignancy. The metastases are generally located in lymph nodes or in the liver. Thus careful radiological evaluation is valuable for the diagnosis of malignancy. Liver metastases of malignant insulinomas may present with a specific aspect on CT-scan (Atwell et al. 2008) and MRI (Sohn et al. 2001) with perilesional steatosis, due to a local effect of insulin. However metastases may be difficult to identify on CT-scan; a combination of pre-contrast, hepatic arterial-dominant phase and portal venous phase imaging improves the sensitivity for detection of liver metastases, since the lesion may be seen on only one of the three phases (Rockall \& Reznek 2007), and large lesions may become necrotic and unenhanced by contrast agents. MRI, ultrasound and contrast-enhanced ultrasound may improve the detection of liver metastases. Typical liver metastases appear as low-signal intensity on T1 and high signal intensity on T2-weighted images, and are hypervascular on hepatic arterial dominant post-gadolinium images (Bader et al. 2001; Rockall \& Reznek 2007). Nuclear imaging with Octreoscan can also be used, but false negative results are observed in small liver metastases, and MRI is better than Octreoscan scintigraphy for liver metastases detection (Dromain et al. 2005). However, Octreoscan uptake provides a tool to select patients for treatment with radio-labelled somatostatin analogues (Reubi et al. 2005). We did not confirm that Octreoscan uptake was predictive of the efficacy of somatostatin analogues on hypoglycaemia (Vezzosi et al. 2008; Maiza et al. 2011), unlike what had been previously shown in secreting endocrine tumours (Lamberts et al. 1990).

More rarely, the diagnosis of malignancy is suspected on the basis of the histo-pathological findings and it is confirmed later by occurrence of metastases. Apart from metastases and invasion of adjacent organs, suspicion of aggressive tumour behaviour is aroused by a tumour size $>2 \mathrm{~cm}$, angioinvasion, and high proliferative activity (Kloppel 2007; Kloppel et al. 2009). A review of classification systems has been made by Klimstra et al (Klimstra et al. 2010).

The diagnosis of malignancy may be more difficult in some patients when the insulinoma has a benign presentation, even on the histo-pathological findings; in 48 operated insulinoma patients, with a median follow-up of 42 months, 2 patients initially diagnosed to have benign insulinomas were finally found to develop metastases (personal data). Therefore a prolonged follow-up is advisable. Since some patients with previous partial pancreatectomy may not fulfil the typical criteria for the diagnosis of insulinomas, recurrence of even mild clinical symptoms must not be neglected. Tumours of "uncertain behaviour" warrant a long-term clinical, biological and radiological follow-up. The follow-up of benign insulinomas after surgical remission is usually thought to be unnecessary (Arnold et al. 2009) but on the basis of our experience, we would recommend a clinical and biological follow-up and at least a radiological evaluation 1-2 years after surgery.

Regarding the treatment, malignant insulinomas can represent a double therapeutic challenge, i.e. that of the control of tumour progression, and the control of symptomatic 
hypoglycaemia. Controlling the hypoglycaemia must not be neglected, since uncontrolled hypoglycaemia results in increased morbidity and mortality.

Regarding the tumour process, 10 year-survival is about $30 \%$ in patients with metastatic insulinomas (Service et al. 1976), with very heterogeneous courses. Some patients may present a very slow progression rate, even with a metastatic disease, and have long-term survival, whereas other patients present with rapid tumour progression and poor shortterm survival rate. Predictive factors for rapid tumour progression remain to be established. They could be similar to those found for endocrine bronchial or digestive carcinomas, which comprise the presence of extra-hepatic metastases, the number of liver metastases, the proliferative index Ki67, the spontaneous progression of tumour volume in 3-6 months (Greenberg et al. 1987; Pape et al. 2004; Lepage et al. 2007). The anti-tumour strategy will not be detailed. Since malignant insulinomas are rare, there is no specific prospective study on this particular topic, so that the therapeutic strategy is similar to that of non secreting pancreatic endocrine carcinomas. Whenever it is possible, surgery must aim at totally removing the detectable lesions. However even in selected patients, post-operative complementary treatments are necessary, due to a frequent underestimation of liver metastases. In addition, even when total removal of the tumour has been performed with a R0-resection, recurrence is frequent (about $60 \%$ after a follow-up of 3 years) and the recurrence-free median survival is 5 years (Danforth et al. 1984). Treatments other than surgery combine local or regional treatments such as intra-arterial chemotherapy or chemoembolization of liver metastases (Roche et al. 2003) and radiofrequency (Berber et al. 2002), and systemic treatments such as radionuclide systemic administration (Ong et al. 2010), cytotoxic chemotherapy (traditional combination of streptozotocin, doxorubicin and 5-fluoro-uracil and more recently, capecitabine and temozolomide) (Moertel et al. 1992; Strosberg et al. 2008; Strosberg et al. 2011), or targeted therapies (Kulke et al. 2006; Dimou et al. 2010)(Raymond et al. 2011; Yao et al. 2011).

Symptomatic treatment of insulinomas aims at achieving short-term control of the hypoglycaemia while awaiting the effects of anti-tumour treatment or when anti-tumour treatments do not prove to be effective. Surgical removal of the tumour and its metastases is valuable in order to control the hypoglycaemia. Even a reduction of the tumour volume may result in reduction or transient subsiding of symptoms of hypoglycaemia (Sarmiento et al. 2002). A medical treatment is performed if there is no possible surgical cure, or as a complementary therapeutic approach. One should choose as first-line therapies medications that can achieve short-term control of hypoglycaemic spells, and do not jeopardize (by their possible adverse effects) the following use of other treatments. A few recent studies have addressed the issue of the control of severe hypoglycaemic spells in patients with inoperable malignant insulinomas (Bourcier et al. 2009; Ong et al. 2010; Maiza et al. 2011). All the medications used to treat hypoglycaemia in benign insulinomas can be employed, but in most cases, a combination of several hyperglycaemic medications is necessary (Vezzosi et al. 2008). Diazoxide or somatostatin analogues (2-3 subcutaneous injections daily, or long-acting forms, or continuous subcutaneous administration with a portable pump) may result in reduction or disappearance of hypoglycaemic spells in patients with metastatic insulinomas. Radiolabelled somatostatin analogues (especially the Lutetium labelled derivative of octreotide) may prove helpful in long-term control of hypoglycaemia and tumour progression in some patients (Ong et al. 2010). Calcium channel blockers like verapamil gave disappointing results (Stehouwer et al. 1989). Glucocorticoids were found to be effective on hypoglycaemia in malignant insulinomas, and some patients were improved even on doses as low as $2.5 \mathrm{mg}$ of 
prednisone per day (Novotny et al. 2005; Starke et al. 2005). m-TOR inhibitors seem now to be very promising regarding the control of the hypoglycaemia, in addition to their antitumour effects (Bourcier et al. 2009; Kulke et al. 2009). They can suppress insulin synthesis and secretion and increase insulin-resistance, thereby resulting in euglycaemia in patients with malignant insulinomas (Di Paolo et al. 2006). Chemoembolization of liver metastases can achieve the control of the hypoglycaemia (Moscetti et al. 2000). Repeated chemoembolization procedures are often necessary. Combining the use of continuous subcutaneous administration of a high dose of octreotide as a first-line treatment, followed if necessary by chemoembolization of liver metastases could achieve control of hypoglycaemic spells in a few inoperable patients (Maiza et al. 2011). Continuous glucose infusion may be necessary in some patients, while awaiting the efficacy of the other treatments. Vitamin B1 supplementation should be systematically implemented for patients with severe recurrent hypoglycaemia requiring large infusions of glucose, in order to prevent Wernicke's encephalopathy (Grunenwald et al. 2009).

\subsection{Insulinomas as part of a genetic disorder}

This section will be focused on 4 genetic disorders that are known to be responsible for pancreatic endocrine tumours in adult patients: multiple endocrine neoplasia 1 (MEN-1, OMIM \# 131100), Von Hippel Lindau's disease (VHL, OMIM \# 193300), tuberous sclerosis (TS) (a disease that is known to involve a dysregulation of the mTOR pathway) (TSC1 and TSC2 genes, OMIM \# 191100 and \# 191092), and neurofibromatosis type 1 (NF1, OMIM \# 162200). Of these 4 disorders, MEN-1 is the most frequent cause of pancreatic endocrine tumours, particularly insulinomas, followed by order of decreasing frequency, by VHL, NF1 and TS (Jensen et al. 2008). It can be noticed that though pancreatic endocrine tumours are found in VHL patients, to our knowledge, there is no case report of a VHL patient with insulinoma. These 4 genetic disorders are caused by mutations in tumour-suppressor genes and are transmitted as autosomal dominant traits. Genetically-determined insulinoma does not differ from sporadic insulinoma regarding the clinical and biological diagnostic criteria. On the other hand, the therapeutic strategy may be different, particularly in MEN-1 insulinomas, since insulinomas are often multiple or associated with other secreting or non secreting endocrine tumours.

MEN-1 is related to a mutation in the menin gene, which maps to chromosome 11q13. Its prevalence is $1-10 / 100,000$. The functional physiological role of menin has not yet been well established. Menin interacts with numerous proteins that play a role in transcriptional regulation, genomic stability, cell division and control of cell cycle (Balogh et al. 2006; Yang \& Hua 2007). The major MEN-1 related endocrine disorders are pituitary adenomas, parathyroid adenomas or parathyroid hyperplasia, and secreting or non secreting pancreatic endocrine tumours. Regarding the secreting pancreatic endocrine tumours, the most frequent are gastrinomas $(54 \%, 20-61 \%$ of patients) and insulinomas $(18 \%, 7-31 \%$ of patients) (Jensen et al. 2008). MEN-1 related insulinomas occur generally in younger patients than sporadic insulinomas, with a greater prevalence in patients aged 25-35 years, but the age of occurrence is very different from patient to patient (5-80 years) (Cougard et al. 2000; Machens et al. 2007). Cystic pancreatic endocrine neoplasms could be more frequent in MEN-1 than in sporadic cases (Bordeianou et al. 2008).

The major characteristic of MEN-1 related insulinomas is that they are generally multiple tumours, so that diffuse microadenomatosis can be observed in the entire pancreatic gland, with multiple infracentimetric lesions of the pancreas (Anlauf et al. 2006). Often in such 
cases there are also secreting or non secreting endocrine tumours that are more than $1 \mathrm{~cm}$ in size and are distributed in the whole pancreatic gland. Thus managing MEN-1-related insulinomas is often managing multiple pancreatic endocrine tumours, that may secrete insulin and other hormones (gastrinoma, glucagonoma...) or may be non secreting endocrine tumours (Cougard et al. 2000).

The natural course of endocrine disorders in MEN-1 patients was previously thought to start almost always by occurrence of primary hyperparathyroidism (Marx et al. 1998). However others have reported cases of MEN-1 revealed by a secreting pancreatic endocrine tumour; hyperparathyroidism had not been identified prior to the diagnosis of the secreting pancreatic tumour, because it had a mild or asymptomatic presentation (Thakker 2000). Thus insulinoma was the endocrine tumour that revealed MEN-1 in 14-30\% of patients (O'Riordain et al. 1994; Cougard et al. 2000). Therefore, apparently sporadic insulinomas in young patients and multiple pancreatic lesions warrant to screen for MEN-1 even if there is no hyperparathyroidism.

The major issue is that of the treatment, since the multiple lesions increase the difficulty in achieving surgical cure of the disease. There is a mean of 3 pancreatic endocrine tumours ( 1 to 10 ) in the reported series of MEN-1 patients with pancreatic lesions who underwent surgery (Bartsch et al. 2005; Triponez et al. 2006). When managing an insulinoma patient with multiple pancreatic tumours, there could be several therapeutic strategies: 1 . to perform total pancreatectomy with its associated morbidity and mortality rates; 2 . to perform an extended resection of the pancreatic gland with enucleations of the tumours on the remaining pancreatic gland, which is also associated with significant morbidity and adds a risk of tumour recurrence. 3. to perform selective enucleations of the detected tumour(s), which increases the risk of re-operation for other tumours, and also may sometimes result in removing a nonsecreting tumour, and not the insulin-secreting tumour if it has not been detected because of its smaller size; this could warrant a functional study of the lesions (with preoperative transhepatic venous sampling or arterial calcium injection, or intra-operative measurement of insulin) 4.to choose a medical therapeutic approach in responders who do not seem to have malignant lesions. In an operable insulinoma patient, curative surgery is generally attempted for the following two reasons. First, the prevalence of malignant insulinomas is similar in MEN-1 patients and in patients with sporadic insulinomas (Jensen et al. 2008). The prognosis of MEN-1 depends on the progression of malignant pancreatic endocrine tumours (Jensen et al. 2008). Second, in insulinoma patients, even in a patient who is thought to be controlled by a medical treatment, the sudden occurrence of severe symptomatic hypoglycaemia cannot be excluded, with its potentially serious and even fatal consequences. Therefore there is a general agreement regarding the necessity to perform surgery in MEN-1 patients with insulinomas. The extent of surgery remains debated. It mainly depends on the number and the location of the lesions, and the possibility to enucleate the lesion. One of the major advantages of preoperative endoscopic ultrasound could be in the evaluation of MEN-1 patients, since it can visualize even small lesions in the head of the pancreas (Proye et al. 2004). Left-sided pancreatectomy with enucleation of the tumours located in the pancreatic head is generally recommended in patients with MEN-1 related insulinomas, whenever it is possible (Cougard et al. 2000). Tumor enucleation gives acceptable results if the choice of the lowest morbidity rates is made. In those patients who present with a small number of pancreatic tumours, surgery may be less extensive and single or multiple tumour enucleation can be performed, when it is technically possible. The patient must be informed about the risk of recurrence and re-operation. 
VHL disease is caused by a mutation in the VHL gene, which maps to chromosome 3p25. Its prevalence is 2 to $3 / 100,000$. It is responsible for occurrence of renal cysts and cancers, hemangioblastomas in the central nervous system, pheochromocytomas and paragangliomas, and pancreatic tumours (Barontini \& Dahia 2010). Pancreatic tumours and cysts are reported in 35-77\% patients with VHL (Mukhopadhyay et al. 2002), but to date, to our knowledge, there is no case report of VHL-related insulinoma. The mean age of VHL patients who present with a pancreatic lesion varies between 29 and 38 years; unlike what is found MEN-1 patients with pancreatic endocrine tumours, $70 \%$ of VHL patients with pancreatic tumours have a single pancreatic tumour (Libutti et al. 2000; Blansfield et al. 2007). Pancreatic endocrine tumours represent only $9-17 \%$ of pancreatic lesions in VHL patients (Mukhopadhyay et al. 2002), most of them being non secreting tumours (Libutti et al. 2000). It has also been reported that pancreatic lesions in VHL patients were significantly associated with renal cancers. Since insulinomas are obviously rare in VHL, it seems reasonable to screen for VHL in an insulinoma patient only if the insulinoma is associated with other typical VHL lesions, particularly renal cancer.

Tuberous sclerosis is a phakomatosis characterized by cutaneous (facial angiofibromas also termed "adenoma sebaceum", hypomelanic macules also termed "ash leaf spots", fibrous raised discoloured forehead plaques, and periungual fibromas), neurological (mental retardation, seizures, subependymal nodules and cortical/subcortical tubers), and ocular (hamartomas, also termed "phakomas") manifestations. The patients also present with renal cysts and angiomyolipomas and cardiac rhabdomyomas. TS is caused by mutations either in the TSC 1 gene (that encodes hamartin, and maps to chromosome 9q34) or in the TSC2 gene (that encodes tuberin, and maps to chromosome 16p13.3) (Lodish \& Stratakis 2010). Its prevalence is about $1 / 10,000$ (Osborne et al. 1991). The occurrence of insulinomas in TS patients has been reported very rarely (Davoren \& Epstein 1992; Kim et al. 1995; Boubaddi et al. 1997; Eledrisi et al. 2002; Dworakowska \& Grossman 2009). It is generally found in patients with mutations in the TSC2 gene (Merritt et al. 2006). In all reported cases, the insulinoma was found in patients aged more than 20, many years after that the diagnosis of TS had been made. Thus insulinoma is never the first manifestation of TS. Consequently, there is no reason to screen for TS in insulinoma patients. On the other hand, in a patient who is known to have TS, the re-occurrence of neurological or psychiatric symptoms warrants measurement of plasma glucose concentration.

Neurofibromatosis type 1 (NF1) ("Von Recklinghausen's disease") is caused by a mutation in the NF1 gene which maps to chromosome 17q11.2 and encodes a protein named fibromin. The main clinical signs are cutaneous "café-au-lait" spots, neurofibromas, Lisch nodules on iris surface, optic gliomas and bone dysplasia. Its prevalence is 1 in 4000 to 5000 . The most frequent endocrine tumour is pheochromocytoma. Pancreatic endocrine tumours are rare (0$10 \%$ ). Digestive tumours in NF1 are gastrointestinal stromal tumours (GIST), and duodenal somatostatinomas that characteristically cause biliary dilatation (Miettinen et al. 2006). Insulinomas are exceptional in NF1 (Perren et al. 2006).

\subsection{Nesidioblastosis}

There is no general agreement regarding the definition of adult nesidioblastosis. Nesidioblastosis represents a state of diffuse beta cell hyperfunction (though not necessarily uniform in all cases), also termed "non-insulinoma persistent hyperinsulinemic hypoglycaemia (NIPHH)" (Christesen et al. 2008). Such patients have insulin-mediated hypoglycaemia, either in the fasting or in the postprandial state. It also comprises cases 
reported as "non insulinoma pancreatogenic hypoglycaemia syndrome (NIPHS)", i.e. patients who only suffer from reactive insulin-mediated hypoglycaemia, who have a negative fast test without definite pancreatic endocrine tumour, and without mutations in the ABCC8 and KCNJ11 genes (Service et al. 1999). Though rare, it is not quite exceptional among adult patients with hypoglycaemia related to endogenous hyperinsulinism: 4/128 (3\%) patients (Raffel et al. 2007), 15/232 (6\%) patients (Anlauf et al. 2005b), and even 5/32 $(16 \%)$ patients (Witteles et al. 2001). We have made the diagnosis of idiopathic nesidioblastosis only in 4 patients for 20 years (1990-2010), while during the same 20 years 69 patients were diagnosed to have insulinomas in our institution; in addition, two other adult patients who had presented symptoms since the early childhood were found to have ABCC8 or glutamate dehydrogenase gene mutations.

Adult nesidioblastosis is likely to represent a heterogeneous disorder and whether it has specific histological correlates remains debated. The first histological reported features were islet cell enlargement, beta cells budding off ductular epithelium, and islets in apposition to ducts. Such aspects were found in an autopsy series in $36 \%$ of subjects without hypoglycaemia (Karnauchow PN 1981), whereas using morphometric criteria, patients with NIPHH could not be distinguished from controls (Goudswaard et al. 1984). In 15 adults with nesidioblastosis, blinded interobserver analysis showed beta-cell hypertrophy with enlarged and hyperchromatic nuclei; the interobserver analysis revealed 100\% specificity and $87.7 \%$ sensitivity for these criteria (Anlauf et al. 2005b). The degree and extent of these features vary much more from patient to patient than in newborns (Kloppel et al. 2008). The interpretation of histological findings is not unequivocal, as shown by the divergent conclusions regarding 6 patients with reactive insulin-mediated hypoglycaemia after bypass surgery (Service et al. 2005; Meier et al. 2006). In addition, Meier et al. reported a positive correlation between beta cell nuclear diameter and body mass index, so that the actual meaning of an increased nuclear size in beta cells can be debated. In 4 operated patients who all had transient remission of hypoglycaemia for about one year after left-sided pancreatectomy, the histological conclusions were nesidioblastosis in 2 patients, micronodular islet cell hyperplasia in one case, and presence of some enlarged nuclei in rare pancreatic areas in one patient (who had two heterozygous mutations of the ABCC 8 gene) (personal data).

Nesidioblastosis must not be confused with the recently identified pathological entity called insulinomatosis (Anlauf et al. 2009) which has been described in 14 patients, and is characterized by the synchronous and metachronous occurrence of insulinomas, multiple insulinoma precursor lesions, and rare development of metastases (all but one patient had benign disease), but common recurrent hypoglycaemia.

Nesidioblastosis may be related to well identified genetic disorders with mutations in genes that regulate beta cell insulin secretion (Flanagan et al. 2011a; Flanagan et al. 2011b; Palladino \& Stanley 2011) (see above, differential diagnosis) and in such cases, it may occasionally be diagnosed in adult patients (Christesen et al. 2008). It has also been reported to be an adult-onset disease occurring in patients who had been previously treated by insulin, or a sulfonylurea, and in patients with MEN-1, Zollinger-Ellison and WernerMorrison syndromes (Service et al. 1999). A higher rate of nesidioblastosis in MEN-1 adult patients has not been confirmed by all studies (Anlauf et al. 2005a). None of our patients with adult nesidioblastosis was found to have MEN-1. Conversion of insulin-dependent diabetes mellitus into nesidioblastosis has also been reported (Raffel et al. 2006). Recently, it has been found in patients after gastric bypass surgery (0.5-8 years after surgery in 5/6 
patients) but whether such patients have actual structural pancreatic abnormalities is still debated (see differential diagnosis, dumping syndrome). Most reported patients with adultonset nesidioblastosis do not have any particular medical history and do not present with mutations known to be associated with hypoglycaemia in young children.

The diagnosis of nesidioblastosis is made in patients with definite biological evidence of hypoglycaemia related to endogenous hyperinsulinism (as in insulinoma patients, see biological diagnosis) in the absence of insulin secretagogues, autoimmune hypoglycaemia, and detectable pancreatic tumour. There is neither clinical nor biological basis to make a distinction between insulinoma and nesidioblastosis. Patients with nesidioblastosis may have a positive fast test (as in all our patients), though patients with NIPHS have negative fast tests and only reactive insulin-mediated hypoglycaemia; on the other hand, very rare insulinoma patients may present with a negative fast test, and some of them have only reactive insulin-mediated hypoglycaemia. The diagnostic specificity of multi-site insulin stimulation by intra-arterial calcium injection is not fully established: such insulin stimulation after intraarterial calcium injection was found in normal pancreatic areas for unknown reasons (Wiesli et al. 2004a; Guettier et al. 2009), and has been reported in patients with factitious hypoglycaemia related to insulin secretagogues (Hirshberg et al. 2001). In addition, intra-arterial calcium stimulation may provide a pseudo-insulinoma response pattern in patients with adult nesidioblastosis, maybe because nesidioblastosis is not evenly distributed in the pancreas. One must also be reminded that nesidioblastosis has been found in patients who had concurrent insulinoma (Bright et al. 2008) (Service et al. 1999). Slight focal pancreatic abnormalities have been reported with radionuclide imaging (Kauhanen et al. 2007).

The natural course of adult-onset nesidioblastosis is not well established. Most patients require a medical and/or surgical treatment. In an obese patient with idiopathic nesidioblastosis who had been treated by left-sided pancreatectomy and high doses of octreotide, hypoglycaemia finally subsided during the perimenopausal years, and changed to mild type- 2 diabetes mellitus. No similar change was observed in other patients with nesidioblastosis, though the dose of diazoxide could be decreased in one patient during the perimenopausal years (unpublished personal data).

A medical treatment is the first-line therapeutic approach for nesidioblastosis, but it may not be sufficient to control the hypoglycaemia, and pancreatic surgery must often be performed. Diazoxide remains the reference medication for nesidioblastosis, and is often effective to control the hypoglycaemia, at least after partial pancreatectomy (Arao et al. 2006). Longterm treatment with somatostatin analogues has also been reported to be effective, without the side effects of diazoxide (Vezzosi et al. 2008). One of our patients was treated with continuous subcutaneous administration of a high dose of octreotide throughout her pregnancy, without any detectable maternal or foetal adverse effect (Boulanger et al. 2004). Calcium channel blockers have been employed (Witteles et al. 2001) (Vella \& Service 2007). Pancreatic surgery, guided by the results of transhepatic venous sampling or those of insulin stimulation after selective intraarterial calcium injection, is often performed. The extent of surgery is controversial, in order to achieve a total control or a significant improvement of hypoglycaemia, without pancreatic insufficiency (Raffel et al. 2007). Selective intra-arterial calcium injection usually helps in choosing the extent of pancreatectomy (Toyomasu et al. 2009). Total pancreatectomy cannot be recommended, since complete or acceptable control of the hypoglycaemia can be achieved in most patients by partial pancreatectomy followed if necessary by a medical treatment. Spleen-preserving distal pancreatectomy is often performed unless the results suggest a proximal pancreatic 
origin for excess insulin secretion (Starke et al. 2006). Four of our patients with nesidioblastosis were treated by left-sided pancreatectomy; all of them had transient remission of hypoglycaemia for about one year, then acceptable control was observed with diazoxide or octreotide, which proved to be more effective to control hypoglycaemia after partial pancreatectomy. 70\%-distal pancreatectomy was performed in 5 patients with nesidioblastosis (Witteles et al. 2001) resulting in long-term remission in 3 patients, and some recurrences of hypoglycaemia in 2 patients, successfully treated by calcium channel blockers, with a follow-up of $1.5-21$ years. Thus $60-75 \%$ resection of the pancreatic gland, guided by insulin venous gradient or insulin stimulation by selective intraarterial calcium injection, and followed if necessary by a medical therapy, appears to be a reasonable treatment for adult nesidioblastosis when enough efficacy cannot be achieved by medical therapy alone.

\section{References}

Agostino, N., Chinchilli V. M., et al. (2010). "Effect of the tyrosine kinase inhibitors (sunitinib, sorafenib, dasatinib, and imatinib) on blood glucose levels in diabetic and nondiabetic patients in general clinical practice." Journal of Oncology Pharmacy Practice 2010 Aug 14 ahead of print.

Ahn, J. E., Byun J. H., et al. (2007). "Case report: neuroendocrine carcinoma of the gallbladder causing hyperinsulinaemic hypoglycaemia." Clinical Radiology 62(4): 391-394.

Altszuler, N., Moraru E., et al. (1977). "On the mechanism of diazoxide-induced hyperglycemia." Diabetes 26(10): 931-935.

An, L., Li W., et al. (2010). "Assessment of contrast-enhanced ultrasonography in diagnosis and preoperative localization of insulinoma." European Journal of Radiology. 2010 Oct 19. ahead of print doi:10.1016/j.ejrad.2010.09.014

Anlauf, M., Perren A., et al. (2005a). "Precursor lesions in patients with multiple endocrine neoplasia type 1-associated duodenal gastrinomas." Gastroenterology 128(5): 11871198.

Anlauf, M., Wieben D., et al. (2005b). "Persistent hyperinsulinemic hypoglycemia in 15 adults with diffuse nesidioblastosis: diagnostic criteria, incidence, and characterization of beta-cell changes." American Journal of Surgical Pathology 29(4): 524-533.

Anlauf, M., Schlenger R., et al. (2006). "Microadenomatosis of the endocrine pancreas in patients with and without the multiple endocrine neoplasia type 1 syndrome." American Journal of Surgical Pathology 30(5): 560-574.

Anlauf, M., Bauersfeld J. et al. (2009) Insulinomatosis : a multicentric insulinoma disease that frequently causes early recurrent hyperinsulinemic hypoglycemia. American Journal of Surgical Pathology 33(3): 339-346.

Arao, T., Okada Y., et al. (2006). "A rare case of adult-onset nesidioblastosis treated successfully with diazoxide." Endocrine Journal 53(1): 95-100.

Ardengh, J. C., Rosenbaum P., et al. (2000). "Role of EUS in the preoperative localization of insulinomas compared with spiral CT." Gastrointestinal Endoscopy 51(5): 552-555.

Arem, R. (1989). "Hypoglycemia associated with renal failure." Endocrinology and Metabolism Clinics of North America 18(1): 103-121.

Arnold, R., Chen Y.J., et al. (2009). ENETS Consensus Guidelines for the standards of care in neuroendocrine tumors: follow-up and documentation. Neuroendocrinology 90(2): 227233. 
Atwell, T. D., Lloyd R. V., et al. (2008). "Peritumoral steatosis associated with insulinomas: appearance at imaging." Abdominal Imaging 33(5): 571-574.

Bader, T. R., Semelka R. C., et al. (2001). "MRI of carcinoid tumors: spectrum of appearances in the gastrointestinal tract and liver." Journal of Magnetic Resonance Imaging 14(3): 261269.

Balogh, K., Racz K., et al. (2006). "Menin and its interacting proteins: elucidation of menin function." Trends in Endocrinology and Metabolism 17(9): 357-364.

Balon, H. R., S. J. Goldsmith, et al. (2001). "Procedure guideline for somatostatin receptor scintigraphy with (111)In-pentetreotide." Journal of Nuclear Medicine 42(7): 1134-1138.

Barontini, M. and Dahia P. L. (2010). "VHL disease." Best Practice and Research Clinical Endocrinology and Metabolism 24(3): 401-413.

Bartsch, D. K., Fendrich V., et al. (2005). "Outcome of duodenopancreatic resections in patients with multiple endocrine neoplasia type 1." Annals of Surgery 242(6): 757-764, discussion 764-756.

Basu, A., Service F. J., et al. (2005). "Insulin autoimmunity and hypoglycemia in seven white patients." Endocrine Practice 11(2): 97-103.

Basu, A., Sheehan M., et al. (2002). "Insulinoma in chronic renal failure: a case report." Journal of Clinical Endocrinology and Metabolism 87(11): 4889-4891.

Ben Salem, C., Fathallah N., et al. (2011). "Drug-induced hypoglycaemia: an update." Drug Safety 34(1): 21-45.

Berber, E., Flesher N., et al. (2002). "Laparoscopic radiofrequency ablation of neuroendocrine liver metastases." World Journal of Surgery 26(8): 985-990.

Bertherat, J., Tenenbaum F., et al. (2003). "Somatostatin receptors 2 and 5 are the major somatostatin receptors in insulinomas: an in vivo and in vitro study." Journal of Clinical Endocrinology and Metabolism 88(11): 5353-5360.

Blansfield, J. A., Choyke L., et al. (2007). "Clinical, genetic and radiographic analysis of 108 patients with von Hippel-Lindau disease (VHL) manifested by pancreatic neuroendocrine neoplasms (PNETs)." Surgery 142(6): 814-818; discussion 818 e811812.

Bombardieri, E., Aktolun C., et al. (2003). "111In-pentetreotide scintigraphy: procedure guidelines for tumour imaging." European Journal of Nuclear Medicine and Molecular Imaging 30(12): BP140-147.

Bordeianou, L., Vagefi P. A., et al. (2008). "Cystic pancreatic endocrine neoplasms: a distinct tumor type?" Journal of the American College of Surgeons 206(3): 1154-1158.

Boubaddi, N. E., Imbert Y., et al. (1997). "[Secreting insulinoma and Bourneville's tuberous sclerosis]." Gastroenterologie Clinique et Biologique 21(4): 343.

Boulanger, C., Vezzosi D., et al. (2004). "Normal pregnancy in a woman with nesidioblastosis treated with somatostatin analog octreotide." Journal of Endocrinological Investigation 27(5): 465-470.

Bourcier, M. E., Sherrod A., et al. (2009). "Successful control of intractable hypoglycemia using rapamycin in an 86-year-old man with a pancreatic insulin-secreting islet cell tumor and metastases." Journal of Clinical Endocrinology and Metabolism 94(9): 3157-3162.

Bright, E., Garcea G., et al. (2008). "An unusual case of concurrent insulinoma and nesidioblastosis." Journal of the Pancreas 9(5): 649-653.

Bruzzone, A., Varaldo M., et al. (2010). "Solitary fibrous tumor." Rare Tumors 2(4): e64. 
Burmeister, J. E., Scapini A., et al. (2007). "Glucose-added dialysis fluid prevents asymptomatic hypoglycaemia in regular haemodialysis." Nephrology Dialysis Transplantation 22(4): 1184-1189.

Carrere, N., Abid S., et al. (2007). "Spleen-preserving distal pancreatectomy with excision of splenic artery and vein: a case-matched comparison with conventional distal pancreatectomy with splenectomy." World Journal of Surgery 31(2): 375-382.

Cassiman, D., Libbrecht L., et al. (2010). "An adult male patient with multiple adenomas and a hepatocellular carcinoma: mild glycogen storage disease type Ia." Journal of Hepatology 53(1): 213-217.

Christ, E., Wild D., et al. (2009). "Glucagon-like peptide-1 receptor imaging for localization of insulinomas." Journal of Clinical Endocrinology and Metabolism 94(11): 4398-4405.

Christesen, H. B., Brusgaard K., et al. (2008). "Non-insulinoma persistent hyperinsulinaemic hypoglycaemia caused by an activating glucokinase mutation: hypoglycaemia unawareness and attacks." Clinical Endocrinology 68(5): 747-755.

Christiansen, E. and Vestergaard H. (2008). "Insulinoma in a third-trimester pregnant woman combined with pre-eclampsia: a case report and review of the diagnostic strategies." Gynecological Endocrinology 24(7): 417-422.

Chung, J. O., Hong S. I., et al. (2008). "Hypoglycemia associated with the production of insulinlike growth factor II in a pancreatic islet cell tumor: a case report." Endocrine Journal 55(3): 607-612.

Cougard, P., Goudet P., et al. (2000). "[Insulinomas in multiple endocrine neoplasia type 1. Report of a series of 44 cases by the multiple endocrine neoplasia study group]." Annales de Chirurgie 125(2): 118-123.

Crippa, S., Bassi C., et al. (2007). "Enucleation of pancreatic neoplasms." British Journal of Surgery 94(10): 1254-1259.

Cryer, P. E. (2008). Glucose homeostasis and hypoglycemia. Williams Textbook of Endocrinology (11th edition): 1503-1533.

Cryer, P. E., Axelrod L., et al. (2009). "Evaluation and management of adult hypoglycemic disorders: an Endocrine Society Clinical Practice Guideline." Journal of Clinical Endocrinology and Metabolism 94(3): 709-728.

Danforth, D. N., Jr., Gorden P., et al. (1984). "Metastatic insulin-secreting carcinoma of the pancreas: clinical course and the role of surgery." Surgery 96(6): 1027-1037.

Davoren, P. M. and Epstein M. T. (1992). "Insulinoma complicating tuberous sclerosis." Journal of Neurology, Neurosurgery and Psychiatry 55(12): 1209.

Di Paolo, S., Teutonico A., et al. (2006). "Chronic inhibition of mammalian target of rapamycin signaling downregulates insulin receptor substrates 1 and 2 and AKT activation: A crossroad between cancer and diabetes?" Journal of the American Society of Nephrology 17(8): 2236-2244.

Diaz, A. G., Herrera J., et al. (2008). "Insulinoma associated with pregnancy." Fertility and Sterility 90(1): 199 e191-194.

Dimou, A. T., Syrigos K. N., et al. (2010). "Neuroendocrine tumors of the pancreas: what's new. Highlights from the "2010 ASCO Gastrointestinal Cancers Symposium". Orlando, FL, USA. January 22-24, 2010." Journal of the Pancreas 11(2): 135-138.

Doppman, J. L., Miller D. L., et al. (1993). "Intraarterial calcium stimulation test for detection of insulinomas." World Journal of Surgery 17(4): 439-443. 
Dörr, U., Wurm K., et al. (1993). "Diagnostic reliability of somatostatin receptor scintigraphy during continuous treatment with different somatostatin analogs." Hormone and Metabolic Research 27(suppl): 36-43.

Dromain, C., de Baere T., et al. (2005). "Detection of liver metastases from endocrine tumors: a prospective comparison of somatostatin receptor scintigraphy, computed tomography, and magnetic resonance imaging." Journal of Clinical Oncology 23(1): 7078.

Druce, M. R., Muthuppalaniappan V. M., et al. (2010). "Diagnosis and localisation of insulinoma: the value of modern magnetic resonance imaging in conjunction with calcium stimulation catheterisation." European Journal of Endocrinology 162(5): 971-978.

Dworakowska, D. and Grossman A. B. (2009). "Are neuroendocrine tumours a feature of tuberous sclerosis? A systematic review." Endocrine-Related Cancer 16(1): 45-58.

Eledrisi, M. S., Stuart C. A., et al. (2002). "Insulinoma in a patient with tuberous sclerosis: is there an association?" Endocrine Practice 8(2): 109-112.

Fendrich, V., Waldmann J., et al. (2009). "Surgical management of pancreatic endocrine tumors." Nature Reviews Clinical Oncology 6(7): 419-428.

Finlayson, E. and Clark O. H. (2004). "Surgical treatment of insulinomas." Surgery Clinics of North America 84(3): 775-785.

Flanagan, S. E., Kapoor R. R., et al. (2011a). "Genetics of congenital hyperinsulinemic hypoglycemia." Seminars in Pediatric Surgery 20(1): 13-17.

Flanagan, S. E., Patch A. M., et al. (2011b). "Genome-Wide Homozygosity Analysis Reveals HADH Mutations as a Common Cause of Diazoxide-Responsive HyperinsulinemicHypoglycemia in Consanguineous Pedigrees." Journal of Clinical Endocrinology and Metabolism 96(3): E498-502.

Gin, H., Brottier E., et al. (1987). "Use of the glucose clamp technique for confirmation of insulinoma autonomous hyperinsulinism." Archives of Internal Medicine 147(5): 985987.

Goldfine, A. B., Mun E. C., et al. (2007). "Patients with neuroglycopenia after gastric bypass surgery have exaggerated incretin and insulin secretory responses to a mixed meal." Journal of Clinical Endocrinology and Metabolism 92(12): 4678-4685.

Goudswaard, W. B., Zwierstra R. P., et al. (1984). "Surgical treatment of organic hyperinsulinism in infancy. Surgical procedure in the absence of a demonstrable insulinoma and a peroperative diagnosis of nesidioblastosis." Zeitschrift für Kinderchirurgie 39(2): 91-95.

Grant, C. (1999). "Surgical aspects of hyperinsulinemic hypoglycemia. " Endocrinology and Metabolism Clinics of North America 28(3): 533-554.

Grant, C., van Heerden J., et al. (1988). "Insulinoma. The value of intraoperative ultrasonography." Archives of Surgery 123(7): 843-848.

Greenberg, R. S., Baumgarten D. A., et al. (1987). "Prognostic factors for gastrointestinal and bronchopulmonary carcinoid tumors." Cancer 60(10): 2476-2483.

Gregersen, G., Holst J. J., et al. (2002). "Case report: somatostatin producing teratoma, causing rapidly alternating extreme hyperglycemia and hypoglycemia, and ovarian somatostatinoma." Metabolism 51(9): 1180-1183.

Grunberger, G., Weiner J. L., et al. (1988). "Factitious hypoglycemia due to surreptitious administration of insulin. Diagnosis, treatment, and long-term follow-up." Annals of Internal Medicine 108(2): 252-257. 
Grunenwald, S., Broussaud S., et al. (2009). "Well-differentiated endocrine pancreatic tumour and Wernicke's encephalopathy." Clinical Endocrinology 70(1): 170-171.

Guettier, J. M., Kam A., et al. (2009). "Localization of insulinomas to regions of the pancreas by intraarterial calcium stimulation: the NIH experience." Journal of Clinical Endocrinology and Metabolism 94(4): 1074-1080.

Habra, M. A., Nunez R., et al. (2010). "Fatal hypoglycemia in malignant pheochromocytoma: direct glucose consumption as suggested by (18)F-2-fluoro-2-deoxy-D-glucose positron emission tomography/computed tomography imaging." Endocrine 37(1): 209-212.

Halsall, D. J., Mangi M., et al. (2007). "Hypoglycemia due to an insulin binding antibody in a patient with an IgA-kappa myeloma." Journal of Clinical Endocrinology and Metabolism 92(6): 2013-2016.

Hanaire, H., Dubet A., et al. (2010). "Usefulness of continuous glucose monitoring for the diagnosis of hypoglycemia after a gastric bypass in a patient previously treated for type 2 diabetes." Obesity Surgery 20(1): 126-129.

Healy, M. L., Dawson S. J., et al. (2007). "Severe hypoglycaemia after long-acting octreotide in a patient with an unrecognized malignant insulinoma." Internal Medicine Journal 37(6): 406-409.

Hirono, S., Tani M., et al. (2009). "A central pancreatectomy for benign or low-grade malignant neoplasms." Journal of Gastrointestinal Surgery 13(9): 1659-1665.

Hirshberg, B., Libutti S. K., et al. (2002). "Blind distal pancreatectomy for occult insulinoma, an inadvisable procedure." Journal of the American College of Surgeons 194(6): 761-764.

Hirshberg, B., Livi A., et al. (2000). "Forty-eight-hour fast: the diagnostic test for insulinoma." Journal of Clinical Endocrinology and Metabolism 85(9): 3222-3226.

Hirshberg, B., Skarulis M. C., et al. (2001). "Repaglinide-induced factitious hypoglycemia." Journal of Clinical Endocrinology and Metabolism 86(2): 475-477.

Hogan, M. J., Service F. J., et al. (1983). "Oral glucose tolerance test compared with a mixed meal in the diagnosis of reactive hypoglycemia. A caveat on stimulation." Mayo Clinic Proceedings 58(8): 491-496.

Hojlund, K., Hansen T., et al. (2004). "A novel syndrome of autosomal-dominant hyperinsulinemic hypoglycemia linked to a mutation in the human insulin receptor gene." Diabetes 53(6): 1592-1598.

Huang, Z. and Sjoholm A. (2008). "Ethanol acutely stimulates islet blood flow, amplifies insulin secretion, and induces hypoglycemia via nitric oxide and vagally mediated mechanisms." Endocrinology 149(1): 232-236.

Ilan, Y., Shamir M., et al. (1996). "Reversal of fulminant-hepatitis-associated hypoglycaemia at the anhepatic stage during liver transplantation." Netherlands Journal of Medicine 48(5): 185-187.

Izumiyama, H., Gotyo N., et al. (2006). "Glucose-responsive and octreotide-sensitive insulinoma." Internal Medicine 45(8): 519-524.

Jarhult, J., Ericsson M., et al. (1981). "Lack of suppression of insulin secretion by exercise in patients with insulinoma." Clinical Endocrinology 15(4): 391-394.

Jensen, R. T., Berna M. J., et al. (2008). "Inherited pancreatic endocrine tumor syndromes: advances in molecular pathogenesis, diagnosis, management, and controversies." Cancer 113(7 Suppl): 1807-1843. 
Kann, P. H., Wirkus B., et al. (2003). "Pitfalls in endosonographic imaging of suspected insulinomas: pancreatic nodules of unknown dignity." European Journal of Endocrinology 148(5): 531-534.

Kar, P., Price P., et al. (2006). "Insulinomas may present with normoglycemia after prolonged fasting but glucose-stimulated hypoglycemia." Journal of Clinical Endocrinology and Metabolism 91(12): 4733-4736.

Kauhanen, S., Seppanen M., et al. (2007). "Fluorine-18-L-dihydroxyphenylalanine (18F-DOPA) positron emission tomography as a tool to localize an insulinoma or beta-cell hyperplasia in adult patients." Journal of Clinical Endocrinology and Metabolism 92(4): 1237-1244.

Kim, H., Kerr A., et al. (1995). "The association between tuberous sclerosis and insulinoma." American Journal of Neuroradiology 16(7): 1543-1544.

Klimstra, D. S., Modlin I. R., et al. (2010). "The pathologic classification of neuroendocrine tumors: a review of nomenclature, grading, and staging systems." Pancreas 39(6): 707712.

Kloppel, G. (2007). "Tumour biology and histopathology of neuroendocrine tumours." Best Practice and Research Clinical Endocrinology and Metabolism 21(1): 15-31.

Kloppel, G., Anlauf M., et al. (2008). "Adult diffuse nesidioblastosis: genetically or environmentally induced?" Human Pathology 39(1): 3-8.

Kloppel, G., Couvelard A., et al. (2009). "ENETS Consensus Guidelines for the Standards of Care in Neuroendocrine Tumors: towards a standardized approach to the diagnosis of gastroenteropancreatic neuroendocrine tumors and their prognostic stratification." Neuroendocrinology 90(2): 162-166.

Kooby, D. A., Gillespie T., et al. (2008). "Left-sided pancreatectomy: a multicenter comparison of laparoscopic and open approaches." Annals of Surgery 248(3): 438-446.

Krenning, E. P., Kwekkeboom D. J., et al. (1993). "Somatostatin receptor scintigraphy with [111In-DTPA-D-Phe1]- and [123I- Tyr3]-octreotide: the Rotterdam experience with more than 1000 patients." European Journal of Nuclear Medicine 20(8): 716-731.

Kulke, M. H., Bergsland E. K., et al. (2009). "Glycemic control in patients with insulinoma treated with everolimus." New England Journal of Medicine 360(2): 195-197.

Kulke, M. H., Stuart K., et al. (2006). "Phase II study of temozolomide and thalidomide in patients with metastatic neuroendocrine tumors." Journal of Clinical Oncology 24(3): 401-406.

Lamberts, S. W., Hofland L. J., et al. (1990). "Parallel in vivo and in vitro detection of functional somatostatin receptors in human endocrine pancreatic tumors: consequences with regard to diagnosis, localization, and therapy." Journal of Clinical Endocrinology and Metabolism 71(3): 566-574.

Lepage, C., Rachet B., et al. (2007). "Survival from malignant digestive endocrine tumors in England and Wales: a population-based study." Gastroenterology 132(3): 899-904.

Lev-Ran, A. and Anderson R. W. (1981). "The diagnosis of postprandial hypoglycemia." Diabetes 30(12): 996-999.

Libutti, S. K., Choyke P. L., et al. (2000). "Clinical and genetic analysis of patients with pancreatic neuroendocrine tumors associated with von Hippel-Lindau disease." Surgery 128(6): 1022-1027; discussion 1027-1028. 
Lionakis, M. S., Samonis G., et al. (2008). "Endocrine and metabolic manifestations of invasive fungal infections and systemic antifungal treatment." Mayo Clinic Proceedings 83(9): 1046-1060.

Lodish, M. B. and Stratakis C. A. (2010). "Endocrine tumours in neurofibromatosis type 1, tuberous sclerosis and related syndromes." Best Practice and Research Clinical Endocrinology and Metabolism 24(3): 439-449.

Lucidi, P., Rossetti P., et al. (2010). "Mechanisms of insulin resistance after insulin-induced hypoglycemia in humans: the role of lipolysis." Diabetes 59(6): 1349-1357.

Machens, A., Schaaf L., et al. (2007). "Age-related penetrance of endocrine tumours in multiple endocrine neoplasia type 1 (MEN1): a multicentre study of 258 gene carriers." Clinical Endocrinology 67(4): 613-622.

Maiza, J., Vezzosi D., et al. (2011). "Treatment with somatostatin analogues and chemoembolization of liver metastases for severe hypoglycemia in malignant insulinomas." Journal of Endocrinological Investigation, in press.

Marks, V. and Teale J. D. (1999). "Drug-induced hypoglycemia." Endocrinology and Metabolism Clinics of North America 28(3): 555-577.

Marx, S., Spiegel A. M., et al. (1998). "Multiple endocrine neoplasia type 1: clinical and genetic topics." Annals of Internal Medicine 129(6): 484-494.

McLaughlin, T., Peck M., et al. (2010). "Reversible hyperinsulinemic hypoglycemia after gastric bypass: a consequence of altered nutrient delivery." Journal of Clinical Endocrinology and Metabolism 95(4): 1851-1855.

McLean, A. M. and Fairclough P. D. (2005). "Endoscopic ultrasound in the localisation of pancreatic islet cell tumours." Best Practice and Research Clinical Endocrinology and Metabolism 19(2): 177-193.

Meier, J. J., Butler A. E., et al. (2006). "Hyperinsulinemic hypoglycemia after gastric bypass surgery is not accompanied by islet hyperplasia or increased beta-cell turnover." Diabetes Care 29(7): 1554-1559.

Merritt, J. L., 2nd, Davis D. M., et al. (2006). "Extensive acrochordons and pancreatic islet-cell tumors in tuberous sclerosis associated with TSC2 mutations." American Journal of Medical Genetics A 140(15): 1669-1672.

Miettinen, M., Fetsch J. F., et al. (2006). "Gastrointestinal stromal tumors in patients with neurofibromatosis 1: a clinicopathologic and molecular genetic study of 45 cases." American Journal of Surgical Pathology 30(1): 90-96.

Moertel, C. G., Lefkopoulo M., et al. (1992). "Streptozocin-doxorubicin, streptozocinfluorouracil or chlorozotocin in the treatment of advanced islet-cell carcinoma." New England Journal of Medicine 326(8): 519-523.

Montravers, F., Kerrou K., et al. (2009). "Impact of fluorodihydroxyphenylalanine-18F positron emission tomography on management of adult patients with documented or occult digestive endocrine tumors." Journal of Clinical Endocrinology and Metabolism 94(4): 1295-1301.

Moscetti, L., Saltarelli R., et al. (2000). "Intra-arterial liver chemotherapy and hormone therapy in malignant insulinoma: case report and review of the literature." Tumori 86(6): 475479.

Mukhopadhyay, B., Sahdev A., et al. (2002). "Pancreatic lesions in von Hippel-Lindau disease." Clinical Endocrinology 57(5): 603-608. 
Muller, M. W., Friess H., et al. (2006). "Middle segmental pancreatic resection: An option to treat benign pancreatic body lesions." Annals of Surgery 244(6): 909-918; discussion 918-920.

Munir, A., Choudhary P., et al. (2008). "Continuous glucose monitoring in patients with insulinoma." Clinical Endocrinology 68(6): 912-918.

Murad, M. H., Coto-Yglesias F., et al. (2009). "Clinical review: Drug-induced hypoglycemia: a systematic review." Journal of Clinical Endocrinology and Metabolism 94(3): 741-745.

Nakamura, T., Kishi A., et al. (2001). "Insulin production in a neuroectodermal tumor that expresses islet factor-1, but not pancreatic-duodenal homeobox 1." Journal of Clinical Endocrinology and Metabolism 86(4): 1795-1800.

Nauck, M., Reinecke M., et al. (2007). "Hypoglycemia due to paraneoplastic secretion of insulin-like growth factor-I in a patient with metastasizing large-cell carcinoma of the lung." Journal of Clinical Endocrinology and Metabolism 92(5): 1600-1605.

Neal, J. M. and Han W. (2008). "Insulin immunoassays in the detection of insulin analogues in factitious hypoglycemia." Endocrine Practice 14(8): 1006-1010.

Nikfarjam, M., Warshaw A. L., et al. (2008). "Improved contemporary surgical management of insulinomas: a 25-year experience at the Massachusetts General Hospital." Annals of Surgery 247(1): 165-172.

Novotny, J., Janku F., et al. (2005). "Symptomatic control of hypoglycaemia with prednisone in refractory metastatic pancreatic insulinoma." Support Care Cancer 13(9): 760-762.

O'Brien, T., O'Brien P. C., et al. (1993). "Insulin surrogates in insulinoma." Journal of Clinical Endocrinology and Metabolism 77(2): 448-451.

O'Riordain, D. S., O'Brien T., et al. (1994). "Surgical management of insulinoma associated with multiple endocrine neoplasia type I." World Journal of Surgery 18(4): 488-493; discussion 493-484.

O'Shea, D., Rohrer-Theurs A. W., et al. (1996). "Localization of insulinomas by selective intraarterial calcium injection." Journal of Clinical Endocrinology and Metabolism 81(4): 1623-1627.

Ong, G. S., Henley D. E., et al. (2010). "Therapies for the medical management of persistent hypoglycaemia in two cases of inoperable malignant insulinoma." European Journal of Endocrinology 162(5): 1001-1008.

Osborne, J. P., Fryer A., et al. (1991). "Epidemiology of tuberous sclerosis." Annals of New York Academy of Sciences 615: 125-127.

Oshikawa, O., Tanaka S., et al. (2002). "Dynamic sonography of pancreatic tumors: comparison with dynamic CT." American Journal of Roentgenology, radium therapy and nuclear medicine 178(5): 1133-1137.

Palladino, A. A., Bennett M. J., et al. (2008). "Hyperinsulinism in infancy and childhood: when an insulin level is not always enough." Clinical Chemistry 54(2): 256-263.

Palladino, A. A. and Stanley C. A. (2011). "A specialized team approach to diagnosis and medical versus surgical treatment of infants with congenital hyperinsulinism." Seminars in Pediatric Surgery 20(1): 32-37.

Pannegeon, V., Pessaux P., et al. (2006). "Pancreatic fistula after distal pancreatectomy: predictive risk factors and value of conservative treatment." Archives of Surgery 141(11): 1071-1076; discussion 1076. 
Pape, U. F., Bohmig M., et al. (2004). "Survival and clinical outcome of patients with neuroendocrine tumors of the gastroenteropancreatic tract in a german referral center." Annals of New York Academy of Sciences 1014: 222-233.

Pasquali, C., Rubello D., et al. (1998). "Neuroendocrine tumor imaging: can 18Ffluorodeoxyglucose positron emission tomography detect tumors with poor prognosis and aggressive behavior?" World Journal of Surgery 22(6): 588-592.

Perren, A., Wiesli P., et al. (2006). "Pancreatic endocrine tumors are a rare manifestation of the neurofibromatosis type 1 phenotype: molecular analysis of a malignant insulinoma in a NF-1 patient." American Journal of Surgical Pathology 30(8): 1047-1051.

Placzkowski, K. A., Vella A., et al. (2009). "Secular trends in the presentation and management of functioning insulinoma at the Mayo Clinic, 1987-2007." Journal of Clinical Endocrinology and Metabolism 94(4): 1069-1073.

Proye, C., Stalnikiewicz G., et al. (2004). "[Genetically-driven or supposed genetic-related insulinomas in adults: validation of the surgical strategy proposed by the A.F.C.E./G.E.N.E.M]." Annales d'Endocrinologie 65(2): 149-161.

Raffel, A., Anlauf M., et al. (2006). "Hyperinsulinemic hypoglycemia due to adult nesidioblastosis in insulin-dependent diabetes." World Journal of Gastroenterology 12(44): 7221-7224.

Raffel, A., Krausch M. M., et al. (2007). "Diffuse nesidioblastosis as a cause of hyperinsulinemic hypoglycemia in adults: a diagnostic and therapeutic challenge." Surgery 141(2): 179184; discussion 185-176.

Raymond, E., Dahan L., et al. (2011) Sunitinib malate for the treatment of pancreatic neuroendocrine tumors. New England Journal of Medicine 365(6): 501-513.

Redmon, J. B. and Nuttall F. Q. (1999). "Autoimmune hypoglycemia." Endocrinology and Metabolism Clinics of North America 28(3): 603-618, vii.

Reubi, J. C., Macke H. R., et al. (2005). "Candidates for peptide receptor radiotherapy today and in the future." Journal of Nuclear Medicine 46 Suppl 1: 67S-75S.

Reubi, J. C., Perren A., et al. (2010). "Glucagon-like peptide-1 (GLP-1) receptors are not overexpressed in pancreatic islets from patients with severe hyperinsulinaemic hypoglycaemia following gastric bypass." Diabetologia 53(12): 2641-2645.

Reubi, J. C., Schär J. C., et al. (2000). "Affinity profiles for human somatostatin receptor subtypes SST1-SST5 of somatostatin radiotracers selected for scintigraphic and radiotherapeutic use." European Journal of Nuclear Medicine 27: 273-282.

Reubi, J. C. and Waser B. (2003). "Concomitant expression of several peptide receptors in neuroendocrine tumours: molecular basis for in vivo multireceptor tumour targeting." European Journal of Nuclear Medicine and Molecular Imaging 30(5): 781-793.

Rich, L. M., Caine M. R., et al. (1990). "Hypoglycemic coma in anorexia nervosa. Case report and review of the literature." Archives of Internal Medicine 150(4): 894-895.

Roche, A., Girish B. V., et al. (2003). "Trans-catheter arterial chemoembolization as first-line treatment for hepatic metastases from endocrine tumors." European Radiology 13(1): 136-140.

Rockall, A. G. and Reznek R. H. (2007). "Imaging of neuroendocrine tumours (CT/MR/US)." Best Practice and Research Clinical Endocrinology and Metabolism 21(1): 43-68.

Rosch, T., Lightdale C. J., et al. (1992). "Localization of pancreatic endocrine tumors by endoscopic ultrasonography." New England Journal of Medicine 326(26): 1721-1726. 
Sapin, R. (2003). "Insulin assays: previously known and new analytical features." Clinical Laboratory 49(3-4): 113-121.

Sarmiento, J. M., Que F. G., et al. (2002). "Concurrent resections of pancreatic islet cell cancers with synchronous hepatic metastases: outcomes of an aggressive approach." Surgery 132(6): 976-982; discussion 982-973.

Schillaci, O., Massa R., et al. (2000). "111In-pentetreotide scintigraphy in the detection of insulinomas: importance of SPECT imaging." Journal of Nuclear Medicine 41(3): 459462.

Seckl, M. J., Mulholland P. J., et al. (1999). "Hypoglycemia due to an insulin-secreting small-cell carcinoma of the cervix." New England Journal of Medicine 341(10): 733-736.

Service, F. (1995). "Hypoglycemic disorders." New England Journal of Medicine 332(17): 11441152.

Service, F. (1999). "Diagnostic approach to adults with hypoglycemic disorders." Endocrinology and Metabolism Clinics of North America 28(3): 519-532.

Service, F., N. Natt, et al. (1999). "Noninsulinoma pancreatogenous hypoglycemia: a novel syndrome of hyperinsulinemic hypoglycemia in adults independent of mutations in Kir6.2 and SUR1 genes." Journal of Clinical Endocrinology and Metabolism 84(5): 15821589.

Service, F. and O'Brien P. (2005). "Increasing serum beta-hydroxybutyrate concentrations during the 72-hour fast: evidence against hyperinsulinemic hypoglycemia." Journal of Clinical Endocrinology and Metabolism 90(8): 4555-4558.

Service, F. J., Dale A. J., et al. (1976). "Insulinoma: clinical and diagnostic features of 60 consecutive cases." Mayo Clinics Proceedings 51(7): 417-429.

Service, F. J., McMahon M. M., et al. (1991). "Functioning insulinoma--incidence, recurrence, and long-term survival of patients: a 60-year study." Mayo Clinic Proceedings 66(7): 711-719.

Service, F. J. and Natt N. (2000). "The prolonged fast." Journal of Clinical Endocrinology and Metabolism 85(11): 3973-3974.

Service, F. J., O'Brien P. C., et al. (1992). "C-peptide suppression test: effects of gender, age, and body mass index; implications for the diagnosis of insulinoma." Journal of Clinical Endocrinology and Metabolism 74(1): 204-210.

Service, G., Thompson G., et al. (2005). "Hyperinsulinemic hypoglycemia with nesidioblastosis after gastric-bypass surgery." New England Journal of Medicine 353(3): 249-254.

Sjoberg, R. J. and Kidd G. S. (1992). "Case report: a glucose responsive insulinoma--implication for the diagnosis of insulin secreting tumors." The American Journal of the Medical Sciences 304(3): 164-167.

Soh, A. W. and Kek P. C. (2010). "Insulinoma in a Patient with Normal Results from Prolonged fast and Glucagon-induced Hypoglycemia." Endocrine Practice 16(5): 838-841.

Sohn, J., Siegelman E., et al. (2001). "Unusual patterns of hepatic steatosis caused by the local effect of insulin revealed on chemical shift MR imaging." American Journal of Roentgenology 176(2): 471-474.

Starke, A., Saddig C., et al. (2005). "Malignant metastatic insulinoma-postoperative treatment and follow-up." World Journal of Surgery 29(6): 789-793.

Starke, A., Saddig C., et al. (2006). "Islet hyperplasia in adults: challenge to preoperatively diagnose non-insulinoma pancreatogenic hypoglycemia syndrome." World Journal of Surgery 30(5): 670-679. 
Stefanini, P., Carboni M., et al. (1974). "Problems of the management of insulinomas. Review of 132 cases treated with medical measures." Acta Diabetologica Latina 11(1): 71-77.

Stehouwer, C. D., Lems W. F., et al. (1989). "Malignant insulinoma: is combined treatment with verapamil and the long-acting somatostatin analogue octreotide (SMS 201-995) more effective than single therapy with either drug?" Netherlands Journal of Medicine 35(1-2): 86-94.

Steigen, S. E., Schaeffer D. F., et al. (2009). "Expression of insulin-like growth factor 2 in mesenchymal neoplasms." Modern Pathology 22(7): 914-921.

Strosberg, J. R., Fine R. L., et al. (2011). "First-line chemotherapy with capecitabine and temozolomide in patients with metastatic pancreatic endocrine carcinomas." Cancer 117(2): 268-275.

Strosberg, J. R., Nasir A., et al. (2008). "Biology and treatment of metastatic gastrointestinal neuroendocrine tumors." Gastrointestinal Cancer Research 2(3): 113-125.

Sundin, A., Vullierme M. P., et al. (2009). "ENETS Consensus Guidelines for the Standards of Care in Neuroendocrine Tumors: radiological examinations." Neuroendocrinology 90(2): 167-183.

Tack, J., Arts J., et al. (2009). "Pathophysiology, diagnosis and management of postoperative dumping syndrome." Nature Reviews Gastroenterology and Hepatology 6(10): 583-590.

Tani, Y., Tateno T., et al. (2008). "Defective expression of prohormone convertase 4 and enhanced expression of insulin-like growth factor II by pleural solitary fibrous tumor causing hypoglycemia." Endocrine Journal 55(5): 905-911.

Taylor, S. I., Barbetti F., et al. (1989). "Syndromes of autoimmunity and hypoglycemia. Autoantibodies directed against insulin and its receptor." Endocrinology and Metabolism Clinics of North America 18(1): 123-143.

Tessonnier, L., Sebag F., et al. (2010). "Limited value of 18F-F-DOPA PET to localize pancreatic insulin-secreting tumors in adults with hyperinsulinemic hypoglycemia." Journal of Clinical Endocrinology and Metabolism 95(1): 303-307.

Thakker, R. V. (2000). "Multiple endocrine neoplasia type 1." Endocrinology and Metabolism Clinics of North America 29(3): 541-567.

Thoeni, R. F., Mueller-Lisse U. G., et al. (2000). "Detection of small, functional islet cell tumors in the pancreas: selection of MR imaging sequences for optimal sensitivity." Radiology 214(2): 483-490.

Todd, J. F., Stanley S. A., et al. (2003). "A tumour that secretes glucagon-like peptide-1 and somatostatin in a patient with reactive hypoglycaemia and diabetes." Lancet 361(9353): 228-230.

Toft-Nielsen, Madsbad M., S., et al. (1998). "Exaggerated secretion of glucagon-like peptide-1 (GLP-1) could cause reactive hypoglycaemia." Diabetologia 41(10): 1180-1186.

Toyomasu, Y., Fukuchi M., et al. (2009). "Treatment of hyperinsulinemic hypoglycemia due to diffuse nesidioblastosis in adults: a case report." American Surgery 75(4): 331-334.

Triponez, F., Dosseh D., et al. (2006). "Epidemiology data on 108 MEN 1 patients from the GTE with isolated nonfunctioning tumors of the pancreas." Annals of Surgery 243(2): 265272.

Unek, I. T., Celtik A., et al. (2009). "Hypoglycemia induced by long-acting somatostatin analogues in a patient with nonfunctional neuroendocrine tumor." Journal of B.U.ON. 14(1): 135-138. 
Vella, A. and Service F. J. (2007). "Incretin hypersecretion in post-gastric bypass hypoglycemia--primary problem or red herring?" Journal of Clinical Endocrinology and Metabolism 92(12): 4563-4565.

Vezzosi, D., Bennet A., et al. (2003). "Insulin levels measured with an insulin-specific assay in patients with fasting hypoglycaemia related to endogenous hyperinsulinism." European Journal of Endocrinology 149(5): 413-419.

Vezzosi, D., Bennet A., et al. (2005). "Octreotide in insulinoma patients: efficacy on hypoglycemia, relationships with Octreoscan scintigraphy and immunostaining with anti-sst2A and anti-sst5 antibodies." European Journal of Endocrinology 152(5): 757-767.

Vezzosi, D., Bennet A., et al. (2007). "Insulin, C-peptide and proinsulin for the biochemical diagnosis of hypoglycaemia related to endogenous hyperinsulinism." European Journal of Endocrinology 157(1): 75-83.

Vezzosi, D., Bennet A., et al. (2008). "Short- and long-term somatostatin analogue treatment in patients with hypoglycaemia related to endogenous hyperinsulinism." Clinical Endocrinology 68(6): 904-911.

Wiesli, P., Brändle M., et al. (2004a). "Insulin determination by specific and unspecific immunoassays in patients with insulinoma evaluated by the arterial stimulation and venous sampling test." European Journal of Endocrinology 151(1): 123-126.

Wiesli, P., Schmid C., et al. (2004b). "Hypoglycemia in response to glucose and glucagon in insulinoma patients with a negative prolonged fast: functional and morphological properties." Journal of Endocrinological Investigation 27(9): 832-838.

Witteles, R. M., Straus I. F., et al. (2001). "Adult-onset nesidioblastosis causing hypoglycemia: an important clinical entity and continuing treatment dilemma." Archives of Surgery 136(6): 656-663.

Yanai, H., Yoshida H., et al. (2008). "Severe hypoglycemia in a patient with anorexia nervosa." Eating and Weight Disorders 13(1): e1-3.

Yang, Y. and Hua X. (2007). "In search of tumor suppressing functions of menin." Molecular and Cellular Endocrinology 265-266: 34-41.

Yao, J.C., Shah M.H., et al. (2011). Everolimus for advanced pancreatic neuroendocrine tumors. New England Journal of Medicine 364(6): 514-523

Yoshioka, R., Saiura A., et al. (2010). "Risk factors for clinical pancreatic fistula after distal pancreatectomy: analysis of consecutive 100 patients." World Journal of Surgery 34(1): 121-125.

Zhao, Y. P., Zhan H. X., et al. (2011). "Surgical management of patients with insulinomas: Result of 292 cases in a single institution." Journal of Surgical Oncology 103(2): 169-174.

Zitzmann, S., Reimann I. R., et al. (2002). "Severe hypoglycemia in an elderly patient treated with metformin." International Journal of Clinical Pharmacology and Therapeutics 40(3): 108-110. 


\section{Part 5}

Aging and Endocrinology 



\title{
Natural Flavonoids in StAR Gene Expression and Testosterone Biosynthesis in Leydig Cell Aging
}

\author{
Xing Jia Wang \\ Garrison Institute on Aging, Department of Neurology \\ Texas Tech University Health Sciences Center \\ USA
}

\section{Introduction}

It is well known that blood testosterone level declines during the course of male aging (Feldman et al., 2002; Harman et al., 2001), a phenomena that is associated with the decreases in bone density, muscle mass and strength, sexual function and other physiological parameters (Kaufman \& Vermeulen, 2005; Matsumoto, 2002; Vermeulen, 2000). Previous studies reported that serum testosterone concentrations were lower in the male patients with Alzheimer's disease in comparison to non-demented and age-matched men (Hogervorst et al., 2001; Moffat et al., 2004). Further studies observed that supplementation with testosterone in rats reduced $\beta$-amyloid peptide and hyperphosphorylation of t-protein, two biomarkers of the disease (Gouras et al., 2000; Papasozomenos \& Shanavas, 2002; Ramsden et al., 2003). The studies suggest that low blood testosterone is a possible risk factor for the development of Alzheimer's disease (Rosario \& Pike, 2008). The decline in blood testosterone is a progressive process in male aging. Several longitudinal studies on the blood testosterone of aging males indicated that the incidence of hypogonadism increased with age (Feldman et al., 2002; Harman et al., 2001). In addition, many pathological and stressrelated factors may accelerate this process. Therefore, delaying the decline in blood testosterone is clinically significant for the health of aging males suffering from hypogonadism.

For delaying the decline in testosterone, understanding the mechanisms responsible for the decline is important. The studies in the last decades reported multiple factors and alterations in aging process that affect the levels of blood testosterone (Wang \& Stocco, 2005). The studies further indicated that the primary reason for the decline is the decrease in testosterone biosynthesis during male aging (Chen et al., 1994). Testosterone is principally synthesized in testicular Leydig cells from the substrate cholesterol and released into the blood circulation (Miller, 1988). The rate-limiting step in testosterone biosynthesis is the transfer of cholesterol to the mitochondrial inner membrane to initiate the steroidogenic process in Leydig cells (Stocco \& Clark, 1996). This step is regulated by the steroidogenic acute regulatory (StAR) protein, a critical factor in steroid hormone biosynthesis that controls the cholesterol transfer to the mitochondrial inner membrane (Clark et al., 1994; Lin et al., 1995; Wang et al., 1998). However, StAR protein also declines in Leydig cell aging and 
the mitochondrial cholesterol transfer is defective in aged Leydig cells (Culty et al., 2002; Leers-Sucheta et al., 1999; Luo et al., 2001). Therefore, understanding the mechanism for the decline in StAR gene expression becomes an important consideration in the research on the age-related decline in testosterone biosynthesis.

Further studies observed that cyclooxygenase-2 (COX2) in Leydig cells increased in male aging, and the increase in COX2 depressed StAR gene expression and testosterone production. Inhibition of COX2 activity in aged Leydig cells reversed the declines in StAR protein and testosterone production. In addition, feeding aged rats with a COX2 inhibitor reversed the decreased StAR protein and blood testosterone concentrations (Wang et al., 2005). These observations suggest a novel mechanism involving COX2 in the age-related decline in testosterone biosynthesis. The results from the studies indicate that it is possible to delay the decline using COX2 inhibitors. However, aging is a long process and long-term application of pharmacological levels of COX2 inhibitors is limited by their potential side effects. In search for safe and practical approaches, a group of natural flavonoids in food and food supplements has been identified being able to block the COX2-dependent signaling. These flavonoids acted at the different steps of the COX2 signaling pathway and significantly enhanced StAR gene expression and testosterone biosynthesis in Leydig cells. This chapter will describe the mechanism involving COX2 in the declines in StAR gene expression and testosterone biosynthesis in Leydig cell aging. The effects of the flavonoids on this mechanism will be reviewed. The potential application of the natural flavonoids in delaying the declines in StAR gene expression and testosterone biosynthesis will be discussed.

\section{Luteinizing hormone-induced signaling in StAR gene expression and testosterone biosynthesis in Leydig cell aging}

StAR gene expression and testosterone biosynthesis in testicular Leydig cells are mainly regulated by luteinizing hormone $(\mathrm{LH})$ secreted from pituitary gland. LH stimulation of Leydig cells induces two messengers: cyclic AMP (cAMP) and arachidonic acid (AA). These two messengers transduce signals to the nucleus through two separated pathways to coregulate StAR gene expression. Both pathways are required with neither one alone being sufficient for LH-induced StAR gene expression and testosterone production (Wang \& Stocco, 1999). In addition, these two pathways transduce both positive and negative signals to regulate StAR gene expression. The negative signals increase in Leydig cell aging, resulting in decreases in StAR gene expression and testosterone biosynthesis.

\subsection{LH-induced positive signaling through cAMP-protein kinase A pathway}

It is documented that LH-induced signaling through cAMP-protein kinase A (PKA) pathway phosphorylates the transcription factors regulating StAR gene expression (Reinhart et al., 1999b). PKA-phosphorylation is important for the activities of several groups of transcription factors, including cAMP-responsive element binding (CREB) protein, steroidogenic factor-1 (SF-1) and GATA-4, which bind on StAR promoter to induce StAR gene transcription. The cAMP-responsive element (CRE)-like sites were found in StAR promoter DNA sequences. The results from electrophoretic mobility shift assays (EMSA) demonstrated the binding of CREB to StAR promoter (Manna et al., 2002; Manna et al., 2003). PKA-phosphorylation is critical for the activity of CREB (Meyer \& Habener, 1993; Montminy et al., 1986), because the phosphorylation of CREB is needed for the recruitment 
of its cofactor CBP (CREB binding protein) that is involved in the transcriptional activity of CREB (Chrivia et al., 1993; Mayr \& Montminy, 2001; Mayr et al., 2001). SF-1 binding sites were also located on StAR promoter (Sandhoff et al., 1998). Binding of SF-1 to these binding sites is crucial for StAR gene transcription (Caron et al., 1997a; Caron et al., 1997b; Sandhoff et al., 1998; Sugawara et al., 1997). PKA-phosphorylation of SF-1 protein was detected at serine and threonine residues (Zhang \& Mellon, 1996), which was further confirmed by the study with R2C rat Leydig cells (Carlone \& Richards, 1997). It appears that PKAphosphorylation is needed for the maximal activity of SF-1 in the regulation of StAR gene transcription (Lopez et al., 2001; Sugawara et al., 1996). GATA-4 is another transcription factor binding on StAR promoter to regulate StAR gene expression. A GATA-4 binding site was found at -61 to -66 in StAR promoter sequences (Silverman et al., 1999; Silverman et al., 2006). Stimulation of MA-10 mouse Leydig cells with cAMP dramatically increased phosphorylated GATA-4 protein (Tremblay et al., 2002), resulting in the increase in StAR promoter activity. The essential role of PKA-phosphorylation in the activity of GATA-4 was further confirmed by over-expression of PKA catalytic subunit. While expression of PKA catalytic subunit significantly increased GATA-4-supported StAR promoter activity, the increased promoter activity was reversed by co-expression of the protein kinase inhibitor (Tremblay et al., 2002).

The signaling through cAMP-PKA pathway is able to increase the activities of a group of transcription factors that bind on StAR promoter and regulate StAR gene transcription, including C/EBP $\beta$ (Christenson et al., 1999), Sp-1 (Sugawara et al., 2000), activator protein-1 (AP-1) (Manna et al., 2004), and sterol regulatory element binding protein (SREBP) (SheaEaton et al., 2001), by inducing the interaction and cooperation among them. The cAMP or PKA-induced interactions among these transcription factors generated synergistic effects that increased the cAMP-induced StAR gene transcription and steroid hormone production in Leydig cells (Reinhart et al., 1999a; Silverman et al., 1999; Silverman et al., 2006; Sugawara et al., 2000; Tremblay et al., 2002).

In addition, it was observed that cAMP stimulation of Leydig cells reduced DAX-1 (dosagesensitive sex reversal, adrenal hypoplasia critical region, on chromosome $X$, gene 1) protein. DAX-1 is a strong transcriptional repressor that binds to a hairpin structure of StAR promoter between -20 to -61 and depresses StAR gene expression (Zazopoulos et al., 1997). The reduction of DAX-1 by cAMP stimulation results in dramatic increases in StAR gene expression and steroid hormone production in Leydig cells (Jo \& Stocco, 2004). Although it is still not clear how the signaling through cAMP-PKA pathway reduces DAX-1 protein, the observations indicate that this signaling pathway generates positive signals to increase StAR gene transcription by reduction of the transcriptional repressor.

\subsection{LH-induced positive signaling through AA pathway}

In addition to the cAMP-PKA signaling pathway, $\mathrm{LH}$ induces positive signaling through AA pathway. Stimulation of Leydig cells with LH induced AA release in one minute (Cooke et al., 1991). Previous studies have described three mechanisms for the AA release by LH or hCG: 1) Binding of the trophic hormones to their receptors activates G protein. G protein directly activates phospholipase A2 (PLA2) that catalyzes AA release from phospholipids (Axelrod et al., 1988; Ronco et al., 2002); 2) G protein increases cAMP formation that induces AA release, possibly through the activation of PLA2 by PKA-phosphorylation (Piomelli \& Greengard, 1991; Wang et al., 2002); 3) AA is released by the co-regulation of acyl-CoA synthetase 4 (ACS-4) and acyl-CoA thioesterase (Acot2). Trophic hormone stimulation 
induces ACS-4, and activates Acot2 by cAMP-PKA-phosphorylation. Co-action of these two enzymes catalyzes AA release from arachidonyl CoA (Cano et al., 2006; Cornejo Maciel et al., 2005; Finkielstein et al., 1998; Maloberti et al., 2005; Maloberti et al., 2007; Paz et al., 1994). The LH-induced AA release is required for testosterone biosynthesis. It was observed that incubation of Leydig cells with AA significantly increased testosterone production (Didolkar \& Sundaram, 1987, 1989). When the AA release was blocked using PLA2 inhibitors, the LH-induced testosterone production was significantly reduced although the inhibitors did not affect the cAMP formation (Abayasekara et al., 1990). Inhibiting AA metabolism in rat Leydig cells produce similar results (Cooke et al., 1984; Dix et al., 1984; Mele et al., 1997; Sullivan \& Cooke, 1985). In addition, blocking AA release by knockdown of the gene expressions of ACS-4 and Acot2 significantly reduced steroidogenesis (Maloberti et al., 2005). The studies indicated that LH induces positive signaling through AA pathway to regulate testosterone biosynthesis in Leydig cells.

To understand how the released AA plays such an important role in LH-induced steroidogenesis in Leydig cells, its effect on mitochondrial cholesterol transfer was investigated. It was found that blocking AA release failed to affect steroidogenesis when Leydig cells were incubated with 22(R)hydroxycholesterol (Abayasekara et al., 1990; Dix et al., 1984; Mele et al., 1997), a water soluble substrate that is able to diffuse to the mitochondrial inner membrane. The studies suggest that AA enhance testosterone biosynthesis by increasing the mitochondrial cholesterol transfer. The observations were corroborated by the increases in StAR protein and steroidogenesis in the Leydig cells incubated with AA. In addition, blocking AA release using PLA2 inhibitors dramatically reduced LH- or cAMP-induced StAR promoter activity, StAR mRNA, StAR protein and steroidogenesis in Leydig cells. Importantly, the reduced StAR gene expression and steroidogenesis by PLA2 inhibitor were reversed by addition of AA in the cell cultures (Wang et al., 2000; Wang et al., 1999). It is clear that AA increases testosterone biosynthesis by enhancing StAR gene expression. Moreover, the results from EMSA show that AA enhanced the binding of nuclear protein(s) to the StAR promoter DNA sequences between 67 and -96 (Wang et al., 2003a). The observation indicates that AA acts on StAR promoter and regulates StAR gene transcription.

AA is metabolized mainly through three metabolic pathways, the lipoxygenase, epoxygenase and cyclooxygenase pathways, generating various metabolites. To determine which pathways are involved in the LH-induced StAR gene expression and steroidogenesis, MA-10 Leydig cells pre-loaded with ${ }^{3} \mathrm{H}-\mathrm{AA}$ were used to study the effects of CAMP on AA metabolism. The results from HPLC analysis of the cell extract showed that cAMP stimulation significantly increased two groups of AA metabolites: the lipoxygenasegenerated metabolites, 5-hydroxyeicosatetraenoic acid (5-HETE) and 5hydroperoxyeicosatetraenoic acid (5-HPETE) (Wang et al., 2003a); and the epoxygenasegenerated metabolites, 5,6-epoxyeicosatrienoic acid (5,6-EET), 8,9-epoxyeicosatrienoic acid (8,9-EET), and 11,12-epoxyeicosatrienoic acid (11,12-EET) (Wang et al., 2006). The roles of these AA metabolites in StAR gene expression were investigated with Leydig cells. It was observed that addition of each of these metabolites into the cultures of Leydig cells significantly increased cAMP-induced StAR promoter activity, StAR mRNA, StAR protein and steroidogenesis. In addition, when activity of lipoxygenase or epoxygenase was inhibited, the cAMP-induced StAR gene expression and steroidogenesis were significantly reduced (Wang et al., 2000). The observations indicated that each of the metabolites enhanced StAR gene expression at the level of transcription. Although how these AA 
metabolites act on StAR promoter is not clear, the studies showed that LH- or cAMPreleased AA is converted to positive signals, 5-HPETE, 5-HETE, 5,6-EET, 8,9-EET and 11,12EET through lipoxygenase and epoxygenase pathways, which enhance StAR gene expression and testosterone biosynthesis in Leydig cells.

\subsection{LH-induced negative signaling in StAR gene expression}

Whereas LH-released AA is metabolized to the positive signals by lipoxygenase and epoxygenase, it is converted to negative signals by cyclooxygenase (COX). It was found that inhibition of COX activity using an inhibitor significantly increased cAMP-induced StAR protein and steroid hormone production in MA-10 mouse Leydig cells. Similar increases were observed in StAR promoter activity and StAR mRNA levels. Although inhibition of COX activity significantly increased the cAMP-induced StAR gene expression, in the absence of cAMP the inhibitor alone did not increase StAR protein expression and steroid hormone production. The studies suggest that the COX inhibitor itself is not able to induce StAR gene expression, but rather reduce the negative signals, resulting in significant increases in the cAMP-induced StAR gene expression and steroidogenesis. There are two isoforms of COX enzymes, COX1 and COX2, in Leydig cells. To determine which isoform is responsible for the inhibitory effect on StAR gene expression, Leydig cells were treated with the selective COX1 inhibitor SC560 or COX2 inhibitor NS398, respectively. Whereas inhibition of COX1 activity did not change StAR protein level, inhibition of COX2 activity dramatically enhanced cAMPinduced StAR protein expression and steroid hormone production. Further studies observed that while COX2 inhibitor significantly increased StAR protein, it did not affect PKA activity. In addition, over-expression of COX2 reduced StAR promoter activity. The observations indicate that COX2, not COX1, converts the LH- or CAMP-released AA to negative signals that depress StAR gene transcription in Leydig cells (Wang et al., 2003b).

The signaling through cAMP-PKA pathway also generates negative signals to inhibit StAR gene expression and steroidogenesis in Leydig cells by increasing COX2 expression. The mechanism responsible for the cAMP-increased COX2 may involve the signaling through cAMP-PKA pathway in the activation of several transcription factors that regulate COX2 promoter activity. One is CREB that binds on the CRE site at -53 to -59 of human COX2 promoter sequences (Schroer et al., 2002). CREB activation by PKA increased its binding to the CRE site and induced COX2 gene transcription. While forskolin or cAMP activated PKA and increased COX2 promoter activity, inhibition of PKA activity reversed the increase in the promoter activity. Another transcription factor NF- $\mathrm{kB}$ plays an essential role in regulating COX2 gene expression (Arun et al., 2009). This transcription factor was activated by PKA-phosphorylation of NF- $\mathrm{BB}$ p65 sub-unit. Inhibition of its phosphorylation using H89 reduced COX2 gene transcription. The involvement of cAMP-PKA signaling pathway in the LH-induced COX2 expression was supported by the studies with Leydig cells. An earlier study reported that hCG stimulation of Leydig cells increased COX2 expression (Frungieri et al., 2006). This observation was corroborated by a latter study that reported a LH-increased COX2 protein in rat Leydig cells. The increase in COX2 was almost abolished by inhibition of PKA activity with its inhibitor H89, indicating that cAMP-PKAphosphorylation is required for the LH-induced COX2 expression in Leydig cells (Chen et al., 2007b).

As LH stimulates testosterone biosynthesis, the increase in testosterone may feed back to induce COX2 expression in Leydig cells. A recent study reported that testosterone induced COX2 expression and prostaglandin F2a production in hamster Leydig cells (Matzkin et al., 
2009). These effects of testosterone were abolished by the anti-androgen bicalutamide. A testosterone-stimulated phosphorylation of the mitogen-activated protein kinase (MAPK) was also observed in the study. It is known that the activity of MAPK is important in COX2 gene expression (Chun \& Surh, 2004), because MAPK is able to activate the transcription factors that regulate COX2 gene transcription.

The studies described above indicate that when LH stimulates positive signals through cAMP-PKA pathway and AA pathway, it also induces negative signals through these two pathways. Therefore, the total effect of LH on StAR gene expression and testosterone biosynthesis depends on the ratio and levels of the positive and negative signals. The alterations of the signals in Leydig cell aging affect StAR gene expression and testosterone biosynthesis.

\subsection{The age-related alterations of the positive and negative signals in StAR gene expression}

Previous studies have reported the multiple alterations or defects during male aging that are involved in the decline in testosterone biosynthesis (Wang \& Stocco, 2005). Many of these alterations or defects in the aging process increase the negative signals and reduce the positive signals in StAR gene expression. These changes reduce the sensitivity of Leydig cells to trophic hormone stimulation and result in the declines in StAR gene expression and testosterone biosynthesis.

It was observed that the age-related alteration in hypothalamic-pituitary-adrenal axis attenuates the sensitivity of the feedback control of adrenal steroidogenesis, resulting in the increases in basal and stress-induced glucocorticoid levels (Hardy \& Cooper, 2010). The inhibitory effect of glucocorticoid on testosterone biosynthesis was reported by previous studies with rat Leydig cells. This steroid hormone was shown being able to inhibit PLA2 activity and block LH-induced AA release (Abayasekara et al., 1990). Further studies observed that blocking AA release using dexamethasone dramatically reduced StAR protein and steroidogenesis in MA-10 mouse Leydig cells. Similar results were obtained in the analyses of StAR promoter activity and StAR mRNA levels. The reduced StAR gene expression and steroidogenesis were reversed by addition of AA to the cell cultures (Wang et al., 2000). The studies suggest that the age-related defect in hypothalamic-pituitaryadrenal axis result in reduction in the LH-induced positive signals through AA pathway.

The positive signaling through cAMP-PKA pathway is also reduced in Leydig cell aging. The previous studies with aged Leydig cells reported a defect in this signaling pathway that caused the decreases in LH-induced cAMP formation and PKA activity (Lin et al., 1980; Luo et al., 2005). The decrease in LH-induced cAMP formation may significantly contribute to the reduced sensitivity of aged Leydig cells to LH stimulation. The mechanism for this defect in aged Leydig cells has not been completely understood. It was observed that the number of the LH-binding sites and their binding affinity decreased in aged Leydig cells, but how the reduced LH-binding capacity affected the cAMP formation remains to be elucidated (Chen et al., 2002). In addition, defect of $G$ protein was investigated. It is possible that inefficiency of $G$ protein or defect in coupling among the signal cascades affects the LHinduced cAMP formation (Chen et al., 2004).

In the aging process, the levels of many biological factors in blood or testis are altered. These alterations may reduce the positive signaling through cAMP-PKA pathway and enhance the negative signaling through COX2 pathway. One group of the biological factors that increase in aging is the inflammatory cytokines, such as Interlukin-1 (IL-1), Transforming growth factor 
(TGF)- $\beta$ and tumor necrosis factor (TNF) (Chung et al., 2001; Morley \& Baumgartner, 2004). IL$1 \beta$ was reported to be inhibitory in hCG-, cAMP-, and forskolin-induced testosterone production (Calkins et al., 1990). While it is able to reduce activities of steroidogenic enzymes (Hales, 1992; Lin et al., 1991), IL-1 $\beta$ induced COX2 expression (Chen et al., 2007b; Walch \& Morris, 2002) and reduced StAR protein expression (Ogilvie et al., 1999). TGF- $\beta$ in testis increases with age (Jung et al., 2004). The increase in TGF- $\beta$ may significantly reduce trophic hormone-induced cAMP formation and testosterone production in Leydig cells (Avallet et al., 1987). TNF-a reduced hCG-stimulated cAMP formation in a concentration-dependent manner in MA-10 mouse Leydig cells (Budnik et al., 1999), which was associated with a reduction in StAR protein. In addition, it was reported that the transcription factor NF-kB increases in the aging process (Chung et al., 2009; Chung et al., 2006). This increase would contribute to the increase in COX2, because NF-kB plays an essential role in COX2 gene transcription. Another group of the biological factors is reactive oxidative species (ROS). An age-related increase in ROS was previously described (Chen et al., 2001b). While ROS may inhibit testosterone through different mechanisms, it is able to activate NF-kB, resulting in the increases in COX2 and various inflammatory factors (Chung et al., 2006).

The age-related increases in the biological factors, such as IL-1 $\beta, N F-k B$ and ROS, suggest an increase in COX2 expression in Leydig cell aging, because these factors induce COX2 as mentioned above. This was supported by the increase in COX2 mRNA level detected in aged Leydig cells of rats (Syntin et al., 2001). It is known that COX2 produces an inhibitory effect on StAR gene expression and steroidogenesis (Wang et al., 2003b). These observations suggest a possibility of involving an age-related increase of COX2 in the declines in StAR gene expression and testosterone production. This possibility was demonstrated by the studies with aged rats (Wang et al., 2005). It was found that from 3 to 30 months of age, the levels of COX2 protein in aged rat Leydig cells increased by $346 \%$ over that of young Leydig cells. The increase in COX2 was associated with the decreases in StAR protein, testosterone biosynthesis, and blood testosterone concentration in aged rats. Inhibition of COX2 activity with the selective COX2 inhibitor NS398 reversed the decreases in StAR protein and testosterone production in aged Leydig cells. In addition, while over-expression of COX2 reduced cAMP-stimulated StAR protein and steroidogenesis, co-incubation with NS398 reversed the reduced StAR protein and steroid hormone. These findings reveal a novel mechanism in the age-related declines in testosterone biosynthesis.

\section{Mechanism for COX2-dependent inhibition of StAR gene expression and testosterone biosynthesis in Leydig cell aging}

The studies described above indicated an involvement of COX2 in the age-related declines in StAR gene expression and testosterone biosynthesis. However, the mechanism for the COX2-dependent inhibition of StAR gene expression in Leydig cells needs to be elucidated. While further investigations are needed for the elucidation, the studies in the recent years have significantly improved the understanding of the mechanism.

\subsection{AA distribution between COX2 and lipoxygenase metabolic pathways}

It is known that the LH-released AA is converted to positive signals through lipoxygenase and epoxygenase pathways (Wang et al., 2006; Wang et al., 2003a), and also negative signals through COX2 pathway (Wang et al., 2003b). This suggests that StAR gene expression and testosterone biosynthesis in Leydig cell aging are regulated by the activities of these AA 
metabolic enzymes, because they control the ratio of the positive and negative signals. To prove this hypothesis, MA-10 mouse Leydig cells pre-loaded with ${ }^{3} \mathrm{H}-\mathrm{AA}$ were incubated with NS398 to inhibit their COX2 activities. AA metabolites were extracted from the cells and analyzed by HPLC. The HPLC profile of AA metabolites indicated that inhibition of COX2 activity increased AA metabolites produced through lipoxygenase pathway, with the levels of 5-HETE and 5-HPETE being significantly increased by the treatment. Incubation of rat Leydig cells with 5-HETE significantly increased testosterone production (Wang et al., 2005). It was previously reported that 5-HETE and 5-HPETE transduce positive signals to enhance StAR gene expression and steroidogenesis in Leydig cells (Wang et al., 2003a). The observations indicated that the distribution of AA between these two metabolic pathways is regulated by their enzyme activities. Thus, inhibition of COX2 activity changed the AA distribution, resulting in the increases in 5-HETE and 5-HPETE that enhanced StAR gene expression. It is possible that as COX2 expression increases in aged Leydig cells, more AA is metabolized through COX2 pathway to produce inhibitory metabolites that depress StAR gene expression and testosterone biosynthesis.

\subsection{The signaling through COX2-prostaglandin F2 $\alpha$-receptor pathway in StAR gene expression}

In the COX2 metabolic pathway, COX2 catalyzes AA to prostsglandin(PG)H2 that is further metabolized to PGD2, PGE2, PGF2a, PGI2 and thromboxane A2 (TBX A2) by different prostaglandin synthases and thromboxane A synthase (TBXAS). Among these metabolites, PGF2 $\alpha$ is involved in the COX2-dependent inhibition of testosterone biosynthesis. Previous studies reported the hCG-induced production of PGF2a (Haour et al., 1979), which acted as a negative signal to inhibit testosterone production in Leydig cells (Bartke et al., 1973; Saksena et al., 1973). The inhibitory effect of PGF2a was verified by several studies. In an in vivo study, the infusion of PGF2a to rats $(250 \mu \mathrm{g} / \mathrm{rat})$ for 4 hours reduced blood testosterone to $50 \%$, whereas the inhibition of PGF2a production with indomethacin increased blood testosterone concentrations. When the decapsulated testis preparation was incubated with PGF2a, LH-induced testosterone production was reduced in a dose-dependent manner (Fuchs \& Chantharaksri, 1981). The observations were corroborated by the additional studies on the inhibitory effects of PGF2a on Leydig cell steroidogenesis (Romanelli et al., 1995; Sawada et al., 1994). To find how PGF2a inhibits testosterone biosynthesis, the PGF2a receptors were located on hamster Leydig cells. Further investigation observed that incubation of the Leydig cells with $1 \mu \mathrm{M}$ of PGF2 $\alpha$ for 10 to 60 minutes significantly reduced StAR protein. The study described a COX-2-depenednt signaling pathway via COX2, PGF2a production, PGF2a receptors, and StAR protein in the regulation of hCG-induced testosterone biosynthesis (Frungieri et al., 2006). How this signaling pathway regulates StAR protein expression is not clear. To understand the mechanism, several regions in rat StAR promoter DNA sequences were detected to be responsive to PGF2a, including the bind sites of DAX-1, c-Fos and YY1. DAX-1 is described above as a transcriptional repressor. Injection of PGF2a for 2 hours resulted in the increase in ovarian DAX-1 protein. The increase in DAX-1 protein was associated with the $50 \%$ reduction in StAR mRNA (Sandhoff \& McLean, 1999). The c-Fos binding sites were located at $-85,-187$ and -1561 of StAR promoter sequences. Administration of PGF2a increased c-Fos expression and reduced StAR gene transcription (Shea-Eaton et al., 2002). The YY1 binding sites were found in StAR promoter sequences at -1230/-1238, -1550/-1559 and -1651/-1660. PGF2a enhanced ovarian YY1 expression, resulting in a decrease in StAR gene expression (Liu et al., 2007; Nackley et al., 
2002). However, whether PGF2a increases the expressions of these transcriptional repressors in Leydig cells remains to be clarified.

\subsection{The signaling through COX2-TBXAS-TBX A2-receptor pathway in StAR gene expression}

Following the studies on PGF2 $\alpha$, TBXAS activity was inhibited to examine the role of the COX2-TBXAS-TBX A2-receptor signaling pathway in Leydig cell steroidogenesis. Inhibition of TBXAS activity with the inhibitor furegrelate significantly enhanced the cAMP-induced steroidogenesis in MA-10 mouse Leydig cells. However, co-incubation of the cells with 22(R)hydroxycholesterol abolished the stimulatory effect of the inhibitor on steroidogenesis, suggesting that TBXAS produce an inhibitory effect on the mitochondrial cholesterol transfer. The results were confirmed by the increase in StAR protein in the cells treated with the TBXAS inhibitor (Wang et al., 2008). Following these observations, luciferase assays of StAR promoter activity and reverse transcription-polymerase chain reaction (RT-PCR) were performed to determine whether the TBXAS inhibitor acted on StAR gene transcription. It was found that inhibition of TBXAS activity significantly increased StAR promoter activity and StAR mRNA levels. To confirm the inhibitory effect of TBXAS on StAR gene expression, the TBXAS gene was silenced using RNA interference (RNAi). As TBXAS gene was silenced by RNAi, StAR mRNA, StAR protein and steroid hormone production in the cells were significantly increased. It is clear that the signaling through COX2 and TBXAS acts on StAR promoter and depresses StAR gene transcription. The study was continued to identify the transcription factor(s) that is affected by the activity of TBXAS. The results from the study reveal that inhibition of TBXAS activity reduced DAX-1 protein. When DAX-1 protein was reduced by inhibiting TBXAS activity, StAR gene transcription was significantly enhanced, suggesting that co-action of COX2 and TBXAS convert AA to inhibitory metabolite(s) that inhibits StAR gene transcription by regulating DAX-1 expression (Wang et al., 2008).

The first AA metabolite in the COX2-TBXAS pathway is TBX A2. The TBX A2 receptors were detected in several mouse Leydig cell lines and identified on the cell surface (Pandey et al., 2009). The specific binding of the receptor antagonist SQ29548 to the receptors on MA10 mouse Leydig cells was demonstrated by binding assay and the binding competition between ${ }^{3} \mathrm{H}-\mathrm{SQ} 29548$ and another receptor antagonist BM567. When the concentrations of BM567 increased from 0 to $10 \mu \mathrm{M}$, the ${ }^{3} \mathrm{H}-\mathrm{SQ} 29548$ bound to the cells was reduced to $3 \%$. The receptor antagonist SQ29548 was used to block the binding of TBX A2 to the receptors and to determine its effect on the Leydig cell steroidogenesis. It was observed that blocking the TBX A2 receptors on the Leydig cells incubated with $0.1 \mathrm{mM}$ cAMP dramatically increased StAR protein in a concentration-dependent manner. The increase in StAR protein was paralleled with the increase in steroid hormone production, with progesterone production being increased from 35 to $208 \mathrm{pg} / \mu \mathrm{g}$ cellular protein as the concentrations of SQ29548 were increased from 0 to $25 \mu \mathrm{M}$. The results were verified using another receptor antagonist BM567 (Pandey et al., 2009). Since the COX2-dependent signaling is involved in the age-related declines in StAR gene expression and testosterone biosynthesis (Wang et al., 2005), aged Leydig cells were used to determine whether blocking the TBX A2 receptors is able to reversed the declines. When the TBX A2 receptors were blocked with SQ29548, StAR protein in the aged Leydig cells increased significantly. In concomitant with the increase in StAR protein, testosterone production by the aged Leydig cells also significantly increased from 86 to 146 pg/ $\mu$ g cellular protein (Pandey et al., 2009). 
To understand how the receptor antagonists enhanced StAR protein expression and steroidogenesis, their effects on StAR gene transcription were investigated. Luciferase assays of StAR promoter activity indicated that blocking the TBX A2 receptors with the antagonists enhanced StAR promoter activity in a concentration-dependent manner in the MA-10 cells incubated with $0.1 \mathrm{mM}$ cAMP. The increase in the promoter activity was associated with a similar increase in StAR mRNA level (Pandey et al., 2009). The observations indicated that blocking the TBX A2 receptor enhanced StAR gene transcription, similar to the observations on the cells treated with TBXAS inhibitor (Wang et al., 2008). Further study showed that blocking the TBX A2 receptors significantly reduced DAX-1 protein and increased StAR protein in MA-10 mouse Leydig cells. The results were confirmed with the Leydig cells isolated from aged rats. The aged Leydig cells expressed high levels of DAX-1 protein, but blocking the TBX A2 receptors dramatically reduced the DAX-1 protein, which was associated with the increases in StAR protein and testosterone production (Pandey et al., 2009). These observations indicated that the signaling through COX2-TBXAS-TBX A2-receptor inhibits StAR gene expression and testosterone biosynthesis by regulation of DAX-1 expression.

In addition, while sub-threshold levels of cAMP were unable to stimulate significant increases in StAR gene expression, interrupting the signaling through this pathway at any step, by inhibiting COX2 activity (Wang et al., 2005; Wang et al., 2003b) or TBXAS activity (Wang et al., 2008) or blocking the TBX A2 receptors (Pandey et al., 2009), reduced the threshold, with sub-threshold levels of cAMP being able to induce maximal levels of StAR protein and steroidogenesis. These studies indicated that the signaling through COX2TBXAS-TBX A2-receptor pathway plays an important role in regulating sensitivity of Leydig cells to LH or cAMP stimulation. Therefore, when COX2 increases in Leydig cell aging, the increase in COX2 enhances the negative signaling through this pathway, which in turn reduces the sensitivity of Leydig cells and inhibits the LH-induced StAR gene expression and testosterone biosynthesis.

\section{Flavonoid intervention in the COX2-dependent inhibition of StAR gene expression and testosterone biosynthesis}

To study the possibility of delaying the decline in blood testosterone by intervention in the mechanism, aged rats were fed with increasing concentrations of a selective COX2 inhibitor mixed in their diet. After 30 days, StAR protein in their Leydig cells increased in a concentration-dependent manner. The blood testosterone concentrations increased up to $120 \%$ over control (Wang et al., 2005). The studies suggest a possibility of delaying the agerelated declines in StAR protein and testosterone using COX2 inhibitors. However, longterm application of the COX2 inhibitors currently used in the clinical practice is limited by their side effects. Therefore, alternative approaches are needed for the health of aging males. In the recent years, steroidogenic effects of natural flavonoids have been studied with Leydig cells. Flavonoids are a group of the polyphenolic compounds that are widely distributed in various food and food supplements, especially in fruits and vegetables. Previous studies have reported the activities of flavonoids in anti-inflammation, anti-cancer, and anti-oxidation (Cardenas et al., 2006; Chen et al., 1990; Ferrandiz \& Alcaraz, 1991). One of the important mechanisms for these activities is the inhibition of COX2 expression and blocking the COX2-dependent signaling by flavonoids, which enables flavonoids to enhance StAR gene expression and testosterone biosynthesis in Leydig cells. A group of flavonoids 
has been identified, including chrysin, apigenin, luteolin, and quercetin (Fig. 1), to be able to enhance StAR gene expression and steroidogenesis in Leydig cells by blocking the COX2dependent signaling.<smiles>O=c1cc(-c2ccccc2)oc2cc(O)cc(O)c12</smiles>

Chrysin

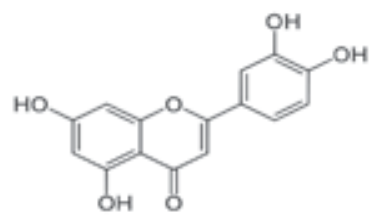

Luteolin

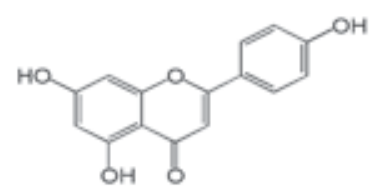

Apigenin

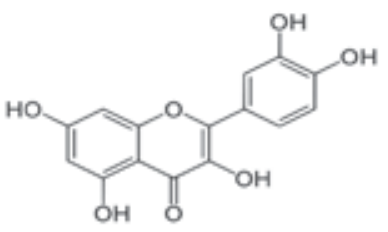

Quercetin

Fig. 1. Chemical structures of the flavonoids used in the experiments to enhance StAR gene expression and steroidogenesis in Leydig cells

\subsection{Chrysin}

Chrysin is present in plants (Williams et al., 1997), honey and propolis (Gambelunghe et al., 2003; Jiang et al., 2008; Kassim et al., 2010). It blocks the COX2-dependent signaling principally by inhibition of COX2 expression. The reduction of COX2 by chrysin is due to its inhibitory effects on the activities of several transcription factors that regulate COX2 gene transcription in different tissues. Chrysin is able to inhibit the activity of NF-kB and reduce COX2 promoter activity (Ha et al., 2010; Li et al., 2010). In macrophages, chrysin suppressed lipopolysaccharide (LPS)-induced COX2 expression by inhibiting activity of nuclear factor for IL-6 (NF-IL6) (Woo et al., 2005). NF-IL6 is a member of the C/EBP family that binds to human COX2 promoter region at $-124 /-132$ and induces COX-2 expression. Another member of C/EBP family is C/EBP $\beta$ that is activated by c-Jun $\mathrm{N}$ terminal kinase (JNK) (Cho et al., 2003). Chrysin inhibited JNK activation and reduced LPS-induced COX2 expression (Ha et al., 2010). In addition, the cytokines, such as IL-1 $\beta$ and TNF- $\alpha$, are able to induce COX2 expression (Chen et al., 2001a; Ishikawa et al., 2005). It was observed that chrysin significantly reduced the LPS-released IL-1 $\beta$ and TNF-a (Ha et al., 2010; Romier et al., 2008). In addition to the inhibition of COX2 gene expression, chrysin and its derivatives are able to inhibit COX2 activity. A group of chrysin derivatives was synthesized by modification of its molecular structure. The modification significantly improves the activities of the derivatives in inhibiting COX2. Some of the chrysin derivatives are able to bind to COX2 molecule and selectively inhibit COX2 activity (Cho et al., 2004; Dao et al., 2004).

Chrysin has been described as a testosterone-increasing agent that blocks further testosterone metabolism by inhibiting aromatase activity (Dhawan et al., 2002; Kellis \& Vickery, 1984). This testosterone-increasing activity of chrysin was confirmed in the recent studies with Leydig cells isolated from mouse and MA-10 mouse Leydig cell line, with the steroid hormone productions of the Leydig cells being significantly enhanced by chrysin 
(Jana et al., 2008). However, it failed to induce the significant increase in steroid hormone when MA-10 Leydig cells were co-incubated with 22(R)hydroxycholesterol, suggesting that this flavonoid increase steroidogenesis mainly by improving the cholesterol transfer to the mitochondrial inner membrane. This was proved by the results from Western blot analyses that showed a significant increase in StAR protein in the Leydig cells treated with chrysin. The observations were corroborated by the significant increases in StAR promoter activity and StAR mRNA levels in the cells, indicating that chrysin acted on StAR promoter and enhanced StAR gene transcription. The transcription factors that act on StAR promoter were examined in the Leydig cells incubated with chrysin. It was found that this flavonoid significantly reduced the transcriptional repressor, DAX-1 protein (Jana et al., 2008). As DAX-1 protein and DAX-1 mRNA were reduced, StAR protein and steroid hormone production dramatically increased. Similar to the effect of COX2 inhibitors, chrysin did not affect PKA activity. In the absence of cAMP, this flavonoid alone was not able to increase StAR protein and steroidogenesis. However, in the presence of $10 \mu \mathrm{m}$ chrysin, sensitivity of Leydig cells dramatically increased, with sub-threshold levels of cAMP being able to induce maximal levels of StAR protein and steroidogenesis. The studies indicated that chrysin enhanced steroidogenesis in Leydig cells mainly by enhancing cAMP-induced StAR gene expression.

\subsection{Apigenin}

Apigenin is present in various plants at different concentrations (Miean \& Mohamed, 2001). It was found in parsley at high level (Nielsen et al., 1999). This flavonoid blocks COX2dependent signaling at two separated steps, by inhibiting COX2 expression and blocking the TBX A2 receptors. It inhibits COX2 expression at the levels of transcription and translation. At the transcriptional level, apigenin inhibits activities of the transcription factors that are important for COX2 gene expression. Previous studies reported that incubation of mouse macrophages with apigenin reduced COX2 expression by inhibition of NF-kB activation, through a mechanism involving the apigenin-reduced degradation of the inhibitor $\mathrm{kB}(\mathrm{IkB})$ (Liang et al., 1999). This observation was enhanced by the study on the apigenin-reduced COX2 expression, in which apigenin-inhibited $\mathrm{IkBa}$ degradation resulted in reductions in NF-kB-binding to the promoter DNA and the TNF-a-induced COX2 expression (Shukla \& Gupta, 2004). In addition, apigenin is able to inhibit the activation of MAPK. It is known that MAPK activation is essential for the activities of several transcription factors, such as CREB, NF-kB, and C/EBP, that induce COX2 expression in various tissues (Chun \& Surh, 2004; Tsatsanis et al., 2006). The inhibitory effects of apigenin on MAPK activation significantly reduced COX2 gene transcription (Ha et al., 2008; Yi Lau \& Leung, 2010). At the translational level, apigenin increased the localization to cytoplasm of two proteins, HuR and T-cell-restricted intracellular antigen 1-related protein (TIAR). HuR and TIAR then bound to the AU-rich elements in the 3'-untranslated region of COX2 mRNA and inhibited COX2 translation (Tong et al., 2007). In addition to its inhibitory effects on COX2 expression, apigenin acts as a natural antagonist of the TBX A2 receptors. Binding of apigenin to the receptors blocked the signaling through COX2-TBXAS-TBX A2-receptors pathway (Guerrero et al., 2007; Navarro-Nunez et al., 2008).

It was reported that blocking the signaling at any step of the COX2-TBXAS-TBX A2receptors pathway significantly increased StAR gene expression and testosterone biosynthesis in Leydig cells (Pandey et al., 2009). Therefore, the effects of apigenin on steroidogenesis were studied using MA-10 mouse Leydig cell line and Leydig cells isolated 
from mouse. The binding of apigenin to the TBX A2 receptors was examined. The binding competition between apigenin and the selective receptor antagonist ${ }^{3} \mathrm{H}-\mathrm{SQ} 29548$ indicated that this flavonoid specifically blocked the TBX A2 receptors on MA-10 mouse Leydig cells. Blocking the receptors with apigenin significantly increased StAR protein and testosterone production in mouse Leydig cells (Li et al., 2011). In MA-10 Leydig cells, apigenin induced concentration-dependent increases in StAR promoter activity, StAR mRNA, StAR protein and steroid hormone production. Further study indicated that this flavonoid enhanced StAR gene transcription by reduction of the transcriptional repressor, DAX-1 protein. While the mechanism for the reduction of DAX-1 protein in apigenin-treated cells is unknown, the results from the study suggest that minimal levels of PKA and protein kinase C (PKC) activities are essential for the effects of apigenin on DAX-1, StAR and steroidogenesis in Leydig cells (Li et al., 2011).

\subsection{Luteolin}

Luteolin is found in fruits and vegetables (Harnly et al., 2006). It was detected in bird chili $(1035.0 \mathrm{mg} / \mathrm{kg}$, in dry weight), belimbi leaves $(464.5 \mathrm{mg} / \mathrm{kg})$, onion leaves $(391.0 \mathrm{mg} / \mathrm{kg})$, belimbi fruit $(202.0 \mathrm{mg} / \mathrm{kg})$, dried asam gelugur $(107.5 \mathrm{mg} / \mathrm{kg})$, local celery $(80.5 \mathrm{mg} / \mathrm{kg})$, broccoli $(74.5 \mathrm{mg} / \mathrm{kg})$, carrot $(37.5 \mathrm{mg} / \mathrm{kg})$, limau purut leaves $(30.5 \mathrm{mg} / \mathrm{kg})$, French bean $(11.0 \mathrm{mg} / \mathrm{kg})$, and white radish $(9.0 \mathrm{mg} / \mathrm{kg})$ (Miean \& Mohamed, 2001). Similar to the effects of apigenin, luteolin is able to inhibit COX2 expression and block the TBX A2 receptors. It was reported that luteolin reduced COX2 expression by inhibiting NF-kB activity (Chen et al., 2007a; Gutierrez-Venegas et al., 2006; Kim \& Jobin, 2005), through the mechanism involving the luteolin-reduced IkB kinase (IKK) activity, IkB degradation, nuclear translocation of NF-kB p65 subunit, and NF-kB-binding to the promoter DNA. Luteolin may reduce COX2 expression by inhibiting activity of MAPK and subsequently reducing the activities of the transcription factors that are essential for COX2 transcription (Choi \& Lee, 2010; Gutierrez-Venegas et al., 2006). It is known that COX2 expression is up-regulated by inflammatory cytokines, such as IL-1 $\beta$ and TNF-a. Luteolin was reported being able to reduce these cytokines, which may contribute to its inhibitory effect on COX2 expression (Wu et al., 2009). In addition, luteolin is also a natural antagonist of the TBX A2 receptors. It blocked the COX2-dependent signaling through COX2-TBXAS-TBX A2-receptor pathway by binding to the receptors (Guerrero et al., 2005; Guerrero et al., 2007).

The inhibitory effect of luteolin on COX2-dependent signaling suggests a possibility of using this flavonoid to enhance StAR gene expression and steroidogenesis in Leydig cells. This possibility was examined by the experiments with MA-10 mouse Leydig cells cultured for 6 hours in the medium containing increasing concentrations of luteolin and a cAMP analog (dbcAMP). StAR and DAX-1 proteins, steroid production, StAR mRNA and StAR promoter activity were analyzed as described in the previous study (Jana et al., 2008). As shown in Fig. 2A, the treatments with luteolin induced a concentration-dependent increase in steroid hormone production. Progesterone concentrations in culture medium were increased from 4.9 to $124.7 \mathrm{ng} / \mathrm{ml}$, as the levels of luteolin in the culture were increased from 0 to $12 \mu \mathrm{M}$. In the presence of 22(R)hydroxycholesterol(22R), there was no significant difference in steroid production among the treatments, suggesting that luteolin increase steroidogenesis by improving mitochondrial cholesterol transfer in Leydig cells. The results were enhanced by the luteolin-increased StAR protein expression. Similar increases were observed in the analyses of StAR promoter activity and StAR mRNA levels (Fig. 2B), indicating a regulatory effect of luteolin on StAR gene transcription. In addition, a synergistic interaction between 
luteolin and cAMP was observed (Fig. 2C), in which luteolin reduced the threshold of cAMP-induced StAR gene expression and increased the sensitivity of Leydig cells to cAMP stimulation. Further study indicated that luteolin enhanced StAR gene transcription by inhibiting DAX-1 expression (Fig. 2D), similar to the observation with apigenin.

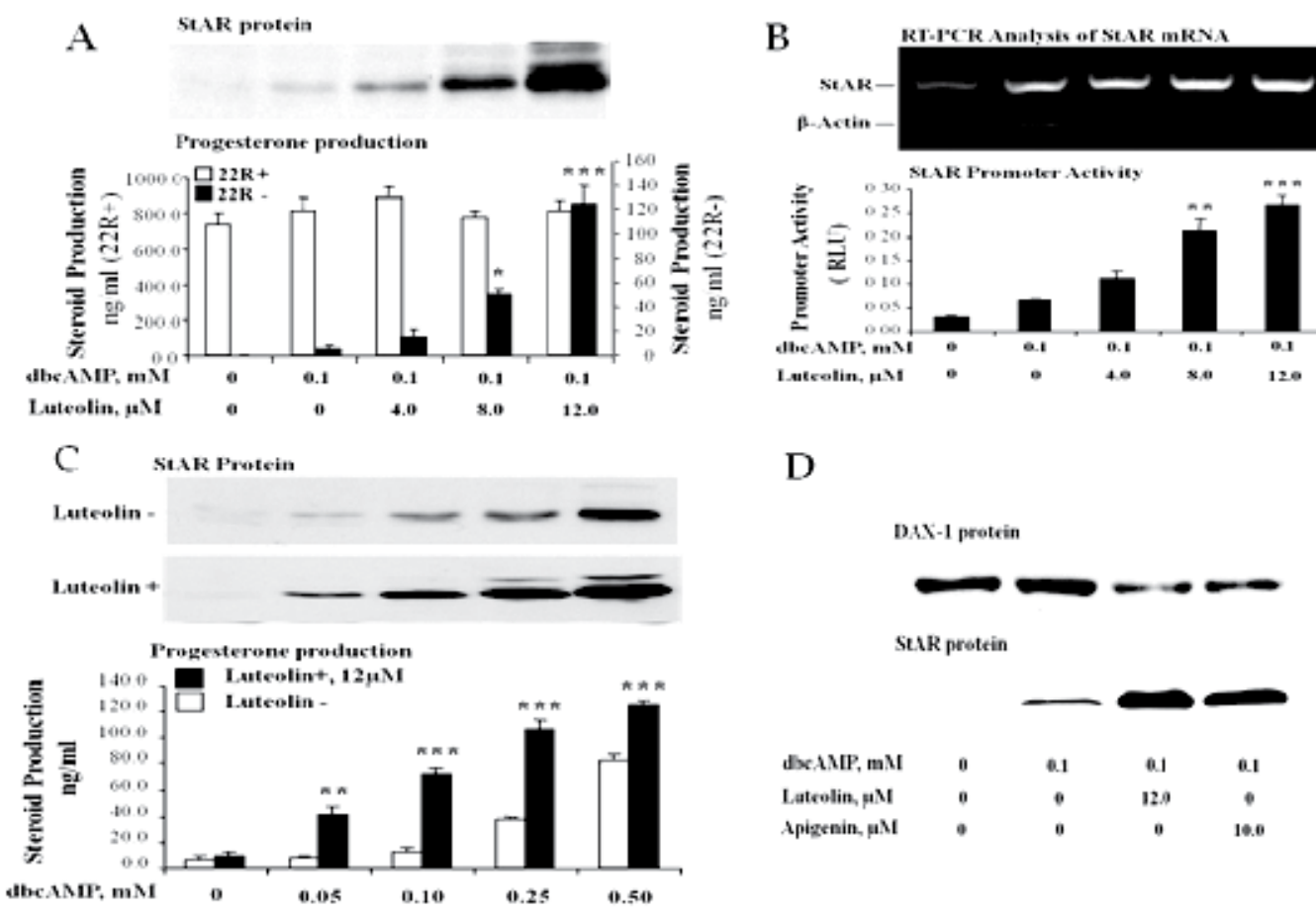

Fig. 2. Effect of luteolin on StAR gene expression and steroidogenesis in MA-10 mouse Leydig cells. MA-10 cells were incubated with luteolin for 6 hours, and then collected for analyses: A, StAR protein and steroidogenesis; B, StAR gene transcription; C, Interaction between luteolin and CAMP; D, Reduction in DAX-1 protein.

\subsection{Quercetin}

Quercetin was reported as one of the major flavonoids in the plants (Miean \& Mohamed, 2001), especially in onions (Slimestad et al., 2007). It blocks the COX2-dependent signaling by inhibiting COX2 expression and TBX A2 production. Similar to other flavonoids, quercetin depresses COX2 expression by inhibiting activities of NF-kB. It was observed that this flavonoid reduced the activity of NF-kB by inhibiting IKK/ІкB signaling cascade (Garcia-Mediavilla et al., 2007), which in turn reduced NF-kB nuclear translocation, its binding to promoter, and COX2 expression (Crespo et al., 2008; Puangpraphant \& de Mejia, 2009). Another signaling pathway regulating COX2 expression is PI3K-Akt pathway. This signaling pathway may activate CREB (Alique et al., 2011) or NF-kB (Yang et al., 2009), and induce COX2 expression. A recent study found that quercetin directly bound with PI3K to inhibit PI3K activity and Akt phosphorylation, resulting in a reduction in COX2 expression (Lee et al., 2010). In the LPS-induced COX2 expression, the members of MAPK, including extracellular signal related kinase (ERK), p38 and JNK, are involved in the LPS-induced 
signaling. While LPS activates the MAPKs, quercetin inhibited the activation of each of them, and subsequently reduced IKB phosphorylation and COX2 expression (GutierrezVenegas et al., 2007). The observations were enhanced by the study on the inhibitory effects of quercetin on ROS-induced MAPK activation and COX2 expression (Huang et al., 2006). The inhibition of MAPKs by quercetin was associated with the reductions in inflammatory cytokines, such as IL-1 $\beta$ and TNF- $\alpha$ (Overman et al., 2011). In addition, quercetin is able to block the COX2-TBXAS-TBX A2-receptor signaling pathway by inhibition of TBX A2 formation (Garcia-Saura et al., 2005; Sheu et al., 2004).

The steroidogenic effect of quercetin was studied with MA-10 mouse Leydig cells. It was reported that quercetin increased StAR mRNA levels, StAR promoter activity and steroid hormone production (Chen et al., 2007c). The observations were corroborated by the results shown in Fig. 3., which indicated the quercetin-enhanced StAR gene transcription and translation in MA-10 cells cultured for 6 hours (Fig. 3 A and B). Following these studies, the transcription factors in StAR gene transcription were examined. It was found that the incubation of MA-10 Leydig cells with quercetin reduced DAX-1 protein, similar to the effects of other flavonoids. The reduction in DAX-1 protein was associated with a dramatic increase in StAR protein (Fig. 3C), suggesting that quercetin enhance StAR gene expression by reduction of DAX-1 expression.

\section{A StAR protein}

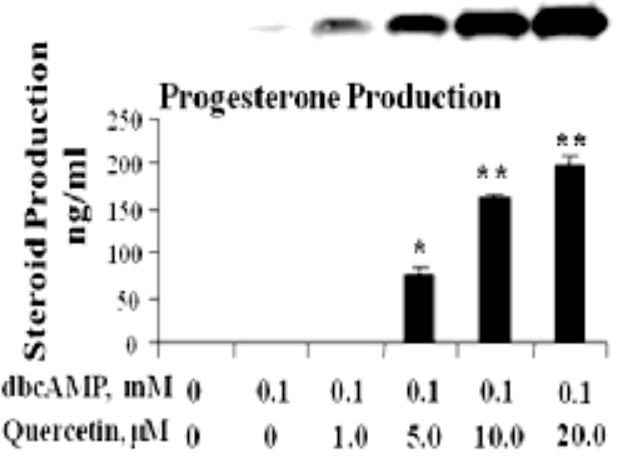

B RT-PCRAmalvsis of StAR inRNA
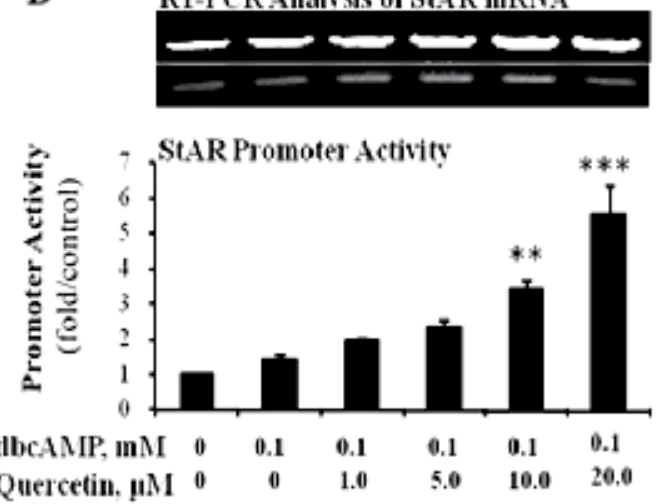

C

\section{DAX-1 protein}

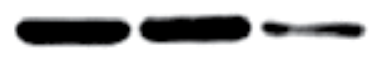

\section{StAR protein}

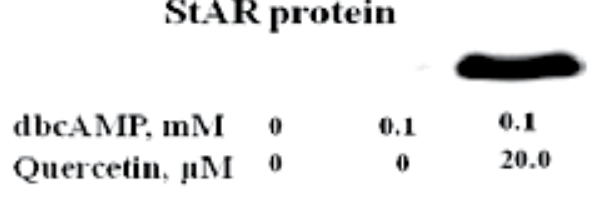

Fig. 3. Effect of quercetin on StAR gene expression and steroidogenesis in MA-10 mouse Leydig cells. MA-10 cells were incubated with quercetin for 6 hours, and then collected for analyses: A, StAR protein and steroidogenesis; B, StAR gene transcription; C, Reduction in DAX-1 protein 


\subsection{Potential application of natural flavonoids in delaying the declines in StAR gene expression and testosterone biosynthesis}

The studies reviewed above suggest that flavonoids are potential resources for alternative medicine to delay the decline in StAR gene expression. Among the various compounds of natural flavonoids, many of them are able to reduce COX2 expression, such as Kaempferol (Garcia-Mediavilla et al., 2007), tectorigenin, tectoridin (Kim et al., 1999), wogonin (Chen et al., 2008) and Silibinin (Kim et al., 2009). Some of the flavonoids reduce the inflammatory factors that induce COX2 expression (Garcia-Lafuente et al., 2009; Khanna et al., 2007; Kim et al., 2004). Another group of flavonoids was reported as receptor antagonists that inhibit the COX2-dependent signaling by blocking the TBX A2-binding to the receptors (NavarroNunez et al., 2009). In addition to the COX2-dependent signaling, StAR gene expression is affected by the signaling through different pathways. For example, calcium influx through L-type calcium channels regulates the threshold of cAMP-induced StAR gene expression, so that blocking the L-type calcium channels reduced the threshold and enhanced StAR gene expression in Leydig cells (Pandey et al., 2010). There is a group of natural flavonoids that are able to block the L-type calcium channels, such as genistein (Belevych et al., 2002), daidzein (Yokoshiki et al., 1996), equol (Liew et al., 2003) and epigallocatechin-3-gallate (EGCG) (Kang et al., 2010). The steroidogenic effects of the flavonoids in this group were described (Yu et al., 2010). It is possible to identify different flavonoids that might enhance StAR gene expression and testosterone biosynthesis through different mechanisms.

The potential for application of natural flavonoids in delaying the decline in testosterone is supported by the animal studies on the flavonoid-enhanced testosterone production and reproductive function. A study with 2-year-old male rats reported that supplementation with chrysin improved their reproductive functions, with their sperm count, fertilization potential and litter size being increased when they were allowed to interact with female rats (Dhawan et al., 2002). It was also observed that lifetime exposure to the flavonoids, including daidzein, glycitein and genistein, increased serum and testicular testosterone concentrations of rats (McVey et al., 2004). The observation was enhanced by the study on the effects of catechins on testosterone biosynthesis in rats, in which injection with catechins or its derivatives increased testosterone in blood (Yu et al., 2010). A recent study reported the beneficial effects of quercetin in diabetic rats, with their sperm viability and motility being improved by the flavonoid. These effects of quercetin are associated with an increase in serum total testosterone (Khaki et al., 2010). In addition, some flavonoids in herbal medicine are able to enhance testosterone production in rats. For example, icariin, a flavonoid in the plants in Epimedium family, has been extracted from traditional Chinese medicine (Du et al., 2002). It was observed that supplementation of icariin to 15-month-old male rats significantly increased their blood testosterone levels (Zhang \& Yang, 2006).

For application of natural flavonoids to improve the health of aging males, further studies, especially long-term animal studies and clinical studies, are needed. Two of the important considerations in the studies are mechanism and efficacy of the flavonoid-enhanced testosterone biosynthesis. The mechanisms reported for the inhibitory effects of flavonoids on COX2-dependent signaling are mostly based on the studies with the cells from various tissues. These mechanisms need to be verified with Leydig cells. In addition to the COX2dependent signaling, other mechanisms might be involved in the flavonoid-enhanced StAR gene expression and testosterone production. Further studies on the mechanisms may improve the understanding of the steroidogenic effects of flavonoids. Regarding the efficacy, bioavailability is an important factor being discussed in the studies on flavonoids 
(Setchell et al., 2001; Setchell et al., 2002). Specifically in the flavonoid-enhanced StAR gene expression and testosterone production, the following factors have been discussed recently: 1) Biphasic effects of flavonoids on StAR gene expression. As mentioned above, some of the flavonoids are able to block L-type calcium channels. It was reported that blocking L-type calcium channel produced biphasic effects on StAR gene expression in Leydig cells (Pandey et al., 2010). While these flavonoids might enhance StAR gene expression by reducing the transcriptional repressor DAX-1 protein, they might inhibit the positive effect of calciumdependent signaling on StAR gene expression; 2) Inhibitory effects of flavonoids on steroidogenic enzymes. It was reported that some of the flavonoids are able to inhibit activities of the enzymes involved in testosterone biosynthesis (Figueiroa et al., 2009; Hu et al., 2010). These inhibitory effects may reduce the efficacy of flavonoid-enhanced testosterone production; 3) Levels of cAMP in Leydig cells. The levels of cAMP-PKAphosphorylation are critical for the flavonoid-enhanced StAR gene expression in Leydig cells. As shown in Fig. 2C, in the absence of cAMP, flavonoid alone is not able to induce significant increases in StAR protein expression and steroid hormone production (Jana et al., 2008; Li et al., 2011). In the studies without exogenous cAMP, the endogenous cAMP becomes important for the steroidogenic effect of flavonoids. When the levels of endogenous cAMP or PKA activity in Leydig cells are not sufficient, flavonoid might not be able to induce significant increase in StAR gene expression. Therefore, minimal level of cAMP or PKA activity should be considered for the flavonoid-enhanced StAR gene expression and testosterone biosynthesis.

\section{Summary}

In summary, LH-stimulation of Leydig cells induces both positive and negative signals in the regulation of StAR gene expression and testosterone biosynthesis. In the aging process, the increase in COX2 enhances the negative signaling, resulting in the declines in StAR gene expression and testosterone biosynthesis in Leydig cells. It was found that some of the flavonoids are able to block the COX2-dependent signaling and enhance StAR gene expression. While further investigations are needed, the studies suggest a potential for application of the natural flavonoids in delaying the age-related declines in StAR gene expression and testosterone biosynthesis.

\section{Acknowledgment}

The author would like to acknowledge the support of NIH Grant AG025349.

\section{References}

Abayasekara, D.R., Band, A.M., \& Cooke, B.A. (1990). Evidence for the involvement of phospholipase A2 in the regulation of luteinizing hormone-stimulated steroidogenesis in rat testis Leydig cells. Molecular Cellular Endocrinology, Vol.70, No.2, pp. 147-153.

Alique, M., Calleros, L., Luengo, A., Griera, M., Iniguez, M.A., Punzon, C., Fresno, M., Rodriguez-Puyol, M., \& Rodriguez-Puyol, D. (2011). Changes in extracellular matrix composition regulate cyclooxygenase- 2 (COX-2) expression in human mesangial cells. Am J Physiol Cell Physiol. 
Arun, P., Brown, M.S., Ehsanian, R., Chen, Z., \& Van Waes, C. (2009). Nuclear NF-kappaB p65 phosphorylation at serine 276 by protein kinase A contributes to the malignant phenotype of head and neck cancer. Clin Cancer Res, Vol.15, No.19, pp. 5974-5984.

Avallet, O., Vigier, M., Perrard-Sapori, M.H., \& Saez, J.M. (1987). Transforming growth factor beta inhibits Leydig cell functions. Biochem Biophys Res Commun, Vol.146, No.2, pp. 575-581.

Axelrod, J., Burch, R.M., \& Jelsema, C.L. (1988). Receptor-mediated activation of phospholipase A2 via GTP-binding proteins: arachidonic acid and its metabolites as second messengers. Trends Neurosci, Vol.11, No.3, pp. 117-123.

Bartke, A., Musto, N., Caldwell, B.V., \& Behrman, H.R. (1973). Effects of a cholesterol esterase inhibitor and of prostaglandin F2alpha on testis cholesterol and on plasma testosterone in mice. Prostaglandins, Vol.3, No.1, pp. 97-104.

Belevych, A.E., Warrier, S., \& Harvey, R.D. (2002). Genistein inhibits cardiac L-type Ca(2+) channel activity by a tyrosine kinase-independent mechanism. Mol Pharmacol, Vol.62, No.3, pp. 554-565.

Budnik, L.T., Jahner, D., \& Mukhopadhyay, A.K. (1999). Inhibitory effects of TNF alpha on mouse tumor Leydig cells: possible role of ceramide in the mechanism of action. Mol Cell Endocrinol, Vol.150, No.1-2, pp. 39-46.

Calkins, J.H., Guo, H., Sigel, M.M., \& Lin, T. (1990). Differential effects of recombinant interleukin-1 alpha and beta on Leydig cell function. Biochem Biophys Res Commun, Vol.167, No.2, pp. 548-553.

Cano, F., Poderoso, C., Cornejo Maciel, F., Castilla, R., Maloberti, P., Castillo, F., Neuman, I., Paz, C., \& Podesta, E.J. (2006). Protein tyrosine phosphatases regulate arachidonic acid release, StAR induction and steroidogenesis acting on a hormone-dependent arachidonic acid-preferring acyl-CoA synthetase. J Steroid Biochem Mol Biol, Vol.99, No.4-5, pp. 197-202.

Cardenas, M., Marder, M., Blank, V.C., \& Roguin, L.P. (2006). Antitumor activity of some natural flavonoids and synthetic derivatives on various human and murine cancer cell lines. Bioorg Med Chem, Vol.14, No.9, pp. 2966-2971.

Carlone, D.L., \& Richards, J.S. (1997). Functional interactions, phosphorylation, and levels of 3',5'-cyclic adenosine monophosphate-regulatory element binding protein and steroidogenic factor-1 mediate hormone-regulated and constitutive expression of aromatase in gonadal cells. Mol Endocrinol, Vol.11, No.3, pp. 292-304.

Caron, K.M., Clark, B.J., Ikeda, Y., \& Parker, K.L. (1997a). Steroidogenic factor 1 acts at all levels of the reproductive axis. Steroids, Vol.62, No.1, pp. 53-56.

Caron, K.M., Ikeda, Y., Soo, S.C., Stocco, D.M., Parker, K.L., \& Clark, B.J. (1997b). Characterization of the promoter region of the mouse gene encoding the steroidogenic acute regulatory protein. Molecular Endocrinology, Vol.11, No.2, pp. 138-147.

Chen, C.C., Sun, Y.T., Chen, J.J., \& Chang, Y.J. (2001a). Tumor necrosis factor-alpha-induced cyclooxygenase-2 expression via sequential activation of ceramide-dependent mitogen-activated protein kinases, and IkappaB kinase $1 / 2$ in human alveolar epithelial cells. Mol Pharmacol, Vol.59, No.3, pp. 493-500.

Chen, C.Y., Peng, W.H., Tsai, K.D., \& Hsu, S.L. (2007a). Luteolin suppresses inflammationassociated gene expression by blocking NF-kappaB and AP-1 activation pathway in mouse alveolar macrophages. Life Sci, Vol.81, No.23-24, pp. 1602-1614. 
Chen, H., Cangello, D., Benson, S., Folmer, J., Zhu, H., Trush, M.A., \& Zirkin, B.R. (2001b). Age-related increase in mitochondrial superoxide generation in the testosteroneproducing cells of Brown Norway rat testes: relationship to reduced steroidogenic function? Exp Gerontol, Vol.36, No.8, pp. 1361-1373.

Chen, H., Hardy, M.P., Huhtaniemi, I., \& Zirkin, B.R. (1994). Age-related decreased Leydig cell testosterone production in the brown Norway rat. In J Androl (Vol. 15, pp. 551557).

Chen, H., Hardy, M.P., \& Zirkin, B.R. (2002). Age-related decreases in Leydig cell testosterone production are not restored by exposure to LH in vitro. Endocrinology, Vol.143, No.5, pp. 1637-1642.

Chen, H., Liu, J., Luo, L., \& Zirkin, B.R. (2004). Dibutyryl cyclic adenosine monophosphate restores the ability of aged Leydig cells to produce testosterone at the high levels characteristic of young cells. Endocrinology, Vol.145, No.10, pp. 4441-4446.

Chen, H., Luo, L., Liu, J., \& Zirkin, B.R. (2007b). Cyclooxygenases in rat Leydig cells: effects of luteinizing hormone and aging. Endocrinology, Vol.148, No.2, pp. 735-742.

Chen, L.G., Hung, L.Y., Tsai, K.W., Pan, Y.S., Tsai, Y.D., Li, Y.Z., \& Liu, Y.W. (2008). Wogonin, a bioactive flavonoid in herbal tea, inhibits inflammatory cyclooxygenase-2 gene expression in human lung epithelial cancer cells. Mol Nutr Food Res, Vol.52, No.11, pp. 1349-1357.

Chen, Y.C., Nagpal, M.L., Stocco, D.M., \& Lin, T. (2007c). Effects of genistein, resveratrol, and quercetin on steroidogenesis and proliferation of MA-10 mouse Leydig tumor cells. J Endocrinol, Vol.192, No.3, pp. 527-537.

Chen, Y.T., Zheng, R.L., Jia, Z.J., \& Ju, Y. (1990). Flavonoids as superoxide scavengers and antioxidants. Free Radic Biol Med, Vol.9, No.1, pp. 19-21.

Cho, H., Yun, C.W., Park, W.K., Kong, J.Y., Kim, K.S., Park, Y., Lee, S., \& Kim, B.K. (2004). Modulation of the activity of pro-inflammatory enzymes, COX-2 and iNOS, by chrysin derivatives. Pharmacol Res, Vol.49, No.1, pp. 37-43.

Cho, Y.H., Lee, C.H., \& Kim, S.G. (2003). Potentiation of lipopolysaccharide-inducible cyclooxygenase 2 expression by C2-ceramide via c-Jun N-terminal kinase-mediated activation of CCAAT/enhancer binding protein beta in macrophages. Mol Pharmacol, Vol.63, No.3, pp. 512-523.

Choi, E.M., \& Lee, Y.S. (2010). Luteolin suppresses IL-1beta-induced cytokines and MMPs production via p38 MAPK, JNK, NF-kappaB and AP-1 activation in human synovial sarcoma cell line, SW982. Food Chem Toxicol, Vol.48, No.10, pp. 2607-2611.

Christenson, L.K., Johnson, P.F., McAllister, J.M., \& Strauss, J.F., 3rd. (1999). CCAAT/enhancer-binding proteins regulate expression of the human steroidogenic acute regulatory protein (StAR) gene. J Biol Chem, Vol.274, No.37, pp. 26591-26598.

Chrivia, J.C., Kwok, R.P., Lamb, N., Hagiwara, M., Montminy, M.R., \& Goodman, R.H. (1993). Phosphorylated CREB binds specifically to the nuclear protein CBP. Nature, Vol.365, No.6449, pp. 855-859.

Chun, K.S., \& Surh, Y.J. (2004). Signal transduction pathways regulating cyclooxygenase-2 expression: potential molecular targets for chemoprevention. Biochem Pharmacol, Vol.68, No.6, pp. 1089-1100. 
Chung, H.Y., Cesari, M., Anton, S., Marzetti, E., Giovannini, S., Seo, A.Y., Carter, C., Yu, B.P., \& Leeuwenburgh, C. (2009). Molecular inflammation: underpinnings of aging and age-related diseases. Ageing Res Rev, Vol.8, No.1, pp. 18-30.

Chung, H.Y., Kim, H.J., Kim, J.W., \& Yu, B.P. (2001). The inflammation hypothesis of aging: molecular modulation by calorie restriction. Ann N Y Acad Sci, Vol.928, pp. 327-335.

Chung, H.Y., Sung, B., Jung, K.J., Zou, Y., \& Yu, B.P. (2006). The molecular inflammatory process in aging. Antioxid Redox Signal, Vol.8, No.3-4, pp. 572-581.

Clark, B.J., Wells, J., King, S.R., \& Stocco, D.M. (1994). The purification, cloning, and expression of a novel luteinizing hormone-induced mitochondrial protein in MA-10 mouse Leydig tumor cells. Characterization of the steroidogenic acute regulatory protein (StAR). The Journal of biological chemistry, Vol.269, No.45, pp. 28314-28322.

Cooke, B.A., Dirami, G., Chaudry, L., Choi, M.S., Abayasekara, D.R., \& Phipp, L. (1991). Release of arachidonic acid and the effects of corticosteroids on steroidogenesis in rat testis Leydig cells. The Journal of steroid biochemistry and molecular biology, Vol.40, No.1-3, pp. 465-471.

Cooke, B.A., Dix, C.J., Habberfield, A.D., \& Sullivan, M.H. (1984). Control of steroidogenesis in Leydig cells: roles of Ca2+ and lipoxygenase products in LH and LHRH agonist action. Ann N Y Acad Sci, Vol.438, pp. 269-282.

Cornejo Maciel, F., Maloberti, P., Neuman, I., Cano, F., Castilla, R., Castillo, F., Paz, C., \& Podesta, E.J. (2005). An arachidonic acid-preferring acyl-CoA synthetase is a hormone-dependent and obligatory protein in the signal transduction pathway of steroidogenic hormones. Journal of Molecular Endocrinology, Vol.34, No.3, pp. 655666.

Crespo, I., Garcia-Mediavilla, M.V., Gutierrez, B., Sanchez-Campos, S., Tunon, M.J., \& Gonzalez-Gallego, J. (2008). A comparison of the effects of kaempferol and quercetin on cytokine-induced pro-inflammatory status of cultured human endothelial cells. Br J Nutr, Vol.100, No.5, pp. 968-976.

Culty, M., Luo, L., Yao, Z.X., Chen, H., Papadopoulos, V., \& Zirkin, B.R. (2002). Cholesterol transport, peripheral benzodiazepine receptor, and steroidogenesis in aging Leydig cells. J Androl, Vol.23, No.3, pp. 439-447.

Dao, T.T., Chi, Y.S., Kim, J., Kim, H.P., Kim, S., \& Park, H. (2004). Synthesis and inhibitory activity against COX-2 catalyzed prostaglandin production of chrysin derivatives. Bioorg Med Chem Lett, Vol.14, No.5, pp. 1165-1167.

Dhawan, K., Kumar, S., \& Sharma, A. (2002). Beneficial effects of chrysin and benzoflavone on virility in 2-year-old male rats. J Med Food, Vol.5, No.1, pp. 43-48.

Didolkar, A.K., \& Sundaram, K. (1987). Arachidonic acid is involved in the regulation of hCG induced steroidogenesis in rat Leydig cells. Life Sci, Vol.41, No.4, pp. 471-477.

Didolkar, A.K., \& Sundaram, K. (1989). Mechanism of LHRH-stimulated steroidogenesis in rat Leydig cells: lipoxygenase products of arachidonic acid may not be involved. J Androl, Vol.10, No.6, pp. 449-455.

Dix, C.J., Habberfield, A.D., Sullivan, M.H., \& Cooke, B.A. (1984). Inhibition of steroid production in Leydig cells by non-steroidal anti-inflammatory and related compounds: evidence for the involvement of lipoxygenase products in steroidogenesis. Biochem J, Vol.219, No.2, pp. 529-537. 
Du, Q., Xia, M., \& Ito, Y. (2002). Purification of icariin from the extract of Epimedium segittatum using high-speed counter-current chromatography. J Chromatogr A, Vol.962, No.1-2, pp. 239-241.

Feldman, H.A., Longcope, C., Derby, C.A., Johannes, C.B., Araujo, A.B., Coviello, A.D., Bremner, W.J., \& McKinlay, J.B. (2002). Age trends in the level of serum testosterone and other hormones in middle-aged men: longitudinal results from the Massachusetts male aging study. J Clin Endocrinol Metab, Vol.87, No.2, pp. 589-598.

Ferrandiz, M.L., \& Alcaraz, M.J. (1991). Anti-inflammatory activity and inhibition of arachidonic acid metabolism by flavonoids. Agents Actions, Vol.32, No.3-4, pp. 283288.

Figueiroa, M.S., Cesar Vieira, J.S., Leite, D.S., Filho, R.C., Ferreira, F., Gouveia, P.S., Udrisar, D.P., \& Wanderley, M.I. (2009). Green tea polyphenols inhibit testosterone production in rat Leydig cells. Asian J Androl, Vol.11, No.3, pp. 362-370.

Finkielstein, C., Maloberti, P., Mendez, C.F., Paz, C., Cornejo Maciel, F., Cymeryng, C., Neuman, I., Dada, L., Mele, P.G., Solano, A., \& Podesta, E.J. (1998). An adrenocorticotropin-regulated phosphoprotein intermediary in steroid synthesis is similar to an acyl-CoA thioesterase enzyme. European journal of biochemistry Vol.256, No.1, pp. 60-66.

Frungieri, M.B., Gonzalez-Calvar, S.I., Parborell, F., Albrecht, M., Mayerhofer, A., \& Calandra, R.S. (2006). Cyclooxygenase-2 and prostaglandin F2 alpha in Syrian hamster Leydig cells: Inhibitory role on luteinizing hormone/human chorionic gonadotropin-stimulated testosterone production. Endocrinology, Vol.147, No.9, pp. 4476-4485.

Fuchs, A.R., \& Chantharaksri, U. (1981). Prostaglandin F2alpha regulation of LH-stimulated testosterone production in rat testis. Biol Reprod, Vol.25, No.3, pp. 492-501.

Gambelunghe, C., Rossi, R., Sommavilla, M., Ferranti, C., Rossi, R., Ciculi, C., Gizzi, S., Micheletti, A., \& Rufini, S. (2003). Effects of chrysin on urinary testosterone levels in human males. J Med Food, Vol.6, No.4, pp. 387-390.

Garcia-Lafuente, A., Guillamon, E., Villares, A., Rostagno, M.A., \& Martinez, J.A. (2009). Flavonoids as anti-inflammatory agents: implications in cancer and cardiovascular disease. Inflamm Res, Vol.58, No.9, pp. 537-552.

Garcia-Mediavilla, V., Crespo, I., Collado, P.S., Esteller, A., Sanchez-Campos, S., Tunon, M.J., \& Gonzalez-Gallego, J. (2007). The anti-inflammatory flavones quercetin and kaempferol cause inhibition of inducible nitric oxide synthase, cyclooxygenase-2 and reactive C-protein, and down-regulation of the nuclear factor kappaB pathway in Chang Liver cells. Eur J Pharmacol, Vol.557, No.2-3, pp. 221-229.

Garcia-Saura, M.F., Galisteo, M., Villar, I.C., Bermejo, A., Zarzuelo, A., Vargas, F., \& Duarte, J. (2005). Effects of chronic quercetin treatment in experimental renovascular hypertension. Mol Cell Biochem, Vol.270, No.1-2, pp. 147-155.

Gouras, G.K., Xu, H., Gross, R.S., Greenfield, J.P., Hai, B., Wang, R., \& Greengard, P. (2000). Testosterone reduces neuronal secretion of Alzheimer's beta-amyloid peptides. Proc Natl Acad Sci U S A, Vol.97, No.3, pp. 1202-1205.

Guerrero, J.A., Lozano, M.L., Castillo, J., Benavente-Garcia, O., Vicente, V., \& Rivera, J. (2005). Flavonoids inhibit platelet function through binding to the thromboxane A2 receptor. J Thromb Haemost, Vol.3, No.2, pp. 369-376. 
Guerrero, J.A., Navarro-Nunez, L., Lozano, M.L., Martinez, C., Vicente, V., Gibbins, J.M., \& Rivera, J. (2007). Flavonoids inhibit the platelet $\operatorname{TxA}(2)$ signalling pathway and antagonize $\mathrm{TxA}(2)$ receptors (TP) in platelets and smooth muscle cells. Br J Clin Pharmacol, Vol.64, No.2, pp. 133-144.

Gutierrez-Venegas, G., Jimenez-Estrada, M., \& Maldonado, S. (2007). The effect of flavonoids on transduction mechanisms in lipopolysaccharide-treated human gingival fibroblasts. Int Immunopharmacol, Vol.7, No.9, pp. 1199-1210.

Gutierrez-Venegas, G., Kawasaki-Cardenas, P., Arroyo-Cruz, S.R., \& Maldonado-Frias, S. (2006). Luteolin inhibits lipopolysaccharide actions on human gingival fibroblasts. Eur J Pharmacol, Vol.541, No.1-2, pp. 95-105.

Ha, S.K., Lee, P., Park, J.A., Oh, H.R., Lee, S.Y., Park, J.H., Lee, E.H., Ryu, J.H., Lee, K.R., \& Kim, S.Y. (2008). Apigenin inhibits the production of NO and PGE2 in microglia and inhibits neuronal cell death in a middle cerebral artery occlusion-induced focal ischemia mice model. Neurochem Int, Vol.52, No.4-5, pp. 878-886.

Ha, S.K., Moon, E., \& Kim, S.Y. (2010). Chrysin suppresses LPS-stimulated proinflammatory responses by blocking NF-kappaB and JNK activations in microglia cells. Neurosci Lett, Vol.485, No.3, pp. 143-147.

Hales, D.B. (1992). Interleukin-1 inhibits Leydig cell steroidogenesis primarily by decreasing 17 alpha-hydroxylase/C17-20 lyase cytochrome P450 expression. Endocrinology, Vol.131, No.5, pp. 2165-2172.

Haour, F., Kouznetzova, B., Dray, F., \& Saez, J.M. (1979). hCG-induced prostaglandin E2 and F2 alpha release in adult rat testis: role in Leydig cell desensitization to hCG. Life Sci, Vol.24, No.23, pp. 2151-2158.

Hardy, R., \& Cooper, M.S. (2010). Adrenal gland and bone. Arch Biochem Biophys, Vol.503, No.1, pp. 137-145.

Harman, S.M., Metter, E.J., Tobin, J.D., Pearson, J., \& Blackman, M.R. (2001). Longitudinal effects of aging on serum total and free testosterone levels in healthy men. Baltimore Longitudinal Study of Aging. J Clin Endocrinol Metab, Vol.86, No.2, pp. 724-731.

Harnly, J.M., Doherty, R.F., Beecher, G.R., Holden, J.M., Haytowitz, D.B., Bhagwat, S., \& Gebhardt, S. (2006). Flavonoid content of U.S. fruits, vegetables, and nuts. J Agric Food Chem, Vol.54, No.26, pp. 9966-9977.

Hogervorst, E., Williams, J., Budge, M., Barnetson, L., Combrinck, M., \& Smith, A.D. (2001). Serum total testosterone is lower in men with Alzheimer's disease. Neuro Endocrinol Lett, Vol.22, No.3, pp. 163-168.

Hu, G.X., Zhao, B.H., Chu, Y.H., Zhou, H.Y., Akingbemi, B.T., Zheng, Z.Q., \& Ge, R.S. (2010). Effects of genistein and equol on human and rat testicular 3betahydroxysteroid dehydrogenase and 17beta-hydroxysteroid dehydrogenase 3 activities. Asian J Androl, Vol.12, No.4, pp. 519-526.

Huang, S.M., Wu, C.H., \& Yen, G.C. (2006). Effects of flavonoids on the expression of the pro-inflammatory response in human monocytes induced by ligation of the receptor for AGEs. Mol Nutr Food Res, Vol.50, No.12, pp. 1129-1139.

Ishikawa, T., Hwang, K., Lazzarino, D., \& Morris, P.L. (2005). Sertoli cell expression of steroidogenic acute regulatory protein-related lipid transfer 1 and 5 domaincontaining proteins and sterol regulatory element binding protein-1 are interleukin- 
1beta regulated by activation of c-Jun $\mathrm{N}$-terminal kinase and cyclooxygenase-2 and cytokine induction. Endocrinology, Vol.146, No.12, pp. 5100-5111.

Jana, K., Yin, X., Schiffer, R.B., Chen, J.J., Pandey, A.K., Stocco, D.M., Grammas, P., \& Wang, X. (2008). Chrysin, a natural flavonoid enhances steroidogenesis and steroidogenic acute regulatory protein gene expression in mouse Leydig cells. J Endocrinol, Vol.197, No.2, pp. 315-323.

Jiang, L., Fang, G., Zhang, Y., Cao, G., \& Wang, S. (2008). Analysis of flavonoids in propolis and Ginkgo biloba by micellar electrokinetic capillary chromatography. J Agric Food Chem, Vol.56, No.24, pp. 11571-11577.

Jo, Y., \& Stocco, D.M. (2004). Regulation of steroidogenesis and steroidogenic acute regulatory protein in R2C cells by DAX-1 (dosage-sensitive sex reversal, adrenal hypoplasia congenita, critical region on the $\mathrm{X}$ chromosome, gene-1). Endocrinology, Vol.145, No.12, pp. 5629-5637.

Jung, J.C., Park, G.T., Kim, K.H., Woo, J.H., An, J.M., Kim, K.C., Chung, H.Y., Bae, Y.S., Park, J.W., Kang, S.S., \& Lee, Y.S. (2004). Differential expression of transforming growth factor-beta in the interstitial tissue of testis during aging. J Cell Biochem, Vol.92, No.1, pp. 92-98.

Kang, J., Cheng, H., Ji, J., Incardona, J., \& Rampe, D. (2010). In vitro electrocardiographic and cardiac ion channel effects of (-)-epigallocatechin-3-gallate, the main catechin of green tea. J Pharmacol Exp Ther, Vol.334, No.2, pp. 619-626.

Kassim, M., Achoui, M., Mustafa, M.R., Mohd, M.A., \& Yusoff, K.M. (2010). Ellagic acid, phenolic acids, and flavonoids in Malaysian honey extracts demonstrate in vitro anti-inflammatory activity. Nutr Res, Vol.30, No.9, pp. 650-659.

Kaufman, J.M., \& Vermeulen, A. (2005). The decline of androgen levels in elderly men and its clinical and therapeutic implications. Endocr Rev, Vol.26, No.6, pp. 833-876.

Kellis, J.T., Jr., \& Vickery, L.E. (1984). Inhibition of human estrogen synthetase (aromatase) by flavones. Science, Vol.225, No.4666, pp. 1032-1034.

Khaki, A., Fathiazad, F., Nouri, M., Maleki, N.A., Khamnei, H.J., \& Ahmadi, P. (2010). Beneficial effects of quercetin on sperm parameters in streptozotocin-induced diabetic male rats. Phytother Res, Vol.24, No.9, pp. 1285-1291.

Khanna, D., Sethi, G., Ahn, K.S., Pandey, M.K., Kunnumakkara, A.B., Sung, B., Aggarwal, A., \& Aggarwal, B.B. (2007). Natural products as a gold mine for arthritis treatment. Curr Opin Pharmacol, Vol.7, No.3, pp. 344-351.

Kim, H.P., Son, K.H., Chang, H.W., \& Kang, S.S. (2004). Anti-inflammatory plant flavonoids and cellular action mechanisms. J Pharmacol Sci, Vol.96, No.3, pp. 229-245.

Kim, J.S., \& Jobin, C. (2005). The flavonoid luteolin prevents lipopolysaccharide-induced NF-kappaB signalling and gene expression by blocking IkappaB kinase activity in intestinal epithelial cells and bone-marrow derived dendritic cells. Immunology, Vol.115, No.3, pp. 375-387.

Kim, S., Kim, S.H., Hur, S.M., Lee, S.K., Kim, W.W., Kim, J.S., Kim, J.H., Choe, J.H., Nam, S.J., Lee, J.E., \& Yang, J.H. (2009). Silibinin prevents TPA-induced MMP-9 expression by down-regulation of COX-2 in human breast cancer cells. J Ethnopharmacol, Vol.126, No.2, pp. 252-257.

Kim, Y.P., Yamada, M., Lim, S.S., Lee, S.H., Ryu, N., Shin, K.H., \& Ohuchi, K. (1999). Inhibition by tectorigenin and tectoridin of prostaglandin E2 production and 
cyclooxygenase-2 induction in rat peritoneal macrophages. Biochim Biophys Acta, Vol.1438, No.3, pp. 399-407.

Lee, K.M., Hwang, M.K., Lee, D.E., Lee, K.W., \& Lee, H.J. (2010). Protective effect of quercetin against arsenite-induced COX-2 expression by targeting PI3K in rat liver epithelial cells. J Agric Food Chem, Vol.58, No.9, pp. 5815-5820.

Leers-Sucheta, S., Stocco, D.M., \& Azhar, S. (1999). Down-regulation of steroidogenic acute regulatory (StAR) protein in rat Leydig cells: implications for regulation of testosterone production during aging. Mech Ageing Dev, Vol.107, No.2, pp. 197-203.

Li, W., Pandey, A.K., Yin, X., Chen, J.J., Stocco, D.M., Grammas, P., \& Wang, X.J. (2011). Effects of Apigenin on Steroidogenesis and Steroidogenic Acute Regulatory Gene Expression in Mouse Leydig Cells J Nutritional Biochemistry.

Li, X., Huang, Q., Ong, C.N., Yang, X.F., \& Shen, H.M. (2010). Chrysin sensitizes tumor necrosis factor-alpha-induced apoptosis in human tumor cells via suppression of nuclear factor-kappaB. Cancer Lett, Vol.293, No.1, pp. 109-116.

Liang, Y.C., Huang, Y.T., Tsai, S.H., Lin-Shiau, S.Y., Chen, C.F., \& Lin, J.K. (1999). Suppression of inducible cyclooxygenase and inducible nitric oxide synthase by apigenin and related flavonoids in mouse macrophages. Carcinogenesis, Vol.20, No.10, pp. 1945-1952.

Liew, R., Williams, J.K., Collins, P., \& MacLeod, K.T. (2003). Soy-derived isoflavones exert opposing actions on Guinea pig ventricular myocytes. J Pharmacol Exp Ther, Vol.304, No.3, pp. 985-993.

Lin, D., Sugawara, T., Strauss, J.F., 3rd, Clark, B.J., Stocco, D.M., Saenger, P., Rogol, A., \& Miller, W.L. (1995). Role of steroidogenic acute regulatory protein in adrenal and gonadal steroidogenesis. Science, Vol.267, No.5205, pp. 1828-1831.

Lin, T., Murono, E., Osterman, J., Allen, D.O., \& Nankin, H.R. (1980). The aging Leydig cell: 1. Testosterone and adenosine $3^{\prime}, 5^{\prime}$-monophosphate responses to gonadotropin stimulation in rats. Steroids, Vol.35, No.6, pp. 653-663.

Lin, T., Wang, T.L., Nagpal, M.L., Calkins, J.H., Chang, W.W., \& Chi, R. (1991). Interleukin-1 inhibits cholesterol side-chain cleavage cytochrome P450 expression in primary cultures of Leydig cells. Endocrinology, Vol.129, No.3, pp. 1305-1311.

Liu, Q., Merkler, K.A., Zhang, X., \& McLean, M.P. (2007). Prostaglandin F2alpha suppresses rat steroidogenic acute regulatory protein expression via induction of Yin Yang 1 protein and recruitment of histone deacetylase 1 protein. Endocrinology, Vol.148, No.11, pp. 5209-5219.

Lopez, D., Nackley, A.C., Shea-Eaton, W., Xue, J., Schimmer, B.P., \& McLean, M.P. (2001). Effects of mutating different steroidogenic factor-1 protein regions on gene regulation. Endocrine, Vol.14, No.3, pp. 353-362.

Luo, L., Chen, H., \& Zirkin, B.R. (2001). Leydig cell aging: steroidogenic acute regulatory protein (StAR) and cholesterol side-chain cleavage enzyme. J Androl, Vol.22, No.1, pp. 149-156.

Luo, L., Chen, H., \& Zirkin, B.R. (2005). Temporal relationships among testosterone production, steroidogenic acute regulatory protein (StAR), and P450 side-chain cleavage enzyme (P450scc) during Leydig cell aging. J Androl, Vol.26, No.1, pp. 2531.

Maloberti, P., Castilla, R., Castillo, F., Maciel, F.C., Mendez, C.F., Paz, C., \& Podesta, E.J. (2005). Silencing the expression of mitochondrial acyl-CoA thioesterase I and acyl- 
CoA synthetase 4 inhibits hormone-induced steroidogenesis. Febs J, Vol.272, No.7, pp. 1804-1814.

Maloberti, P., Maciel, F.C., Castillo, A.F., Castilla, R., Duarte, A., Toledo, M.F., Meuli, F., Mele, P., Paz, C., \& Podesta, E.J. (2007). Enzymes involved in arachidonic acid release in adrenal and Leydig cells. Mol Cell Endocrinol, Vol.265-266, pp. 113-120.

Manna, P.R., Dyson, M.T., Eubank, D.W., Clark, B.J., Lalli, E., Sassone-Corsi, P., Zeleznik, A.J., \& Stocco, D.M. (2002). Regulation of steroidogenesis and the steroidogenic acute regulatory protein by a member of the cAMP response-element binding protein family. Mol Endocrinol, Vol.16, No.1, pp. 184-199.

Manna, P.R., Eubank, D.W., Lalli, E., Sassone-Corsi, P., \& Stocco, D.M. (2003). Transcriptional regulation of the mouse steroidogenic acute regulatory protein gene by the cAMP response-element binding protein and steroidogenic factor $1 . J$ Mol Endocrinol, Vol.30, No.3, pp. 381-397.

Manna, P.R., Eubank, D.W., \& Stocco, D.M. (2004). Assessment of the role of activator protein-1 on transcription of the mouse steroidogenic acute regulatory protein gene. Mol Endocrinol, Vol.18, No.3, pp. 558-573.

Matsumoto, A.M. (2002). Andropause: clinical implications of the decline in serum testosterone levels with aging in men. J Gerontol A Biol Sci Med Sci, Vol.57, No.2, pp. M76-99.

Matzkin, M.E., Gonzalez-Calvar, S.I., Mayerhofer, A., Calandra, R.S., \& Frungieri, M.B. (2009). Testosterone induction of prostaglandin-endoperoxide synthase 2 expression and prostaglandin $\mathrm{F}(2 \mathrm{alpha})$ production in hamster Leydig cells. Reproduction, Vol.138, No.1, pp. 163-175.

Mayr, B., \& Montminy, M. (2001). Transcriptional regulation by the phosphorylationdependent factor CREB. Nat Rev Mol Cell Biol, Vol.2, No.8, pp. 599-609.

Mayr, B.M., Canettieri, G., \& Montminy, M.R. (2001). Distinct effects of cAMP and mitogenic signals on CREB-binding protein recruitment impart specificity to target gene activation via CREB. Proc Natl Acad Sci U S A, Vol.98, No.19, pp. 10936-10941.

McVey, M.J., Cooke, G.M., \& Curran, I.H. (2004). Increased serum and testicular androgen levels in F1 rats with lifetime exposure to soy isoflavones. Reprod Toxicol, Vol.18, No.5, pp. 677-685.

Mele, P.G., Dada, L.A., Paz, C., Neuman, I., Cymeryng, C.B., Mendez, C.F., Finkielstein, C.V., Cornejo Maciel, F., \& Podesta, E.J. (1997). Involvement of arachidonic acid and the lipoxygenase pathway in mediating luteinizing hormone-induced testosterone synthesis in rat Leydig cells. Endocr Res, Vol.23, No.1-2, pp. 15-26.

Meyer, T.E., \& Habener, J.F. (1993). Cyclic adenosine 3',5'-monophosphate response element binding protein (CREB) and related transcription-activating deoxyribonucleic acidbinding proteins. Endocr Rev, Vol.14, No.3, pp. 269-290.

Miean, K.H., \& Mohamed, S. (2001). Flavonoid (myricetin, quercetin, kaempferol, luteolin, and apigenin) content of edible tropical plants. J Agric Food Chem, Vol.49, No.6, pp. 3106-3112.

Miller, W.L. (1988). Molecular biology of steroid hormone synthesis. Endocr Rev, Vol.9, No.3, pp. 295-318.

Moffat, S.D., Zonderman, A.B., Metter, E.J., Kawas, C., Blackman, M.R., Harman, S.M., \& Resnick, S.M. (2004). Free testosterone and risk for Alzheimer disease in older men. Neurology, Vol.62, No.2, pp. 188-193. 
Montminy, M.R., Sevarino, K.A., Wagner, J.A., Mandel, G., \& Goodman, R.H. (1986). Identification of a cyclic-AMP-responsive element within the rat somatostatin gene. Proc Natl Acad Sci U S A, Vol.83, No.18, pp. 6682-6686.

Morley, J.E., \& Baumgartner, R.N. (2004). Cytokine-related aging process. J Gerontol A Biol Sci Med Sci, Vol.59, No.9, pp. M924-929.

Nackley, A.C., Shea-Eaton, W., Lopez, D., \& McLean, M.P. (2002). Repression of the steroidogenic acute regulatory gene by the multifunctional transcription factor Yin Yang 1. Endocrinology, Vol.143, No.3, pp. 1085-1096.

Navarro-Nunez, L., Castillo, J., Lozano, M.L., Martinez, C., Benavente-Garcia, O., Vicente, V., \& Rivera, J. (2009). Thromboxane A2 receptor antagonism by flavonoids: structure-activity relationships. J Agric Food Chem, Vol.57, No.4, pp. 1589-1594.

Navarro-Nunez, L., Lozano, M.L., Palomo, M., Martinez, C., Vicente, V., Castillo, J., Benavente-Garcia, O., Diaz-Ricart, M., Escolar, G., \& Rivera, J. (2008). Apigenin inhibits platelet adhesion and thrombus formation and synergizes with aspirin in the suppression of the arachidonic acid pathway. J Agric Food Chem, Vol.56, No.9, pp. 2970-2976.

Nielsen, S.E., Young, J.F., Daneshvar, B., Lauridsen, S.T., Knuthsen, P., Sandstrom, B., \& Dragsted, L.O. (1999). Effect of parsley (Petroselinum crispum) intake on urinary apigenin excretion, blood antioxidant enzymes and biomarkers for oxidative stress in human subjects. Br J Nutr, Vol.81, No.6, pp. 447-455.

Ogilvie, K.M., Held Hales, K., Roberts, M.E., Hales, D.B., \& Rivier, C. (1999). The inhibitory effect of intracerebroventricularly injected interleukin 1beta on testosterone secretion in the rat: role of steroidogenic acute regulatory protein. Biol Reprod, Vol.60, No.2, pp. 527-533.

Overman, A., Chuang, C.C., \& McIntosh, M. (2011). Quercetin attenuates inflammation in human macrophages and adipocytes exposed to macrophage-conditioned media. Int J Obes (Lond).

Pandey, A.K., Li, W., Yin, X., Stocco, D.M., Grammas, P., \& Wang, X. (2010). Blocking L-type calcium channels reduced the threshold of cAMP-induced steroidogenic acute regulatory gene expression in MA-10 mouse Leydig cells. J Endocrinol, Vol.204, No.1, pp. 67-74.

Pandey, A.K., Yin, X., Schiffer, R.B., Hutson, J.C., Stocco, D.M., Grammas, P., \& Wang, X. (2009). Involvement of the thromboxane A2 receptor in the regulation of steroidogenic acute regulatory gene expression in murine Leydig cells. Endocrinology, Vol.150, No.7, pp. 3267-3273.

Papasozomenos, S., \& Shanavas, A. (2002). Testosterone prevents the heat shock-induced overactivation of glycogen synthase kinase-3 beta but not of cyclin-dependent kinase 5 and c-Jun NH2-terminal kinase and concomitantly abolishes hyperphosphorylation of tau: implications for Alzheimer's disease. Proc Natl Acad Sci U S A, Vol.99, No.3, pp. 1140-1145.

Paz, C., Dada, L.A., Cornejo Maciel, M.F., Mele, P.G., Cymeryng, C.B., Neuman, I., Mendez, C.F., Finkielstein, C.V., Solano, A.R., Park, M., \& et al. (1994). Purification of a novel 43-kDa protein ( $\mathrm{p} 43$ ) intermediary in the activation of steroidogenesis from rat adrenal gland. Eur J Biochem, Vol.224, No.2, pp. 709-716. 
Piomelli, D., \& Greengard, P. (1991). Bidirectional control of phospholipase A2 activity by $\mathrm{Ca} 2+/$ calmodulin-dependent protein kinase II, cAMP-dependent protein kinase, and casein kinase II. Proc Natl Acad Sci U S A, Vol.88, No.15, pp. 6770-6774.

Puangpraphant, S., \& de Mejia, E.G. (2009). Saponins in yerba mate tea ( Ilex paraguariensis A. St.-Hil) and quercetin synergistically inhibit iNOS and COX-2 in lipopolysaccharide-induced macrophages through NFkappaB pathways. J Agric Food Chem, Vol.57, No.19, pp. 8873-8883.

Ramsden, M., Nyborg, A.C., Murphy, M.P., Chang, L., Stanczyk, F.Z., Golde, T.E., \& Pike, C.J. (2003). Androgens modulate beta-amyloid levels in male rat brain. J Neurochem, Vol.87, No.4, pp. 1052-1055.

Reinhart, A.J., Williams, S.C., Clark, B.J., \& Stocco, D.M. (1999a). SF-1 (steroidogenic factor1) and C/EBP beta (CCAAT/enhancer binding protein-beta) cooperate to regulate the murine StAR (steroidogenic acute regulatory) promoter. Mol Endocrinol, Vol.13, No.5, pp. 729-741.

Reinhart, A.J., Williams, S.C., \& Stocco, D.M. (1999b). Transcriptional regulation of the StAR gene. Molecular Cellular Endocrinology, Vol.151, No.1-2, pp. 161-169.

Romanelli, F., Valenca, M., Conte, D., Isidori, A., \& Negro-Vilar, A. (1995). Arachidonic acid and its metabolites effects on testosterone production by rat Leydig cells. J Endocrinol Invest, Vol.18, No.3, pp. 186-193.

Romier, B., Van De Walle, J., During, A., Larondelle, Y., \& Schneider, Y.J. (2008). Modulation of signalling nuclear factor-kappaB activation pathway by polyphenols in human intestinal Caco-2 cells. Br J Nutr, Vol.100, No.3, pp. 542-551.

Ronco, A.M., Moraga, P.F., \& Llanos, M.N. (2002). Arachidonic acid release from rat Leydig cells: the involvement of $G$ protein, phospholipase A2 and regulation of cAMP production. Journal of Endocrinology, Vol.172, No.1, pp. 95-104.

Rosario, E.R., \& Pike, C.J. (2008). Androgen regulation of beta-amyloid protein and the risk of Alzheimer's disease. Brain Res Rev, Vol.57, No.2, pp. 444-453.

Saksena, S.K., el-Safoury, S., \& Bartke, A. (1973). Prostaglandins E2 and F2 decrease plasma testosterone levels in male rats. Prostaglandins, Vol.4, No.2, pp. 235-242.

Sandhoff, T.W., Hales, D.B., Hales, K.H., \& McLean, M.P. (1998). Transcriptional regulation of the rat steroidogenic acute regulatory protein gene by steroidogenic factor 1 . Endocrinology, Vol.139, No.12, pp. 4820-4831.

Sandhoff, T.W., \& McLean, M.P. (1999). Repression of the rat steroidogenic acute regulatory (StAR) protein gene by PGF2alpha is modulated by the negative transcription factor DAX-1. Endocrine, Vol.10, No.1, pp. 83-91.

Sawada, T., Asada, M., \& Mori, J. (1994). Effects of single and repeated administration of prostaglandin F2 alpha on secretion of testosterone by male rats. Prostaglandins, Vol.47, No.5, pp. 345-352.

Schroer, K., Zhu, Y., Saunders, M.A., Deng, W.G., Xu, X.M., Meyer-Kirchrath, J., \& Wu, K.K. (2002). Obligatory role of cyclic adenosine monophosphate response element in cyclooxygenase- 2 promoter induction and feedback regulation by inflammatory mediators. Circulation, Vol.105, No.23, pp. 2760-2765.

Setchell, K.D., Brown, N.M., Desai, P., Zimmer-Nechemias, L., Wolfe, B.E., Brashear, W.T., Kirschner, A.S., Cassidy, A., \& Heubi, J.E. (2001). Bioavailability of pure isoflavones in healthy humans and analysis of commercial soy isoflavone supplements. J Nutr, Vol.131, No.4 Suppl, pp. 1362S-1375S. 
Setchell, K.D., Brown, N.M., Zimmer-Nechemias, L., Brashear, W.T., Wolfe, B.E., Kirschner, A.S., \& Heubi, J.E. (2002). Evidence for lack of absorption of soy isoflavone glycosides in humans, supporting the crucial role of intestinal metabolism for bioavailability. Am J Clin Nutr, Vol.76, No.2, pp. 447-453.

Shea-Eaton, W., Sandhoff, T.W., Lopez, D., Hales, D.B., \& McLean, M.P. (2002). Transcriptional repression of the rat steroidogenic acute regulatory (StAR) protein gene by the AP-1 family member c-Fos. Mol Cell Endocrinol, Vol.188, No.1-2, pp. 161-170.

Shea-Eaton, W.K., Trinidad, M.J., Lopez, D., Nackley, A., \& McLean, M.P. (2001). Sterol regulatory element binding protein-1a regulation of the steroidogenic acute regulatory protein gene. Endocrinology, Vol.142, No.4, pp. 1525-1533.

Sheu, J.R., Hsiao, G., Chou, P.H., Shen, M.Y., \& Chou, D.S. (2004). Mechanisms involved in the antiplatelet activity of rutin, a glycoside of the flavonol quercetin, in human platelets. J Agric Food Chem, Vol.52, No.14, pp. 4414-4418.

Shukla, S., \& Gupta, S. (2004). Suppression of constitutive and tumor necrosis factor alphainduced nuclear factor (NF)-kappaB activation and induction of apoptosis by apigenin in human prostate carcinoma PC-3 cells: correlation with down-regulation of NF-kappaB-responsive genes. Clin Cancer Res, Vol.10, No.9, pp. 3169-3178.

Silverman, E., Eimerl, S., \& Orly, J. (1999). CCAAT enhancer-binding protein beta and GATA-4 binding regions within the promoter of the steroidogenic acute regulatory protein (StAR) gene are required for transcription in rat ovarian cells. J Biol Chem, Vol.274, No.25, pp. 17987-17996.

Silverman, E., Yivgi-Ohana, N., Sher, N., Bell, M., Eimerl, S., \& Orly, J. (2006). Transcriptional activation of the steroidogenic acute regulatory protein (StAR) gene: GATA-4 and CCAAT/enhancer-binding protein beta confer synergistic responsiveness in hormone-treated rat granulosa and HEK293 cell models. Mol Cell Endocrinol, Vol.252, No.1-2, pp. 92-101.

Slimestad, R., Fossen, T., \& Vagen, I.M. (2007). Onions: a source of unique dietary flavonoids. J Agric Food Chem, Vol.55, No.25, pp. 10067-10080.

Stocco, D.M., \& Clark, B.J. (1996). Regulation of the acute production of steroids in steroidogenic cells. Endocrine Review, Vol.17, No.3, pp. 221-244.

Sugawara, T., Holt, J.A., Kiriakidou, M., \& Strauss, J.F., 3rd. (1996). Steroidogenic factor 1dependent promoter activity of the human steroidogenic acute regulatory protein (StAR) gene. Biochemistry, Vol.35, No.28, pp. 9052-9059.

Sugawara, T., Kiriakidou, M., McAllister, J.M., Holt, J.A., Arakane, F., \& Strauss, J.F., 3rd. (1997). Regulation of expression of the steroidogenic acute regulatory protein (StAR) gene: a central role for steroidogenic factor 1. Steroids, Vol.62, No.1, pp. 5-9.

Sugawara, T., Saito, M., \& Fujimoto, S. (2000). Sp1 and SF-1 interact and cooperate in the regulation of human steroidogenic acute regulatory protein gene expression. Endocrinology, Vol.141, No.8, pp. 2895-2903.

Sullivan, M.H., \& Cooke, B.A. (1985). Effects of calmodulin and lipoxygenase inhibitors on LH (lutropin)- and LHRH (luliberin)-agonist-stimulated steroidogenesis in rat Leydig cells. Biochem J, Vol.232, No.1, pp. 55-59.

Syntin, P., Chen, H., Zirkin, B.R., \& Robaire, B. (2001). Gene expression in Brown Norway rat Leydig cells: effects of age and of age-related germ cell loss. Endocrinology, Vol.142, No.12, pp. 5277-5285. 
Tong, X., Van Dross, R.T., Abu-Yousif, A., Morrison, A.R., \& Pelling, J.C. (2007). Apigenin prevents UVB-induced cyclooxygenase 2 expression: coupled mRNA stabilization and translational inhibition. Mol Cell Biol, Vol.27, No.1, pp. 283-296.

Tremblay, J.J., Hamel, F., \& Viger, R.S. (2002). Protein kinase A-dependent cooperation between GATA and CCAAT/enhancer-binding protein transcription factors regulates steroidogenic acute regulatory protein promoter activity. Endocrinology, Vol.143, No.10, pp. 3935-3945.

Tsatsanis, C., Androulidaki, A., Venihaki, M., \& Margioris, A.N. (2006). Signalling networks regulating cyclooxygenase-2. Int J Biochem Cell Biol, Vol.38, No.10, pp. 1654-1661.

Vermeulen, A. (2000). Andropause. Maturitas, Vol.34, No.1, pp. 5-15.

Walch, L., \& Morris, P.L. (2002). Cyclooxygenase 2 pathway mediates IL-1beta regulation of IL-1alpha, -1beta, and IL-6 mRNA levels in Leydig cell progenitors. Endocrinology, Vol.143, No.9, pp. 3276-3283.

Wang, X., Shen, C.L., Dyson, M.T., Eimerl, S., Orly, J., Hutson, J.C., \& Stocco, D.M. (2005). Cyclooxygenase-2 regulation of the age-related decline in testosterone biosynthesis. Endocrinology, Vol.146, No.10, pp. 4202-4208.

Wang, X., Shen, C.L., Dyson, M.T., Yin, X., Schiffer, R.B., Grammas, P., \& Stocco, D.M. (2006). The involvement of epoxygenase metabolites of arachidonic acid in cAMPstimulated steroidogenesis and steroidogenic acute regulatory protein gene expression. J Endocrinol, Vol.190, No.3, pp. 871-878.

Wang, X., \& Stocco, D.M. (2005). The decline in testosterone biosynthesis during male aging: a consequence of multiple alterations. Mol Cell Endocrinol, Vol.238, No.1-2, pp. 1-7.

Wang, X., Yin, X., Schiffer, R.B., King, S.R., Stocco, D.M., \& Grammas, P. (2008). Inhibition of thromboxane a synthase activity enhances steroidogenesis and steroidogenic acute regulatory gene expression in MA-10 mouse Leydig cells. Endocrinology, Vol.149, No.2, pp. 851-857.

Wang, X.J., Dyson, M.T., Jo, Y., Eubank, D.W., \& Stocco, D.M. (2003a). Involvement of 5lipoxygenase metabolites of arachidonic acid in cyclic AMP-stimulated steroidogenesis and steroidogenic acute regulatory protein gene expression. The Journal of Steroid Biochemistry and Molecular Biology, Vol.85, No.2-5, pp. 159-166.

Wang, X.J., Dyson, M.T., Jo, Y., \& Stocco, D.M. (2003b). Inhibition of cyclooxygenase-2 activity enhances steroidogenesis and steroidogenic acute regulatory gene expression in MA-10 mouse Leydig cells. Endocrinology, Vol.144, No.8, pp. 33683375.

Wang, X.J., Dyson, M.T., Mondillo, C., Patrignani, Z., Pignataro, O., \& Stocco, D.M. (2002). Interaction between arachidonic acid and cAMP signaling pathways enhances steroidogenesis and StAR gene expression in MA-10 Leydig tumor cells. Molecular Cellular Endocrinology, Vol.188, No.1-2, pp. 55-63.

Wang, X.J., Liu, Z., Eimerl, S., Timberg, R., Weiss, A.M., Orly, J., \& Stocco, D.M. (1998). Effect of truncated forms of the steroidogenic acute regulatory protein on intramitochondrial cholesterol transfer. Endocrinology, Vol.139, No.9, pp. 3903-3912.

Wang, X.J., \& Stocco, D.M. (1999). Cyclic AMP and arachidonic acid: a tale of two pathways. Molecular Cellular Endocrinology, Vol.158, No.1-2, pp. 7-12.

Wang, X.J., Walsh, L.P., Reinhart, A.J., \& Stocco, D.M. (2000). The role of arachidonic acid in steroidogenesis and steroidogenic acute regulatory (StAR) gene and protein expression. The Journal of Biological Chemistry., Vol.275, No.26, pp. 20204-20209. 
Wang, X.J., Walsh, L.P., \& Stocco, D.M. (1999). The role of arachidonic acid on LHstimulated steroidogenesis and steroidogenic acute regulatory protein accumulation in MA-10 mouse Leydig tumor cells. Endocrine, Vol.10, No.1, pp. 7-12.

Williams, C.A., Harborne, J.B., Newman, M., Greenham, J., \& Eagles, J. (1997). Chrysin and other leaf exudate flavonoids in the genus Pelargonium. Phytochemistry, Vol.46, No.8, pp. 1349-1353.

Woo, K.J., Jeong, Y.J., Inoue, H., Park, J.W., \& Kwon, T.K. (2005). Chrysin suppresses lipopolysaccharide-induced cyclooxygenase-2 expression through the inhibition of nuclear factor for IL-6 (NF-IL6) DNA-binding activity. FEBS Lett, Vol.579, No.3, pp. 705-711.

Wu, C.H., Wu, C.F., Huang, H.W., Jao, Y.C., \& Yen, G.C. (2009). Naturally occurring flavonoids attenuate high glucose-induced expression of proinflammatory cytokines in human monocytic THP-1 cells. Mol Nutr Food Res, Vol.53, No.8, pp. 984-995.

Yang, C.M., Lee, I.T., Lin, C.C., Yang, Y.L., Luo, S.F., Kou, Y.R., \& Hsiao, L.D. (2009). Cigarette smoke extract induces COX-2 expression via a PKCalpha/c-Src/EGFR, PDGFR/PI3K/Akt/NF-kappaB pathway and p300 in tracheal smooth muscle cells. Am J Physiol Lung Cell Mol Physiol, Vol.297, No.5, pp. L892-902.

Yi Lau, G.T., \& Leung, L.K. (2010). The dietary flavonoid apigenin blocks phorbol 12myristate 13-acetate-induced COX-2 transcriptional activity in breast cell lines. Food Chem Toxicol, Vol.48, No.10, pp. 3022-3027.

Yokoshiki, H., Sumii, K., \& Sperelakis, N. (1996). Inhibition of L-type calcium current in rat ventricular cells by the tyrosine kinase inhibitor, genistein and its inactive analog, daidzein. J Mol Cell Cardiol, Vol.28, No.4, pp. 807-814.

Yu, P.L., Pu, H.F., Chen, S.Y., Wang, S.W., \& Wang, P.S. (2010). Effects of catechin, epicatechin and epigallocatechin gallate on testosterone production in rat leydig cells. J Cell Biochem, Vol.110, No.2, pp. 333-342.

Zazopoulos, E., Lalli, E., Stocco, D.M., \& Sassone-Corsi, P. (1997). DNA binding and transcriptional repression by DAX-1 blocks steroidogenesis. Nature, Vol.390, No.6657, pp. 311-315.

Zhang, P., \& Mellon, S.H. (1996). The orphan nuclear receptor steroidogenic factor-1 regulates the cyclic adenosine 3',5'-monophosphate-mediated transcriptional activation of rat cytochrome P450c17 (17 alpha-hydroxylase/c17-20 lyase). Mol Endocrinol, Vol.10, No.2, pp. 147-158.

Zhang, Z.B., \& Yang, Q.T. (2006). The testosterone mimetic properties of icariin. Asian J Androl, Vol.8, No.5, pp. 601-605. 


\title{
Role of Central Insulin-Like Growth Factor-1 Receptor Signalling in Ageing and Endocrine Regulation
}

\author{
Lorna Moll, Johanna Zemva and Markus Schubert \\ Center of Endocrinology, Diabetes and Preventive Medicine
}

Germany

\section{Introduction}

Insulin-like growth factors (IGFs) are, besides other mechanisms, controlled by growth hormone $(\mathrm{GH})$ secretion and there are at least two different IGFs: IGF-1 and IGF-2. IGFs regulate various cellular processes e.g. survival, differentiation and proliferation (McMorris et al. 1986; McMorris \& Dubois-Dalcq 1988; Mozell \& McMorris 1991).

Growth hormone, which induces IGF-1 secretion from the liver, is generated in the anterior pituitary and regulated by the hypothalamus via growth hormone releasing hormone (GHRH) and growth hormone inhibiting hormone (GHIH) (Jansson et al., 1985; Carlsson \& Jansson 1990). IGFs in the brain are synthesised de novo or transported across the blood brain barrier (BBB) and seem to induce a variety of effects on the central nervous system (CNS). So far, the exact transport mechanisms of IGFs into the brain are not fully understood (Duffy, Pardridge, and Rosenfeld 1988).

In the rodent brain, IGF-1 is mainly expressed in neuron-dense regions like the hippocampus, striatum, thalamus, hypothalamus and olfactory bulb (Rotwein et al. 1988; Bondy et al. 1990; Garcia-Segura et al. 1991). Accordingly, the insulin-like growth factor-1 receptors (IGF-1Rs) are mainly found in the olfactory bulb, cerebellar cortex and granule cell layer of the dentate gyrus (Rotwein et al. 1988; Bondy et al. 1990; Bondy and Lee 1993; Werther et al. 1990). However, the function of IGF-1R mediated signals in the central nervous system (CNS) is still under investigation.

After binding of IGF-1 to the IGF-1R, a signalling cascade is activated which leads to recruitment and subsequently phosphorylation of intracellular adaptor proteins, the so called insulin receptor substrates (IRS) (Jacobs et al. 1983; Rubin et al., 1983; Sun et al. 1991; Lavan et al. 1997; Lavan et al., 1997). Via these adaptor proteins, the MAP kinase (MAPK, mitogen activated protein kinase) cascade, as well as the phosphatidylinositide(PI)3-kinase signalling pathway, is turned on leading to protein kinase B (PKB/AKT) activation, which phosphorylates forkhead box $\mathrm{O}$ transcription factors (FoxO) causing their nuclear export (Stokoe et al. 1997; Alessi et al. 1996; Partridge \& Bruning 2008). FoxO mediated transcription is involved in cell proliferation, differentiation and oxidative stress defence (Clark et al. 1993; Brunet et al. 1999; Dijkers et al. 2000; Dijkers, Medema, Pals et al. 2000; Medema et al. 2000) suggesting a function of FoxO during development and cellular stress response. 
Recently, the function of the IGF-1R signalling pathway in neurons has been investigated using different model organisms like worms and flies as well as conventional and conditional mutagenesis in mice. These experiments revealed possible functions of IGF-1 mediated signals in endocrine regulation, longevity, protein turnover and in the pathogenesis for ageing-associated diseases e.g. Alzheimer's Disease (AD). The current article discusses the mechanisms of regulation and the physiological as well as a possible pathophysiological role of IGF-1 mediated signals in the CNS.

\section{The $\mathrm{GH} /$ insulin-like growth factor system}

\subsection{The somatotropic system}

Growth hormone (GH, somatotropin) is produced in the anterior pituitary by certain specified cells and regulated via the hypothalamus by the growth hormone releasing hormone (GHRH, somatoliberin), the growth hormone inhibiting hormone (GHIH, somatostatin), but also by suppression of the short loop negative feedback of GH itself (Jansson, Eden, and Isaksson 1985; Carlsson and Jansson 1990).

The GH-producing cells of the anterior pituitary, also called somatotropes or somatotroph, form $30-40 \%$ of the anterior pituitary (Gage et al. 1996). These cells require transcription factors of the POU-family (Mullis 2010) including the homeoproteins Pit-1 and Prop-1 (prophet of Pit-1) for normal embryonic development and differentiation (Mullis 2005) as well as for GH expression. The expression of these transcription factors and therefore the differentiation of the somatotroph are controlled by GHRH producing neurons of the hypothalamus. Additionally, GH-release in the pituitary is inhibited by serum IGF-1 and enhanced by serum ghrelin (Wortley et al. 2005; Zigman et al. 2005) (Figure 1).

In the periphery, GH mainly influences growth and development via IGF-1. IGF-1 and IGF-2 can act endocrine, paracrine and autocrine (Cohick and Clemmons 1993; Stewart and Rotwein 1996; Mohan, Baylink, and Pettis 1996; Butler and LeRoith 2001). Additionally, there is a truncated form of IGF-1, Des(1-3)IGF-1, which lacks the tripeptide Gly-Pro-Glu at the N-terminus probably resulting from post-translational cleavage of IGF-1. Des(1-3)IGF-1 is mainly expressed in brain and active in lower concentrations than un-truncated IGF-1 (Ballard et al. 1996; Francis et al. 1988; Carlsson-Skwirut et al. 1989; Ogasawara et al. 1989). Studies on hypoxic-ischemic brain injuries in rats suggest that the tripeptide fragment has neuroprotective properties and influences neuronal activity (Guan et al. 1999).

Circulating IGF-1 is mainly produced in the liver, but both IGF-1 and IGF-2 are expressed in many non-hepatic tissues (Cohick and Clemmons 1993; Stewart and Rotwein 1996; Butler and LeRoith 2001). The most important effects of IGFs are cell proliferation and differentiation, skeletal growth and mineralisation as well as the development and function of the reproductive organs and the central nervous system (CNS) (Duan and Xu 2005).

GH is secreted pulsatile in rodents as well as in humans (Jansson, Eden, and Isaksson 1985; Frohman and Jansson 1986; Giustina and Veldhuis 1998) and follows a circadian pattern with one major peak after falling asleep. There is a sexual dimorphism in GH secretion, which is more dominant in rodents than in humans (Jansson, Eden, and Isaksson 1985; Tannenbaum and Martin 1976). In females, the GH secretory pattern seems to be less regular compared to males (Giustina and Veldhuis 1998), with higher basal interpulse GH levels, more frequent but lower amplitude pulses and a lower major nocturnal GH pulse (Jaffe et al. 1998; Jessup et al. 2003). Spontaneous and GHRH-stimulated GH secretion is suppressed more efficiently by IGF-1 in men than in women (Ohlsson et al. 2009) suggesting that also 
sex steroids interfere with GH secretion (Veldhuis et al. 2008, 2009; Leung et al. 2004). Body growth is influenced more efficiently by GH if it is applicated in a pulsatile fashion than applied continuously (Jansson, Eden, and Isaksson 1985; Clark et al. 1985). This might be due to a higher induction of IGF-1 expression in growth plates and skeletal muscles by pulsatile GH, whereas continuous GH secretion stimulates liver IGF-1 expression and serum IGF-1 levels at least as well as a pulsatile GH release (Isgaard et al. 1988; Bick et al. 1992). Therefore, liver-derived IGF-1 is not essential for body growth itself. This effect might be achieved by locally produced IGF-1 and/or other factors (Ohlsson et al. 2009).

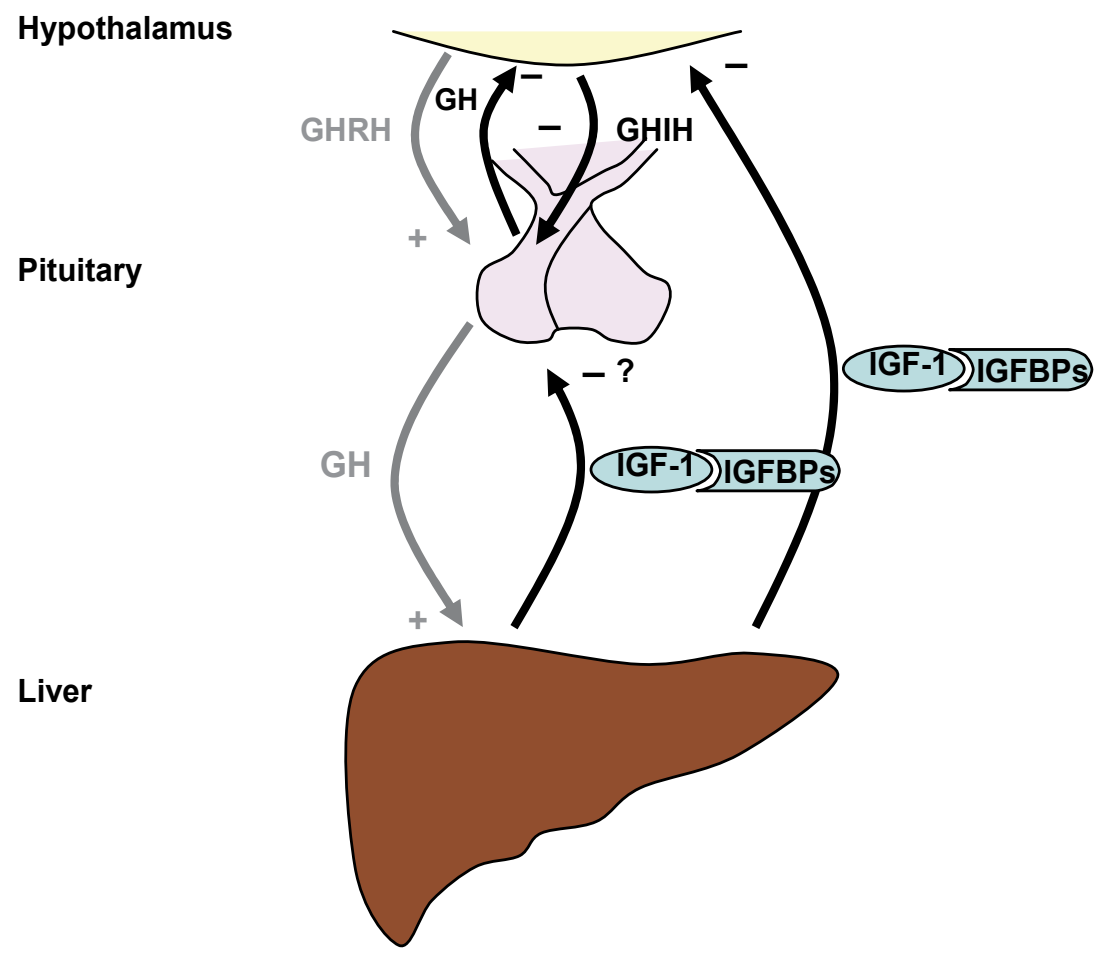

Fig. 1. GH/ IGF-1 system

Growth hormone releasing hormone (GHRH) and growth hormone inhibiting hormone $(\mathrm{GHIH})$ are produced in neurons of the hypothalamus and transported via the hypothalmopituitary portal vein system to the anterior pituitary where they regulate growth hormone (GH) secretion and expression. GH stimulates insulin-like growth factor-1 (IGF-1) production in the liver. In addition, free IGF-1 serum levels are regulated by binding to the insulin-like growth factor binding proteins (IGFBPs). A short negative feedback loop of $\mathrm{GH}$, as well as a negative feedback mechanism of IGF-1 on the hypothalamus and possibly on the anterior pituitary, determines serum IGF-1 levels.

Mouse models with tissue specific IGF-1 inactivation indicate that normal longitudinal bone growth is maintained by local bone-derived IGF-1 (Sjogren et al. 1999; Yakar et al. 1999). However, several other phenotypes, for example the one observed in the liver IGF-1 
deficient (LID) mouse, suggest that locally derived IGF-1 cannot fully replace liver-derived IGF-1 function and vice versa.

A lacking negative feedback of liver-derived IGF-1 on GH secretion leads to a compensatory increase in serum GH levels in mice (Yakar et al. 1999; Sjogren et al. 1999) and also in humans (Veldhuis et al. 2001). Hence, the phenotype of the LID mice might either arise directly or is mediated by the elevated GH-levels. LID mice show an increased expression of pituitary GHRH- and ghrelin-receptors indicating that at least some action of up-regulating GH secretion influences the pituitary (Ohlsson et al. 2009). However, the target sites of IGF-1 for regulating GH-release remain unclear and might either be located in the hypothalamus and/ or the pituitary. Recently, a cell-specific knockout mouse in which the IGF-1 receptor (IGF-1R) was ablated from the somatotroph, the so called somatotroph IGF-1 receptor knockout (SIGFRKO) mouse, has been generated (Romero et al. 2010). The phenotype of the SIGFRKO mouse includes increased GH expression and secretion as well as increased serum IGF-1 levels (Romero et al. 2010). Feedback mechanisms in the hypothalamus resulted in decreased GHRH and increased GHIH mRNA levels (Romero et al. 2010). Furthermore, decreased growth hormone releasing hormone receptor (GHRH-R) expression was observed in the anterior pituitary (Romero et al. 2010). However, these changes were not able to reduce GH secretion in the SIGFRKO mouse indicating a role of IGF-1R signalling in the pituitary in addition to the hypothalamus in regulating GH secretion (Romero et al. 2010). IGF-1 influences glucose metabolism directly, e.g. by inducing insulin-like effects on glucose-uptake in tissues expressing IGF-1-receptors, but also by suppressing the GHrelease from the pituitary. GH is known to have diabetogenic effects (Yakar et al. 2004) by decreasing insulin-sensitivity in skeletal muscle, liver and fat. Consequently, LID mice show an impaired insulin-sensitivity. At the same time, those mice are protected against the increase in body fat mass that occurs in older age (Sjogren et al. 2001; Tang et al. 2005). This might be explained by elevated GH-levels in these mice (Ohlsson et al. 2009) as decreased $\mathrm{GH}$ secretion in both rodents and humans has been proposed to contribute to age-related obesity (Sonntag et al. 1980; Rudman et al. 1990).

The inactivation of IGF-1 or its receptor during early development reduces brain size including a reduction of the granule cell layer in the dentate gyrus and the number of oligodendrocytes and myelinated axons (Beck et al. 1995; Holzenberger et al. 2001; VicarioAbejon et al. 2003) demonstrating the importance of IGF-1 signalling during brain development. LID mice show a milder phenotype with reduced exploratory activity (Svensson et al. 2005; Bohlooly et al. 2001), as well as impaired spatial learning and memory, suggesting that liver-derived IGF-1 enhances brain functions (Svensson et al. 2006). Circulating IGF-1 is essential for mediating exercise induced effects on the adult brain by promoting the numbers of newly generated neurons in the adult hippocampus, brain vessel growth, spatial learning and reducing anxiety (Trejo, Carro, and Torres-Aleman 2001; Trejo, Llorens-Martin, and Torres-Aleman 2008; Lopez-Lopez, LeRoith, and Torres-Aleman 2004). Additionally, liver-derived IGF-1 might enhance the clearance of brain amyloid- $\beta$ (A $\beta$ ), whose aggregation is one of the hallmarks of AD (see 5.1).

\subsection{IGF-binding proteins}

Only a small amount of IGF-1 ( 1 \%) circulates "free" within the blood. The remaining $99 \%$ are bound to IGF-binding proteins (IGFBPs). IGFBPs are a family of at least six proteins (IGFBP-1 to IGFBP-6), which bind IGF-1 with high affinities that are equal to or greater than 
those of the IGF-1 receptor (Duan and Xu 2005). Additionally, there are several proteins with lower IGF-1 binding affinity, called IGFBP-related peptides (IGFBP-rPs), which have significant structural homologies with the amino(N)-terminal region of high-affinity IGFBPs (Rechler 1993; Kelley et al. 1996; Rajaram, Baylink, and Mohan 1997; Kim et al. 1997; Poretsky et al. 1999; Baxter 2000). So far, the functions of the IGFBP-rPs, also referred to as IGFBP- 7 to 10, are not known (Mohan and Baylink 2002). Approximately 75-80 \% of IGF is present as a $150 \mathrm{kDa}$ complex, which consists of IGF-1/IGF-2 plus IGFBP-3 (70-75 \%) or IGFPB-5 (5-10 \%) and an acid-labile subunit (ALS) (Baxter, Meka, and Firth 2002). ALS is mainly produced in the liver (Baxter 1988; Baxter and Martin 1989; Baxter, Martin, and Beniac 1989) and its gene disruption leads to a reduction of circulating IGFs of $80 \%$ (Boisclair et al. 2001). The ternary complex of IGF-1 or -2/ IGFBP-3 or -5/ ALS extends the half-life of IGFs to 15-20 h, compared to a half-life of 20-30 min for free IGF-1 in circulation (Guler, Zapf, and Froesch 1987) suggesting a reservoir function of this complex, which cannot cross the vascular endothelial barrier (Rajaram, Baylink, and Mohan 1997; Baxter 2000). 20-25 \% of the IGFs bind to IGFBP-1,2,-4 or -6 to form a complex, which is able to cross vascular endothelium (Baxter 2000; Rajaram, Baylink, and Mohan 1997). Thus, the endocrine actions of IGF-1 in serum are regulated by the IGFBPs determining how much IGF is bio-available to the local tissues.

Furthermore, IGFBPs are located in the extracellular matrix or on the cell surface where they either inhibit (mainly IGFBP-4 and -6) or potentiate (mainly IGFBP-3 and -5) IGF-1 binding to its receptors (Rajaram, Baylink, and Mohan 1997; Mohan et al. 1995; Qin et al. 1998; Jones and Clemmons 1995; Firth and Baxter 2002; Rechler and Clemmons 1998). Functions of the IGFBPs might vary indicated by the inhibiting or potentiating effect of IGFBP-1, $-2,-3$ and -5 on IGF-1 action depending on the experimental conditions (Yin, $\mathrm{Xu}$, and Duan 2004).

The actions of IGFBPs are, in turn, modulated by IGFBP proteases that are further dependent on activators and inhibitors (Mohan et al. 2002). Those IGFBP proteases are able to cleave IGFBPs, thereby reducing their affinity for IGF-1. Some of them are relatively specific for a given IGFBP. For example, pregnancy-associated plasma protein-A (PAPP-A), which is produced by a variety of cell types, cleaves specifically IGFBP-4 (Lawrence et al. 1999; Byun et al. 2001; Conover et al. 2001), whereas complement C1s (Busby et al. 2000) and a disintigrin and metalloprotease-like (ADAM)-9 (Mohan et al. 2002) were identified to be relatively specific for IGFBP-5. Additionally, a number of other serum proteases were shown to be capable of cleaving IGFBPs, e.g. plasmin, cathepsin D and prostate specific antigen (Conover 1995; Fowlkes et al. 1995; Rajah et al. 1995; Rajaram, Baylink, and Mohan 1997; Maile and Holly 1999). Therefore, the binding affinity and hence the bio-availability of IGF-1 is regulated via the degradation of IGFBPs through the IGFBP protease system.

IGFBPs also have IGF independent functions, for example IGFBP-2 and -3 can induce direct cellular effects (Firth and Baxter 2002; Oh et al. 1993; Yamanaka et al. 1999; Schutt et al. 2004) and it has been shown that IGFBP-3 at least partially mediates these effects by binding to the cell surface, possibly to specific receptors (Mohseni-Zadeh and Binoux 1997; Rechler and Clemmons 1998). IGFBP-2, -3 and -5 contain sequences for nuclear localisation (Schutt et al. 2004; Radulescu 1994; Schedlich et al. 1998; Hoeflich et al. 2004) and might as well influence gene expression.

\subsection{The insulin- and insulin-like growth factor-1 signalling pathway}

Insulin and IGF-1 receptors are receptor tyrosine kinases. Receptor tyrosine kinases contain a membrane-bound domain with tyrosine kinase activity which phosphorylates tyrosineresidues of downstream signalling proteins. Typical members of the receptor tyrosine kinase 
family are the epidermal growth factor receptor (EGFR), the nerve growth factor receptor (NGFR) and the insulin receptor (IR). The IR was discovered in 1974 and its tyrosine kinase was found in 1982 (Kasuga, Karlsson, and Kahn 1982; Kasuga et al. 1982). Later, in addition to the IR, the insulin-like growth factor-1 receptor (IGF-1R) was discovered as a tyrosine kinase activity containing receptor (Jacobs et al. 1983; Rubin, Shia, and Pilch 1983).

The IR and IGF-1R are heterotetrameric structures. The different subunits are linked by disulfide bonds. The a-subunits are exclusively localised extracellular (Van Obberghen et al. 1981; Ullrich et al. 1986). The $\beta$-subunits consist of a short extracellular part, a transmembrane domain and an intracellular part with ATP-binding motifs, autophosphorylation sites and tyrosine-specific protein kinase activity, which is activated after binding of insulin or IGF-1 to their receptors (Chou et al. 1987).

The insulin receptor gene consists of 22 exons and 21 introns (Seino et al. 1989). Alternative splicing of exon 11, which codes for 12 amino acids, causes two different isoforms: A, which lacks the 12 amino acids, and B. This alternative splicing does not exist for the IGF-1 receptor, because this receptor contains no equivalent to exon 11 of the IR. The A- and Bisoforms both bind to insulin with similar affinity (McClain 1991). The A-isoform has a higher affinity to IGF-1 (Yamaguchi et al. 1991) and IGF-2 (Frasca et al. 1999) compared to the B-isoform. The A-isoform is expressed in hematopoietic cells, fetal tissue and the adult nervous system. The B-isoform of the IR is mainly present in liver, adipose tissue and muscle (Seino and Bell 1989; Moller et al. 1989; Goldstein and Kahn 1989; Mosthaf et al. 1990). The selective binding of insulin or IGF-1 is also dependent on the assembly of the receptors (Pandini et al. 2002). The hybrid of IGF-1 receptor and the A-isoform of the IR binds IGF-1, IGF-2 and insulin with similar affinity. The hybrid of the IGF-1R and the Bisoform of the IR only binds IGF-1 (Louvi, Accili, and Efstratiadis 1997).

\subsubsection{Insulin receptor substrates}

The binding of IGF-1 or IGF-2 to the IGF-1R causes a conformational change of the receptor, which induces autophosphorylation. This leads to the recruitment of insulin receptor substrates (IRS) to the autophosphorylated receptor tyrosine kinase, which in turn phosphorylates the tyrosine residues of the IRS proteins (Figure 2). The IRS protein family consists at least of four proteins, IRS-1 to IRS-4 (Sun et al. 1991; Lavan et al. 1997; Lavan, Lane, and Lienhard 1997).

The IRS proteins show different expression patterns. IRS-1 and -2 are ubiquitously expressed, but IRS-3 is only present in rodent adipose tissue. IRS-4 mainly occurs in thymus, hypothalamus, kidney and heart. All IRS proteins share the same structural characteristics and have similar functions (Giovannone et al. 2000; Schubert et al. 2003).

The four IRS family members contain an N-terminal pleckstrin homology (PH) domain, a phosphotyrosine-binding (PTB) domain and a C-terminal tail containing multiple tyrosine phosphorylation sites. The phosphotyrosine motifes of the IRS proteins are binding sites for Src homology(SH)2 domain-containing proteins (Yenush and White 1997). The PH domain binds to lipids and with high affinity to phosphoinositides (Fruman, Rameh, and Cantley 1999). The PTB domain of IRS binds to phosphotyrosine residues of other proteins including the IR and IGF-1R. In more detail, the PTB domain binds to the phosphorylated NPXP motif at the juxtamembrane domain of the receptor after binding of insulin or IGF-1. Following binding to this motif, the IRS proteins are tyrosinephosphorylated (Cheatham and Kahn 1995; White 2002). 
Only IRS-2 contains a domain which binds to the phosphorylated kinase regulatory loop of the $\beta$-subunit of the IR. This domain is called the KLRB domain (Sawka-Verhelle et al. 1997; Sawka-Verhelle et al. 1996). However, the physiological function of the KLRB domain of IRS-2 remains unclear.

Insulin induces tyrosine and serine phosphorylation of IRS-1 (Gual, Le Marchand-Brustel, and Tanti 2005). These phosphorylations lead to specific regulation of downstream signalling. The phosphorylation of serine residues of IRS-1 contribute to positive or negative regulation of IRS-1 action (Weigert et al. 2005; Weigert et al. 2008). Important for this regulation are the particular phosphorylation sites (Herschkovitz et al. 2007) as well as the timing of phosphorylation (Weigert et al. 2005; Weigert et al. 2008). Currently, the serine phosphorylation sites with positive effect on IRS-1 action are regarded to be phosphorylated at first to support IRS-1 activity protecting from phosphorylation at residues with inhibitory effect (Weigert et al. 2005; Weigert et al. 2008; Gual, Le Marchand-Brustel, and Tanti 2005; Luo et al. 2007). In addition, serine phosphorylation with activating effect might prevent the association of IRS-1 with tyrosine phosphatases (Luo et al. 2005). The serine residues with inhibitory effect are located near the PTB domain. These residues are phosphorylated later than the residues with positive effect upon insulin stimulation or other signals. The phosphorylation of serine sites near the PTB domain causes disruption of the binding between IRS-1 and the IR followed by degradation of IRS-1. The phosphorylation of inhibitory serine residues in the C-terminus of IRS-1 disturb their interaction with the phosphatidylinositide (PI)3-kinase (Figure 2) (Gual, Le Marchand-Brustel, and Tanti 2005; Boura-Halfon and Zick 2009). Serine sites with inhibitory effect are phosphorylated by serine kinases like the mammalian target of rapamycin (mTor), PKCzeta and p70S6 (S6K) kinase (Boura-Halfon and Zick 2009; Herschkovitz et al. 2007; Gual et al. 2003). Insulin and IGF-1 resistance might be induced via kinases like c-Jun N-terminal kinase (JNK), mTor/S6K, inhibotory-kB kinase $\beta$ (IKK $\beta$ ), SIK-2 and extracellular signal regulated kinases (ERK) promoting the phosphorylation of the inhibitory sites of the IRS proteins (BouraHalfon and Zick 2009; Herschkovitz et al. 2007). The IRS-2 serine phosphorylation sites are still under investigation. It is known that JNK phosphorylates Thr348 of IRS-2 which is located near the PTB domain (Solinas et al. 2006) and might cause disruption of the binding between IRS-2 and the receptor. Furthermore, JNK phosphorylates Ser488 of IRS-2 promoting the phosphorylation at Ser484 by glycogen synthase kinase (GSK)-3 $\beta$ and thereby inhibiting the signalling pathway (Sharfi and Eldar-Finkelman 2008).

\subsubsection{PI3K signalling}

The mammalian phosphatidylinositide(PI)3-kinases are subdivided into three classes, class I-III. Class I is further divided into Ia and Ib (Vanhaesebroeck et al. 2005). These classes catalyse the phosphorylation of the 3'hydroxyl position of phosphatidyl-myo-inositol lipids. The PI3K of the insulin and IGF-1 signalling pathway belongs to the class Ia kinases (Fruman, Meyers, and Cantley 1998). These kinases display a heterodimeric structure containing a catalytic subunit of $110 \mathrm{kDa}$. This subunit is non-covalently associated with a $50-, 55-$ or $85 \mathrm{kDa}$ regulatory subunit. Following activation of the insulin receptor and IRS binding, the PI3K is recruited to the membrane via the p85 regulatory subunit. Other recruited factors are the growth factor receptor binding protein (GRB)-2 and the SH2Phosphatase(SHP)2 (Figure 2).

The activated $\mathrm{PI} 3 \mathrm{~K}$, in turn, phosphorylates phosphatidylinositide-diphosphate $\left(\mathrm{PI}_{4,5} \mathrm{P}\right)$ to produce phosphatidylinositide-triphosphate $\left(\mathrm{PI}_{3,4,5} \mathrm{P}\right)$. This event is reversible by PTEN (the 
phosphatase and tensin homolog deleted on chromosome ten). The generation of $\mathrm{PI}_{3,4,5} \mathrm{P}$ causes activation of the downstream signalling proteins like phosphoinositide-dependent protein kinase (PDK) and protein kinase $\mathrm{B}(\mathrm{PKB}, \mathrm{AKT})$. PDK is present in two isoforms, PDK-1 and PDK-2. PDK-1 phosphorylates AKT at Thr308, which partially activates AKT. To completely activate AKT, phosphorylation of Ser473 is necessary (Alessi et al. 1996; Lawlor and Alessi 2001; Stokoe et al. 1997). AKT is a serine/threonine kinase with a size of $57 \mathrm{kDa}$. It contains a PH domain and there are three isoformes, AKT-1, AKT-2 and AKT-3. These isoforms display a conserved domain structure: a kinase domain, a $\mathrm{PH}$-domain at the $\mathrm{N}$ - as well as a regulatory subunit at the C-terminus (Hresko, Murata, and Mueckler 2003). AKT phosphorylates tuberin 2 (TSC-2). TSC-1 and -2 form a heterodimer with GTPase activity that inhibits the GTPase RHEB (RAS homolog enriched in brain). The phosphorylation via AKT causes the accumulation of the RHEB-GTP complex which activates mTOR (Astrinidis and Henske 2005; Hay and Sonenberg 2004). Furthermore, S6K is activated by phosphorylation of PDK-1 and mTOR (Figure 2). The regulation of protein synthesis via IGF-1 occurs through controlling the intrinsic activity and/or binding properties of specific translation initiation and elongation factors called eIFs and eEFs. mTOR phosphorylates 4EBP (4E binding protein). This causes the release of eIF4E (eukaryotic initiation factor 4E) to form an active complex, which promotes translation initiation and also activation of S6K. S6K phosphorylates the eEF2 (eukaryotic elongation factor 2) kinase which releases eEF2 and initiates elongation (Figure 2) (Nojima et al. 2003; Oshiro et al. 2004).

Other proteins, which are regulated via IR and IGF-1R signalling, are the glycogen synthase kinase(GSK)-3 $\beta$, a major tau kinase, and BAD (Bcl-2/Bcl-X-associated death promoter), a proapoptotic factor. These proteins are inactivated via the IR/IGF-1R signalling cascade (Song, Ouyang, and Bao 2005). BAD interacts with the apoptosis suppressors Bcl-2 and more intense with Bcl- $\mathrm{X}_{\mathrm{L}}$ (Yang et al. 1995). BAD directly binds to Bcl- $\mathrm{X}_{\mathrm{L}}$ with its $\mathrm{BH} 3$ homology domain (Zha et al. 1997). This interaction is regulated by the phosphorylation state of BAD. Therefore, the IGF-1R signalling is a potent inhibitor of neuronal apoptosis (Schubert et al. 2003).

\subsubsection{Forkhead box $\mathrm{O}$ transcription factor}

AKT phosphorylates the Forkhead box $\mathrm{O}$ transcription factors (FoxOs). This induces the binding to 14-3-3 and nuclear exclusion of FoxOs and thereby inactivation of FoxOmediated transcription. FoxOs regulate transcription of genes, which are involved in apoptosis, metabolism, growth, ageing and development (Partridge and Bruning 2008).

The mammalian FoxO protein family consists of 4 members: FoxO1, FoxO3a, FoxO4 and FoxO6. These transcription factors contain a conserved DNA binding domain, the forkhead domain (FKHR) (Clark et al. 1993). FoxO1 and FoxO3a are ubiquitously expressed, whereas FoxO6 is exclusively found in the brain, and FoxO4 has yet not been detected in the brain (Furuyama et al. 2000; Jacobs et al. 2003). The expression pattern of the different FoxOs in the adult mouse brain is distinct. FoxO1 is predominantly expressed in the striatum, dentate gyrus and ventral hippocampus and FoxO3a in the cortex, cerebellum and hippocampus. FoxO6 is expressed in amygdala, hippocampus and cingulite cortex (Hoekman et al. 2006).

The FoxO transription factors are regulated by post-translational modifications. One major modification is the phosphorylation of the FoxOs. FoxO1 is phosphorylated by AKT at Thr24, Ser256 and Ser319 (Biggs et al. 1999; Brunet et al. 1999; Kops et al. 1999; Rena et al. 1999; Tang et al. 1999). Phosphorylation triggers binding to 14-3-3 and subsequently 
translocation out of the nucleus terminating FoxO mediated transcription (Figure 2) (Brunet et al. 1999). Additionally, FoxOs are phosphorylated by other kinases depending on the stimulus (Huang and Tindall 2007). Furthermore, FoxOs are regulated by ubiquitylation. Ubiquitylation is dependent on phosphorylation of Ser256 of FoxO1 via AKT (Huang et al. 2005). FoxO1 and FoxO3a need to be polyubiquitylated for degradation. In contrast, FoxO4 requires monoubiquitylation to be degraded (van der Horst et al. 2006). Another regulatory mechanism for FoxO transcription is acetylation. CBP and p300 with their associated proteins, for example CBP- and p300-associated factor (PCAF), display intrinsic histone acetyl-transferase activity. These proteins promote transcription via histone acetylation and they directly regulate transcription via acetylation of particular transcription factors ( $\mathrm{Li}$ et al. 2002). It has been shown that CBP acetylates FoxO transcription factors and inhibits their action (Daitoku et al. 2004). Silent information regulator 1 (SIRT1) is a nicotinamide adenine dinucleotide(NAD)-dependent histone deacetylase, which forms a complex with acetylated FoxOs upon stress stimuli and deacetylates the transcription factors (Brunet et al. 2004; Kitamura et al. 2005) to regulate FoxO mediated transcription.

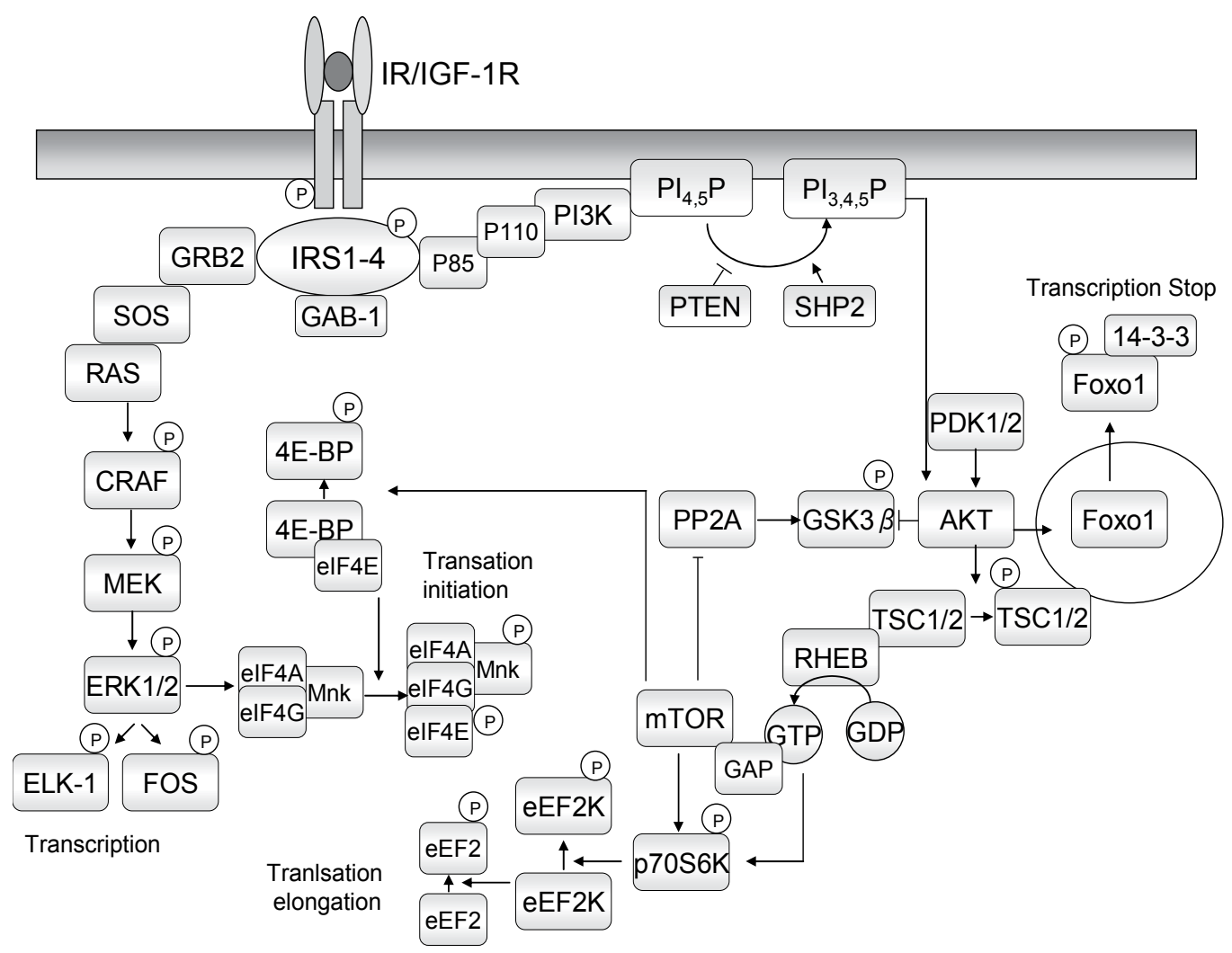

Fig. 2. IR/IGF-R signalling

The binding of Insulin or IGF-1 to the IR/IGF-1R causes autophosphorylation and activation of the receptor. Insulin receptor substrates (1-4) are recruited to the activated receptor and IRS phosphorylation results in activation of the MAP kinase (MAPK, mitogen activated protein kinase) and phosphatidylinositide(PI)3-kinase (PI3K) pathway. 


\section{IGF-1 signalling in the brain}

\subsection{IGF-1's transport across the blood brain barrier}

In the brain, present IGFs arise either by de novo synthesis or by transport from the blood into the brain. So far, the exact mechanisms of how IGFs cross the blood-brain barrier (BBB) are not fully understood. Early in vitro studies by Duffy and colleagues on isolated human brain capillaries showed that the affinity of IGF-2 to isolated human brain capillaries was approximately twofold higher than the affinity of IGF-1 binding and binding of both IGFs was nonsaturable over the range of 1 to $200 \mathrm{ng} / \mathrm{ml}$ IGF suggesting that there is a very efficient endocytosis mechanism (Duffy, Pardridge, and Rosenfeld 1988). Insulin displaced binding of IGF-1 (50\% inhibited by $2 \mu \mathrm{g} / \mathrm{ml}$ Insulin) and IGF-2 ( $50 \%$ inhibited by $0,5 \mu \mathrm{g} / \mathrm{ml}$ Insulin). Furthermore, binding was largely inhibited by adding human serum, which was assumed to be due to the presence of IGFBPs (Duffy, Pardridge, and Rosenfeld 1988). Subsequent studies suggested that there might be a high capacity transport system across the BBB, which is influenced by the IGFBPs (Pan and Kastin 2000). Tores-Aleman and coworkers found that via the choroid plexus epithelium, circulating IGF-1 is transported into the CSF through a mechanism involving the multicargo protein tranporter low-density lipoprotein receptor related protein 2 (LRP2), and concluded that increasing levels of IGF-1 in the CSF, as a result of increasing IGF-1 levels in the serum, might be explained via this transport mechanism (Carro et al. 2000; Carro et al. 2005). LRP1, another membrane cargotransporter, was suggested as targeting platform for the circulating IGF-1/IGFBP-3/ALScomplex (Nishijima et al. 2010). LRP1 is abundantly expressed in brain endothelium and seems to be a cellular receptor for IGFBP-3 (Huang et al. 2003). Recently, it has been demonstrated that neuronal activity increases the permeability of the BBB for IGF-1 through neurovascular coupling (Nishijima et al. 2010). Therefore, serum IGF-1 might influence brain processes like synaptic plasticity and cognition. Furthermore, neurovascular coupling was proposed to locally change cerebral blood flow leading to activation of matrix metalloprotease 9 (MMP9) through diverse mediators (arachdonic acid derivates, ATP, etc.). MMP9 is an IGFBP-3 cleaving protease, which is released in response to neuronal activity (Michaluk and Kaczmarek 2007) and might link neuronal activation to the transport of serum IGF-1 via a LRP1 depending mechanism across the BBB (Nishijima et al. 2010). Hence, neurovascular coupling might result in neurotrophic coupling explaining the neuroprotective effects of physical as well as mental exercise and active social life on brain function (Carro et al. 2000; Fratiglioni, Paillard-Borg, and Winblad 2004).

\subsection{Brain IGF receptors}

IGF-1 and to less extend IGF-2 bind and therefore activate the type 1 IGF-receptor (IGF-1R) (Rubin and Baserga 1995; White and Kahn 1994; LeRoith 2000). Several IGF-1R subtypes have been reported, for example the hybrid IGF-1Rs, which are hybrid dimers of the insulinreceptor (IR) and the IGF-1R (see 2.3) binding insulin as well as IGFs with similar affinity (Soos and Siddle 1989; Soos et al. 1990; Siddle et al. 1994; Moxham, Duronio, and Jacobs 1989; Pandini et al. 2002). The physiological significance of these receptor subtypes is still unclear (Russo et al. 2005).

Additionally, there is a type 2 IGF-receptor (IGF-2R) with a short cytoplasmic domain lacking a tyrosine kinase harbouring a higher affinity for IGF-2 than the IGF-1R (Sakano et al. 1991; Oh et al. 1991; Dore, Kar, and Quirion 1997; Braulke 1999; Kiess et al. 1994). This IGF-2R is a cation-independent mannose-6 phosphate (M6P) receptor binding not only IGF- 
2 but M6P-containing ligands. This receptor functions in the mediation of endocytosis and lysosomal enzyme trafficking and regulation of apoptotic/ mitogenic effects (Morgan et al. 1987; von Figura and Hasilik 1986; Ghahary et al. 2000). Recent studies have demonstrated that IGF-2 influences memory enhancement via the IGF-2R suggesting that the IGF-2R might transmit some intracellular signalling (Chen et al. 2011).

\subsection{IGF receptor expression in the brain}

IGF-1R mRNA is widely expressed in the developing CNS and persists at high levels in the mature brain especially in neuron-rich regions such as the olfactory bulb, the granule cell layer of the dentate gyrus and cerebellar cortex (Rotwein et al. 1988; Bondy et al. 1990; Bondy and Lee 1993; Werther et al. 1990). Glia cells have a lower IGF-1R expression than neurons and therefore regions mainly containing those cells, like white matter zones, show low IGF-1R mRNA levels (Bondy and Lee 1993). Some neurons, which are still in the process of developing, express increasing IGF-1R mRNA levels postnatal until they have reached maturity, for example Purkinje cells (Bondy et al. 1992). In the adult brain, high expression levels of IGF-1R mRNA are also found in the choroid plexus, meninges and vascular sheaths (Bondy et al. 1992; Bohannon et al. 1988; Werther et al. 1989; Matsuo et al. 1989; Marks, Porte, and Baskin 1991).

The IGF-2R is abundantly expressed in the CNS, especially in the pyramidal cell layers of the hippocampus, the granule cell layer of the dentate gyrus, olfactory bulbus, choroid plexus as well as in the microvasculature, retina, pituitary, brainstem and spinal cord (Hawkes and Kar 2004; Couce, Weatherington, and McGinty 1992; Wilczak et al. 2000; Valentino, Ocrant, and Rosenfeld 1990).

In addition to the IGF-1R and the IGF-2R, IR and IGF-1R hybrids are expressed in the brain, through which IGFs and insulin induce intracellular signalling. IRs are mainly expressed in regions that are linked to olfaction, appetite and autonomic functions, such as the olfactory bulb, limbic system and hypothalamus (Werther et al. 1987; Unger, Livingston, and Moss 1991) and seem to play a key-role in controlling feeding, body weight and reproduction (Bruning et al. 2000). Furthermore, IR expression is also present in remarkable concentration in the choroid plexus, circumventricular organs and brain microvessels (van Houten and Posner 1979, 1981; Werther et al. 1987) suggesting the IRs might contribute to the transport of insulin and possibly IGF-1 across the BBB.

\section{IGF-1 action in the developing brain}

\subsection{Brain growth and myelination}

Different mouse models indicated the essential actions of IGF-1 signalling for normal brain development. Homozygous IGF-1 knockout mice (IGF-1-/-), homozygous IGF-2 knockout mice (IGF-2 $/$ ) as well as doubly deficient mutants are viable but have small brains (Beck et al. 1995; Liu et al. 1993). The majority of homozygous IGF-1\%- mice die perinatally and those which survive $(<5 \%)$ demonstrate severe growth retardation with reduction in brain weight of $38 \%$ distributed evenly over all major brain areas (Beck et al. 1995). However, certain cell-types and brain-regions were especially affected by the IGF-1 gene disruption such as white matter, striatum and hippocampus (Beck et al. 1995). The reduction of white matter was due to a net loss of axons and an additional shift from myelinated to unmyelintated fibres indicating the role of IGF-1 in axonal growth and/or maturation and its effect on the amount of oligodendrocytes and axon-myelination (Beck et al. 1995). These findings are in line with many in vitro studies, which demonstrated a stimulating effect of 
IGF-1 on oligodendrocyte survival, development and proliferation (McMorris et al. 1986; McMorris and Dubois-Dalcq 1988; Mozell and McMorris 1991). In addition, formation of hippocampal granule cells and striatal parvalbumin-containing neurons was reduced in IGF-1/- mice and therefore seems to require IGF-1 (Beck et al. 1995). Most dentate granule neurons as well as the myelination of axons are generated during postnatal development (Altman and Bayer 1990, 1990; Morell et al. 1972; Matthieu, Widmer, and Herschkowitz 1973) suggesting that IGF-1 plays a more important role during late embryonic and postnatal development. Intrauterine development was analysed in detail in single and combined homozygous knockout mice for IGF-1 and IGF-2 suggesting that before E13.5 the IGF-1R exclusively mediates IGF-2 actions and later, with increasing IGF-1 expression, the IGF-1R interacts with both IGFs (Baker et al. 1993). IGF-2 was found to be upregultaed in IGF-1 $\%$ mice suggesting that IGF-2 may partially compensate for the loss of IGF-1 expression and function (Ye et al. 2002).

Homozygous IGF-1R knockout mice (IGF-1R-/-) die at birth and have smaller brains (Liu et al. 1993). A similar growth retardation of the CNS was observed in transgenic mice overexpressing human IGFBP-1 (hIGFBP-1) suggesting reduced IGF-1 action via IGF-1Rs (D'Ercole et al. 1994). Conversely, transgenic mice overexpressing human IGF-1 (hIGF-1) show increased brain growth and myelination (Carson et al. 1993; Ye, Carson, and D'Ercole 1995). In both mouse models, the transgenic hIGFBP-1 and hIGF-1 mouse, the cerebral cortex, hippocampus and diencephalon were the most affected brain regions (Ye, Carson, and D'Ercole 1995). Myelination was increased in hIGF-1 and reduced in hIGFBP-1 transgenic mice as well as the number of oligodendrocytes and the expression of myelinspecific proteins, respectively (Ye, Carson, and D'Ercole 1995). During development, the increase of myelin protein expression in the cerebral cortex of hIGF-1 transgenic mice correlates with the hIGF-1 transgene mRNA levels (Ye, Carson, and D'Ercole 1995). In conclusion, IGF-1 plays a crucial role in regulating neuronal growth and differentiation (Werther et al. 1998), but also enhances oligodendrocyte survival and myelination (Beck et al. 1995).

Several studies suggested that transcriptional programs control the development of axons or dendrites including their growth and branching (Jan and Jan 2003; Goldberg 2004; Polleux, Ince-Dunn, and Ghosh 2007). Recently, the role of FoxO-transcription factors, major downstream-targets of IIS (Insulin/IGF-1 signalling pathway), within the developing brain and their action of conducting IGF-1 signalling started to become clearer. FoxO proteins were found to be key-regulators of neuronal polarity in the mammalian brain and to trigger differentiation from immature neurons to post-mitotic neurons with specified axon- and dendrite-formations (de la Torre-Ubieta et al. 2010). In addition, protein kinase Pak1 was identified as direct target of FoxO-transcription factors linking FoxO-dependent transcription in the nucleus to an enzyme that promotes axonal polarity by controlling actin and microtubule dynamics (Edwards et al. 1999; Wittmann, Bokoch, and Waterman-Storer 2004) as well as dendritic spine morphogenesis and synapse differentiation (Hayashi et al. 2004; Hayashi et al. 2007; Nikolic 2008). Apart from Pak1, FoxO knockdown neurons demonstrated a number of downregulated polarity genes, such as Par6, R-Ras, APC and CRMP2 (de la Torre-Ubieta et al. 2010). Additionally, FoxO3a was shown to regulate homeostasis of neuronal stem cells (NSCs) both in vitro and in vivo by controlling a set of genes that determines cell cycle re-entry and optimal oxygen and glucose metabolism (Renault et al. 2009). However, the effect of FoxO3a deficiency in NSCs only became apparent in adult animals, as NSCs were shown to influence learning, memory and mood 
(Zhang et al. 2008). Therefore, NSC homeostasis regulated by FoxO3a might influence the decline of cognitive function and possibly the onset of neurodegenerative diseases (de la Torre-Ubieta et al. 2010).

\subsection{Neuroendocrine regulation}

Embryonic brain IGF-1R and therefore the action of the IGF-1 pathway in the developing brain was found to play a crucial role in determining somatotrophic plasticity and hence postnatal GH and IGF-1 signalling. These observations were made in a brain specific IGF-1R knockout mouse model (bIGF-1RKO-/; bIGF-1RKO ${ }^{+-}$) by the group of Holzenberger (Kappeler et al. 2008). Whereas homozygous mutants (bIGF-1RKO-/-) showed severe growth retardation and were infertile, heterozygous mutants (bIGF-1RKO ${ }^{+/-}$) were healthy and had an increased mean lifespan compared to controls (Kappeler et al. 2008). In bIGF-1RKO ${ }^{+/-}$ mutants, serum IGF-1 and GH were lowered and pituitaries, like most other organs, were smaller compared to controls (Kappeler et al. 2008). As IGF-1Rs are only diminished in the brain but not in the anterior pituitary in this mouse model, the observed phenotype was proposed to result from alterations in GH-regulatory neurons of the hypothalamus. Hypothalamic GHRH expression was found to be significantly lower, as well as the Pit-1 mRNA levels. bIGF-1RKO ${ }^{+/-}$mice had preserved gonado- and thyrotropic functions but were growth retarded with a body length $5 \%$ shorter than controls and a body weight of about $90 \%$ of controls at the age of 90 days (Kappeler et al. 2008). Interestingly, weight gain with age was slightly higher in adult bIGF-1RKO+/- mice than in controls, and female mutants finally reached the same body weight than controls (Kappeler et al. 2008). The gain of weight was most probably due to an enlargement of subcutaneous adipose tissue (AT), as there was less or no increase in visceral AT (Kappeler et al. 2008). In line with GH-deficient mouse models (Berryman et al. 2004; Berryman et al. 2006), the bIGF-1RKO+/- mice showed impaired glucose homeostasis and fat metabolism. Heterozygous inactivation of IGF-1R had no detectable effects on behaviour or other brain functions apart from the somatotrophic deficit. Compared to control littermates, bIGF-1RKO ${ }^{+/-}$mice had a significantly longer mean lifespan. However maximum lifespan was unchanged probably due to increased late-life mortality caused by hyperglycemia and dyslipidemia (Kappeler et al. 2008). Early dietary restriction showed a similar neuroendocrine response as the brain specific IGF-1R knockout (Kappeler et al. 2008), indicating a connection between nutrition, somatotrophic hormones, growth and their determination of lifespan.

Similar observations, in which morbidity in later life was determined during prenatal development, were made in humans. Long-term studies have been conducted on the Dutch famine birth cohort as well as on the Chinese famine cohort. Babies exposed in utero to calory restriction in late or mid gestation were growth retarded and showed impaired glucose tolerance in later life (Ravelli et al. 1998; Painter, Roseboom, and Bleker 2005). However, babies exposed in early gestation were not smaller than controls but demonstrated the most striking consequences of in utero undernutrition, namely a threefold increase in coronary heart disease, hyper-/dyslipidemia and more frequent obesity (Painter, Roseboom, and Bleker 2005; Ravelli et al. 1999; Roseboom, van der Meulen, Osmond, Barker, Ravelli, Schroeder-Tanka et al. 2000; Roseboom, van der Meulen, Osmond, Barker, Ravelli, and Bleker 2000). Interestingly, mortality rates at older (50+) ages are significantly higher in the exposed group, and residual life expectancy at age of 50 was reduced by approximately 3 years (Lindeboom, Portrait, and van den Berg 2010), which is in line with the increased late-life mortality observed in the bIGF-1R+/- mice. In the cohort of 
the Chinese famine, fetal and infant exposure to undernutrition also resulted in increased risk for metabolic syndrome (Li et al. 2010; Li et al. 2011; Yang et al. 2008; Luo et al. 2006). In summary, IGF-1 signalling during early development is defined by the number of brain IGF-1Rs or their sensitivity and determines endocrine as well as metabolic function in later life possibly playing a key-role in pathogenesis of age-associated diseases.

\begin{tabular}{|c|c|}
\hline $\begin{array}{l}\text { IGF-1 function in the developing } \\
\text { brain }\end{array}$ & IGF-1 function in the adult brain \\
\hline $\begin{array}{ll}\text { - } & \text { growth and differentiation } \\
\text { of neurons } \\
\text { - } & \text { neuronal polarity and } \\
\text { - } & \text { gynapse formation } \\
\text { growth of } \\
\text { oligodendrocytes } \\
\text { - } \quad \text { enhancement of myelination } \\
\text { - } \\
\text { neuroendocrine regulation of } \\
\text { metabolism }\end{array}$ & $\begin{array}{ll}\text { - } & \text { preservation of neuronal } \\
\text { plasticity, for example in the } \\
\text { olfactory bulb } \\
\text { - } \quad \text { brain vessel growth } \\
\text { - } \\
\text { spatial learning and other } \\
\text { cognitive functions } \\
\text { neuroprotecetive in ischemic or } \\
\text { traumatic injuries and several } \\
\text { neurological disorders } \\
\text { reduced signalling extends } \\
\text { lifespan }\end{array}$ \\
\hline
\end{tabular}

Table 1. Function of IGF-1 in the brain

\section{IGF-1 in Alzheimer's disease}

Alzheimer's disease (AD) is a chronic and progressiv neurodegenerative disease and the most common form of dementia leading to the loss of cognitive abilities and finally to death (Citron 2002; Cole et al. 2007).

AD was first described by Alois Alzheimer, a German physician, in 1906 (Alzheimer et al. 1995). The disease is characterised by $\beta$-amyloid accumulation, formation of extracellular amyloid plaques as well as neurofibrillary tangles. The $\beta$-amyloid plaques mainly contain aggregated amyloid- $\beta$ (A $\beta$ ) peptides (Masters et al. 1985). In contrast, the main components of neurofibrillary tangles are hyperphosphorylated and aggregated tau proteins (Ross et al., 2005). The aggregation of $A \beta$ is thought to be the molecular basis of neurodegenration in $A D$ (Masters et al. 1985).

\subsection{Tau}

The tau proteins consist of a N-terminal projection domain, a short tail sequence and a Cterminal domain with microtubule-binding (MTB) repeats. Six isoforms of tau are known in the human brain. These isoforms emerge from alternative splicing of exons 2, 3 and 10. Exon 2 and 3 encode $\mathrm{N}$-terminal parts of tau and exon 10 codes for an additional MTB repeat. Thus, tau can present three or four MTB repeats (Ballatore, Lee, and Trojanowski 2007; Goedert and Spillantini 2006). Tau is predominantly located in the axons of neurons (Hirokawa et al. 1996) and is to less extend found in dendrites (Ittner et al. 2010). The function of tau is yet not completely understood, but it might influence the stabilisation of microtubules and regulation of axonal transport (Gotz, Ittner, and Kins 2006). Tau is phosporylated at several sites via kinases like glycogen synthase kinase 3 (GSK-3 $\beta$ ), cyclin-dependent kinase 5 (Cdk5), c-Jun N- 
terminal kinase (JNK) and ERK1/2 (Robertson et al. 1993; Hanger et al. 1992; Flaherty et al. 2000; Cho and Johnson 2004; Stoothoff and Johnson 2005). Abnormal high phosphorylation is called "hyperphosphorylation". Hyperphosphorylated tau proteins form so called paired helical filaments, which are characteristic for AD. The degradation of tau is inhibited by phosphorylation at the caspase cleavage sites. It has been shown that the mutation of Ser422, which causes a stable phosphorylation at this site, prevents caspase cleavage (GuillozetBongaarts et al. 2006). GSK-3 $\beta$ is one of the major tau kinases and is inactivated upon phosphorylation of Akt at Ser9 connecting insulin and IGF-1 signalling to tau phosphorylation. The major tau phosphatase in human brain is PP2A (Sontag et al. 1996), which is as well regulated via the IR/IGF-1R pathway suggesting that IR/IGF-1R signalling maintains an equilibrium of phosphorylation and dephosphorylation of tau (Liu et al. 2008; Millward, Zolnierowicz, and Hemmings 1999).

\subsection{Amyloid- $\beta$}

$\mathrm{A} \beta$ is generated by proteolytic cleavage of the amyloid precursor protein (APP), a type-1 integral membrane protein. APP was first described and cloned in 1987 (Kang et al. 1987; Tanzi et al. 1987; Goldgaber et al. 1987; Robakis et al. 1987). The APP gene is located on chromosome 21. Hence, patients with trisomy 21 show a higher risk to develop Alzheimer's disease, because of the additional APP allele. Accordingly, the duplication of the isolated APP gene causes cerebral amyloid angiopathy and amyloidosis suggesting that increased APP expression itself is sufficient to cause Alzheimer-like pathology (Rovelet-Lecrux et al. 2006; Sleegers et al. 2006). Another risk factor for AD are mutations of the APP gene (Vassar 2004; Bertram and Tanzi 2005). APP contains a N-terminal extracellular domain and a shorter C-terminal cytoplasmic domain. Alternative splicing of the APP gene results in different isoforms of APP which are distinguishable by length. APP with 751 and 770 (APP751 and APP770) amino acids mainly occur in non-neuronal tissue. APP695 is mainly localised in neurons (Kang and Muller-Hill 1990). The function of APP and the APP-like proteins (APLP) is not clear yet. These proteins are possibly involved in cell adhesion, apoptosis and axonal transport.

The $\beta$-secretase BACE1 ( $\beta$-site APP-cleaving enzyme) plays an essential role in the production of $\mathrm{A} \beta$. It cleaves $\mathrm{APP}$ at $\mathrm{Asp}^{+1}$ at the $\mathrm{N}$-terminus. The resulting fragments are called APPs $\beta$ and the C-terminal fragment C99. Upon cleavage of C99 by the $\gamma$-secretase, a complex formed by presenilin, nicastrin, Aph- 1 and Pen-2, A $\beta$ peptides $(4 \mathrm{kDa})$ and the APP intracellular domain (AICD) with a size of $6 \mathrm{kDa}$ are generated. $A \beta$-peptides mainly occur in two variants: $A \beta 40$ which ends at residue 40 and $A \beta 42$ ending at residue 42 after cleavage. Predominantly, the A $\beta 42$ is prone to aggregate and forms toxic oligomers. Furthermore, APP is cleaved by the a-secretases ADAM10 (a disintegrin and metalloproteinase-like 10) or TACE (tumour necrosis factor-alpha convertase). This results in the C-terminal fragment C83 and APPsa. The cleavage of APP by a- or $\beta$-secretase is dependent on the competition between both enzymes. In case the $\beta$-secretase cleavage of APP increases, a-secretase processing decreases and vice versa (Vassar et al. 1999; Skovronsky et al. 2000) (Figure 3).

In a healthy brain, there is more production of $A \beta 40(\sim 90 \%)$ than there is of $A \beta 42(\sim 5-10 \%)$ (Walsh and Selkoe 2007). The accumulation of $A \beta 42$ is an important step in the formation of amyloid plaques (Iwatsubo et al. 1994). The A $\beta 42$ :A $\beta 40$ ratio is a diagnostic tool for APP processing and development of AD (Haass and Selkoe 2007).

In addition to age-associated $A \beta 42$ accumulation, mutations in presenilin 1, presenilin 2 and the APP gene lead to familiar early-onset AD (Tabaton and Tamagno 2007; Sherrington et al. 
1996; Tanzi et al. 1992; Schellenberg et al. 1992; Van Broeckhoven et al. 1992; St GeorgeHyslop et al. 1992; Rogaev et al. 1995).

The toxic effect of $A \beta$ is not fully understood yet, but might be induced via generation of ion channels, membrane disruption, oxidative stress, induction of apoptosis and inflammation (Hardy and Selkoe 2002; Nakagawa et al. 2000; Soto 2003; Roberson and Mucke 2006). The $\mathrm{A} \beta$ aggregation process produces different intermediates. $\mathrm{A} \beta$ monomers are soluble and amphipathic with an a-helical conformation and kink regions in water-alcohol mixture (Coles et al. 1998; Crescenzi et al. 2002). A $\beta 40$ displays a random coil structure in aqueous solution (Zhang et al. 2000) and $A \beta 42$ shows $\beta$-sheet structure at physiological conditions (Barrow and Zagorski 1991). A $\beta$ dimers are located intracellular in vivo and show a hydrophobic core (Roher et al. 1996). Small $A \beta$ oligomers are highly cytotoxic compared to mature A $\beta$ fibrils (Dahlgren et al. 2002; McLean et al. 1999; Cleary et al. 2005; Lesne et al. 2006). The so called A $\beta$-derived diffusible ligands (ADDLs) show no fibrillar structure and are neurotoxic in a size of about 17 to $42 \mathrm{kDa}$ (Chromy et al. 2003; Klein, Stine, and Teplow 2004; Lambert et al. 1998). The levels of ADDLs are linked to cognitive impairments in AD (Georganopoulou et al. 2005). A $\beta$ protofibrils are the precursors of $A \beta$ fibrils. These protofibrils are present as rod-like and flexible structures. The dyes Congo red and thioflavin $\mathrm{T}$ bind to the core of the protofibrils, which indicates a high level of $\beta$-sheets (Harper et al. 1999; Arimon et al. 2005; Harper et al. 1997; Kheterpal et al. 2003; Walsh et al. 1997; Williams et al. 2005). A $\beta$ fibrils are insoluble, thermodynamically stable aggregates containing repeats of $\beta$-sheets (Ross and Poirier 2005). They also bind Congo red and thioflavin T (Klunk, Jacob, and Mason 1999; LeVine 1999). The amyloid plaques are extracellular aggregates of insoluble A $\beta$ fibrils (Muller-Hill and Beyreuther 1989). These plaques are surrounded by activated microglia, astrocytes and dystrophic dendrites (Selkoe 2004).

Different clinical studies revealed an association of AD and type 2 diabetes (Janson et al. 2004; Ott et al. 1999; Stewart and Liolitsa 1999). A connection of glucose intolerance, impairment of insulin secretion and the risk to develop AD was recently discovered (Ott et al. 1996; Luchsinger et al. 2004; Ronnemaa et al. 2008). Furthermore, AD patients develop more frequently impaired glucose tolerance and type 2 diabetes (Janson et al. 2004) indicating that IR/IGF-1R signalling might influence AD pathogenesis.

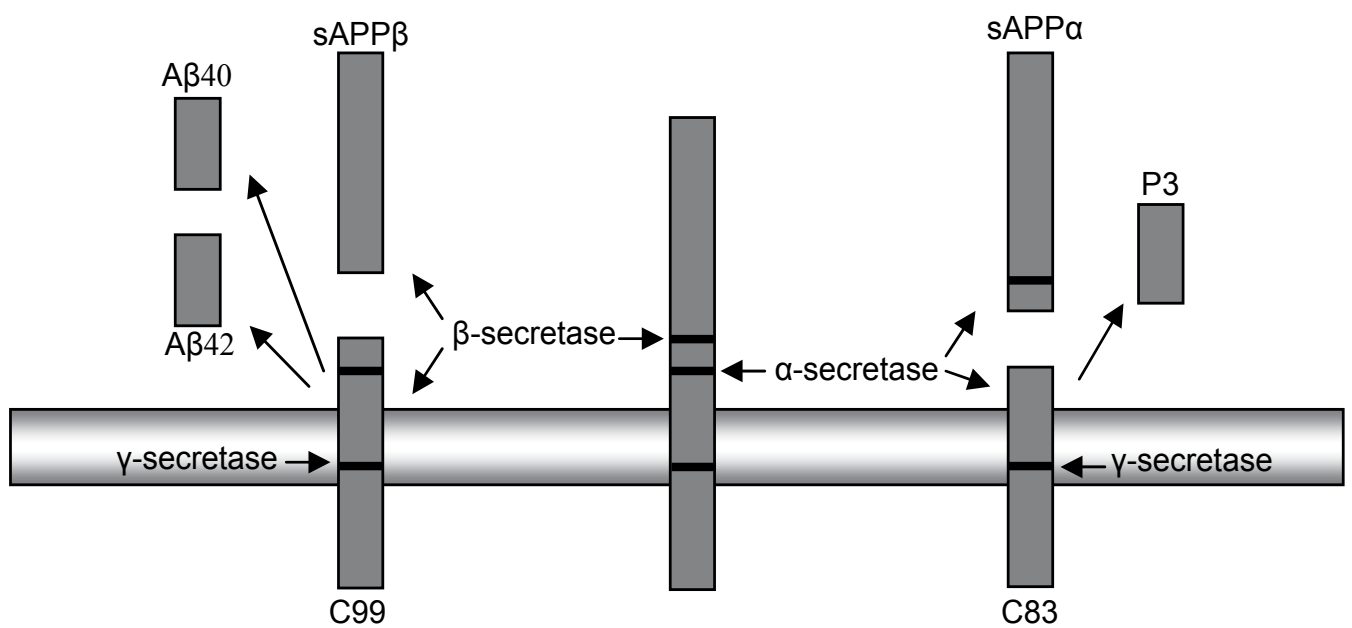

Fig. 3. Processing of amyloid precursor protein (APP). 
APP might be cleaved via the $\alpha-$, $\beta$ - or $\gamma$-secretase. $\alpha$-secretase cleavage generates a membrane bound C83 fragment and sAPPa. In case C83 is proteolytically cleaved by the $\gamma$ secretase the P3 fragment occurs. $\beta$-secreatse processing produces the fragments SAPP $\beta$ and $C 99$. In case of a simultaneous or subsequent cleavage via $\beta$ - and $\gamma$ - secretase the $A \beta 40$ or A $\beta 42$ peptides are released.

\subsection{IR, IGF-1R signalling and Alzheimer's disease}

The IR and IGF-1R signalling pathway is disturbed in the central nervous system (CNS) of AD patients (Frolich et al. 1998; Frolich et al. 1999; Moloney et al. 2010). Analysis of the mRNA level of insulin and the IR showed a decrease of about $80 \%$ in AD patients. Additionally, the expression of the IGF-1R was reduced in AD brains compared to controls (Moloney et al. 2010; Rivera et al. 2005). In contrast, the IGF-1 serum levels of AD patients are increased indicating IGF-1 resistance in AD (Rivera et al. 2005; Vardy et al. 2007). Furthermore, IRS-1 and -2 expression is reduced in AD brains and phosphorylation of IRS-1 at Ser312 and Ser616 is increased, which decreases IRS-1 action characterising AD as "brain type" diabetes (Pilcher 2006). Thus, brains of AD patients are insulin and IGF-1 resistant. Whether these changes are cause or consequence of neurodegeneration is a matter of debate. IGF-1 knockout mice display increase of tau phosphorylation at Ser396 and Ser202 while the tau protein level was not influenced (Cheng et al. 2005). In NIRKO mice, the brain-specific IR knockout mice, tau was hyperphosphorylated at Thr231 (Schubert et al. 2004), whereas IRS-2 knockout mice showed hyperphosphorylation at Ser202 (Schubert et al. 2003). The different phosphorylation patterns of tau in different insulin and IGF-1 resistant mouse models indicate that additional factors may play a role for tau phosphorylation in these models (Freude et al. 2009).

Tg2576 mice express the Swedish mutation of APP (APPsw) and are an established mouse model for analysing amyloid pathology (Vassar et al. 1999; De Strooper 2003; Harada et al. 2006). IRS-2 (IRS-2-/-) or neuron specific IGF-1R knockout (nIGF-1R-/-) in Tg2576 mice protects these mice from premature death and decreases $A \beta$-accumulation (Freude et al. 2009).

BACE-1 and Presenilin-1/-2, which cleave APP and generate neurotoxic A $\beta 42$, are possible targets for $\mathrm{AD}$ treatment since $\beta$-secretase cleavage is the rate limiting step of $\mathrm{A} \beta$ generation. During ageing, the expression of the neurotrophin receptor tyrosine kinase receptor $A$ (TrkA) and the p75 neurotrophin receptor ( $\left.p 75^{\mathrm{NTR}}\right)$ changes considerably. Whereas TrkA receptor expression decreases, the p75 neurotrophin receptor increases with age. Human neuroblastoma cells SHSY5Y and primary cultured neurons showed a switch from TrkA to p75 ${ }^{\text {NTR }}$ expression after treatment with IGF-1 (Costantini, Scrable, and Puglielli 2006). This increases BACE-1 activity via hydrolysis of sphingomyelin and release of ceramide stabilising BACE-1 (Puglielli 2008; Puglielli et al. 2003). It has been shown that embryonic hippocampal neurons treated with $A \beta 42$ as ligand of p75NTR cause cell death. Neurons, which are deficient in p75NTR and also treated with A $\beta 42$, show less cell death. This may represent the molecular mechanism linking IR and IGF-1R signalling pathway to ageing and neurodegeneration (Sotthibundhu et al. 2008).

In Caenorhabditis elegans the knockdown of DAF-2, the orthologue of mammalian IR and IGF-1R, reduces A $\beta 42$ toxicity (Cohen et al. 2006). This reduced $A \beta 42$ toxicity results from the activity of the downstream transcription factors DAF-16, the orthologue of mammalian FoxO1 and $3 \mathrm{a}$ as well as heat shock transcription factor-1 (HSF-1) (Hsu, Murphy, and Kenyon 2003; Birkenkamp and Coffer 2003; Cohen et al. 2006). The 
detoxification of A $\beta 42$ by decreased DAF-2 signalling involves two possible mechanisms. First, HSF-1 regulates disaggregation of toxic oligomers followed by degradation of the resulting fragments. Second, DAF-16 regulates the formation of aggregates with high molecular weight and low toxicity, which are built from aggregates with low molecular weight but high toxicity (A $\beta$ hyperaggregation) (Cohen et al. 2006). Recently, A $\beta$ hyperaggregation has been identified as a mechanism of $A \beta$ detoxification in an IGF-1 resistant mouse model of $\mathrm{AD}$ (Cohen et al. 2009).

Several ways of $A \beta$ clearance from the brain have been discovered contributing to $A \beta$ detoxification. $A \beta$ clearance is achieved via transport over the blood brain barrier, enzymatic degradation and phagocytosis by microglia. Recently, several enzymes have been discovered which degrade $A \beta$, e.g. insulin degrading enzyme (IDE), endothelin converting enzyme (ECE), neprilysin, and angiotensin converting enzyme (ACE). The expression of IDE is activated by IR and IGF-1R signalling (Zhao et al. 2004). Transport across the blood brain barrier (BBB) is mediated by distinct receptors. This transport is achieved via binding to the low-density lipoprotein receptor related protein (LRP). The binding of A $\beta$ to LRP occurs directly or in complex with APOE (apolipoprotein E) and/or a2-macroglobulin (a2M). After crossing the $\mathrm{BBB}, \mathrm{A} \beta$ is transported to peripheral tissues for degradation, for example the liver (Tanzi, Moir, and Wagner 2004). It has been proposed that high IGF-1 levels cause degradation or clearance of $\mathrm{A} \beta$. Tg2576 mice present decreased IGF-1 levels compared to wild type mice. The treatment with IGF-1 yield to increased transport of $A \beta$ from the brain, possibly via the choroid plexus (Carro et al. 2002). Accordingly, the inactivation of the IGF1R signalling in the choroid plexus caused AD-like pathology (Carro et al. 2006). In contrast, studies in rats and Tg2576 mice using acute, subchronic and chronic IGF-1 treatment found no changes in tau phosphorylation and A $\beta$ concentrations (Lanz et al. 2008). Possibly, chronic peripheral treatment with IGF-1 causes downregulation of the IGF-1R signalling pathway as it has been shown for a cohort of individuals with high serum IGF-1 level but low IGF-1R signalling (Suh et al. 2008). This might explain the conflicting results of the different studies. AD mouse models with induced insulin resistance via high fat diet displayed an exacerbation of amyloid pathology (Ho et al. 2004).

The different studies dealing with IR/IGF-1R signalling and AD prove a connection between this signalling pathways and AD pathology. However, the exact molecular mechanisms need to be elucidated.

\section{IGF-1 in the brain and ageing}

IR/IGF-1R signalling is a conserved pathway functioning in development, fertility (Liang et al. 2003; Tatar, Bartke, and Antebi 2003; Broughton et al. 2005), growth (Butler and Le Roith 2001; Ikeya et al. 2002) and metabolic regulation (Saltiel and Kahn 2001). Decreased IR/IGF$1 \mathrm{R}$ signalling causes lifespan extension in model organisms like Drosophila melanogaster, Caenorhabditis elegans and Mus musculus (Clancy et al. 2001; Holzenberger et al. 2003; Tatar et al. 2001).

The life expenctancy of humans has been increased upon environmental amelioration (Wilmoth 2000). However, this is accompanied by an increase of age associated disorders. Therefore, the study of the molecular mechanism of ageing might lead to identification of disease modifying pathways. One of these pathways is the IR/IGF-1R signalling cascade. Studies investigating temporal or spatial restricted changes of the IR/IGF-1R signalling pathway in different model organisms, using the RU486-induced GAL4/UAS (upstream 
activation sequence) in Drosophila, as well as RNAi (RNA interference) incorparation via feeding of bacteria to C. elegans and Cre/loxP system in mice (Roman et al. 2001; Sauer 1998), have been performed.

The CNS is responsible for endocrine release of insulin-like peptides which activate the IR/IGF-1R signalling cascade and subsequently shorten lifespan (Ikeya et al. 2002; Broughton et al. 2005). Confusingly, acute increase of IR/IGF1-R signalling is neuroprotective but reduction of the signalling causes lifespan extension (Bateman and McNeill 2006; Chrysis et al. 2001).

\subsection{IGF-1 signalling in C. elegans}

The impact of IR/IGF-1R-like signalling (IIS) pathway on lifespan was first discovered in C. elegans. IIS in C. elegans is similar to the pathway in mammals (Taguchi and White 2008). It is activated through binding of insulin-like peptides (INS) to DAF-2 (abnormal Dauer formation-2), the IR/IGF-1R in worms (Kenyon et al. 1993). Upon stimulation of DAF-2 an insulin receptor substrate 1 orthologue (IST-1) is recruited to DAF-2 and AGE-1 (AGEing alteration-1), orthologue to human p110. P110, the catalytic subunit of PI3K, promotes the generation of phosphatidylinositide-triphosphate $\left(\mathrm{PI}_{3,4,5} \mathrm{P}\right)$ which then activates AKT kinase family members (Morris, Tissenbaum, and Ruvkun 1996; Kops et al. 1999; Paradis and Ruvkun 1998).

The mutations of DAF-2 and AGE-1 cause lifespan extension in a DAF-16 dependent manner which is a forkhead transcription factor in worms (Kenyon et al. 1993; Lin et al. 1997; Ogg et al. 1997; Morris, Tissenbaum, and Ruvkun 1996) and homologue to the mammalian FoxO1 and FoxO3a.

AGE-1 and DAF-2 mutant worms show enhanced thermotaxis learning behaviour during ageing. This might be due to resistance to neuronal diseases and oxidative stress (Murakami 2007).

The insulin-like peptides (INS) are found throughout the whole body of C. elegans (Pierce et al. 2001; Li, Kennedy, and Ruvkun 2003). Specific sensory neurons regulate lifespan through DAF-16 (Alcedo and Kenyon 2004). The ablation of olfactory neurons causes lifespan extension being only partially dependent on DAF-16 indicating an involvement of other factors. The regulation of INS is not well analysed, but the sensory neurons seem to be the major source of INS for peripheral tissues (Alcedo and Kenyon 2004).

A study using tissue-specific expression of AGE-1 and DAF-16 revealed that wild-type AGE-1 recovers the extended lifespan of AGE-1 mutants. This was shown for wild-type AGE-1 expressed in neurons and the intestine. In addition, wild-type DAF-16 rescues reduced lifespan of DAF-16/ AGE-1 double mutants when expressed in neurons or intestine. Moreover, wild-type DAF-16 exerts its full effect when expressed in neurons and the intestine exclusively. However, DAF-16 expression showed only minor effects when expressed in other tissues (Broughton and Partridge 2009; Iser, Gami, and Wolkow 2007).

\subsection{IGF-1 signalling in Drosophila melanogaster}

D. melanogaster posseses endocrine tissues, which are similar to mammals (Toivonen and Partridge 2009). The median neurosecretory cells (mNSCs) of Drosophila are localised in the pars intercerebralis. mNSCs generate three of the seven Drosophila insulin-like peptides (DILPs). These mNSCs are functionally similar to $\beta$-cells of the pancreas which produce 
insulin. These neurosecretory cells show an analogue development to the mammalian anterior pituitary (Wang et al. 2007). The ablation of mNSCs causes lifespan extension, because of the depletion of DILP-2, -3 and -5 (Broughton et al. 2005). In a further study using a dominant-negative form of p53 expressed in the CNS of flies, lifespan extension was induced (Bauer et al. 2005; Slee, O'Connor, and Lu 2004). This correlates with decreased DILP-2 expression and reduced PI3K activity in the periphery (Bauer et al. 2007).

In addition to ablation of mNSCs, mutation of the insulin-like receptor (InR) or of its substrate Chico extends lifespan (Clancy et al. 2001; Tu, Epstein, and Tatar 2002; Tatar et al. 2001). The activation of the InR causes phosphorylation of $\mathrm{dFOXO}$, which is equivalent to nematode DAF-16 and mammalian FoxO1 and FoxO3a (Puig et al. 2003; Junger et al. 2003). $\mathrm{dFOXO}$ activation in the pericerebral fat body has been shown to regulate ageing. This activation of $\mathrm{dFOXO}$ reduces the expression of DLP-2 in mNSCs followed by downregulation of the InR signalling pathway in peripheral fat tissue (Hwangbo et al. 2004) The JNK signalling pathway in neurons enhances stress resistance and lifespan extension partially via dFOXO (Essers et al. 2004; Wang, Bohmann, and Jasper 2005). Oxidative stress induces JNK signalling and subsequently promotes the nuclear localisation of dFOXO and induces expression of antioxidant proteins (Huang and Tindall 2007; Kops et al. 2002). Neurons are prone to oxidative stress based on the high production of ROS and low amount of antioxidant proteins (Lin and Beal 2006). Peroxiredoxin abolishes hydroperoxide using thioredoxin as hydrogen donor, which decreases ROS (reactive oxygen species) (Lim et al. 1993). Mammalians express six peroxiredoxins (I-VI). Peroxiredoxin II is solely expressed in the brain (Jin et al. 2005). Jafrac1, the homologue of the human Peroxiredoxin II (hPrxII), is a downstream protein of JNK signalling and target gene of dFOXO in neurons. Jafrac1 reduces reactive oxygen species (ROS) and extends lifespan (Lee et al. 2009) linking decreased IIS to increased clearance of ROS as possible mechanism for lifespan extension.

\subsection{IGF-1 signalling regulates mammalian lifespan}

In mice, it is well known that adult body size is an indicator of GH/IGF-1 actions and negatively correlated to longevity (Rollo 2002; Miller et al. 2002). Furthermore, IGF-1 plasma levels are negatively correlated with median lifespan (Yuan et al. 2009). Up to date, several mouse models of healthy ageing and longevity have been identified and analysed. Most of those long-lived mice have alterations within the IIS, GH or mTOR signalling pathway, indicating their key-role in influencing the process of ageing itself (Broughton and Partridge 2009; Kenyon 2010; Kenyon 2005; Piper et al. 2008; Bluher, Kahn, and Kahn 2003; Kappeler et al. 2008; Selman et al. 2008).

Highest impact on lifespan extension seems to have the ablation of GH signalling, as mutants with impaired $\mathrm{GH}$ action demonstrate higher increase of median and maximal lifespan than those with mutations that directly impact IGF-1 signalling (Coschigano et al. 2000; Coschigano et al. 2003; Brown-Borg et al. 1996; Flurkey et al. 2001). Examples for altered GH signalling are the Ames dwarf mice (Prop1def/def), Snell dwarf mice (Pit-1def/def) and Laron dwarf mice (GHR-/-). As the transcription factors Prop1 and Pit-1 are also essential for induction of thyroidea stimulating hormone (TSH) and prolactin, Ames dwarf mice and Snell dwarf mice are not only GH deficient but in addition produce less thyroidea stimulating hormone (TSH) and prolactin. Therefore, it can not be excluded that some of the effects seen in Ames and Snell dwarf mice might arise through deletion of TSH and prolactin. Laron dwarf mice (GHRKO ,GHR-/-) are only resistant to $\mathrm{GH}$ signalling, and their longevity phenotype has been reproducible in different laboratories on different genetic 
backgrounds and diets (Coschigano et al. 2003; Bartke and Brown-Borg 2004; Bonkowski et al. 2006).

As described above, GH action is mainly, but not completely, mediated by IGF-1 and circulating levels of IGF-1 are drastically reduced in GH-deficient Ames and Snell dwarf mice as well as in GH-resistant Laron dwarf mice (Brown-Borg et al. 1996; Coschigano et al. 2000; Flurkey et al. 2001). This reduction is primarily due to decreased expression of IGF-1 in the liver, whereas locally derived IGF-1 is, if at all, less affected (Bartke 2011). Normal expression of IGF-1 in the brain, especially in the hippocampus, might explain the maintenance of cognitive function in the long-lived mutants of the GH/IGF-1 system (Kinney et al. 2001). Besides reduced circulating IGF-1, lower insulin levels and enhanced insulin sensitivity are among the most prominent endocrine features shared by Ames dwarf, Snell dwarf and GHRKO mice (Bartke 2006) and have been found to be beneficial for ageing and survival (Bartke 2011). Additionally, increased adiponectin levels, which are associated with improved insulin sensitivity, anti-inflammatory and anti-atherogenic effects, were observed in all three mouse lines (Berryman et al. 2004; Wang et al. 2006). GH-deficient and -resistant mice were also found to have other phenotypic characteristics through which lifespan is thought to be increased, such as resistance to oxidative and other cytotoxic stresses (Bartke et al. 2001; Murakami, Salmon, and Miller 2003), increased activity of antioxidant enzymes (Hauck et al. 2002; Bartke et al. 2001; Romanick, Rakoczy, and BrownBorg 2004), reduced body temperature (Hunter et al. 1999; Hauck et al. 2001) and reduced susceptibility to cancer (Yang et al. 1996; Deitel et al. 2002; Ikeno et al. 2003).

Another model for extended healthy lifespan in mammals is the fat-specific insulin receptor knockout (FIRKO) mouse (Bluher, Kahn, and Kahn 2003). These mutant mice maintain low body fat despite normal food intake, have normal lipid metabolism and demonstrate improved glucose tolerance and insulin sensitivity throughout life (Bluher, Kahn, and Kahn 2003). The underlying mechanisms of this model are not well understood and apart from impaired IR signalling, altered inflammatory state and mitochondrial activity in these animals are discussed.

A remarkable increase of mean and maximal lifespan has been found in female and male mice lacking PAPP-A. PAPP-A is a metalloproteinase that cleaves inhibitory IGFBPs (as described above), thereby increasing local bioavailability of IGF-1 without altering IGF-1 expression (Lawrence et al. 1999). Conversely, deletion of PAPP-A in PAPP-A $/-$ mice results in reduced local IGF-1 levels, and thus PAPP-A $/$ - mice are born as dwarfs (Conover et al. 2004). In these mutants, extension of lifespan was not associated with impaired glucose or fat metabolism and serum IGF-1, insulin and GH levels were unaltered (Conover and Bale 2007). However, these mice have markedly reduced incidence of spontaneous tumors (Conover and Bale 2007) and were found to be resistant to develop experimentally induced neointimal hyperplasia and atherosclerosis (Harrington, Simari, and Conover 2007; Resch, Simari, and Conover 2006).

As described above, homozygous deletion of the IGF-1R or IGF-1 is lethal or produces severe developmental defects, however extended lifespan was reported in mice with heterozygous deletion of the IGF-1R (IGF-1R+/-) (Holzenberger et al. 2003). IGF-1R+/- mice have upregulated serum IGF-1 levels, which might indicate an endocrine compensatory response to the reduced numbers of IGF-1R, and these mice do not develop dwarfism (Holzenberger et al. 2003). Those mutants have no alterations in energy metabolism, physical activity, fertility and reproduction but display greater resistance to oxidative stress (Holzenberger et al. 2003) probably causing the observed lifespan extension, which is 
predominantly seen in females. As described earlier, the selective reduction of IGF-1 signalling in the brain of bIGF1R + - mice leads to an increase in median but not maximal lifespan (Kappeler et al. 2008).

The knockout models for IRS-proteins provide evidence that interference with IGF1 /insulin signalling downstream of the IGF-1 and insulin receptor influences lifespan in mice. Female IRS-1 knockout (IRS-1/-) mice were reported to be long-lived and resistant to a number of conditions related to neurological and neuromuscular, immune, skin and bone disease (Selman et al. 2008). In these animals, body weight including fat mass was reduced, but endocrine function of the pituitary as well as circulating IGF-1 levels were preserved (Selman et al. 2008). Additionally, female IRS-1//- mice were hyperinsulinemic and IGF1 /insulin resistant and rectal temperature was significantly elevated (Selman et al. 2008). All these characteristics are in contrast to the long-lived GH-deficient and GH-resistant mice, however female IRS-1 $/$ - mutants have similar alterations in expression of genes involved in oxidative stress defence and DNA repair (Selman et al. 2008). In the same study, no significant increase of lifespan was found for male IRS-1/- mice, as well as for IRS-1//- and IRS-2+/- mice of both sexes, and IRS-2-/- mice were even short-lived (Selman et al. 2008).

IRS-2+/- mice were found to be long-lived, slightly larger and more insulin sensitive and glucose tolerant than wild-type mice (Taguchi, Wartschow, and White 2007). However, the animals studied by Selman et al. (2008) were fed a 'standard' rodent diet with a fat content of $5 \%$, while those studied by Taguchi et al. (2007) were on a 'high energy' diet with a fat content of $9 \%$, hence indicating that the IRS-2+/- mice might be protected from the harming effects of a high-fat diet (Bartke 2008). In addition, Taguchi et al. (2007) reported that brain specific alterations of IRS-2 in bIRS-2+/- and bIRS-2 $/$ mice result in increased lifespan despite glucose and insulin resistance (Taguchi, Wartschow, and White 2007). Further work will be needed to clarify and reconcile the observations made in those two laboratories (Bartke 2008).

Regardless the criticism on the reproducibility of the observations made by Holzenberger (Kappeler et al. 2008) and Taguchi (2007), they provide evidence that selective disruption of the IIS pathway in neurons might not only extend lifespan in C.elegans and Drosophila (Wolkow et al. 2000; Kenyon 2005) but also in mammals. These findings may indirectly be verified by other studies that demonstrate a protection from AD pathology in a transgenic AD mouse model via deletion of IGF-1R or IRS-2 (Cohen et al. 2009; Freude et al. 2009; Killick et al. 2009).

\subsection{IGF-1 signalling and its relevance to human longevity}

The IIS pathway is highly conserved throughout evolution from nematodes and flies to mammals. In the last years, an increasing body of data suggests that this pathway is important for human longevity as well.

GH secretion and IGF-1 levels decrease with age (Rudman et al. 1981), which contributes to ageing-associated changes in body composition such as increased adipose tissue and reduced lean body mass leading to impaired insulin sensitivity and cardiovascular disease. The same observations are made in patients with GH deficiency (Khan et al. 2001) and mutation in the GHR gene: Low serum IGF-1 levels, short stature, obesity, glucose intolerance and possible mental retardation but no decrease in life expectancy (Rincon, Rudin, and Barzilai 2005). Conversely, pathologic GH excess in acromegaly leads to reduced life expectancy due to cardiovascular disease, diabetes and malignancies (Orme et al. 1998). Additionally, body height has been identified as a cancer risk in a number of large 
population studies (Bartke 2011) and serum IGF-1 levels correlate with cancer mortality in elderly men (Major et al. 2010). Therefore, the decline of GH secretion in the process of ageing might not simply reflect a progressive failure of the hypothalamus-somatotrope axis, but might be protective for the development of insulin resistance and cancer (Bartke 2003; Shechter et al. 2007). GH/IGF-1 therapy in elderly and GH deficient patients improves the ratio of lean and fat body mass, the lipid profile, protein synthesis, bone density, immune functions and memory (Khan et al. 2001), but certainly bears adverse side-effects, as GH is known to be diabetogenic and IGF-1 might increase the risk of cancer (Juul 1999; Khan et al. 2001; Pollak, Schernhammer, and Hankinson 2004; Major et al. 2010).

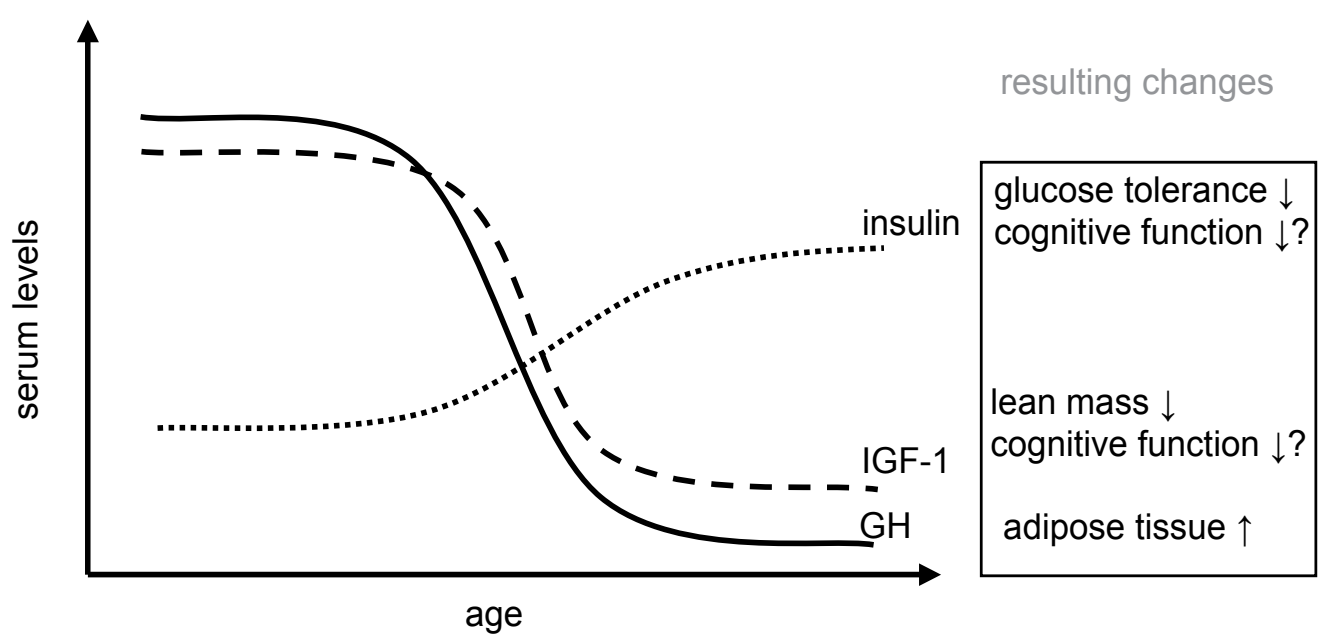

Fig. 4. GH/IGF-1 in ageing

Serum levels of growth hormone (GH) and insulin-like growth factor-1 (IGF-1) decrease during ageing contributing to increased fat mass and decreased lean mass and might influence cognitive function negatively. Serum insulin levels increase with age indicating age-associated insulin insensitivity possibly leading to impaired glucose tolerance and diabetes.

Recently, a study on a cohort of Ecuadorian patients carrying mutations in the GHR gene was published after 22 years of monitoring. Patients demonstrated severe GH resistance and reduced circulating IGF-1 and IGF-2 levels resulting in short stature (Guevara-Aguirre et al. 2011). No extension in lifespan was found in this cohort, which is in contrast to the GHR deficient mouse model (Guevara-Aguirre et al. 2011). However, causes of death were different in unaffected relatives compared to GHR deficient subjects, which died much more frequently from accidents, alcohol-related diseases and convulsive disorders, which might be the reason for unchanged lifespan (Guevara-Aguirre et al. 2011). Cancer accounted for 17 $\%$ and diabetes for $5 \%$ of all diseases in non-affected relatives, whereas only one nonlethal malignancy and no cases of diabetes, probably due to improved insulin sensitivity, were reported for the individuals with GHR mutations (Guevara-Aguirre et al. 2011). Importantly, GHR deficient subjects appear to have no increased mortality from vascular diseases compared to their relatives (30\% of deaths verses $33 \%$ of deaths in the nonaffected relatives), however the proportion of strokes (3\% verses $12 \%$ ) and cardiac disease (27\% verses $21 \%$ ) was slightly different (Guevara-Aguirre et al. 2011). 
In a cohort of Ashkenazi Jewish centenarians, a gender-specific increase in serum IGF-1 associated with smaller stature in female offspring was found to be due to heterozygous mutations in the IGF-1R gene (Suh et al. 2008). These rare mutations were significantly more common in female centenarians and overrepresented compared to controls (Suh et al. 2008). These observations are in line with the IGF-1R ${ }^{+/-}$mouse model, in which female mice show growth retardation and extended lifespan (Holzenberger et al. 2003) but IGF-1 resistance.

Further studies on human centenarians, mainly screening selectively genes of the IIS pathway, identified certain genes in the insulin/IGF-1 pathway to be important for human longevity. Several cohorts with different genetic background have reported an association of FOXO3A single nucleotide polymorphisms (SNPs) with longevity (Willcox et al. 2008; Flachsbart et al. 2009; Anselmi et al. 2009; Pawlikowska et al. 2009; Li et al. 2009). Interestingly, the study on long-lived Han Chinese revealed a SNP of FOXO1 associated with female longevity exclusively (Li et al. 2009).

Furthermore, in the Leiden 85-plus Study an association of a certain FOXO1 haplotype with higher $\mathrm{HbA1c}$ levels, higher prevalence of diabetes, myocardial infarction as well as increased mortality was observed (Kuningas et al. 2007). In addition, a certain haplotype of the FOXO3A gene revealed increased risks for stroke and mortality (Kuningas et al. 2007). These findings indicate that alterations within the FOXO genes might be causative involved in age-associated diseases and regulation of lifespan (Flachsbart et al. 2009).

\section{Conclusion}

Recent studies in different model organisms, including C. elegans, Drosophila melanogaster and Mus musculus have generated piling knowledge about the IIS pathway and its relevance for healthy ageing and longevity. The data obtained in these model organisms have been translated to humans and lead to the identification of the IIS pathway as regulator for human lifespan and ageing.

The GH and IGF-1 signalling pathway plays a key-role in regulating growth and metabolism, and alterations within this pathway have crucial effects on health and lifespan. Model-organisms with reduced GH or IGF-1 signalling are frequently long-lived or show an increased mean lifespan. Interestingly, serum GH and IGF-1 levels decrease with age, and this might be interpreted not solely as progressive failure of the hypothalamus-somatotrope axis but rather as protection for insulin resistance and malignancies.

IGF-1R signalling is required for normal brain development, and acute IGF-1 action might enhance cognitive functions and ameliorates ischemic or traumatic brain injuries. Additionally, recent studies demonstrate that IGF-1R signalling or the number of IGF-1Rs in the brain during early development determines metabolism and possibly age-associated diseases indicating a role of IGF-1 mediated signals as neuroendocrine regulator of health and lifespan.

Foxo-transcription factors have been identified as main downstream-target of IIS and seem to be essential for activating gene transcripton that mediates longevity. Furthermore, genomic screening of centenarians with different genetic background found matching SNPs or haplotypes in the FOXO3A gene suggesting a key-role of FOXO3A in influencing lifespan not only in model organisms but also in humans.

However, the role of IIS in AD still raises questions, as the impaired signalling might be cause or consequence of neurodegeneration. 
Therapeutic approaches altering the IIS pathway might not only improve treatment of neurodegenerative disorders but provide a possibility to prevent ageing-associated diseases in the future.

\section{References}

Alcedo, J., and C. Kenyon. (2004). Regulation of C. elegans longevity by specific gustatory and olfactory neurons. Neuron 41 (1):45-55.

Alessi, D. R., M. Andjelkovic, B. Caudwell, P. Cron, N. Morrice, P. Cohen, and B. A. Hemmings. (1996). Mechanism of activation of protein kinase B by insulin and IGF-1. EMBO J 15 (23):6541-51.

Altman, J., and S. A. Bayer. (1990). Migration and distribution of two populations of hippocampal granule cell precursors during the perinatal and postnatal periods. $J$ Comp Neurol 301 (3):365-81.

Altman, J., and S. A. Bayer. (1990). Mosaic organization of the hippocampal neuroepithelium and the multiple germinal sources of dentate granule cells. J Comp Neurol 301 (3):32542.

Alzheimer, A., R. A. Stelzmann, H. N. Schnitzlein, and F. R. Murtagh. (1995). An English translation of Alzheimer's 1907 paper, "Uber eine eigenartige Erkankung der Hirnrinde". Clin Anat 8 (6):429-31.

Anselmi, C. V., A. Malovini, R. Roncarati, V. Novelli, F. Villa, G. Condorelli, R. Bellazzi, and A. A. Puca. (2009). Association of the FOXO3A locus with extreme longevity in a southern Italian centenarian study. Rejuvenation Res 12 (2):95-104.

Arimon, M., I. Diez-Perez, M. J. Kogan, N. Durany, E. Giralt, F. Sanz, and X. FernandezBusquets. (2005). Fine structure study of Abeta1-42 fibrillogenesis with atomic force microscopy. FASEB J 19 (10):1344-6.

Astrinidis, A., and E. P. Henske. (2005). Tuberous sclerosis complex: linking growth and energy signaling pathways with human disease. Oncogene 24 (50):7475-81.

Baker, J., J. P. Liu, E. J. Robertson, and A. Efstratiadis. (1993). Role of insulin-like growth factors in embryonic and postnatal growth. Cell 75 (1):73-82.

Ballard, F. J., J. C. Wallace, G. L. Francis, L. C. Read, and F. M. Tomas. (1996). Des(1-3)IGF-I: a truncated form of insulin-like growth factor-I. Int J Biochem Cell Biol 28 (10):1085-7.

Ballatore, C., V. M. Lee, and J. Q. Trojanowski. (2007). Tau-mediated neurodegeneration in Alzheimer's disease and related disorders. Nat Rev Neurosci 8 (9):663-72.

Barrow, C. J., and M. G. Zagorski. (1991). Solution structures of beta peptide and its constituent fragments: relation to amyloid deposition. Science 253 (5016):179-82.

Bartke, A. (2003). Is growth hormone deficiency a beneficial adaptation to aging? Evidence from experimental animals. Trends Endocrinol Metab 14 (7):340-4.

Bartke, A. (2006). New findings in transgenic, gene knockout and mutant mice. Exp Gerontol 41 (12):1217-9.

Bartke, A. (2008). Impact of reduced insulin-like growth factor-1/insulin signaling on aging in mammals: novel findings. Aging Cell 7 (3):285-90.

Bartke, A. (2011). Growth hormone, insulin and aging: the benefits of endocrine defects. Exp Gerontol 46 (2-3):108-11.

Bartke, A., and H. Brown-Borg. (2004). Life extension in the dwarf mouse. Curr Top Dev Biol 63:189-225. 
Bartke, A., H. Brown-Borg, J. Mattison, B. Kinney, S. Hauck, and C. Wright. (2001). Prolonged longevity of hypopituitary dwarf mice. Exp Gerontol 36 (1):21-8.

Bateman, J. M., and H. McNeill. (2006). Insulin/IGF signalling in neurogenesis. Cell Mol Life Sci 63 (15):1701-5.

Bauer, J. H., C. Chang, S. N. Morris, S. Hozier, S. Andersen, J. S. Waitzman, and S. L. Helfand. (2007). Expression of dominant-negative Dmp53 in the adult fly brain inhibits insulin signaling. Proc Natl Acad Sci U S A 104 (33):13355-60.

Bauer, J. H., P. C. Poon, H. Glatt-Deeley, J. M. Abrams, and S. L. Helfand. (2005). Neuronal expression of p53 dominant-negative proteins in adult Drosophila melanogaster extends life span. Curr Biol 15 (22):2063-8.

Baxter, R. C. (1988). Characterization of the acid-labile subunit of the growth hormonedependent insulin-like growth factor binding protein complex. J Clin Endocrinol Metab 67 (2):265-72.

Baxter, R. C. (2000). Insulin-like growth factor (IGF)-binding proteins: interactions with IGFs and intrinsic bioactivities. Am J Physiol Endocrinol Metab 278 (6):E967-76.

Baxter, R. C., and J. L. Martin. (1989). Structure of the Mr 140,000 growth hormone-dependent insulin-like growth factor binding protein complex: determination by reconstitution and affinity-labeling. Proc Natl Acad Sci U S A 86 (18):6898-902.

Baxter, R. C., J. L. Martin, and V. A. Beniac. (1989). High molecular weight insulin-like growth factor binding protein complex. Purification and properties of the acid-labile subunit from human serum. J Biol Chem 264 (20):11843-8.

Baxter, R. C., S. Meka, and S. M. Firth. (2002). Molecular distribution of IGF binding protein-5 in human serum. J Clin Endocrinol Metab 87 (1):271-6.

Beck, K. D., L. Powell-Braxton, H. R. Widmer, J. Valverde, and F. Hefti. (1995). Igf1 gene disruption results in reduced brain size, CNS hypomyelination, and loss of hippocampal granule and striatal parvalbumin-containing neurons. Neuron 14 (4):717-30.

Berryman, D. E., E. O. List, K. T. Coschigano, K. Behar, J. K. Kim, and J. J. Kopchick. (2004). Comparing adiposity profiles in three mouse models with altered $\mathrm{GH}$ signaling. Growth Horm IGF Res 14 (4):309-18.

Berryman, D. E., E. O. List, D. T. Kohn, K. T. Coschigano, R. J. Seeley, and J. J. Kopchick. (2006). Effect of growth hormone on susceptibility to diet-induced obesity. Endocrinology 147 (6):2801-8.

Bertolotto, C., L. Maulon, N. Filippa, G. Baier, and P. Auberger. (2000). Protein kinase C theta and epsilon promote T-cell survival by a rsk-dependent phosphorylation and inactivation of BAD. J Biol Chem 275 (47):37246-50.

Bertram, L., and R. E. Tanzi. (2005). The genetic epidemiology of neurodegenerative disease. J Clin Invest 115 (6):1449-57.

Bick, T., Z. Hochberg, T. Amit, O. G. Isaksson, and J. O. Jansson. (1992). Roles of pulsatility and continuity of growth hormone $(\mathrm{GH})$ administration in the regulation of hepatic $\mathrm{GH}$ receptors, and circulating GH-binding protein and insulin-like growth factor-I. Endocrinology 131 (1):423-9.

Biggs, W. H., 3rd, J. Meisenhelder, T. Hunter, W. K. Cavenee, and K. C. Arden. (1999). Protein kinase B/Akt-mediated phosphorylation promotes nuclear exclusion of the winged helix transcription factor FKHR1. Proc Natl Acad Sci U S A 96 (13):7421-6. 
Birkenkamp, K. U., and P. J. Coffer. (2003). Regulation of cell survival and proliferation by the FOXO (Forkhead box, class O) subfamily of Forkhead transcription factors. Biochem Soc Trans 31 (Pt 1):292-7.

Bluher, M., B. B. Kahn, and C. R. Kahn. (2003). Extended longevity in mice lacking the insulin receptor in adipose tissue. Science 299 (5606):572-4.

Bohannon, N. J., E. S. Corp, B. J. Wilcox, D. P. Figlewicz, D. M. Dorsa, and D. G. Baskin. (1988). Characterization of insulin-like growth factor I receptors in the median eminence of the brain and their modulation by food restriction. Endocrinology 122 (5):1940-7.

Bohlooly, Y. M., B. Olsson, A. Gritli-Linde, O. Brusehed, O. G. Isaksson, C. Ohlsson, B. Soderpalm, and J. Tornell. (2001). Enhanced spontaneous locomotor activity in bovine GH transgenic mice involves peripheral mechanisms. Endocrinology 142 (10):4560-7.

Boisclair, Y. R., R. P. Rhoads, I. Ueki, J. Wang, and G. T. Ooi. (2001). The acid-labile subunit (ALS) of the $150 \mathrm{kDa}$ IGF-binding protein complex: an important but forgotten component of the circulating IGF system. J Endocrinol 170 (1):63-70.

Bondy, C. A., and W. H. Lee. (1993). Patterns of insulin-like growth factor and IGF receptor gene expression in the brain. Functional implications. Ann N Y Acad Sci 692:33-43.

Bondy, C. A., H. Werner, C. T. Roberts, Jr., and D. LeRoith. (1990). Cellular pattern of insulinlike growth factor-I (IGF-I) and type I IGF receptor gene expression in early organogenesis: comparison with IGF-II gene expression. Mol Endocrinol 4 (9):1386-98.

Bondy, C., and W. H. Lee. (1993). Correlation between insulin-like growth factor (IGF)-binding protein 5 and IGF-I gene expression during brain development. J Neurosci 13 (12):5092-104.

Bondy, C., H. Werner, C. T. Roberts, Jr., and D. LeRoith. (1992). Cellular pattern of type-I insulin-like growth factor receptor gene expression during maturation of the rat brain: comparison with insulin-like growth factors I and II. Neuroscience 46 (4):909-23.

Bonkowski, M. S., R. W. Pamenter, J. S. Rocha, M. M. Masternak, J. A. Panici, and A. Bartke. (2006). Long-lived growth hormone receptor knockout mice show a delay in agerelated changes of body composition and bone characteristics. J Gerontol A Biol Sci Med Sci 61 (6):562-7.

Boura-Halfon, S., and Y. Zick. (2009). Phosphorylation of IRS proteins, insulin action, and insulin resistance. Am J Physiol Endocrinol Metab 296 (4):E581-91.

Braulke, T. (1999). Type-2 IGF receptor: a multi-ligand binding protein. Horm Metab Res 31 (23):242-6.

Broughton, S. J., M. D. Piper, T. Ikeya, T. M. Bass, J. Jacobson, Y. Driege, P. Martinez, E. Hafen, D. J. Withers, S. J. Leevers, and L. Partridge. (2005). Longer lifespan, altered metabolism, and stress resistance in Drosophila from ablation of cells making insulinlike ligands. Proc Natl Acad Sci U S A 102 (8):3105-10.

Broughton, S., and L. Partridge. (2009). Insulin/IGF-like signalling, the central nervous system and aging. Biochem J 418 (1):1-12.

Brown-Borg, H. M., K. E. Borg, C. J. Meliska, and A. Bartke. (1996). Dwarf mice and the ageing process. Nature 384 (6604):33.

Brunet, A., A. Bonni, M. J. Zigmond, M. Z. Lin, P. Juo, L. S. Hu, M. J. Anderson, K. C. Arden, J. Blenis, and M. E. Greenberg. (1999). Akt promotes cell survival by phosphorylating and inhibiting a Forkhead transcription factor. Cell 96 (6):857-68. 
Brunet, A., D. Roux, P. Lenormand, S. Dowd, S. Keyse, and J. Pouyssegur. (1999). Nuclear translocation of $\mathrm{p} 42 / \mathrm{p} 44$ mitogen-activated protein kinase is required for growth factor-induced gene expression and cell cycle entry. EMBO J 18 (3):664-74.

Brunet, A., L. B. Sweeney, J. F. Sturgill, K. F. Chua, P. L. Greer, Y. Lin, H. Tran, S. E. Ross, R. Mostoslavsky, H. Y. Cohen, L. S. Hu, H. L. Cheng, M. P. Jedrychowski, S. P. Gygi, D. A. Sinclair, F. W. Alt, and M. E. Greenberg. (2004). Stress-dependent regulation of FOXO transcription factors by the SIRT1 deacetylase. Science 303 (5666):2011-5.

Bruning, J. C., D. Gautam, D. J. Burks, J. Gillette, M. Schubert, P. C. Orban, R. Klein, W. Krone, D. Muller-Wieland, and C. R. Kahn. (2000). Role of brain insulin receptor in control of body weight and reproduction. Science 289 (5487):2122-5.

Busby, W. H., Jr., T. J. Nam, A. Moralez, C. Smith, M. Jennings, and D. R. Clemmons. (2000). The complement component $\mathrm{C} 1 \mathrm{~s}$ is the protease that accounts for cleavage of insulinlike growth factor-binding protein-5 in fibroblast medium. J Biol Chem 275 (48):3763844.

Butler, A. A., and D. Le Roith. (2001). Control of growth by the somatropic axis: growth hormone and the insulin-like growth factors have related and independent roles. Annu Rev Physiol 63:141-64.

Butler, A. A., and D. LeRoith. (2001). Minireview: tissue-specific versus generalized gene targeting of the igf1 and igf1r genes and their roles in insulin-like growth factor physiology. Endocrinology 142 (5):1685-8.

Byun, D., S. Mohan, M. Yoo, C. Sexton, D. J. Baylink, and X. Qin. (2001). Pregnancy-associated plasma protein-A accounts for the insulin-like growth factor (IGF)-binding protein-4 (IGFBP-4) proteolytic activity in human pregnancy serum and enhances the mitogenic activity of IGF by degrading IGFBP-4 in vitro. J Clin Endocrinol Metab 86 (2):847-54.

Carlsson-Skwirut, C., M. Lake, M. Hartmanis, K. Hall, and V. R. Sara. (1989). A comparison of the biological activity of the recombinant intact and truncated insulin-like growth factor 1 (IGF-1). Biochim Biophys Acta 1011 (2-3):192-7.

Carlsson, L., and J. O. Jansson. (1990). Endogenous growth hormone (GH) secretion in male rats is synchronized to pulsatile GH infusions given at 3-hour intervals. Endocrinology $126(1): 6-10$.

Carro, E., A. Nunez, S. Busiguina, and I. Torres-Aleman. (2000). Circulating insulin-like growth factor I mediates effects of exercise on the brain. J Neurosci 20 (8):2926-33.

Carro, E., C. Spuch, J. L. Trejo, D. Antequera, and I. Torres-Aleman. (2005). Choroid plexus megalin is involved in neuroprotection by serum insulin-like growth factor I. $J$ Neurosci 25 (47):10884-93.

Carro, E., J. L. Trejo, T. Gomez-Isla, D. LeRoith, and I. Torres-Aleman. (2002). Serum insulinlike growth factor I regulates brain amyloid-beta levels. Nat Med 8 (12):1390-7.

Carro, E., J. L. Trejo, C. Spuch, D. Bohl, J. M. Heard, and I. Torres-Aleman. (2006). Blockade of the insulin-like growth factor I receptor in the choroid plexus originates Alzheimer'slike neuropathology in rodents: new cues into the human disease? Neurobiol Aging 27 (11):1618-31.

Carson, M. J., R. R. Behringer, R. L. Brinster, and F. A. McMorris. (1993). Insulin-like growth factor I increases brain growth and central nervous system myelination in transgenic mice. Neuron 10 (4):729-40. 
Cheatham, B., and C. R. Kahn. (1995). Insulin action and the insulin signaling network. Endocr Rev 16 (2):117-42.

Chen, J., P. R. Somanath, O. Razorenova, W. S. Chen, N. Hay, P. Bornstein, and T. V. Byzova. (2005). Akt1 regulates pathological angiogenesis, vascular maturation and permeability in vivo. Nat Med 11 (11):1188-96.

Cheng, C. M., V. Tseng, J. Wang, D. Wang, L. Matyakhina, and C. A. Bondy. (2005). Tau is hyperphosphorylated in the insulin-like growth factor-I null brain. Endocrinology 146 (12):5086-91.

Cho, J. H., and G. V. Johnson. (2004). Primed phosphorylation of tau at Thr231 by glycogen synthase kinase 3beta (GSK3beta) plays a critical role in regulating tau's ability to bind and stabilize microtubules. J Neurochem 88 (2):349-58.

Chou, C. K., T. J. Dull, D. S. Russell, R. Gherzi, D. Lebwohl, A. Ullrich, and O. M. Rosen. (1987). Human insulin receptors mutated at the ATP-binding site lack protein tyrosine kinase activity and fail to mediate postreceptor effects of insulin. J Biol Chem 262 (4):1842-7.

Chromy, B. A., R. J. Nowak, M. P. Lambert, K. L. Viola, L. Chang, P. T. Velasco, B. W. Jones, S. J. Fernandez, P. N. Lacor, P. Horowitz, C. E. Finch, G. A. Krafft, and W. L. Klein. (2003). Self-assembly of Abeta(1-42) into globular neurotoxins. Biochemistry 42 (44):12749-60.

Chrysis, D., A. S. Calikoglu, P. Ye, and A. J. D'Ercole. (2001). Insulin-like growth factor-I overexpression attenuates cerebellar apoptosis by altering the expression of $\mathrm{Bcl}$ family proteins in a developmentally specific manner. J Neurosci 21 (5):1481-9.

Citron, M. (2002). Alzheimer's disease: treatments in discovery and development. Nat Neurosci 5 Suppl:1055-7.

Clancy, D. J., D. Gems, L. G. Harshman, S. Oldham, H. Stocker, E. Hafen, S. J. Leevers, and L. Partridge. (2001). Extension of life-span by loss of CHICO, a Drosophila insulin receptor substrate protein. Science 292 (5514):104-6.

Clark, K. L., E. D. Halay, E. Lai, and S. K. Burley. (1993). Co-crystal structure of the HNF3/fork head DNA-recognition motif resembles histone H5. Nature 364 (6436):412-20.

Clark, R. G., J. O. Jansson, O. Isaksson, and I. C. Robinson. (1985). Intravenous growth hormone: growth responses to patterned infusions in hypophysectomized rats. $J$ Endocrinol 104 (1):53-61.

Cleary, J. P., D. M. Walsh, J. J. Hofmeister, G. M. Shankar, M. A. Kuskowski, D. J. Selkoe, and K. H. Ashe. (2005). Natural oligomers of the amyloid-beta protein specifically disrupt cognitive function. Nat Neurosci 8 (1):79-84.

Cohen, E., J. Bieschke, R. M. Perciavalle, J. W. Kelly, and A. Dillin. (2006). Opposing activities protect against age-onset proteotoxicity. Science 313 (5793):1604-10.

Cohen, E., J. F. Paulsson, P. Blinder, T. Burstyn-Cohen, D. Du, G. Estepa, A. Adame, H. M. Pham, M. Holzenberger, J. W. Kelly, E. Masliah, and A. Dillin. (2009). Reduced IGF-1 signaling delays age-associated proteotoxicity in mice. Cell 139 (6):1157-69.

Cohick, W. S., and D. R. Clemmons. (1993). The insulin-like growth factors. Annu Rev Physiol 55:131-53.

Cole, A. R., A. Astell, C. Green, and C. Sutherland. (2007). Molecular connexions between dementia and diabetes. Neurosci Biobehav Rev 31 (7):1046-63. 
Coles, M., W. Bicknell, A. A. Watson, D. P. Fairlie, and D. J. Craik. (1998). Solution structure of amyloid beta-peptide(1-40) in a water-micelle environment. Is the membranespanning domain where we think it is? Biochemistry 37 (31):11064-77.

Conover, C. A. (1995). Insulin-like growth factor binding protein proteolysis in bone cell models. Prog Growth Factor Res 6 (2-4):301-9.

Conover, C. A., and L. K. Bale. (2007). Loss of pregnancy-associated plasma protein A extends lifespan in mice. Aging Cell 6 (5):727-9.

Conover, C. A., L. K. Bale, M. T. Overgaard, E. W. Johnstone, U. H. Laursen, E. M. Fuchtbauer, C. Oxvig, and J. van Deursen. (2004). Metalloproteinase pregnancy-associated plasma protein A is a critical growth regulatory factor during fetal development. Development 131 (5):1187-94.

Conover, C. A., G. F. Faessen, K. E. Ilg, Y. A. Chandrasekher, M. Christiansen, M. T. Overgaard, C. Oxvig, and L. C. Giudice. (2001). Pregnancy-associated plasma proteina is the insulin-like growth factor binding protein- 4 protease secreted by human ovarian granulosa cells and is a marker of dominant follicle selection and the corpus luteum. Endocrinology 142 (5):2155.

Coschigano, K. T., D. Clemmons, L. L. Bellush, and J. J. Kopchick. (2000). Assessment of growth parameters and life span of GHR/BP gene-disrupted mice. Endocrinology 141 (7):2608-13.

Coschigano, K. T., A. N. Holland, M. E. Riders, E. O. List, A. Flyvbjerg, and J. J. Kopchick. (2003). Deletion, but not antagonism, of the mouse growth hormone receptor results in severely decreased body weights, insulin, and insulin-like growth factor I levels and increased life span. Endocrinology 144 (9):3799-810.

Costantini, C., H. Scrable, and L. Puglielli. (2006). An aging pathway controls the TrkA to p75NTR receptor switch and amyloid beta-peptide generation. EMBO J 25 (9):19972006.

Couce, M. E., A. J. Weatherington, and J. F. McGinty. (1992). Expression of insulin-like growth factor-II (IGF-II) and IGF-II/mannose-6-phosphate receptor in the rat hippocampus: an in situ hybridization and immunocytochemical study. Endocrinology 131 (4):163642.

Crescenzi, O., S. Tomaselli, R. Guerrini, S. Salvadori, A. M. D'Ursi, P. A. Temussi, and D. Picone. (2002). Solution structure of the Alzheimer amyloid beta-peptide (1-42) in an apolar microenvironment. Similarity with a virus fusion domain. Eur J Biochem 269 (22):5642-8.

D'Ercole, A. J., Z. Dai, Y. Xing, C. Boney, M. B. Wilkie, J. M. Lauder, V. K. Han, and D. R. Clemmons. (1994). Brain growth retardation due to the expression of human insulin like growth factor binding protein-1 in transgenic mice: an in vivo model for the analysis of igf function in the brain. Brain Res Dev Brain Res 82 (1-2):213-22.

Dahlgren, K. N., A. M. Manelli, W. B. Stine, Jr., L. K. Baker, G. A. Krafft, and M. J. LaDu. (2002). Oligomeric and fibrillar species of amyloid-beta peptides differentially affect neuronal viability. J Biol Chem 277 (35):32046-53.

Daitoku, H., M. Hatta, H. Matsuzaki, S. Aratani, T. Ohshima, M. Miyagishi, T. Nakajima, and A. Fukamizu. (2004). Silent information regulator 2 potentiates Foxo1-mediated transcription through its deacetylase activity. Proc Natl Acad Sci U S A 101 (27):100427. 
de la Torre-Ubieta, L., B. Gaudilliere, Y. Yang, Y. Ikeuchi, T. Yamada, S. DiBacco, J. Stegmuller, U. Schuller, D. A. Salih, D. Rowitch, A. Brunet, and A. Bonni. (2010). A FOXO-Pak1 transcriptional pathway controls neuronal polarity. Genes Dev 24 (8):799-813.

De Strooper, B. (2003). Aph-1, Pen-2, and Nicastrin with Presenilin generate an active gammaSecretase complex. Neuron 38 (1):9-12.

Deitel, K., D. Dantzer, P. Ferguson, M. Pollak, W. Beamer, I. Andrulis, and R. Bell. (2002). Reduced growth of human sarcoma xenografts in hosts homozygous for the lit mutation. J Surg Oncol 81 (2):75-9.

Dijkers, P. F., R. H. Medema, J. W. Lammers, L. Koenderman, and P. J. Coffer. (2000). Expression of the pro-apoptotic Bcl-2 family member Bim is regulated by the forkhead transcription factor FKHR-L1. Curr Biol 10 (19):1201-4.

Dijkers, P. F., R. H. Medema, C. Pals, L. Banerji, N. S. Thomas, E. W. Lam, B. M. Burgering, J. A. Raaijmakers, J. W. Lammers, L. Koenderman, and P. J. Coffer. (2000). Forkhead transcription factor FKHR-L1 modulates cytokine-dependent transcriptional regulation of p27(KIP1). Mol Cell Biol 20 (24):9138-48.

Dong, M. Q., J. D. Venable, N. Au, T. Xu, S. K. Park, D. Cociorva, J. R. Johnson, A. Dillin, and J. R. Yates, 3rd. (2007). Quantitative mass spectrometry identifies insulin signaling targets in C. elegans. Science 317 (5838):660-3.

Dore, S., S. Kar, and R. Quirion. (1997). Presence and differential internalization of two distinct insulin-like growth factor receptors in rat hippocampal neurons. Neuroscience 78 (2):373-83.

Duan, C., and Q. Xu. (2005). Roles of insulin-like growth factor (IGF) binding proteins in regulating IGF actions. Gen Comp Endocrinol 142 (1-2):44-52.

Duffy, K. R., W. M. Pardridge, and R. G. Rosenfeld. (1988). Human blood-brain barrier insulinlike growth factor receptor. Metabolism 37 (2):136-40.

Edwards, D. C., L. C. Sanders, G. M. Bokoch, and G. N. Gill. (1999). Activation of LIM-kinase by Pak1 couples Rac/Cdc42 GTPase signalling to actin cytoskeletal dynamics. Nat Cell Biol 1 (5):253-9.

Essers, M. A., S. Weijzen, A. M. de Vries-Smits, I. Saarloos, N. D. de Ruiter, J. L. Bos, and B. M. Burgering. (2004). FOXO transcription factor activation by oxidative stress mediated by the small GTPase Ral and JNK. EMBO J 23 (24):4802-12.

Firth, S. M., and R. C. Baxter. (2002). Cellular actions of the insulin-like growth factor binding proteins. Endocr Rev 23 (6):824-54.

Flachsbart, F., A. Caliebe, R. Kleindorp, H. Blanche, H. von Eller-Eberstein, S. Nikolaus, S. Schreiber, and A. Nebel. (2009). Association of FOXO3A variation with human longevity confirmed in German centenarians. Proc Natl Acad Sci U S A 106 (8):2700-5.

Flaherty, D. B., J. P. Soria, H. G. Tomasiewicz, and J. G. Wood. (2000). Phosphorylation of human tau protein by microtubule-associated kinases: GSK3beta and cdk5 are key participants. J Neurosci Res 62 (3):463-72.

Flurkey, K., J. Papaconstantinou, R. A. Miller, and D. E. Harrison. (2001). Lifespan extension and delayed immune and collagen aging in mutant mice with defects in growth hormone production. Proc Natl Acad Sci U S A 98 (12):6736-41.

Fowlkes, J. L., K. M. Thrailkill, D. M. Serra, K. Suzuki, and H. Nagase. (1995). Matrix metalloproteinases as insulin-like growth factor binding protein-degrading proteinases. Prog Growth Factor Res 6 (2-4):255-63. 
Francis, G. L., F. M. Upton, F. J. Ballard, K. A. McNeil, and J. C. Wallace. (1988). Insulin-like growth factors 1 and 2 in bovine colostrum. Sequences and biological activities compared with those of a potent truncated form. Biochem J 251 (1):95-103.

Frasca, F., G. Pandini, P. Scalia, L. Sciacca, R. Mineo, A. Costantino, I. D. Goldfine, A. Belfiore, and R. Vigneri. (1999). Insulin receptor isoform A, a newly recognized, high-affinity insulin-like growth factor II receptor in fetal and cancer cells. Mol Cell Biol 19 (5):327888.

Fratiglioni, L., S. Paillard-Borg, and B. Winblad. (2004). An active and socially integrated lifestyle in late life might protect against dementia. Lancet Neurol 3 (6):343-53.

Freude, S., M. M. Hettich, C. Schumann, O. Stohr, L. Koch, C. Kohler, M. Udelhoven, U. Leeser, M. Muller, N. Kubota, T. Kadowaki, W. Krone, H. Schroder, J. C. Bruning, and M. Schubert. (2009). Neuronal IGF-1 resistance reduces Abeta accumulation and protects against premature death in a model of Alzheimer's disease. FASEB J 23 (10):3315-24.

Freude, S., K. Schilbach, and M. Schubert. (2009). The role of IGF-1 receptor and insulin receptor signaling for the pathogenesis of Alzheimer's disease: from model organisms to human disease. Curr Alzheimer Res 6 (3):213-23.

Frohman, L. A., and J. O. Jansson. (1986). Growth hormone-releasing hormone. Endocr Rev 7 (3):223-53.

Frolich, L., D. Blum-Degen, H. G. Bernstein, S. Engelsberger, J. Humrich, S. Laufer, D. Muschner, A. Thalheimer, A. Turk, S. Hoyer, R. Zochling, K. W. Boissl, K. Jellinger, and P. Riederer. (1998). Brain insulin and insulin receptors in aging and sporadic Alzheimer's disease. J Neural Transm 105 (4-5):423-38.

Frolich, L., D. Blum-Degen, P. Riederer, and S. Hoyer. (1999). A disturbance in the neuronal insulin receptor signal transduction in sporadic Alzheimer's disease. Ann N Y Acad Sci 893:290-3.

Fruman, D. A., R. E. Meyers, and L. C. Cantley. (1998). Phosphoinositide kinases. Annu Rev Biochem 67:481-507.

Fruman, D.A., L.E. Rameh, and L.C. Cantley. (1999). Phosphoinositide binding domains: Embracing 3-phosphate. Cell. 97(7):817-820

Furuyama, T., T. Nakazawa, I. Nakano, and N. Mori. (2000). Identification of the differential distribution patterns of mRNAs and consensus binding sequences for mouse DAF-16 homologues. Biochem J 349 (Pt 2):629-34.

Gage, P. J., M. L. Roller, T. L. Saunders, L. M. Scarlett, and S. A. Camper. (1996). Anterior pituitary cells defective in the cell-autonomous factor, df, undergo cell lineage specification but not expansion. Development 122 (1):151-60.

Garcia-Segura, L. M., J. Perez, S. Pons, M. T. Rejas, and I. Torres-Aleman. (1991). Localization of insulin-like growth factor I (IGF-I)-like immunoreactivity in the developing and adult rat brain. Brain Res 560 (1-2):167-74.

Georganopoulou, D. G., L. Chang, J. M. Nam, C. S. Thaxton, E. J. Mufson, W. L. Klein, and C. A. Mirkin. (2005). Nanoparticle-based detection in cerebral spinal fluid of a soluble pathogenic biomarker for Alzheimer's disease. Proc Natl Acad Sci U S A 102 (7):2273-6.

Ghahary, A., E. E. Tredget, Q. Shen, R. T. Kilani, P. G. Scott, and Y. Houle. (2000). Mannose-6phosphate/IGF-II receptors mediate the effects of IGF-1-induced latent transforming growth factor beta 1 on expression of type I collagen and collagenase in dermal fibroblasts. Growth Factors 17 (3):167-76. 
Giovannone, B., M.L. Scaldaferri, M. Federici, O. Porzio, D. Lauro, A. Fusco, P. Sbraccia, P. Borboni, R. Lauro and G. Sesti. Insulin receptor substrate (IRS) transduction system: distinct and overlapping signaling potential. (2000). Diabetes Metab Res Rev. 16(6):434441.

Giustina, A., and J. D. Veldhuis. (1998). Pathophysiology of the neuroregulation of growth hormone secretion in experimental animals and the human. Endocr Rev 19 (6):717-97.

Goedert, M., and M. G. Spillantini. (2006). A century of Alzheimer's disease. Science 314 (5800):777-81.

Goldberg, J. L. (2004). Intrinsic neuronal regulation of axon and dendrite growth. Curr Opin Neurobiol 14 (5):551-7.

Goldgaber, D., M. I. Lerman, O. W. McBride, U. Saffiotti, and D. C. Gajdusek. (1987). Characterization and chromosomal localization of a cDNA encoding brain amyloid of Alzheimer's disease. Science 235 (4791):877-80.

Goldstein, B. J., and C. R. Kahn. (1989). Analysis of mRNA heterogeneity by ribonuclease H mapping: application to the insulin receptor. Biochem Biophys Res Commun 159 (2):6649.

Gotz, J., L. M. Ittner, and S. Kins. (2006). Do axonal defects in tau and amyloid precursor protein transgenic animals model axonopathy in Alzheimer's disease? J Neurochem 98 (4):993-1006.

Gual, P., T. Gremeaux, T. Gonzalez, Y. Le Marchand-Brustel, and J. F. Tanti. (2003). MAP kinases and mTOR mediate insulin-induced phosphorylation of insulin receptor substrate-1 on serine residues 307, 612 and 632. Diabetologia 46 (11):1532-42.

Gual, P., Y. Le Marchand-Brustel, and J. F. Tanti. (2005). Positive and negative regulation of insulin signaling through IRS-1 phosphorylation. Biochimie 87 (1):99-109.

Guan, J., H. J. Waldvogel, R. L. Faull, P. D. Gluckman, and C. E. Williams. (1999). The effects of the N-terminal tripeptide of insulin-like growth factor-1, glycine-proline-glutamate in different regions following hypoxic-ischemic brain injury in adult rats. Neuroscience 89 (3):649-59.

Guevara-Aguirre, J., P. Balasubramanian, M. Guevara-Aguirre, M. Wei, F. Madia, C. W. Cheng, D. Hwang, A. Martin-Montalvo, J. Saavedra, S. Ingles, R. de Cabo, P. Cohen, and V. D. Longo. (2011). Growth hormone receptor deficiency is associated with a major reduction in pro-aging signaling, cancer, and diabetes in humans. Sci Transl Med 3 (70):70ra13.

Guillozet-Bongaarts, A. L., M. E. Cahill, V. L. Cryns, M. R. Reynolds, R. W. Berry, and L. I. Binder. (2006). Pseudophosphorylation of tau at serine 422 inhibits caspase cleavage: in vitro evidence and implications for tangle formation in vivo. J Neurochem 97 (4):1005-14.

Haass, C., and D. J. Selkoe. (2007). Soluble protein oligomers in neurodegeneration: lessons from the Alzheimer's amyloid beta-peptide. Nat Rev Mol Cell Biol 8 (2):101-12.

Hanger, D. P., K. Hughes, J. R. Woodgett, J. P. Brion, and B. H. Anderton. (1992). Glycogen synthase kinase-3 induces Alzheimer's disease-like phosphorylation of tau: generation of paired helical filament epitopes and neuronal localisation of the kinase. Neurosci Lett 147 (1):58-62.

Harada, H., B. Becknell, M. Wilm, M. Mann, L. J. Huang, S. S. Taylor, J. D. Scott, and S. J. Korsmeyer. (1999). Phosphorylation and inactivation of BAD by mitochondriaanchored protein kinase A. Mol Cell 3 (4):413-22. 
Hardy, J., and D. J. Selkoe. (2002). The amyloid hypothesis of Alzheimer's disease: progress and problems on the road to therapeutics. Science 297 (5580):353-6.

Harper, J. D., and P. T. Lansbury, Jr. (1997). Models of amyloid seeding in Alzheimer's disease and scrapie: mechanistic truths and physiological consequences of the timedependent solubility of amyloid proteins. Annu Rev Biochem 66:385-407.

Harper, J. D., S. S. Wong, C. M. Lieber, and P. T. Lansbury, Jr. (1999). Assembly of A beta amyloid protofibrils: an in vitro model for a possible early event in Alzheimer's disease. Biochemistry 38 (28):8972-80.

Harrington, S. C., R. D. Simari, and C. A. Conover. (2007). Genetic deletion of pregnancyassociated plasma protein-A is associated with resistance to atherosclerotic lesion development in apolipoprotein E-deficient mice challenged with a high-fat diet. Circ Res 100 (12):1696-702.

Hauck, S. J., J. M. Aaron, C. Wright, J. J. Kopchick, and A. Bartke. (2002). Antioxidant enzymes, free-radical damage, and response to paraquat in liver and kidney of long-living growth hormone receptor/binding protein gene-disrupted mice. Horm Metab Res 34 (9):481-6.

Hauck, S. J., W. S. Hunter, N. Danilovich, J. J. Kopchick, and A. Bartke. (2001). Reduced levels of thyroid hormones, insulin, and glucose, and lower body core temperature in the growth hormone receptor/binding protein knockout mouse. Exp Biol Med (Maywood) $226(6): 552-8$.

Hawkes, C., and S. Kar. (2004). The insulin-like growth factor-II/mannose-6-phosphate receptor: structure, distribution and function in the central nervous system. Brain Res Brain Res Rev 44 (2-3):117-40.

Hayashi, M. L., S. Y. Choi, B. S. Rao, H. Y. Jung, H. K. Lee, D. Zhang, S. Chattarji, A. Kirkwood, and S. Tonegawa. (2004). Altered cortical synaptic morphology and impaired memory consolidation in forebrain- specific dominant-negative PAK transgenic mice. Neuron 42 (5):773-87.

Hayashi, M. L., B. S. Rao, J. S. Seo, H. S. Choi, B. M. Dolan, S. Y. Choi, S. Chattarji, and S. Tonegawa. (2007). Inhibition of p21-activated kinase rescues symptoms of fragile $X$ syndrome in mice. Proc Natl Acad Sci U S A 104 (27):11489-94.

Herschkovitz, A., Y. F. Liu, E. Ilan, D. Ronen, S. Boura-Halfon, and Y. Zick. (2007). Common inhibitory serine sites phosphorylated by IRS-1 kinases, triggered by insulin and inducers of insulin resistance. J Biol Chem 282 (25):18018-27.

Hirokawa, N., T. Funakoshi, R. Sato-Harada, and Y. Kanai. (1996). Selective stabilization of tau in axons and microtubule-associated protein $2 \mathrm{C}$ in cell bodies and dendrites contributes to polarized localization of cytoskeletal proteins in mature neurons. J Cell Biol 132 (4):667-79.

Ho, L., W. Qin, P. N. Pompl, Z. Xiang, J. Wang, Z. Zhao, Y. Peng, G. Cambareri, A. Rocher, C. V. Mobbs, P. R. Hof, and G. M. Pasinetti. (2004). Diet-induced insulin resistance promotes amyloidosis in a transgenic mouse model of Alzheimer's disease. FASEB J 18 (7):902-4.

Hoeflich, A., R. Reisinger, B. S. Schuett, M. W. Elmlinger, V. C. Russo, G. A. Vargas, P. M. Jehle, H. Lahm, I. Renner-Muller, and E. Wolf. (2004). Peri/nuclear localization of intact insulin-like growth factor binding protein-2 and a distinct carboxyl-terminal IGFBP-2 fragment in vivo. Biochem Biophys Res Commun 324 (2):705-10. 
Hoekman, M. F., F. M. Jacobs, M. P. Smidt, and J. P. Burbach. (2006). Spatial and temporal expression of FoxO transcription factors in the developing and adult murine brain. Gene Expr Patterns 6 (2):134-40.

Holzenberger, M., J. Dupont, B. Ducos, P. Leneuve, A. Geloen, P. C. Even, P. Cervera, and Y. Le Bouc. (2003). IGF-1 receptor regulates lifespan and resistance to oxidative stress in mice. Nature 421 (6919):182-7.

Holzenberger, M., G. Hamard, R. Zaoui, P. Leneuve, B. Ducos, C. Beccavin, L. Perin, and Y. Le Bouc. (2001). Experimental IGF-I receptor deficiency generates a sexually dimorphic pattern of organ-specific growth deficits in mice, affecting fat tissue in particular. Endocrinology 142 (10):4469-78.

Hresko, R. C., H. Murata, and M. Mueckler. (2003). Phosphoinositide-dependent kinase-2 is a distinct protein kinase enriched in a novel cytoskeletal fraction associated with adipocyte plasma membranes. J Biol Chem 278 (24):21615-22.

Hsu, A. L., C. T. Murphy, and C. Kenyon. (2003). Regulation of aging and age-related disease by DAF-16 and heat-shock factor. Science 300 (5622):1142-5.

Huang, H., K. M. Regan, F. Wang, D. Wang, D. I. Smith, J. M. van Deursen, and D. J. Tindall. (2005). Skp2 inhibits FOXO1 in tumor suppression through ubiquitin-mediated degradation. Proc Natl Acad Sci U S A 102 (5):1649-54.

Huang, H., and D. J. Tindall. (2007). Dynamic FoxO transcription factors. J Cell Sci 120 (Pt 15):2479-87.

Hunter, W. S., W. B. Croson, A. Bartke, M. V. Gentry, and C. J. Meliska. (1999). Low body temperature in long-lived Ames dwarf mice at rest and during stress. Physiol Behav 67 (3):433-7.

Hwangbo, D. S., B. Gershman, M. P. Tu, M. Palmer, and M. Tatar. (2004). Drosophila dFOXO controls lifespan and regulates insulin signalling in brain and fat body. Nature 429 (6991):562-6.

Ikeno, Y., R. T. Bronson, G. B. Hubbard, S. Lee, and A. Bartke. (2003). Delayed occurrence of fatal neoplastic diseases in ames dwarf mice: correlation to extended longevity. $J$ Gerontol A Biol Sci Med Sci 58 (4):291-6.

Ikeya, T., M. Galic, P. Belawat, K. Nairz, and E. Hafen. (2002). Nutrient-dependent expression of insulin-like peptides from neuroendocrine cells in the CNS contributes to growth regulation in Drosophila. Curr Biol 12 (15):1293-300.

Iser, W. B., M. S. Gami, and C. A. Wolkow. (2007). Insulin signaling in Caenorhabditis elegans regulates both endocrine-like and cell-autonomous outputs. Dev Biol 303 (2):434-47.

Isgaard, J., L. Carlsson, O. G. Isaksson, and J. O. Jansson. (1988). Pulsatile intravenous growth hormone $(\mathrm{GH})$ infusion to hypophysectomized rats increases insulin-like growth factor I messenger ribonucleic acid in skeletal tissues more effectively than continuous GH infusion. Endocrinology 123 (6):2605-10.

Ittner, L. M., Y. D. Ke, F. Delerue, M. Bi, A. Gladbach, J. van Eersel, H. Wolfing, B. C. Chieng, M. J. Christie, I. A. Napier, A. Eckert, M. Staufenbiel, E. Hardeman, and J. Gotz. (2010). Dendritic function of tau mediates amyloid-beta toxicity in Alzheimer's disease mouse models. Cell 142 (3):387-97.

Iwatsubo, T., A. Odaka, N. Suzuki, H. Mizusawa, N. Nukina, and Y. Ihara. (1994). Visualization of A beta 42(43) and A beta 40 in senile plaques with end-specific A beta monoclonals: evidence that an initially deposited species is A beta 42(43). Neuron 13 (1):45-53. 
Jacobs, F. M., L. P. van der Heide, P. J. Wijchers, J. P. Burbach, M. F. Hoekman, and M. P. Smidt. (2003). FoxO6, a novel member of the FoxO class of transcription factors with distinct shuttling dynamics. J Biol Chem 278 (38):35959-67.

Jacobs, S., F. C. Kull, Jr., H. S. Earp, M. E. Svoboda, J. J. Van Wyk, and P. Cuatrecasas. (1983). Somatomedin-C stimulates the phosphorylation of the beta-subunit of its own receptor. J Biol Chem 258 (16):9581-4.

Jaffe, C. A., B. Ocampo-Lim, W. Guo, K. Krueger, I. Sugahara, R. DeMott-Friberg, M. Bermann, and A. L. Barkan. (1998). Regulatory mechanisms of growth hormone secretion are sexually dimorphic. J Clin Invest 102 (1):153-64.

Jan, Y. N., and L. Y. Jan. (2003). The control of dendrite development. Neuron 40 (2):229-42.

Janson, J., T. Laedtke, J. E. Parisi, P. O'Brien, R. C. Petersen, and P. C. Butler. (2004). Increased risk of type 2 diabetes in Alzheimer disease. Diabetes 53 (2):474-81.

Jansson, J. O., S. Eden, and O. Isaksson. (1985). Sexual dimorphism in the control of growth hormone secretion. Endocr Rev 6 (2):128-50.

Jessup, S. K., E. V. Dimaraki, K. V. Symons, and A. L. Barkan. (2003). Sexual dimorphism of growth hormone $(\mathrm{GH})$ regulation in humans: endogenous GH-releasing hormone maintains basal GH in women but not in men. J Clin Endocrinol Metab 88 (10):4776-80.

Jin, M. H., Y. H. Lee, J. M. Kim, H. N. Sun, E. Y. Moon, M. H. Shong, S. U. Kim, S. H. Lee, T. H. Lee, D. Y. Yu, and D. S. Lee. (2005). Characterization of neural cell types expressing peroxiredoxins in mouse brain. Neurosci Lett 381 (3):252-7.

Jones, J. I., and D. R. Clemmons. (1995). Insulin-like growth factors and their binding proteins: biological actions. Endocr Rev 16 (1):3-34.

Junger, M. A., F. Rintelen, H. Stocker, J. D. Wasserman, M. Vegh, T. Radimerski, M. E. Greenberg, and E. Hafen. (2003). The Drosophila forkhead transcription factor FOXO mediates the reduction in cell number associated with reduced insulin signaling. $J$ Biol 2 (3):20.

Kang, J., H. G. Lemaire, A. Unterbeck, J. M. Salbaum, C. L. Masters, K. H. Grzeschik, G. Multhaup, K. Beyreuther, and B. Muller-Hill. (1987). The precursor of Alzheimer's disease amyloid A4 protein resembles a cell-surface receptor. Nature 325 (6106):733-6.

Kang, J., and B. Muller-Hill. (1990). Differential splicing of Alzheimer's disease amyloid A4 precursor RNA in rat tissues: PreA4(695) mRNA is predominantly produced in rat and human brain. Biochem Biophys Res Commun 166 (3):1192-200.

Kappeler, L., C. De Magalhaes Filho, J. Dupont, P. Leneuve, P. Cervera, L. Perin, C. Loudes, A. Blaise, R. Klein, J. Epelbaum, Y. Le Bouc, and M. Holzenberger. (2008). Brain IGF-1 receptors control mammalian growth and lifespan through a neuroendocrine mechanism. PLoS Biol 6 (10):e254.

Kasuga, M., F. A. Karlsson, and C. R. Kahn. (1982). Insulin stimulates the phosphorylation of the 95,000-dalton subunit of its own receptor. Science 215 (4529):185-7.

Kasuga, M., Y. Zick, D. L. Blithe, M. Crettaz, and C. R. Kahn. (1982). Insulin stimulates tyrosine phosphorylation of the insulin receptor in a cell-free system. Nature 298 (5875):667-9.

Kelley, K. M., Y. Oh, S. E. Gargosky, Z. Gucev, T. Matsumoto, V. Hwa, L. Ng, D. M. Simpson, and R. G. Rosenfeld. (1996). Insulin-like growth factor-binding proteins (IGFBPs) and their regulatory dynamics. Int J Biochem Cell Biol 28 (6):619-37.

Kenyon, C. (2005). The plasticity of aging: insights from long-lived mutants. Cell 120 (4):449-60.

Kenyon, C., J. Chang, E. Gensch, A. Rudner, and R. Tabtiang. (1993). A C. elegans mutant that lives twice as long as wild type. Nature 366 (6454):461-4. 
Kenyon, C. J. (2010). The genetics of ageing. Nature 464 (7288):504-12.

Khan, A. S., C. D. Lynch, D. C. Sane, M. C. Willingham, and W. E. Sonntag. (2001). Growth hormone increases regional coronary blood flow and capillary density in aged rats. $J$ Gerontol A Biol Sci Med Sci 56 (8):B364-71.

Kheterpal, I., H. A. Lashuel, D. M. Hartley, T. Walz, P. T. Lansbury, Jr., and R. Wetzel. (2003). Abeta protofibrils possess a stable core structure resistant to hydrogen exchange. Biochemistry 42 (48):14092-8.

Kiess, W., Y. Yang, U. Kessler, and A. Hoeflich. (1994). Insulin-like growth factor II (IGF-II) and the IGF-II/mannose-6-phosphate receptor: the myth continues. Horm Res 41 Suppl 2:66-73.

Killick, R., G. Scales, K. Leroy, M. Causevic, C. Hooper, E. E. Irvine, A. I. Choudhury, L. Drinkwater, F. Kerr, H. Al-Qassab, J. Stephenson, Z. Yilmaz, K. P. Giese, J. P. Brion, D. J. Withers, and S. Lovestone. (2009). Deletion of Irs2 reduces amyloid deposition and rescues behavioural deficits in APP transgenic mice. Biochem Biophys Res Commun 386 (1):257-62.

Kim, H. S., S. R. Nagalla, Y. Oh, E. Wilson, C. T. Roberts, Jr., and R. G. Rosenfeld. (1997). Identification of a family of low-affinity insulin-like growth factor binding proteins (IGFBPs): characterization of connective tissue growth factor as a member of the IGFBP superfamily. Proc Natl Acad Sci U S A 94 (24):12981-6.

Kinney, B. A., K. T. Coschigano, J. J. Kopchick, R. W. Steger, and A. Bartke. (2001). Evidence that age-induced decline in memory retention is delayed in growth hormone resistant GH-R-KO (Laron) mice. Physiol Behav 72 (5):653-60.

Kitamura, Y. I., T. Kitamura, J. P. Kruse, J. C. Raum, R. Stein, W. Gu, and D. Accili. (2005). FoxO1 protects against pancreatic beta cell failure through NeuroD and MafA induction. Cell Metab 2 (3):153-63.

Klein, W. L., W. B. Stine, Jr., and D. B. Teplow. (2004). Small assemblies of unmodified amyloid beta-protein are the proximate neurotoxin in Alzheimer's disease. Neurobiol Aging 25 (5):569-80.

Kops, G. J., T. B. Dansen, P. E. Polderman, I. Saarloos, K. W. Wirtz, P. J. Coffer, T. T. Huang, J. L. Bos, R. H. Medema, and B. M. Burgering. (2002). Forkhead transcription factor FOXO3a protects quiescent cells from oxidative stress. Nature 419 (6904):316-21.

Kops, G. J., N. D. de Ruiter, A. M. De Vries-Smits, D. R. Powell, J. L. Bos, and B. M. Burgering. (1999). Direct control of the Forkhead transcription factor AFX by protein kinase B. Nature 398 (6728):630-4.

Kuningas, M., R. Magi, R. G. Westendorp, P. E. Slagboom, M. Remm, and D. van Heemst. (2007). Haplotypes in the human Foxola and Foxo3a genes; impact on disease and mortality at old age. Eur J Hum Genet 15 (3):294-301.

Lambert, M. P., A. K. Barlow, B. A. Chromy, C. Edwards, R. Freed, M. Liosatos, T. E. Morgan, I. Rozovsky, B. Trommer, K. L. Viola, P. Wals, C. Zhang, C. E. Finch, G. A. Krafft, and W. L. Klein. (1998). Diffusible, nonfibrillar ligands derived from Abeta1-42 are potent central nervous system neurotoxins. Proc Natl Acad Sci U S A 95 (11):6448-53.

Lanz, T. A., C. T. Salatto, A. R. Semproni, M. Marconi, T. M. Brown, K. E. Richter, K. Schmidt, F. R. Nelson, and J. B. Schachter. (2008). Peripheral elevation of IGF-1 fails to alter Abeta clearance in multiple in vivo models. Biochem Pharmacol 75 (5):1093-103. 
Lavan, B. E., V. R. Fantin, E. T. Chang, W. S. Lane, S. R. Keller, and G. E. Lienhard. (1997). A novel $160-\mathrm{kDa}$ phosphotyrosine protein in insulin-treated embryonic kidney cells is a new member of the insulin receptor substrate family. J Biol Chem 272 (34):21403-7.

Lavan, B. E., W. S. Lane, and G. E. Lienhard. (1997). The 60-kDa phosphotyrosine protein in insulin-treated adipocytes is a new member of the insulin receptor substrate family. J Biol Chem 272 (17):11439-43.

Lawlor, M. A., and D. R. Alessi. (2001). PKB/Akt: a key mediator of cell proliferation, survival and insulin responses? J Cell Sci 114 (Pt 16):2903-10.

Lawrence, J. B., C. Oxvig, M. T. Overgaard, L. Sottrup-Jensen, G. J. Gleich, L. G. Hays, J. R. Yates, 3rd, and C. A. Conover. (1999). The insulin-like growth factor (IGF)-dependent IGF binding protein-4 protease secreted by human fibroblasts is pregnancyassociated plasma protein-A. Proc Natl Acad Sci U S A 96 (6):3149-53.

Lee, K. S., K. Iijima-Ando, K. Iijima, W. J. Lee, J. H. Lee, K. Yu, and D. S. Lee. (2009). JNK/FOXO-mediated neuronal expression of fly homologue of peroxiredoxin II reduces oxidative stress and extends life span. J Biol Chem 284 (43):29454-61.

LeRoith, D. (2000). Insulin-like growth factor I receptor signaling--overlapping or redundant pathways? Endocrinology 141 (4):1287-8.

Lesne, S., M. T. Koh, L. Kotilinek, R. Kayed, C. G. Glabe, A. Yang, M. Gallagher, and K. H. Ashe. (2006). A specific amyloid-beta protein assembly in the brain impairs memory. Nature 440 (7082):352-7.

Leung, K. C., G. Johannsson, G. M. Leong, and K. K. Ho. (2004). Estrogen regulation of growth hormone action. Endocr Rev 25 (5):693-721.

LeVine, H., 3rd. (1999). Quantification of beta-sheet amyloid fibril structures with thioflavin T. Methods Enzymol 309:274-84.

Li, M., J. Luo, C. L. Brooks, and W. Gu. (2002). Acetylation of p53 inhibits its ubiquitination by Mdm2. J Biol Chem 277 (52):50607-11.

Li, W., S. G. Kennedy, and G. Ruvkun. (2003). daf-28 encodes a C. elegans insulin superfamily member that is regulated by environmental cues and acts in the DAF-2 signaling pathway. Genes Dev 17 (7):844-58.

Li, Y., Y. He, L. Qi, V. W. Jaddoe, E. J. Feskens, X. Yang, G. Ma, and F. B. Hu. (2010). Exposure to the Chinese famine in early life and the risk of hyperglycemia and type 2 diabetes in adulthood. Diabetes 59 (10):2400-6.

Li, Y., V. W. Jaddoe, L. Qi, Y. He, D. Wang, J. Lai, J. Zhang, P. Fu, X. Yang, and F. B. Hu. (2011). Exposure to the Chinese Famine in Early Life and the Risk of Metabolic Syndrome in Adulthood. Diabetes Care.

Li, Y., W. J. Wang, H. Cao, J. Lu, C. Wu, F. Y. Hu, J. Guo, L. Zhao, F. Yang, Y. X. Zhang, W. Li, G. Y. Zheng, H. Cui, X. Chen, Z. Zhu, H. He, B. Dong, X. Mo, Y. Zeng, and X. L. Tian. (2009). Genetic association of FOXO1A and FOXO3A with longevity trait in Han Chinese populations. Hum Mol Genet 18 (24):4897-904.

Liang, H., E. J. Masoro, J. F. Nelson, R. Strong, C. A. McMahan, and A. Richardson. (2003). Genetic mouse models of extended lifespan. Exp Gerontol 38 (11-12):1353-64.

Lim, Y. S., M. K. Cha, H. K. Kim, T. B. Uhm, J. W. Park, K. Kim, and I. H. Kim. (1993). Removals of hydrogen peroxide and hydroxyl radical by thiol-specific antioxidant protein as a possible role in vivo. Biochem Biophys Res Commun 192 (1):273-80. 
Lin, K., J. B. Dorman, A. Rodan, and C. Kenyon. (1997). daf-16: An HNF-3/forkhead family member that can function to double the life-span of Caenorhabditis elegans. Science 278 (5341):1319-22.

Lin, M. T., and M. F. Beal. (2006). Mitochondrial dysfunction and oxidative stress in neurodegenerative diseases. Nature 443 (7113):787-95.

Lindeboom, M., F. Portrait, and G. J. van den Berg. (2010). Long-run effects on longevity of a nutritional shock early in life: the Dutch Potato famine of 1846-1847. J Health Econ 29 (5):617-29.

Liu, J. P., J. Baker, A. S. Perkins, E. J. Robertson, and A. Efstratiadis. (1993). Mice carrying null mutations of the genes encoding insulin-like growth factor I (Igf-1) and type 1 IGF receptor (Igf1r). Cell 75 (1):59-72.

Liu, R., X. W. Zhou, H. Tanila, C. Bjorkdahl, J. Z. Wang, Z. Z. Guan, Y. Cao, J. A. Gustafsson, B. Winblad, and J. J. Pei. (2008). Phosphorylated PP2A (tyrosine 307) is associated with Alzheimer neurofibrillary pathology. J Cell Mol Med 12 (1):241-57.

Lopez-Lopez, C., D. LeRoith, and I. Torres-Aleman. (2004). Insulin-like growth factor I is required for vessel remodeling in the adult brain. Proc Natl Acad Sci U S A 101 (26):9833-8.

Louvi, A., D. Accili, and A. Efstratiadis. (1997). Growth-promoting interaction of IGF-II with the insulin receptor during mouse embryonic development. Dev Biol 189 (1):33-48.

Luchsinger, J. A., M. X. Tang, S. Shea, and R. Mayeux. (2004). Hyperinsulinemia and risk of Alzheimer disease. Neurology 63 (7):1187-92.

Luo, M., P. Langlais, Z. Yi, N. Lefort, E. A. De Filippis, H. Hwang, C. Y. Christ-Roberts, and L. J. Mandarino. (2007). Phosphorylation of human insulin receptor substrate-1 at Serine 629 plays a positive role in insulin signaling. Endocrinology 148 (10):4895-905.

Luo, M., S. Reyna, L. Wang, Z. Yi, C. Carroll, L. Q. Dong, P. Langlais, S. T. Weintraub, and L. J. Mandarino. (2005). Identification of insulin receptor substrate 1 serine/threonine phosphorylation sites using mass spectrometry analysis: regulatory role of serine 1223. Endocrinology 146 (10):4410-6.

Luo, Z. C., W. D. Fraser, P. Julien, C. L. Deal, F. Audibert, G. N. Smith, X. Xiong, and M. Walker. (2006). Tracing the origins of "fetal origins" of adult diseases: programming by oxidative stress? Med Hypotheses 66 (1):38-44.

Maile, L. A., and J. M. Holly. (1999). Insulin-like growth factor binding protein (IGFBP) proteolysis: occurrence, identification, role and regulation. Growth Horm IGF Res 9 (2):85-95.

Major, J. M., G. A. Laughlin, D. Kritz-Silverstein, D. L. Wingard, and E. Barrett-Connor. (2010). Insulin-like growth factor-I and cancer mortality in older men. J Clin Endocrinol Metab 95 (3):1054-9.

Marks, J. L., D. Porte, Jr., and D. G. Baskin. (1991). Localization of type I insulin-like growth factor receptor messenger RNA in the adult rat brain by in situ hybridization. Mol Endocrinol 5 (8):1158-68.

Masters, C. L., G. Simms, N. A. Weinman, G. Multhaup, B. L. McDonald, and K. Beyreuther. (1985). Amyloid plaque core protein in Alzheimer disease and Down syndrome. Proc Natl Acad Sci U S A 82 (12):4245-9.

Matsuo, K., M. Niwa, M. Kurihara, K. Shigematsu, S. Yamashita, M. Ozaki, and S. Nagataki. (1989). Receptor autoradiographic analysis of insulin-like growth factor-I (IGF-I) binding sites in rat forebrain and pituitary gland. Cell Mol Neurobiol 9 (3):357-67. 
Matthieu, J. M., S. Widmer, and N. Herschkowitz. (1973). Biochemical changes in mouse brain composition during myelination. Brain Res 55 (2):391-402.

McClain, D. A. (1991). Different ligand affinities of the two human insulin receptor splice variants are reflected in parallel changes in sensitivity for insulin action. Mol Endocrinol 5 (5):734-9.

McLean, C. A., R. A. Cherny, F. W. Fraser, S. J. Fuller, M. J. Smith, K. Beyreuther, A. I. Bush, and C. L. Masters. (1999). Soluble pool of Abeta amyloid as a determinant of severity of neurodegeneration in Alzheimer's disease. Ann Neurol 46 (6):860-6.

McMorris, F. A., and M. Dubois-Dalcq. (1988). Insulin-like growth factor I promotes cell proliferation and oligodendroglial commitment in rat glial progenitor cells developing in vitro. J Neurosci Res 21 (2-4):199-209.

McMorris, F. A., T. M. Smith, S. DeSalvo, and R. W. Furlanetto. (1986). Insulin-like growth factor I/somatomedin C: a potent inducer of oligodendrocyte development. Proc Natl Acad Sci U S A 83 (3):822-6.

Medema, R. H., G. J. Kops, J. L. Bos, and B. M. Burgering. (2000). AFX-like Forkhead transcription factors mediate cell-cycle regulation by Ras and PKB through p27kip1. Nature 404 (6779):782-7.

Michaluk, P., and L. Kaczmarek. (2007). Matrix metalloproteinase-9 in glutamate-dependent adult brain function and dysfunction. Cell Death Differ 14 (7):1255-8.

Miller, R. A., J. M. Harper, A. Galecki, and D. T. Burke. (2002). Big mice die young: early life body weight predicts longevity in genetically heterogeneous mice. Aging Cell 1 (1):229.

Millward, T. A., S. Zolnierowicz, and B. A. Hemmings. (1999). Regulation of protein kinase cascades by protein phosphatase 2A. Trends Biochem Sci 24 (5):186-91.

Mohan, S., and D. J. Baylink. (2002). IGF-binding proteins are multifunctional and act via IGFdependent and -independent mechanisms. J Endocrinol 175 (1):19-31.

Mohseni-Zadeh, S., and M. Binoux. (1997). Insulin-like growth factor (IGF) binding protein-3 interacts with the type 1 IGF receptor, reducing the affinity of the receptor for its ligand: an alternative mechanism in the regulation of IGF action. Endocrinology 138 (12):5645-8.

Moller, D. E., A. Yokota, J. F. Caro, and J. S. Flier. (1989). Tissue-specific expression of two alternatively spliced insulin receptor mRNAs in man. Mol Endocrinol 3 (8):1263-9.

Moloney, A. M., R. J. Griffin, S. Timmons, R. O'Connor, R. Ravid, and C. O'Neill. (2010). Defects in IGF-1 receptor, insulin receptor and IRS-1/2 in Alzheimer's disease indicate possible resistance to IGF-1 and insulin signalling. Neurobiol Aging 31 (2):22443.

Morell, P., S. Greenfield, E. Costantino-Ceccarini, and H. Wisniewski. (1972). Changes in the protein composition of mouse brain myelin during development. J Neurochem 19 (11):2545-54.

Morgan, D. O., J. C. Edman, D. N. Standring, V. A. Fried, M. C. Smith, R. A. Roth, and W. J. Rutter. (1987). Insulin-like growth factor II receptor as a multifunctional binding protein. Nature 329 (6137):301-7.

Morris, J. Z., H. A. Tissenbaum, and G. Ruvkun. (1996). A phosphatidylinositol-3-OH kinase family member regulating longevity and diapause in Caenorhabditis elegans. Nature 382 (6591):536-9. 
Moxham, C. P., V. Duronio, and S. Jacobs. (1989). Insulin-like growth factor I receptor betasubunit heterogeneity. Evidence for hybrid tetramers composed of insulin-like growth factor I and insulin receptor heterodimers. J Biol Chem 264 (22):13238-44.

Mozell, R. L., and F. A. McMorris. (1991). Insulin-like growth factor I stimulates oligodendrocyte development and myelination in rat brain aggregate cultures. $J$ Neurosci Res 30 (2):382-90.

Muller-Hill, B., and K. Beyreuther. (1989). Molecular biology of Alzheimer's disease. Annu Rev Biochem 58:287-307.

Mullis, P. E. (2005). Genetic control of growth. Eur J Endocrinol 152 (1):11-31.

Murakami, S. (2007). Caenorhabditis elegans as a model system to study aging of learning and memory. Mol Neurobiol 35 (1):85-94.

Murakami, S., A. Salmon, and R. A. Miller. (2003). Multiplex stress resistance in cells from long-lived dwarf mice. FASEB J 17 (11):1565-6.

Nakagawa, T., H. Zhu, N. Morishima, E. Li, J. Xu, B. A. Yankner, and J. Yuan. (2000). Caspase12 mediates endoplasmic-reticulum-specific apoptosis and cytotoxicity by amyloidbeta. Nature 403 (6765):98-103.

Nikolic, M. (2008). The Pak1 kinase: an important regulator of neuronal morphology and function in the developing forebrain. Mol Neurobiol 37 (2-3):187-202.

Nishijima, T., J. Piriz, S. Duflot, A. M. Fernandez, G. Gaitan, U. Gomez-Pinedo, J. M. Verdugo, F. Leroy, H. Soya, A. Nunez, and I. Torres-Aleman. (2010). Neuronal activity drives localized blood-brain-barrier transport of serum insulin-like growth factor-I into the CNS. Neuron 67 (5):834-46.

Nojima, H., C. Tokunaga, S. Eguchi, N. Oshiro, S. Hidayat, K. Yoshino, K. Hara, N. Tanaka, J. Avruch, and K. Yonezawa. (2003). The mammalian target of rapamycin (mTOR) partner, raptor, binds the mTOR substrates p70 S6 kinase and 4E-BP1 through their TOR signaling (TOS) motif. J Biol Chem 278 (18):15461-4.

Ogasawara, M., K. P. Karey, H. Marquardt, and D. A. Sirbasku. (1989). Identification and purification of truncated insulin-like growth factor I from porcine uterus. Evidence for high biological potency. Biochemistry 28 (6):2710-21.

Ogg, S., S. Paradis, S. Gottlieb, G. I. Patterson, L. Lee, H. A. Tissenbaum, and G. Ruvkun. (1997). The Fork head transcription factor DAF-16 transduces insulin-like metabolic and longevity signals in C. elegans. Nature 389 (6654):994-9.

Oh, Y., M. W. Beukers, H. M. Pham, P. A. Smanik, M. C. Smith, and R. G. Rosenfeld. (1991). Altered affinity of insulin-like growth factor II (IGF-II) for receptors and IGF-binding proteins, resulting from limited modifications of the IGF-II molecule. Biochem J 278 ( Pt 1):249-54.

Oh, Y., H. L. Muller, G. Lamson, and R. G. Rosenfeld. (1993). Insulin-like growth factor (IGF)independent action of IGF-binding protein-3 in Hs578T human breast cancer cells. Cell surface binding and growth inhibition. J Biol Chem 268 (20):14964-71.

Ohlsson, C., S. Mohan, K. Sjogren, A. Tivesten, J. Isgaard, O. Isaksson, J. O. Jansson, and J. Svensson. (2009). The role of liver-derived insulin-like growth factor-I. Endocr Rev 30 (5):494-535.

Orme, S. M., R. J. McNally, R. A. Cartwright, and P. E. Belchetz. (1998). Mortality and cancer incidence in acromegaly: a retrospective cohort study. United Kingdom Acromegaly Study Group. J Clin Endocrinol Metab 83 (8):2730-4. 
Oshiro, N., K. Yoshino, S. Hidayat, C. Tokunaga, K. Hara, S. Eguchi, J. Avruch, and K. Yonezawa. (2004). Dissociation of raptor from mTOR is a mechanism of rapamycininduced inhibition of mTOR function. Genes Cells 9 (4):359-66.

Ott, A., R. P. Stolk, A. Hofman, F. van Harskamp, D. E. Grobbee, and M. M. Breteler. (1996). Association of diabetes mellitus and dementia: the Rotterdam Study. Diabetologia 39 (11):1392-7.

Ott, A., R. P. Stolk, F. van Harskamp, H. A. Pols, A. Hofman, and M. M. Breteler. (1999). Diabetes mellitus and the risk of dementia: The Rotterdam Study. Neurology 53 (9):1937-42.

Ott, A., C. T. van Rossum, F. van Harskamp, H. van de Mheen, A. Hofman, and M. M. Breteler. (1999). Education and the incidence of dementia in a large population-based study: the Rotterdam Study. Neurology 52 (3):663-6.

P, E. Mullis. (2010). Genetics of isolated growth hormone deficiency. J Clin Res Pediatr Endocrinol 2 (2):52-62.

Painter, R. C., T. J. Roseboom, and O. P. Bleker. (2005). Prenatal exposure to the Dutch famine and disease in later life: an overview. Reprod Toxicol 20 (3):345-52.

Pan, W., and A. J. Kastin. (2000). Interactions of IGF-1 with the blood-brain barrier in vivo and in situ. Neuroendocrinology 72 (3):171-8.

Pandini, G., F. Frasca, R. Mineo, L. Sciacca, R. Vigneri, and A. Belfiore. (2002). Insulin/insulinlike growth factor I hybrid receptors have different biological characteristics depending on the insulin receptor isoform involved. J Biol Chem 277 (42):39684-95.

Paradis, S., and G. Ruvkun. (1998). Caenorhabditis elegans Akt/PKB transduces insulin receptor-like signals from AGE-1 PI3 kinase to the DAF-16 transcription factor. Genes Dev 12 (16):2488-98.

Partridge, L., and J. C. Bruning. (2008). Forkhead transcription factors and ageing. Oncogene 27 (16):2351-63.

Pawlikowska, L., D. Hu, S. Huntsman, A. Sung, C. Chu, J. Chen, A. H. Joyner, N. J. Schork, W. C. Hsueh, A. P. Reiner, B. M. Psaty, G. Atzmon, N. Barzilai, S. R. Cummings, W. S. Browner, P. Y. Kwok, and E. Ziv. (2009). Association of common genetic variation in the insulin/IGF1 signaling pathway with human longevity. Aging Cell 8 (4):460-72.

Pierce, S. B., M. Costa, R. Wisotzkey, S. Devadhar, S. A. Homburger, A. R. Buchman, K. C. Ferguson, J. Heller, D. M. Platt, A. A. Pasquinelli, L. X. Liu, S. K. Doberstein, and G. Ruvkun. (2001). Regulation of DAF-2 receptor signaling by human insulin and ins-1, a member of the unusually large and diverse C. elegans insulin gene family. Genes Dev 15 (6):672-86.

Pilcher, H. (2006). Alzheimer's disease could be "type 3 diabetes". Lancet Neurol 5 (5):388-9.

Piper, M. D., C. Selman, J. J. McElwee, and L. Partridge. (2008). Separating cause from effect: how does insulin/IGF signalling control lifespan in worms, flies and mice? J Intern Med 263 (2):179-91.

Pollak, M. N., E. S. Schernhammer, and S. E. Hankinson. (2004). Insulin-like growth factors and neoplasia. Nat Rev Cancer 4 (7):505-18.

Polleux, F., G. Ince-Dunn, and A. Ghosh. (2007). Transcriptional regulation of vertebrate axon guidance and synapse formation. Nat Rev Neurosci 8 (5):331-40.

Poretsky, L., N. A. Cataldo, Z. Rosenwaks, and L. C. Giudice. (1999). The insulin-related ovarian regulatory system in health and disease. Endocr Rev 20 (4):535-82. 
Puglielli, L. (2008). Aging of the brain, neurotrophin signaling, and Alzheimer's disease: is IGF1-R the common culprit? Neurobiol Aging 29 (6):795-811.

Puglielli, L., B. C. Ellis, A. J. Saunders, and D. M. Kovacs. (2003). Ceramide stabilizes beta-site amyloid precursor protein-cleaving enzyme 1 and promotes amyloid beta-peptide biogenesis. J Biol Chem 278 (22):19777-83.

Puig, O., M. T. Marr, M. L. Ruhf, and R. Tjian. (2003). Control of cell number by Drosophila FOXO: downstream and feedback regulation of the insulin receptor pathway. Genes Dev 17 (16):2006-20.

Qin, X., D. D. Strong, D. J. Baylink, and S. Mohan. (1998). Structure-function analysis of the human insulin-like growth factor binding protein-4. J Biol Chem 273 (36):23509-16.

Radulescu, R. T. (1994). Nuclear localization signal in insulin-like growth factor-binding protein type 3. Trends Biochem Sci 19 (7):278.

Rajah, R., L. Katz, S. Nunn, P. Solberg, T. Beers, and P. Cohen. (1995). Insulin-like growth factor binding protein (IGFBP) proteases: functional regulators of cell growth. Prog Growth Factor Res 6 (2-4):273-84.

Rajaram, S., D. J. Baylink, and S. Mohan. (1997). Insulin-like growth factor-binding proteins in serum and other biological fluids: regulation and functions. Endocr Rev 18 (6):801-31.

Ravelli, A. C., J. H. van der Meulen, R. P. Michels, C. Osmond, D. J. Barker, C. N. Hales, and O. P. Bleker. (1998). Glucose tolerance in adults after prenatal exposure to famine. Lancet 351 (9097):173-7.

Ravelli, A. C., J. H. van Der Meulen, C. Osmond, D. J. Barker, and O. P. Bleker. (1999). Obesity at the age of $50 \mathrm{y}$ in men and women exposed to famine prenatally. Am J Clin Nutr 70 (5):811-6.

Rechler, M. M. (1993). Insulin-like growth factor binding proteins. Vitam Horm 47:1-114.

Rechler, M. M., and D. R. Clemmons. (1998). Regulatory Actions of Insulin-like Growth Factorbinding Proteins. Trends Endocrinol Metab 9 (5):176-83.

Rena, G., S. Guo, S. C. Cichy, T. G. Unterman, and P. Cohen. (1999). Phosphorylation of the transcription factor forkhead family member FKHR by protein kinase B. J Biol Chem 274 (24):17179-83.

Renault, V. M., V. A. Rafalski, A. A. Morgan, D. A. Salih, J. O. Brett, A. E. Webb, S. A. Villeda, P. U. Thekkat, C. Guillerey, N. C. Denko, T. D. Palmer, A. J. Butte, and A. Brunet. (2009). FoxO3 regulates neural stem cell homeostasis. Cell Stem Cell 5 (5):527-39.

Resch, Z. T., R. D. Simari, and C. A. Conover. (2006). Targeted disruption of the pregnancyassociated plasma protein-A gene is associated with diminished smooth muscle cell response to insulin-like growth factor-I and resistance to neointimal hyperplasia after vascular injury. Endocrinology 147 (12):5634-40.

Rincon, M., E. Rudin, and N. Barzilai. (2005). The insulin/IGF-1 signaling in mammals and its relevance to human longevity. Exp Gerontol 40 (11):873-7.

Rivera, E. J., A. Goldin, N. Fulmer, R. Tavares, J. R. Wands, and S. M. de la Monte. (2005). Insulin and insulin-like growth factor expression and function deteriorate with progression of Alzheimer's disease: link to brain reductions in acetylcholine. J Alzheimers Dis 8 (3):247-68.

Robakis, N. K., H. M. Wisniewski, E. C. Jenkins, E. A. Devine-Gage, G. E. Houck, X. L. Yao, N. Ramakrishna, G. Wolfe, W. P. Silverman, and W. T. Brown. (1987). Chromosome 21q21 sublocalisation of gene encoding beta-amyloid peptide in cerebral vessels and 
neuritic (senile) plaques of people with Alzheimer disease and Down syndrome. Lancet 1 (8529):384-5.

Roberson, E. D., and L. Mucke. (2006). 100 years and counting: prospects for defeating Alzheimer's disease. Science 314 (5800):781-4.

Robertson, J., T. L. Loviny, M. Goedert, R. Jakes, K. J. Murray, B. H. Anderton, and D. P. Hanger. (1993). Phosphorylation of tau by cyclic-AMP-dependent protein kinase. Dementia 4 (5):256-63.

Rogaev, E. I., R. Sherrington, E. A. Rogaeva, G. Levesque, M. Ikeda, Y. Liang, H. Chi, C. Lin, K. Holman, T. Tsuda, and et al. (1995). Familial Alzheimer's disease in kindreds with missense mutations in a gene on chromosome 1 related to the Alzheimer's disease type 3 gene. Nature 376 (6543):775-8.

Roher, A. E., M. O. Chaney, Y. M. Kuo, S. D. Webster, W. B. Stine, L. J. Haverkamp, A. S. Woods, R. J. Cotter, J. M. Tuohy, G. A. Krafft, B. S. Bonnell, and M. R. Emmerling. (1996). Morphology and toxicity of Abeta-(1-42) dimer derived from neuritic and vascular amyloid deposits of Alzheimer's disease. J Biol Chem 271 (34):20631-5.

Rollo, C. D. (2002). Growth negatively impacts the life span of mammals. Evol Dev 4 (1):55-61.

Roman, G., K. Endo, L. Zong, and R. L. Davis. (2001). P[Switch], a system for spatial and temporal control of gene expression in Drosophila melanogaster. Proc Natl Acad Sci $U$ $S$ A 98 (22):12602-7.

Romanick, M. A., S. G. Rakoczy, and H. M. Brown-Borg. (2004). Long-lived Ames dwarf mouse exhibits increased antioxidant defense in skeletal muscle. Mech Ageing Dev 125 (4):269-81.

Romero, C. J., Y. Ng, R. M. Luque, R. D. Kineman, L. Koch, J. C. Bruning, and S. Radovick. (2010). Targeted deletion of somatotroph insulin-like growth factor-I signaling in a cell-specific knockout mouse model. Mol Endocrinol 24 (5):1077-89.

Ronnemaa, E., B. Zethelius, J. Sundelof, J. Sundstrom, M. Degerman-Gunnarsson, C. Berne, L. Lannfelt, and L. Kilander. (2008). Impaired insulin secretion increases the risk of Alzheimer disease. Neurology 71 (14):1065-71.

Roseboom, T. J., J. H. van der Meulen, C. Osmond, D. J. Barker, A. C. Ravelli, and O. P. Bleker. (2000). Plasma lipid profiles in adults after prenatal exposure to the Dutch famine. Am J Clin Nutr 72 (5):1101-6.

Roseboom, T. J., J. H. van der Meulen, C. Osmond, D. J. Barker, A. C. Ravelli, J. M. SchroederTanka, G. A. van Montfrans, R. P. Michels, and O. P. Bleker. (2000). Coronary heart disease after prenatal exposure to the Dutch famine, 1944-45. Heart 84 (6):595-8.

Ross, C. A., and M. A. Poirier. (2005). Opinion: What is the role of protein aggregation in neurodegeneration? Nat Rev Mol Cell Biol 6 (11):891-8.

Rotwein, P., S. K. Burgess, J. D. Milbrandt, and J. E. Krause. (1988). Differential expression of insulin-like growth factor genes in rat central nervous system. Proc Natl Acad Sci U S A 85 (1):265-9.

Rovelet-Lecrux, A., D. Hannequin, G. Raux, N. Le Meur, A. Laquerriere, A. Vital, C. Dumanchin, S. Feuillette, A. Brice, M. Vercelletto, F. Dubas, T. Frebourg, and D. Campion. (2006). APP locus duplication causes autosomal dominant early-onset Alzheimer disease with cerebral amyloid angiopathy. Nat Genet 38 (1):24-6.

Rubin, J. B., M. A. Shia, and P. F. Pilch. (1983). Stimulation of tyrosine-specific phosphorylation in vitro by insulin-like growth factor I. Nature 305 (5933):438-40. 
Rubin, R., and R. Baserga. (1995). Insulin-like growth factor-I receptor. Its role in cell proliferation, apoptosis, and tumorigenicity. Lab Invest 73 (3):311-31.

Rudman, D., A. G. Feller, H. S. Nagraj, G. A. Gergans, P. Y. Lalitha, A. F. Goldberg, R. A. Schlenker, L. Cohn, I. W. Rudman, and D. E. Mattson. (1990). Effects of human growth hormone in men over 60 years old. N Engl J Med 323 (1):1-6.

Rudman, D., M. H. Kutner, C. M. Rogers, M. F. Lubin, G. A. Fleming, and R. P. Bain. (1981). Impaired growth hormone secretion in the adult population: relation to age and adiposity. J Clin Invest 67 (5):1361-9.

Russo, V. C., P. D. Gluckman, E. L. Feldman, and G. A. Werther. (2005). The insulin-like growth factor system and its pleiotropic functions in brain. Endocr Rev 26 (7):916-43.

Russo, V. C., B. S. Schutt, E. Andaloro, S. I. Ymer, A. Hoeflich, M. B. Ranke, L. A. Bach, and G. A. Werther. (2005). Insulin-like growth factor binding protein-2 binding to extracellular matrix plays a critical role in neuroblastoma cell proliferation, migration, and invasion. Endocrinology 146 (10):4445-55.

Sakano, K., T. Enjoh, F. Numata, H. Fujiwara, Y. Marumoto, N. Higashihashi, Y. Sato, J. F. Perdue, and Y. Fujita-Yamaguchi. (1991). The design, expression, and characterization of human insulin-like growth factor II (IGF-II) mutants specific for either the IGFII/cation-independent mannose 6-phosphate receptor or IGF-I receptor. J Biol Chem 266 (31):20626-35.

Saltiel, A. R., and C. R. Kahn. (2001). Insulin signalling and the regulation of glucose and lipid metabolism. Nature 414 (6865):799-806.

Sauer, B. (1998). Inducible gene targeting in mice using the Cre/lox system. Methods 14 (4):38192.

Sawka-Verhelle, D., V. Baron, I. Mothe, C. Filloux, M. F. White, and E. Van Obberghen. (1997). Tyr624 and Tyr628 in insulin receptor substrate- 2 mediate its association with the insulin receptor. J Biol Chem 272 (26):16414-20.

Sawka-Verhelle, D., S. Tartare-Deckert, M. F. White, and E. Van Obberghen. (1996). Insulin receptor substrate-2 binds to the insulin receptor through its phosphotyrosinebinding domain and through a newly identified domain comprising amino acids 591786. J Biol Chem 271 (11):5980-3.

Schedlich, L. J., T. F. Young, S. M. Firth, and R. C. Baxter. (1998). Insulin-like growth factorbinding protein (IGFBP)-3 and IGFBP-5 share a common nuclear transport pathway in T47D human breast carcinoma cells. J Biol Chem 273 (29):18347-52.

Schellenberg, G. D., T. D. Bird, E. M. Wijsman, H. T. Orr, L. Anderson, E. Nemens, J. A. White, L. Bonnycastle, J. L. Weber, M. E. Alonso, and et al. (1992). Genetic linkage evidence for a familial Alzheimer's disease locus on chromosome 14. Science 258 (5082):668-71.

Schubert, M., D. P. Brazil, D. J. Burks, J. A. Kushner, J. Ye, C. L. Flint, J. Farhang-Fallah, P. Dikkes, X. M. Warot, C. Rio, G. Corfas, and M. F. White. (2003). Insulin receptor substrate-2 deficiency impairs brain growth and promotes tau phosphorylation. $J$ Neurosci 23 (18):7084-92.

Schubert, M., D. Gautam, D. Surjo, K. Ueki, S. Baudler, D. Schubert, T. Kondo, J. Alber, N. Galldiks, E. Kustermann, S. Arndt, A. H. Jacobs, W. Krone, C. R. Kahn, and J. C. Bruning. (2004). Role for neuronal insulin resistance in neurodegenerative diseases. Proc Natl Acad Sci U S A 101 (9):3100-5. 
Schutt, B. S., M. Langkamp, U. Rauschnabel, M. B. Ranke, and M. W. Elmlinger. (2004). Integrin-mediated action of insulin-like growth factor binding protein-2 in tumor cells. J Mol Endocrinol 32 (3):859-68.

Seino, S., and G. I. Bell. (1989). Alternative splicing of human insulin receptor messenger RNA. Biochem Biophys Res Commun 159 (1):312-6.

Seino, S., M. Seino, S. Nishi, and G. I. Bell. (1989). Structure of the human insulin receptor gene and characterization of its promoter. Proc Natl Acad Sci U S A 86 (1):114-8.

Selkoe, D. J. (2004). Cell biology of protein misfolding: the examples of Alzheimer's and Parkinson's diseases. Nat Cell Biol 6 (11):1054-61.

Selman, C., S. Lingard, A. I. Choudhury, R. L. Batterham, M. Claret, M. Clements, F. Ramadani, K. Okkenhaug, E. Schuster, E. Blanc, M. D. Piper, H. Al-Qassab, J. R. Speakman, D. Carmignac, I. C. Robinson, J. M. Thornton, D. Gems, L. Partridge, and D. J. Withers. (2008). Evidence for lifespan extension and delayed age-related biomarkers in insulin receptor substrate 1 null mice. FASEB J 22 (3):807-18.

Sharfi, H., and H. Eldar-Finkelman. (2008). Sequential phosphorylation of insulin receptor substrate-2 by glycogen synthase kinase-3 and c-Jun NH2-terminal kinase plays a role in hepatic insulin signaling. Am J Physiol Endocrinol Metab 294 (2):E307-15.

Shechter, M., S. Ginsberg, M. Scheinowitz, M. S. Feinberg, and Z. Laron. (2007). Obese adults with primary growth hormone resistance (Laron Syndrome) have normal endothelial function. Growth Horm IGF Res 17 (2):165-70.

Sherrington, R., S. Froelich, S. Sorbi, D. Campion, H. Chi, E. A. Rogaeva, G. Levesque, E. I. Rogaev, C. Lin, Y. Liang, M. Ikeda, L. Mar, A. Brice, Y. Agid, M. E. Percy, F. ClergetDarpoux, S. Piacentini, G. Marcon, B. Nacmias, L. Amaducci, T. Frebourg, L. Lannfelt, J. M. Rommens, and P. H. St George-Hyslop. (1996). Alzheimer's disease associated with mutations in presenilin 2 is rare and variably penetrant. Hum Mol Genet 5 (7):985-8.

Siddle, K., M. A. Soos, C. E. Field, and B. T. Nave. (1994). Hybrid and atypical insulin/insulinlike growth factor I receptors. Horm Res 41 Suppl 2:56-64; discussion 65.

Sjogren, K., J. L. Liu, K. Blad, S. Skrtic, O. Vidal, V. Wallenius, D. LeRoith, J. Tornell, O. G. Isaksson, J. O. Jansson, and C. Ohlsson. (1999). Liver-derived insulin-like growth factor I (IGF-I) is the principal source of IGF-I in blood but is not required for postnatal body growth in mice. Proc Natl Acad Sci U S A 96 (12):7088-92.

Skovronsky, D. M., D. B. Moore, M. E. Milla, R. W. Doms, and V. M. Lee. (2000). Protein kinase C-dependent alpha-secretase competes with beta-secretase for cleavage of amyloidbeta precursor protein in the trans-golgi network. J Biol Chem 275 (4):2568-75.

Slee, E. A., D. J. O'Connor, and X. Lu. (2004). To die or not to die: how does p53 decide? Oncogene 23 (16):2809-18.

Sleegers, K., N. Brouwers, I. Gijselinck, J. Theuns, D. Goossens, J. Wauters, J. Del-Favero, M. Cruts, C. M. van Duijn, and C. Van Broeckhoven. (2006). APP duplication is sufficient to cause early onset Alzheimer's dementia with cerebral amyloid angiopathy. Brain 129 (Pt 11):2977-83.

Solinas, G., W. Naugler, F. Galimi, M. S. Lee, and M. Karin. (2006). Saturated fatty acids inhibit induction of insulin gene transcription by JNK-mediated phosphorylation of insulinreceptor substrates. Proc Natl Acad Sci U S A 103 (44):16454-9.

Sompol, P., W. Ittarat, J. Tangpong, Y. Chen, I. Doubinskaia, I. Batinic-Haberle, H. M. Abdul, D. A. Butterfield, and D. K. St Clair. (2008). A neuronal model of Alzheimer's disease: 
an insight into the mechanisms of oxidative stress-mediated mitochondrial injury. Neuroscience 153 (1):120-30.

Song, G., G. Ouyang, and S. Bao. (2005). The activation of Akt/PKB signaling pathway and cell survival. J Cell Mol Med 9 (1):59-71.

Sonntag, W. E., R. W. Steger, L. J. Forman, and J. Meites. (1980). Decreased pulsatile release of growth hormone in old male rats. Endocrinology 107 (6):1875-9.

Sontag, E., V. Nunbhakdi-Craig, G. Lee, G. S. Bloom, and M. C. Mumby. (1996). Regulation of the phosphorylation state and microtubule-binding activity of Tau by protein phosphatase 2A. Neuron 17 (6):1201-7.

Soos, M. A., and K. Siddle. (1989). Immunological relationships between receptors for insulin and insulin-like growth factor I. Evidence for structural heterogeneity of insulin-like growth factor I receptors involving hybrids with insulin receptors. Biochem J 263 (2):553-63.

Soos, M. A., J. Whittaker, R. Lammers, A. Ullrich, and K. Siddle. (1990). Receptors for insulin and insulin-like growth factor-I can form hybrid dimers. Characterisation of hybrid receptors in transfected cells. Biochem J 270 (2):383-90.

Soto, C. (2003). Unfolding the role of protein misfolding in neurodegenerative diseases. Nat Rev Neurosci 4 (1):49-60.

Sotthibundhu, A., A. M. Sykes, B. Fox, C. K. Underwood, W. Thangnipon, and E. J. Coulson. (2008). Beta-amyloid(1-42) induces neuronal death through the p75 neurotrophin receptor. J Neurosci 28 (15):3941-6.

St George-Hyslop, P., J. Haines, E. Rogaev, M. Mortilla, G. Vaula, M. Pericak-Vance, J. F. Foncin, M. Montesi, A. Bruni, S. Sorbi, and et al. (1992). Genetic evidence for a novel familial Alzheimer's disease locus on chromosome 14. Nat Genet 2 (4):330-4.

Stewart, C. E., and P. Rotwein. (1996). Growth, differentiation, and survival: multiple physiological functions for insulin-like growth factors. Physiol Rev 76 (4):1005-26.

Stewart, R., and D. Liolitsa. (1999). Type 2 diabetes mellitus, cognitive impairment and dementia. Diabet Med 16 (2):93-112.

Stokoe, D., L. R. Stephens, T. Copeland, P. R. Gaffney, C. B. Reese, G. F. Painter, A. B. Holmes, F. McCormick, and P. T. Hawkins. (1997). Dual role of phosphatidylinositol-3,4,5trisphosphate in the activation of protein kinase B. Science 277 (5325):567-70.

Stoothoff, W. H., and G. V. Johnson. (2005). Tau phosphorylation: physiological and pathological consequences. Biochim Biophys Acta 1739 (2-3):280-97.

Suh Y, Atzmon G, Cho MO, Hwang D, Liu B, Leahy DJ, Barzilai N, Cohen P. (2008). Functionally significant insulin-like growth factor I receptor mutations in centenarians. Proc Natl Acad Sci U S A 105(9):3438-3442.

Sun, X. J., P. Rothenberg, C. R. Kahn, J. M. Backer, E. Araki, P. A. Wilden, D. A. Cahill, B. J. Goldstein, and M. F. White. (1991). Structure of the insulin receptor substrate IRS-1 defines a unique signal transduction protein. Nature 352 (6330):73-7.

Svensson, J., M. Diez, J. Engel, C. Wass, A. Tivesten, J. O. Jansson, O. Isaksson, T. Archer, T. Hokfelt, and C. Ohlsson. (2006). Endocrine, liver-derived IGF-I is of importance for spatial learning and memory in old mice. J Endocrinol 189 (3):617-27.

Tabaton, M., and E. Tamagno. (2007). The molecular link between beta- and gamma-secretase activity on the amyloid beta precursor protein. Cell Mol Life Sci 64 (17):2211-8.

Taguchi, A., L. M. Wartschow, and M. F. White. (2007). Brain IRS2 signaling coordinates life span and nutrient homeostasis. Science 317 (5836):369-72. 
Taguchi, A., and M. F. White. (2008). Insulin-like signaling, nutrient homeostasis, and life span. Annu Rev Physiol 70:191-212.

Tang, E. D., G. Nunez, F. G. Barr, and K. L. Guan. (1999). Negative regulation of the forkhead transcription factor FKHR by Akt. J Biol Chem 274 (24):16741-6.

Tang, Z., R. Yu, Y. Lu, A. F. Parlow, and J. L. Liu. (2005). Age-dependent onset of liver-specific IGF-I gene deficiency and its persistence in old age: implications for postnatal growth and insulin resistance in LID mice. Am J Physiol Endocrinol Metab 289 (2):E288-95.

Tannenbaum, G. S., and J. B. Martin. (1976). Evidence for an endogenous ultradian rhythm governing growth hormone secretion in the rat. Endocrinology 98 (3):562-70.

Tanzi, R. E., J. F. Gusella, P. C. Watkins, G. A. Bruns, P. St George-Hyslop, M. L. Van Keuren, D. Patterson, S. Pagan, D. M. Kurnit, and R. L. Neve. (1987). Amyloid beta protein gene: cDNA, mRNA distribution, and genetic linkage near the Alzheimer locus. Science 235 (4791):880-4.

Tanzi, R. E., R. D. Moir, and S. L. Wagner. (2004). Clearance of Alzheimer's Abeta peptide: the many roads to perdition. Neuron 43 (5):605-8.

Tanzi, R. E., G. Vaula, D. M. Romano, M. Mortilla, T. L. Huang, R. G. Tupler, W. Wasco, B. T. Hyman, J. L. Haines, B. J. Jenkins, and et al. (1992). Assessment of amyloid betaprotein precursor gene mutations in a large set of familial and sporadic Alzheimer disease cases. Am J Hum Genet 51 (2):273-82.

Tatar, M., A. Bartke, and A. Antebi. (2003). The endocrine regulation of aging by insulin-like signals. Science 299 (5611):1346-51.

Tatar, M., A. Kopelman, D. Epstein, M. P. Tu, C. M. Yin, and R. S. Garofalo. (2001). A mutant Drosophila insulin receptor homolog that extends life-span and impairs neuroendocrine function. Science 292 (5514):107-10.

Toivonen, J. M., and L. Partridge. (2009). Endocrine regulation of aging and reproduction in Drosophila. Mol Cell Endocrinol 299 (1):39-50.

Trejo, J. L., E. Carro, and I. Torres-Aleman. (2001). Circulating insulin-like growth factor I mediates exercise-induced increases in the number of new neurons in the adult hippocampus. J Neurosci 21 (5):1628-34.

Trejo, J. L., M. V. Llorens-Martin, and I. Torres-Aleman. (2008). The effects of exercise on spatial learning and anxiety-like behavior are mediated by an IGF-I-dependent mechanism related to hippocampal neurogenesis. Mol Cell Neurosci 37 (2):402-11.

Tu, M. P., D. Epstein, and M. Tatar. (2002). The demography of slow aging in male and female Drosophila mutant for the insulin-receptor substrate homologue chico. Aging Cell 1 (1):75-80.

Ullrich, A., A. Gray, A. W. Tam, T. Yang-Feng, M. Tsubokawa, C. Collins, W. Henzel, T. Le Bon, S. Kathuria, E. Chen, and et al. (1986). Insulin-like growth factor I receptor primary structure: comparison with insulin receptor suggests structural determinants that define functional specificity. EMBO J 5 (10):2503-12.

Valentino, K. L., I. Ocrant, and R. G. Rosenfeld. (1990). Developmental expression of insulinlike growth factor-II receptor immunoreactivity in the rat central nervous system. Endocrinology 126 (2):914-20.

van der Horst, A., A. M. de Vries-Smits, A. B. Brenkman, M. H. van Triest, N. van den Broek, F. Colland, M. M. Maurice, and B. M. Burgering. (2006). FOXO4 transcriptional activity is regulated by monoubiquitination and USP7/HAUSP. Nat Cell Biol 8 (10):1064-73. 
Van Obberghen, E., M. Ksauga, A. Le Cam, J. A. Hedo, A. Itin, and L. C. Harrison. (1981). Biosynthetic labeling of insulin receptor: studies of subunits in cultured human IM-9 lymphocytes. Proc Natl Acad Sci U S A 78 (2):1052-6.

Vanhaesebroeck, B., K. Ali, A. Bilancio, B. Geering, and L. C. Foukas. (2005). Signalling by PI3K isoforms: insights from gene-targeted mice. Trends Biochem Sci 30 (4):194-204.

Vardy, E. R., P. J. Rice, P. C. Bowie, J. D. Holmes, P. J. Grant, and N. M. Hooper. (2007). Increased circulating insulin-like growth factor-1 in late-onset Alzheimer's disease. $J$ Alzheimers Dis 12 (4):285-90.

Vassar, R. (2004). BACE1: the beta-secretase enzyme in Alzheimer's disease. J Mol Neurosci 23 (1-2):105-14.

Vassar, R., B. D. Bennett, S. Babu-Khan, S. Kahn, E. A. Mendiaz, P. Denis, D. B. Teplow, S. Ross, P. Amarante, R. Loeloff, Y. Luo, S. Fisher, J. Fuller, S. Edenson, J. Lile, M. A. Jarosinski, A. L. Biere, E. Curran, T. Burgess, J. C. Louis, F. Collins, J. Treanor, G. Rogers, and M. Citron. (1999). Beta-secretase cleavage of Alzheimer's amyloid precursor protein by the transmembrane aspartic protease BACE. Science 286 (5440):735-41.

Veldhuis, J. D., M. Bidlingmaier, S. M. Anderson, Z. Wu, and C. J. Strasburger. (2001). Lowering total plasma insulin-like growth factor I concentrations by way of a novel, potent, and selective growth hormone $(\mathrm{GH})$ receptor antagonist, pegvisomant (B2036-peg), augments the amplitude of GH secretory bursts and elevates basal/nonpulsatile GH release in healthy women and men. J Clin Endocrinol Metab 86 (7):3304-10.

Veldhuis, J. D., D. M. Keenan, J. N. Bailey, A. Adeniji, J. M. Miles, R. Paulo, M. Cosma, and C. Soares-Welch. (2008). Estradiol supplementation in postmenopausal women attenuates suppression of pulsatile growth hormone secretion by recombinant human insulin-like growth factor type I. J Clin Endocrinol Metab 93 (11):4471-8.

Veldhuis, J. D., D. M. Keenan, J. N. Bailey, A. Adeniji, J. M. Miles, R. Paulo, M. Cosma, and C. Soares-Welch. (2009). Testosterone supplementation in older men restrains insulinlike growth factor's dose-dependent feedback inhibition of pulsatile growth hormone secretion. J Clin Endocrinol Metab 94 (1):246-54.

Vicario-Abejon, C., M. J. Yusta-Boyo, C. Fernandez-Moreno, and F. de Pablo. (2003). Locally born olfactory bulb stem cells proliferate in response to insulin-related factors and require endogenous insulin-like growth factor-I for differentiation into neurons and glia. J Neurosci 23 (3):895-906.

von Figura, K., and A. Hasilik. (1986). Lysosomal enzymes and their receptors. Annu Rev Biochem 55:167-93.

Walsh, D. M., A. Lomakin, G. B. Benedek, M. M. Condron, and D. B. Teplow. (1997). Amyloid beta-protein fibrillogenesis. Detection of a protofibrillar intermediate. J Biol Chem 272 (35):22364-72.

Walsh, D. M., and D. J. Selkoe. (2007). A beta oligomers - a decade of discovery. J Neurochem 101 (5):1172-84.

Wang, M. C., D. Bohmann, and H. Jasper. (2005). JNK extends life span and limits growth by antagonizing cellular and organism-wide responses to insulin signaling. Cell 121 (1):115-25. 
Wang, S., N. Tulina, D. L. Carlin, and E. J. Rulifson. (2007). The origin of islet-like cells in Drosophila identifies parallels to the vertebrate endocrine axis. Proc Natl Acad Sci U S A 104 (50):19873-8.

Wang, Z., K. A. Al-Regaiey, M. M. Masternak, and A. Bartke. (2006). Adipocytokines and lipid levels in Ames dwarf and calorie-restricted mice. J Gerontol A Biol Sci Med Sci 61 (4):323-31.

Weigert, C., A. M. Hennige, T. Brischmann, A. Beck, K. Moeschel, M. Schauble, K. Brodbeck, H. U. Haring, E. D. Schleicher, and R. Lehmann. (2005). The phosphorylation of Ser318 of insulin receptor substrate 1 is not per se inhibitory in skeletal muscle cells but is necessary to trigger the attenuation of the insulin-stimulated signal. J Biol Chem 280 (45):37393-9.

Werther, G. A., M. Abate, A. Hogg, H. Cheesman, B. Oldfield, D. Hards, P. Hudson, B. Power, K. Freed, and A. C. Herington. (1990). Localization of insulin-like growth factor-I mRNA in rat brain by in situ hybridization--relationship to IGF-I receptors. Mol Endocrinol 4 (5):773-8.

Werther, G. A., A. Hogg, B. J. Oldfield, M. J. McKinley, R. Figdor, and F. A. Mendelsohn. (1989). Localization and Characterization of Insulin-Like Growth Factor-I Receptors in Rat Brain and Pituitary Gland Using in vitro Autoradiography and Computerized Densitometry* A Distinct Distribution from Insulin Receptors. J Neuroendocrinol 1 (5):369-77.

Werther, G. A., V. Russo, N. Baker, and G. Butler. (1998). The role of the insulin-like growth factor system in the developing brain. Horm Res 49 Suppl 1:37-40.

White, M. F., and C. R. Kahn. (1994). The insulin signaling system. J Biol Chem 269 (1):1-4.

Wilczak, N., P. De Bleser, P. Luiten, A. Geerts, A. Teelken, and J. De Keyser. (2000). Insulin-like growth factor II receptors in human brain and their absence in astrogliotic plaques in multiple sclerosis. Brain Res 863 (1-2):282-8.

Willcox, B. J., T. A. Donlon, Q. He, R. Chen, J. S. Grove, K. Yano, K. H. Masaki, D. C. Willcox, B. Rodriguez, and J. D. Curb. (2008). FOXO3A genotype is strongly associated with human longevity. Proc Natl Acad Sci U S A 105 (37):13987-92.

Williams, A. D., M. Sega, M. Chen, I. Kheterpal, M. Geva, V. Berthelier, D. T. Kaleta, K. D. Cook, and R. Wetzel. (2005). Structural properties of Abeta protofibrils stabilized by a small molecule. Proc Natl Acad Sci U S A 102 (20):7115-20.

Wilmoth, J. R. (2000). Demography of longevity: past, present, and future trends. Exp Gerontol 35 (9-10):1111-29.

Wittmann, T., G. M. Bokoch, and C. M. Waterman-Storer. (2004). Regulation of microtubule destabilizing activity of Op18/stathmin downstream of Rac1. J Biol Chem 279 (7):6196203.

Wolkow, C. A., K. D. Kimura, M. S. Lee, and G. Ruvkun. (2000). Regulation of C. elegans lifespan by insulinlike signaling in the nervous system. Science 290 (5489):147-50.

Wortley, K. E., J. P. del Rincon, J. D. Murray, K. Garcia, K. Iida, M. O. Thorner, and M. W. Sleeman. (2005). Absence of ghrelin protects against early-onset obesity. J Clin Invest 115 (12):3573-8.

Yakar, S., J. L. Liu, B. Stannard, A. Butler, D. Accili, B. Sauer, and D. LeRoith. (1999). Normal growth and development in the absence of hepatic insulin-like growth factor I. Proc Natl Acad Sci U S A 96 (13):7324-9. 
Yakar, S., J. Setser, H. Zhao, B. Stannard, M. Haluzik, V. Glatt, M. L. Bouxsein, J. J. Kopchick, and D. LeRoith. (2004). Inhibition of growth hormone action improves insulin sensitivity in liver IGF-1-deficient mice. J Clin Invest 113 (1):96-105.

Yamaguchi, Y., J. S. Flier, A. Yokota, H. Benecke, J. M. Backer, and D. E. Moller. (1991). Functional properties of two naturally occurring isoforms of the human insulin receptor in Chinese hamster ovary cells. Endocrinology 129 (4):2058-66.

Yamanaka, Y., J. L. Fowlkes, E. M. Wilson, R. G. Rosenfeld, and Y. Oh. (1999). Characterization of insulin-like growth factor binding protein-3 (IGFBP-3) binding to human breast cancer cells: kinetics of IGFBP-3 binding and identification of receptor binding domain on the IGFBP-3 molecule. Endocrinology 140 (3):1319-28.

Yang, E., J. Zha, J. Jockel, L. H. Boise, C. B. Thompson, and S. J. Korsmeyer. (1995). Bad, a heterodimeric partner for Bcl-XL and Bcl-2, displaces Bax and promotes cell death. Cell 80 (2):285-91.

Yang, X. F., W. G. Beamer, H. Huynh, and M. Pollak. (1996). Reduced growth of human breast cancer xenografts in hosts homozygous for the lit mutation. Cancer Res 56 (7): 1509-11.

Yang, Z., W. Zhao, X. Zhang, R. Mu, Y. Zhai, L. Kong, and C. Chen. (2008). Impact of famine during pregnancy and infancy on health in adulthood. Obes Rev 9 Suppl 1:95-9.

Ye, P., J. Carson, and A. J. D'Ercole. (1995). In vivo actions of insulin-like growth factor-I (IGF-I) on brain myelination: studies of IGF-I and IGF binding protein-1 (IGFBP-1) transgenic mice. J Neurosci 15 (11):7344-56.

Ye, P., L. Li, R. G. Richards, R. P. DiAugustine, and A. J. D'Ercole. (2002). Myelination is altered in insulin-like growth factor-I null mutant mice. J Neurosci 22 (14):6041-51.

Yenush, L., and M.F.White MF. (1997). The IRS-signalling system during insulin and cytokine action. Bioessays 19(6):491-500

Yin, P., Q. Xu, and C. Duan. (2004). Paradoxical actions of endogenous and exogenous insulinlike growth factor-binding protein-5 revealed by RNA interference analysis. J Biol Chem 279 (31):32660-6.

Yuan, R., S. W. Tsaih, S. B. Petkova, C. Marin de Evsikova, S. Xing, M. A. Marion, M. A. Bogue, K. D. Mills, L. L. Peters, C. J. Bult, C. J. Rosen, J. P. Sundberg, D. E. Harrison, G. A. Churchill, and B. Paigen. (2009). Aging in inbred strains of mice: study design and interim report on median lifespans and circulating IGF1 levels. Aging Cell 8 (3):277-87.

Zha, J., H. Harada, K. Osipov, J. Jockel, G. Waksman, and S. J. Korsmeyer. (1997). BH3 domain of $\mathrm{BAD}$ is required for heterodimerization with BCL-XL and pro-apoptotic activity. J Biol Chem 272 (39):24101-4.

Zhang, C. L., Y. Zou, W. He, F. H. Gage, and R. M. Evans. (2008). A role for adult TLX-positive neural stem cells in learning and behaviour. Nature 451 (7181):1004-7.

Zhang, S., K. Iwata, M. J. Lachenmann, J. W. Peng, S. Li, E. R. Stimson, Y. Lu, A. M. Felix, J. E. Maggio, and J. P. Lee. (2000). The Alzheimer's peptide a beta adopts a collapsed coil structure in water. J Struct Biol 130 (2-3):130-41.

Zhao, L., B. Teter, T. Morihara, G. P. Lim, S. S. Ambegaokar, O. J. Ubeda, S. A. Frautschy, and G. M. Cole. (2004). Insulin-degrading enzyme as a downstream target of insulin receptor signaling cascade: implications for Alzheimer's disease intervention. J Neurosci 24 (49):11120-6. 
Zigman, J. M., Y. Nakano, R. Coppari, N. Balthasar, J. N. Marcus, C. E. Lee, J. E. Jones, A. E. Deysher, A. R. Waxman, R. D. White, T. D. Williams, J. L. Lachey, R. J. Seeley, B. B. Lowell, and J. K. Elmquist. (2005). Mice lacking ghrelin receptors resist the development of diet-induced obesity. J Clin Invest 115 (12):3564-72. 


\section{Part 6}

Endocrinology of Stress 



\title{
The Endocrine Response to Stress - A Comparative View
}

\author{
Lluis Tort and Mariana Teles \\ Dpt. of Cell Biology, Physiology and Immunology \\ Universitat Autonoma de Barcelona \\ Spain
}

\section{Introduction}

\subsection{The stress concept}

The word stress is used extensively to name a situation of tension that can be applied to living organisms such as animals or plants but also to ecosystems or in geological phenomena. Nevertheless, the concept of biological stress is closely connected to the historic development of the meaning of this word by Hans Selye after his short paper in Nature (Selye, 1936), following a first approach by Walter Cannon who restricted the physiological changes of stress and injuries to the effects of catecholamines and the adrenal medulla. Other key contributions of Selye to the stress associated concepts were the word stressor, meaning the agent causing stress effects and the non-specificity of the neuroendocrine response, even after positive or negative stressors (Szabo, 1998). Being such a general and widely used concept, the term stress has received many definitions, some of them trying to characterize the phenomenon, others focusing the elicited response and others even including the types of stressors, i.e. symbolic or real (physical, chemical, pathogenic). Nevertheless, in all of them some key elements are included: A source or stressor, the nonspecific reaction and the neuroendocrine response.

As a relevant physiological mechanism, the stress response by itself is not inherently bad. For example, glucocorticoids are released in animals in response to situations that are not normally regarded as stressful, including courtship, copulation and hunting. In addition, hormones which increase during stress periods, are also part of the reproductive process and induce hormonal cascades causing parturition in some species (Möestl and Palme, 2002). As an example, brine shrimp Artemia exposed under gnotobiotic conditions to a nonlethal heat shock increases the expression of Heat Shock Protein-70 (HSP-70), thus inducing a non-specific molecular stress response. When Artemia was challenged with pathogenic bacteria, Vibrio campbellii and Vibrio proteolyticus, a cross-protection against pathogens was observed if an appropriate combination of heat application and recovery treatment was applied (Sung et al., 2007).

\subsection{Stress, a general phenomenon in living organisms}

The overall stress response, meaning the array of reactions generated in most body compartments as a result of the threat of the stressor, is common to all organisms. The fightor-fight response and the fear reactions can be seen as a common behavior from 
invertebrates to man and the necessary energetic supply and coordination of neural circuits for these reactions are also common patterns among animals along the phylogenetic tree. Nonetheless, evolutive ancient organisms are also sharing some of the basic responses that are seen in lower vertebrates and mammals, for instance, heat shock protein expression or the increase of antioxidant enzymes.

Stress responses have been also described in microorganisms. It has been shown that mitogenactivated protein kinase (MAPK) cascades play an important role in transducing environmental threats to transcriptional machinery by means of phosphorilation and regulation of several key transcription factors (Karin, 1998). Although it is well known that these cascades are activated by hormones or cytokines in vertebrates, stressors such as anoxia, osmotic shock or radiation may also induce this activation. In bacteria such responses have been detected as well as the heat shock response. Thus, in Escherichia coli it has been shown that transcription factors recognize specific heat-shock promoters, and that in most bacteria the control of major Heat-Shock genes is highly regulated (Segal and Ron, 1998). In fungi, it has been observed that stress originated from nutrient deprivation causes debilitation of fungal propagules, autolysis, inhibition of spores and loss of pathogenic aggressiveness (Hyakumachi and Arora 1998). This is another common aspect of the stress reaction response, i.e. the consequences derived from energy depletion that can be mirrored with the higher vertebrate stress responses. Thus, all these changes are related to a reorganization of metabolic and energetic pathways to face the effects of the stressor, a mechanism that is essentially the same type of stress response in higher vertebrates and mammals.

The stress concept has also been applied to plants when facing unfavorable environment or constriction of nutrients, water or inadequate soil conditions and a significant amount of scientific literature is available concerning plant stress, mostly related to unfavorable or changing environmental conditions. In plants, a multitude of stressors with different modes of action elicit very similar non-specific responses, besides those specific ones related to the particular stressor. Larcher (1987) defined the stress response in plants as the state in which increasing demands made upon a plant lead to an initial destabilization of functions followed by normalization and improved resistance. Lichtenthaler (1984) extended the stress concept in plants by including regeneration and differentiating between eustress (activating and stimulating positive elements for plant development) and distress (severe stress that affects negatively the plant, causing damage), concepts that have been used also in animals. Plants have a centralized system of stress response that enables to develop physiological responses and this has been shown to work under low-resource environments such as deserts, shaded understory or infertile soils. This response includes slow growth, low synthetic rate (photosynthesis) and low nutrient uptake. As in animals, these responses are driven by hormones and include changes in their balance, for instance producing more abscisic acid and often cytokinins. Thus, there is now strong evidence that the plant hormone abscisic acid (ABA) plays an important role in the regulation of drought stress, since a plant can use the ABA signalling mechanism and other chemical signals to adjust the amount of water loss in response to changes in both the rhizospheric and the aerial environment. This hormone will work as an equivalent of renal hormones of animals after environmental stress. Another example is the biotic stress that induces changes in hormone synthesis and hormonal signalling cascades in the auxin, gibberellin, ABA, ethylene and jasmonate pathways, and in addition modifying plant defense mechanisms, some of them associated to the ubiquitin/proteasome system, a similar pathway that is found in vertebrates (Wilkinson and Davies, 2002). 


\section{The stress response}

The stress response in vertebrates has been defined following the model proposed in mammals by Selye. Together with the conserved cellular response, some other common elements such as the non-specific neuroendocrine activation and the interaction between regulatory systems, are also observed in non-mammalian vertebrates.

\subsection{Molecular and cellular responses}

Cells encounter a range of physiological and environmental stresses that require adaptive changes in gene expression. Stress conditions include ultraviolet (UV) irradiation, temperature changes, nutrient limitation, oxidative stress, hypoxia and exposure to various drugs or toxins. Exposure of cells to stress elicits adaptive responses that require the coordinated expression of stress-response genes, which affect cell survival, apoptosis, cellcycle progression and differentiation (Holcik and Sonenberg 2005). The cell stress response assesses and counteracts stress-induced damage, temporarily increases tolerance to such damage, and/or removes terminally damaged cells by programmed cell death (apoptosis). The capacity of the response depends on the proteome expressed in a cell at a particular time and is therefore species- and cell type-dependent (Kultz, 2005).

One of the major cell stressors is the oxygen radical. Although the concept of endogenous oxidants was at first controversial, the identification of superoxide dismutase (SOD), an enzyme whose main function is the removal of superoxide anions, involved that oxygen radicals are main stressors for the cells and that removal mechanisms are stimulated to reduce adverse effects. In terms of aging it was also proposed that higher metabolism and elevated use of oxygen involve protein and cell damage and overall life reduction at longer term. Given that mitochondria produce most of the energy in the cell, and correspondingly consume the bulk of intracellular oxygen, the free-radical theory of ageing supports the hypothesis that the higher the metabolic rate of an organism, the greater the production of reactive oxygen species (ROS) and hence the shorter the life span. In this way, studies on reactive oxygen species related to aging have determined a number of key molecules that are regulating common mechanisms in organisms, from invertebrates to humans. For instance, work done in a model organism, the worm Caenorhabditis elegans has determined that the forkhead transcription factor, DAF-16, seems to be in a central position to integrate a variety of signals induced by stress and the nutritional status, such as MAPK pathways (through JNK-1), insulin (through DAF-2) and steroid hormone signalling through DAF-12 (Dawson \& Dawson 2003). Moreover, insulin and insulin/IGF signalling may not only be involved in the regulation of oxidative stress response and longevity, but also it is quite likely that they may have a role in other degenerative disease mechanisms involving cellular stress. (Baumeister et al., 2006).

However, in some species the strict correlation between metabolic rate and life span is not maintained and this would depend on the production rate of reactive oxygen species combined with the prevention mechanisms that avoid this production. This is particularly true for birds and primates, who tend to live longer than would be predicted by their metabolic rates. Careful analysis of oxidative production rates demonstrated that at a given metabolic rate, mitochondria from these species tend to produce fewer ROS. (Finkel and Holbrooke, 2000). This indicates that ROS production rather than metabolic rate provides the strongest correlation with overall longevity. Another consequence, in terms of stress regulation in cells, is that under situations of metabolic stress, mitochondrial oxidant 
products seem to function as signalling molecules (Finkel and Holbrooke, 2000). Therefore, stress episodes involving a rise in intracellular oxidant levels have three important effects: damage to various cell components, triggering of the activation of specific signalling pathways and development of mechanisms reducing ROS production.

Another of the cell responses to stress is selective translation as it has been shown that this event commonly occurs during cellular stress and during apoptosis. Moreover, global translation is reduced in response to most types of cellular stress. This results in savings of cellular energy, which is mainly consumed in the process of translation, estimated as an average of about $50 \%$ of the cellular energetic resources. Remarkably, the stress-induced attenuation of global translation is often accompanied by a switch towards the upregulation of the selective translation of proteins that are required for cell survival under stress (Holcik and Sonenberg 2005).

Another key aspect of the cell response is the modulation of major pathways of energy metabolism, closely linked to the oxidative burst in stressed cells. Selected enzymes related to energetic pathways contribute strongly to the control of key pathways such as glycolysis, pentose phosphate pathway, and the citrate cycle. Induction of these enzymes during stress may be necessary for generating reducing equivalents (NADH, NADPH) that are needed for cellular antioxidant systems. In this way, a number of key enzymes such as the enzyme Enolase have been shown to be highly induced under different types of potential stressors. Thus, in vertebrates Enolase is expressed in most tissues as a response to either physical or chemical stressors, pathogens or immune stimuli and even under pathogenic states such as cancer. As it is a key enzyme of the glycolytic pathway, the role of this enzyme appears to be relevant in switching the energetic flows under any type of stress source (Ribas et al.,2004). Regarding cellular responses to stressors, heat shock proteins (Hsp) are considered one of the main cell mechanisms responding against stressors. Stressors disturb cellular homeostasis and induce a corresponding homeostatic response of these proteins that in most cases have the characteristic of being permanent until environmental conditions change again, and that are triggered by stressor-specific sensors that monitor specific environmental variables. Hsp are a defined set of proteins that are conserved along evolution and perform protective cellular functions such as cell cycle control, protein chaperoning and repair, DNA and chromatin stabilization and repair, or removal of damaged proteins. Thus, from a number of 300 common proteins that have been identified in many organisms from human to yeast or bacteria, about 40 of them are involved in the cell response to stress. This response can occur via stressorspecific interactions, post-translational modifications, and fragmentation of stress proteins resulting in an induction of a common set of stress proteins triggered by molecular damage or oxidative accumulation (Kültz, 2005). In combination with the DNA repair machinery, molecular chaperones are required to recognize unfolded proteins and either target them for removal, stop their aggregation, or assist in their refolding into the native, functional state. These proteins are extensively utilized as bioindicators of environmental stress in many different types of organisms.

\subsection{The integrated physiological response}

The stress response system in vertebrates has both central nervous system (CNS) and peripheral components. The central tissue components of the stress system in mammals are located in the hypothalamus and the Locus ceruleus in the brainstem, and include a number of endocrine messengers with a principal role in mediating the neuroendocrine stress response, being the $\mathrm{CRH}$ (Corticotrophin Releasing Hormone) the key peptide in this 
activation. The roles of the related peptides, the urocortins, in stress responses are beginning to be understood in mammals, but very little is known about their expression and function in non mammalian species. Also, $\mathrm{CRH}$ and urocortins are expressed throughout the body where they may play diverse, but as yet poorly characterized, roles in tissue development and homeostasis (Denver, 2009). Another hypothalamic peptide, TRH (Thyrotropin Releasing Hormone) also has such activation properties in fish. These hypothalamic factors stimulate the release of the Adrenocorticotropic Hormone (ACTH) from the pituitary which in turn induces production and release of the major stress steroid, cortisol, by interrenal cells located within the head kidney (Tort, 2010).

The components of the stress system include the peripheral limbs of the hypothalamicpituitary-adrenal (HPA) axis; the efferent sympathetic-adrenomedullary system; and components of the parasympathetic system. Given the potential for the convergence of these mechanisms, specifically in the nervous system, it may be suggested that interactions between the two systems would be produced already at the initial stages of corticosteroid signalling (Riedemann et al., 2010). In emergency situations, the hypothalamus is activated and stimulates the sympathetic nervous system and the adrenal medulla which releases adrenaline and noradrenalin, and the adrenal cortex which releases GCs. The effects are global, and the nerves as well as hormones stimulate the systems needed for fight-orflight (it is usually a short duration stress response). These peripheral components may be limited to these former elements, or one could include other hormonal axes and structures that are stimulated by the neuroendocrine agents and that exert important actions on the whole metabolism and the overall energetics. These other peripheral components are considered below.

\section{Comparative endocrine response to stress}

Endocrine changes after stress are clearly observed in vertebrates where a common endocrine pattern can be recognized (see table 1). Nevertheless, invertebrates also experience changes in hormones after stressors. For instance, in crustaceans, the hyperglycemic hormone $(\mathrm{CHH})$ from the lobster, Homarus americanus increases in hemolymph following emersion. Significant levels of hemolymph $\mathrm{CHH}$ have been also measured in lobsters that had been eyestalk-ablated and it has been observed that these animals continued to produce $\mathrm{CHH}$, even though the main source of $\mathrm{CHH}$ had been removed, probably produced in other portions of the central nervous system (Chang et al., 1999). As another example, in arthropods, proteins of the hemocyanin gene family are involved in major physiological processes, including aerobic respiration, the innate immune response, and molting. Members of this hemocyanin family, cryptocyanin, and phenoloxidase, are multi-subunit molecules that assemble into hexamers and higher aggregates. The hemocyanin hexamer heterogeneity is maintained as a mechanism of selection for functional diversity under environmental stress when changing developmental and environmental conditions (Terwilliger et al., 2006), a similar response that can be observed in vertebrates related to specific endocrine or immune molecules.

\subsection{Mammals}

The stress response in the brain starts in the parvocellular neurons of corticotropin-releasing hormone (CRH); the arginine vasopressin (AVP) neurons of the paraventricular nuclei (PVN) of the hypothalamus; the $\mathrm{CRH}$ neurons of the paragigantocellular and parabranchial 


\begin{tabular}{|c|c|c|c|c|c|}
\hline & Fish & Amphibians & Reptiles & Birds & Mammals \\
\hline $\begin{array}{l}\text { Pituitary } \\
\text { anatomy }\end{array}$ & $\begin{array}{l}\text { Bigger pars } \\
\text { intermedia } \\
\text { Smaller } \\
\text { median } \\
\text { eminence }\end{array}$ & $\begin{array}{c}\text { Bigger pars } \\
\text { intermedia } \\
\text { Smaller ventral } \\
\text { lobe }\end{array}$ & $\begin{array}{l}\text { Longer pars } \\
\text { nervosa } \\
\text { Bigger pars } \\
\text { itermedia }\end{array}$ & $\begin{array}{l}\text { Bigger ventral } \\
\text { lobe } \\
\text { Bigger median } \\
\text { eminence } \\
\text { Smaller pars } \\
\text { intermedia }\end{array}$ & $\begin{array}{l}\text { Bigger ventral } \\
\text { lobe }\end{array}$ \\
\hline $\begin{array}{l}\text { Adrenal } \\
\text { anatomy }\end{array}$ & $\begin{array}{c}\text { Cells } \\
\text { scattered in } \\
\text { the head } \\
\text { part of the } \\
\text { kidney }\end{array}$ & $\begin{array}{l}\text { Cells inside the } \\
\text { kidney in islets } \\
\text { (urodele) or } \\
\text { strands (anuran) }\end{array}$ & $\begin{array}{l}\text { Cells in lobular } \\
\text { structures close } \\
\text { to the gonads }\end{array}$ & $\begin{array}{l}\text { Cells in lobular } \\
\text { structures at } \\
\text { top of the } \\
\text { kidneys }\end{array}$ & $\begin{array}{l}\text { Cells in lobular } \\
\text { or irregular } \\
\text { structures at top } \\
\text { of the kidneys }\end{array}$ \\
\hline Catecholamine & Adrenaline & Adrenaline & Adrenaline & $\begin{array}{l}\text { Adrenaline and } \\
\text { Noradrenalin }\end{array}$ & Adrenaline \\
\hline Corticosteroid & Cortisol & Corticosterone & Corticosterone & Corticosterone & $\begin{array}{c}\text { Cortisol or } \\
\text { Corticosterone }\end{array}$ \\
\hline
\end{tabular}

Table 1. Details of the pituitary and adrenal anatomy and the main secretion, catecholamines and corticosteroids in vertebrates

nuclei of the medulla and the Locus ceruleus (LC); and other mostly noradrenergic (NE) cell groups in the medulla and pons (LC/NE system). The principal effectors include CRH, $\mathrm{AVP}$, the proopiomelanocortin-derived peptides (POMC) a-melanocyte-stimulating hormone (MSH) and $\beta$-endorphin, the glucocorticoids (GC) and the catecholamines noradrenalin and adrenaline. Signalling by CRH-like peptides is mediated by at least two distinct $G$ protein-coupled receptors and modulated by a secreted binding protein. These neuropeptides function as hypophysiotropins and as neurotransmitters/ neuromodulators, influencing stress-related behaviors, such as anxiety and fear. In addition to modulating HPA activity and behavioral stress responses, CRH-like peptides are implicated in timing key life history transitions, such as metamorphosis in amphibians and birth in mammals. $\mathrm{CRH}$-like peptides and signalling components are also expressed outside of the central nervous system where they have diverse physiological functions (Denver, 2009).

In mammals, the adrenal gland, also known as the suprarenal gland, is a two-paired gland, yellow- or orange-colored, triangle-shaped, located over the superior part of the kidney, one on each side. The adrenals are mainly responsible for regulating the response to stress through the synthesis of catecholamines and corticosteroid hormones. In other vertebrates, this gland is also associated with kidneys but its anatomical arrangement is different, as it will be described latter on this chapter. In mammals, the adrenals have a distinct outercortex and inner-medulla arrangement, which is characteristic of this group of vertebrates. The adrenal medulla occupies the central part of each adrenal gland and accounts for $22 \%$ of the gland weight; the remaining $78 \%$ of the weight corresponds to the adrenal cortex and adrenal capsule that surrounds the gland. Both the adrenal medulla and cortex receive regulatory input from the nervous system (Binkley, 1995).

The central region (medulla) of the adrenal gland, have specific cells called chromaffin cells, which are considered modified postganglionic cells of the sympathetic nervous system. These chromaffin cells secrete catecholamines, adrenaline (or epinephrine), noradrenalin (or norepinephrine) and to a lesser extent, dopamine. The mammalian adrenal cortex can be divided into three layers: zona glomerulosa, zona fasciculata and zona reticularis; all three layers produce corticosterone, but otherwise, the layers are specialized as regards their main 
hormone products. Briefly, the zona glomerulosa, which represent about $15 \%$ of the adrenal weight, is the outer layer and is specialized in production of aldosterone. The zona fasciculata is the central and widest layer of the adrenal cortex (around 50\% of adrenal weight) and secretes cortisol and androgens. Finally, the zona reticularis, represents $10 \%$ of the adrenal weight, secrete cortisol and androgens. These two last zones respond to ACTH stimulation.

In an initial alarm phase, catecholamines are released into the circulatory system, where they circulate in a free form or conjugated to blood proteins; in blood, catecholamines have a short half-life of about 3 to 4 minutes. Its biosynthetic pathway of synthesis is highly conserved throughout the animal kingdom with the rate-limiting step controlled by the enzyme tyrosine hydroxylase (Perry and Capaldo, 2010). Both catecholamines have a large number of actions, most of which contribute to the sympathetic fight-or-flight response. The best well known functions of adrenaline and noradrenalin are their actions in the cardiovascular system, the stimulation of glycogenolysis in skeletal and cardiac muscle, mobilizing glucose in those tissues, which aimed at reducing the detrimental effects of stressors on physiological function or optimizing physiological processes during periods of increased energetic demand. In the more highly evolved vertebrates, such as mammals and birds, the acute humoral adrenergic stress response effectively complements the neuronal regulation of physiological systems via the sympathetic division of the autonomic nervous system (Perry and Capaldo, 2010).

Cells of adrenal cortex respond to the HPA axis and mediate the stress response through production of steroid hormones, namely mineralocorticoids and GCs. The HPA axis involves the release of corticotropin releasing hormone (CRH) and Vasopressin from hypothalamic PVN, and $\mathrm{CRH}$ is the main responsible for stimulating adrenocorticotropic hormone $(\mathrm{ACTH})$ release from the anterior pituitary gland. ACTH arrives at the target cells in the adrenal cortex where it stimulates the synthesis of GCs. In humans, monkeys, sheep and cats cortisol is predominantly secreted; whereas rodents mainly secrete corticosterone. Some other mammals, such as dogs, secrete a mixture of cortisol and corticosterone in a similar ratio (Boonstra, 2004). GCs act at multiple sites within the body in an attempt to maintain homeostasis, but because of the potential damaging effects of chronic exposure to GCs, the HPA axis is tightly regulated through classic negative feedback loops. Thus, cortisol feeds back on hypothalamus and pituitary to cause rapid inhibition of CRH release. Under acute stress conditions, feedback mechanisms are efficient and the system returns to normal, resulting in short-term effects on body processes. Under conditions of chronic stress, feedback signals are weak and the system remains activated for longer periods, resulting in effects on body processes that can be long term and detrimental (Boonstra et al., 2004).

After short-term stressors, cortisol affects the intermediary metabolism by stimulating gluconeogenesis in liver, increasing glycogen formation and increasing the availability of substrates derived from proteins and fats. All these actions tend to produce hyperglycemia, increasing the availability of quick energy to muscle and nervous tissue. Chronic or repeated exposure to a stressor, characterized by lower but prolonged endocrine secretions, often involve longer recovery periods and much higher energetic and performance costs, due to both stressor persistence and the derived effects of the stress response effectors, i.e., GCs. These negative effects include alterations at several physiological levels, from impaired growth and reproductive capacity to immune suppression (Tort, 2010). 


\subsection{Birds}

In birds adrenal glands may be a single median structure or two separate organs, in close contact with each other, lying just cranial to the kidneys and gonads on either side of the aorta and caudal vena cava. The adrenals are small, ovoid in form, with a yellow or orange color, and are surrounded by a loose connective capsule. In contrast to mammals, the cortex is not well differentiated from the medulla. Clusters of chromaffin cells are mixed with blood vessels and the interrenal steroidogenic cells are radially arranged in the subcapsular zone and in the inner part of the gland (reviewed by Ghosh et al., 2001).

Adrenaline and noradrenalin are secreted by the medullary part of the gland and unlike in mammals, the enzyme PNMT exists in all adrenomedullary chromaffin cells, so it cannot be considered a marker in differentiating adrenaline from noradrenalin cells. PNMT exists in its active form only in the adrenaline-storing cells (Ghosh et al., 2001). The chromaffin cells are usually mixed and arranged without any preferential location, but unlike most other vertebrate groups, there is strong inter-specific variation in the noradrenalin/adrenaline cell ratio (Varano, 1980). This ratio seems to bear a distinct relation to avian phylogeny; thus, less evolved birds have more noradrenalin, while recently evolved birds have more adrenaline. In these terms, birds occupy an intermediate evolutionary position having noradrenalin/adrenaline ratios around 1/1 (Ghosh, 1977; Varano, 1980).

The most important glucocorticoid in birds is corticosterone, which is secreted by the cortical part of the gland and has both glucocorticoid and mineralocorticoid activity, having a more important role than aldosterone in electrolyte balance. In general, birds have low basal circulating corticosteroids levels, but these levels increase during stress-related responses as occurs in mammals (Boonstra et al., 2004). The acute short action stress response (fight or flight) is activated within seconds by the sympathetic nervous system which induces release of catecholamines from chromaffin cells of the adrenal medulla into the general circulation and release of $\mathrm{CRH}$ primarily from the hypothalamus, which induces $\mathrm{ACTH}$ secretion from the anterior pituitary and, in response to ACTH, release of corticosterone into the general circulation within minutes.

Ghosh and collaborators (2001) demonstrated that catecholamines cause hepatic and muscle glycogenolysis which can lead to hyperglycemia, as it occurs in mammals. The avian adrenal chromaffin tissue is influenced by the steroidogenic cells; GCs increase noradrenalin content in the chick and adrenaline content in the pigeon adrenal glands, with a synergistic action requiring activity of the splanchnic nerve (Ghosh et al., 2001). Compared to mammals, less is known about the effects of catecholamines on bird metabolism. Starvation experiments on birds of different food habits demonstrated a simultaneous depletion and release of catecholamines and glycogen.

\subsection{Reptiles}

In reptiles, the adrenal glands are discrete bodies; yellow/red in color, separated from the kidneys, and in close relationship with the gonads, lying in its dorsal part. The only exception to this pattern is in the chelonians where the adrenal gland is in close contact with the ventral surface of the kidney, as in anuran amphibians. Chelonians have dorsoventrally glands which lie against the kidney. Ventrally, they are covered by peritoneum that extends forward to form the mesorchium or mesovarium of the adjacent gonads. Snakes and lizards have adrenal glands incorporated into the mesorchium or mesovarium, close to their respective gonads. They are elongated in snakes and usually globular in lizards. The right gland is attached to the caudal vena cava (reviewed by Perry and Capaldo, 2010). 
The chromaffin and the steroidogenic tissues are associated, but there is a substantial variation in the degree of mixing that depends on the considered group. Thus, in Crocodilians and Chelonians, chromaffin and steroidogenic tissues are largely intermingled. In Rincocephalian lizards, most of the chromaffin tissue forms a dorsal mass that send extensions between the interrenal cells; moreover, many clusters of chromaffin cells are present within the steroidogenic parenchyma, and some clusters of chromaffin cells are present on the ventral surface of the gland. Most Squamata lizards or iguanas show a similar distribution, with the exception of the ventral chromaffin tissue, usually absent in these reptiles (reviewed by Perry and Capaldo, 2010). Moreover, the distribution of the two tissues presents a great variability, which is correlated to the phylogeny of the species. Generally, a high degree of separation between the two tissues is typical of ancient species, whereas a trend toward the close association between them is typical of more recent species (Laforgia et al., 1991).

The distribution of noradrenalin and adrenaline cells is different among groups of reptiles. Usually, the islets intermingled in the steroidogenic parenchyma are occupied only by adrenaline cells, whereas noradrenalin and adrenaline cells are present in the chromaffin superficial tissue. In reptiles, the ratio between noradrenalin/adrenaline reflects the degree of separation between steroidogenic and chromaffin tissues. Thus, high values of this ratio, and therefore a high number of noradrenalin cells, correspond to a high degree of separation of the two tissues whereas low values of this ratio, correspond to a high degree of mixing between them. The reason for this correspondence, as it has been clarified by Perry and Capaldo (2010), is that in reptiles and mammals, the enzyme PNMT, that catalyses the methylation of noradrenalin into adrenaline, is activated by GCs. Therefore, when the two tissues are spatially separated, GC delivery to the chromaffin cells is likely to be impeded, whereas, when the degree of integration is high, GC delivery to the chromaffin cells is likely to be facilitated.

In response to stress, reptiles produce different patterns of catecholamine release, which can increase or decrease according to the type of stressor. For example, restraint stress in alligators causes a decrease in plasma adrenaline and noradrenalin levels at $24 \mathrm{~h}$, and an increase in noradrenalin levels by $48 \mathrm{~h}$. The role of catecholamines in regulating reptilian metabolism is poorly studied although it is clear that adrenaline causes hyperglycemia and promotes glycogenolysis in liver and glycogen deposition (Norris, 2007).

Corticosterone is the major adrenal corticosteroid secreted by reptiles (see Tyrrel and Cree, 1998) but the patterns of basal corticosterone secretion vary considerably among them. However, almost all studies concerning the HPA modulation by stressors show that reptiles respond to stressors by increasing plasma levels of corticosterone (Tyrrel and Cree, 1998; Moore and Jessop, 2003). Nonetheless, it is evident a variation in the rate, duration and magnitude of the adrenocortical response to the same type of stressor, reflecting a change in the sensitivity of the HPA axis to stressors (Wingfield and Romero, 2001). A number of studies have demonstrated that differences in physiological state among individuals, such as body condition, reproductive state, disease status, age, sex, genotypic variation, and social status can result in adrenocortical modulation (Dunlap and Schall, 1995). In addition, differences in external environment such as variation in rainfall, temperature, food availability, and humidity or general habitat quality can result in individual adrenocortical modulation between populations (Moore et al., 2001).

\subsection{Amphibians}

The adrenal glands of amphibians are found in close association with the kidneys, although their exact location varies with the species. Like reptiles and birds, the adrenal gland 
appears homogenous on cut surface, and histologically it is comprised of intermingled cortical and medullary elements, rather than having the clear delineation between cortex and medulla seen in mammalian species. Thus, in amphibians the chromaffin cells are closely associated with the steroidogenic cells; additionally, chromaffin cells can be found in the extra-adrenal chromaffin tissue, within the paravertebral sympathetic ganglia and in the abdominal para-aortic region, but their precise role at these sites is not well understood. The arrangement of adrenal chromaffin cells is markedly different in anurans and urodeles (Accordi, 1991; Chimenti and Accordi, 2008). In urodeles, the steroidogenic tissue forms numerous small bodies, partially embedded in the ventral surface of the kidney with groups of chromaffin cells interspersed (reviewed by Perry and Capaldo, 2010). In anurans, noradrenalin and adrenaline cells are usually intermingled, with no preferential distribution. The adrenal gland produces both catecholamines and corticosteroids (Wright 2001).

Amphibian chromaffin cells generally receive a scarce nerve supply and because of the tight intermingling between steroidogenic and chromaffin tissues, regulation of the chromaffin cell activity is likely achieved by paracrine interactions between the two tissues (Capaldo et al., 2008a, b). Amphibian chromaffin cells are regulated by multiple factors, including humoral agents carried from the blood stream, neurotransmitters and neuropeptides.

It is known that ACTH is one of the main regulators of steroidogenic tissue activity in amphibians (Norris, 2007; Sicard and Vaudry, 2000) and that corticosterone, the main corticosteroid secreted by amphibians, generally increase as a response to stress (reviewed by Moore et al., 2003). However despite the existence of adrenocortical modulation, there is little understanding of what physiological mechanisms operate within the HPA axis to enable modulation of corticosterone release during stress both in amphibians and in reptiles (Moore et al., 2001). A limited number of studies have documented the effects of stressors on the catecholamine release in amphibians. But, in general, stress situations such as hypoxia and forced exercise (Romero et al., 2004) elicit an increase in plasma catecholamines. Elevated catecholamine concentrations cause hyperglycemia via its stimulatory action on glycogenolysis in both liver and muscle (Norris, 2007).

Adaptation to an unfavorable environment can take place under very difficult conditions, as demonstrated in desert amphibians: tadpoles of these species can accelerate metamorphosis as their pond dries, with earlier birth of a more mature product, as long as an unfavorable larval environment is not experienced too early or too severely. Significant changes in the hormonal patterns are found under these circumstances. Similar adaptive phenomena are observed in humans involving elevation of corticosteroid secretion when fetal adverse circumstances are too severe. However, there is very likely a price to pay for this immediate beneficial effect on survival. Hippocampal damage could explain the high rate of learning disabilities and a number of diseases in adulthood (Amiel-Tison et al., 2004).

\subsection{Fish}

Although few studies have been undertaken in fish regarding the mechanisms and the neurophysiology of stress detection by the central nervous system (CNS) and sensory organs, the scheme of stress induced neuroactivation is similar than in other vertebrates. Stressors are detected and first processed in the CNS and then through neuroendocrine axis. In most species the Corticotropin Releasing Hormone or CRH-like activity has been found in the preoptic nucleus of the hypothalamus. The $\mathrm{CRH}$ travels to the pituitary where it 
stimulates the corticotrope cells to release ACTH but in fish, it also stimulates the melanotropic cells to release $\alpha$-Melanocyte-stimulating-hormone $(\alpha-\mathrm{MSH})$ and $\beta$-endorphin. Similarly, other peptides as TRH activates ACTH release and the HPI cascade. In the interrenal tissue of fish, $\mathrm{ACTH}$ is the main responsible for the cortisol release but other agents, like Angiotensin, Urotensin and Atrial Natriuretic Factor (ANF), may interact with $\mathrm{ACTH}$ in the cortisol secretion. It has also been shown that melanotroph products $(\alpha-\mathrm{MSH}$ and $\beta$-Endorphin) may be important regulators of the corticosteroidogenesis and cortisol secretion.

In fish there is close association between adrenocortical and chromaffin tissue except in elasmobranch fishes where the tissues are completely separated and the adrenocortical tissue comprise a discrete gland which lies dorsally between the two posterior lobes of the kidney. The arrangement of chromaffin cells varies among the various groups of fishes along an evolutionary timeline. For example, in hagfish (Myxine) and lampreys (Lampetra), chromaffin cells are located within the heart (reviewed by Perry and Capaldo, 2010), as well as in the great veins returning blood to the heart (Gallo and Civinini, 2003). In teleost fish, the chromaffin cells are located within the walls of the posterior cardinal vein and in close association with the lymphoid tissue of the kidney. In general, chromaffin cells are often observed either singly or clustered into groups of several cells. The association of chromaffin cells with the steroidogenic interrenal cells may vary amongst different teleost species (Perry and Capaldo, 2010). Noradrenalin and adrenaline are the main catecholamines produced by fish chromaffin cells as it occurs in the other vertebrate groups. Noradrenalin and adrenaline producing cells can be distinguished on the basis of morphological characteristics. In teleost fish as in the other groups of fishes, the aminergic chromaffin and interrenal steroidogenic tissues form a diffuse organ at the anterior part of the kidney (called the head kidney), which is situated around the posterior cardinal vein and their branches (Gallo and Civini, 2004). Thus, the head kidney is the homolog to the adrenal gland, and is an organ of particular importance due to its cellular diversity and multiple functions associated (e.g. phagocytosis, hematopoiesis, catecholamine secretion by chromaffin cells, and cortisol secretion by interrenal cells).

Catecholamines, predominantly adrenaline, are released from chromaffin cells (Reid et al., 1998), immediately after stress. Once in the circulation, these hormones diminish the detrimental consequences frequently associated with stressful situations as in the other groups of vertebrates. Similarly, one of the primary roles of catecholamines is to modulate cardiovascular and respiratory function in order to maintain adequate levels of oxygen in the blood and, therefore, sufficient supply to the tissues mobilizing energy stores for the increased energy demands that often accompany stress (Perry and Wood, 1989; Randall and Perry, 1992 in Reid et al., 1998).

Activation of the hypothalamo-pituitary axis and release of ACTH into the circulation by the pituitary is also an integral part of the primary stress response of fish. ACTH stimulates the interrenal cells embedded in the kidney to synthesize and release cortisol into circulation for distribution to target tissues (Barton, 2002; Tort, 2010). The release of cortisol in teleostean and other bony fishes is delayed relative to catecholamine release. In fish, high plasma cortisol levels have a wide range of metabolic effects including, the modulation of carbohydrate metabolism through gluconeogenesis, increases in protein turnover, regulation of amino acid metabolism, ammonia output, glutamine synthetase and aminotransferase activity, and increased lipolysis (reviewed in Mommsen et al., 1999). Cortisol modulates the inflammatory response (Mackenzie et al., 2006; Aluru and Vijayan, 
2009) and a range of other immune system responses (Maule and VanDerKooi, 1999), and appears to attenuate the cellular heat shock protein response to thermal insult (Ackerman et al., 2000; Basu et al., 2001 in Pankhurst 2010). Corticosteroid hormones also play a key role in osmoregulation (reviewed in McCormick, 1995), and are critical for controlling metabolism, hydromineral balance, and the overall stress response. Among corticosteroid hormones that have been well characterized in most vertebrate groups, the identity of one of the earliest vertebrate corticosteroid hormones, 11-deoxycortisol has been recently found in lampreys, a member of the agnathans that evolved more than 500 million years ago. This corticosteroid is regulated by the hypothalamus-pituitary axis and responds to acute stress (Close et al., 2010). This indicates that a complex and highly specific corticosteroid signalling pathway evolved at least 500 million years ago with the arrival of the earliest vertebrate, although it is assumed that this molecule may be derived also from an early ancestral corticosteroid receptor molecule (Thornton and Carroll, 2011).

Regarding the nuclear glucocorticoid receptor (GR), found in all vertebrates, it is known that in fish regulates cell growth, bone density, metabolism and modulates the cardiovascular system. Besides cortisol, also significant levels of 11-deoxycortisol and 11deoxycorticosterone occur and these ligands bind to GRs and Mineralocorticoid receptors (MRs). It has been shown in fish that teleosts may have one or two different GR genes (Acerete et al., 2007; Bury et al. 2003). This discrepancy likely results from the fish specific genome duplication event. One of these two GR genes has two different transcripts that are generated by alternative splicing (Bury et al. 2003; Greenwood et al. 2003). Most interestingly, the three different GR forms in fish are differentially expressed in vivo and show different transactivational capacities, but only slightly different affinity for their ligand. As both genes and different splice variants are transcriptionally active, it is suggested that they both play an important and probably different role in the fish physiology (Bury et al. 2003, Greenwood et al. 2003). This multiple corticoid receptors in fish and a more complex signalling mechanism by related steroids provides an interesting model for comparative GR function (Stolte et al., 2006).

\section{Consequences of the neuroendocrine activation}

Response involving the sympatico-chromaffin axis, involves the activation of chromaffin tissue by specific neurons, resulting in the release of catecholamines, adrenalin and noradrenalin, which in turn induce the generation of large amounts of energy to meet the energetic needs of this active reaction. This is a very rapid response among all vertebrates and mainly involves the cardiovascular system. Regarding the HPA axis, a longer time is needed, since an endocrine cascade is activated and therefore the effects will be produced when the final hormone in the cascade, a corticosteroid has been released. Looking at the knowledge on comparative animal physiology, it can be sustained that the proteins, gene structures, and signalling pathways of the HPA axis are present in the earliest vertebrates and have been maintained by natural selection because of their critical adaptive roles. In all vertebrates so far studied, the HPA axis is activated as a response to stressors and is controlled centrally by peptides of the CRH family. It can be assumed that, irrespective of the behavioral or physiological outcomes, acute and chronic elevations of corticosteroid secretion initiate metabolic alterations and biochemical processes. Because of the dichotomy in the effects of acute and chronic GC responses, studies generally focus on either acute or chronic elevations of GCs (elevated basal values). When basal GC concentrations are 
elevated, a common consequence is a weakening of the further acute GC response, probably through negative feedback mechanisms in the hypothalamic-pituitary-adrenal axis. This is an endocrine vicious circle: a chronically high baseline can provoke pathologies, and a weak acute response is ineffective at handling short-term stressors (Creel, 2001).

Since the energetic cost of the stress situation is high, it is clear that other hormone axes, mostly devoted to the metabolic support will have an influence on the immune function. Thus, the growth hormone and the somatotropic axis have also been shown to affect immune processes, and opioids and thyroid hormones have also been shown to modulate immune responses. The activation of catecholamines and corticosteroids induce a wide number of changes, in particular because these molecules have receptors in most tissues. Therefore, many if not all of the hormones involved in stress responses possess, in addition to their direct effects, induce pleiotropic or collateral consequences that may or may not reinforce direct or primary effect. These other effects can mediate the mechanisms that might affect other unrelated adaptive needs, as for example to modulate the responses of the cardiovascular system, osmotic equilibrium, disease resistance mechanisms and immunocompetence, energetic metabolism and reproduction (see Figure 1).

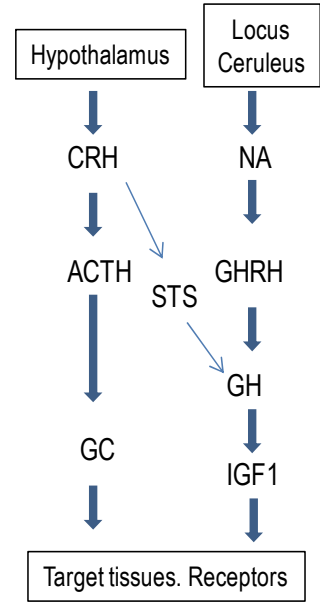

Stress axis \& growth axis

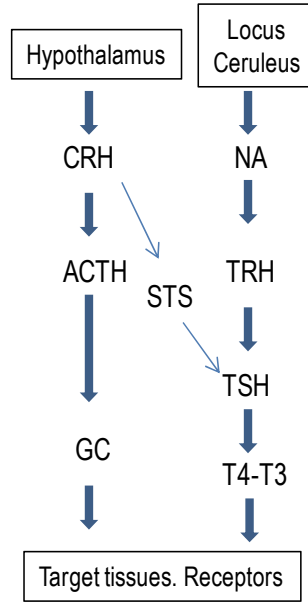

Stress axis \& energetics axis

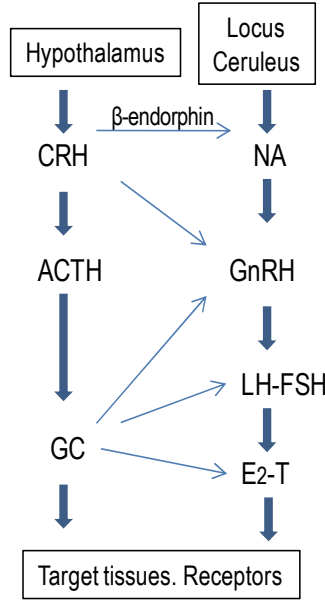

Stress axis \& reproductive axis

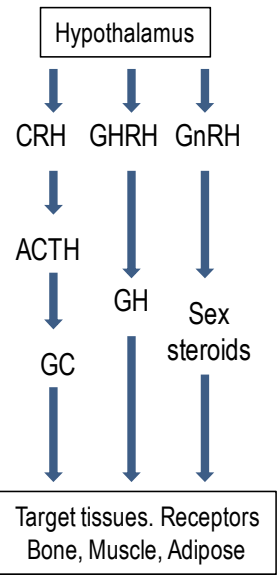

Stress axis \& metabolic axis

Fig. 1. Schematic diagrams of the endocrine interactions between the stress axis and growth, reproduction, energetics and metabolism

In terms of energetics and growth effects, stress generally shows depressive effects, inhibiting feeding behavior in all vertebrates. The effects of CRH on food intake are evolutionarily ancient, as this peptide inhibits feeding already in fishes, and the same effect is observed in birds and mammals. The effects of melanocortins on food intake have not been as extensively studied, but available evidence suggests that the anorexic role of neuronal melanocortins has been conserved. Data from mammals suggest an important role for hypothalamic neuropeptides, in particular the melanocortins and CRH-like peptides, in mediating stress-induced inhibition of feeding. Although there is evidence that CRH and the melanocortins influence hypothalamic circuitry controlling food intake, these peptides may have a more primitive role in modulating visuomotor pathways involved in the recognition 
and acquisition of food. (Carr, 2002). Stress rapidly reduces visually guided prey-catching behavior in toads, an effect that can be mimicked by administration of $\mathrm{CRH}$, while corticosterone and isoproterenol are without effect. Melanocortins also reduce prey oriented turning movements in amphibians and, in addition, facilitate the acquisition of habituation to a moving prey. The effects of these neuropeptides are rapid, occurring within 30 min after administration. By modulating visual and motor processing circuits these neuropeptides may help animals make appropriate behavioral decisions during stress episodes.

Many studies in the last decade have shown that stress can affect immune system both in mammals and lower vertebrates (Verburg-Van Kemenade et al., 2009; Dhabhar et al., 2009), although most of the reports are related to the effects of corticosteroids, and describe generally suppressive effects. Studies with human, murine and rat immune cells showed the immunosuppressive effects of elevated GC levels following stressful circumstances. GCs suppress Th1 cellular immunity and mediate a Th2 shift by suppressing production of $\mathrm{T}$ helper cells type 1/(Th1; tumor necrosis factor-a, interferon-g, interleukin-2 and interleukin -12 cytokines and inducing production of T helper cells type 1 (Elenkov 2004). Suppressive effects have been shown also in fish, where administration of cortisol induce a reduction of cytokine expression in cultured macrophages (Mackenzie et al., 2006; Castillo et al, 2009). Husbandry stressors applied to different species of fish result in a reduction of immunocompetence, showing decreased activity of immune response mechanisms (Montero et al., 1999), and reduction in efficiency after a combination of stress and pathogen treatment (Mauri et al., 2011).

Nevertheless, there are also episodes in which enhancement of immune function is observed, for instance during the immediate reaction, and this may depend on several considerations. One is the time-course, since acute or short-term stress often enhances innate and adaptive immune responses whereas chronic or long-term stress normally suppress or dysregulate immune function (Dhabhar et al., 2009; Tort, 2011). Another is the body compartment at which we are looking. Thus, skin is enriched with immune cells during acute stress, showing immuno-enhancement, while circulating blood may show depletion of leukocytes. A third factor may be the energetic situation of the animal since the demand of resources after stress are increased and they may be insufficient for other needs than facing the coping with stress itself. Whether there is an excess of demands and a shortage of energy resources, the immune system can be suppressed. Nevertheless, these arguments based on conservation of energy have been invoked to explain potential adaptive benefits of stress-induced immuno-suppression, but in one hand, some mechanisms for immunosuppression expend, rather than conserve, energy. On the other hand, it can be also observed that while some immune responses are depressed or delayed, others are present without any decrease in efficiency, for instance, reducing the number of lymphocytes but increasing granulocytes. Therefore, the hypothesis is rather a temporal reorganization of immune resources than a pure suppression response. Maladaptive implications are present when stress becomes chronic; a situation that is unusual in nature and that evolution has yet to resolve (Dhabhar et al., 2009).

Stressors have been shown to reduce reproductive performance and, in lower vertebrates, even impair completely the reproductive process (Pottinger, 1999; Pankhurst 2009; Tort, 2011). In fact, the Hypothalamic-Pituitary-Gonadal axis and the Hypothalamic-PituitaryAdrenal/Interrenal axis share a number of mediators, mainly steroid hormones. Therefore, stress and the activation of HPA axis affects the production of steroids. Interestingly, the 
reproductive system can become resistant to inhibition by GCs in some reproductive contexts. For example, if GCs allocate resources away from reproduction, and thereby reduce individual fitness by impairing successful production of offspring, the benefit of the reproductive system ignoring the GC signal may outweigh the cost of not responding to the stressor. In salmon species and several marsupials, death occurs shortly after breeding. The proximate cause of death is the extremely high levels of GCs that catabolize essential proteins (Wingfield \& Romero, 2001). Reproduction in these animals clearly continues despite elevated GCs. Furthermore, GCs do not inhibit reproduction in many short-lived species and in older individuals, and in dominant individuals in some species where the dominant individual has a limited period with access to mates (Wingfield \& Sapolsky, 2003). Consequently, susceptibility to GC-induced inhibition of reproduction is highly specific depending on the importance of continuing reproduction in the presence of stress, which may vary depending upon age, sex or stage of the breeding cycle and of course, the species (Romero and Butler, 2007).

In the regulation of the stress response by steroid hormones it has been assumed that the production and regulation of steroid hormones has been viewed as a multi-organ process involving glucocorticoids and sex steroids. However, active steroids can also be synthesized locally in target tissues, either from circulating inactive precursors or de novo from cholesterol. This may be the case in the brain for neurosteroids and in the immune system. Furthermore, recent evidence suggests that other steroid hormones LH, GnRH, ACTH and $\mathrm{CRH}$ are expressed locally in target tissues, potentially providing a mechanism for local regulation of neurosteroid and immunosteroid synthesis. The balance between systemic and local steroid signals depends critically on life history stage, species adaptations, and the costs of systemic signals. Thus, individual tissues and organs may become capable of autonomously synthesizing and modulating local steroid signals, perhaps interacting with the HPG and HPA axes and the overall response to stress (Schmidt et al., 2008).

\section{Integration and regulation}

The stress response is characterized by the interplaying of several centers, mechanisms and systems, in order to reestablish the homeostatic conditions. Although it has been known for long time that the stress response is initiated by the activation of the SympatheticChromaffin (SC) and the hypothalamus-pituitary-interrenal (HPI) axes, it was also known from the beginning that other regulatory systems are involved from the initial stages in the building of the stress response. Thus, it was already described by Selye that some pathological components were usually included in the events related to the General Adaptation Syndrome, such as gastrointestinal ulcers and thymolymphatic atrophy, clear signs of immunosuppressed status. Later on, an increasing number of evidences obtained during the last decades, both in lower and higher vertebrates, indicate that the stress response includes also the immune system. Even at the early life stages, the neuroimmunoendocrine interaction is active under stress. Hence, an important number of interconnections are established after stress, not only between the nervous and the endocrine system, but also between the endocrine and immune system, thus constituting a complex network of transmitters between the three regulatory systems. Although this aspect has not been extensively studied in all vertebrates (Verburg-Van Kemenade et al., 2009), it seems apparent that in all of them the nervous, endocrine and immune systems do not operate independently but rather they are part of the repertoire of the physiological 
responses available to react in front of particular circumstances out of the normal physiological range, i.e.: disease, exercise, extreme environmental changes. Communication between these three physiological systems has had less attention in lower vertebrates compared to mammals, mainly because the amount of effort dedicated to such species is less and because of the lack of specific biochemical tools. However, such functional connections are present in all vertebrates and therefore this interconnection network may be an early mechanism in the evolution (see figure 2).

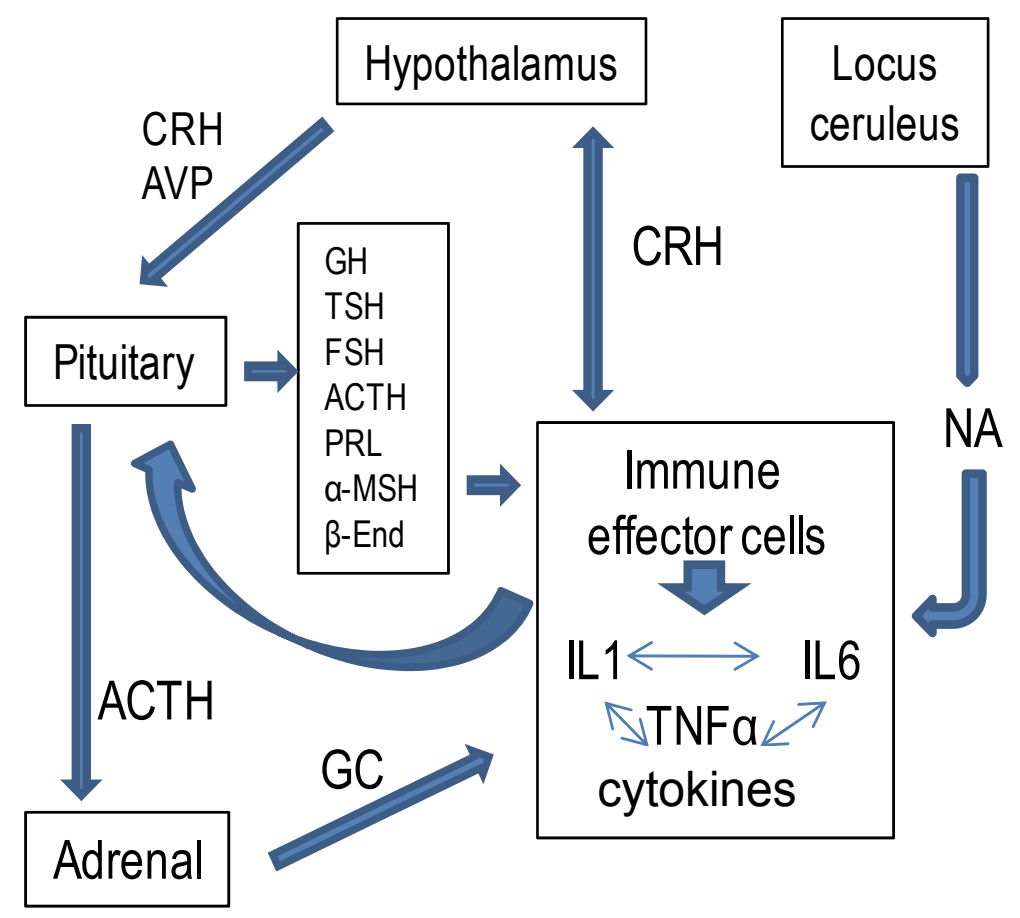

Fig. 2. Stress axis and main neuroimmunoendocrine interactions

These interactions start already at the central levels and there are multiple sites of interaction among the various components of the stress system. Neural control of stress is a complex process that requires the integration of information regarding both actual and potential outcomes. The organization of stress pathways further suggests that inputs on the physiological status of the animal can contribute to the eventual endocrine or autonomic response to the stressor. The majority of the pathways initiating physiological stress responses seem to be made at the level of limbic structures, which communicate information to subcortical sites positioned to interface with ongoing homeostatic feedback (Ulrich-Lai and Herman, 2009). The physical separation of autonomic and HPA stress effector circuits promotes some degree of independence of the two stress-modulatory cascades, allowing for appropriate tuning of neural and hormonal responses to specific demand characteristics of the actual or anticipated event. However, these two physiological systems also work together, both in terms of overlap in their underlying neural circuitry and in terms of their physiological functions. Charmandari et al., (2005) reviewed some of these connections. Reciprocal neural connections exist between the $\mathrm{CRH}$ and noradrenergic neurons of the 
central stress system, with CRH and noradrenalin stimulating each other primarily through $\mathrm{CRH}$ type 1 and a1-noradrenergic receptors, respectively. Autoregulatory negative feedback loops are also present in both the PVN, CRH and brainstem noradrenergic neurons, with collateral fibers inhibiting $\mathrm{CRH}$ and catecholamine secretion via presynaptic $\mathrm{CRH}$ and $a 2-$ noradrenergic receptors, respectively. Both the $\mathrm{CRH}$ and the noradrenergic neurons also receive stimulatory innervations from the serotoninergic and cholinergic systems, and inhibitory input from the $\gamma$-aminobutyric acid (GABA)-benzodiazepine (BZD) and opioid peptide neuronal systems of the brain, as well as from the end-product of the HPA axis, the GCs (Charmandari et al., 2005). It is likely that dysfunctions of information processing across these circuits, resulting from environmental adversity and/or genetic factors, generate alterations that can culminate in maladaption.

In terms of the bidirectional relationships between endocrine and immune systems many of the hormones assessed so far can have an influence on immune agents or mechanisms, and even more some of them play significant roles in the regulation of the immune response. This is the case of the hypothalamic $\mathrm{CRH}$ and the adrenal hormone cortisol. The other axis related to stress, the sympathetico-chromaffin axis also influences immune response through catecholamines. In the reverse direction, the majority of evidence indicates that either direct or indirect stimulation of hypothalamic CRH secretion is the primary means by which cytokines (IL-1, IL-6, and TNF-a) activate the HPA axis. Thus, the neural pathways which IL-1 have been proposed to influence the neuroendocrine hypothalamus in mammals are numerous and diverse, including the inhibitory effects of either inhibitors of prostaglandin synthesis or disruption of catecholaminergic input into the hypothalamus (Turnbull and Rivier, 1999)

Moreover, a reduced number of family molecules appear consistently in the interconnection pathways in all vertebrates. For example, immunocytes can release Proopiomelanocortin (POMC)-derived peptides which have been shown to be involved in the regulation of the immune system. The Growth Hormone can stimulate the activity of the immune system. Sympathetic neurotransmitters can modulate the respiratory burst activity of trout phagocytes. Melanotropins, Melanocyte Stimulating Hormone (MSH), and Melanocyte Concentrating Hormone, $(\mathrm{MCH})$ exert relevant stimulatory effects of the immune system. In mammalian species POMC is produced not only by neuroendocrine tissues, but also in lymphoid cells, which reinforces the neuroimmunoendocrine connection. More work has to be done to ascertain the regulatory mechanisms, and in particular, the role of the receptors and the role of putative paracrine mechanisms that may explain at some extent the interconnection mechanisms between regulatory systems.

This may be the case of organs such the head kidney in fish, as it concentrates several secretory cells belonging to either immune or endocrine systems. It should be emphasized that in fish the head kidney or pronephros is an important centre of the endocrine response. In fact this organ becomes key player in the organization of the integrated response to stressors. Head kidney plays a substantial endocrine role in the secretion of the two main hormones of the hormonal axes, cortisol from interrenal cells, the major fish glucocorticoid and mineralocorticoid, and catecholamines, released by chromaffin cells which are components of the sympathetic nervous system releasing, and receiving specific connections from the central nervous system [30]. Moreover, not only the neural and the endocrine system meet in this organ, but also the immune and hematopoietic systems are found in the pronephros. Thus, this organ is the homologous to the bone marrow of higher vertebrates which involves that the production of lymphocytes, monocytes and neutrophils is localized 
in this organ. It is concluded, then, that the head kidney deals with a number of key physiological responses in fish species. Therefore, fish represent an interesting comparative model for the study of the stress effects on the nervous, endocrine and immune systems, due to the structure and composition of the head kidney (Tort, 2010). In summary, the concept of neuroimmunoendocrine connection identifying specific tissues with specific systems (lymphoid tissue/ immune system, gland/ hormones or neurones/ nervous system) appears to be no longer appropriate or complete as well in lower vertebrates [28]. Clearly in this case, the head kidney in fish represents a tissue in which all three regulatory systems are integrally connected forming a centralized network to coordinate endocrine, neural, and immune, responses after stress.

\section{Stress and adaptation in vertebrates}

The adaptive value of responsiveness to stressors in animals in nature may provide invaluable information regarding the dynamics and flexibility of neuroendocrine responses. Absolute levels of transmitters or hormones may not matter in the induction of responses and survival. Relative elevation or inhibition related to previous experience may adjust specific neural centers to produce relevant output specifically related to the appropriate environmental context. The neural mechanisms for transduction of relevant information are necessarily very plastic, with many transmitters, neuromodulators and peripheral hormone systems interacting between them. These systems influence behavioral and physiological stress responses, but are also influenced by that output (Greenberg and Summers, 2002).

Taking the whole amount of data on the research in stress, it can be said that it generally focuses on the use of negative stimuli. However, positive stimuli such as immediate reaction or novel rewards can cause comparable physiological stress responses (Ulrich-Lai and Herman, 2009). It has been proposed that acute rises in corticosteroids following perturbations of the environment may actually avoid chronic stress as they may work primarily as "anti-stress" hormones. Free-living populations may have elevated circulating levels of corticosteroids under emergency stages. However, this situation may not always be advantageous and there is accumulating evidence from birds that the adrenocortical responses to perturbating factors are modulated both on seasonal and individual bases. These data suggest that corticosteroid secretions allow flexibility so that the response is integrated in relation to time of year, time of the day, as well as for individual differences owing to body condition, disease and social status (Wingfield and Kitaysky 2002).

Although GC responses are viewed as a major evolutionary mechanism to maximize fitness through stress management, phenotypic variability exists within animal populations, and it remains unclear whether inter-individual differences in stress physiology can explain variance in unequivocal components of fitness. For instance, it has been shown that the magnitude of the adrenocortical response to a standardized perturbation during development is negatively related to survival and recruitment in a wild population of birds, providing empirical evidence for a link between stress response, not exposure to stressors, and fitness in a vertebrate under natural conditions. Recent studies suggest that variability in the adrenocortical response to stress may be maintained if high and low responders represent alternative coping strategies, with differential adaptive value depending on environmental conditions (Blas et al., 2007). In fish it has been shown that such a coping strategy is an important determinant of the physiological response, either in behavior, physiology and even gene expression, and therefore much of the phenotypic expression 
may be significantly conditioned by the coping strategy, not only in one species but specifically in groups of individuals (Mackenzie et al., 2009).

\section{Conclusion}

All living organisms have developed responses to face stress situations, and some at cellular level such as heat shock protein activation, have been well conserved along evolution. In vertebrates the physiological stress response is driven by the neuroendocrine axes which in turn affect many other physiological compartments until the homeostasis is regained. In this chapter, after revisiting the stress concept, we have reviewed the general character of the stress phenomenon and the cellular responses, and afterwards we summarize the physiological stress response in vertebrates: mammals, birds, reptiles, amphibians and fish. Finally, the consequences of the endocrine activation and the neuroimmunoendocrine integrated response to stressors have been reviewed in relation to the adaptive value of the stress reaction.

\section{Acknowledgements}

The authors want to thank the support of the Spanish Ministry of Science and Innovation (BFU2009-07354) and Generalitat de Catalunya (SGR2009-0554). LT and MT are members of the Xarxa de Referencia en Aquicultura de Catalunya.

\section{References}

Accordi, F. (1991). The chromaffin cells of urodele amphibians. Journal of Anatomy 179: 1-8

Acerete, L., Balasch , J.C., Roher, N., Castellana, B., Redruello, B., Canario' A.V., Planas, J.V., MacKenzie, S. and Tort, L. (2007). Cloning of glucocorticoid receptor (GR) in gilthead seabream (Sparus aurata). Differential expresion of GR and immune genes after an immune change. Comparative Biochemistry Physiology 148, 32-43.

Ackerman, P. A., R. B. Forsyth, Mazur C.F.and Iwama G.K. (2000). Stress hormones and the cellular stress response in salmonids. Fish Physiology Biochemistry 23: 327-336.

Aluru, N. and M. M. Vijayan (2009). Stress transcriptomics in fish: A role for genomic cortisol signalling. General and Comparative Endocrinology 164(2-3): 142-150.

Amiel-Tison, C., Cabrol D., Denver, R., Jarreau, P., Papiernik H., Piazza, P.V. (2004). Fetal adaptation to stress: Part II. Evolutionary aspects; Stress-induced hippocampal damage; long-term effects on behavior; consequences on adult health. Early human development 78: 81-94.

Barton, B. A. (2002). Stress in fishes: A diversity of responses with particular reference to changes in circulating corticosteroids. Integrative Comparative Biology 42: 517-525.

Basu, N., T. Nakano, Grau, E. G. Iwama, G. K. (2001). The effects of cortisol on heat shock protein 70 levels in two fish species. General Comparative Endocrinology 124: 97-105.

Baumeister, R., Schaffitzel, E., Hertweck, M. (2006). Endocrine signalling in Caenorhabditis elegans controls stress response and longevity Journal of Endocrinology 190: 191-202

Binkley, S.A. (1995). Endocrinology. HarperCollins College Publishers. New York, pp. 283-327.

Blas J., Bortolotti G. R., Tella J. L., Baos R., and Marchant T. A. (2007). Stress response during development predicts fitness in a wild, long lived vertebrate. Proceedings of the New York Academy of Sciences 104: 8880-8884 
Boonstra, R. (2004). Coping with Changing Northern Environments: The Role of the Stress Axis in Birds and Mammals. Integrative and Comparative Biology 44: 95-108.

Bury, N. R., A. Sturm, Le Rouzic P., Lethimonier C., Ducouret B., Guiguen Y., RobinsonRechavi M., Laudet V., Rafestin-Oblin M.E., and Prunet P. (2003). Evidence for two distinct functional glucocorticoid receptors in teleost fish. Journal of Molecular Endocrinology 31(1): 141-56.

Carr, J. A. (2002). Stress, Neuropeptides, and Feeding Behavior: A Comparative Perspective. Integrative and Comparative Biology 42: 582-590.

Castillo, J., M.Teles, S. Mackenzie, L. Tort (2009). Stress-related hormones modulate cytokine expression in the head kidney of Gilthead seabream (Sparus aurata). Fish and Shellfish Immunology 27 (3), .493-499

Chang, C. L. and S. Y. Hsu (2004). Ancient evolution of stress-regulating peptides in vertebrates. Peptides 25(10): 1681-8.

Charmandari, E., Tsigos C, Chrousos G. (2005). Endocrinology of the stress response. Annualof Review Physiology 67: 259-284.

Chimenti, C. and F. Accordi (2010). Morphology and Ultrastructure of the Pronephros of Testudo hermanni Gmelin, 1789 (Chelonian Reptiles). Anatomia, Histologia, Embryologia 40(2): 142-148.

Close, D. A., S.-S. Yun, et al. 11-Deoxycortisol is a corticosteroid hormone in the lamprey. Proceedings of the New York Academy of Sciences 107: 13942-13947.

Creel, S. (2001). Social dominance and stress hormones. Trends in Ecology and Evolution 16(9): 491-497.

Dawson, V. L. and T. M. Dawson (2004). Deadly Conversations: Nuclear-Mitochondrial CrossTalk. Journal of Bioenergetics and Biomembranes 36(4): 287-294.

DeKloet E.R. (2004). Hormones and the stressed brain. Annals of the New York Academy Sciences 1018:1-15.

Denver, R. J. (2009). Structural and Functional Evolution of Vertebrate Neuroendocrine Stress Systems. Annals of the New York Academy of Sciences 1163(1): 1-16.

Dhabhar, F. S. (2009). Enhancing versus Suppressive Effects of Stress on Immune Function: Implications for Immunoprotection and Immunopathology. Neuroimmunomodulation 16(5): 300-317.

Dunlap K. D. Schall J.J. (1995). Hormonal alterations and reproductive inhibition in male fence lizards (Sceloporus occidentalis) infected with the malarial parasite Plasmodium mexicanum. Physiological Zoology, 1995

Elenkov, I. J. (2004). Glucocorticoids and the Th1/Th2 Balance. Annals of the New York Academy of Sciences 1024(1): 138-146.

Engelsma, M. Y.,Huising, M. O., van Muiswinkel, W. B., Flik, G., Kwang, J., Savelkoul, H. F.,Verburg-van Kemenade, B. M. (2002). Neuroendocrine-immune interactions in fish: a role for interleukin-1. Veterinary Immunology and Immunopathology 87(3-4): 46779.

Finkel, T. and N. J. Holbrook (2000). Oxidants, oxidative stress and the biology of ageing. Nature 408(6809): 239-247.

Fowles, J. R., A. Fairbrother, Fix, M Schiller S.and Kerkvliet. N. I. (1993). Glucocorticoid effects on natural and humoral immunity in mallard. Developmental and Comparative Immunology 17: 165-177. 
Fuzzen, M. L. M., Alderman S. L., Bristow E. N. and Bernier N. J. (2010). Ontogeny of the corticotropin-releasing factor system in rainbow trout and differential effects of hypoxia on the endocrine and cellular stress responses during development. General and Comparative Endocrinology 170(3): 604-612.

Gallo, P. V., and Civinini, A. (2003). Survey of the Adrenal Homolog in Teleosts. International Review of Cytology, Academic Press. 230: 89-187.

Ghosh A, Carmichael S. W., Mukherje M. (2001). Avian adrenal medulla: cytomorphology and function. Acta Biologica Szegediensis, 45(1-4):1-11

Greenwood, A. K., P. C. Butler, White R.B., DeMarco U., Pearce D. and F. D. Russell (2003). Multiple corticosteroid receptors in a teleost fish: distinct sequences, expression patterns, and transcriptional activities. Endocrinology 144(10): 4226-36.

Haddad, J. J., N. E. Saade, Safieh-Garabedian, B (2002). Cytokines and neuro-immuneendocrine interactions: a role for the hypothalamic-pituitary-adrenal revolving axis. Journal of Neuroimmunology 133(1-2): 1-19.

Harris, J. and D. J. Bird (2000). Modulation of the fish immune system by hormones. Veterinary Immunology and Immunopathology. 77: 163-176.

Holcik, M. and N. Sonenberg (2005). Translational control in stress and apoptosis. Nature Reviews in Molecular and Cell Biology 6(4): 318-327.

Hyakumachi, M. and Arora, D.K. (1998). The response of fungal propagules to competitive stress in soil. In Stress of life. From molecules to man. Ed. by P. Csermely. Annals of the New York Academy of Sciences 851: 139-146

Karin, M. (1998). Mitogen-activated protein kinase cascades as regulators of stress responses. In Stress of life. From molecules to man. Ed. by P. Csermely. Annals of the New York Academy of Sciences 851: 139-146

Kultz, D. (2005). Molecular and evolutionary bassis of the cellular stress response. Annual Review of Physiology 67: 225-257.

Laforgia, V., L. Varano, et al. (1991). Comparative morphology of the adrenal gland in selected species of the genus Podarcis. Amphibia-Reptilia 12: 153-160.

Lance, V. A. and R. M. Elsey (1999). Plasma catecholamines and plasma corticosterone following restraint stress in juvenile alligators. Journal of Experimental Zoology 283(6): 559-565.

Landsberg, L. and J. B. Young (1992). Catecholamines and the adrenal medulla. Williams Textbook of endocrinology. J. J. a. F. Wilson, D.W. Philadelphia, Saunders: pp 621.

Larcher, W. (1987). Stre $\beta$ bei pflanzen. Naturwissenschaften 74: 158-167

Lichtenthaler , H.K. (1998). The stress concept in plants. In: Stress of life. From molecules to man. Ed. by P. Csermely. Annals of the New York Academy of Sciences 851, pp. 187-198

Mackenzie, S., Iliev,D., Liarte,C., Koskinnen,H., Planas,J.V., Goetz,F.W., Molsa, H., Krasnov,A., Tort, L. (2006). Transcriptional analysis of LPS-stimulated activation of trout (Oncorhynchus mykiss) monocyte/ macrophage cells in primary culture treated with cortisol. Molecular Immunology. 43: 1340-1348.

MacKenzie S, Ribas L, Pilarczyk M, Capdevila DM, Kadri S, Huntingford, F.A. (2009) Screening for Coping Style Increases the Power of Gene Expression Studies. PLoS ONE 4(4): e5314

Maule, A. and VanDerKooi, S.P. (1999). Stress-induced immune-endocrine interactions. In: Stress physiology in animals. Ed. by: P. Balm. Sheffield Biological Sciences. 205-245 
Mauri I., Roher N., MacKenzie S., Romero A., Manchado M., Balasch J.C, Béjar J., Álvarez MC and Tort L (2011). Molecular cloning and characterization of European seabass (Dicentrarchus labrax) and Gilthead seabream (Sparus aurata) complement component C3. Fish and Shellfish Immunology. In press.

McCormick, S. D. (1996). Effects of growth hormone and insulin-like growth factor I on salinity tolerance and gill $\mathrm{Na}+, \mathrm{K}+$-ATPase in Atlantic salmon (Salmo salar): interaction with cortisol. General and Comparative Endocrinology 101(1): 3-11.

Mommsen, T. P., M. M. Vijayan, Moon, T.W. (1999). Cortisol in teleosts: dynamics, mechanisms of action, and metabolic regulation. Reviews in Fish Biology and Fisheries 9(3): 211-268.

Montero, D., M. Marrero, et al. (1999). Effect of Vitamin E and C and dietary supplementation on some immune parameters of gilthead seabream (Sparus aurata) juveniles subjected to crowding stress. Aquaculture 171: 269-278.

Moore I. T., Greene M. J., Mason R.T. (2001) Environmental and Seasonal Adaptations of the Adrenocortical and Gonadal Responses to Capture Stress in Two Populations of the Male Garter Snake, Thamnophis sirtalis. Journal of Experimental Zoology 289:99-108

Moore, I. T. and T. S. Jessop (2003). Stress, reproduction, and adrenocortical modulation in amphibians and reptiles. Hormones and Behavior 43(1): 39-47.

Möstl, E. and R. Palme (2002). Hormones as indicators of stress. Domestic Animal Endocrinology 23(1-2): 67-74.

Norris, D.O. (2007). Vertebrate endocrinology. Academic Press 4th Edition 560pp

Palme, R., S. Rettenbacher, Touma, C., El-Bahr, S. M., Möstl, E (2005). Stress Hormones in Mammals and Birds: Comparative Aspects Regarding Metabolism, Excretion, and Noninvasive Measurement in Fecal Samples. Annals of the New York Academy of Sciences 1040(1): 162-171.

Pankhurst, N. W. (2011). The endocrinology of stress in fish: An environmental perspective. General and Comparative Endocrinology 170(2): 265-275.

Perry, S. F. and A. Capaldo (2010). The autonomic nervous system and chromaffin tissue: Neuroendocrine regulation of catecholamine secretion in non-mammalian vertebrates. Autonomic Neuroscience. In Pres

Perry S. F. and Wood C. M.. (1989). Control and coordination of gas transfer in fishes. Canadian Journal of Zoology 67(12): 2961-2970

Pottinger, T.G. (1999). The impact of stress on nimal reproductive activities. In: Stress physiology in animals. Ed by P. Balm. Sheffield Academic Press, pp: 130-177.

Randall, D. J. and Perry, S. F. (1992). Catecholamines. In Fish Physiology, vol.XIIB (ed. W. S. Hoar, D. J. Randall and A. P. Farrell), pp. 255-300

Reid, S. G., N. J. Bernier, Perry, S.F. (1998). The adrenergic stress response in fish: control of catecholamine storage and release. Comparative Biochemistry and Physiology 120C: 1-27.

Ribas,L., Planas,J.V., Barton,B., Monetti,C., Bernardini,G., Saroglia,M., Tort,L. and Mackenzie,S. (2004). A differentially expressed gene isolated from the gilthead sea bream (Sparus aurata) under high-density conditions is up-regulated in brain after in vivo lipopolisaccharide challenge. Aquaculture 241: 195-206

Riedemann T., Patchev A. V., Cho K., Almeida O.F.X. (2010). Corticosteroids: way upstream. Molecular Brain, 3: 2-20

Romero, L. M. (2004). Physiological stress in ecology: lessons from biomedical research. Trends in Ecology and Evolution19(5): 249-55. 
Romero L. Michael and Butler Luke K. (2007). Endocrinology of Stress. International Journal of Comparative Psychology, 2007, 20, 89-95.

Schmidt, K. L., D. S. Pradhan, et al. (2008). Neurosteroids, immunosteroids, and the Balkanization of endocrinology. General and Comparative Endocrinology 157(3): 266-274.

Segal G. and E Z Ron. (1993). Heat shock transcription of the groESL operon of Agrobacterium tumefaciens may involve a hairpin-loop structure. Journal of Bacteriology 175: 3083-30

Selye, H. (1936). A syndrome produced by diverse nocious agents. Nature 138, 32.

Sicard,F., Vaudry,H., Braun, B., Chartrel,N., Leprince J., Conlon, J. M. and C. Delarue C. (2000). Immunohistochemical Localization, Biochemical Characterization, and Biological Activity of Neurotensin in the Frog Adrenal Gland. Endocrinology 141(7): 2450-2457

Sung, Y. , Van Damme,Y., Els J.M., Sorgeloos P. and Bossier P.( 2007). Non-lethal heat shock protects gnotobiotic Artemia franciscana larvae against virulent Vibrios. Fish and Shellfish Immunology 22, 318-326

Stolte E. H., Lidy Verburg van Kemenade B. M., Savelkoul H. F J and Flik G. (2006). Evolution of glucocorticoid receptors with different glucocorticoid sensitivity. Journal of Endocrinology (2006) 190, 17-28

Szabo, S. (1998). Hans Selye and the development of stress concept: Special reference to gastroduodenal ulcerogenesis. Annals of the New York Academy of Sciences 851: 19-27

Terwilliger, N. B., M. Ryan, Phillips, M., Michelle R. (2006). Crustacean hemocyanin gene family and microarray studies of expression change during eco-physiological stress. Integrative ComparativeBiol 46: 991-999.

Thornton, J. W. and S. M. Carroll (2011). Lamprey endocrinology is not ancestral. Proceedings of the New York Academy of Sciences, 108: E5.

Tort, L. (2010). Stress in farmed fish. Its consequences in health and performance. In: Recent advances in Aquaculture Research. Ed: G. Koumoundouros. Transworld Research Network.Trivandrum, Kerala, India pp. 55-74

Tort, L., M. Pavlidis and N.Y.S. Woo (2011). Stress and welfare in sparid fishes. In: Sparidae. Biology and Aquaculture. Edited by M. Pavlidis and C. Mylonas. Wiley-Blackwell. pp:75-94

Turnbull, A. V. and C. L. Rivier (1999). Regulation of the Hypothalamic-Pituitary-Adrenal Axis by Cytokines: Actions and Mechanisms of Action. Proceedings of the New York Academy of Sciences: 1-71.

Tyrrell, C. L. and A. Cree (1998). Relationships between Corticosterone Concentration and Season, Time of Day and Confinement in a Wild Reptile (Tuatara,Sphenodon punctatus). General and Comparative Endocrinology 110(2): 97-108.

Ulrich-Lai, Y. M. and J. P. Herman (2009). Neural regulation of endocrine and autonomic stress responses. Nature Reviews Neuroscience 10(6): 397-409.

Varano, (1980). Comparative aspects of the adrenal chromaffin cells of Vertebrates. In H. Parvez and S. Parvez. (eds): Biogenic Amines in Development. Elsevier North-Holland. Pp: 159-183.

Verburg-VanKemenade, B.M.L., Stolte, E.H., Metz, J.R., Chadzinska, M.,(2009). Neuroendocrine-immune interactions in teleost fish. In: Fish Neuroendocrinology, vol. 28. Elsevier, pp. 313-364.

Wilkinson S. \& Davies W. J. (2002). ABA-based chemical signalling: the co-ordination of responses to stress in plants. Plant, Cell and Environment 25, 195-210. 
Wingfield, J. C. and A. S. Kitaysky (2002). Endocrine Responses to Unpredictable Environmental Events: Stress or Anti-Stress Hormones? Integrative and Comparative Biology 42: 600-609.

Wingfield, J. C. and Romero, L. M. (2001). Adrenocortical Responses to Stress and Their Modulation in Free-Living Vertebrates, Comprehensive Physiology. John Wiley \& Sons, Inc. pp: $453-460$

Wingfield, J. C. and R. M. Sapolsky (2003). Reproduction and Resistance to Stress: When and How. Journal of Neuroendocrinology 15(8): 711-724. 


\section{Part 7}

Steroid Induced Osteoporosis 



\title{
Genistein Aglycone Demonstrates a Protective and Reversible Effect on the Development of Steroid-Induced Secondary Osteoporosis and Increases Bone Breaking Strength in Rats
}

\author{
Alessandra Bitto ${ }^{1}$, Francesca Polito 2 , Bruce P. Burnett ${ }^{3}$, Herbert Marini², \\ Robert Levy ${ }^{3}$, Domenica Altavilla ${ }^{1}$ and Francesco Squadrito ${ }^{1}$ \\ ${ }^{1}$ Department of Clinical and Experimental Medicine and Pharmacology \\ Section of Pharmacology, University of Messina \\ ${ }^{2}$ Department of Biochemical, Physiological and Nutritional Sciences \\ Section of Physiology and Human Nutrition, University of Messina \\ 3Primus Pharmaceuticals, Inc. Scottsdale, Arizona \\ 1,2Italy \\ ${ }^{3}$ USA
}

\section{Introduction}

Glucocorticoids are used in the treatment of inflammatory and autoimmune diseases, cancers, and following organ transplantation. Glucocorticoid-induced osteoporosis is one of the primary side effects of glucocorticoid use resulting in increased risk of fractures. In a large meta-analysis study of glucocorticoid users, for example, van Staa et al (2002) found a relative risk increase of 1.91 for any fracture, 2.86 for vertebral fracture, 1.61 for hip fracture, and 1.13 for forearm fracture. Glucocorticoid-induced osteoporosis is characterized by low bone turnover and fractures, which occur in $30-50 \%$ of patients (van Staa et al., 2000). Glucocorticoids affect predominantly cancellous or trabecular bone, increasing the risk of vertebral fractures, which may be asymptomatic and occur early during the first months of glucocorticoid treatment (Laan et al., 1993; van Staa et al., 2000) and (Angeli et al., 2006). Trabecular bone accounts for approximately $20 \%$ of the total mass of bone (Bertazzo \& Bertran, 2006) and also contributes to the ability of bone to tolerate stress to avoid fracture, especially in the spine. Long-term use of glucocorticoids also increases the risk of all osteoporotic fractures.

Published reports suggest no course of glucocorticoid therapy is safe for the skeleton. Regimens of daily prednisone at doses as low as $2.5 \mathrm{mg}$ have been associated with an increased risk of hip and vertebral fractures. The risk increases by 5 -fold, with prednisone doses above $7.5 \mathrm{mg}$ daily. A dramatic 17 -fold increase in vertebral fracture incidence was observed in subjects who used prednisone continuously more than $10 \mathrm{mg}$ per day for longer than 3 months with increased fracture incidence in postmenopausal females and elderly males. The risk of osteoporotic fractures was also elevated in patients undergoing cyclic corticosteroid treatment at high doses (Van Staa et al., 2006) Although variable in onset, 
fracture risk decreases after discontinuation of oral corticosteroids (Vestergaard et al., 2008). The risk of osteoporosis associated with inhaled glucocorticoids or with budesonide, a topical steroid used in inflammatory bowel disease, is small because their absorption is limited. Due to the high risk of fracture in glucocorticoid-administered patients, treatment guidelines exist.

Treatment guidelines for the use of glucocorticoids have been established which advise that if prednisolone is administered at $\geq 5 \mathrm{mg}$ per day for three months or longer requires regular monitoring of bone mineral density (BMD) and treatment to prevent osteoporosis must be initiated (American college of Rheumatology, 2001; Adler \& Hochberg, 2003; National Osteoporosis Society, 1998). Vitamin D and calcium are also recommended for the management of all patients treated with glucocorticoids. Bisphosphonates should be considered for the prevention and treatment of this disorder, because they can prevent the initial loss of bone mass from glucocoriticoids. Alendronate, risedronate, and zoledronic acid were shown to prevent and reverse the loss of BMD in glucocorticoid-induced osteoporosis with greater effects than those observed with vitamin D and calcium (Doga et al., 2008) and (Amin et al., 2002). In fact, bisphosphonates induce improvement of BMD that is 2-fold greater than that observed during vitamin D treatment alone $(4.6 \%$ vs. $2.0 \%$, respectively) (Amin et al., 2002). Anabolic therapy is also utilized for treatment of glucocorticoid-induced osteoporosis. Teriparatide causes a greater increase in BMD than alendronate and greater reduction in the risk of vertebral fractures (Saag et al., 2007). Even with these evidentiary clinical trials and guidelines, patient bone loss is, in general, poorly managed (Eastell et al., 1998; Walsh et al., 1996; Gudbjornsson et al., 2002). In glucocorticoidinduced osteoporosis, fractures also occur at higher BMDs than in postmenopausal osteoporosis in untreated women (van Staa et al., 2003). Consequently, guidelines for the treatment of postmenopausal osteoporosis are not applicable to glucocorticoid-induced osteoporosis, and patients should be treated at BMD T-scores of $\leq-1.0$ to -1.5 (Compston, 2004). In addition, vertebral fractures may be asymptomatic and often require radiological diagnosis before treatment. Since the incidence of fractures is higher in the spine compared to other areas of the body, glucocorticoid therapy appears to affect rapid bone remodelling. During the initial phases of glucocorticoid exposure bone resorption is increased (van Staa et al., 2000). Glucocorticoids inhibit the formation of mature osteoblasts, but also activate apoptosis in these cell types (Jones \& Sambrook, 1994; Canalis et al., 2007). Osteoprotegrin (OPG) expression, a key factor involved in modulating maturation of osteoclasts, is reduced also by glucocorticoids resulting in increased osteoclastogenesis (Orcel, 2005). Therefore, the combination of reduced osteoblast formation, increased osteoclast maturation leads to accelerated bone loss while on glucocorticoid therapy. Therapies are needed which modulate osteoclast as well as osteoblast activity to restore a more normal balance to the bone remodeling process in glucocorticoid treated patients.

\section{Glucocorticoid-induced osteoporosis: Is there a role for genistein?}

Among the anabolic compounds tested in recent years genistein aglycone seems a promising agent able to stimulate bone formation and to reduce bone resorption, acting via a genomic as well as a non-genomic pathways. Genistein is an isoflavone found in small quantities in certain legumes throughout the plant kingdom. Soybeans are a particularly rich source of genistin, the glucosidal precursor of genistein, although the concentration varies with the strain, location and environmental conditions of cultivation 
of the plant. Another widely utilized source of genistin is Sophora japonica L (Tian et al., 2004). The glucosidal form and acetyl- and malonyl-glucosides are the major isoforms found in soybean derivates. The conversion from the glucosides to the aglycone form occurs in the gut, where the sugar residue is removed with the generation of genistein (Larkin et al., 2008).

Genistein is freely absorbed from the intestine and a large fraction is converted to the 7ß-Oglucuronide as it crosses the brush border and ultimately enters the portal vein (Sfakianos et al., 1997), a process that is influenced by intestinal bacteria (Setchell et al., 2002; Day et al., 1998). Recent ex vivo data using isolated human gastrointestinal tract tissue also suggest that genistein may also undergo sulfonation in the small intestine, though the extent to which these sulfonates are absorbed following dietary intake is unknown (Ronis et al., 2006). The exact percentages of glucuronidated and sulfonated metabolites after crossing the lumen are also unknown, although it is clear that only a small percentage of the parent molecule remains as unconjugated genistein once it reaches the liver. Once in the liver, genistein undergoes additional biotransformation via CYP450-mediated hydroxylation ( $\mathrm{Hu}$ et al., 2003) followed by glucuronidation and sulfonation by UDP-glucuronosyl transferase and sulphotransferases, respectively (Sfakianos et al. 1997). Genistein 7 $\beta$-O-glucuronide can be recovered from bile after infusion of genistein into the small bowel of rats (Prasain et al., 2006). As much as $70 \%$ of the recovered genistein from bile is in the form of glucuronidated conjugates with smaller amounts reappearing in the distal duodenum and jejunum (Sfakianos et al., 1997). The vast majority of circulating genistein in serum has been found to be in the form of glucuronidated and sulfonated conjugates which represent excretion forms of the molecule (Setchell et al., 2002). Little is known about the bioactivity of conjugated isoflavones. Genistein is composed of two benzene rings (A and B) linked through a heterocyclic pyrane $\mathrm{C}$ ring. The hydroxyl group on the $\mathrm{A}$ ring confers to genistein a greater activity both in vitro and in vivo, compared to other isoflavones (Choi et al., 2008).

In addition to competing with endogenous estrogens for binding to the estrogen receptors at high concentrations, genistein may exert anti-estrogenic effects by several potential mechanisms (Tham et al., 1998). Genistein has both ER agonist and antagonist activity in different cell types and works in a promoter specific manner in gene activation via ERs. The ER domain structure is typical of nuclear receptors. The amino-terminal region is involved in trans-activation of gene expression and has been termed the activation function domain or AF1 domain. The middle region contains a two-zinc finger structure, which plays an important role in binding to specific DNA response elements and in receptor dimerization. The carboxyl-terminal region contains an activation domain, termed AF2. A ligand binding domain, lying within AF2, is crucial for binding to receptor specific ligands and also corepressors and co-activators. This binding interaction affects receptor dimerization, nuclear translocation and modulation of target gene expression by AF2. The ligand-binding domain is structurally conserved among the nuclear receptor family and consists of between 10 and $12 \alpha$ helices folded in a globular domain. A central hydrophobic pocket accommodates the cognate ligand, which upon binding induces a conformational change in the ligand-binding domain, exposing a coactivator-docking site on ligand binding surface. However the binding of SERMs to ERs results in a different conformation change in which the coactivator-binding site is blocked from interaction with coactivator, thereby blocking AF2 mediated transcriptional activity (Liu et al., 2003). Several classes of nuclear receptor coactivators interact with ERs receptors and are specific for either ER $\alpha$ or ER $\beta$. Using specifying coactivator recruitment and fluorescence resonance energy transfer, the genistein 
interaction with ER receptors was investigated (Kuiper et al., 1998). Compounds with estrogen agonism induce agonist-mediated recruitment and allow fluorescence resonance energy transfer. Compounds with estrogen antagonism block the agonist-mediated recruitment of coactivators and prevents fluorescence resonance energy transfer. Genistein showed full agonism for ER $\alpha$ and only partial agonism for ER $\beta$, but higher affinity for ER $\beta$ than ER $\alpha$ (Kuiper et al., 1998).

A second action of genistein on membrane associated protein (membrane receptors) has been proposed, and remains still not fully elucidated. In this mechanism, several possible second messengers, including kinase enzymes, are activated and in turn stimulate or inhibit downstream pathways of metabolism and protein products. The duration of this effect via a membrane protein is short lasting and of limited efficacy. The positive effects of genistein on primary osteoporosis, due to estrogen fall, have been extensively investigated by our group as well as by others and have been recently summarized in a review article (Bitto et al., 2010); however pre-clinical evidence point out a role for genistein also in secondary osteoporosis induced by corticosteroid use.

\subsection{Evidence from in vitro studies}

Genistein has been most investigated for its effect on the proliferation and differentiation of a number of cell types. Through its effect on tyrosine kinase, genistein is able to modulate cell cycle progression in the $S$ phase, to induce G2/M arrest and to induce apoptosis (Matsukawa et al., 1993). Numerous in vitro studies with human or animal osteoclast- or osteoblast-like cell lines have been carried out with consistent observations of direct effects of genistein on both cell types. Effects of genistein on bone metabolism derived from direct and indirect actions on bone cells and can be summarized in stimulation of osteoblastic bone formation and inhibition of osteoclastic bone resorption (Gao \& Yamaguchi, 1999a; Sugimoto \& Yamaguchi, 2000; Chen et al., 2003; Heim et al., 2004). In vitro studies indicate that genistein is able to stimulate osteoblastic activity and inhibit osteoclast formation and action at a range of concentrations $\left(10^{-5}-10^{-7} \mathrm{M}\right)$ consistent with the levels observed in human subjects after ingestion of genistein. With regard to effects on osteoclast genistein inhibits their formation and function (Amano et al., 1998; Gao \& Yamaguchi, 2000; Yamagishi et al., 2001; Albertazzi, 2002; Blair et al., 1996; Gao \& Yamaguchi, 1999a; Kajiya et al, 2000; Williams et al, 1998). Genistein suppress osteoclast activity by a number of possible mechanisms, including induction of apoptosis, activation of protein tyrosine phosphatase, inhibition of cytokines, changes in intracellular $\mathrm{Ca}^{2+}$, and membrane depolarization. More in details, in mouse marrow cultures genistein has a potent inhibitory effect on osteoclast-like cell formation, and this effect is similar to others anti-bone-resorbing agents, such as calcitonin and 17 $\beta$-estradiol, and may involve cAMP signaling. Sliwiñski and coworkers (2005) compared the effects of genistein, estradiol and raloxifene, compounds affecting in different ways estrogen receptors, on formation and viability of osteoclast from neonatal rat bone marrow; the results shown that all treatments decrease the number of osteoclasts formed from bone marrow, particularly genistein at the lower concentration decreases the number of osteoclasts by induction cell death, while at higher concentration genistein prevents the formation of osteoclasts. These observations are consistent with the results of another study (Rickard et al. 2003), showing that genistein, acting as agonist of estrogen receptors, mimicked estradiol in affecting gene expression of progesterone receptor, the proteoglycan versican, alkaline phosphatase and osteopontin, and production of 
interleukin-6 protein. However, actions of genistein at the cellular level depend on the target tissue, receptor status of the tissue, and the level of endogenous estrogen. Both estrogen receptors ER $\alpha$ and ER $\beta$ are present in bone tissue, although the expression of these subtypes varies considerably during differentiation. The greatly increased expression of ER $\beta$ during bone mineralization is particularly pertinent to the potential hormonal effects of isoflavones because compounds such as genistein show a much higher affinity for ER $\beta$ than for ER $\alpha$ (Arts et al., 1997).

One of the mechanism by which genistein induces apoptosis of mature osteoclasts involves the $\mathrm{Ca} 2+$ signaling, the inhibition of protein kinase and the activation of protein tyrosine phosphatase in osteoclasts. In this study the suppressive effect of genistein was completely abolished by the presence of inhibitors of $\mathrm{Ca}^{2+}$-dependent protein kinases (Gao \& Yamaguchi, 1999b). The most important cytokine machinery, which is involved in bone metabolism, is osteoprotegerin (OPG)/receptor activator of nuclear factor-kB (RANK)/RANK ligand (RANKL) system. The molecular triad OPG/RANK/RANKL plays important roles in bone remodeling. RANKL is expressed by osteoblasts and is necessary and sufficient for osteoclastogenesis. RANKL binds to its receptor RANK, present at the surface of osteoclast precursors and mature osteoclasts, inducing osteoclast formation and activation. RANKL activity can be blocked by the soluble decoy receptor OPG, resulting in prevention of bone resorption. Studies, in vitro, have found that genistein induces apoptosis and inhibits RANKL signaling-related gene expression (Uchiyama \& Yamaguchi, 2007).

Genistein was also reported to increase osteoblastic differentiation and affect osteoblast activity (Rickard et al., 2003; Pan et al., 2005; Morris et al., 2006; Okumura et al., 2006). In osteoblasts genistein stimulates a concentration-dependent increase in alkaline phosphatase activity. In osteoblastic MC3T3-E1 cells, genistein increases protein content, DNA content and alkaline phosphatase activity (Yamaguchi \& Sugimoto, 2000; Sugimoto \& Yamaguchi, 2000). This effect has also been demonstrated in tissue cultures. In femoral metaphyseal tissue from elderly female rats genistein increases $\mathrm{Ca}^{2+}$ content and alkaline phosphatase activity. This effect is blocked by tamoxifen, indicating an ER-mediated pathway, and also by cycloheximide, suggesting that this isoflavone influence transcriptional or translational events (Yamaguchi \& Gao, 1997, 1998). On the other hand, genistein also causes apoptosis of osteoblasts by activating caspase- 3 and cleaving adhesion molecules such as cadherins and catenins (Hunter et al., 2001). In normal fetal osteoblast cells, genistein increases the progesterone receptor and alkaline phosphatase gene expression and inhibits osteopontin and interleukin-6 gene expression (Rickard et al. 2003).

\subsection{Evidence from in vivo studies}

The manner by which glucocorticoids induce bone loss is complex and incompletely understood (Patschan et al., 2001; Canalis et al., 2007), in part because there are no animal models absolutely comparable to humans. A major effect on the skeleton is a decrease in bone formation and unchanged or enhanced bone resorption (Lane et al., 2001). The main effect of glucocorticoids on bone is inhibition of osteoblastogenesis, augmented continued osteoclastogenesis and osteocyte apoptosis, leading to a decrease in bone formation, a rapid weakening of bone architecture and an increase in fracture risk (Manolagas \& Weinstein, 1999). Chronic administration of steroids also causes avascular necrosis via an apoptotic mechanism of osteocytes and osteoblasts (Weinstein et al., 2000, Bekler et al., 2007). Once osteonecrosis occurs, glucocorticoids also cause inhibition of bone regeneration (Takano- 
Murakami et al., 2009). In a rat model, we studied genistein preservative effects on methylprednisolone-induced bone loss and osteonecrosis of the femoral head (Bitto et al., 2009). In our study (Figure 1), genistein succeeded in preventing osteoporosis and osteonecrosis of the femoral head when co-administered with the glucocorticoid. The isoflavone statistically maintained bone mineral density (Figure 2) and content (Bitto et al., 2009) over the methylprednisolone-treated group and showed comparable efficacy with the vehicle group. Genistein co-administered with methylprednisolone also statistically maintained femoral bone's resistance to rupture compared with the methylprednisolone group (Figure 3C) and preserved the normal architecture of cartilage as well as both cortical and trabecular bones with a well-organized matrix in femoral head (Figure $3 \mathrm{~A}$ and $\mathrm{B}$ ).

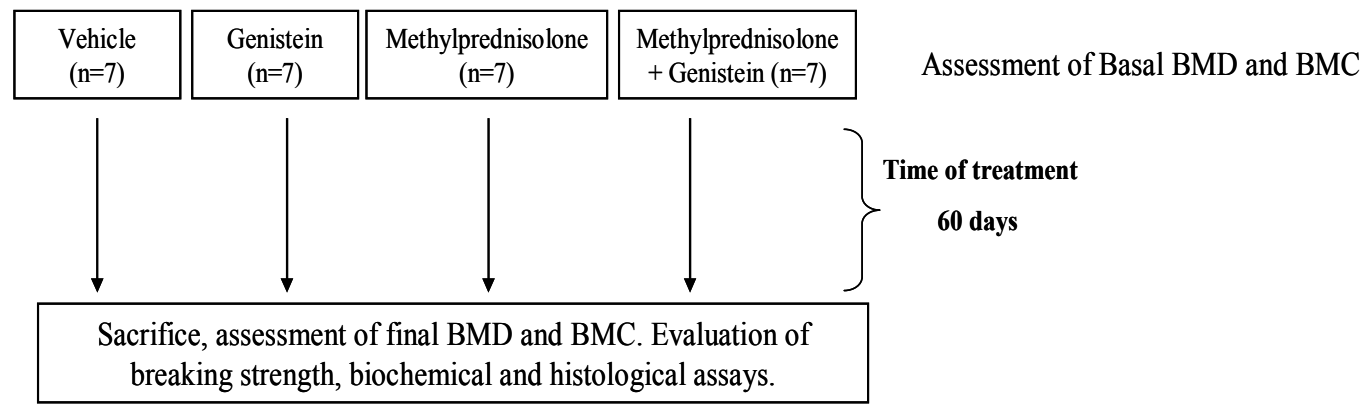

Fig. 1. Flow-chart of the experimental protocol.

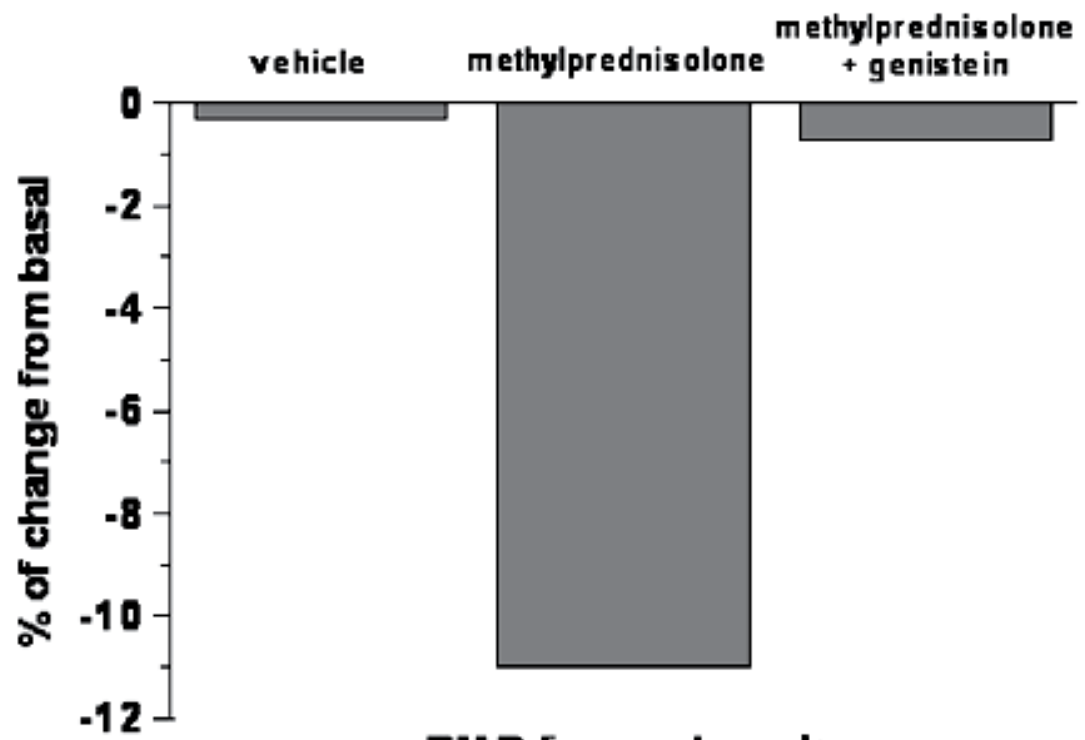

BMD femoral neck

Fig. 2. Effects of aglycone genistein on femoral bone mineral density (BMD) in methylprednisolone-treated rats. Data are shown as \% of variation from basal values in the same group of animals. ${ }^{*} p<0.005$ vs. methylprednisolone. 

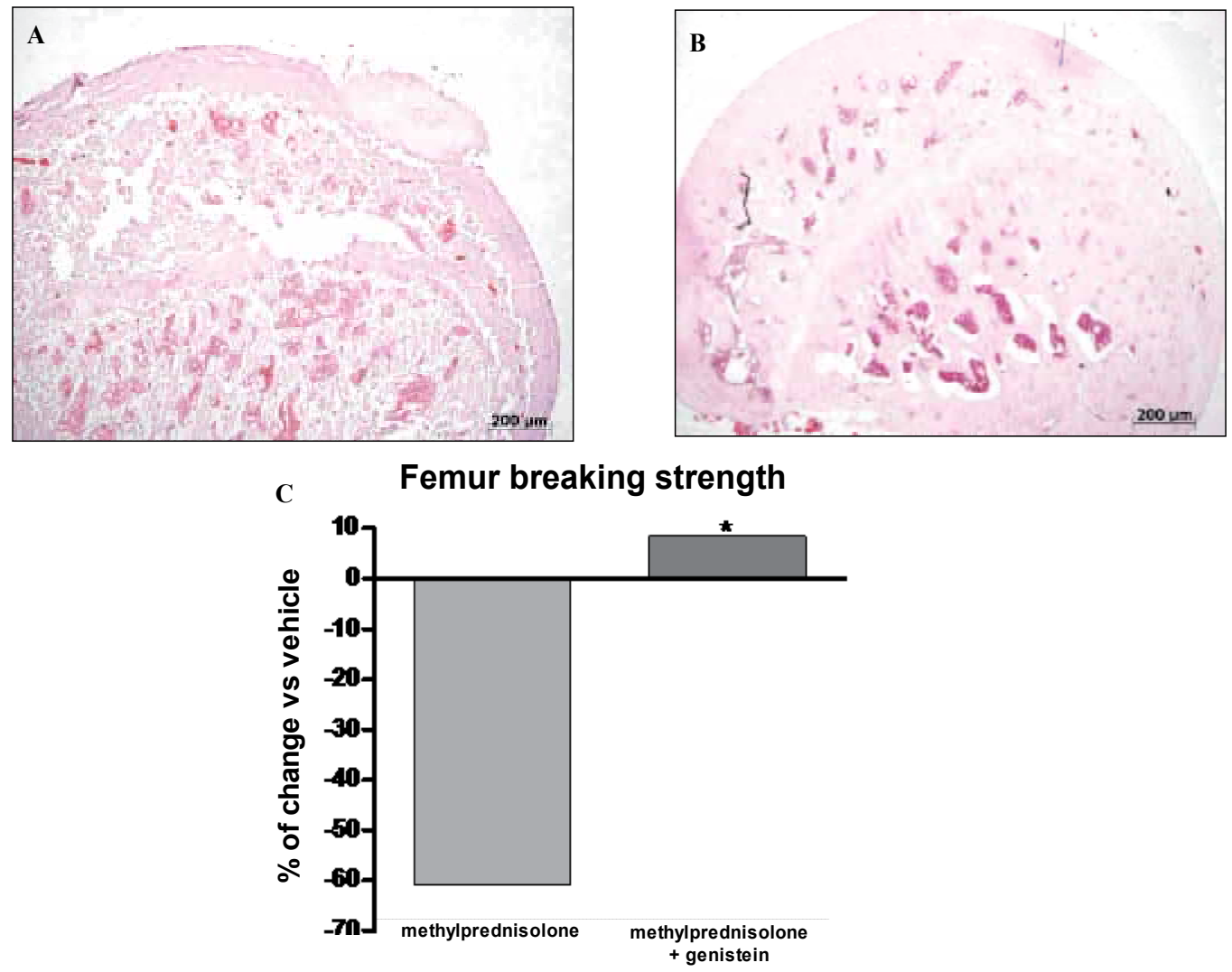

Fig. 3. A and B: Light microscopy of the bone structure of the femur head obtained from animals treated with methylprednisolone $(\mathrm{A})$ or methylprednisolone plus genistein aglycone (B). (H\&E original magnification X5). C: Femur breaking strength: * $p<0.001$ vs. methylprednisolone. Data are shown as \% of variation from vehicle treated animals.

In addition, genistein caused a significant increase in b-ALP and OPG over methylprednisolone and vehicle confirming its role as an anabolic bone-forming agent (Figure 4A and B). Genistein administration also significantly reduced CTX circulating levels suggesting an anti-resorptive effect (Figure 4C).

Corticosteroid therapy has been shown to cause apoptosis in osteoblasts and inhibit the production of OPG required for bone formation, while RANKL accumulates resulting in further bone resorption (Bejar et al. 2005). Genistein has been shown to stimulate the production of osteoblasts via inhibition of a RANKL-resorptive mechanism by producing OPG (Viereck et al. 2002). This was also confirmed in our study where genistein increased OPG levels in glucocorticoid-treated animals. Osteoprotegrin is a glycoprotein secreted by osteoblasts in a differentiation-dependent manner and acts as a 'decoy receptor' (a soluble receptor that acts as antagonist) for RANKL regulating osteoclast functions and lifespan. In postmenopausal women with bone loss, genistein stimulated the production of OPG, downregulated RANKL and decreased the RANKL/OPG ratio suggesting a direct effect on the RANK cytokine system (Marini et al., 2008). This work on genistein also suggests that increases in OPG in humans modulates the maturation process of osteoclast formation, thus 
clarifying the putative antiresorptive effect being a non-apoptotic process, rather than an apoptotic process induced in antiresorptive therapy with bisphosphonates. Other mechanisms of genistein binding to glucocorticoid receptors have also been implicated.

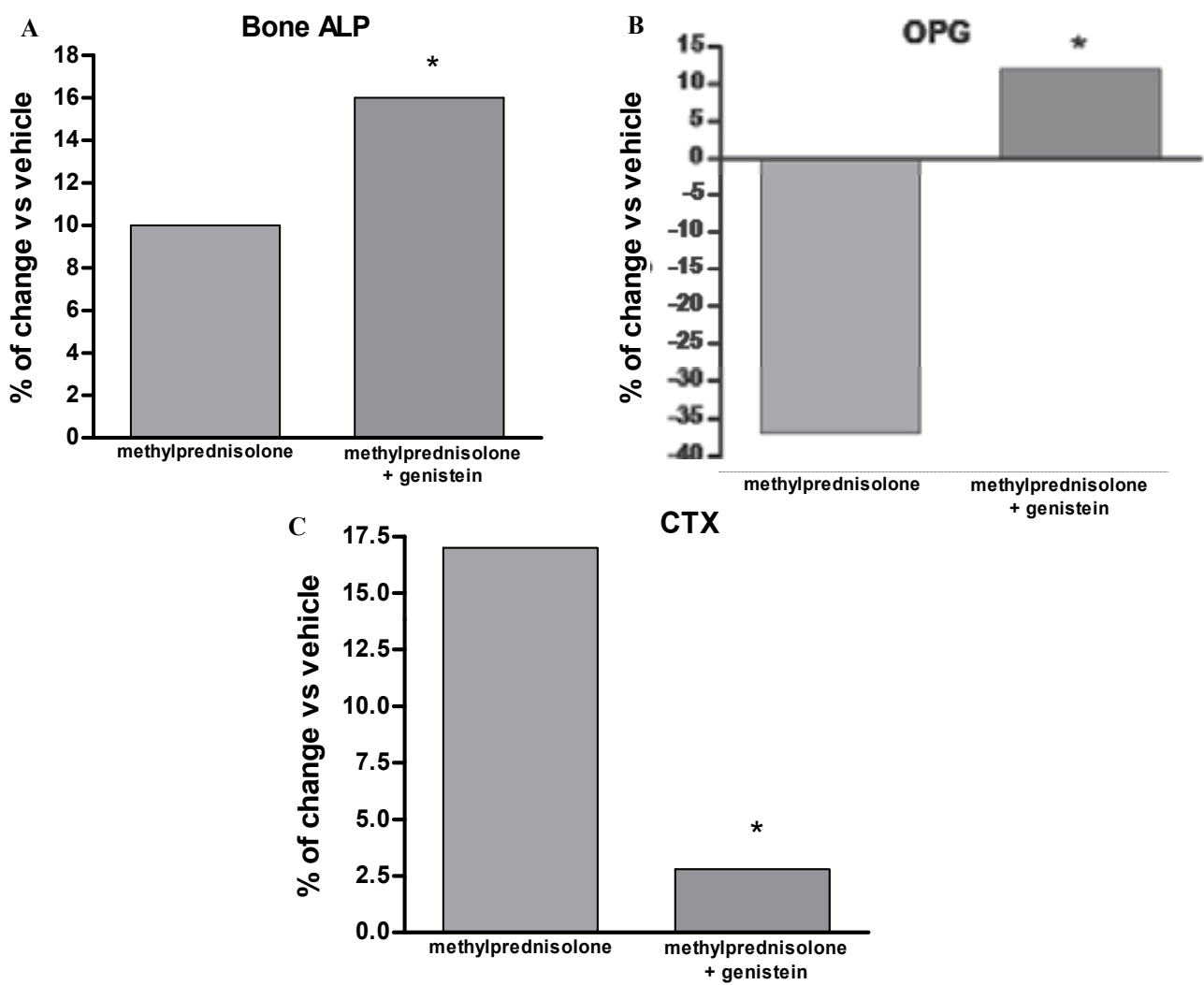

Fig. 4. A-C: Effects of aglycone genistein on serum bone-alkaline phosphatase (b-ALP), osteoprotegerin (OPG) and collagen C-telopeptides (CTX). Data are shown as \% of variation from vehicle treated animals. b-ALP: * $p<0.005$ vs methylprednisolone. OPG: ${ }^{*} p<0.001$ vs. methylprednisolone. CTX: ${ }^{*} p<0.001$ vs. methylprednisolone.

It has been demonstrated that genistein inhibits glucocorticoid receptor transactivation and may also induce a proteosomal degradation of the glucocorticoid receptor complex via the p53 and ubiquitin pathways (Kinyamu \& Archer 2003). Another mechanism might involve genistein activity as a tyrosine kinase inhibitor via the limitation of the subcellular nuclear transport and the recycling of the glucocorticoid receptors, blunting in turn the effects of glucocorticoids on bone (Yang et al., 1997).

\section{Conclusions}

Several studies and reports show a decrease in BMD and an increased risk of fractures during glucocorticoid use as well as an increase in osteonecrosis with chronic steroid use. Approximately $30 \%$ of all fractures of the hip and almost half of all fractures of the spine can 
be attributed to chronic, high-dose glucocorticoid administration in humans (van Staa et al., 2001). Prior and current exposure to glucocorticoids increases the risk of fractures beyond that explained by values of BMD (Civitelli \& Ziambaras, 2008). Pharmacological intervention for prevention of glucocorticoid-induced osteoporosis is needed depending on dose, expected duration of treatment, age and gender of the patient, and sometimes BMD at the start of the glucocorticoid therapy. At present, calcium and vitamin $\mathrm{D}_{3}$ supplementation are considered as important support for the prevention of glucocorticoid-induced osteoporosis (Williams et al., 2004). Bisphosphonates are largely used to avoid bone loss and are cost effective in certain subgroups of patients depending on age, gender, glucocorticoid dose, and previous fracture history (Williams et al., 2004; Prinsloo \& Hosking, 2006). Unfortunately, calcium and vitamin $\mathrm{D}_{3}$ supplementation may not be enough to stave off bone deterioration and bisphosphonates have safety risks associated with long-term use, such as esophageal burns, bone and muscular pain (Ettinger et al., 1998; Wysowski \& Chang, 2005). Osteonecrosis of the jaw, although rare and found primarily in cancer patients undergoing dental surgery, is a very serious and debilitating side effect of bisphosphonate use (Durie et al., 2005). Therefore, a safe and effective treatment for the prevention of bone loss and osteonecrosis of the femoral head in glucocorticoid-treated subjects is still needed. Collectively, our results strongly suggest that genistein might be a new potential therapy for the prevention of glucocorticoid-induced osteoporosis, the most important secondary cause of osteoporosis in humans. And in the minority of cases, genistein may prevent necrotic deterioration of the femoral head. Usually, drugs used in management of osteoporosis have been classified as predominantly 'antiresorptive agents' or as 'bone-forming agents', but, on the basis of the present results, genistein might represent the first therapy to overcome this classification combining a powerful bone-forming as well as an anti-resorptive activity.

\section{References}

Adler, R.A. \& Hochberg, M.C. Suggested guidelines for evaluation and treatment of glucocorticod-induced osteoporosis for the Department of Veterans Affairs. Arch Intern Med. 2003; 163:2619-24.

Albertazzi, P. Purified phytoestrogens in postmenopausal bone health: is there a role for genistein? Climacteric 2002; 5: 190-196

Amano, H., Yamada, S. \& Felix, R. Colony-stimulating factor-1 stimulates the fusion process in osteoclasts. J Bone Miner Res, 1998; 13: 846-853.

American college of Rheumatology Ad Hoc Committee on glucocorticod-induced osteoporosis. Recommendation for the prevention and treatment of glucocorticodinduced osteoporosis. 2001 Update. Arthritis and Rheumat 2001; 44:1496-503.

Amin, S., Lavalley, M.P., Simms, R.W. \& Felson, D.T. The comparative efficacy of drug therapies used for the management of corticosteroid induced osteoporosis: a metaregression. J Bone Miner Res. 2002; 17: 1512-1526.

Angeli, A., Guglielmi, G., Dovio, A., Capelli, G., de Feo, D., Giannini, S., Giorgino, R., Moro, L. \& Giustina, A. High prevalence of asymptomatic vertebral fractures in postmenopausal women receiving chronic glucocorticoid therapy: a cross-sectional outpatient study. Bone 2006; 39: 253-259

Arts, J., Kuiper, G.G., Janssen, J.M., Gustafsson, J.A., Löwik, C.W., Pols, H.A. \& van Leeuwen, J.P. Differential expression of estrogen receptors alpha and beta mRNA during differentiation of human osteoblast SV-HFO cells. Endocrinology. 1997; 138: 5067-70 
Bejar, J., Peled, E. \& Boss, J.H. Vasculature deprivation - induced osteonecrosis of the rat femoral head as a model for therapeutic trials. Theor Biol Med Mod 2005; 2: 24.

Bekler, H., Uygur, A.M., Gökçe, A. \& Beyzadeoğlu, T. The effect of steroid use on the pathogenesis of avascular necrosis of the femoral head: an animal model. Acta Orthop Traumatol Turc. 2007; 41: 58-63.

Bertazzo, S. \& Bertran, C.A. Morphological and dimensional characteristics of bone mineral crystals. Bioceramics. 2006; 309-311:7-10

Bitto, A., Polito, F., Burnett, B., Levy, R., Di Stefano, V., Armbruster, M.A., Marini, H., Minutoli, L., Altavilla, D. \& Squadrito, F. Protective effect of genistein aglycone on the development of osteonecrosis of the femoral head and secondary osteoporosis induced by methylprednisolone in rats. J Endocrinol. 2009; 201: 321-8.

Bitto, A., Polito, F., Squadrito, F., Marini, H., D'Anna, R., Irrera, N., Minutoli, L., Granese, R. \& Altavilla, D. Genistein aglycone: a dual mode of action anti-osteoporotic soy isoflavone rebalancing bone turnover towards bone formation. Curr Med Chem. 2010; 17: 3007-18. Review.

Blair, H.C., Jordan, S.E., Peterson, T.G. \& Barnes, S. Variable effects of tyrosine kinase inhibitors on avian osteoclastic activity and reduction of bone loss in ovariectomized rats. J Cell Biochem, 1996, 61, 629-637.,

Canalis, E., Mazziotti, G., Giustina A., \& Bilezikian, J.P. Glucocorticoid-induced osteoporosis: pathophysiology and therapy. Osteoporos Int 2007; 18: 1319-1328.

Chen, X., Garner, S.C., Quarles, L.D. \& Anderson, J.J. Effects of genistein on expression of bone markers during MC3T3-E1 osteoblastic cell differentiation. J Nutr Biochem. 2003;14: 342-9

Choi, S.Y., Ha, T.Y., Ahn, J.Y., Kim, S.R., Kang, K.S., Hwang, I.K. \& Kim, S. Estrogenic activities of isoflavones and flavones and their structure-activity relationships. Planta Med. 2008; 74: 25-32.

Civitelli, R. \& Ziambaras, K. Epidemiology of glucocorticoid-induced osteoporosis. J Endocrinol Invest 2008; 31: 2-6.

Compston, J. US and UK guidelines for glucocorticoid-induced osteoporosis similarities and differences. Curr Rheumatol Rep. 2004; 6: 66-69.

Day, A.J., DuPont, M.S., Ridley, S., Rhodes, M., Rhodes, M.J., Morgan, M.R. \& Williamson, G. Deglycosylation of flavonoid and isoflavonoid glycosides by human small intestine and liver beta-glucosidase activity. FEBS Lett. 1998; 436: 71-5

Doga, M., Mazziotti, G., Bonadonna, S., Patelli, I., Bilezikian, J.P., Canalis, E. \& Giustina, A. Prevention and treatment of glucocorticoid-induced osteoporosis. J Endocrinol Invest. 2008; 31: 53-88.

Durie, B.G., Katz, M. \& Crowley, J. Osteonecrosis of the jaw and bisphosphonates. New Engl J Med 2005; 353: 99-102.

Eastell, R., Reid, D.M., Compston, J., Cooper, C., Fogelman, I., Francis, R.M., Hosking, D.J., Purdie, D.W., Ralston, S.H., Reeve, J., Russell, R.G., Stevenson, J.C. \& Torgerson, D.J. A UK Consensus Group on management of glucocorticoid-induced osteoporosis: an update. J Intern Med 1998; 244:271-92.

Ettinger, B., Pressman, A. \& Schein, J. Clinic visits and hospital admissions for care of acidrelated upper gastrointestinal disorders in women using alendronate for osteoporosis. Am J Man Care 1998; 4: 1377-1382. 
Gao, Y.H. \& Yamaguchi, M. Inhibitory effect of genistein on osteoclast-like cell formation in mouse marrow cultures. Biochem Pharmacol, 1999a; 58: 767-772.

Gao, Y.H. \& Yamaguchi, M. Suppressive effect of genistein on rat bone osteoclasts: apoptosis is induced through Ca2+ signaling. Biol Pharm Bull. 1999b; 22: 805-9.

Gao, Y.H. \& Yamaguchi, M. Suppressive effect of genistein on rat bone osteoclasts: involvement of protein kinase inhibition and protein tyrosine phosphatase activation. Int J Mol Med 2000; 5: 261-267.

Gudbjornsson, B., Juliusson, U.I. \& Gudjonsson, F.V. Prevalence of long term steroid treatment and the frequency of decision making to prevent steroid induced osteoporosis in daily clinical practice. Ann rheum Dis 2002; 61:32-6.

Heim, M., Frank, O., Kampmann, G., Sochocky, N., Pennimpede, T., Fuchs, P., Hunziker, W., Weber, P., Martin, I. \& Bendik, I. The phytoestrogen genistein enhances osteogenesis and represses adipogenic differentiation of human primary bone marrow stromal cells. Endocrinology. 2004; 145: 848-59.

$\mathrm{Hu}, \mathrm{M} ., \mathrm{Krausz}$ K., Chen, J., Ge, X., Li, J., Gelboin, H.L. \& Gonzalez, F.J. Identification of CYP1A2 as the main isoform for the phase I hydroxylated metabolism of genistein and a prodrug converting enzyme of methylated isoflavones. Drug Metab Dispos. 2003; 31: 924-31

Hunter, I., McGregor, D. \& Robins SP. Caspase-dependent cleavage of cadherins and catenins during osteoblast apoptosis. J Bone Miner Res. 2001; 16: 466-77.

Jones, G. \& Sambrook, P.H. Drug-induced disorders of bone metabolism. Drug Safety 1994; 10: 480-489

Kajiya, H., Okabe, K., Okamoto, F., Tsuzuki, T. \& Soeda, H. Protein tyrosine kinase inhibitors increase cytosolic calcium and inhibit actin organization as resorbing activity in rat osteoclasts. J Cell Physiol 2000; 183: 83-90,

Kinyamu, H.K. \& Archer, T.K. Estrogen receptor-dependent proteasomal degradation of the glucocorticoid receptor is coupled to an increase in Mdm2 protein expression. Mol Cell Biol 2003; 23: 5867-5881.

Kuiper, G.G., Lemmen, J.G., Carlsson, B., Corton, J.C., Safe, S.H., van der Saag, P.T., van der Burg, B. \& Gustafsson, J.A. Interaction of estrogenic chemicals and phytoestrogens with estrogen receptor beta. Endocrinology. 1998; 139: 4252-63.

Laan, R.F., Buijs, W.C., van Erning, L.J., Lemmens, J.A., Corstens, F.H., Ruijs, S.H., van de Putte, L.B. \& van Riel, P.L. Differential effects of glucocorticoids on cortical appendicular and cortical vertebral bone mineral content. Calcif Tissue Int 1993; 52:59.

Lane, N.E., Yao, W., Balooch, M., Nalla, R.K., Balooch, G., Habelitz, S., Kinney, J.H. \& Bonewald, L.F. Glucocorticoid-treated mice have localized changes in trabecular bone material properties and osteocyte lacunar size that are not observed in placebo treated or estrogen-deficient mice. J Bone Miner Res. 2006; 21: 466-76

Larkin, T., Price, W.E. \& Astheimer, L. The key importance of soy isoflavone bioavailability to understanding health benefits. Crit Rev Food Sci Nutr. 2008; 48: 538-52

Liu, J., Knappenberger, K.S., Kack, H., Andersson, G., Nilsson, E., Dartsch, C. \& Scott, C.W. A homogeneous in vitro functional assay for estrogen receptors: coactivator recruitment. Mol Endocrinol. 2003; 17: 346-55.

Manolagas, S.C. \& Weinstein, R.S. New developments in the pathogenesis and treatment of steroid-induced osteoporosis. J Bone Miner Res. 1999; 14: 1061-6. 
Marini, H., Minutoli, L., Polito, F., Bitto, A., Altavilla, D., Atteritano, M., Gaudio, A., Mazzaferro, S., Frisina, A., Frisina, N., Lubrano, C., Bonaiuto, M., D'Anna, R., Cannata, M.L., Corrado, F., Cancellieri, F., Faraci, M., Marini, R., Adamo, E.B., Wilson, S. \& Squadrito, F. OPG and sRANKL Serum Concentrations in Osteopenic, Postmenopausal Women After 2-Year Genistein Administration. J Bone Min Res. 2008; 23: 715-720

Matsukawa, Y., Marui, N., Sakai, T., Satomi, Y., Yoshida, M., Matsumoto, K., Nishino, H. \& Aoike, A. Genistein arrests cell cycle progression at G2M. Cancer Research 1993; 53: 1328-1331.

Morris, C., Thorpe, J., Ambrosio, L. \& Santin, M. The soybean isoflavone genistein induces differentiation of MG63 human osteosarcoma osteoblasts. J Nutr. 2006; 136: 1166-70.

National Osteoporosis Society. Guidelines on the prevention and management of corticosteroid-induced osteoporosis. Bath, England: National Osteoporosis Society; 1998.

Okumura, N., Yoshikawa, T., Iida, J., Nonomura, A. \& Takakura, Y. Bone formationpromoting effect of genistein on marrow mesenchymal cell culture. Biomed Mater Eng. 2006; 16: 23-32.

Orcel, P. Prevention and treatment of glucocorticoidinduced osteoporosis in 2005. Joint Bone Spine 2005; 72: 461-465

Pan, W., Quarles, L.D., Song, L.H., Yu, Y.H., Jiao, C., Tang, H.B., Jiang, C.H., Deng, H.W., Li, Y.J., Zhou, H.H. \& Xiao, Z.S. Genistein stimulates the osteoblastic differentiation via NO/cGMP in bone marrow culture. J Cell Biochem. 2005; 94: 307-16.

Patschan, D., Loddenkemper, K. \& Buttgereit F. Molecular mechanisms of glucocorticoidinduced osteoporosis. Bone. 2001; 29: 498-505.

Prasain, J.K., Xu, J., Kirk, M., Smith Johnson, M., Sfakianos, J. \& Barnes, S. Differential biliary excretion of genistein metabolites following intraduodenal and intravenous infusion of genistin in female rats. J Nutr. 2006; 136: 2975-9

Prinsloo, P.J.J. \& Hosking, D.J. Alendronate sodium in the management of osteoporosis. J Therap Clin Risk Manag 2006; 2: 235-249.

Rickard, D.J., Monroe, D.G., Ruesink, T.J., Khosla, S., Riggs, B.L. \& Spelsberg, T.C. Phytoestrogen genistein acts as an estrogen agonist on human osteoblastic cells through estrogen receptors alpha and beta. J Cell Biochem. 2003; 89: 633-46.

Ronis, M.J., Little, J.M., Barone, G.W., Chen, G., Radominska-Pandya, A. \& Badger, T.M. Sulfation of the isoflavones genistein and daidzein in human and rat liver and gastrointestinal tract. J Med Food. 2006; 9: 348-55

Saag, K.G., Shane, E., Boonen, S., Marín, F., Donley, D.W., Taylor, K.A., Dalsky, G.P. \& Marcus, $\mathrm{R}$. Teriparatide or alendronate in glucocorticoid-induced osteoporosis. N Engl J Med. 2007;357:2028-2039.

Setchell, K.D., Brown, N.M. \& Lydeking-Olsen, E. The clinical importance of the metabolite equol-a clue to the effectiveness of soy and its isoflavones. J Nutr. 2002; 132: 3577-84

Sfakianos, J., Coward, L., Kirk, M. \& Barnes, S. Intestinal uptake and biliary excretion of the isoflavone genistein in rats. J Nutr. 1997; 127: 1260-8

Sliwiński, L., Folwarczna, J., Janiec, W., Grynkiewicz, G. \& Kuzyk, K. Differential effects of genistein, estradiol and raloxifene on rat osteoclasts in vitro. Pharmacol Rep. 2005; 57: 352-9. 
Sugimoto, E. \& Yamaguchi, M. Anabolic effect of genistein in osteoblastic MC3T3-E1 cells. Int J Mol Med. 2000; 5: 515-20.

Takano-Murakami, R., Tokunaga, K., Kondo, N., Ito, T., Kitahara, H., Ito, M. \& Endo, N. Glucocorticoid inhibits bone regeneration after osteonecrosis of the femoral head in aged female rats. Tohoku J Exp Med. 2009; 217:51-8.

Tham, D.M., Gardner, C.D. \& Haskell, W.L. Clinical review 97: Potential health benefits of dietary phytoestrogens: a review of the clinical, epidemiological, and mechanistic evidence. J Clin Endocrinol Metab. 1998; 83: 2223-35.

Tian, Z, Wan, M., Wang, Z. \& Wang, B. The preparation of genistein and LC-MS/MS on-line analysis. Drug Dev Res. 2004; 61: 6-12

Uchiyama, S. \& Yamaguchi, M. Genistein and zinc synergistically stimulate apoptotic cell death and suppress RANKL signaling-related gene expression in osteoclastic cells. J Cell Biochem. 2007; 101: 529-42.

van Staa, T.P. The pathogenesis, epidemiology and management of glucocorticoid-induced osteoporosis. Calcif Tissue Int. 2006; 79: 129-37.

van Staa, T.P., Laan, R.F., Barton, I.P, Cohen, S., Reid, D.M. \& Cooper, C. Bone density threshold and other predictors of vertebral fracture in patients receiving oral glucocorticoid therapy. Arthritis Rheum. 2003; 48: 3224-3229.

van Staa, T.P., Leufkens, H.G. \& Cooper, C. The epidemiology of corticosteroid-induced osteoporosis: a meta-analysis. Osteoporos Int 2002; 13:777-87.

van Staa, T.P., Leufkens, H.G., Abenhaim, L., Zhang, B. \& Cooper, C. Use of oral corticosteroids and risk of fractures, J Bone Miner Res 15 (2000), pp. 993-1000.

Vestergaard, P., Rejnmark, L. \& Mosekilde, L. Fracture risk associated with different types of oral corticosteroids and effect of termination of corticosteroids on the risk of fractures. Calcif Tissue Int. 2008; 82: 249-257.

Viereck, V., Grundker, C., Blaschke, S., Siggelkow, H., Emons, G. \& Hofbauer, L.C. Phytoestrogen genistein stimulates the production of osteoprotegrin by human trabecular osteoblasts. J Cell Biochem 2002; 84: 725-735.

Walsh, I.J., Wong, C.A., Pringle, M. \& Tattersfield, A.E. Use of oral corticosteroids in community and the prevention of secondary osteoporosis: a cross sectional study. BMJ 1996; 313:344-6.

Weinstein, R.S., Nicholas, R.W. \& Manolagas, S.C. Apoptosis of osteocytes in glucocorticoidinduced osteonecrosis of the hip. J Clin Endocrinol Metab. 2000; 85: 2907-12.

Williams, D., Bennett, K. \& Feely, J. Prescribing for osteoporosis following the use of inhaled and oral glucocorticoids in general practice. Br J Clin Pharmacol 2004; 58: 665-672.

Williams, J.P., Jordan, S.E., Barnes, S. \& Blair, H.C. Tyrosine kinase inhibitor effects on avian osteoclastic acid transport. Am J Clin Nutr 1998; 68: 1369S-1374S.

Wysowski, D.K. \& Chang, J.T. Alendronate and risedronate: reports of severe bone, joint, and muscle pain. Arch Int Med 2005; 165: 346-347.

Yamagishi, T., Otsuka, E. \& Hagiwara, H. Reciprocal control of expression of mRNAs for osteoclast differentiation factor and OPG in osteogenic stromal cells by genistein: evidence for the involvement of topoisomerase II in osteoclastogenesis. Endocrinology 2001; 142: 3632-3637.

Yamaguchi, M. \& Gao, Y.H. Anabolic effect of genistein on bone metabolism in the femoralmetaphyseal tissues of elderly rats is inhibited by the anti-estrogen tamoxifen. Res Exp Med (Berl). 1997; 197: 101-7. 
Yamaguchi, M. \& Gao, Y.H. Inhibitory effect of genistein on bone resorption in tissue culture. Biochem Pharmacol. 1998; 55: 71-6.

Yamaguchi, M. \& Sugimoto, E. stimulatory effect of genistein and daidzein on protein synthesis in osteoblastic MC3T3-E1 cells: activation of aminoacyl-t-RNA synthetase. Mol Cell Biochem 2000; 214: 97-102

Yang, J., Liu, J. \& De Franco, D.B. Subnuclear trafficking of glucocorticoid receptors in vitro: chromatin recycling and nuclear export. J Cell Biol 1997; 137: 523-538. 


\section{Part 8}

Chronic Renal Disease and Endocrinology 



\title{
Hormonal Actions and Interactions in Proximal Tubule Cells Associated with the Development of Chronic Kidney Disease
}

\author{
Akihiko Saito ${ }^{1}$, Michihiro Hosojima ${ }^{2}$ and Hiroyoshi Sato ${ }^{1}$ \\ ${ }^{1}$ Department of Applied Molecular Medicine \\ 2Division of Clinical Nephrology and Rheumatology \\ Niigata University Graduate School of Medical and Dental Sciences \\ Japan
}

\section{Introduction}

As the first tubular segment of the kidney between the Bowman's capsule and the loop of Henle, the proximal tubule is exposed to initial glomerular filtrates. Proximal tubule cells (PTCs) have a variety of functions including 1) reabsorption and intracellular processing of glomerular-filtered substances such as proteins, peptides, glucose, amino acids, uric acid, sodium, potassium, phosphate, bicarbonate and water via apical membrane receptors, transporters, and channels; 2) uptake of substances such as protein-bound compounds via basolateral membrane transporters, followed by metabolism or secretion to the urinary space; and 3) synthesis of bioactive substances that are released to peritubular capillaries (Fig. 1).

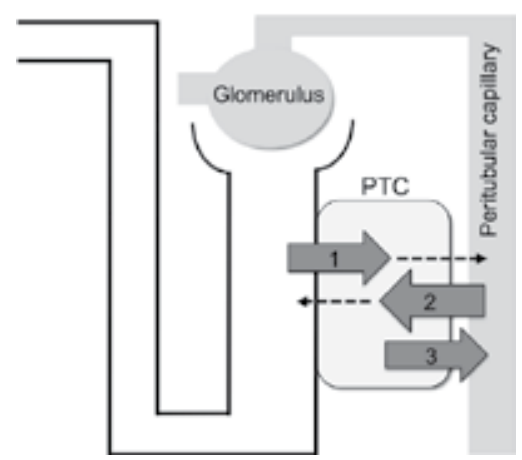

Normal functions of PTCs (indicated by arrows) include: 1) reabsorption and intracellular processing of glomerular-filtered substances via apical membrane receptors, transporters, and channels; 2 ) uptake of substances via basolateral membrane transporters followed by metabolism or secretion into the urinary space; and 3) synthesis of bioactive substances that are released to peritubular capillaries.

Fig. 1. Normal functions of proximal tubule cells (PTCs)

Impairment of these diverse functions is likely to affect systemic hemodynamic and metabolic homeostasis and can lead to the development of chronic kidney disease (CKD) and cardiovascular disease (CVD) (Saito, Kaseda et al. 2010). In particular, PTC injury occurs during the early stages of diabetic nephropathy, a leading cause of CKD. 
In this review, we focus on actions and interactions of various hormones and hormone-like substances on the regulation of apical membrane receptors and transporters that mediate three major functions of PTCs: 1) receptor-mediated protein endocytosis, 2) sodium reabsorption, and 3) phosphate reabsorption, which are particularly associated with the pathophysiology of CKD and the increased risk of CVD (Fig. 2).

\section{Hormonal actions and interactions for regulating protein endocytosis in PTCs}

Receptor-mediated endocytosis is a pivotal function of PTCs through which the cells reabsorb and metabolize proteins (and other substances) from glomerular filtrates (Saito, Sato et al. 2010). This reabsorption process is extremely efficient as urine is virtually proteinfree in humans, and it accounts for the essential conservation of nutrients, carrier-bound vitamins, and trace elements filtered by glomeruli. Impairment of the process results in a loss of such substances and development of proteinuria.

\subsection{Endocytic receptors involved in protein reabsorption in PTCs}

The two major endocytic receptors expressed at the apical membranes of PTCs are megalin and cubilin (Saito, Sato et al. 2010) which act cooperatively in the uptake of glomerularfiltered proteins and mediate their metabolism in PTCs (Fig. 2).

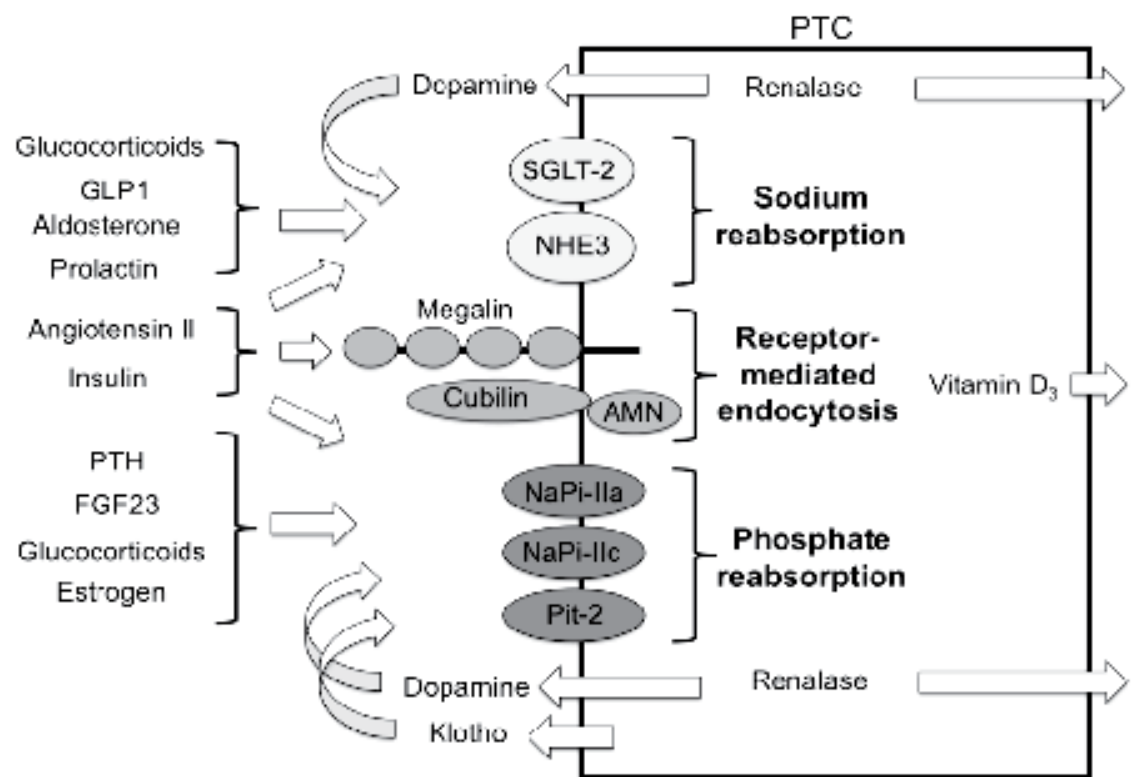

Some hormones, such as dopamine, renalase, vitamin D3 and klotho, are synthesized in PTCs and others come from other organs. Renalase acts to metabolize dopamine.

AMN, amnionless; FGF23, fibroblast growth factor 23; GLP1, glucagon-like peptide 1; NaPi-IIa, sodiumdependent phosphate cotransporter type IIa; NaPi-IIc, sodium-dependent phosphate cotransporter type IIc; NHE3, $\mathrm{Na}^{+} / \mathrm{H}^{+}$exchanger isoform 3; Pit-2, sodium-dependent phosphate symporter 2; PTC, proximal tubule cell; PTH, parathormone; SGLT2, sodium-glucose cotransporter 2

Fig. 2. Hormonal actions and interactions on the functions of receptors and transporters involved in receptor-mediated protein endocytosis and reabsorption of sodium and phosphate in the apical membrane of PTCs. 


\subsubsection{Megalin}

Megalin is a large $(\sim 600 \mathrm{kDa})$ glycoprotein member of the low-density lipoprotein receptor family that is primarily expressed in clathrin-coated pits (Saito, Sato et al. 2010). Megalinligand complexes are internalized by invagination of clathrin-coated pits mediated by multiple adaptor proteins and motor molecules, forming endosomal vesicles. Acidification of the intravesicular lumen dissociates the ligands from megalin and they are transported to lysosomes for degradation or storage or are secreted into the cytosol for further processing or transport. Megalin is then recycled to the apical membranes through a recycling compartment. Megalin thus plays a critical role in reabsorption and metabolism of glomerular-filtered substances including albumin and low molecular weight proteins. Vitamin D-binding protein (DBP) is an endocytic ligand of megalin, and megalin knockout mice display decreased utilization of vitamin D for its activation in PTCs (Nykjaer et al. 1999; Leheste et al. 2003) (Fig. 3).

Decreased megalin expression in PTCs has been observed in the early diabetic stages of experimental animals (Tojo et al. 2001; Russo et al. 2007), and it has been suggested that the functions of megalin are also impaired in patients during the early stages of diabetic nephropathy, since low molecular weight proteinuria is frequently observed in patients at these stages (Pontuch et al. 1992; Hong et al. 2003). Therefore, the altered regulation of megalin expression and its functions must be primarily responsible for the early development of proteinuria/albuminuria in diabetic patients.

Megalin also interacts with various membrane receptors and transporters such as the cubilin/amnionless complex, sodium-hydrogen exchanger isoform 3 (NHE3) and sodiumdependent phosphate cotransporter type IIa (NaPi-IIa) as discussed in the following sections.

\subsubsection{Cubilin}

Cubilin is a $460-\mathrm{kDa}$ peripheral glycoprotein that lacks transmembrane and intracellular segments but is anchored to apical PTC membranes. It was originally identified as the receptor for intrinsic factor-vitamin $B_{12}$ complex (Seetharam et al. 1988; Seetharam et al. 1997). Cubilin requires interaction with megalin to regulate its endocytic functions (Yammani, Seetharam, and Seetharam 2001; Kozyraki et al. 2001); however, it is bound more firmly by a protein called amnionless forming the complex CUBAM (Fyfe et al. 2004; Coudroy et al. 2005). Cubilin gene defects are the cause of hereditary megaloblastic anaemia 1 and Imerslund-Gräsbeck syndrome, also known as selective vitamin $B_{12}$ malabsorption with proteinuria (Aminoff et al. 1999). Cubilin is also involved in the absorption of various protein ligands present in glomerular filtrates, including albumin, transferrin and DBP (Christensen, Verroust, and Nielsen 2009). A recent meta-analysis of genome-wide association studies identified a missense cubilin gene variant associated with levels of albuminuria in both the general population and in diabetic individuals (Boger et al. 2011).

\subsubsection{Amnionless}

Amnionless is a $38-50 \mathrm{kDa}$ membrane protein with a single transmembrane domain that was initially identified as a component required for normal development of the trunk mesoderm derived from the middle streak (Kalantry et al. 2001). In addition, defects of the amnionless gene cause hereditary megaloblastic anaemia (Tanner et al. 2003). 


\subsection{Hormones regulating the expression and function of endocytic receptors}

Angiotensin II and insulin are two major hormones involved in regulating the expression and function of megalin (Hosojima et al. 2009) (Fig. 2), but no hormones have been identified that regulate cubilin and amnionless expression.

\subsubsection{Angiotensin II}

Angiotensin II downregulates the expression and function of megalin via the extracellularsignal-regulated kinase (ERK)1/2 signaling pathway in cultured PTCs (Hosojima et al. 2009). Intrarenal levels of angiotensin II are augmented in CKD (Kobori et al. 2007), which is involved in the development of hypertension as discussed below. Angiotensin-converting enzyme inhibitors and angiotensin II receptor blockers are thus likely to target the increased action of angiotensin II in the kidney. These agents may be effective in suppressing the reduced expression of megalin in CKD and in preventing proteinuria/albuminuria (Tojo et al. 2003).

Megalin also appears to regulate the intrarenal actions of angiotensin II by internalizing angiotensin II (Gonzalez-Villalobos et al. 2005) and angiotensin-(1-7) (Gonzalez-Villalobos et al. 2006), as well as mediating the endocytosis of angiotensinogen that is filtered by glomeruli (Pohl et al. 2010).

\subsubsection{Insulin}

Insulin is involved in the upregulation of megalin, which in turn may be associated with increased endocytosis and metabolism of glomerular-filtered proteins, leading to intracellular metabolic overload. Cross-talk between insulin-insulin receptor substrate/phosphoinositide 3-kinase and angiotensin II-ERK1/2 signaling pathways was previously observed in cultured PTCs (Hosojima et al. 2009), and the balance between the actions and interactions of angiotensin II and insulin may also be important in regulating the expression of megalin in vivo. Hyperinsulinemia associated with metabolic syndrome is thought to stimulate insulin signaling in PTCs, while impaired insulin signaling (so-called insulin resistance) is suggested to occur in kidney cells in type 2 diabetic models; moreover, the intrarenal activation of angiotensin II appears to be associated with the development of insulin resistance (Tiwari et al. 2007). Recently, megalin was shown to be downregulated by the lipopolysaccharide-tumor necrosis factor$\alpha$-ERK1/2 signaling pathway that may also impair insulin signaling in diabetes (Takeyama et al. 2011). In addition, positive control of megalin expression has been demonstrated by peroxisome proliferator-activated receptor isoforms peroxisome proliferator-activated receptor (PPAR) $\alpha$ and PPAR $\gamma$ and their insulin-sensitizing agonists (Cabezas et al. 2011).

\section{Hormonal actions and interactions for regulating sodium reabsorption in PTCs}

Sodium reabsorption from glomerular filtrates is an important function of PTCs in the maintenance of systemic hemodynamics. Impairment of this function is associated with the abnormal regulation of blood pressure, especially in patients with CKD. Moreover, increased PTC sodium reabsorption causes glomerular hyperfiltration via the tubuloglomerular feedback mechanism, particularly in diabetes (Thomson, Vallon, and Blantz 2004). 


\subsection{Major transporters involved in sodium reabsorption and regulated by hormones in PTCs}

Various transporters and channels are involved in sodium reabsorption in the apical and basolateral membranes of PTCs. Here, we focus on three types of apical transporters (Fig. 2).

\subsubsection{Sodium-hydrogen exchanger isoform 3}

Sodium-hydrogen exchanger isoform 3 (NHE3), the main NHE isoform of PTCs, mediates isotonic reabsorption of approximately two-thirds of filtered $\mathrm{NaCl}$ and water, the reabsorption of bicarbonate, and the secretion of ammonium (Bobulescu and Moe 2009). It also contributes to the reabsorption of filtered citrate, amino acids, and oligopeptides by providing $\mathrm{H}^{+}$used by $\mathrm{H}^{+}$-coupled cotransporters. Indeed, enhanced NHE3 activity is assumed to be a factor for the increased sodium reabsorption and the development of hypertension in diabetes. NHE3 was reported to interact with megalin in PTC intermicrovillar clefts (Biemesderfer et al. 1999; Biemesderfer, DeGray, and Aronson 2001) and, following endocytosis with megalin, it is postulated to utilize the outward transvesicular sodium gradient of endocytic vesicles and early endosomes to drive the inward movement of $\mathrm{H}^{+}$and endosomal acidification. This is important for dissociating reabsorbed ligand proteins from megalin both for further processing and megalin recycling to the cell surface. Hormonal regulation of NHE3 has been intensively investigated and reviewed elsewhere (Bobulescu and Moe 2009).

\subsubsection{Sodium-glucose cotransporter-2}

Glucose is freely filtered by glomeruli before being almost entirely reabsorbed into the circulation from PTCs. Reabsorption of the majority of glucose is achieved by sodiumglucose cotransporter-2 (SGLT2), which is present in the S1 segment of proximal tubules. Expression of SGLT2 is enhanced in the kidney of diabetic Zucker rats (Tabatabai et al. 2009). SGLT2 inhibitors currently in development are expected not only to treat hyperglycemia but also to have an effect on hypertension and glomerular hyperfiltration in diabetic patients (Bailey et al. 2010; List and Whaley 2011).

\subsubsection{Sodium-dependent phosphate cotransporters}

Sodium-dependent phosphate cotransporters reabsorb inorganic phosphate in a sodiumdependent manner in PTCs. These will be discussed in detail in section 4.1.

\subsection{Hormones regulating the expression and function of the transporters involved in sodium reabsorption in PTCs}

Many hormones are involved in the regulation of sodium reabsorption in PTCs, particularly through the function of NHE3 (Fig. 2).

\subsubsection{Angiotensin II}

Angiotensin II is important for increasing sodium uptake by PTCs. Intrarenal levels of angiotensin II are augmented in CKD and are also involved in the development of hypertension (Kobori et al. 2007; Navar et al. 2011). The action of angiotensin II on NHE3 has been intensively investigated, indicating biphagic dosage-dependent acute effects and chronic stimulatory effects on NHE3 (Bobulescu and Moe 2009). Classically, angiotensin II has been thought to act on its specific receptors in PTC plasma membranes by endocrine 
and local tissue paracrine mechanisms. However, more recently it was also shown to function in an autocrine or intracrine manner (Li et al. 2011).

\subsubsection{Insulin}

Insulin is an important hormone that regulates sodium uptake as well as glucose metabolism in PTCs. In patients with metabolic syndrome, serum levels of insulin are elevated by a mechanism of insulin resistance in the liver and skeletal muscles. Increased levels of insulin are likely to augment sodium uptake in PTCs (Baum 1987) as well as other nephron segments such as thick ascending limbs (Mandon et al. 1993) and collecting ducts (Takahashi, Ito, and Abe 1996), causing extracellular fluid expansion and hypertension. Insulin has been shown to acutely and chronically stimulate the function of NHE3 in cultured PTCs (Fuster et al. 2007), and its infusion is associated with increased blood pressure in rats (Brands et al. 1991) and humans (Gans et al. 1991).

Diabetic kidneys, however, have been demonstrated to have impaired expression of renal insulin receptors (Tiwari et al. 2007). In kidney-specific insulin receptor KO mice, basal systolic blood pressure was increased and natriuresis was reduced in response to a volume load (Tiwari et al. 2008). The greatest relative reduction of the insulin receptor in these mice was found in the thick ascending limb and collecting duct, and renal production of NO was likely to be reduced. A previously uncharacterized role of the insulin receptor in these nephron segments may thus be associated with sodium and water reabsorption via NO production.

\subsubsection{Glucocorticoids}

Glucocorticoids, whether endogenous, as in Cushing syndrome, or exogenous, via pharmacologic provision, induce hypertension (Mangos et al. 2003). They directly stimulate NHE3 through both acute and chronic mechanisms (Bobulescu and Moe 2009). The acute effect of glucocorticoids on cell surface NHE3 is mediated by the activation of HNE3 exocytosis (Bobulescu et al. 2005) and a glucocorticoid receptor-dependent mechanism that activates serum and glucocorticoid-inducible kinase1 (SGK1) in a nongenomic manner (Wang et al. 2007). Glucocorticoids have also been found to enhance the function of insulin in stimulating NHE3 activity (Klisic et al. 2002).

\subsubsection{Glucagon-like peptide 1}

Glucagon-like peptide 1 (GLP1) receptors are expressed in pancreatic cells and other cells such as PTCs (Schlatter et al. 2007). Administration of recombinant GLP1 to Dahl saltsensitive rats resulted in an antihypertensive effect, due mainly to its diuretic and natriuretic actions (Yu et al. 2003). GLP1 was also found to induce natriuresis in healthy subjects and insulin-resistant obese men through its action on PTCs (Gutzwiller et al. 2004). Hyperglomerular filtration in obese men was improved following this treatment, which was likely to be mediated by tubuloglomerular feedback mechanisms.

GLP1 receptor agonistic agents have been used in the treatment of hyperglycemia by acting on GLP1 receptors in pancreatic B-cells to stimulate insulin synthesis. The GLP1 receptor agonist exendin-4 also decreases sodium reabsorption in PTCs by affecting NHE3 activity (Carraro-Lacroix, Malnic, and Girardi 2009) and reduces blood pressure in a salt-sensitive hypertension mice model (Hirata et al. 2009). Such agents are also suggested to be clinically relevant in reducing blood pressure (Vilsboll et al. 2007; Klonoff et al. 2008). 


\subsubsection{Aldosterone}

Aldosterone stimulates the activity and surface expression of NHE3 in human primary PTCs, which is inhibited by the mineralocorticoid receptor blocker spironolactone and by the epidermal growth factor receptor (EGFR)-kinase inhibitor (Drumm et al. 2006). Aldosterone was found to regulate NHE3 by a nongenomic mechanism (Good, George, and Watts 2006). Aldosterone/mineralocorticoid receptor stimulation is also known to affect PTCs by inducing cellular senescence (Fan et al. 2011), suggesting that it is a potential therapeutic target in CKD.

\subsubsection{Prolactin, dopamine and renalase}

Prolactin is also a natiriuretic hormone that inhibits $\mathrm{Na}^{+}, \mathrm{K}^{+}$, ATPase activity in PTCs, depending on the renal dopamine system (Ibarra et al. 2005). Dopamine is known to both acutely and chronically inhibit the function of NHE3 by reducing its cellular expression (Bobulescu and Moe 2009). Renalase, a secreted amine oxidase that is synthesized in the kidney, metabolizes circulating catecholamines (Xu et al. 2005). Urinary renalase metabolizes urinary catecholamines, and perhaps regulates dopamine concentration in luminal fluid, and modulate the function of NHE3 for proximal tubular sodium transport (Desir 2011).

\section{Hormonal actions and interactions for regulating phosphate reabsorption in PTCs}

Phosphate uptake is an important function of PTCs which is regulated by the actions and interactions of various hormones and hormone-like substances, such as parathormone (PTH), fibroblast growth factor 23 (FGF23), klotho, glucocorticoids, vitamin $\mathrm{D}_{3}$, dopamine and so on (Figs. 2 and 3). Phosphate regulation is particularly associated with the development of cardiovascular disease and high mortality in patients with CKD, independently of the glomerular filtration rate (Kestenbaum et al. 2005). Therefore, the regulation of phosphate uptake in PTCs is clinically important.

\subsection{Transporters involved in PTC phosphate reabsorption that is hormonally regulated}

At least three types of sodium-dependent phosphate transporters have been identified in the brush border membrane of PTCs: NaPi-IIa, NaPi-IIc, and sodium-dependent phosphate symporter 2 (Pit-2) (Fig. 2). Renal reabsorption of inorganic phosphate is mainly (about 70\%) mediated by NaPi-IIa in the adult kidney (Ohkido et al. 2003).

\subsubsection{NaPi-lla}

$\mathrm{NaPi}$-IIa is a major phosphate transporter of PTCs, and changes in renal phosphate handling are primarily attributable to altered $\mathrm{NaPi}$-IIa brush border membrane expression (Hernando et al. 2005). NaPi-IIa is expressed in the S1-S3 segment of superficial and juxtamedullary nephrons (Picard et al. 2010) and mediates the electrogenic transport of inorganic phosphate coupled to three sodium ions (Murer, Forster, and Biber 2004). NaPi-Ila is regulated by several hormones and other factors, as described in section 4.2. Adequate steady-state expression of $\mathrm{NaPi}$-IIa and its inactivation by endocytosis and intracellular translocation require the presence of megalin (Bachmann et al. 2004), such that megalin dysfunction is likely to impair $\mathrm{NaPi}$-Ila inactivation, inducing the increased reabsorption of phosphate (Fig. 3). 


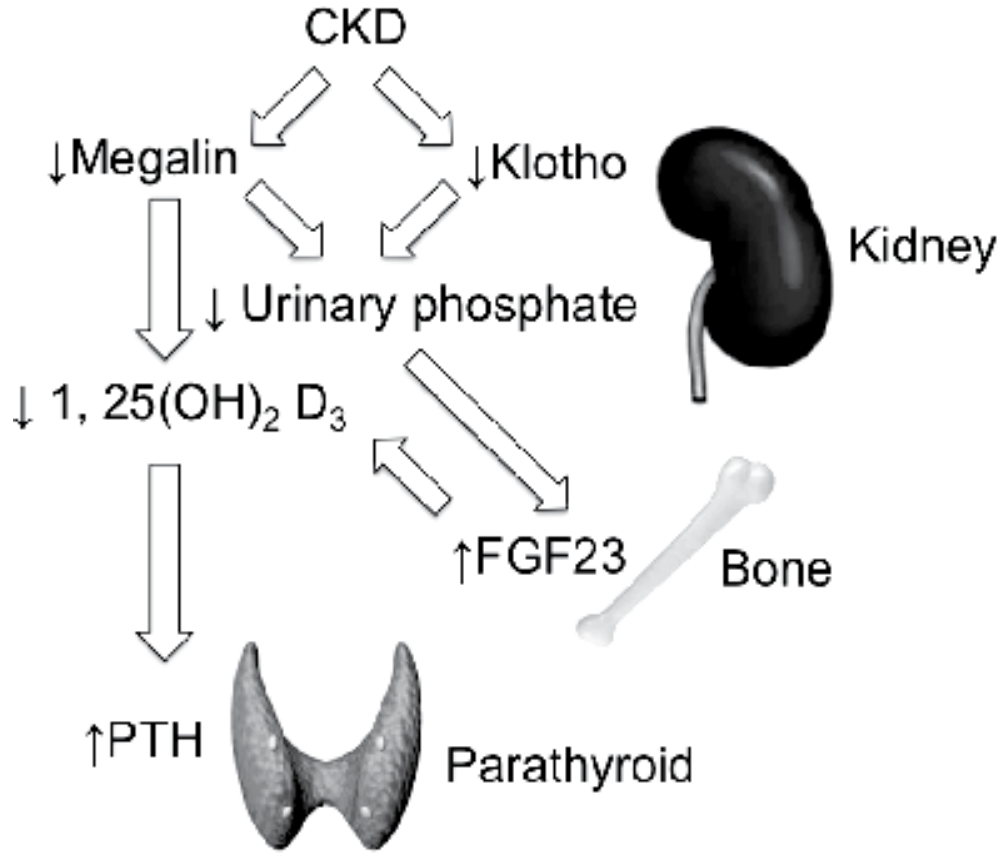

In CKD, renal expression of megalin and klotho is decreased, resulting in increased urinary phosphate excretion. Decreased megalin expression also causes decreased renal synthesis of $1,25(\mathrm{OH})_{2} \mathrm{D}_{3}$. Synthesis of FGF23 in the bone is then stimulated, which also suppresses renal $1,25(\mathrm{OH})_{2} \mathrm{D}_{3}$ synthesis, increasing the synthesis of PTH in the parathyroid.

Fig. 3. Presumed hormonal network involved in phosphate regulation in CKD

\subsubsection{NaPi-Ilc}

$\mathrm{NaPi}$-IIc is a growth-related transporter that is more active in the young and has a reduced role in adults (Segawa et al. 2002). NaPi-IIc transports inorganic phosphate in an electroneutral fashion and is highly $\mathrm{pH}$ dependent, exhibiting more transport at a more alkaline $\mathrm{pH}$ (Segawa et al. 2002). It is expressed in the S1 segment of PTCs (Picard et al. 2010) and mutations of the NaPi-IIc gene were found to cause hereditary hypophosphatemic rickets with hypercalciuria (HHRH), a Mendelian disorder of renal inorganic phosphate reabsorption (Bergwitz et al. 2006; Lorenz-Depiereux et al. 2006).

\subsubsection{Pit-2}

Pit-2, expressed in S1 and weakly in S2 segments of superficial and juxtamedullary nephrons (Picard et al. 2010), mediates the electrogenic transport of inorganic phosphate (Ravera et al. 2007).

\subsection{Hormones regulating the expression and function of PTC transporters involved in phosphate reabsorption}

Several hormones and hormone-like substances are involved in the regulation of phosphate cotransporters. In particular, the actions and interactions of PTH, fibroblast growth factor 23 (FGF23), klotho and vitamin $\mathrm{D}_{3}$ are important in maintaining phosphate homeostasis and the development of CKD-mineral bone disease (MBD) (Fig. 2 and 3). 


\subsubsection{PTH}

PTH was first identified as an inactivator of NaPi-IIa through endocytic retrieval and degradation (Bacic et al. 2006). It was then found to be also associated with the endocytic regulation of NaPi-IIc (Segawa et al. 2007), although its acute effects differentially regulate these cotransporters including Pit-2 (Picard et al. 2010). The synthesis of PTH is increased in the progression of secondary hyperparathyroidism in CKD.

\subsubsection{FGF23}

FGF23 is a 32-kDa protein that is secreted mainly by bone osteocytes (Liu et al. 2006). Administration of FGF23 to mice decreases the renal expression of both NaPi-IIa and NaPiIIc and induces hypophosphatemia predominantly via FGF receptor 1 (Gattineni et al. 2009).

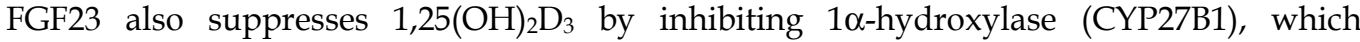
converts 25-hydroxyvitamin $\mathrm{D}_{3}\left[25(\mathrm{OH}) \mathrm{D}_{3}\right]$ to $1,25(\mathrm{OH})_{2} \mathrm{D}_{3}$, and by stimulating 24hydroxylase (CYP24), which converts $1,25(\mathrm{OH})_{2} \mathrm{D}_{3}$ to inactive metabolites in PTCs (Shimada et al. 2004). Increased FGF23 appears to play a causative role in the abnormal renal phosphate handling and vitamin $\mathrm{D}_{3}$ metabolism of rats with $\mathrm{CKD}$, leading to the development of secondary hyperparathyroidism and increased production of PTH (Hasegawa et al. 2010). The ternary complex of klotho-FGF23-FGF receptor in distal convoluted tubules (DCTs) has been thought to be a prerequisite for the exertion of FGF23 effects (Kurosu et al. 2006), and, indeed, initial FGF23-mediated signaling occurs in DCTs (Farrow et al. 2009). However, it remains undetermined how FGF23-mediated signaling in DCTs leads to the regulation of NaPi-IIa and NaPi-IIc in PTCs. It may be possible that FGF23 has a direct action on PTCs (Huang and Moe 2011).

\subsubsection{Klotho}

Klotho was first identified as an aging suppressor gene product (Kuro-o et al. 1997). It is a single-pass transmembrane protein expressed predominantly in the kidney, intensely in DCTs and to a lesser extent in PTCs and parathyroid gland (Kuro-o 2011). Klotho-/- and Fgf23-/- mice show very similar phenotypes such as premature aging and abnormal mineral metabolism (Kuro-o 2011). As mentioned above, klotho acts with FGF receptor as a coreceptor in the binding of FGF23 in DCTs for phosphate and vitamin $\mathrm{D}_{3}$ regulation (Kurosu et al. 2006). The Klotho-FGF23-FGF receptor complex in DCTs may produce putative paracrine factors on PTCs where phosphate transporters and enzymes for vitamin $\mathrm{D}_{3}$ regulation are located (Huang and Moe 2011). The extracellular domain of Klotho is also known to be cleaved from plasma membranes, secreted to the circulatoin and present in urine (Hu et al. 2011); this soluble klotho form may directly act on PTCs. Klotho was also found to act as a PTC-synthesized autocrine factor in the FGF23-independent inhibition of $\mathrm{NaPi}$-IIa function by ß-glucuronidase-like enzymatic activity (Hu et al. 2011). Decreased Klotho expression in the kidney may be one of initial factors triggering dysregulation of various hormones involved in phosphate homeostasis and the development of secondary hyperparathyroidism in CKD (Kuro-o 2011).

\subsubsection{Vitamin $D_{3}$}

As mentioned above, megalin and cubilin take up the $25(\mathrm{OH}) \mathrm{D}_{3} / \mathrm{DBP}$ complex from glomerular filtrates (Nykjaer et al. 1999; Nykjaer et al. 2001; Leheste et al. 2003). In PTCs, $25(\mathrm{OH}) \mathrm{D}_{3}$ is dissociated from DBP and converted by $1 \alpha$-hydroxylase to the biologically active form $1,25(\mathrm{OH})_{2} \mathrm{D}_{3}$, which is released to peritubular capillaries. Therefore, dysfunction of these endocytic receptors is an important cause of deficiency of both $25(\mathrm{OH}) \mathrm{D}_{3}$ and 
$1,25(\mathrm{OH})_{2} \mathrm{D}_{3}$ in $\mathrm{CKD}$. The activation of vitamin $\mathrm{D}_{3}$ is also upregulated by PTH and downregulated by FGF23 (Shimada et al. 2004). Vitamin $\mathrm{D}_{3}$ deficiency develops very early in the course of CKD, especially in diabetic nephropathy, and is associated with the development of CVD or mortality in patients at the predialysis stage (Mehrotra et al. 2009).

\subsubsection{Other hormones}

Dopamine mediates renal phosphate excretion, which is affected by the function of renalase (Weinman et al. 2011). Chronic infusion of angiotensin II into rats was demonstrated to increase the expression of NaPi-IIa in PTC brush border membranes by posttranscriptional mechanisms (Xu et al. 2004). This increase of NaPi-IIa may be associated with an angiotensin II-mediated decrease in the expression of megalin that plays a role in endocytosis and the degradation of NaPi-IIa (Bachmann et al. 2004). Insulin may also be involved in regulating sodium-dependent phosphate transporters (Kunkler et al. 1991; Li et al. 1996). Glucocorticoids inhibit phosphate uptake in primary cultured rabbit PTCs via both nongenomic and genomic mechanisms (Park, Taub, and Han 2001). In addition, estrogen causes the PTH-independent downregulation of NaPi-IIa in PTCs (Faroqui et al. 2008).

\section{Conclusion}

There are a variety of hormonal actions and interactions involved in the regulation of important PTC functions such as receptor-mediated endocytosis and the reabsorption of sodium and phosphate. The impaired counterbalance of these hormones is likely to be associated with the development and/or progression of CKD. Elucidation of the mechanisms of such hormonal actions and interactions would therefore be of great benefit in the future development of novel therapeutic strategies for CKD.

\section{Acknowledgment}

This work was supported by a Grant-in-Aid for Scientific Research from the Ministry of Education, Science, and Culture of Japan (21591023).

\section{References}

Aminoff, M., J. E. Carter, R. B. Chadwick, C. Johnson, R. Grasbeck, M. A. Abdelaal, H. Broch, L. B. Jenner, P. J. Verroust, S. K. Moestrup, A. de la Chapelle, and R. Krahe. 1999. Mutations in CUBN, encoding the intrinsic factor-vitamin B12 receptor, cubilin, cause hereditary megaloblastic anaemia 1. Nat Genet 21 (3):309-13.

Bachmann, S., U. Schlichting, B. Geist, K. Mutig, T. Petsch, D. Bacic, C. A. Wagner, B. Kaissling, J. Biber, H. Murer, and T. E. Willnow. 2004. Kidney-specific inactivation of the megalin gene impairs trafficking of renal inorganic sodium phosphate cotransporter (NaPi-IIa). J Am Soc Nephrol 15 (4):892-900.

Bacic, D., M. Lehir, J. Biber, B. Kaissling, H. Murer, and C. A. Wagner. 2006. The renal $\mathrm{Na}+$ /phosphate cotransporter $\mathrm{NaPi}$-IIa is internalized via the receptor-mediated endocytic route in response to parathyroid hormone. Kidney Int 69 (3):495-503.

Bailey, C. J., J. L. Gross, A. Pieters, A. Bastien, and J. F. List. 2010. Effect of dapagliflozin in patients with type 2 diabetes who have inadequate glycaemic control with metformin: a randomised, double-blind, placebo-controlled trial. Lancet 375 (9733):2223-33. 
Baum, M. 1987. Insulin stimulates volume absorption in the rabbit proximal convoluted tubule. J Clin Invest 79 (4):1104-9.

Bergwitz, C., N. M. Roslin, M. Tieder, J. C. Loredo-Osti, M. Bastepe, H. Abu-Zahra, D. Frappier, K. Burkett, T. O. Carpenter, D. Anderson, M. Garabedian, I. Sermet, T. M. Fujiwara, K. Morgan, H. S. Tenenhouse, and H. Juppner. 2006. SLC34A3 mutations in patients with hereditary hypophosphatemic rickets with hypercalciuria predict a key role for the sodium-phosphate cotransporter NaPi-IIc in maintaining phosphate homeostasis. Am J Hum Genet 78 (2):179-92.

Biemesderfer, D., B. DeGray, and P. S. Aronson. 2001. Active (9.6 s) and inactive (21 s) oligomers of NHE3 in microdomains of the renal brush border. J Biol Chem 276 (13):10161-7.

Biemesderfer, D., T. Nagy, B. DeGray, and P. S. Aronson. 1999. Specific association of megalin and the $\mathrm{Na}+\mathrm{H}+$ exchanger isoform NHE3 in the proximal tubule. J Biol Chem 274 (25):17518-24.

Bobulescu, I. A., V. Dwarakanath, L. Zou, J. Zhang, M. Baum, and O. W. Moe. 2005. Glucocorticoids acutely increase cell surface $\mathrm{Na}+\mathrm{H}+$ exchanger-3 (NHE3) by activation of NHE3 exocytosis. Am J Physiol Renal Physiol 289 (4):F685-91.

Bobulescu, I. A., and O. W. Moe. 2009. Luminal $\mathrm{Na}(+) / \mathrm{H}(+)$ exchange in the proximal tubule. Pflugers Arch 458 (1):5-21.

Boger, C. A., M. H. Chen, A. Tin, M. Olden, A. Kottgen, I. H. Deboer, C. Fuchsberger, C. M. O'Seaghdha, C. Pattaro, A. Teumer, C. T. Liu, N. L. Glazer, M. Li, J. R. O'Connell, T. Tanaka, C. A. Peralta, Z. Kutalik, J. Luan, J. H. Zhao, S. J. Hwang, E. Akylbekova, H. Kramer, P. van der Harst, A. V. Smith, K. Lohman, M. de Andrade, C. Hayward, B. Kollerits, A. Tonjes, T. Aspelund, E. Ingelsson, G. Eiriksdottir, L. J. Launer, T. B. Harris, A. R. Shuldiner, B. D. Mitchell, D. E. Arking, N. Franceschini, E. Boerwinkle, J. Egan, D. Hernandez, M. Reilly, R. R. Townsend, T. Lumley, D. S. Siscovick, B. M. Psaty, B. Kestenbaum, T. Haritunians, S. Bergmann, P. Vollenweider, G. Waeber, V. Mooser, D. Waterworth, A. D. Johnson, J. C. Florez, J. B. Meigs, X. Lu, S. T. Turner, E. J. Atkinson, T. S. Leak, K. Aasarod, F. Skorpen, A. C. Syvanen, T. Illig, J. Baumert, W. Koenig, B. K. Kramer, O. Devuyst, J. C. Mychaleckyj, C. Minelli, S. J. Bakker, L. Kedenko, B. Paulweber, S. Coassin, K. Endlich, H. K. Kroemer, R. Biffar, S. Stracke, H. Volzke, M. Stumvoll, R. Magi, H. Campbell, V. Vitart, N. D. Hastie, V. Gudnason, S. L. Kardia, Y. Liu, O. Polasek, G. Curhan, F. Kronenberg, I. Prokopenko, I. Rudan, J. Arnlov, S. Hallan, G. Navis, A. Parsa, L. Ferrucci, J. Coresh, M. G. Shlipak, S. B. Bull, A. D. Paterson, H. E. Wichmann, N. J. Wareham, R. J. Loos, J. I. Rotter, P. P. Pramstaller, L. A. Cupples, J. S. Beckmann, Q. Yang, I. M. Heid, R. Rettig, A. W. Dreisbach, M. Bochud, C. S. Fox, and W. H. Kao. 2011. CUBN Is a Gene Locus for Albuminuria. J Am Soc Nephrol. 22(3): 555-70

Brands, M. W., D. A. Hildebrandt, H. L. Mizelle, and J. E. Hall. 1991. Sustained hyperinsulinemia increases arterial pressure in conscious rats. Am J Physiol $2604 \mathrm{Pt}$ 2):R764-8.

Cabezas, F., J. Lagos, C. Cespedes, C. P. Vio, M. Bronfman, and M. P. Marzolo. 2011. Megalin/LRP2 expression is induced by peroxisome proliferator-activated receptor -alpha and -gamma: implications for PPARs' roles in renal function. PLoS One 6 (2):e16794. 
Carraro-Lacroix, L. R., G. Malnic, and A. C. Girardi. 2009. Regulation of Na+/H+ exchanger NHE3 by glucagon-like peptide 1 receptor agonist exendin-4 in renal proximal tubule cells. Am J Physiol Renal Physiol 297 (6):F1647-55.

Christensen, E. I., P. J. Verroust, and R. Nielsen. 2009. Receptor-mediated endocytosis in renal proximal tubule. Pflugers Arch.

Coudroy, G., J. Gburek, R. Kozyraki, M. Madsen, G. Trugnan, S. K. Moestrup, P. J. Verroust, and M. Maurice. 2005. Contribution of cubilin and amnionless to processing and membrane targeting of cubilin-amnionless complex. J Am Soc Nephrol 16 (8):2330-7.

Desir, G. V. 2011. Role of renalase in the regulation of blood pressure and the renal dopamine system. Curr Opin Nephrol Hypertens 20 (1):31-6.

Drumm, K., T. R. Kress, B. Gassner, A. W. Krug, and M. Gekle. 2006. Aldosterone stimulates activity and surface expression of NHE3 in human primary proximal tubule epithelial cells (RPTEC). Cell Physiol Biochem 17 (1-2):21-8.

Fan, Y. Y., M. Kohno, H. Hitomi, K. Kitada, Y. Fujisawa, J. Yatabe, M. Yatabe, R. A. Felder, H. Ohsaki, K. Rafiq, S. J. Sherajee, T. Noma, A. Nishiyama, and D. Nakano. 2011. Aldosterone/Mineralocorticoid receptor stimulation induces cellular senescence in the kidney. Endocrinology 152 (2):680-8.

Faroqui, S., M. Levi, M. Soleimani, and H. Amlal. 2008. Estrogen downregulates the proximal tubule type IIa sodium phosphate cotransporter causing phosphate wasting and hypophosphatemia. Kidney Int 73 (10):1141-50.

Farrow, E. G., S. I. Davis, L. J. Summers, and K. E. White. 2009. Initial FGF23-mediated signaling occurs in the distal convoluted tubule. J Am Soc Nephrol 20 (5):955-60.

Fuster, D. G., I. A. Bobulescu, J. Zhang, J. Wade, and O. W. Moe. 2007. Characterization of the regulation of renal $\mathrm{Na}+/ \mathrm{H}+$ exchanger NHE3 by insulin. Am J Physiol Renal Physiol 292 (2):F577-85.

Fyfe, J. C., M. Madsen, P. Hojrup, E. I. Christensen, S. M. Tanner, A. de la Chapelle, Q. He, and S. K. Moestrup. 2004. The functional cobalamin (vitamin B12)-intrinsic factor receptor is a novel complex of cubilin and amnionless. Blood 103 (5):1573-9.

Gans, R. O., L. vd Toorn, H. J. Bilo, J. J. Nauta, R. J. Heine, and A. J. Donker. 1991. Renal and cardiovascular effects of exogenous insulin in healthy volunteers. Clin Sci (Lond) 80 (3):219-25.

Gattineni, J., C. Bates, K. Twombley, V. Dwarakanath, M. L. Robinson, R. Goetz, M. Mohammadi, and M. Baum. 2009. FGF23 decreases renal NaPi-2a and NaPi-2c expression and induces hypophosphatemia in vivo predominantly via FGF receptor 1. Am J Physiol Renal Physiol 297 (2):F282-91.

Gonzalez-Villalobos, R., R. B. Klassen, P. L. Allen, K. Johanson, C. B. Baker, H. Kobori, L. G. Navar, and T. G. Hammond. 2006. Megalin binds and internalizes angiotensin-(17). Am J Physiol Renal Physiol 290 (5):F1270-5.

Gonzalez-Villalobos, R., R. B. Klassen, P. L. Allen, L. G. Navar, and T. G. Hammond. 2005. Megalin binds and internalizes angiotensin II. Am J Physiol Renal Physiol 288 (2):F420-7.

Good, D. W., T. George, and B. A. Watts, 3rd. 2006. Nongenomic regulation by aldosterone of the epithelial NHE3 $\mathrm{Na}(+) / \mathrm{H}(+)$ exchanger. Am J Physiol Cell Physiol 290 (3):C757-63.

Gutzwiller, J. P., S. Tschopp, A. Bock, C. E. Zehnder, A. R. Huber, M. Kreyenbuehl, H. Gutmann, J. Drewe, C. Henzen, B. Goeke, and C. Beglinger. 2004. Glucagon-like peptide 1 induces natriuresis in healthy subjects and in insulin-resistant obese men. J Clin Endocrinol Metab 89 (6):3055-61.

Hasegawa, H., N. Nagano, I. Urakawa, Y. Yamazaki, K. Iijima, T. Fujita, T. Yamashita, S. Fukumoto, and T. Shimada. 2010. Direct evidence for a causative role of FGF23 in 
the abnormal renal phosphate handling and vitamin D metabolism in rats with early-stage chronic kidney disease. Kidney Int 78 (10):975-80.

Hernando, N., S. M. Gisler, S. Pribanic, N. Deliot, P. Capuano, C. A. Wagner, O. W. Moe, J. Biber, and H. Murer. 2005. NaPi-Ila and interacting partners. J Physiol 567 (Pt 1):21-6.

Hirata, K., S. Kume, S. Araki, M. Sakaguchi, M. Chin-Kanasaki, K. Isshiki, T. Sugimoto, A. Nishiyama, D. Koya, M. Haneda, A. Kashiwagi, and T. Uzu. 2009. Exendin-4 has an anti-hypertensive effect in salt-sensitive mice model. Biochem Biophys Res Commun 380 (1):44-9.

Hong, C. Y., K. Hughes, K. S. Chia, V. Ng, and S. L. Ling. 2003. Urinary alpha1microglobulin as a marker of nephropathy in type 2 diabetic Asian subjects in Singapore. Diabetes Care 26 (2):338-42.

Hosojima, M., H. Sato, K. Yamamoto, R. Kaseda, T. Soma, A. Kobayashi, A. Suzuki, H. Kabasawa, A. Takeyama, K. Ikuyama, N. Iino, A. Nishiyama, T. J. Thekkumkara, T. Takeda, Y. Suzuki, F. Gejyo, and A. Saito. 2009. Regulation of megalin expression in cultured proximal tubule cells by angiotensin II type 1A receptor- and insulinmediated signaling cross talk. Endocrinology 150 (2):871-8.

Hu, M. C., M. Shi, J. Zhang, H. Quinones, C. Griffith, M. Kuro-o, and O. W. Moe. 2011. Klotho deficiency causes vascular calcification in chronic kidney disease. J Am Soc Nephrol 22 (1):124-36.

Huang, C. L., and O. W. Moe. 2011. Klotho: a novel regulator of calcium and phosphorus homeostasis. Pflugers Arch.

Ibarra, F., S. Crambert, A. C. Eklof, A. Lundquist, P. Hansell, and U. Holtback. 2005. Prolactin, a natriuretic hormone, interacting with the renal dopamine system. Kidney Int 68 (4):1700-7.

Kalantry, S., S. Manning, O. Haub, C. Tomihara-Newberger, H. G. Lee, J. Fangman, C. M. Disteche, K. Manova, and E. Lacy. 2001. The amnionless gene, essential for mouse gastrulation, encodes a visceral-endoderm-specific protein with an extracellular cysteine-rich domain. Nat Genet 27 (4):412-6.

Kestenbaum, B., J. N. Sampson, K. D. Rudser, D. J. Patterson, S. L. Seliger, B. Young, D. J. Sherrard, and D. L. Andress. 2005. Serum phosphate levels and mortality risk among people with chronic kidney disease. J Am Soc Nephrol 16 (2):520-8.

Klisic, J., M. C. Hu, V. Nief, L. Reyes, D. Fuster, O. W. Moe, and P. M. Ambuhl. 2002. Insulin activates $\mathrm{Na}(+) / \mathrm{H}(+)$ exchanger 3: biphasic response and glucocorticoid dependence. Am J Physiol Renal Physiol 283 (3):F532-9.

Klonoff, D. C., J. B. Buse, L. L. Nielsen, X. Guan, C. L. Bowlus, J. H. Holcombe, M. E. Wintle, and D. G. Maggs. 2008. Exenatide effects on diabetes, obesity, cardiovascular risk factors and hepatic biomarkers in patients with type 2 diabetes treated for at least 3 years. Curr Med Res Opin 24 (1):275-86.

Kobori, H., M. Nangaku, L. G. Navar, and A. Nishiyama. 2007. The intrarenal reninangiotensin system: from physiology to the pathobiology of hypertension and kidney disease. Pharmacol Rev 59 (3):251-87.

Kozyraki, R., J. Fyfe, P. J. Verroust, C. Jacobsen, A. Dautry-Varsat, J. Gburek, T. E. Willnow, E. I. Christensen, and S. K. Moestrup. 2001. Megalin-dependent cubilin-mediated endocytosis is a major pathway for the apical uptake of transferrin in polarized epithelia. Proc Natl Acad Sci U S A 98 (22):12491-6.

Kunkler, K. J., L. M. Everett, D. K. Breedlove, and S. A. Kempson. 1991. Insulin stimulates sodium-dependent phosphate transport by osteoblast-like cells. Am J Physiol 260 (5 Pt 1):E751-5. 
Kuro-o, M., Y. Matsumura, H. Aizawa, H. Kawaguchi, T. Suga, T. Utsugi, Y. Ohyama, M. Kurabayashi, T. Kaname, E. Kume, H. Iwasaki, A. Iida, T. Shiraki-lida, S. Nishikawa, R. Nagai, and Y. I. Nabeshima. 1997. Mutation of the mouse klotho gene leads to a syndrome resembling ageing. Nature 390 (6655):45-51.

Kuro-o. M. 2011. Phosphate and Klotho. Kidney Int 79 (S121):S20-S23.

Kurosu, H., Y. Ogawa, M. Miyoshi, M. Yamamoto, A. Nandi, K. P. Rosenblatt, M. G. Baum, S. Schiavi, M. C. Hu, O. W. Moe, and M. Kuro-o. 2006. Regulation of fibroblast growth factor-23 signaling by klotho. J Biol Chem 281 (10):6120-3.

Leheste, J. R., F. Melsen, M. Wellner, P. Jansen, U. Schlichting, I. Renner-Muller, T. T. Andreassen, E. Wolf, S. Bachmann, A. Nykjaer, and T. E. Willnow. 2003. Hypocalcemia and osteopathy in mice with kidney-specific megalin gene defect. Faseb J 17 (2):247-9.

Li, H., P. Ren, M. Onwochei, R. J. Ruch, and Z. Xie. 1996. Regulation of rat Na+/Pi cotransporter-1 gene expression: the roles of glucose and insulin. Am J Physiol 271 (6 Pt 1):E1021-8.

Li, X. C., J. L. Cook, I. Rubera, M. Tauc, F. Zhang, and J. L. Zhuo. 2011. Intrarenal transfer of an intracellular cyan fluorescent fusion of angiotensin II selectively in proximal tubules increases blood pressure in rats and mice. Am J Physiol Renal Physiol.

List, J. F., and J. M. Whaley. 2011. Glucose dynamics and mechanistic implications of SGLT2 inhibitors in animals and humans. Kidney Int 79 Suppl 120:S20-7.

Liu, S., J. Zhou, W. Tang, X. Jiang, D. W. Rowe, and L. D. Quarles. 2006. Pathogenic role of Fgf23 in Hyp mice. Am J Physiol Endocrinol Metab 291 (1):E38-49.

Lorenz-Depiereux, B., A. Benet-Pages, G. Eckstein, Y. Tenenbaum-Rakover, J. Wagenstaller, D. Tiosano, R. Gershoni-Baruch, N. Albers, P. Lichtner, D. Schnabel, Z. Hochberg, and T. M. Strom. 2006. Hereditary hypophosphatemic rickets with hypercalciuria is caused by mutations in the sodium-phosphate cotransporter gene SLC34A3. Am J Hum Genet 78 (2):193-201.

Mandon, B., E. Siga, D. Chabardes, D. Firsov, N. Roinel, and C. De Rouffignac. 1993. Insulin stimulates $\mathrm{Na}+, \mathrm{Cl}-, \mathrm{Ca} 2+$, and $\mathrm{Mg} 2+$ transports in TAL of mouse nephron: crosspotentiation with AVP. Am J Physiol 265 (3 Pt 2):F361-9.

Mangos, G. J., J. A. Whitworth, P. M. Williamson, and J. J. Kelly. 2003. Glucocorticoids and the kidney. Nephrology (Carlton) 8 (6):267-73.

Mehrotra, R., D. A. Kermah, I. B. Salusky, M. S. Wolf, R. I. Thadhani, Y. W. Chiu, D. Martins, S. G. Adler, and K. C. Norris. 2009. Chronic kidney disease, hypovitaminosis D, and mortality in the United States. Kidney Int 76 (9):977-83.

Murer, H., I. Forster, and J. Biber. 2004. The sodium phosphate cotransporter family SLC34. Pflugers Arch 447 (5):763-7.

Navar, L. G., M. C. Prieto, R. Satou, and H. Kobori. 2011. Intrarenal angiotensin II and its contribution to the genesis of chronic hypertension. Curr Opin Pharmacol.

Nykjaer, A., D. Dragun, D. Walther, H. Vorum, C. Jacobsen, J. Herz, F. Melsen, E. I. Christensen, and T. E. Willnow. 1999. An endocytic pathway essential for renal uptake and activation of the steroid 25-(OH) vitamin D3. Cell 96 (4):507-15.

Nykjaer, A., J. C. Fyfe, R. Kozyraki, J. R. Leheste, C. Jacobsen, M. S. Nielsen, P. J. Verroust, M. Aminoff, A. de la Chapelle, S. K. Moestrup, R. Ray, J. Gliemann, T. E. Willnow, and E. I. Christensen. 2001. Cubilin dysfunction causes abnormal metabolism of the steroid hormone 25(OH) vitamin D(3). Proc Natl Acad Sci U S A 98 (24):13895-900. 
Ohkido, I., H. Segawa, R. Yanagida, M. Nakamura, and K. Miyamoto. 2003. Cloning, gene structure and dietary regulation of the type-IIc $\mathrm{Na} / \mathrm{Pi}$ cotransporter in the mouse kidney. Pflugers Arch 446 (1):106-15.

Park, S., M. Taub, and H. Han. 2001. Regulation of phosphate uptake in primary cultured rabbit renal proximal tubule cells by glucocorticoids: evidence for nongenomic as well as genomic mechanisms. Endocrinology 142 (2):710-20.

Picard, N., P. Capuano, G. Stange, M. Mihailova, B. Kaissling, H. Murer, J. Biber, and C. A. Wagner. 2010. Acute parathyroid hormone differentially regulates renal brush border membrane phosphate cotransporters. Pflugers Arch 460 (3):677-87.

Pohl, M., H. Kaminski, H. Castrop, M. Bader, N. Himmerkus, M. Bleich, S. Bachmann, and F. Theilig. 2010. Intrarenal renin angiotensin system revisited: role of megalindependent endocytosis along the proximal nephron. J Biol Chem 285 (53):41935-46.

Pontuch, P., T. Jensen, T. Deckert, P. Ondrejka, and M. Mikulecky. 1992. Urinary excretion of retinol-binding protein in type 1 (insulin-dependent) diabetic patients with microalbuminuria and clinical diabetic nephropathy. Acta Diabetol 28 (3-4):206-10.

Ravera, S., L. V. Virkki, H. Murer, and I. C. Forster. 2007. Deciphering PiT transport kinetics and substrate specificity using electrophysiology and flux measurements. Am J Physiol Cell Physiol 293 (2):C606-20.

Russo, L. M., E. del Re, D. Brown, and H. Y. Lin. 2007. Evidence for a role of transforming growth factor (TGF)-beta1 in the induction of postglomerular albuminuria in diabetic nephropathy: amelioration by soluble TGF-beta type II receptor. Diabetes 56 (2):380-8.

Saito, A., R. Kaseda, M. Hosojima, and H. Sato. 2010. Proximal tubule cell hypothesis for cardiorenal syndrome in diabetes. Int J Nephrol 2011:957164.

Saito, A., H. Sato, N. Iino, and T. Takeda. 2010. Molecular mechanisms of receptor-mediated endocytosis in the renal proximal tubular epithelium. I Biomed Biotechnol 2010:403272.

Schlatter, P., C. Beglinger, J. Drewe, and H. Gutmann. 2007. Glucagon-like peptide 1 receptor expression in primary porcine proximal tubular cells. Regul Pept 141 (1-3):120-8.

Seetharam, B., E. I. Christensen, S. K. Moestrup, T. G. Hammond, and P. J. Verroust. 1997. Identification of rat yolk sac target protein of teratogenic antibodies, gp280, as intrinsic factor-cobalamin receptor. J Clin Invest 99 (10):2317-22.

Seetharam, B., J. S. Levine, M. Ramasamy, and D. H. Alpers. 1988. Purification, properties, and immunochemical localization of a receptor for intrinsic factor-cobalamin complex in the rat kidney. J Biol Chem 263 (9):4443-9.

Segawa, H., I. Kaneko, A. Takahashi, M. Kuwahata, M. Ito, I. Ohkido, S. Tatsumi, and K. Miyamoto. 2002. Growth-related renal type II Na/Pi cotransporter. J Biol Chem 277 (22):19665-72.

Segawa, H., S. Yamanaka, A. Onitsuka, Y. Tomoe, M. Kuwahata, M. Ito, Y. Taketani, and K. Miyamoto. 2007. Parathyroid hormone-dependent endocytosis of renal type IIc NaPi cotransporter. Am J Physiol Renal Physiol 292 (1):F395-403.

Shimada, T., M. Kakitani, Y. Yamazaki, H. Hasegawa, Y. Takeuchi, T. Fujita, S. Fukumoto, K. Tomizuka, and T. Yamashita. 2004. Targeted ablation of Fgf23 demonstrates an essential physiological role of FGF23 in phosphate and vitamin D metabolism. J Clin Invest 113 (4):561-8. 
Tabatabai, N. M., M. Sharma, S. S. Blumenthal, and D. H. Petering. 2009. Enhanced expressions of sodium-glucose cotransporters in the kidneys of diabetic Zucker rats. Diabetes Res Clin Pract 83 (1):e27-30.

Takahashi, N., O. Ito, and K. Abe. 1996. Tubular effects of insulin. Hypertens Res 19 Suppl 1:S41-5.

Takeyama, A., H. Sato, T. Soma-Nagae, H. Kabasawa, A. Suzuki, K. Yamamoto-Kabasawa, M. Hosojima, R. Kaneko, F. Higuchi, R. Kaseda, S. Ogasawara, I. Narita, and A. Saito. 2011. Megalin is downregulated via LPS-TNF-alpha-ERK1/2 signaling pathway in proximal tubule cells. Biochem Biophys Res Commun.

Tanner, S. M., M. Aminoff, F. A. Wright, S. Liyanarachchi, M. Kuronen, A. Saarinen, O. Massika, H. Mandel, H. Broch, and A. de la Chapelle. 2003. Amnionless, essential for mouse gastrulation, is mutated in recessive hereditary megaloblastic anemia. Nat Genet 33 (3):426-9.

Thomson, S. C., V. Vallon, and R. C. Blantz. 2004. Kidney function in early diabetes: the tubular hypothesis of glomerular filtration. Am J Physiol Renal Physiol 286 (1):F8-15.

Tiwari, S., V. K. Halagappa, S. Riazi, X. Hu, and C. A. Ecelbarger. 2007. Reduced expression of insulin receptors in the kidneys of insulin-resistant rats. J Am Soc Nephrol 18 (10):2661-71.

Tiwari, S., N. Sharma, P. S. Gill, P. Igarashi, C. R. Kahn, J. B. Wade, and C. M. Ecelbarger. 2008. Impaired sodium excretion and increased blood pressure in mice with targeted deletion of renal epithelial insulin receptor. Proc Natl Acad Sci U S A 105 (17):6469-74.

Tojo, A., M. L. Onozato, H. Ha, H. Kurihara, T. Sakai, A. Goto, T. Fujita, and H. Endou. 2001. Reduced albumin reabsorption in the proximal tubule of early-stage diabetic rats. Histochem Cell Biol 116 (3):269-76.

Tojo, A., M. L. Onozato, H. Kurihara, T. Sakai, A. Goto, and T. Fujita. 2003. Angiotensin II blockade restores albumin reabsorption in the proximal tubules of diabetic rats. Hypertens Res 26 (5):413-9.

Vilsboll, T., M. Zdravkovic, T. Le-Thi, T. Krarup, O. Schmitz, J. P. Courreges, R. Verhoeven, I. Buganova, and S. Madsbad. 2007. Liraglutide, a long-acting human glucagon-like peptide-1 analog, given as monotherapy significantly improves glycemic control and lowers body weight without risk of hypoglycemia in patients with type 2 diabetes. Diabetes Care 30 (6):1608-10.

Wang, D., H. Zhang, F. Lang, and C. C. Yun. 2007. Acute activation of NHE3 by dexamethasone correlates with activation of SGK1 and requires a functional glucocorticoid receptor. Am J Physiol Cell Physiol 292 (1):C396-404.

Weinman, E. J., R. Biswas, D. Steplock, P. Wang, Y. S. Lau, G. V. Desir, and S. Shenolikar. 2011. Increased renal dopamine and the acute renal adaptation to a high phosphate diet. Am J Physiol Renal Physiol.

Xu, J., G. Li, P. Wang, H. Velazquez, X. Yao, Y. Li, Y. Wu, A. Peixoto, S. Crowley, and G. V. Desir. 2005. Renalase is a novel, soluble monoamine oxidase that regulates cardiac function and blood pressure. J Clin Invest 115 (5):1275-80.

Xu, L., M. P. Dixit, R. Chen, N. M. Dixit, J. F. Collins, and F. K. Ghishan. 2004. Effects of angiotensin II on NaPi-IIa co-transporter expression and activity in rat renal cortex. Biochim Biophys Acta 1667 (2):114-21.

Yammani, R. R., S. Seetharam, and B. Seetharam. 2001. Identification and characterization of two distinct ligand binding regions of cubilin. J Biol Chem 276 (48):44777-84.

Yu, M., C. Moreno, K. M. Hoagland, A. Dahly, K. Ditter, M. Mistry, and R. J. Roman. 2003. Antihypertensive effect of glucagon-like peptide 1 in Dahl salt-sensitive rats. J Hypertens 21 (6):1125-35. 


\section{Part 9}

Estrogens and Endothelium 



\title{
Estradiol Regulation of Prostanoids Production in Endothelium
}

\author{
Susana Novella and Carlos Hermenegildo \\ Department of Physiology, University of Valencia \\ Research Foundation- INCLIVA, Hospital Clínico UniversitarioValencia \\ Spain
}

\section{Introduction}

The endothelium is a continuous cellular monolayer lining the interior of the blood vessels and heart. Classically considered to exert its actions only as a mechanical barrier, also plays important roles in vascular physiology. Endothelium participates in numerous metabolic and regulatory functions such as the control of primary hemostasis, blood coagulation and fibrinolysis, interaction with lipoprotein metabolism, platelet and leukocyte interactions with the vessel wall, presentation of histocompatibility antigens, regulation of vascular tone and growth, and of blood pressure. The endothelium exerts these actions through the release of such vasoactive compounds as prostacyclin, thromboxane $\mathrm{A}_{2}$, nitric oxide (NO), bradykinin, endothelin, angiotensin, and free radicals that control the functions of vascular smooth muscle cells and of circulating blood cells (Ross, 1999; Vapaatalo \& Mervaala, 2001).

The integrity and functionality of the arterial endothelium play a crucial role in the physiology of circulation (Filipe et al., 2008) and, as a consequence, in preventing the development of cardiovascular diseases, whose genesis is currently considered a consequence of the anatomical and functional disruption of the endothelium (Spyridopoulos et al., 1997). When the ability of the endothelial cells to release relaxing is reduced, and in particular if the propensity to produce contractile factors is enhanced, endothelial dysfunction appears as a first step in the sequence of events that leads to atherosclerosis and coronary disease. Thus, no single mechanism is responsible for all endothelium dependent responses and their modulation by pathophysiological states leads to endothelial dysfunction characterized by an imbalance in endothelial regulators (Vanhoutte et al., 2009).

Clinical and experimental data support the consideration of endothelium as a target for estradiol and other sexual hormones. A number of studies have demonstrated a favourable profile for estrogens in both experimental animal, as well as in in vitro models (Turgeon et al., 2006). However, the protective effect detected in a considerable number of observational clinical studies (Barrett-Connor \& Grady, 1998) has not been confirmed by randomized placebo-controlled trials (Hulley et al., 1998; Grady et al., 2002), which described clinical complications, such as thrombosis in veins and coronary arteries, developed in postmenopausal women during the administration of exogenous hormones (Cano et al., 2007). 
A number of studies have demonstrated that estrogens exert significant benefits on the cardiovascular system, and at least a part of these benefits are attributed to the direct effect of estradiol on vascular endothelial cells (Mendelsohn \& Karas, 1999; Rubanyi et al., 2002; Sader \& Celermajer, 2002). Estradiol is able to stimulate endothelial NO production through several mechanisms, including increased expression of NO synthases (mainly endothelial NO synthase), increased L-arginine availability, non-genomic activation of second messengers (Simoncini, 2009), translocation to intracellular sites, modulation of NO degrading sites (Tostes et al., 2003), and modulation of endogenous antagonist levels (Monsalve et al., 2007).

Additionally, estradiol is able to exert antioxidant actions on endothelium (Shwaery et al., 1998; Hermenegildo et al., 2002), to modulate the renin-angiotensin system (Farhat et al., 1996; Alvarez et al., 2002), and to decrease endothelin-1 production (Mikkola et al., 1995; Akishita et al., 1998). Furthermore, estradiol regulates endothelial cell expression of adhesion molecules (Caulin-Glaser et al., 1996; Abu-Taha et al., 2009).

Estradiol has also been implicated on the regulation of prostanoids production in endothelial cells. Two main vascular prostanoids, prostacyclin and thromboxane $A_{2}$, play an essential role in the maintenance of vascular homeostasis. Prostacyclin is a vasodilator and an inhibitor of platelet aggregation; in contrast, thromboxane $\mathrm{A}_{2}$ is a vasoconstrictor and a promoter of platelet aggregation. As a consequence of their opposing roles, an imbalance in prostacyclin or thromboxane production has been implicated in the physiopathology of many thrombotic and cardiovascular disorders. In this chapter, we will discuss clinical and experimental data that document the endothelial effects of estradiol on prostanoid production and regulation, and their vascular consequences.

\section{Prostanoids in endothelium}

Prostanoids are unstable lipid mediators that, after intracellular biosynthesis, are released outside the endothelial cell. It is believed that prostanoids work mostly locally in an autocrine or paracrine way. Prostanoids are ubiquitous compounds that coordinate a wide variety of physiological and pathological processes via membrane receptors on the surface of target cells (FitzGerald, 2002). Prostanoids include prostaglandins (such as prostaglandins $\mathrm{D}_{2}, \mathrm{E}_{2}, \mathrm{~F}_{2}, \mathrm{~F}_{2 a}, \mathrm{PGI}_{2}$-or prostacyclin-) and thromboxanes (such as $\mathrm{TXA}_{2}$ ) (Smith et al., 2000; Linton \& Fazio, 2002).

Prostanoids production is mainly regulated by the availability of free arachidonic acid and the activity of cyclooxygenases (COX). Release of arachidonate from cell membrane phospholipids is mediated through phospholipases, mainly phospholipase $A_{2}$. Once arachidonate is released, it is sequentially converted to prostaglandins $\mathrm{G}_{2}$ and $\mathrm{H}_{2}$ by two COX isoenzymes (COX-1 and COX-2). The unstable prostaglandin $\mathrm{H}_{2}$ is then transformed into biologically active prostanoids by specific synthases in different cells. Prostaglandins interact with G-protein-coupled receptors, classified in function of their preferential affinity towards the five primary prostaglandins (Tsuboi et al., 2002) (Figure 1).

COX isoenzymes (also known as prostaglandin endoperoxide synthases or prostaglandin $\mathrm{H}$ synthases) are the rate-limiting step in the formation of prostanoids from arachidonic acid and represent the main control mechanism for prostaglandin production (Smith et al., 2000). Both enzymes have similar biochemical activity in converting arachidonic acid to $\mathrm{PGH}_{2}$ in tissue or in recombinant enzyme systems (Vane et al., 1998).

COX-1 and COX-2 are encoded by two different genes derived from human chromosomes 9 and 1, respectively. In spite of there is a $60-65 \%$ homology between the isoforms within 
species, the activity and the pattern of gene expression of these enzymes are differentially regulated (Davidge, 2001).

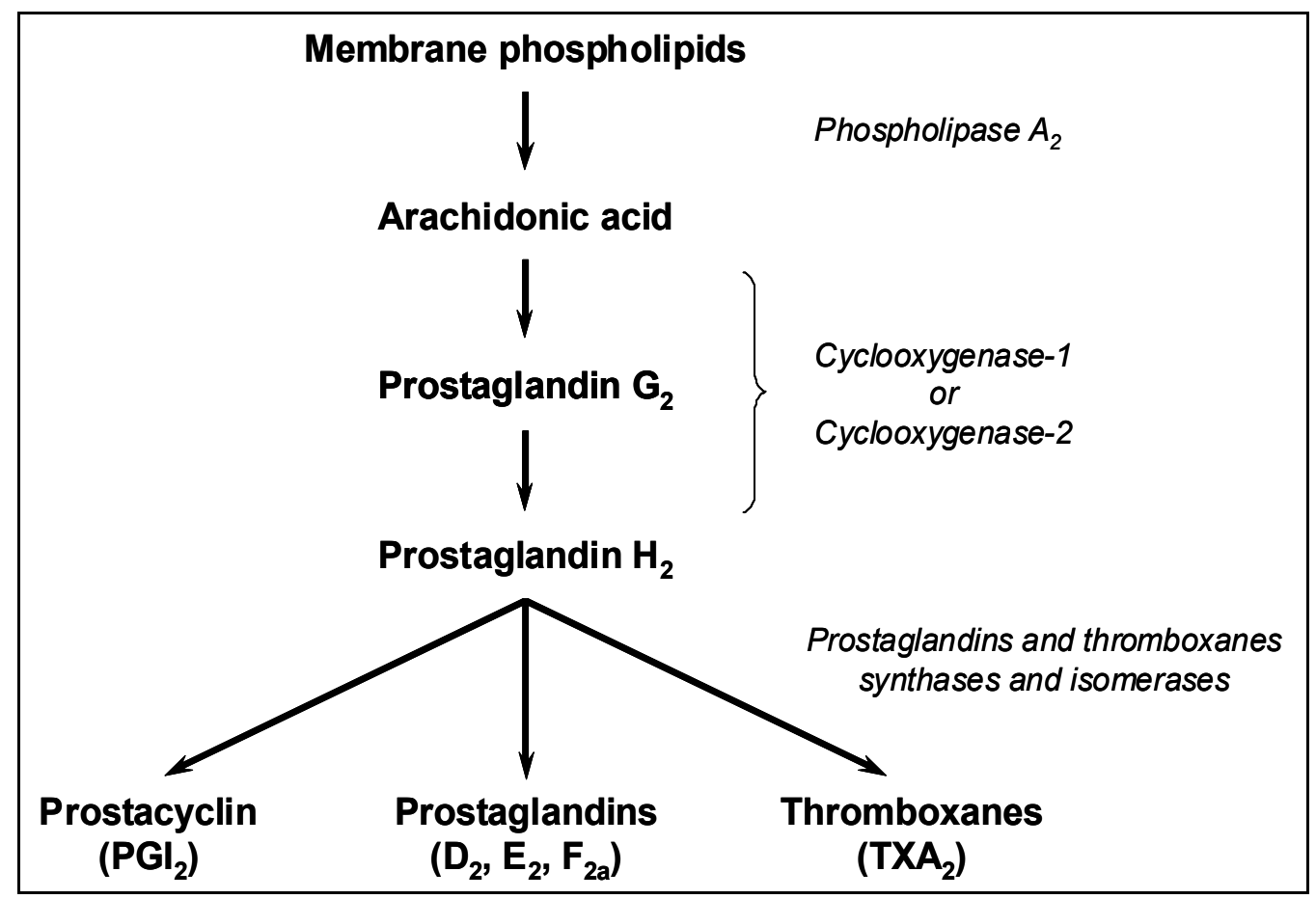

Fig. 1. Biosynthesis of prostaglandins and thromboxanes.

COX-1 has been considered to be the constitutively expressed protein, while COX-2 is induced at sites of inflammation. Following that hypothesis, COX-1 would generate prostaglandins for physiological, housekeeping functions like gastrointestinal mucosal integrity and regulation of renal blood flow, while COX-2 would form the prostaglandins responsible for inflammatory symptoms (Smith et al., 2000; Parente \& Perretti, 2003).

But this separation of functions is so not clear. For instance, COX-2 is constitutively expressed in some regions of the central nervous system, and in renal and uterus tissues, suggesting it may play a role under physiologic conditions (Kim et al., 1999; FitzGerald, 2002; Cheng \& Harris, 2004). In fact, both COX-1 and COX-2 are involved not only in physiological, but also in pathological processes. The importance of this topic has impelled many outstanding reviews (Vane et al., 1998; Parente \& Perretti, 2003; Cipollone et al., 2008; Vanhoutte, 2009).

Regarding the vascular system, both isoenzymes are expressed in endothelium and smooth muscle cells. However, endothelial cells contain up to 20 times more COX than smooth muscle cells (DeWitt et al., 1983). As mentioned before for other organs, COX-1 has usually been considered in endothelium as the constitutive isoform, while COX-2 is induced by a number of cardiovascular risk factors, such as cytokines, cholesterol, lipoproteins, and hypoxia. Actually, both COX isoenzymes share characteristics of constitutive and inducible enzymes in endothelium. Shear stress induces COX-1 gene expression in human umbilical vein endothelial cells (HUVEC) (Doroudi et al., 2000), while clinical studies with a selective 
inhibitor of COX-2 (celecoxib) have shown that this enzyme exerts control of most systemic prostacyclin production in healthy humans (McAdam et al., 1999).

Although prostaglandins $\mathrm{E}_{2}$ and $\mathrm{F}_{2 \alpha}$ can contribute to vascular phenotype, two main prostanoids play an essential role in vascular physiology: thromboxane $\mathrm{A}_{2}$ and prostacyclin. On the one hand, in the cardiovascular system, thromboxane $A_{2}$ is predominantly derived from platelet COX-1, but can also be produced by other cell types including the endothelial cells. The stimulation of thromboxane receptors elicits not only platelet aggregation and smooth muscle contraction, but also the expression of adhesion molecules and the adhesion and infiltration of monocytes/macrophages (Nakahata, 2008). As platelets are anucleate, there can be no induction of COX-2 enzyme synthesis (Patrignani et al., 1999). Thromboxane $A_{2}$ can also be synthesized from endothelial cells (Sellers \& Stallone, 2008). The third possibility is a transcellular formation of thromboxane $\mathrm{A}_{2}$ by platelets from prostaglandin $\mathrm{H}_{2}$ released by endothelial cells (Camacho \& Vila, 2000). Thromboxane $A_{2}$ promotes irreversible platelet aggregation, vasoconstriction, and smooth muscle proliferation and, consequently, plays an important role as a mediator of not only haemostasis, but also of acute vascular occlusive events and atherogenesis (FitzGerald, 2002; Weir et al., 2003).

On the other hand, in most blood vessels prostacyclin is the main prostanoid produced by endothelial cells, and the endothelium is its major source (Moncada \& Vane, 1978). Both COX-1 and COX-2 isoenzymes contribute to the production of endothelial prostacyclin. By stimulating its preferential receptor, prostacyclin is a potent inhibitor of platelet adhesion to the endothelial cell surface and of platelet aggregation, and generally acts as an endothelium-derived vasodilator and an inhibitor of vascular smooth muscle migration and proliferation (Moncada \& Vane, 1978; Fetalvero et al., 2007).

Under physiological conditions, endothelial prostacyclin is a counterregulatory influence to platelet-derived thromboxane, and eicosanoids produced by the COX pathways generally induce vasorelaxation. Nevertheless, in some pathologic circumstances, such as oxidative stress and dyslipidemia, there may be an imbalance where COX-dependent vasoconstrictors and platelet aggregation become more predominant. Reactive oxygen species, such as superoxide anion and hydrogen peroxide are derived from multiple sources within inflammatory leukocytes and vascular tissues including NADPH oxidase, uncoupled endothelial and inducible endothelial NO synthase, xanthine oxidase, cyclooxygenases, lipoxygenases, cytochrome P450 monooxygenases and excess substrate utilization by mitochondria. Additionally, NO reacts with superoxide anion to form the extremely potent oxidant, peroxynitrite. Low concentrations of peroxinitrite selectively nitrate and inactivate prostacyclin synthase, which not only eliminates the vasodilatory, growth-inhibiting, antithrombotic, and antiadhesive effects of prostacyclin, but also increases release of the potent vasoconstrictor, prothrombotic, growth- and adhesion-promoting agents, prostaglandin $\mathrm{H}_{2}$ and thromboxane $\mathrm{A}_{2}$ being in general deleterious to vascular function (Zou et al., 2004; Schildknecht \& Ullrich, 2009; Feletou et al., 2010).

\section{Estrogens actions on endothelium}

Estradiol is the most potent estrogen in humans, and exerts its actions mainly through binding and activation of estrogen receptors (ER). Two major subtypes of ER (ERa and ER $\beta$ ) have been identified. These receptors vary not only in their tissue distributions, but also in their agonist/antagonist profile of several compounds (Cano \& Hermenegildo, 2000). Both 
types of ER belong to the class of intracellular receptors classically defined as nuclear ligand-activated transcription factors. Activation of these receptors by the corresponding hormones affects gene expression by acting on specific sequences in the target genes, known as estrogen-response elements, and by modulating transcriptional events.

The contribution of both receptors to the regulation of vascular effects is still under study. There is controversy about whether estrogenic effects are mediated through ERa, ER $\beta$ or both. In the cardiovascular system, ERa and ER $\beta$ have been identified by different techniques in the endothelium, smooth muscle cells and adventitia and on adrenergic nerve endings of arteries from various territories and several species, including humans (Karas et al., 1994; Kim-Schulze et al., 1996; Venkov et al., 1996; Register \& Adams, 1998). Although it has been reported cultured endothelial cells do not express ERa (Toth et al., 2008), other investigators have demonstrated the presence of both ERa and ER $\beta$ mRNA in endothelium (Wagner et al., 2001) and data from our group demonstrate the protein expression of both ERa and ER $\beta$ in HUVEC (Sobrino et al., 2009; Sobrino et al., 2010).

Although the relative significance of both ER subtypes in the vascular actions of estrogens is still under study, data from mice lacking either ERa (Pare et al., 2002; Arnal et al., 2010) or ER $\beta$ (Zhu et al., 2002), and also from a non-functional mutation of ERa in a male patient (Sudhir et al., 1997), reveal an impaired vascular function. Therefore, ERa is probably critical for the production of estrogen vascular protective actions (Favre et al., 2010), but ER $\beta$ may have relevant functions at the vascular level too (Simoncini et al., 2004). The changes in vascular cell gene and protein expression mediated by those ERa and/or ER $\beta$ produce the classic, and better known, longer-term effects of estrogen (Cano \& Hermenegildo, 2000).

$\mathrm{ER}$ act in the nucleus as ligand-activated transcription factors that regulate gene expression in response to hormone binding. ER can also regulate vascular cell gene expression in the absence of estrogen following activation by growth factor signalling pathways, a process referred to as ligand-independent transcriptional activation. In addition, ER are able to signal rapidly (from seconds to minutes), in an apparently non-nuclear manner, resulting in downstream activation of specific kinases and their effectors molecules (Mendelsohn \& Karas, 2010).

The rapid effects of estrogens have been also explained by ER-independent mechanisms of action. For instance, the $G$ protein-coupled receptor GPR30 has been proposed to be a third form of ER, although it is controversial whether GPR30 is a biologically-relevant ER or a collaborator in non-nuclear functions of the classical ER in certain contexts (Levin, 2009). Moreover, even though GPR30 is expressed in certain endothelial cells, there is currently a lack of clear evidence of a role for the receptor in estrogen action in endothelium (Wu et al., 2011).

Rapid actions of estradiol include several endothelial pathways, being the activity of endothelial nitric oxide synthase the most studied (Chow et al., 2010). Other signalling pathways acutely activated by estradiol in endothelium are several kinases, such as phosphotidylinositol 3-kinase (PI3K) (Razandi et al., 2000), protein kinase C (PKC) (Akarasereenont et al., 2000) and Rho-associated kinase (ROCK) (Simoncini et al., 2006; Oviedo et al., 2011). Rapid actions are responsible for the acute and potent vasorelaxation induced by estradiol both at physiological (Teoh et al., 2000; Tep-areenan et al., 2003) or supraphysiological (Naderali et al., 2001; Salom et al., 2002) concentrations, and it has been demonstrated in isolated vessels from animals such as rats (Tep-areenan et al., 2003), pigs (Teoh et al., 2000), rabbits (Salom et al., 2002), guinea pigs (Naderali et al., 2001), and even from human beings (Chester et al., 1995). 
In addition, steroid hormone genomic and non-genomic effects may occur simultaneously and may act at different levels, revealing the complexity of estrogen regulation of vascular function (Tostes et al., 2003).

\section{Estrogens actions on prostanoids vascular regulation}

The actions of estrogens on prostanoids vascular production will be presented in two sections: first, those experimental data that are rapid in onset and short in duration (within minutes; "non-genomic" effects); second, those experimental data that are delayed in onset and prolonged in duration (require from hours to days to occur; "genomic" effects).

\subsection{Rapid effects of estrogens on prostanoids vascular production}

Physiological concentrations of estradiol cause a rapid stimulation of prostacyclin synthesis (within $15 \mathrm{~min}$ ) in two types of cultured endothelial cells, ovine fetal pulmonary artery endothelial cells (PAEC) (Sherman et al., 2002) and HUVEC (Alvarez et al., 2002). In both cases, the use of the ER-antagonist ICI182780 reveals that the increased prostacyclin production is mediated through ER activation. In ovine PAEC, it seems mediated through ER $\beta$, since prostacyclin stimulation with estradiol was fully blocked by the ER $\beta$ - antagonist RR-tetrahydrochrysene. Moreover, in ovine PAEC, the increased prostacyclin production is not related to changes in COX-1 or COX-2 protein abundance, thus reinforcing the implication of non-genomic mechanisms (Table 1) (Sherman et al., 2002).

COX-pathway activity is involved in the acute relaxation afforded by estradiol. In rat mesenteric vessels and aorta, COX inhibition with indomethacin enhances the vasodilator potency of estradiol, suggesting an endogenous release of vasoconstrictor prostanoids (Tepareenan et al., 2003). But estradiol also indirectly affects vasoreactivity to contracting and relaxing substances. In epicardial porcine coronary arteries activation of ERa, but not of $\mathrm{ER} \beta$, reduces thromboxane $\mathrm{A}_{2}$ vasoconstriction, indicating another indirect and vasodilator function of ERa (Traupe et al., 2007). Other data suggest that the estrogen-dependent constrictor prostanoid mechanism in the vascular wall may play an important role in the regulation of vascular tone in the female, in both normal and pathophysiological states. In that way, endogenous estrogen acts as an important regulator of constrictor prostanoid function in female rat aorta, involving the potentiation of COX-2 and thromboxane synthase expression in vascular wall (Li et al., 2008).

Data from studies performed on postmenopausal women also supports the importance of COX-pathway in acute estrogen-induced vasodilation. Estradiol induces a rapid increase of cholinergic cutaneous vasodilation, which is eliminated in women treated for 6 weeks with celecoxib, suggesting that the COX-2 pathway plays a specific role in the rapid estradiolinduced vasodilation in postmenopausal women (Calkin et al., 2002).

Some studies have been performed at times that do not clarify whether the observed effects are genomic or non-genomic actions. Estrogen stimulates rat aortic endothelial cell release of prostacyclin after 1 hour of incubation without affecting COX-1 levels (Myers et al., 1996). That stimulation could be mediated by NO, since endogenous NO increased production of prostacyclin and thromboxane $\mathrm{A}_{2}$ in bovine coronary microvascular endothelial cells within 1 hour, without affecting COX-1 or COX-2 expressions (Davidge et al., 1995). At molecular level, exposure of HUVEC for $40 \mathrm{~min}$ to estradiol significantly increases the expression of roughly 250 genes, measured by DNA microarray analysis. Among them, the COX-2 gene was the strongest up-regulated by estradiol. In fact, estradiol induced COX-2 gene 
expression and new COX-2 protein synthesis by 40 and 60 min, respectively, and quickly stimulated the secretion of prostacyclin and prostaglandin $\mathrm{E}_{2}$ in an ER-dependent manner (Pedram et al., 2002). A similar, significant induction of COX-2 mRNA levels is obtained in human placental villous endothelial cells exposed to estradiol up to 1 hour, without an increased protein production (Su et al., 2009).

\begin{tabular}{lllll}
\hline \hline Cell type & Time & $\begin{array}{l}\mathrm{E}_{2} \\
(\mathrm{nM})\end{array}$ & $\begin{array}{l}\text { Prostacyclin } \\
\text { production }\end{array}$ & COX-1 COX-2 Reference \\
\hline \hline
\end{tabular}

\section{$\underline{\text { Rapid effects }}$}

$\begin{array}{rrccccc}\text { Ovine fetal PAEC } & 15 \mathrm{~min} & 10 & \uparrow 52 \% & \leftrightarrow & \leftrightarrow & \text { (Sherman } \text { et al., 2002) } \\ \text { HUVEC } & 15 \mathrm{~min} & 1 & \uparrow 57 \% & \text { NA } & \text { NA } & \text { (Alvarez } \text { et al., 2002) } \\ \text { HUVEC } & 30 \mathrm{~min} & 1 & \uparrow 134 \% & \text { NA } & \text { NA } & \text { (Alvarez } \text { et al., 2002) }\end{array}$

\section{Delayed effects}

\begin{tabular}{|c|c|c|c|c|c|c|}
\hline HUVEC & $24 \mathrm{~h}$ & 10 & $\uparrow 26 \%$ & NA & NA & (Mikkola et al., 1995) \\
\hline HUVEC & $24 \mathrm{~h}$ & 0.1 & $\uparrow 16 \%$ & NA & NA & (Mikkola et al., 1996) \\
\hline HUVEC & $24 \mathrm{~h}$ & 1 & $\uparrow 78 \%$ & $\leftrightarrow$ & $\uparrow$ & $\begin{array}{c}\text { (Akarasereenont et al., } \\
\text { 2000) }\end{array}$ \\
\hline HUVEC & $24 \mathrm{~h}$ & 1 & $\uparrow 30 \%$ & $\uparrow$ & $\leftrightarrow$ & (Sobrino et al., 2009) \\
\hline HUVEC & $24 \mathrm{~h}$ & 10 & $\uparrow 33 \%$ & $\uparrow$ & $\leftrightarrow$ & (Sobrino et al., 2010) \\
\hline Human coronary EC & $24 \mathrm{~h}$ & 100 & $\uparrow 45 \%$ & NA & NA & (Mueck et al., 2002) \\
\hline Bovine coronary EC & $24 \mathrm{~h}$ & 1 & $\downarrow 83 \%$ & $\leftrightarrow$ & $\leftrightarrow$ & (Stewart et al., 1999) \\
\hline Ovine fetal PAEC & $48 \mathrm{~h}$ & 10 & $\uparrow 64 \%$ & $\uparrow$ & NA & (Jun et al., 1998) \\
\hline
\end{tabular}

Table 1. Summary of estradiol effects on cultured cell production of prostacyclin. $E_{2}$ : concentration of estradiol in nM. Prostacyclin production is expressed as increased $(\uparrow)$ or decreased $(\downarrow)$ percentage of control values. COX-1 and COX-2 expression: increased $(\uparrow)$, decreased $(\downarrow)$, unchanged $(\leftrightarrow)$ or not available (NA). PAEC: pulmonary artery endothelial cells. HUVEC: human umbilical vein endothelial cells. EC: endothelial cells.

\subsection{Delayed (genomic) effects of estrogens on prostanoids vascular production}

Estrogen also exerts vascular delayed effects on the metabolism of prostaglandins and the activity of COX, as has been demonstrated in studies performed both in cultured cells, as well as in isolated vascular preparations.

A time-course analysis performed in HUVEC, demonstrates that estradiol effects on prostacyclin production were evident only after 8 or 24 hours (10 and $1 \mathrm{nM}$ estradiol, respectively), suggesting an ER-mediated genomic effect (Sobrino et al., 2010). Moreover, physiological concentrations of estradiol stimulate the production of prostaglandins, mainly 
prostacyclin, in a variety of cultured endothelial cells, such as ovine fetal PAEC (Jun et al., 1998), HUVEC (Mikkola et al., 1995; Mikkola et al., 1996; Akarasereenont et al., 2000; Sobrino et al., 2010), and human coronary endothelial cell (Mueck et al., 2002). In the vast majority of experiments, cells were exposed to estradiol during 24-48 hours, and the increase of prostacyclin above control values ranged from $16 \%$ to $78 \%$ (Table 1 ).

In addition, it has been shown that estradiol stimulates production of prostaglandins in a variety of preparations of arteries, including ovine uterine arteries (Vagnoni \& Magness, 1998; Janowiak et al., 1998; Habermehl et al., 2000), mesenteric arteries from ovariectomized rats (Davidge \& Zhang, 1998; Armstrong et al., 2002), rat cerebral blood vessels (Ospina et al., 2002; Ospina et al., 2003), and aorta from ovariectomized monkeys (O'Sullivan et al., 2001). The increase of prostacyclin production is of a similar magnitude to that obtained with cultured endothelial cells.

Concerning endothelial production of thromboxane $\mathrm{A}_{2}$ under estradiol, the literature indirectly suggests that estrogen would have a beneficial effect by decreasing the production of thrombogenic compounds. In men, there is a decrease in the formation of thromboxane $\mathrm{A}_{2}$ after the use of high dosage intra-muscular estrogen therapy (Henriksson et al., 1996). Moreover, the ratio of in vivo prostacyclin to thromboxane $\mathrm{A}_{2}$ formation increases 2-fold during estrogen replacement therapy (Mueck et al., 2001). Nevertheless, it has also been documented that estrogen increases platelet activation with the liberation of thromboxane $\mathrm{A}_{2}$ in women treated with hormone replacement therapy (Oliveira et al., 2005) and that estrogen enhances the constrictor prostanoid function in female rat aorta (Li et al., 2008). However, in cultured endothelial cells, thromboxane $A_{2}$ production remains unchanged when measured after exposure to estradiol (Sobrino et al., 2010).

The regulatory role of estradiol on the biosynthesis pathway of prostanoids in endothelium (Figure 1) has been scarcely studied, with the only exception of COX-1 and COX-2 expressions. Concerning the first enzyme, soluble phospholipase $A_{2}$ is highly expressed in HUVEC and umbilical smooth muscle cells (Ost et al., 1998), but it does not appear to be regulated by estradiol. Phospholipase $\mathrm{A}_{2}$ expression remains unchanged after exposure to estradiol in HUVEC (Sobrino et al., 2010) or in human myometrial cells prepared from second trimester pregnant women (Korita et al., 2004).

The roles of COX-1 and/or COX-2 isoenzymes in endothelial cells exposed to estradiol have been studied in some cases, and both enzymes have been implicated in estradiol effects. In ovine fetal PAEC after exposure to estradiol, both COX-1 mRNA and protein expressions were up-regulated (Jun et al., 1998), whereas in HUVEC estradiol only induces COX-2 expression protein (Akarasereenont et al., 2000). Genome-wide analysis performed in HUVEC exposed to estradiol for 24 hours demonstrated that COX-1 was among the $5 \%$ of proteins which expression was changed more than 1.5 fold-times compared to controls, data that was verified by western blot analysis (Sobrino et al., 2009).

Prostacyclin increased levels after vessel stimulation with estradiol have been mainly associated with enhanced expression of COX-1. In this way, COX-1 protein content is increased in rat (Ospina et al., 2002) and mice (Geary et al., 2001) cerebral blood vessels, and in ovine uterine arteries in response to treatment with estrogen (Rupnow et al., 2002). Indeed, COX-1 (but not COX-2) expression is increased in the endothelium of the ovine uterine artery during the follicular phase of the ovarian cycle and during pregnancy, where estrogen levels are highest (Janowiak et al., 1998; Habermehl et al., 2000). In spite of the classic consideration of COX-2 as an inducible enzyme, it seems that COX-2 does not contribute to the estradiol-increased prostacyclin production. Estrogen has even been found 
to decrease COX-2 expression in mesenteric arteries from ovariectomized aged rats (Armstrong et al., 2002).

However, similar experiments have occasionally produced contradictory results. Exposure of culture bovine coronary microvascular endothelial cells to physiological concentrations of estradiol for 24 hours reduced both prostacyclin and thromboxane $\mathrm{A}_{2}$ production (Stewart et al., 1999). In the case of whole tissue experiments, arteries respond in a different way to estradiol. This is the case of artery segments from different vascular beds (thoracic aorta, pulmonary artery, ear artery and coronary arteries) from adult male rabbits in which estradiol may cause both vasorelaxation and vasoconstriction (Saetrum et al., 2002). Moreover, in thoracic aorta the contractile effects of estrogen are mediated through the release of vasoconstrictor prostaglandins (Saetrum et al., 2002).

These discrepancies could indicate a difference in the effects of estrogen depending on its previous serum concentration, the reproductive condition of the animal and/or the vascular bed being studied (Armstrong et al., 2002; Saetrum et al., 2002; Tostes et al., 2003).

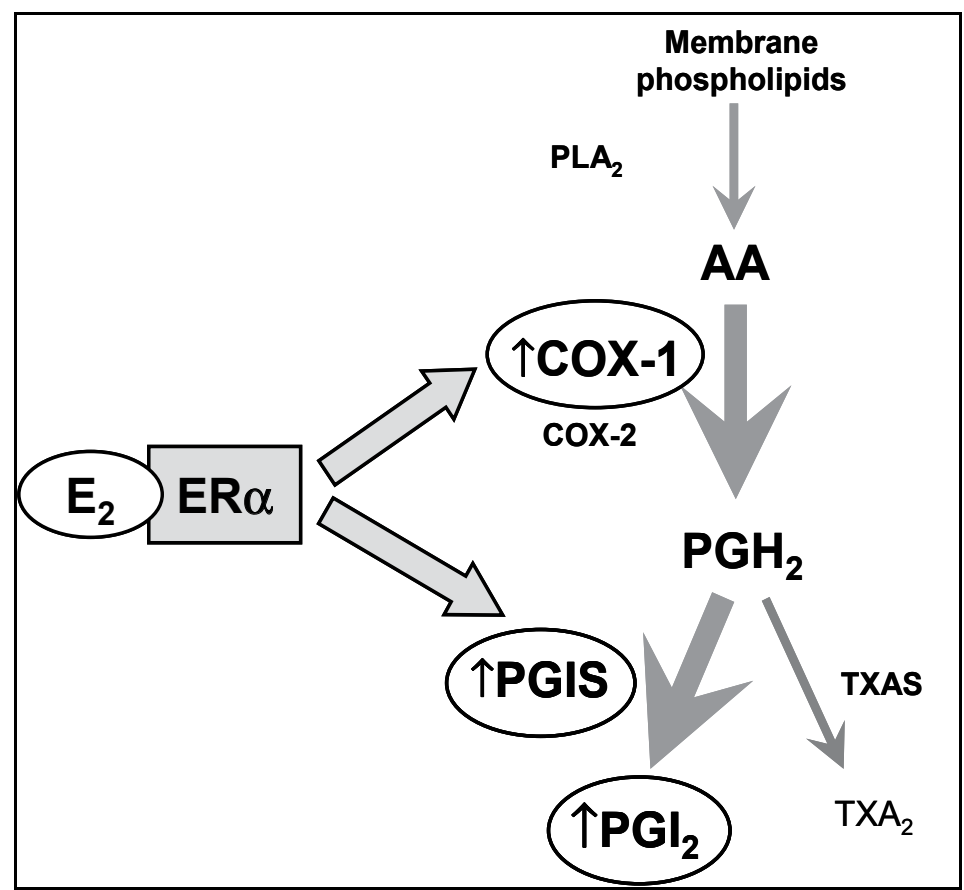

Fig. 2. Estradiol-induced modifications on prostanoid pathway through ERa. Estradiol $\left(\mathrm{E}_{2}\right)$, acting on ERa, increased cyclooxygenase-1 (COX-1) and prostacyclin synthase (PGIS) expression, resulting in an increased prostacyclin $\left(\mathrm{PGI}_{2}\right)$ production. Phospholipase $\mathrm{A}_{2}$, cyclooxygenase-2 (COX-2) and thromboxane synthase (TXAS) expressions, along with thromboxane $\mathrm{A}_{2}$ production $\left(\mathrm{TX}_{2}\right)$, remained unchanged after exposure to estradiol.

The regulatory actions of estradiol on the prostanoids biosynthesis pathway are mediated through ER activation. The use of ICI182780, a non-selective ER-antagonists, completely blocks estradiol-stimulated prostacyclin production in ovine fetal PAEC (Jun et al., 1998), HUVEC (Sobrino et al., 2009), and tamoxifen blocked it in HUVEC (Mikkola et al., 1995; Mikkola et al., 1996). 
Moreover, data support a specific role for ERa on estradiol-stimulated prostacyclin production. Recently, selective ERa agonist 1,3,5-tris(4-hydroxyphenyl)-4-propyl-1h-pyrazole (PPT), selective ER $\beta$ agonist (diarylpropionitril; DPN), and selective ERa antagonist, methylpiperidino-pyrazole (MPP), have become available (Krom et al., 2007). With their use, it has been demonstrated that estradiol increased prostacyclin production, and COX-1 and prostacyclin synthase protein and gene expressions through ERa, whereas COX-2, phospholipases and thromboxane synthase expression remained unaltered (Sobrino et al., 2010). The regulatory role of estradiol through ERa is supported by other studies. Estradiol increases levels of COX-1 in cerebral blood vessels from wild-type mice but was ineffective in ERa knockout mice (Geary et al., 2001) and also increases COX-1 expression through ERa in ovine endothelial cells transfected with the human COX-1 promoter (Gibson et al., 2005).

\section{Conclusion}

Remarkable progress has been made in elucidating the effects of estrogens on the vascular system, and the cellular and molecular mechanisms by which those effects are achieved. The analysis of published data supports estradiol increases prostacyclin vascular production in accordance with experimental and clinical research. This effect seems to be mediated mainly through ERa-dependent pathways which involve an increase in COX-1 and, in some cases, COX-2 activation and/or expression, and an augment in prostacyclin synthase expression, without affecting thromboxane A2 production. As a consequence, estradiol may reduce vascular tone and improve endothelium-dependent vasodilation (Figure 2).

\section{Acknowledgments}

Supported by the Spanish Ministerio de Ciencia e Innovación, Instituto de Salud Carlos III (grants FIS PI10/00518 and Red HERACLES RD06/0009/0005), Consellería de Sanidad (grants AP 117/ 2010 and GE 021/2010).

\section{References}

Abu-Taha, M., Rius, C., Hermenegildo, C., Noguera, I., Cerda-Nicolas, J.M., Issekutz, A.C., Jose, P.J., Cortijo, J., Morcillo, E.J. \& Sanz, M.J. (2009). Menopause and Ovariectomy Cause a Low Grade of Systemic Inflammation that May Be Prevented by Chronic Treatment with Low Doses of Estrogen or Losartan. J. Immunol. 183, 1393-1402.

Akarasereenont, P., Techatraisak, K., Thaworn, A. \& Chotewuttakorn, S. (2000). The induction of cyclooxygenase-2 by 17beta-estradiol in endothelial cells is mediated through protein kinase C. Inflamm. Res. 49, 460-465.

Akishita, M., Kozaki, K., Eto, M., Yoshizumi, M., Ishikawa, M., Toba, K., Orimo, H. \& Ouchi, Y. (1998). Estrogen attenuates endothelin-1 production by bovine endothelial cells via estrogen receptor. Biochem. Biophys. Res. Commun. 251, 17-21.

Alvarez, A., Hermenegildo, C., Issekutz, A.C., Esplugues, J.V. \& Sanz, M.J. (2002). Estrogens inhibit angiotensin II-induced leukocyte-endothelial cell interactions in vivo via rapid endothelial nitric oxide synthase and cyclooxygenase activation. Circ. Res. 91, 1142-1150. 
Armstrong, S.J., Zhang, Y., Stewart, K.G. \& Davidge, S.T. (2002). Estrogen replacement reduces PGHS-2-dependent vasoconstriction in the aged rat. Am. J. Physiol. Heart. Circ. Physiol. 283, H893-H898.

Arnal, J.F., Fontaine, C., Billon-Gales, A., Favre, J., Laurell, H., Lenfant, F. \& Gourdy, P. (2010). Estrogen Receptors and Endothelium. Arterioscler. Thromb. Vasc. Biol. 30, 1506-1512.

Barrett-Connor, E., Grady, D. (1998). Hormone replacement therapy, heart disease, and other considerations. Annu. Rev. Pub. Health. 19, 55-72.

Calkin, A.C., Sudhir, K., Honisett, S., Williams, M.R., Dawood, T. \& Komesaroff, P.A. (2002). Rapid potentiation of endothelium-dependent vasodilation by estradiol in postmenopausal women is mediated via cyclooxygenase 2. J. Clin. Endocrinol. Metab. 87, 5072-5075.

Camacho, M., Vila, L. (2000). Transcellular formation of thromboxane A2 in mixed incubations of endothelial cells and aspirin-treated platelets strongly depends on the prostaglandin I-synthase activity. Thromb. Res. 99, 155-164.

Cano, A., Hermenegildo, C. (2000). Modulation of the oestrogen receptor: a process with distinct susceptible steps. Hum. Reprod. Update. 6, 207-211.

Cano, A., Hermenegildo, C., Oviedo, P. \& Tarin, J.J. (2007). The risk for cardiovascular disease in women: from estrogens to selective estrogen receptor modulators. Front. Biosci. 12, 49-68.

Caulin-Glaser, T., Watson, C.A., Pardi, R. \& Bender, J.R. (1996). Effects of 17beta-estradiol on cytokine-induced endothelial cell adhesion molecule expression. J. Clin. Invest. 98, $36-42$.

Cheng, H.F., Harris, R.C. (2004). Cyclooxygenases, the Kidney, and Hypertension. Hypertension 43, 525-530.

Chester, A.H., Jiang, C., Borland, J.A., Yacoub, M.H. \& Collins, P. (1995). Oestrogen relaxes human epicardial coronary arteries through non-endothelium-dependent mechanisms. Coron. Artery Dis. 6, 417-422.

Chow, R.W.Y., Handelsman, D.J. \& Ng, M.K.C. (2010). Rapid Actions of Sex Steroids in the Endothelium. Endocrinology 151, 2411-2422.

Cipollone, F., Cicolini, G. \& Bucci, M. (2008). Cyclooxygenase and prostaglandin synthases in atherosclerosis: Recent insights and future perspectives. Pharmacol. Ther.118, 161-180.

Davidge, S.T. (2001). Prostaglandin H Synthase and Vascular Function. Circ. Res. 89, 650-660.

Davidge, S.T., Baker, P.N., McLaughlin, M.K. \& Roberts, J.M. (1995). Nitric oxide produced by endothelial cells increases production of eicosanoids through activation of prostaglandin H synthase. Circ. Res. 77, 274-283.

Davidge, S.T., Zhang, Y. (1998). Estrogen replacement suppresses a prostaglandin H synthase-dependent vasoconstrictor in rat mesenteric arteries. Circ. Res. 83, 388-395.

DeWitt, D.L., Day, J.S., Sonnenburg, W.K. \& Smith, W.L. (1983). Concentrations of prostaglandin endoperoxide synthase and prostaglandin I2 synthase in the endothelium and smooth muscle of bovine aorta. J. Clin. Invest. 72, 1882-1888.

Doroudi, R., Gan, LM., Selin Sjogren, L. \& Jern, S. (2000). Effects of shear stress on eicosanoid gene expression and metabolite production in vascular endothelium as studied in a novel biomechanical perfusion model. Biochem. Biophys. Res. Commun. 269, 257-264.

Farhat, M.Y., Lavigne, M.C. \& Ramwell, P.W. (1996). The vascular protective effects of estrogen. FASEB J. 10, 615-624. 
Favre, J., Gao, J., Henry, J.P., Remy-Jouet, I., Fourquaux, I., Billon-Gales, A., Thuillez, C., Arnal, J.F., Lenfant, F. \& Richard, V. (2010). Endothelial Estrogen Receptor \{alpha\} Plays an Essential Role in the Coronary and Myocardial Protective Effects of Estradiol in Ischemia/Reperfusion. Arterioscler. Thromb. Vasc. Biol. 30, 2562-2567.

Feletou, M., Cohen, R.A., Vanhoutte, P.M. \& Verbeuren, T.J. (2010). TP receptors and oxidative stress hand in hand from endothelial dysfunction to atherosclerosis. Adv. Pharmacol 60, 85-106.

Fetalvero, K.M., Martin, K.A. \& Hwa, J. (2007). Cardioprotective prostacyclin signaling in vascular smooth muscle. Prostaglandins Lipid Mediators 82, 109-118.

Filipe, C., Lam Shang Leen, L., Brouchet, L., Billon, A., Benouaich, V., Fontaine, V., Gourdy, P., Lenfant, F., Arnal, J.F., Gadeau, A.P. \& Laurell, H. (2008). Estradiol accelerates endothelial healing through the retrograde commitment of uninjured endothelium. Am. J. Physiol. Heart Circ. Physiol. 294, H2822-H2830.

FitzGerald, G.A. (2002). Cardiovascular pharmacology of nonselective nonsteroidal antiinflammatory drugs and coxibs: clinical considerations. Am. J. Cardiol. 89, 26-32.

Geary, G.G., McNeill, A.M., Ospina, J.A., Krause, D.N., Korach, K.S. \& Duckles, S.P. (2001). Cerebrovascular NOS and cyclooxygenase are unaffected by estrogen in mice lacking estrogen receptor-alpha. J. Appl. Physiol. 91, 2391-2399.

Gibson, L.L., Hahner, L., Osborne-Lawrence, S., German, Z., Wu, K.K., Chambliss, K.L. \& Shaul, P.W. (2005). Molecular Basis of Estrogen-Induced Cyclooxygenase Type 1 Upregulation in Endothelial Cells. Circ. Res. 96, 518-525.

Grady, D., Herrington, D., Bittner, V., Blumenthal, R., Davidson, M., Hlatky, M., Hsia, J., Hulley, S., Herd, A., Khan, S., Newby, L.K., Waters, D., Vittinghoff, E. \& Wenger, N. (2002). Cardiovascular disease outcomes during 6.8 years of hormone therapy: Heart and Estrogen/progestin Replacement Study follow-up (HERS II). JAMA 288, 49-57.

Habermehl, D.A., Janowiak, M.A., Vagnoni, K.E., Bird, I.M. \& Magness, R.R. (2000). Endothelial vasodilator production by uterine and systemic arteries. IV. Cyclooxygenase isoform expression during the ovarian cycle and pregnancy in sheep. Biol. Reprod. 62, 781-788.

Henriksson, P., Stege, R. \& Green, K. (1996). Profound decrease of in vivo formation of thromboxane during oestrogen therapy. Eur. J. Clin. Invest. 26, 1186-1188.

Hermenegildo, C., Garcia-Martinez, M.C., Tarin, J.J. \& Cano, A. (2002). Estradiol reduces F2alpha -isoprostane production in cultured human endothelial cells. Am. J. Physiol Heart Circ. Physiol. 283, H2644-H2649.

Hulley, S., Grady, D., Bush, T., Furberg, C., Herrington, D., Riggs, B. \& Vittinghoff, E. (1998). Randomized trial of estrogen plus progestin for secondary prevention of coronary heart disease in postmenopausal women. Heart and Estrogen/progestin Replacement Study (HERS) Research Group. JAMA 280, 605-613.

Janowiak, M.A., Magness, R.R., Habermehl, D.A. \& Bird, I.M. (1998). Pregnancy increases ovine uterine artery endothelial cyclooxygenase-1 expression. Endocrinology 139, 765-771.

Jun, S.S., Chen, Z., Pace, M.C. \& Shaul, P.W. (1998). Estrogen upregulates cyclooxygenase-1 gene expression in ovine fetal pulmonary artery endothelium. J. Clin. Invest. 102, 176-183.

Karas, R.H., Patterson, B.L. \& Mendelsohn, M.E. (1994). Human vascular smooth muscle cells contain functional estrogen receptor. Circulation 89, 1943-1950. 
Kim, J.J., Wang, J., Bambra, C., Das, S.K., Dey, S.K. \& Fazleabas, A.T. (1999). Expression of cyclooxygenase-1 and -2 in the baboon endometrium during the menstrual cycle and pregnancy. Endocrinology 140, 2672-2678.

Kim-Schulze, S., McGowan, K.A., Hubchak, S.C., Cid, M.C., Martin, M.B., Kleinman, H.K., Greene, G.L. \& Schnaper, H.W. (1996). Expression of an estrogen receptor by human coronary artery and umbilical vein endothelial cells. Circulation 94, 1402-1407.

Korita, D., Itoh, H., Sagawa, N., Yura, S., Yoshida, M., Kakui, K., Takemura, M. \& Fujii, S. (2004). 17[beta]-estradiol up-regulates prostacyclin production in cultured human uterine myometrial cells via augmentation of both cyclooxygenase- 1 and prostacyclin synthase expression. J. Soc. Gynecol.c Invest. 11, 457-464.

Krom, Y.D., Pires, N.M.M., Jukema, J.W., de Vries, M.R., Frants, R.R., Havekes, L.M., van Dijk, K.W. \& Quax, P.H.A. (2007). Inhibition of neointima formation by local delivery of estrogen receptor alpha and beta specific agonists. Cardiovasc. Res. 73, 217-226.

Levin, E.R. (2009). G Protein-Coupled Receptor 30: Estrogen Receptor or Collaborator? Endocrinology 150, 1563-1565.

Li, M., Kuo, L. \& Stallone, J.N. (2008). Estrogen potentiates constrictor prostanoid function in female rat aorta by upregulation of cyclooxygenase- 2 and thromboxane pathway expression. Am. J. Physiol. Heart Circ. Physiol. 294, H2444-H2455.

Linton, M.F., Fazio, S. (2002). Cyclooxygenase-2 and atherosclerosis. Curr. Opin. Lipidol. 13, 497-504.

McAdam, B.F., Catella-Lawson, F., Mardini, I.A., Kapoor, S., Lawson, J.A. \& FitzGerald, G.A. (1999). Systemic biosynthesis of prostacyclin by cyclooxygenase (COX)-2: the human pharmacology of a selective inhibitor of COX-2. Proc. Natl. Acad. Sci. USA 96, 272-277.

Mendelsohn, M.E., Karas, R.H. (1999). The protective effects of estrogen on the cardiovascular system. N. Engl. J. Med. 340, 1801-1811.

Mendelsohn, M.E., Karas, R.H. (2010). Rapid progress for non-nuclear estrogen receptor signaling. J. Clin. Invest. 120, 2277-2279.

Mikkola, T., Ranta, V., Orpana, A., Ylikorkala, O. \& Viinikka, L. (1996). Effect of physiological concentrations of estradiol on PGI2 and NO in endothelial cells. Maturitas 25, 141-147.

Mikkola, T., Turunen, P., Avela, K., Orpana, A., Viinikka, L. \& Ylikorkala, O. (1995). 17 betaestradiol stimulates prostacyclin, but not endothelin-1, production in human vascular endothelial cells. J. Clin. Endocrinol. Metab. 80, 1832-1836.

Moncada, S., Vane, J.R. (1978). Pharmacology and endogenous roles of prostaglandin endoperoxides, thromboxane A2, and prostacyclin. Pharmacol. Rev. 30, 293-331.

Monsalve, E., Oviedo, P.J., Garcia-Perez, M.A., Tarin, J.J., Cano, A. \& Hermenegildo, C. (2007). Estradiol counteracts oxidized LDL-induced asymmetric dimethylarginine production by cultured human endothelial cells. Cardiovasc. Res. 73, 66-72.

Mueck, A.O., Seeger, H., Ludtke, R., Graser, T. \& Wallwiener, D. (2001). Effect on biochemical vasoactive markers during postmenopausal hormone replacement therapy: estradiol versus estradiol/dienogest. Maturitas 38, 305-313.

Mueck, A.O., Seeger, H. \& Wallwiener, D. (2002). Medroxyprogesterone acetate versus norethisterone: effect on estradiol-induced changes of markers for endothelial function and atherosclerotic plaque characteristics in human female coronary endothelial cell cultures. Menopause 9, 273-281. 
Myers, S.I., Turnage, R.H., Bartula, L., Kalley, B. \& Meng, Y. (1996). Estrogen increases male rat aortic endothelial cell (RAEC) PGI2 release. Prostaglandins Leukot. Essent. Fatty Acids 54, 403-409.

Naderali, E.K., Smith, S.L., Doyle, P.J. \& Williams, G. (2001). Vasorelaxant effects of oestradiols on guinea pigs: a role for gender differences. Eur. J. Clin. Invest. 31, 215-220.

Nakahata, N. (2008). Thromboxane A2: Physiology/pathophysiology, cellular signal transduction and pharmacology. Pharmacol. Ther. 118, 18-35.

O'Sullivan, M.G., Goodrich, J.A. \& Adams, M.R. (2001). Increased prostacyclin synthesis by atherosclerotic arteries from estrogen-treated monkeys. Life Sci. 69, 395-401.

Oliveira, R.L., Aldrighi, J.M., Gebara, O.E., Rocha, T.R.F., D'Amico, E., Rosano, G.M.C. \& Ramires, J.A. (2005). Postmenopausal hormone replacement therapy increases plasmatic thromboxane [beta]2. Int. J. Cardiol. 99, 449-454.

Ospina, J.A., Duckles, S.P. \& Krause, D.N. (2003). 17beta-Estradiol decreases vascular tone in cerebral arteries by shifting COX-dependent vasoconstriction to vasodilation. Am. J. Physiol. Heart. Circ. Physiol. 285, H241-H250.

Ospina, J.A., Krause, D.N. \& Duckles, S.P. (2002). 17beta-estradiol increases rat cerebrovascular prostacyclin synthesis by elevating cyclooxygenase-1 and prostacyclin synthase. Stroke 33, 600-605.

Ost, M., Uhl, E., Carlsson, M., Gidlof, A., Soderkvist, P. \& Sirsjo, A. (1998). Expression of mRNA for phospholipase A2, cyclooxygenases, and lipoxygenases in cultured human umbilical vascular endothelial and smooth muscle cells and in biopsies from umbilical arteries and veins. J. Vasc. Res. 35, 150-155.

Oviedo, P.J., Sobrino, A., Laguna-Fernandez, A., Novella, S., TarÆn, J.J., GarcÆa-Pqrez, M.A., SanchÆs, J., Cano, A. \& Hermenegildo, C. (2011). Estradiol induces endothelial cell migration and proliferation through estrogen receptor-enhanced RhoA/ROCK pathway. Mol. Cell. Endocrinol. 335, 96-103.

Pare, G., Krust, A., Karas, R.H., Dupont, S., Aronovitz, M., Chambon, P. \& Mendelsohn, M.E. (2002). Estrogen receptor-alpha mediates the protective effects of estrogen against vascular injury. Circ. Res. 90, 1087-1092.

Parente, L., Perretti, M. (2003). Advances in the pathophysiology of constitutive and inducible cyclooxygenases: two enzymes in the spotlight. Biochem. Pharmacol. 65, 153-159.

Patrignani, P., Sciulli, M.G., Manarini, S., Santini, G., Cerletti, C. \& Evangelista, V. (1999). COX-2 is not involved in thromboxane biosynthesis by activated human platelets. J. Physiol. Pharmacol. 50, 661-667.

Pedram, A., Razandi, M., Aitkenhead, M., Hughes, C.C. \& Levin, E.R. (2002). Integration of the Non-genomic and Genomic Actions of Estrogen. Membrane-initiated signaling by steroid to transcription and cell biology. J Biol. Chem. 277, 50768-50775.

Razandi, M., Pedram, A. \& Levin, E.R. (2000). Estrogen Signals to the Preservation of Endothelial Cell Form and Function. J. Biol. Chem. 275, 38540-38546.

Register, T.C., Adams, M.R. (1998). Coronary artery and cultured aortic smooth muscle cells express mRNA for both the classical estrogen receptor and the newly described estrogen receptor beta. J. Steroid Biochem. Mol. Biol. 64, 187-191.

Ross, R. (1999). Atherosclerosis: an inflammatory disease. N. Engl. J Med. 340, 115-126.

Rubanyi, G.M., Johns, A. \& Kauser, K. (2002). Effect of estrogen on endothelial function and angiogenesis. Vascul. Pharmacol. 38, 89-98.

Rupnow, H.L., Phernetton, T.M., Modrick, M.L., Wiltbank, M.C., Bird, I.M. \& Magness, R.R. (2002). Endothelial vasodilator production by uterine and systemic arteries. VIII. 
Estrogen and progesterone effects on cPLA2, COX-1, and PGIS protein expression. Biol. Reprod. 66, 468-474.

Sader, M.A., Celermajer, D.S. (2002). Endothelial function, vascular reactivity and gender differences in the cardiovascular system. Cardiovasc. Res. 53, 597-604.

Saetrum, O.O., Duckles, S.P. \& Krause, D.N. (2002). Regional differences in the effect of oestrogen on vascular tone in isolated rabbit arteries. Pharmacol. Toxicol. 91, 77-82.

Salom, J.B., Burguete, M.C., Perez-Asensio, F.J., Centeno, J.M., Torregrosa, G. \& Alborch, E. (2002). Acute relaxant effects of 17-beta-estradiol through non-genomic mechanisms in rabbit carotid artery. Steroids 67, 339-346.

Schildknecht, S., Ullrich, V. (2009). Peroxynitrite as regulator of vascular prostanoid synthesis. Arch. Biochem. Biophys. 484, 183-189.

Sellers, M.M., Stallone, J.N. (2008). Sympathy for the devil: the role of thromboxane in the regulation of vascular tone and blood pressure. Am. J. Physiol. Heart Circ. Physiol. 294, H1978-H1986.

Sherman, T.S., Chambliss, K.L., Gibson, L.L., Pace, M.C., Mendelsohn, M.E., Pfister, S.L. \& Shaul, P.W. (2002). Estrogen acutely activates prostacyclin synthesis in ovine fetal pulmonary artery endothelium. Am. J. Respir. Cell Mol. Biol. 26, 610-616.

Shwaery, G.T., Vita, J.A. \& Keaney, J.F.J. (1998). Antioxidant protection of LDL by physiologic concentrations of estrogens is specific for 17-beta-estradiol. Atherosclerosis 138, 255-262.

Simoncini, T. (2009). Mechanisms of action of estrogen receptors in vascular cells: relevance for menopause and aging. Climacteric 12 Suppl 1, 6-11.

Simoncini, T., Mannella, P., Fornari, L., Caruso, A., Varone, G. \& Genazzani, A.R. (2004). Genomic and non-genomic effects of estrogens on endothelial cells. Steroids 69, 537542.

Simoncini, T., Scorticati, C., Mannella, P., Fadiel, A., Giretti, M.S., Fu, X.D., Baldacci, C., Garibaldi, S., Caruso, A., Fornari, L., Naftolin, F. \& Genazzani, A.R. (2006). Estrogen Receptor \{alpha\} Interacts with G\{alpha\}13 to Drive Actin Remodeling and Endothelial Cell Migration via the RhoA/Rho Kinase/Moesin Pathway. Mol. Endocrinol. 20, 1756-1771.

Smith, W.L., DeWitt, D.L. \& Garavito, R.M. (2000). Cyclooxygenases: structural, cellular, and molecular biology. Annu. Rev. Biochem. 69, 145-182.

Sobrino, A., Mata, M., Laguna-Fernandez, A., Novella, S., Oviedo, P.J., Garcia-Perez, M.A., Tarin, J.J., Cano, A. \& Hermenegildo, C. (2009). Estradiol Stimulates Vasodilatory and Metabolic Pathways in Cultured Human Endothelial Cells. PLoS ONE 4, e8242.

Sobrino, A., Oviedo, P.J., Novella, S., Laguna-Fernandez, A., Bueno, C., Garcia-Perez, M.A., Tarin, J.J., Cano, A. \& Hermenegildo, C. (2010). Estradiol selectively stimulates endothelial prostacyclin production through estrogen receptor a. J. Mol. Endocrinol. $44,237-246$.

Spyridopoulos, I., Sullivan, A.B., Kearney, M., Isner, J.M. \& Losordo, D.W. (1997). Estrogenreceptor-mediated inhibition of human endothelial cell apoptosis. Estradiol as a survival factor. Circulation 95, 1505-1514.

Stewart, K.G., Zhang, Y. \& Davidge, S.T. (1999). Estrogen decreases prostaglandin H synthase products from endothelial cells. J. Soc. Gynecol. Investig. 6, 322-327.

Su, E.J., Lin, Z.H., Zeine, R., Yin, P., Reierstad, S., Innes, J.E. \& Bulun, S.E. (2009). Estrogen receptor-beta mediates cyclooxygenase- 2 expression and vascular prostanoid levels in human placental villous endothelial cells. Am. J. Obstet. Gynecol. 200, 427. 
Sudhir, K., Chou, T.M., Messina, L.M., Hutchison, S.J., Korach, K.S., Chatterjee, K. \& Rubanyi, G.M. (1997). Endothelial dysfunction in a man with disruptive mutation in oestrogen-receptor gene. Lancet 349, 1146-1147.

Teoh, H., Quan, A., Leung, S.W. \& Man, R.Y. (2000). Differential effects of 17beta-estradiol and testosterone on the contractile responses of porcine coronary arteries. $\mathrm{Br} . \mathrm{J}$. Pharmacol. 129, 1301-1308.

Tep-areenan, P., Kendall, D.A. \& Randall, M.D. (2003). Mechanisms of vasorelaxation to 17[beta]-oestradiol in rat arteries. Eur. J. Pharmacol. 476, 139-149.

Tostes, R.C., Nigro, D., Fortes, Z.B. \& Carvalho, M.H. (2003). Effects of estrogen on the vascular system. Braz. J. Med. Biol. Res. 36, 1143-1158.

Toth, B., Scholz, C., Saadat, G., Geller, A., Schulze, S., Mylonas, I., Friese, K. \& Jeschke, U. (2008). Estrogen receptor modulators and estrogen receptor beta immunolabelling in human umbilical vein endothelial cells. Acta Histochem. 111, 508-519.

Traupe, T., Stettler, C.D., Li, H., Haas, E., Bhattacharya, I., Minotti, R. \& Barton, M. (2007). Distinct Roles of Estrogen Receptors \{alpha\} and \{beta\} Mediating Acute Vasodilation of Epicardial Coronary Arteries. Hypertension 49, 1364-1370.

Tsuboi, K., Sugimoto, Y. \& Ichikawa, A. (2002). Prostanoid receptor subtypes. Prostaglandins Other Lipid Mediat. 68-69, 535-556.

Turgeon, J.L., Carr, M.C., Maki, P.M., Mendelsohn, M.E. \& Wise, P.M. (2006). Complex Actions of Sex Steroids in Adipose Tissue, the Cardiovascular System, and Brain: Insights from Basic Science and Clinical Studies. Endocr. Rev. 27, 575-605.

Vagnoni, K.E., Magness, R.R. (1998). Estrogen and lipopolysaccharide stimulation of prostacyclin production and the levels of cyclooxygenase and nitric oxide synthase in ovine uterine arteries. Biol. Reprod. 59, 1008-1015.

Vane, J.R., Bakhle, Y.S. \& Botting, R.M. (1998). Cyclooxygenases 1 and 2. Annu. Rev. Pharmacol. Toxicol. 38, 97-120.

Vanhoutte, P.M. (2009). COX-1 and Vascular Disease. Clin Pharmacol Ther 86, 212-215.

Vanhoutte, P.M., Shimokawa, H., Tang, E.H. \& Feletou, M. (2009). Endothelial dysfunction and vascular disease. Acta Physiol (Oxf) 196, 193-222.

Vapaatalo, H., Mervaala, E. (2001). Clinically important factors influencing endothelial function. Med. Sci. Monit. 7, 1075-1085.

Venkov, C.D., Rankin, A.B. \& Vaughan, D.E. (1996). Identification of authentic estrogen receptor in cultured endothelial cells. A potential mechanism for steroid hormone regulation of endothelial function. Circulation 94, 727-733.

Wagner, A.H., Schroeter, M.R. \& Hecker, M. (2001). 17beta-estradiol inhibition of NADPH oxidase expression in human endothelial cells. FASEB J. 15, 2121-2130.

Weir, M.R., Sperling, R.S., Reicin, A. \& Gertz, B.J. (2003). Selective COX-2 inhibition and cardiovascular effects: a review of the rofecoxib development program. Am. Heart J. 146, 591-604.

Wu, Q., Chambliss, K., Umetani, M., Mineo, C. \& Shaul, P.W. (2011). Non-nuclear Estrogen Receptor Signaling in Endothelium. J. Biol. Chem .(in press). DOI: 10.1074/jbc.R110.191791

Zhu, Y., Bian, Z., Lu, P., Karas, R.H., Bao, L., Cox, D., Hodgin, J., Shaul, P.W., Thoren, P., Smithies, O., Gustafsson, J.A. \& Mendelsohn, M.E. (2002). Abnormal Vascular Function and Hypertension in Mice Deficient in Estrogen Receptor beta. Science 295, 505-508.

Zou, M.H., Cohen, R. \& Ullrich, V. (2004). Peroxynitrite and vascular endothelial dysfunction in diabetes mellitus. Endothelium 11, 89-97. 


\section{Part 10}

Factors Affecting Farrowing 



\title{
Factors Affecting Physiology and Endocrinology of Farrowing
}

\author{
Olli Peltoniemi and Claudio Oliviero \\ Dept Production Animal Medicine \\ Faculty of Veterinary Medicine \\ University of Helsinki \\ Finland
}

\section{Introduction}

The highly prolific sow, defined as one giving birth to 16 or more liveborn piglets, presents a challenge to reproductive management of a sow herd (Boulot et al., 2008). From the point of view of reproductive management of the sow, feeding plays a key role. Therefore, recent findings related to feeding and how it affects farrowing, lactation and oestrus management are given the highest priority in the present paper. We report on recent findings related to feeding sows a high fiber diet during the period preceding parturition and its beneficial effect on gut function and duration of farrowing (Oliviero et al., 2009). In addition to feeding, arrangement of the farrowing pen (crate vs. pen; barren vs. enriched) appears as a critical factor determining the course of parturition. Our latest findings suggest that prohibiting the sow to exhibit nest building behaviour (Algers and Uvnäs - Moberg, 2007) prolongs parturition by an average of 90 minutes (Oliviero et al., 2008; 2010).

In addition, feeding sows with a high fiber diet during pregnancy, apart from being a beneficial feeding strategy from the welfare point of view, appears to increase the ad libitum feed intake during lactation. This effect seems to be carried over to the average daily gain of piglets, especially during the neonatal period (Quesnel et al., 2009, Peltoniemi et al., 2009). Amount of feed eaten by sows during lactation, on the other hand, appears as a key in enhancing gonadotrophin secretion and follicle development throughout lactation, however these effects of feeding become more evident towards the end of lactation (Kauffold et al., 2008). Follicles grow after weaning, as triggered by gonadotrophins FSH and LH, occurs the faster the better the stimulation by gonadotrophins has been prior to weaning (Prunier and Quesnel, 2000; Kauffold et al., 2008).

\section{Successful farrowing}

Successful farrowing can be defined as (1) sows given a chance to exhibit species specific nest building behaviour, (2) duration of farrowing not exceeding 5 hours, (3) all piglets in the litter born alive and (4) the first sucklings resulting in all newborn piglets receiving colostrum.

As fetuses grow fast at the end of pregnancy, there is a need to increase the energy intake by the sow. A common feeding strategy has been to put sows on lactation diet during the period before farrowing, in anticipation of the great energy requirement during lactation. 
While being understandable as a strategy from the energy intake point of view during lactation, this strategy by large ignores the intestinal function and dietary metabolism during and shortly after farrowing.

In one of our studies (Oliviero et al., 2009) we investigated the energy balance related parameters of the sow around farrowing. The parameters indicating catabolism (NEFA and creatinine) increased significantly a few days before farrowing, showing a positive peak almost on the day of parturition (Figure 1a), concerning NEFA this is in agreement with the results of Le Cozler et al. (1999). On the other hand, the metabolic markers of dietary energy (urea, insulin and glucose), decreased significantly with the approach of farrowing, yielding a negative peak on the day of parturition (Figure $1 \mathrm{~b}$ ). This may be the result of an internal regulation of the metabolism as the sow approaches farrowing. At this time, metabolism of
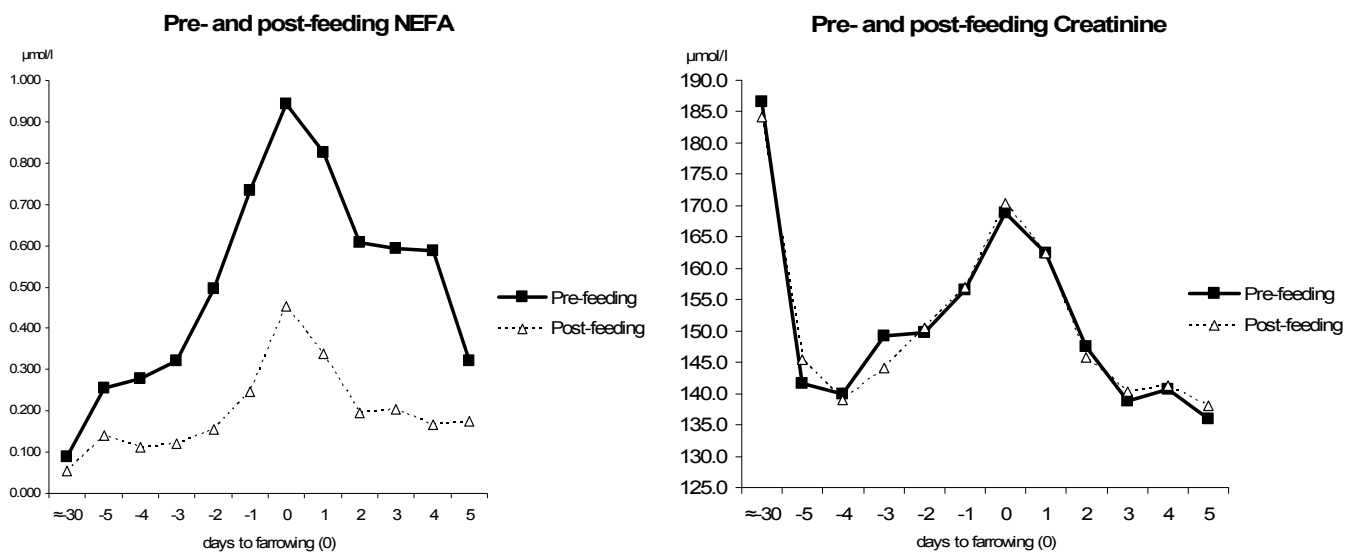

(a)
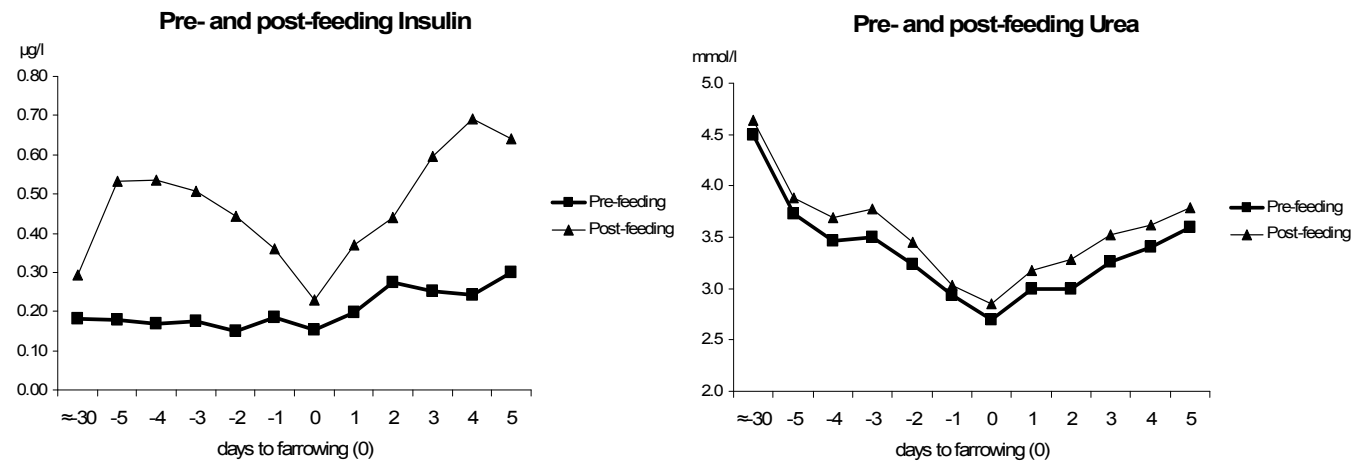

(b)

Fig. 1. Energy balance related parameters in sows $(n=41)$. At the top (a) there are the parameters indicating catabolism (NEFA and Creatinine) which have high levels at farrowing; at the bottom (b) there are the metabolic markers of dietary energy which on the contrary have low levels at farrowing. 
the external source of energy decreases and the main source of energy becomes the internal body reserves (fat and muscles) as the peaks of NEFA and creatinine demonstrate. In this sensitive phase, diet and intestinal activity seems of secondary importance. The parturition process clearly takes priority over digestive and intestinal activity, but the demand for energy remains high or even higher, and it's supplied mobilising internal reserves. Therefore, around farrowing it appears important, to promote good intestinal activity with an adequate amount of fibre rather than just increase dietary energy intake.

We observed that after having been on a traditional lactation diet with 3,8\% of crude fiber prior to farrowing, sows showed an increased constipation incidence of up to $22 \%$ for several days after farrowing (Figure 2; Oliviero et al., 2009). Gut function slows down during parturition anyway and overgrowth of bacteria in a gut filled with an energy-rich diet may lead into activation of the GALT (gut associated lymphoid tissue) system (Oliviero et al, 2009; Reiner et al., 2009). The activation of the GALT system would stimulate $\mathrm{PGE}_{2}$ release, which may further suppress intestinal function until a leak of endotoxins through the gut wall occurs, bringing about a systemic response and clinical symptoms found in post partum dysgalactia syndrome, PDS (Reiner et al., 2009). Therefore, avoiding constipation by any means should be of interest to managers of any well functioning piglet producing unit.

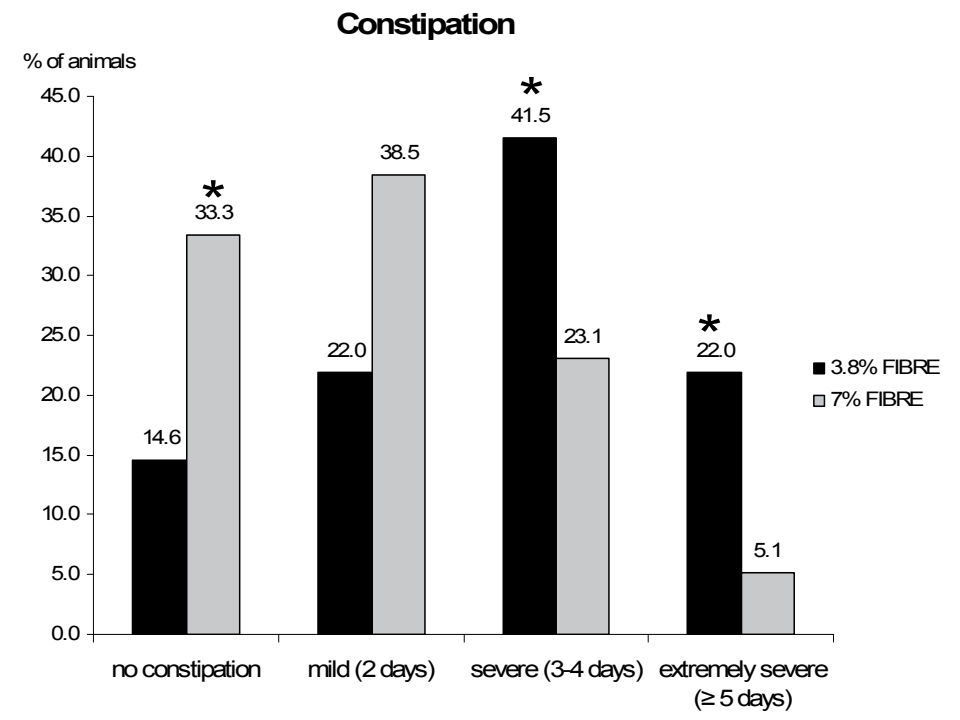

Fig. 2. Incidence of different grades of constipation in the 3.8\% FIBRE group $(n=40)$ and in the $7 \%$ FIBRE group $(n=41)$, during the observational period (from 5 days before to 5 days after farrowing). Consecutive days of constipation are recorded, and for constipation is meant absence produced of feces. Asterisks represent significant differences between the two groups with $\mathrm{P}<0.05$.

While feeding sows laxatives like Glauber salt, cooked linseed mixture and commercial laxatives are among traditional measures to avoid constipation, our experiences support adding more fiber into sow diets before farrowing (Oliviero et al., 2009). A 7-11 \% crude fiber content prior to farrowing appears as a reasonable measure to prevent constipation and an important part of management of successful farrowing (Oliviero et al., 2009; Quesnel 
et al., 2009; Peltoniemi et al., 2009). The first beneficial function of a high fiber diet is the improved intestinal activity (Oliviero et al., 2009). However, other beneficial effects relating to the use of high fiber diets have also been reported. These include improved intestinal immunity due to an increased mucin production as well as improved energy utilization of the feed consumed.

Water intake of the sow before farrowing is an important parameter to monitor, since it is elementary to milk production. On average, sows drink 10-30 liters of water around farrowing (Oliviero et al., 2009). However, variation between individual sows was considerably large and sows on the high fiber diet drank significantly more than did sows on the traditional diet (Figure 3; Oliviero et al., 2009). This was attributed to either stimulating effect of fiber on water intake as such or the increased volume related to the higher fiber diet possibly explaining the difference compared to the traditional prefarrowing diet (Oliviero et al., 2009). Whatever the cause, these findings encourage use of diets containing more fiber prior to farrowing. The usual flow recommendation of drinking water from nipples is 3-4 liters / minute and this is one of the easiest parameters to be measured on a health check call in a farrowing unit.

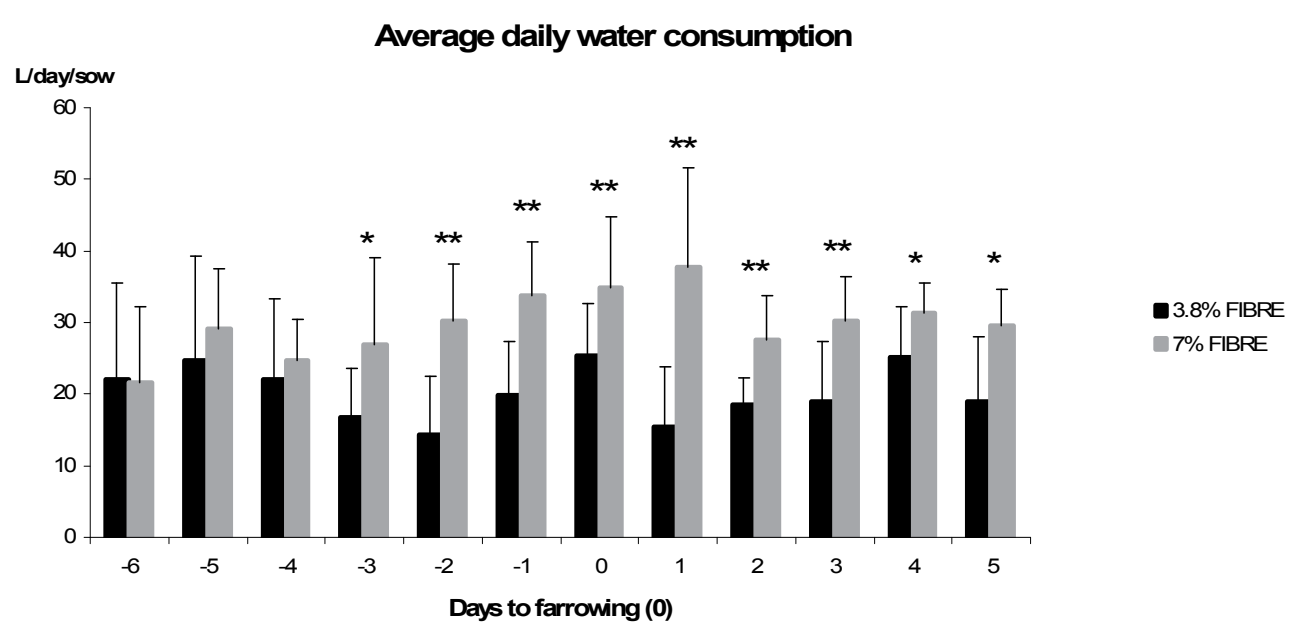

Fig. 3. Individual average daily water consumption and respective SD bars in the FIBRE group $(n=12)$ and in the LACT group $(n=12)$. The asterisk indicate the degree of significance $\left({ }^{*}=\mathrm{P}<0.05 ;{ }^{* *}=\mathrm{P}<0.01\right)$.

Data from our group show that sows not given a chance to express nest building behaviour have higher circulating cortisol concentrations before farrowing and lower oxytocin concentrations during the expulsion phase of farrowing (Figure 4; Oliviero et al., 2008a). From the practical viewpoint, however, maybe the most important observation was the one related to the duration of farrowing. If placed in a crate and not given a chance to build up a nest, it took an average of 1,5 hours longer from our experimental sows to deliver the litter than sows placed in a free pen with nesting material (Figure 4; Oliviero et a., 2008a; 2009). Furthermore, the average interval between piglets was considerably longer in crated sows with no nest building material (25 minutes CRATE vs. 16 minutes in PEN; Oliviero et al., 2008a). 


\section{Duration of farrowing and Oxytocin}

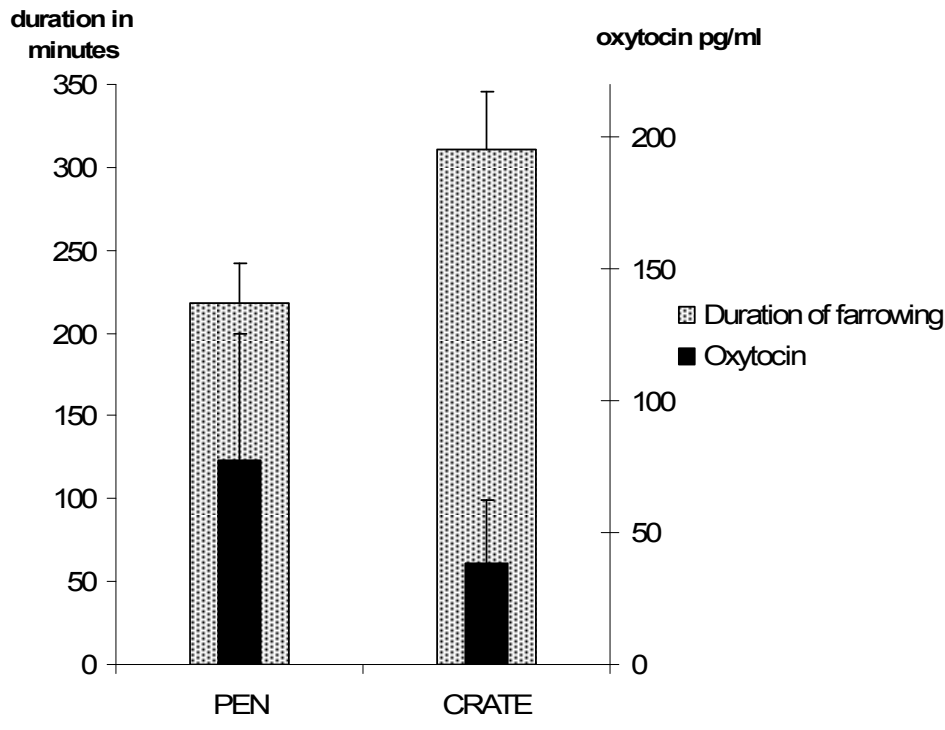

Fig. 4. Average duration of farrowing and average Oxytocin post-expulsion pulses in the $\operatorname{PEN}(n=9)$ and CRATE $(n=9)$ groups of sows (mean \pm SD). Data from Oliviero et al., 2008.

Another explanation could be hormonal impairment due to the higher level of fat circulating in overfed sows. A higher level of fat can affect lipid-soluble steroids, and especially the progesterone:oestrogen ratio, which is known to affect oxytocin receptor activation (McCracken et al., 1999; Russell et al., 2003). Abnormalities due to oxytocin receptor activation may weaken the expulsive phase of parturition. A decline in progesterone and a concomitant increase in the oestrogen profile should occur 36 to 24 hours prior to parturition (Cowart, 2007). We observed a delayed decline in progesterone beyond day 1 after parturition in a number of our trial sows (Figure 5; Oliviero et al., 2008a), a delay that may be linked to obesity and the prolongation of parturition. If so, progesterone bound to fat may be too stable to promptly react to CL regression.

We have recorded duration of farrowing in several studies by now (Oliviero et al., 2008; 2010). From these studies it is apparent that a farrowing lasting longer than 5 hours is deemed unsuccessful and easily leads to complications for both the dam and the newborn. Therefore, we suggest that with the modern sow lines, a 5 hours threshold may be applied when making a difference between successful and unsuccessful farrowing. Several factors, as constipation, body condition of the sow, parity, breed and number of stillborn piglets affect duration of farrowing (Oliviero et al., 2010). Constipation, as discussed above, may be alleviated by increasing fiber content of the diet. Backfat thickness of higher than $17 \mathrm{~mm}$, however, also appeared as a risk factor for prolonged farrowing in the genetically lean Finnish sow population (Oliviero et al., 2010).

Number of piglets stillborn prolonged duration of farrowing (Oliviero et al., 2010). It is known from previous studies that fetuses are usually alive shortly before farrowing. The great majority $(>80 \%)$ of piglets that are deemed to born still, die during the course of parturition. It is therefore reasonable to assume that dystocia, whether due to the dam or the 
fetus, is the major cause for piglets born still. According to Jackson (1972), in the sow, inertia uteri $(37 \%)$ used to be considered as the most common cause for dystocia followed by the breech presentation $(14,5 \%)$, obstruction of the birth canal $(13 \%)$, simultaneous presentation $(10 \%)$, downward torsion of the uterus $(9 \%)$, downward deviation of the head $(4 \%)$ and fetal oversize $(3,5 \%)$. However, these robust classifications do not account for the more precise causes for intrapartum deaths of piglets, such as strangulation or early rupture of the umbilical cord or considerations relating to uterine contractions.

\section{Progesterone}

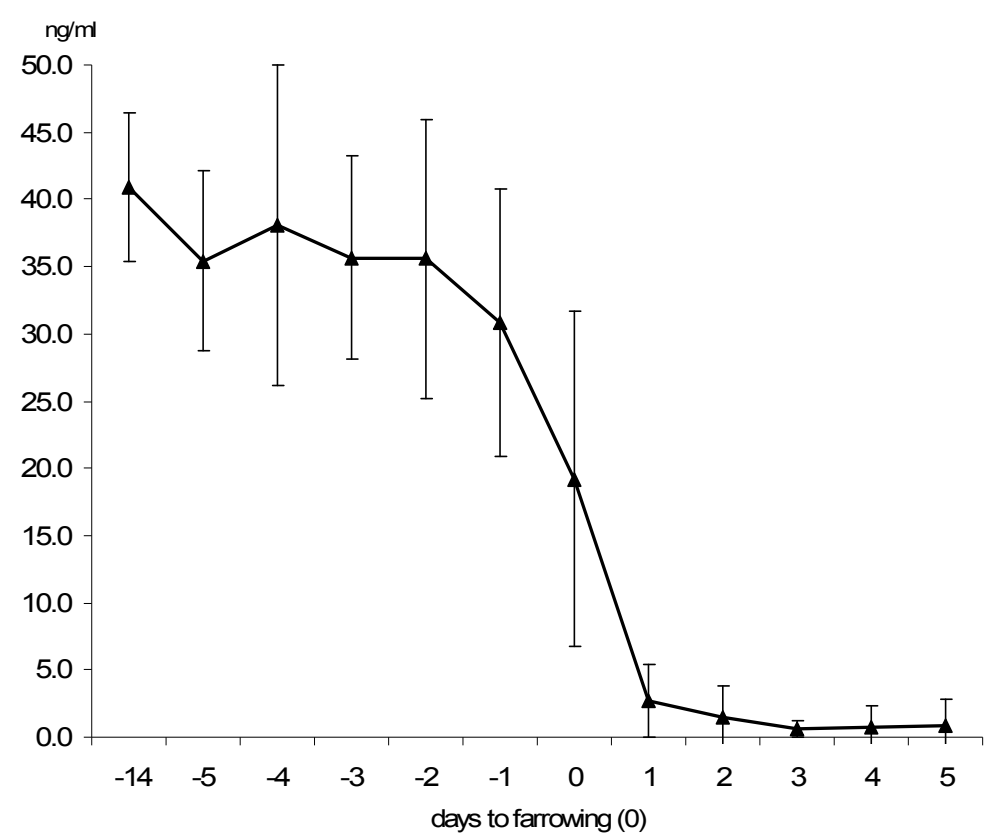

Fig. 5. Some sows showed a delayed decline in circulating progesterone before farrowing. The sows in this study $(n=38)$ showed still high levels of progesterone on the day of farrowing.

We found that also the level of back fat affected the duration of farrowing even though the sows used in this study were not particularly fat (Figure 6). Sows with a back fat average higher than $17 \mathrm{~mm}$ had an average duration of farrowing of $385 \pm 197 \mathrm{~min}(\mathrm{n}=48)$, whereas those with a back fat average of less than $17 \mathrm{~mm}$ had an average duration of farrowing of $230 \pm 103$ min $(n=124 ; p<0.001)$. One explanation could be a progesterone impairment due to the higher level of fat in those sows as described in the paragraph above. Another hypothesis could be that fat sows have more adipose layers around the birth canal (Cowart, 2007), thereby reducing the diameter of the birth canal, which can create a physical obstacle to birth during the expulsive phase with delayed farrowing.

It is very well known, that piglets need their passive immunity acquired through colostrum, otherwise they will not be able to cope with the environmental infective pressure. As every piglet is in need of colostrum and one that is missing out is clearly the one at risk of loosing 
life already in the early days. Colostrum transmission through the gut wall of the piglet can only occur during the first day of life and the amount of colostrum is not increasing according to the number of piglets born. Therefore, in a large litter, supervision is required, not only during the process of parturition, but also attending that even the last piglets born will receive adequate amount of colostrum. We found that, after stillborn, the most common primary cause of perinatal mortality is starvation (Table 1). Piglets which are unable to adequately feed themselves within the first days of life have less chance to survive and more chances to get crushed by the sow because of their state of lethargy which reduce their ability to move and react fast.

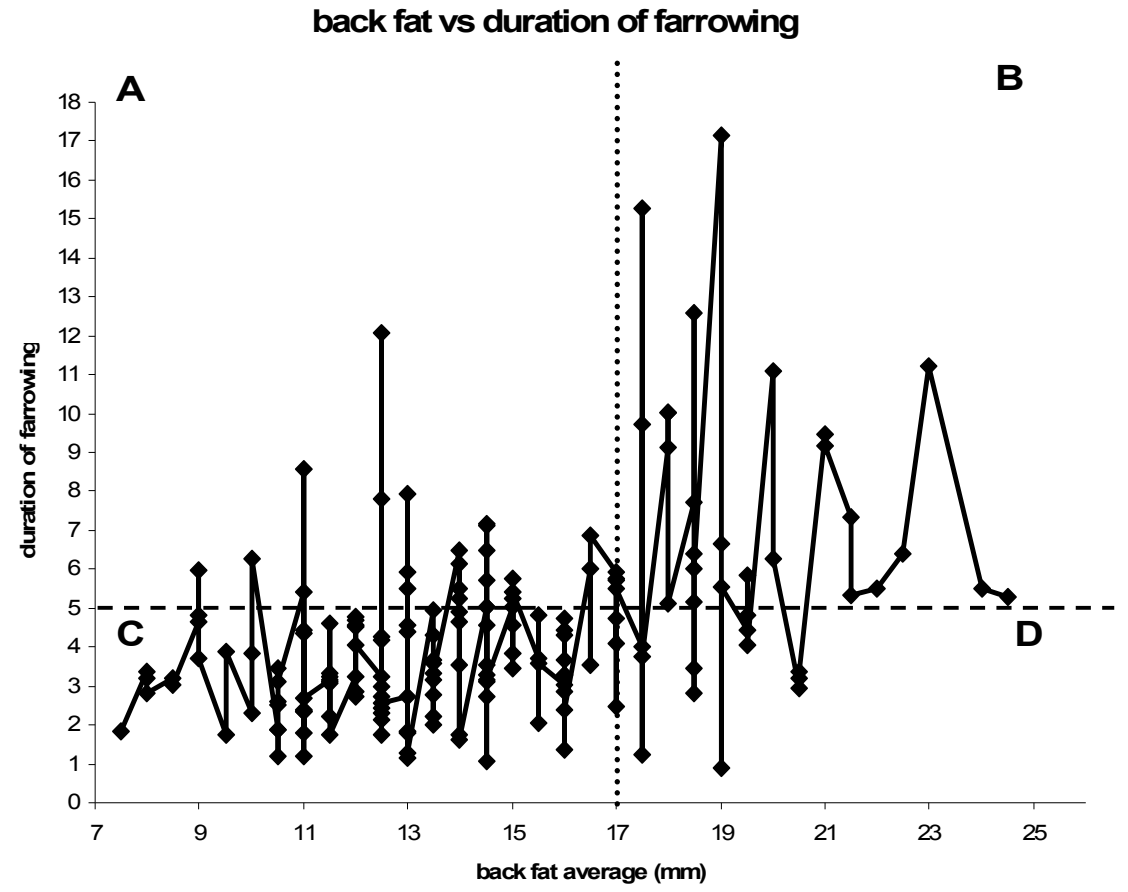

Fig. 6. Individual sows plotted by back fat average $(\mathrm{mm})$ and the duration of farrowing (hours). The horizontal dashed line discriminates prolonged farrowing ( $>5 \mathrm{~h} ; \mathrm{A}, \mathrm{B})$; the vertical dotted line discriminates the fatter sows $(B, D)$. Most of the fatter sows had duration of farrowing longer than 5 hours (area B), while most of the thinner sows had farrowings duration shorter than 5 hours (area C).

\section{Lactation performance of the sow and piglets}

To care for a large litter, adequate feed intake of the sow is of great significance. A drop in feed intake around farrowing can be considered as physiological. Stepwise rise in feed intake by $0,5 \mathrm{~kg}$ of feed / day until day 10 or so will be enough to reach the target daily intake of about $8 \mathrm{~kg}$, equal to about $100 \mathrm{MJ}$ ME for a sow nursing 12 piglets (Peltoniemi and Kemp., 2009). A too steep rise in feed intake after farrowing will jeopardize the success of the whole lactation, since there will be a decline in intake, followed by fluctuation of it for most of the duration of lactation. 


\begin{tabular}{lll}
\hline Cause of mortality & $n$ & $\%$ \\
\hline Stillborn & 50 & 34.5 \\
Starvation & 30 & 20.7 \\
Trauma & 27 & 18.6 \\
Infections & 17 & 11.7 \\
Other* & 21 & 14.5 \\
& & \\
\hline Total & 145 & 100
\end{tabular}

Table 1. Primary causes of piglet mortality (from birth to day 5 of life) determined after postmortem examination (41 litters).

A balanced nutritional program designed to avoid excessive weight loss during lactation is of great importance for successful lactation. It has been shown that feeding the sow with higher amounts of fiber during pregnancy, intake of feed during lactation can be increased with a corresponding increase in performance of piglets (Quesnel et al., 2009). It has also been shown, that increasing fiber intake throught the reproductive life of the sow appears as a feasible approach, contributing to improved welfare of the sow as well as good reproductive performance of the sow and improved growth performance of piglets (Peltoniemi et al., 2009).

Piglet mortality and mean birth weight appear to be closely associated with littersize. When litter size increased from 10 to 15, number of stillborn piglets went up from 0,3 to 1,0 and the proportion of piglets weighing less than $1 \mathrm{~kg}$ went up from 3 to $15 \%$, respectively (Boulot et al., 2008). In large litters, supervision of farrowing is therefore necessary. The first issue there is an accurate prediction of farrowing. We have developed techniques, whereby prediction of farrowing becomes possible and feasible. Movement sensors monitoring impending farrowing can be used to predict the expulsion phase of farrowing 24 hours prior to the first birth of the first piglet (Oliviero et al., 2008b). Other modern technology, such as use of thermocameras may be applied to detect hypothermic newborn piglets that require immediate attention by the caretakers.

We argue that the present development regarding piglets born in the pig industry is not on a sustainable basis. Instead of the number of piglets born alive, more research effort should be aimed at increasing the birth weight of piglets born and decreasing the still birth rate. Moreover, more attention should be paid to the quality of newborn piglets, the quality of piglets weaned and the quality of fattening pigs. The quality of piglets and fattening pigs in the pig production may be achieved by long term studies, starting during the fetal period, focusing on early development of the piglet and finally exploring the fattening phase of the pig.

\section{Gonadotrophins and follicle development}

Intake of feed by sows during lactation appears as a key in enhancing gonadotrophin secretion and follicle development throughout lactation, however these effects of feeding become more evident towards the end of lactation (Kauffold et al., 2008). Follicle growth after weaning, as triggered by gondatrophins FSH and LH, then occurs the faster the better the stimulation by gonadotrophins has been prior to weaning (Kauffold et al., 2008). 
Decreasing lactation length is a commonly taken strategy in Europe to hasten the reproductive cycle of the high producing sow and avoid excessive weight loss. However, the sustainability and ethical grounds for these strategies need thorough attention in the near future.

After weaning follicles grow approximately $1 \mathrm{~mm} /$ day. They reach the ovulatory size at about 7-10 mm within a week after weaning. The most recent findings in our group suggest that follicles ovulating at the size of 7 or $8 \mathrm{~mm}$ result in improved fertilization rates and larger litters than follicles ovulating at $<7 \mathrm{~mm}$ or $>8 \mathrm{~mm}$ (Vehmas et al., unpublished). Ultrasound technology (US) can nowadays be effectively applied in mating units to monitor insemination accuracy of insemination operators. In problem farms, inseminations occuring too early or too late in relation to ovulation can be picked up by US and relevant recommendations to change the AI strategy can be given. The optimal insemination time is estimated to be $0-16$ hours prior to ovulation, which occurs at approximately when two thirds of the standing oestrus has passed.

Follicle development can also be monitored with regard to possible not-expected physiological or pathological findings at the ovary. After weaning, detection of corpora lutea may indicate lactational oestrus, while cystic follicles, for instance, are among classical examples of application of ultrasound technology in sow herds.

\section{Conclusions}

Successful farrowing includes components of maternal behavior, duration of farrowing, piglet mortality and colostrum intake. Feeding is considered as the major factor in the reproductive management of the hyperprolific sow. New insights such as adding more fiber to sow diets during pregnancy and especially in the period prior to farrowing prevent constipation, increase water intake of the sow around parturition and increase milk intake and performance of piglets. Use of modern technology in supervision of farrowing may improve losses related to large litters. Use of ultrasound technology after weaning to monitor follicular growth may further improve littersize. In breeding programs, new components of maternal characteristics such as maternal behavior, ease of parturition, colostrum production, and piglet quality parameters may be taken to further improve success rate of reproductive management.

\section{References}

Algers B, Uvnäs-Moberg K. (2007). Maternal behavior in pigs. Horm Behav. Jun;52(1):78-85. Epub 2007 Apr 1. Review.

Boulot S, Quesnel H, Quiniou N, 2008. Management of High Prolificacy in French Herds: Can We Alleviate Side Effects on Piglet Survival? Advances in Pork Production 19; $1-8$

Cowart, R.P., 2007. Parturition and dystocia in swine, in: Youngquist, R.S., Threlfall, W.R., (Eds.), Large animal theriogenology. Saunders, St. Louis, Missouri, pp. 778-784.

Kauffold J, Gottschalk J, Schneider F, Beynon N, Wähner M 2008: Effects on feeding level during lactation on LH and FSH scretion patterns, and follicular development in primiparous sows. Reprod Dom Anim 43: 234-238.

Le Cozler, Y., Beaumal, V., Neil, M., David, C., Dourmand, J.Y., 1999. Changes in the concentrations of glucose, non-esterified fatty acids, urea, insulin, cortisol and some 
mineral elements in the plasma of the primiparous sow before, during and after induced parturition. Reprod. Nutr. Dev. 39, 161-169.

McCracken J.A., Custer E.E., Lamsa J.C., 1999. Luteolysis: a neuroendocrine-mediated event. Physiol Rev. 79, 263-323.

Oliviero C., Heinonen, M., Valros A., Hälli O. and Peltoniemi O.A.T. 2008. Effect of the environment on the physiology of the sow during late pregnancy, farrowing and early lactation. Anim. Reprod. Sci., 105(3-4):365-77

Oliviero C, Pastell M, Heinonen M, Heikkonen J, Valros A, Ahokas J, Vainio O and Peltoniemi OAT 2008b Using movement sensors to detect the onset of farrowing. Biosystems Engineering, 100: 281-285

Oliviero C, Kokkonen T, Heinonen M, Sankari S and Peltoniemi OAT 2009. Feeding sows with different amount of fibre during late pregnancy, farrowing and early lactation: Impact on the intestinal function, the energy balance and the litter., Reserch in Veterinary Science 86(2): 314-9

Oliviero C, Heinonen M, Valros A, Peltoniemi OAT, 2010: Environmental and sow related factors affecting duration of farrowing. Anim. Reprod. Sci. 119: 85-91

Peltoniemi OAT1 ${ }^{*}$, Tast $\mathrm{A}^{2}$, Heinonen $\mathrm{M}^{1}$, Oravainen $\mathrm{J}^{3}$, Munsterhjelm $\mathrm{C}^{1}$, Hälli $\mathrm{O}^{1}$, Oliviero $\mathrm{C}^{1}$, Hämeenoja $\mathrm{P}^{4}$ and Virolainen JV2, 2009: Fertility of pregnant sows fed ad libitum with a high fibre diet, Reproduction in Domestic Animals, doi: 10.1111/j.1439-0531.2009.01477.x

Peltoniemi OAT, Kemp B. 2009. Infertility and subferility in gilts and sows. In: Veterinary Reproduction and Obstetrics, edited by David E. Noakes, Timothy J. Parkinson, Gary C.W. England.. 9 p. Saunders Elsevier, Edinburgh 2009 pp 632-645.

Quesnel H, Meunier-Salaun M-C, Hamard A, Guillimet R, Etienne M, Farmer C, Dourmad JY, Pere M-C, 2009. Dietary fiber for pregnant sows: influence for sow physiology and performance during lacatation. J Anim Sci 87: 532-543

Reiner G, Hertampf B, Richard HF 2009: Postpartales dysgalaktiesyndrom der Sau - eine Ubersicht mit besonderer Berucksichtigung der Pathogenese. Tierärzl Prax 37 (G): 305-318

Russell, J.A., Leng, G., Douglas, A.J., 2003. The magnocellular oxytocin system, the fount of maternity: adaptations in pregnancy. Front. Neuroendocrinol. 24, 27-61. 



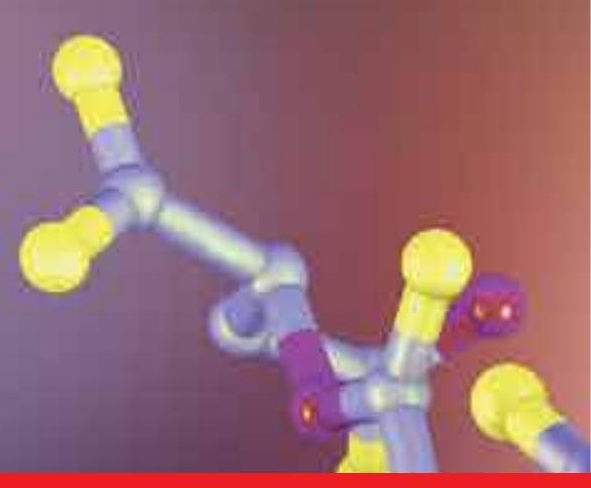

\section{Edited by Fulya Akin}

This book provides the most up-to-date information on the basic and clinical aspects of endocrinology. It offers both researchers and clinicians experts, gold-standard analysis of endocrine research and translation into the treatment of diseases such as insulinoma,

endocrine disease in pregnancy and steroid induced osteoporosis. Investigates both the endocrine functions of the kidneys and how the kidney acts as a target for hormones from other organ systems. Presents a uniquely comprehensive look at all aspects of endocrine changes in pregnancy and cardiovascular effects of androgens. 